\title{
Planktic foraminiferal proxy development and application to paleoceanographic change in the Southwest Pacific Ocean
}

\author{
Julene Marr \\ Antarctic Research Centre
}

A dissertation submitted for the Degree of Doctor of Philosophy

Victoria University of Wellington

February, 2013 
This thesis represents original work conducted by the author, except where specifically stated and acknowledged, during PhD candidature at the Antarctic Research Centre, School of Geography, Environmental and Earth Sciences, Victoria University of Wellington, New Zealand. No part of the thesis has been submitted to another University or institution.

Julene Marr

February, 2013 


\section{Abstract}

This thesis investigates the use of foraminiferal calcite geochemical and physical properties as paleoceanographic proxies, to improve identification of past climatic change and provide a more quantitative basis for forecasts of future climate. I have developed and used these proxies on a high resolution, well-dated marine sediment core, MD97 2121 from north of the Subtropical Front (STF) off the eastern central North Island of New Zealand to determine paleoceanographic changes in the South Pacific Gyre since the last glacial period, $25 \mathrm{ka}$ to present.

Various analytical methods to measure foraminiferal calcite trace element geochemistry were first investigated using core top samples. Two main analytical techniques were deployed; "pseudo" solution- or laser ablation-based ICPMS analysis. Ratios tested include $\mathrm{Mg} / \mathrm{Ca}, \mathrm{Sr} / \mathrm{Ca}, \mathrm{Ba} / \mathrm{Ca}, \mathrm{Zn} / \mathrm{Ca}, \mathrm{Mn} / \mathrm{Ca}$ and $\mathrm{Al} / \mathrm{Ca}$. Trace element/calcium ratios $\mathrm{Mg} / \mathrm{Ca}$ and $\mathrm{Sr} / \mathrm{Ca}$ values were consistent between these methods, provided that currently recommended 'Mg-cleaning' protocols were followed for solution-based measurements. However, discrepancies of up to an order-of-magnitude for $\mathrm{Zn} / \mathrm{Ca}, \mathrm{Mn} / \mathrm{Ca}$ and $\mathrm{Ba} / \mathrm{Ca}$ occurred between solution and laser ablation-based measurements if both oxidative and reductive cleaning techniques were not employed prior to solution-based analysis.

Using down-core trace element values $\mathrm{Mg} / \mathrm{Ca}, \mathrm{Zn} / \mathrm{Ca}, \mathrm{Mn} / \mathrm{Ca}$ and $\mathrm{Ba} / \mathrm{Ca}$ from $\mathrm{MD} 972121$, coupled with modern core top and plankton-tow samples, multiple geochemical proxies for the SW Pacific Ocean were developed and/or tested. Results suggest that $\mathrm{Zn} / \mathrm{Ca}$ may act as (i) a surface water mass tracer, in this case differentiating between subtropical and subantarctic surface waters and (ii) a proxy for nutrients. $\mathrm{Mg} / \mathrm{Ca}$ and $\mathrm{Zn} / \mathrm{Ca}$ values from different test chambers in Globigerina bulloides were also found to reliably re-construct surface ocean temperature and nutrient stratification. Using these new proxies, coupled with oxygen isotopes, standard $\mathrm{Mg} / \mathrm{Ca}$ paleothermometry and foraminiferal assemblage data, I show that surface water nutrient and thermal stratification significantly reduced during the last glacial period. In addition, the relative strength of the South Pacific Gyre, which affects the inflow of subtropical water to New Zealand, was a major influence during the last glacial termination. In particular, the period from 17-14.5 ka, otherwise known as the 'Mystery Interval', appears to be genuinely anomalous with foraminifera indicating cooling trends while alkenones continue to warm. This may reflect changes to both gyre strength and Antarctic forcing prior to the Antarctic Cold Reversal (14.2-12.5ka) and an offset in the timing of species productivity.

The high resolution $\mathrm{Mg} / \mathrm{Ca}$ paleotemperature record developed here, together with published alkenone paleotemperatures were compared to core MD97 2120, south of the STF to evaluate the relationship between $\mathrm{Mg} / \mathrm{Ca}$ and alkenones temperatures and how these reflect environmental change. It appears that the season of maximum alkenone and G. bulloides flux 
varied over the last $25 \mathrm{kyr}$ in response to insolation and water mass changes. During the glacial period north and south of the STF alkenone seasonal flux was summer dominated. However, during the Holocene while seasonal alkenone flux remained summer or annual dominated in the north, it shifted to a spring productivity cycle south of the STF. The foraminifera $G$. bulloides glacial period flux was likely have been spring dominated both north and south of the STF, maintaining a spring bloom cycle south of the STF, while shifting to a summer or annual cycle to the north during the Holocene. These seasonal offsets may have acted to dampen or exacerbate the glacial-Holocene temperature offsets by up to $4{ }^{\circ} \mathrm{C}$ especially for the surface dwelling, alkenone producing coccolithophores. Seasonality changes of the coccolithophore and foraminifera make direct comparison of alkenone and $\mathrm{Mg} / \mathrm{Ca}$ G. bulloides paleothermometers challenging. However, despite the complexity, offsets in the paleotemperatures may help to elucidate changes in the paleoceanography.

The use of G. bulloides size normalised weight (SNW) as a proxy for surface water carbonate ion concentration $\left(\left[\mathrm{CO}_{3}{ }^{-}\right]\right.$) was investigated by comparing modern SNW data sets from five different ocean regions to their specific environmental variables including $\left[\mathrm{CO}_{3}{ }^{=}\right]$, chlorophyll- $a$, nutrient and temperature values. It was identified that the 'ocean' from which the foraminifera originated appeared to have the strongest control over shell SNW, potentially reflecting geographically distinct, genetic variations within the G. bulloides species. Within 'ocean' regions no consistent environmental variable(s) could be identified that appeared to control shell SNW in all regions. From the $25 \mathrm{ka}$ to present, shell SNWs from the SW Pacific Ocean were compared to the North Atlantic and were found to be heavier during the glacial period regardless of ocean region. This may reflect multiple factors including increased surface ocean $\mathrm{CO}_{3}{ }^{2}$, possibly combined with changes in primary productivity. Calcification of G. bulloides tests appears to be region specific; therefore, proxy calibrations based on shell SNW for one ocean are not applicable to other settings. 


\section{Acknowledgements}

Thank you first and foremost needs to go to my official supervisors: Lionel Carter, Helen Bostock, Monica Handler and unofficial supervisor: Euan Smith. Lionel, thank you for your patience and open-door policy as I attempted to wend my way through what at times seemed to be the 'mysterious world' of paleoceanography. Helen, for your heroic efforts at turning around paper revisions, Monica for your assistance with what at times felt like the equally frustrating/exciting world of geochemistry, and my invaluable supervisor on all things statistic, Euan. Thank you for keeping the faith, and seeing me through. Also, in a similar vein but separate category, I would like to thank Julie Vry. Julie, I have greatly enjoyed working with you for the past three $(+)$ years on the ESCI course. I have learnt an enormous amount and without your support through the trials and tribulations of first year angst I would still be trying to complete my thesis.

Thank you also needs to go to those organisations from which I received funding, namely the Victoria University School of Geography, Environmental and Earth Sciences, Faculty of Science Strategic Research Grants, Antarctic Research Centre Endowed Development Fund, New Zealand Marine Sciences Society, AGU grants, and the Geochemical Society Goldschmidt Grants.

Furthermore, thank you needs to go to those who provided 'know how' but may not have been a part of the official supervision team. Your expertise on the way things worked such as technical support on the lab equipment, the construction of epoxy mounts/drilling of holes or insights into the world of microscopic living organisms was invaluable. On my list of those 'in the know' that I need to thank are; VUW Geochemistry Lab: Aidan Allan, George Cooper, Marc Alban-Millet; VUW School of Chemical and Physical Sciences: Richard Tilley and David Flynn; GNS: Martin Crundwell, Denise Kulhanek, Christine Prior, George Scott; NIWA: Helen Neil, Alan Orpin, Lisa Northcote, Hoe Chang. From student support at VUW Gerard Hoffman.

On a more personal note, I feel as though my family have lived this $\mathrm{PhD}$ just as much as I have - my children Mica and Eddie (now 7 and 4 years old) have grown up knowing what a thesis is, how long it takes to get one, and have the idea that everyone needs to attend 'school' for a very long time. As they so clearly articulate now when asked how Mummy is - 'Mummy needs to finish her thesis and have a holiday'. I couldn't put it better myself. To Aidan, who would have thought nine years ago that we would have two children and be attempting to complete our doctoral theses at roughly the same time. Words cannot express the extent of my gratitude for which your on-going/tireless support has enabled my forays into the world of academia and paleoceanography/geochemistry to be realised. Thank you for everything.

Family and friends support and encouragement has played a large role in completing what will be my last ever thesis (I promise!). From babysitting to organisation of ballet practices, exciting expeditions with the kids (that I don't need to be on), after school pick-ups, providing a comforting/listening ear, endeavouring to sit through multiple graduations and general moral support; Bridget Marr, Carol and Rodney Allan, 'Nana Mac' Lorraine McIntyre, Pat and George Bristol, Tam Goer (nee Ali), Juvena Jalal and Katie Peters you have been wonderful.

And to those people I need to thank at Victoria - I feel like I have been here so long now, half of those I want to thank have moved on, while others are still continuing on their journey here. While our relationship may have changed through the years at different stages many of you have been integral to completing my thesis, whether it was through a regular supply of friendly office chat (/crisis support depending on the situation), passing conversation or coffee/tea and cake. On my list of people I need to thank are; Katie Peters, Annette Bolton, Alexa Van Eaton, Sarah Martin, Denise Tang, Kylie Christiansen, Ben Hines, Bella Duncan, and Shaun Eaves in addition to multiple others who have made life just that little bit easier through passing contact or a friendly smiling face. Also, while not a person but rather a group of people; as a collective, being a part of the team in the Antarctic Research Centre has been wonderful, it has provided both a great place to work and a refuge from the stresses, trials and tribulations of 'getting this done'.

Once again, thank you to everyone. I am delighted to have this thesis done and looking forward to what is to come next. Best wishes to you all and your future endeavours. Julene. 


\section{Contents}

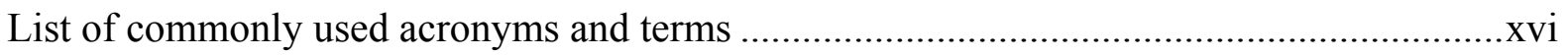

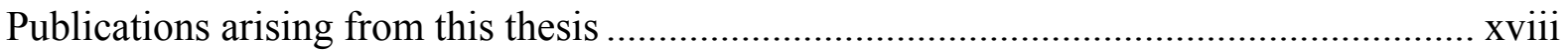

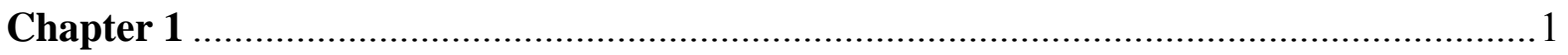

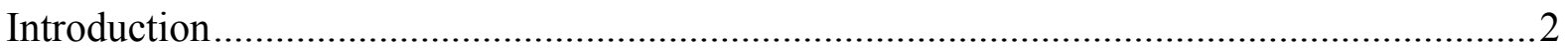

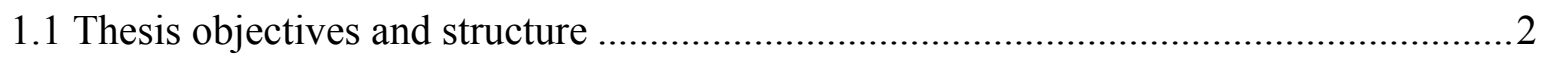

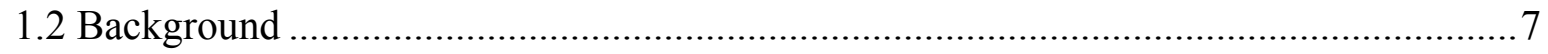

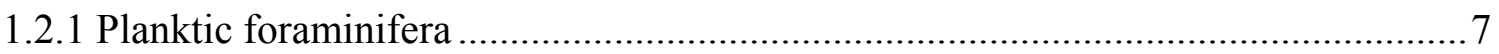

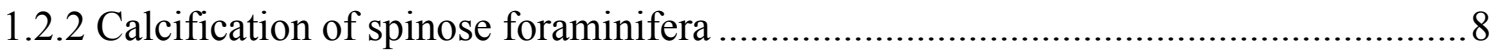

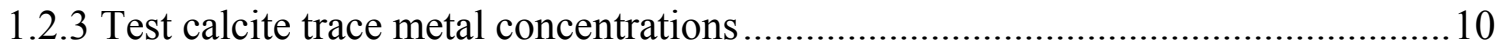

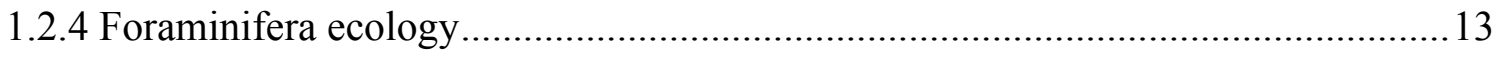

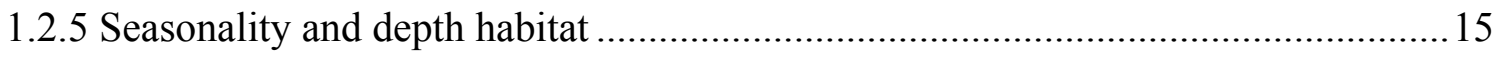

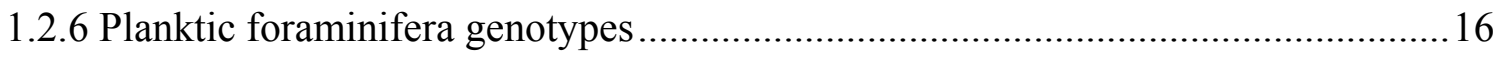

1.2.7 Other controls on foraminifera calcification - The carbonate ion effect ................19

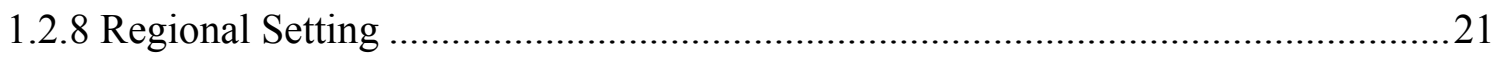

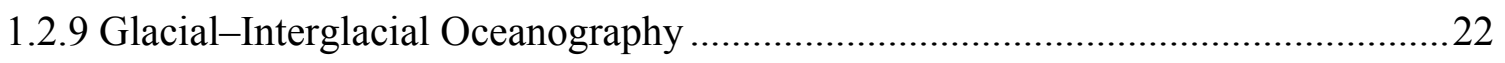

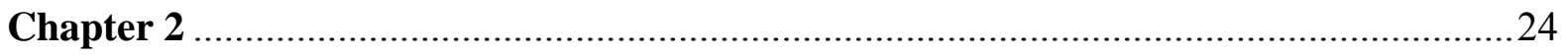

Differential effects of cleaning procedures on the trace element chemistry of planktic

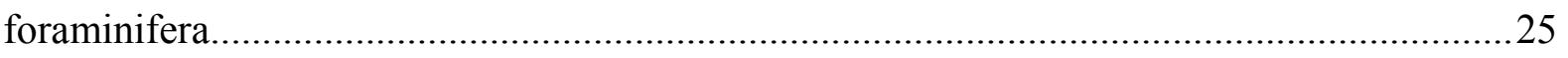

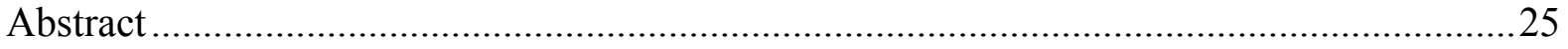

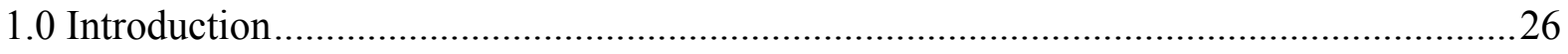

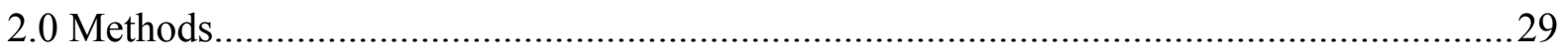

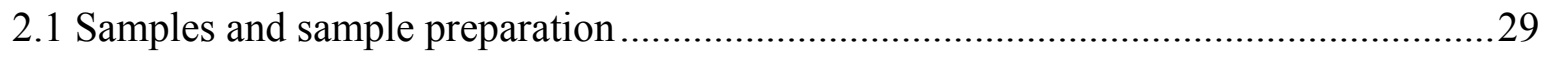

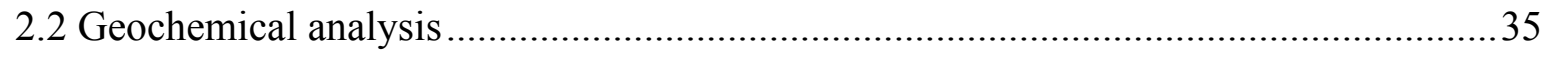

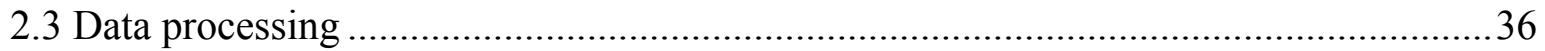




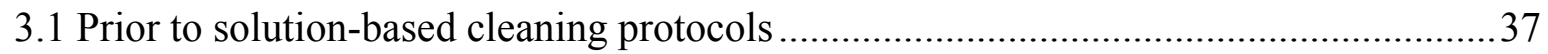

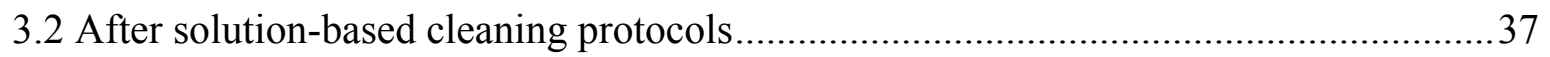

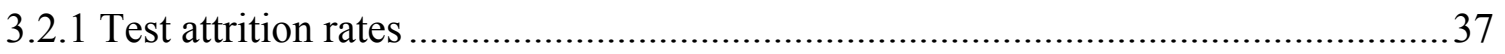

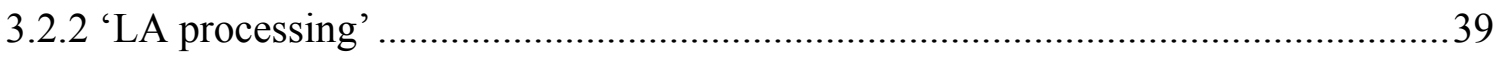

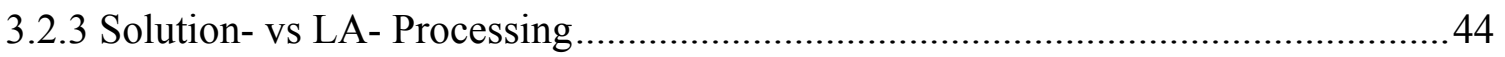

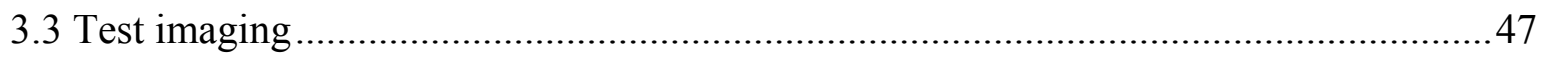

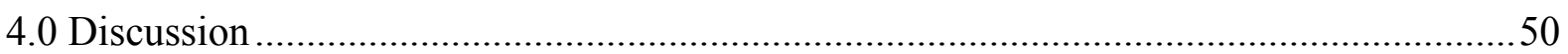

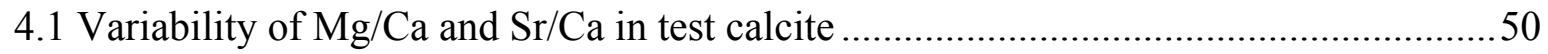

4.2 Sensitivity of ultra-trace element values to cleaning and analytical protocols .............51

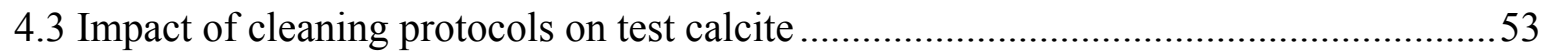

4.4 Effects of cleaning techniques on laser ablation results.........................................55

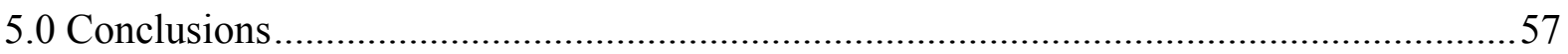

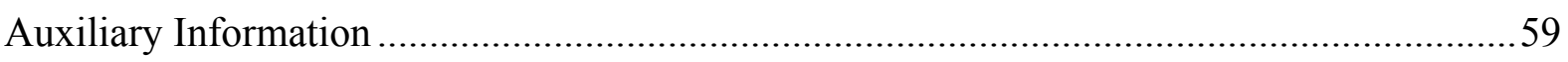

AI. 1.0. Stepwise cleaning procedure for the preparation of foraminiferal calcite for

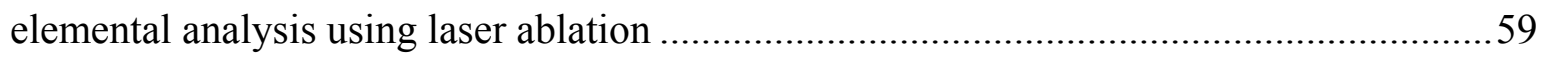

AI . 1.1. Laser Ablation Clean, Clay Removal..............................................................59

AI. 1.2. Mounting for Laser Ablation Analysis................................................................60

AI. 1.3. Oxidative Clean- Oxidative treatment is design to remove organic matter. .......61

AI. 1.4. Reductive Clean - Reductive cleaning is designed to remove any Mn-rich oxide

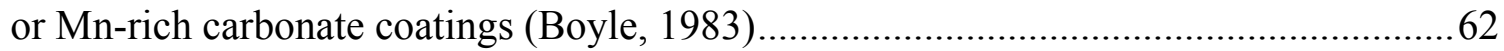

AI. 1.5. Dilute Acid Leach - the acid leach is designed to remove adsorbed contaminants and further leaching may be used to dissolve a Mn-carbonate coating where necessary 62

AI. 2.0. Stepwise procedure for laser ablation data processing .64

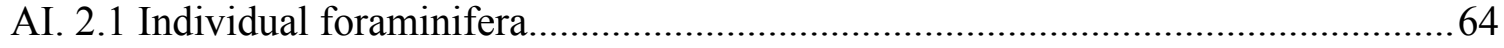

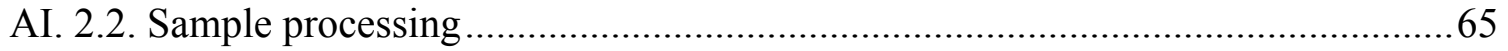

AI. 3.0. Reagents used for chemical cleaning, sufficient for a 20 samples........................66 
Auxiliary 4.0. Individual foraminifera TE/Ca data before and after chemical cleaning. .67

Chapter 3

Southwest Pacific Ocean response to a warming world: using $\mathrm{Mg} / \mathrm{Ca}, \mathrm{Zn} / \mathrm{Ca}$ and $\mathrm{Mn} / \mathrm{Ca}$ in foraminifera to track surface ocean water masses during the last deglaciation .......................70

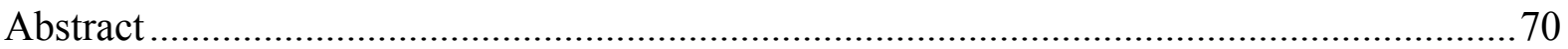

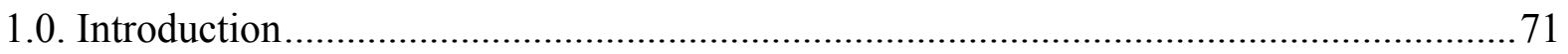

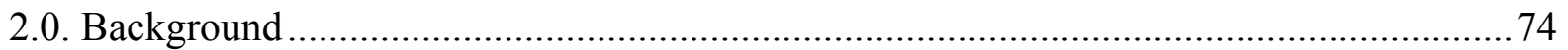

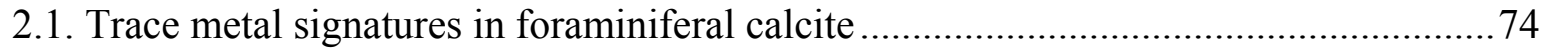

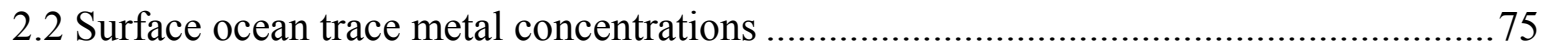

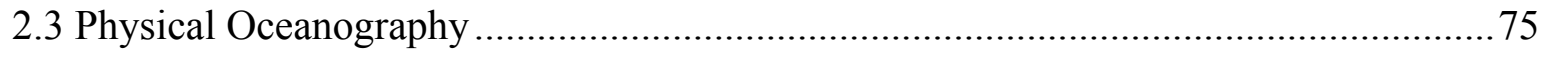

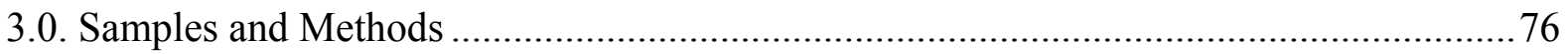

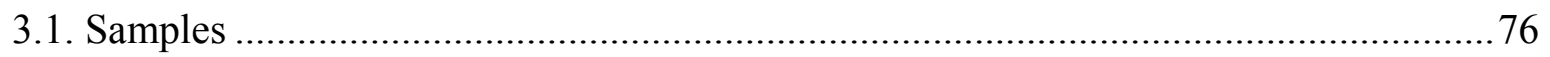

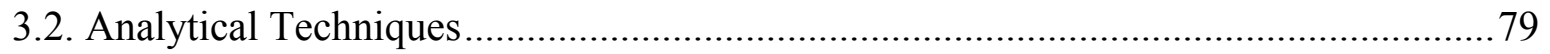

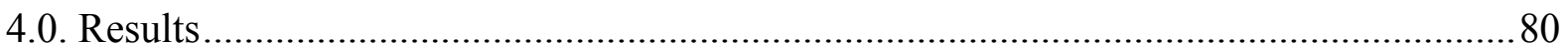

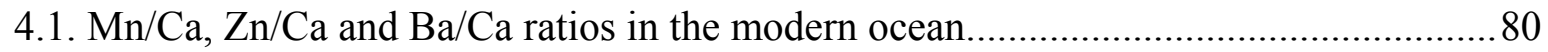

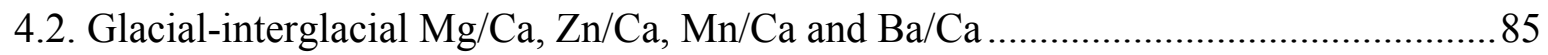

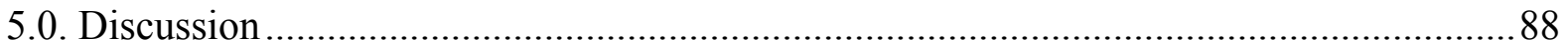

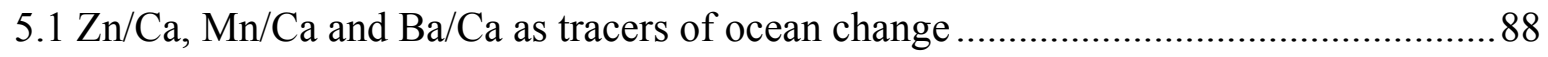

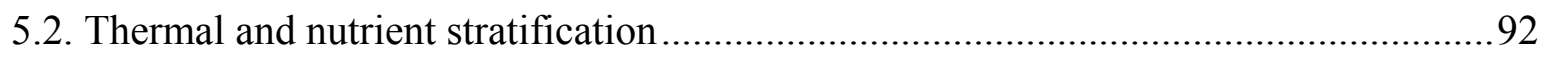

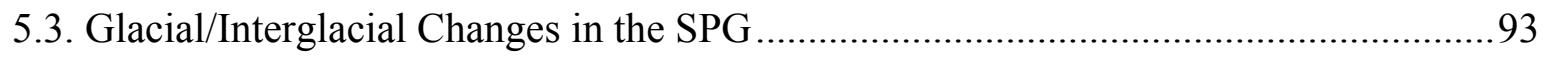

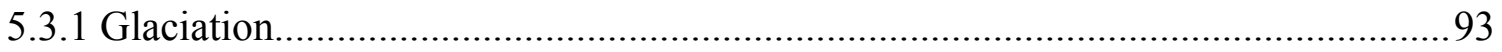

5.3.2 17-14.5 ka or Mystery Interval, early deglacial................................................95

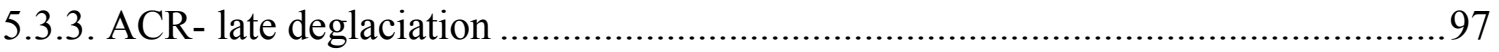

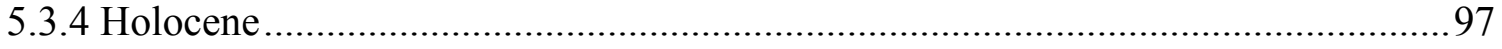

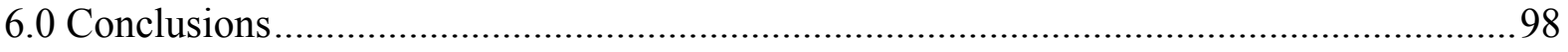

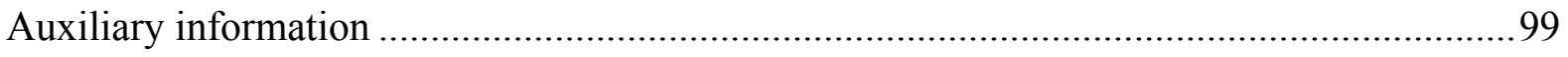

AI 1.0. Table of $\mathrm{Mg}, \mathrm{Al}, \mathrm{Mn}, \mathrm{Zn}, \mathrm{Sr}$ and $\mathrm{Ba} / \mathrm{Ca}$ ratios and sample means .........................99 
AI 2.0. Trace metal concentrations in the surface ocean and foraminiferal test calcite..... 103

AI 2.1. Surface ocean trace metal concentrations ........................................................ 103

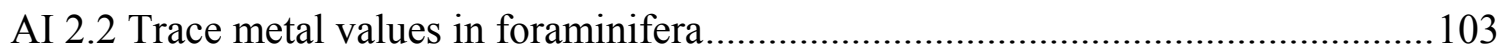

AI 3.0. Complexity in interpretation of test trace metal values as paleo-ocean proxies .... 104

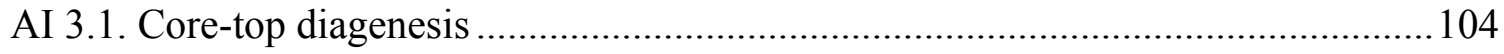

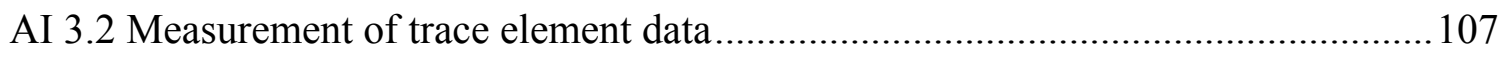

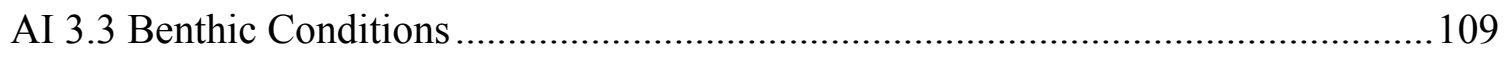

AI 3.4 Water column concentrations ..................................................................... 109

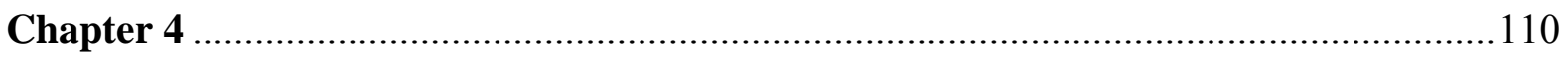

Impact of seasonality and changing oceanography on paleothermometry records ...............111

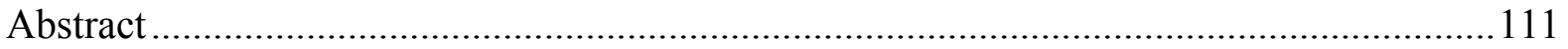

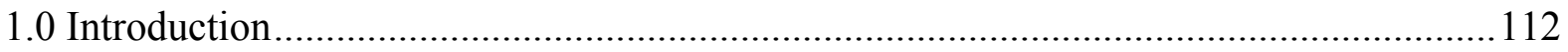

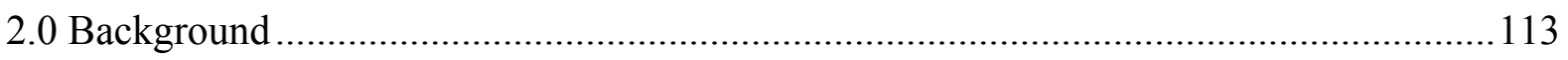

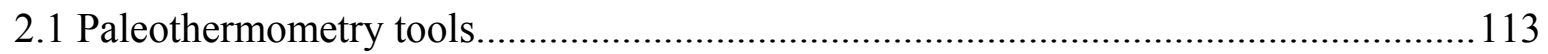

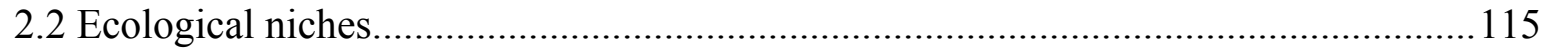

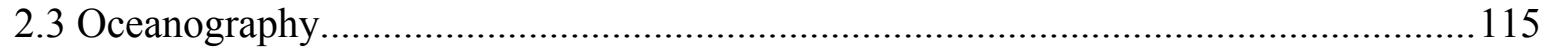

2.4 Modern seasonality of coccolithophores and G. Bulloides production........................116

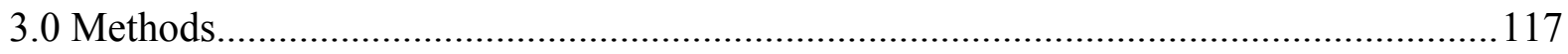

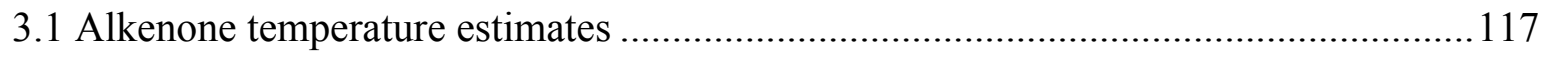

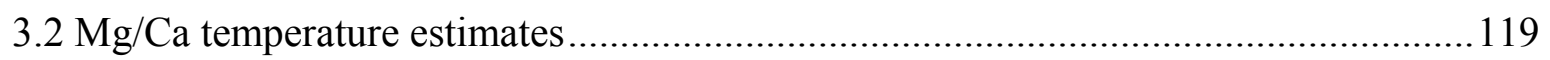

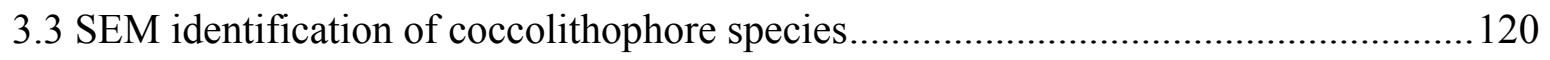

3.4 Determination of the difference between alkenone and $\mathrm{Mg} / \mathrm{Ca}$ temperature proxies .. 121

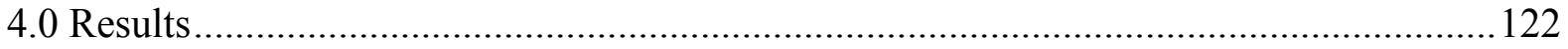

4.1 Difference between alkenone and $\mathrm{Mg} / \mathrm{Ca}$ temperature proxies ................................. 122

4.2 Identification of alkenone producing coccolithophore species ............................... 123

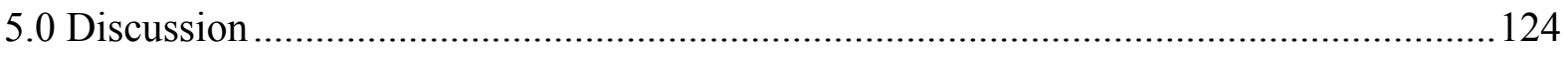

5.1 Alteration to samples following completion of its life cycle ................................. 124 
5.2 Change in the organisms' environmental preferences or niches

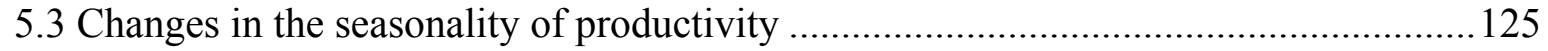

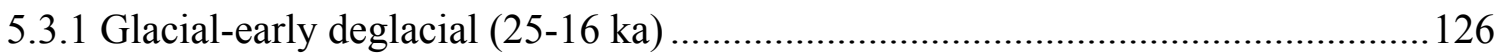

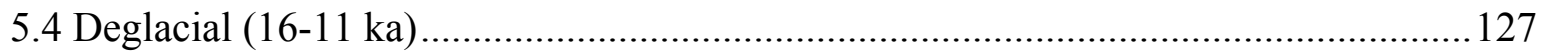

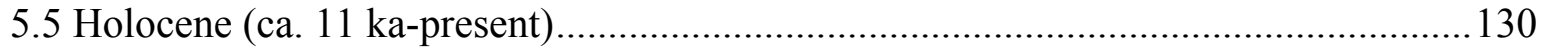

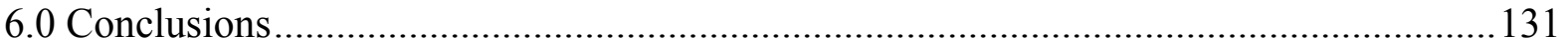

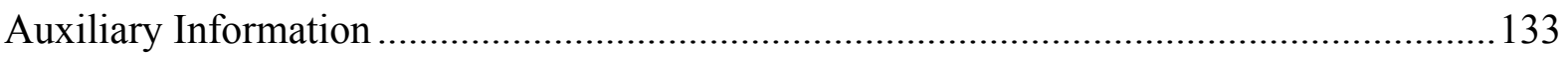

AI 1.0. Difference in alkenone based temperature estimates from 25ka-present at MD97

2121-blue and MD97 2120-grey using two different temperature calibrations.

AI 2.0. Total number of Gephyrocapsa spp. And E. Huxleyi identified in SEM images. 134

AI 2.0. Core X-Ray imaging

Chapter 5

Weighing in: are size-normalised foraminifera weights a proxy for surface water carbonate ion concentrations?

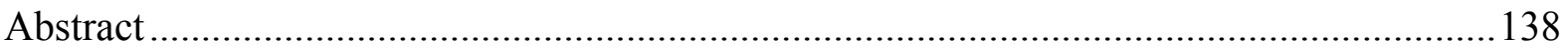

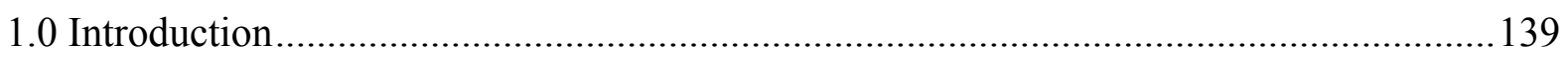

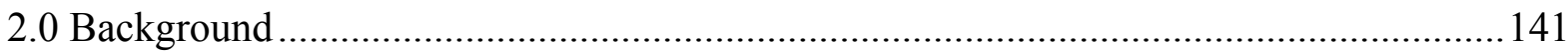

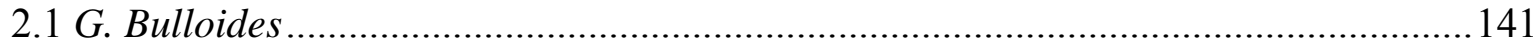

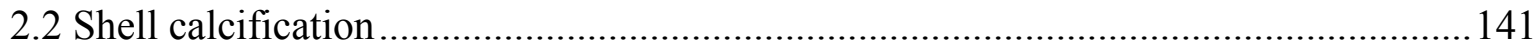

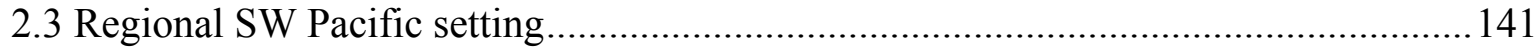

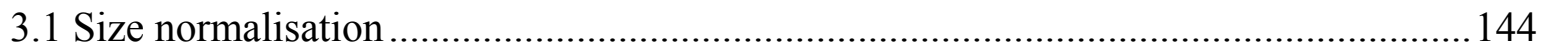

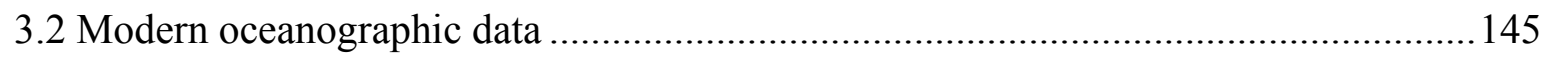

3.3 Regression of SNW against environmental variables and temperature ..................... 146

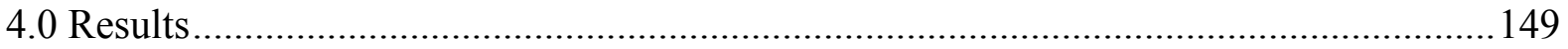

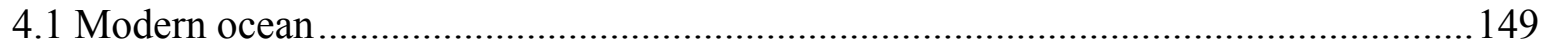

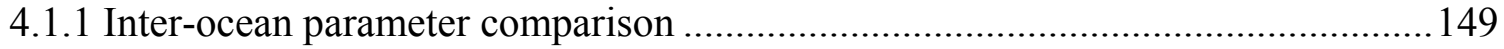

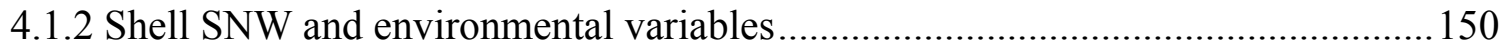


4.2 Paleoceanography.

5.0 Discussion

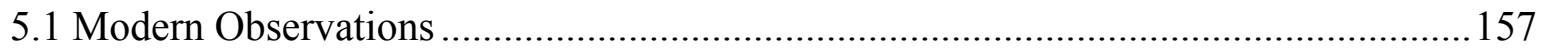

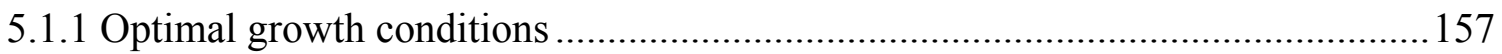

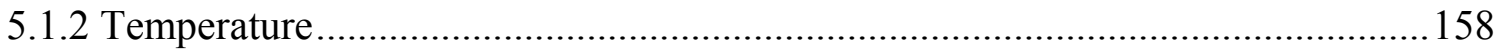

5.1.3 Surface water carbonate ion concentration.................................................... 158

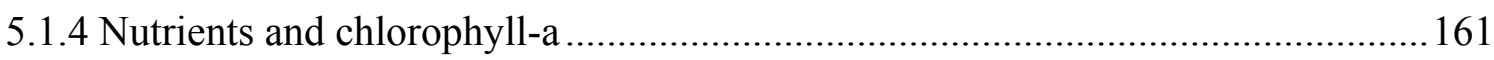

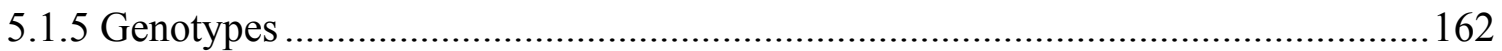

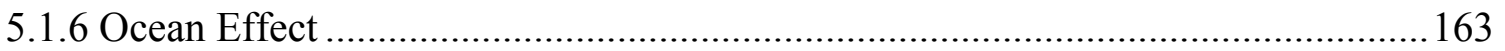

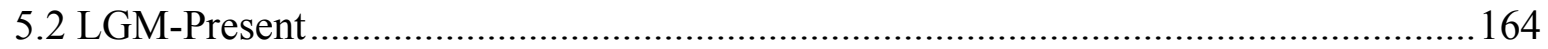

5.2.1 Environmental forcing of species ecological optimum ...................................... 164

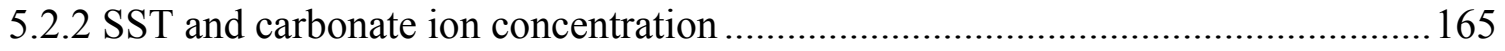

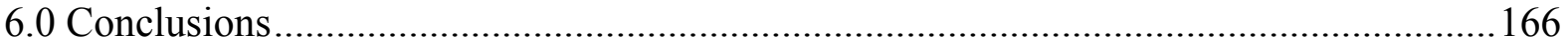

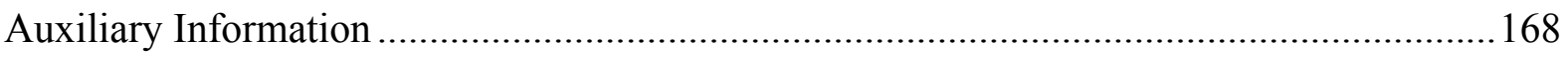

AI 1.0. Modern environmental, core-top and plankton tow data used in this study.......... 168

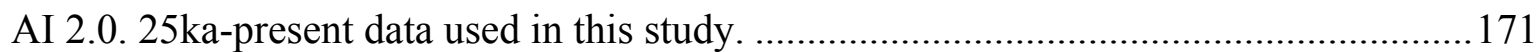

AI 3.0. MD97 2121 G. Bulloides SNW compared to biogenic carbonate and silica mass

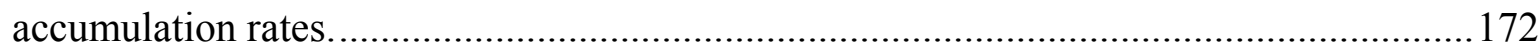

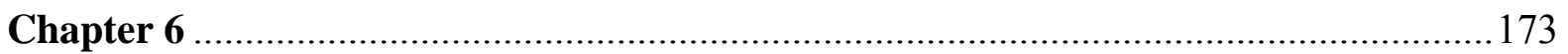

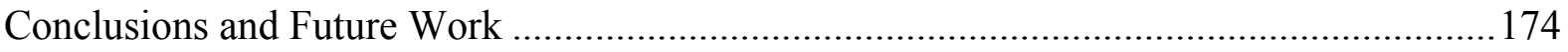

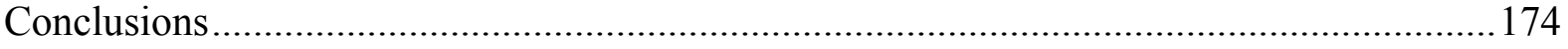

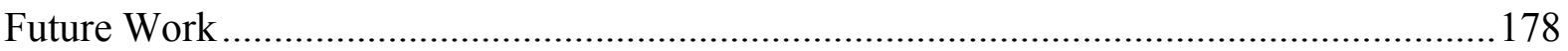

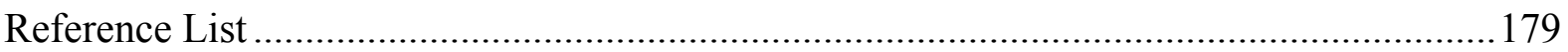




\section{List of figures and tables}

\section{Figures}

Figure 1. Calcification of the foraminifera test wall

Figure 2. Mean element distributions in seawater for the Pacific and Atlantic Oceans of trace metals investigated in this study.

Figure 3. Scanning electron microscope images of G. rube and G. bulloides analysed using laser ablation inductively coupled plasma mass spectrometry (LA-ICPMS) in this study.....14 Figure 4. Species specific $\mathrm{Mg} / \mathrm{Ca}$-temperature calibrations for G. bulloides and G. ruber from the Southwest Pacific Ocean

Figure 5. The biogeographical distribution and evolutionary relationships for genotypes of $G$. bulloides

Figure 6. The biogeographical distribution and evolutionary relationships for genotypes of the species $G$. ruber

Figure 7. Bjerrum plot showing the relative contributions of $\mathrm{CO}_{2}$, bicarbonate $\left(\mathrm{HCO}_{3}{ }^{-}\right)$and carbonate $\left(\mathrm{CO}_{3}{ }^{2-}\right)$ ions to total dissolved inorganic carbon as a function of $\mathrm{pH}$. .20

Figure 8. Generalised modern surface ocean currents and bathymetry surrounding New Zealand. .22

Figure 9. Calcification of the foraminifera test wall 30

Figure 10. Flow diagram summary of the sample preparation and analytical procedures .....32

Figure 11. Electron backscattered images of two adult G. bulloides....................................33

Figure 12. Histograms showing initial range in G. bulloides chamber $f-2 \mathrm{TE} / \mathrm{Ca}$ values .......38

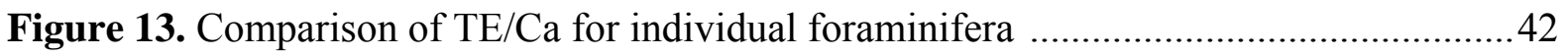

Figure 14. Comparison of TE/Ca for individual foraminifera. ............................................42

Figure 15. Comparison of TE/Ca for individual foraminifera ..........................................44

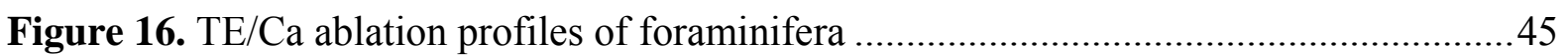

Figure 17. Comparison of sample means using the two different types of data acquisition.. 46

Figure 18. SEM backscatter images through foraminifera test walls showing various signs of dissolution. 48 
Figure 19. SEM back scattered imaging images of calcite crystals through the test wall of foraminifera

Figure 20. Generalised modern surface ocean currents and bathymetry surrounding New Zealand.

Figure 21. Scanning electron microscopy image of Globigerinoides ruber and Globigerina bulloides

Figure 22. Comparison of sample trace element/Ca ratios for modern G. bulloides chambers $f-1$ to $f-3$ (inclusive) and $G$. ruber chamber $f-2$. .84

Figure 23. Geochemical and isotopic proxy data from MD97 2121 and Antarctica for the last $25 \mathrm{kyr}$

Figure 24. $\mathrm{Mg} / \mathrm{Ca}, \mathrm{Zn} / \mathrm{Ca}$ and $\mathrm{Ba} / \mathrm{Ca}$ records of core MD97 2121 for the past $25 \mathrm{ka}$ for $\mathrm{G}$. ruber and G. bulloides with each sample mean comprised of measurements from multiple individual specimens.

Figure 25. Geochemical, biogenic sediment based productivity indicators for the MD97 2121 paleo record and abundance of key faunal taxa

Figure 26. Compilation of regional water mass proxy data with global deglaciation trends. 94

Figure 27. Summary of surface water changes in the thermocline, nutricline and dominant forcing from $25 \mathrm{ka}$ - present.

Figure 28. Generalised modern surface ocean currents and bathymetry surrounding New

Zealand

Figure 29. Alkenone and foraminiferal seasonal productivity fluxes north and south of the Subtropical Front

Figure 30. Example of an SEM image of coccolithophore and terrigenous material

Figure 31. Relative abundances of alkenone producing coccolithophore identified under SEM

Figure 32. 25 ka-present faunal and paleotemperature records from MD97 2121 and MD97 2120

Figure 33. Summary of surface water stratification, nutrient, seasonality, and species changes from $25 \mathrm{ka}$ - present.

Figure 34. Global location map of core-top, plankton tow, sediment trap and down core locations

Figure 35. G. bulloides SNW-environmental variable comparison between water mass 
Figure 36. An illustration of the relative environmental and 'ocean' significance in controlling shell SNW.

Figure 37. Summary of G. bulloides data from SW Pacific core site, MD97 2121 from 25 kapresent

Figure 38. Comparison between G. bulloides North Atlantic, NEAP 8K and SW Pacific MD97 2121 157

Figure 39. Surface water $\left[\mathrm{CO}_{3}{ }^{=}\right]$ 159

\section{Tables}

Table 1. Mean TE/Ca values in primary test calcite calculated prior and subsequent to chemical cleaning using LA and solution data processing.

Table 2. Details of core-top and ${ }^{\Delta}$ plankton tow locations, water depth and number of foraminifera analysed.

Table 3. Environmental variable correlation coefficients from linear regressions

Table 4. Correlation coefficient table of single environmental variables with G. bulloides shell SNW.

Table 5. The $\mathrm{r}^{2}$ values for models

\section{List of figures and tables in Auxiliary Information:}

C2-AI- Fig. 1. Individual foraminifera TE/Ca data before and after chemical cleaning with laser ablation processing.

C3-AI. Fig. 1. X-ray map of $\mathrm{Mn} / \mathrm{Ca}$ relative intensity of a single G. bulloides and timeresolved laser ablation profile

C4-AI. Fig. 1. Difference in alkenone based temperature estimates from $25 \mathrm{ka}$-present at MD97 2121 and MD97 2120.

C4-AI. Fig. 2. Total number of Gephyrocapsa spp. and E. huxleyi identified in SEM images of MD97 2121 samples.

C4-AI. Fig. 3. MD97 2121 core x-ray images. 136 
C5-AI. Fig. 1. MD97 2121 G. bulloides SNW compared to biogenic carbonate and silica mass accumulation rates

C5-AI. Table 1. Modern environmental, core-top and plankton tow data. 168

C5-AI. Table 2. 25ka-present data used in this study. 


\section{List of commonly used acronyms and terms}

\section{Oceanographic}

\begin{tabular}{|l|l|}
\hline STW & Subtropical Surface Water \\
\hline SAW & Subantarctic Surface Water \\
\hline CSW & Circumpolar Surface Water \\
\hline STF & Subtropical Front \\
\hline SAW & Subantarctic Front \\
\hline TF & Tropical Front \\
\hline SPG & South Pacific Gyre \\
\hline EAC & East Australian Current \\
\hline EAUC & East Auckland Current \\
\hline WE & Wairarapa Eddy \\
\hline MIS & Marine Isotope Stage \\
\hline SST & Sea Surface Temperature \\
\hline AAIW & Antarctic Intermediate Water \\
\hline SAMW & Subantarctic Mode Water \\
\hline
\end{tabular}

\section{Foraminifera}

\begin{tabular}{|l|l|}
\hline G. bulloides & Globigerina bulloides \\
\hline G. ruber & Globigerinoides ruber \\
\hline Tests & Shells \\
\hline Gametogenesis & reproduction \\
\hline
\end{tabular}




\section{Analytical}

\begin{tabular}{|l|l|}
\hline SEM & Scanning electron microscope \\
\hline LA-ICPMS & Laser ablation-inductively coupled plasma mass spectrometry \\
\hline MilliQ & Ultrapure water (equivalent to $>18.2 \mathrm{M} \Omega \mathrm{H}_{2} \mathrm{O}$ ) \\
\hline$>18.2 \mathrm{M} \Omega \mathrm{H}_{2} \mathrm{O}$ & Ultrapure water (equivalent to MilliQ) \\
\hline NIST & National Institute of Standards and Technology \\
\hline TE & Trace element \\
\hline LA-ICPMS & Laser ablation - inductively coupled plasma mass spectrometry \\
\hline
\end{tabular}

\section{General}

\begin{tabular}{|l|l|}
\hline LGM & Last Glacial Maximum (ca. 25 ka) \\
\hline $\mathrm{ka}$ & A specific time in the geological record \\
\hline $\mathrm{kyr}$ & A length of time \\
\hline $\mathrm{CI}$ & Confidence interval \\
\hline SI & Supplementary information \\
\hline
\end{tabular}




\section{Publications arising from this thesis}

Journal articles

Marr, J. P., H. C. Bostock, L. Carter, A. Bolton and E. Smith, 2013. Differential effects of contrasting cleaning procedures on the trace element chemistry of planktic foraminifera. Chemical Geology, http://dx.doi.org/10.1016/j.chemgeo.2013.05.019

Marr, J. P., L. Carter, H. C. Bostock, Euan Smith and A. Bolton, 2013. Southwest Pacific Ocean response to a warming world: using $\mathrm{Mg} / \mathrm{Ca}, \mathrm{Zn} / \mathrm{Ca}$ and $\mathrm{Mn} / \mathrm{Ca}$ in foraminifera to track surface ocean water masses during the last deglaciation. Paleoceanography, DOI: $10.1002 /$ palo. 20032

Marr, J. P., H. C. Bostock, L. Carter, in review. Impact of seasonality on paleothermometry records: implications for paleothermometry records derived from frontal regions, Paleoceanography Paleoclimatology Paleoecology

Marr, J. P., H. C. Bostock, L. Carter and E. Smith, in review. Weighing in: are sizenormalised foraminifera weights a proxy for surface water carbonate ion concentrations? Marine Micropaleontology.

Conference abstracts $\left(^{*}\right)$ indicates oral presentation

Marr, J. P., L. Carter, H. C. Bostock, M. Handler and A. Bolton, 2012. Tracing water masses in the SW Pacific Ocean, Urbino Summer School in Paleoclimatology, 13-31 July, 2012

*Marr, J. P., L. Carter, H. C. Bostock, M. Handler and A. Bolton, 2012. Southwest Pacific Ocean response to a warming world using $\mathrm{Mg} / \mathrm{Ca}, \mathrm{Mn} / \mathrm{Ca}$ and $\mathrm{Zn} / \mathrm{Ca}$ to track the surface ocean water masses, AMSA-NZMSS Conference, Tasmania, 1-5 July, 2012.

*Marr, J. P., J. A. Baker, L. Carter, A. S.R. Allan, K. Christensen, and H. C. Bostock, 2011. Horizontal and vertical water mass tracing of the SW Pacific Ocean during the last deglaciation, Goldschmidt Conference, Prague, 14-19 August, 2011, 1408pp.

Marr, J., Baker, J., Carter, L., Dunbar, G., 2009. LA-ICP-MS core-top Mg/Ca-temperature calibration for G. bulloides and a high resolution record of the last deglaciation in the 
Southwest Pacific Ocean, American Geophysical Union, San Francisco, Fall Meeting 2010, abstract \#PP41B-1639 
Chapter 1 


\section{Introduction}

\subsection{Thesis objectives and structure}

This work focuses on the development and use of trace metals and physical properties measured in the planktic foraminifers, Globigerina bulloides and Globigerinoides ruber as paleoenvironmental proxies in the Southwest Pacific Ocean. These foraminifera are characterised by widespread biogeographical and paleoceanographical coverage, they live in the surface layers of the ocean (Bé, 1977; Bé and Hutson, 1977; Hemleben et al., 1989), and their shells (tests) are composed primarily of calcium carbonate, with minor inclusions of other trace elements (e.g. Boyle, 1981; Delaney et al., 1985). Previously, trace metal proxy development for foraminiferal calcite has primarily focused on the ratio of $\mathrm{Mg}$ to $\mathrm{Ca}$ as a paleothermometer (e.g. Anand et al., 2003; Bender et al., 1975; Rosenthal et al., 1997). However, fundamental challenges to the use and understanding of $\mathrm{Mg} / \mathrm{Ca}$ as a paleotemperature proxy have been ongoing in the biogeochemical and paleoceanographical communities (e.g. Dekens et al., 2002; Eggins et al., 2003a; Erez, 2003). The emphasis on developing a more holistic understanding about changes in the ocean environment is also becoming more prominent as our understanding about the role of nutrients, surface ocean stratification, heat transportation and biology in global climate change develops (e.g. Ridgway and Hill, 2009; Rost and Riebesell, 2004). Further, it is vital that we identify natural temperature variability if we are to better isolate the current potential anthropogenic effect.

The central purpose of this thesis is to provide new perspectives on the use of foraminifera trace metal values and physical properties as paleoenvironmental proxies. I have used core top and plankton tow samples from the Southwest Pacific Ocean region, coupled with samples from a 25 ka cored sedimentary record from site MD97 2121 off Hawke Bay, New Zealand. My approach integrates geochemical data, electron microscope imaging, and trace element mapping of foraminifera tests to reconstruct the surface ocean paleoenvironment in the Southwest Pacific Ocean. Building on the existing geochemical data base from Marr (2011) and Bolton (2011), I establish new proxies for distinguishing between subantarctic (SAW) and subtropical water masses (STW), in addition to paleo surface ocean thermal and nutrient stratification based on the geochemical offsets between $G$. bulloides chambers and $G$. 
ruber/G. bulloides species. These proxies are then used to determine the interaction between these surface water masses overlying the core site from the last glacial maximum (LGM) to present. Further, I investigate (i) reasons behind the apparent differences between different paleothermometry proxy records, and (ii) the potential of the ratio of foraminifera weight to diameter to provide a reliable record of surface water carbonate ion concentration and therefore atmospheric $\mathrm{CO}_{2}$ levels.

This work contributes to a well-established, yet still developing paleoceanographical research field. Techniques such as the bulk (solution) and in situ (e.g. laser ablation) geochemical analysis of foraminifera have been used by previous workers (e.g. Sadekov et al., 2008; Barker and Elderfield, 2002) to develop and apply paleoceanographic proxies to foraminifera recovered from sedimentary archives from all of the major ocean basins. However, some fundamental aspects concerning these approaches require further scrutiny. For example, little is known about the physical effects on the foraminiferal shell of the chemical pre-treatments applied prior to solution analysis.. Structural damage to the calcite shell may exacerbate the effect of the chemical e.g. untended dissolution of the primary calcite, thus potentially making the results incomparable. These aspects of foraminiferal cleaning procedures, and their implications for subsequent interpretations of geochemical data, are explored in this thesis. Further, because foraminifera live and calcify their shells within the ocean, they potentially provide a 'snap-shot' of ocean chemistry and/or conditions at the time of calcification. As such, in situ geochemical analysis of individual foraminifera has the potential to extend the utility of foraminifera in paleoceanographic reconstructions beyond the temperature reconstructions for which they are most widely currently used. Investigated in this thesis is whether foraminifera are able to be used as proxies for other part of the ocean system, e.g. changes to the water mass and stratification.

An inherent assumption surrounding the application of $\mathrm{Mg} / \mathrm{Ca}$ values of foraminifera and alkenone ratios of coccolithophore as proxies is that these geochemical features primarily reflect temperature changes. However, comparison between where these particular temperature proxies have been applied (e.g. Barrows et al., 2007) clearly indicate that other factors, in addition to temperature, are influencing the geochemical signature. At present it is not clear what effect, if any, these 'other influences' may have on the validity of temperature estimates. For example, do the differences between foraminiferal versus coccolithophore temperature records in these studies (Barrows et al. 2007) reflect a breakdown of one or other 
of the temperature proxies, or simply an indication that the two proxies are recording different aspects of the temperature (e.g. depth, season etc)? This thesis addresses what some of these other influences may be, explores to what extent they may affect the validity of such temperature estimates, and identifies ways in which contrasting records from foraminifera and coccolithophore may be interpreted to understanding wider hydrological and environmental changes.In addition to chemistry-based proxies, the weight of foraminiferal shells have previously been identified as having potential utility as a paleo-proxy (e.g. Barker and Elderfield, 2002). The current proposed applications include the use of foraminiferal weight as a proxy for surface ocean carbonate ion concentration, temperature and nutrient levels (e.g. Barker and Elderfield, 2002; Marr et al., 2011; Aldridge et al., 2012). A criticism of these studies is that the calibrations have tended to be developed for isolated and specific oceanic regions, and while it is theorised that their results may apply in a wider context, little actual comparison of size normalised weights, either in the modern or from the paleocean, has been attempted. In this thesis size-normalised foraminifera weights from modern day records from ocean basins including the Southwest Pacific, Southern Ocean, and North Atlantic are compared to assess whether there are consistent trends in data between ocean basins.

\section{Hence, the primary objectives of this thesis are to:}

i) Determine the utility of the laser ablation technique for measurement of $\mathrm{Mg} / \mathrm{Ca}$ and other trace element to calcium $(\mathrm{TE} / \mathrm{Ca})$ ratios in foraminifera.

ii) Compare laser- and solution-based analytical techniques to understand the effect of the analytical method on $\mathrm{TE} / \mathrm{Ca}$ results for use in established and novel geochemical paleo proxies.

iii) Develop foraminiferal $\mathrm{Mg} / \mathrm{Ca}$ and other 'trace elements' $(\mathrm{TE} / \mathrm{Ca})$ as proxies for thermal and nutrient concentration and potentially upper ocean stratification.

iv) Apply thermal and nutrient paleo proxies to a paleoceanographic record from the Southwest Pacific to potential reveal major shifts the oceanography and climate over the last 25 kyr.

v) Evaluate the reason(s) behind differences between various proxies used to determine sea surface temperatures. 
vi) Investigate the potential use of G. bulloides test weights as a paleoceanographic proxy.

These specific aims are addressed within five interrelated chapters, structured around the central theme of developing, understanding and applying $\mathrm{TE} / \mathrm{Ca}$ upper ocean paleoenvironmental proxies. The chapters are written in a science journal style suitable for publication, and are thus presented as self-contained studies, each building on findings from the previous chapter. As a result there is some necessary replication of information, in particular, that pertaining to the general setting of the study area and methods. Published or accepted papers have been modified only slightly (stylistically and in terms of formatting, but not in content) for incorporation into the thesis. 
Chapter 1: Provides background information for the research including; the relative effects of ecology, biology, water geochemistry, physical oceanography and sedimentation processes on paleoceanographic records, and the theory behind the use of test weights as atmospheric $\mathrm{CO}_{2}$ proxies, focusing on planktic foraminifera test calcite as archives of the paleocean environment.

Chapter 2: Compares analytical techniques for deriving trace element and ultra-trace element measurements from foraminiferal test calcite, including investigation of the efficacy of cleaning for laser ablation-ICPMS, and the compatibility between solution-based and laser ablation-based data.

Chapter 3: Presents modern and paleoceanographic geochemical data from G. bulloides and G. ruber to investigate the use of chamber specific $\mathrm{Mg} / \mathrm{Ca}, \mathrm{Zn} / \mathrm{Ca}, \mathrm{Mn} / \mathrm{Ca}$ and $\mathrm{Ba} / \mathrm{Ca}$ as paleoenvironmental proxies for the surface ocean conditions in the Southwest Pacific Ocean.

Chapter 4: Uses the MD97 2121 core record as a case study for assessing the use of two common paleothermometry techniques; alkenone undersaturation levels and foraminiferal $\mathrm{Mg} / \mathrm{Ca}$, to evaluate any differences and develop a coherent paleoceanographic record.

Chapter 5: Investigates the modern calibrations relating G. bulloides size-normalised test weights to temperature and carbonate ion levels in the surface ocean. Regional core top and LGM to present data, are evaluated from five different oceans, with the most detailed comparison made for the North Atlantic and Southwest Pacific Oceans.

Chapter 6: Integrates the primary findings of this doctoral work, and outlines new areas for targeted research in the future. 


\subsection{Background}

\subsubsection{Planktic foraminifera}

Planktic foraminifera are unicellular, free-floating protozoa found throughout the major ocean basins. Although they represent a fairly minor proportion of the total living zooplankton, their calcium carbonate shells (tests) constitute a major component of the marine sedimentary record in areas of moderate to high productivity where the bottom waters are favourable for test preservation. The earliest taxonomic descriptions of foraminifera were given by d'Orbigny $(1826 ; 1839)$ and later revised and updated by Brady $(1876 ; 1884)$. Since that time studies on foraminiferal ecology and the chemical composition of their tests have provided the basis for a multitude of tools aimed at understanding paleoceanographic and environmental variability over timescales ranging from short-term seasonal and inter-decadal cycles: to relatively long term changes over hundreds and millions of years (Hemleben et al., 1989).

The chemical composition of foraminiferal shells is primarily determined by the chemistry of the ambient seawater (Kucera, 2007). Foraminifera also have some control over trace metal incorporation into test calcite, either through passive mechanisms, such as a change in its habitat, or via actively controlling or 'pumping' the metal to remove it from its cytoplasm (e.g. de Nooijer et al., 2009; Lea, 2003). Foraminiferal vertical migration through the water column, and thus a change in calcification depth, is an example of passive control over test calcite trace metal incorporation. The fossil assemblage is also biased toward shells deposited during the time of maximum production. This means that, depending on the species and its ecological niche, the geochemical signal measured on any given sample of specimens may represent the yearly average, spring, summer, or autumn conditions. Therefore the use of these organisms as a basis for geochemical proxies is increasingly reliant upon a detailed knowledge of the ecology of the signal carrier (e.g. Allen et al., 2011; Rohling et al., 2004).

Planktonic foraminifera generally inhabit the surface mixed layer and upper thermocline of the oceans. Foraminifera species have a range of environmental preferences or tolerances. In addition, their growth and reproductive habits can vary between ocean basins and latitudes. These conditions can only be replicated with varying degrees of success in laboratory culture experiments (e.g. Bender et al., 1975; Lea et al., 1999; Lea and Spero, 1992; Lombard et al., 
2009). However, with improved understanding of these species specific complexities, opportunities for more paleo proxy tools may arise. Here, the properties of foraminiferal calcification, ecology and genetic diversity are described with reference to the species involved in this study.

\subsubsection{Calcification of spinose foraminifera}

Calcification of chambers in spinose species such as G. bulloides and G. ruber occur along the 'ridges' or undulations of the test surface between spines during the ontogenetic stages of growth (Fig. 1). During ontogenetic calcification, spines protrude from the intersection between the ridge sections, and small flat calcite plaques (ca. $0.2 \mu \mathrm{m}$ in diameter) are secreted on top of each other forming the ridges that connect the spine bases (Fig. 1) (Bé et al., 1980). This calcite forms the basic structural units that make up the test wall and is hereafter referred to as 'primary calcite'. Subsequent thickening of the test wall occurs with the secretion of calcite layers that accompany chamber-by-chamber growth (Fig. 1). Thin layers of organic material, similar in composition to the primary organic membrane on the inside of the test wall, are deposited between each subsequent layer of calcite associated with new chamber formation (Bé, 1980; Sen Gupta and Hansen, 2003). Prior to gametogenesis (reproduction) foraminifera migrate lower in the upper water column, possibly to the euphotic zone, and the final chamber is formed followed by the resorption of the spines into the rhizopodial (Bé et al., 1980; Erez et al., 1991). Gametes are then released before gametogenic calcification. This gametogenic calcite deposits euhedral crystallites over the ridges, and can infill pore basins and thereby smooth the appearance of the inter-pore ridges (Fig. 1) (Bé, 1980; Bé et al., 1980; Erez et al., 1991). When grown under laboratory conditions very few specimens carry out gametogenic calcification (Bé, 1980). 

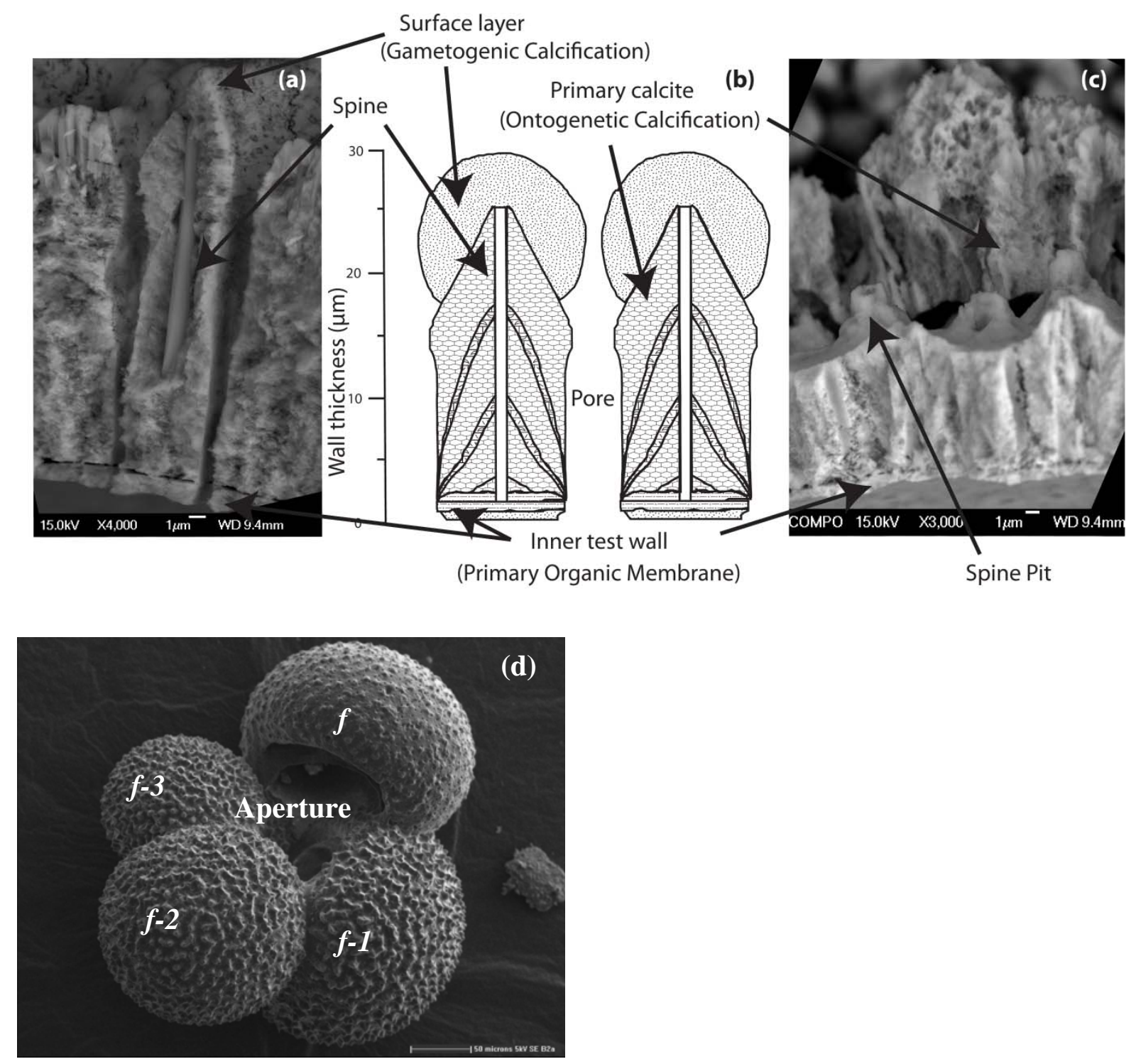

Figure 1. Calcification of the foraminifera test wall. (a) Electron backscattered image of G. bulloides chamber $f$ 1 , which has undergone oxidative and $1 \mathrm{x}$ acid leach cleaning. Spines of the foraminifera have been incompletely resorbed, leaving a remnant in the test wall, the top of which was subsequently covered with gametogenic calcite. (b) Schematic diagram illustrating wall and pore structure of an adult G. bulloides showing successive growth stages of ontogenetic calcification. Successive primary calcite/ontogenetic calcification layers are indicated by bricks with the thin, possibly organic layers between chamber formation indicated by blocks with crescents, inner test wall/primary organic membrane is indicated by dashed lines. Gametogenic calcification/surface layer is indicated by stippling. (Bé, 1980; Erez, 2003; Sadekov et al., 2005). (c) Crosssection through the test wall of foraminifera chamber $f-1$, which has undergone oxidative and reductive cleaning treatments. Complete resorbtion of spines has occurred, with remnants of the outer spine wall clearly visible after primary calcite layer separation. Also illustrated is the relationship between stronger calcite formed in the inner test wall and immediately around the spines, and primary calcite layers. No distinctive dark or light 
banding was observed in these or other samples in this study to indicate the presence of organic layers (Erez, 2003). (d) SEM image of G. bulloides indicating key parts of the foraminifera including the chambers from oldest $(f-2)$ to youngest $(f)$ and the aperture.

\subsubsection{Test calcite trace metal concentrations}

Foraminifera tests are primarily composed of calcite, however within the calcite lattice are inclusions of small amounts of other elements such as $\mathrm{Mg}, \mathrm{Sr}, \mathrm{Al}, \mathrm{Mn}, \mathrm{Zn}$, and $\mathrm{Ba}$, which are known as 'trace metals'. There are three potential primary influences on the concentration of trace metals in primary test calcite; 1) trace metal availability in the ambient water mass (Fig. 2) (Bruland and Lohan, 2003); 2) biological controls on metal incorporation including the minimum metal quota for phytoplankton growth; 3) the species depth in the water column at the time of calcification (Morel et al., 1991; Lea and Boyle et al., 1991; Anand et al., 2003). Post-deposition diagenetic effects can also affect trace metal concentrations in test calcite including dissolution, recrystallisation or adhesion of particles such as clay (e.g. Boyle, 1983; Pena et al., 2005; Sadekov et al., 2010).

Trace metal concentration through the water column varies depending on the elemental source(s), uptake and ocean residency times, and upper ocean stratification, which in turn affect its vertical distribution. Where the respective residency time is shorter than the mixing time required for water column homogenisation, and organic or inorganic demand exceeds supply, the element becomes depleted at the surface and increasingly replete with depth to give a nutrient-like profile, as in the case of $\mathrm{Zn}$ and $\mathrm{Ba}$ (Fig. 2). Alternatively, relatively high flux, low uptake and short residency times leads to scavenged-type profile where the element has maximum concentrations in surface waters e.g. $\mathrm{Mn}$ and $\mathrm{Al}$ (Fig. 2). $\mathrm{Mg} / \mathrm{Ca}$ thermometry takes advantage of the conservative nature and long residency times of both $\mathrm{Mg}$ and $\mathrm{Ca}$ in seawater, providing a relatively uniform temporal and spatial distribution in the water column. As a result of the conservative nature of these elements, it is not the ambient concentration in the water mass that primarily causes variability of $\mathrm{Mg} / \mathrm{Ca}$ in test calcite on time scales shorter than $c a .1 \mathrm{Ma}$, but rather biologically mediated, thermodynamically controlled incorporation of Mg into the calcite lattice (Fig. 2) (Bender et al., 1975; Broecker and Peng, 1982; Lea et al., 1999). Application of the $\mathrm{Mg} / \mathrm{Ca}$ paleothermometer derives from the empirical observation that foraminiferal $\mathrm{Mg} / \mathrm{Ca}$ values increase systematically with seawater temperature (e.g. Anand et al., 2003; Lohmann, 1995; Savin and Douglas, 1973). The usefulness of other trace metals in paleoceanographic research is derived from their close relationships with other 
oceanographic properties such as nutrient distribution in the case of $\mathrm{Zn}$ and $\mathrm{Cd}$ (Boyle, 1981). In addition, the strong inter-basin fractionation of elements with such as Al or Ba short residency times may be a valuable source of information about circulation and mixing between water masses (Boyle and Keigwin, 1985; Bruland and Lohan, 2003; Lea and Spero, 1994). 

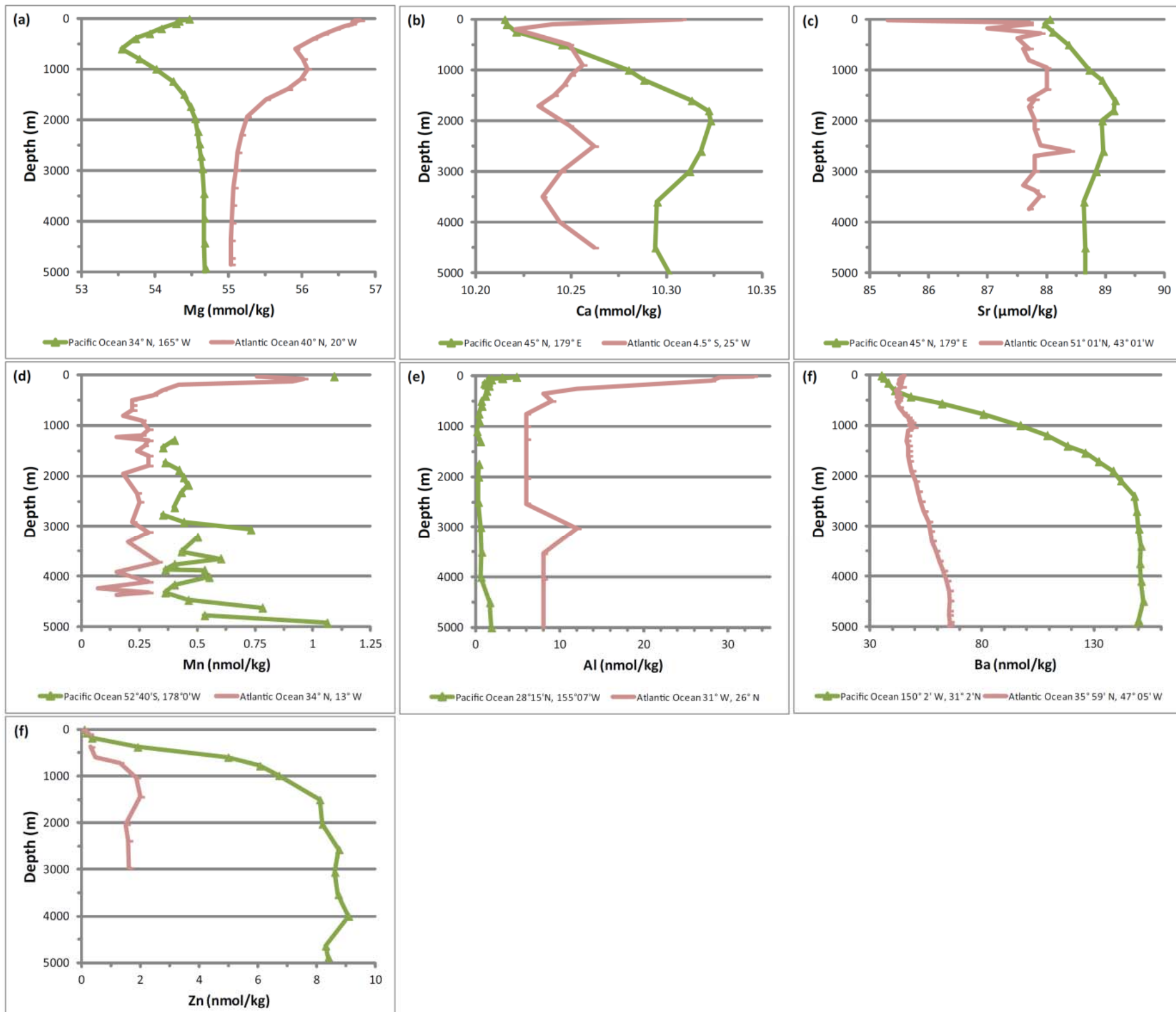

-Pacific Ocean $28^{\circ} 15^{\prime} \mathrm{N}, 155^{\circ} 07^{\prime} \mathrm{W}-$ Atlantic Ocean $31^{\circ} \mathrm{W}, 26^{\circ} \mathrm{N}$

-Pacific Ocean $150^{\circ} 2^{\prime} \mathrm{W}, 31^{\circ} 2^{\prime} \mathrm{N} \longrightarrow$ Atlantic Ocean $35^{\circ} 59^{\circ} \mathrm{N}, 47^{\circ} 05^{\prime} \mathrm{W}$

-Atlantic Ocean $34^{\circ} 06^{\prime}$ N. $66^{\circ} 07^{\prime} \mathrm{W}$

Figure 2. Mean element distributions in seawater for the Pacific (pink symbols/line) and Atlantic Oceans (green symbols/line) of trace metals investigated in this study. (a) $\mathrm{Mg}$, has a residency time of ca.13 Myr and thus a conservative distribution with higher values in the Atlantic due to higher salinity (Broecker and Peng, 1982); (b) Ca has a residency time of $1.1 \mathrm{Myr}$ and is the fifth most abundant element in seawater with a nearly conservative distribution (Broecker and Peng, 1982); (c) Sr, has a residency time of $5.1 \mathrm{Myr}$ and a near vertical profile with a slight surface depletion due to the strontium sulphate shell production of Acantharia plankton (Broecker and Peng, 1982; de Villiers, 1999); (d) Mn has a scavenged vertical profile, with a high surface concentration becoming increasingly replete with depth, and in certain regions, a subsurface maximum in places with low oxygen concentrations. Mn has a residency time of ca.60 yrs (Johnson et al., 1996; Klinkhammer and Bender, 1980; Martin and Knauer, 1980); (e) Al has an ocean residency time of ca.200 yrs and the vertical profile of a scavenged element (Orians and Bruland, 1986). (f) Ba has a ocean residency time of $10 \mathrm{ka}$ and a 
nutrient-like vertical profile with depleted concentrations found at the surface and values increasing to a deep maximum (Chan et al., 1976). (g) $\mathrm{Zn}$ has a residency time of ca.50 ka and a nutrient like vertical profile, highly correlated with Si (Shiller and Boyle, 1985). Graphs adapted from (Johnson et al., 1999).

The degree to which biology controls trace metal incorporation has been the subject of several studies (Delaney, 1989; Delaney et al., 1985; Hathorne et al., 2003; Hönisch et al., 2011; Lea et al., 1999; Nürnberg et al., 1996). For example, biology plays a significant role in controlling the incorporation of trace elements such as Mg. Surface seawater is supersaturated in $\mathrm{Mg}$ with respect to $\mathrm{Ca}$, however foraminifera generally produce a test with a low $\mathrm{Mg}$ content indicating that the organism must actively remove $\mathrm{Mg}^{2+}$ from vacuolized seawater (seawater within the cytoplasm) prior to calcite precipitation (Bentov and Erez, 2006; Lea et al., 1999). This removal likely occurs in conjunction with $\mathrm{pH}$ elevation at the site of calcification to overcome Mg precipitation-inhibition (de Nooijer et al., 2009).

As a result of biologically mediated controls on foraminiferal test calcite $\mathrm{Mg}$ levels, the $\mathrm{Mg} / \mathrm{Ca}$ ratios differ markedly from that predicted by thermodynamic calculations (Bender et al., 1975) in two fundamental ways. First, foraminifera contain 5-10 times less Mg than predicted by thermodynamics. Second, the response of shell $\mathrm{Mg}$ to temperature is $\mathrm{ca} .3$ times larger averaging 9-10 \% per ${ }^{\circ} \mathrm{C}$, than the thermodynamic prediction and inorganic observation of $3 \%$ per ${ }^{\circ} \mathrm{C}$ (Cléroux et al., 2008; Lea et al., 1999; Marr et al., 2011; McConnell and Thunell, 2005). While it is possible that these biological controls also mediate the incorporation of bioactive trace metals such as $\mathrm{Zn}$ and $\mathrm{Mn}$, or metals which appear to not have a biological function such as $\mathrm{Ba}$ and $\mathrm{Sr}$, the mechanism(s) by which this may happen is currently unknown. Such biological effects are commonly referred to as 'vital effects' and are a source of natural 'noise' or variance within data (e.g. Bentov and Erez, 2006; Lear et al., 2002; Sadekov et al., 2005).

\subsubsection{Foraminifera ecology}

It is commonly recognised that upper ocean organisms inhabit specific depth(s), dependant on the prevailing surface water conditions and stage of lifecycle (Hemleben et al., 1989). Thus foraminiferal vertical migration pattern and depth of calcification determine what level in the water column the geochemical signal represents. Typically, the planktic foraminiferal lifecycle is no longer than a month. It takes less than 8 hours to fully calcify any one chamber, with final chamber calcification (chambers $f$ to $f-3$ in G. bulloides or $f$ to $f-2$ in G. ruber - Fig. 3) occurring in the final two weeks (Spero pers. comm, 2012). Therefore, the calcite of any 
specific chamber preserves a 'snapshpot' of surface water conditions at the time and depth of calcification (Bé et al., 1979; Hemleben et al., 1989).
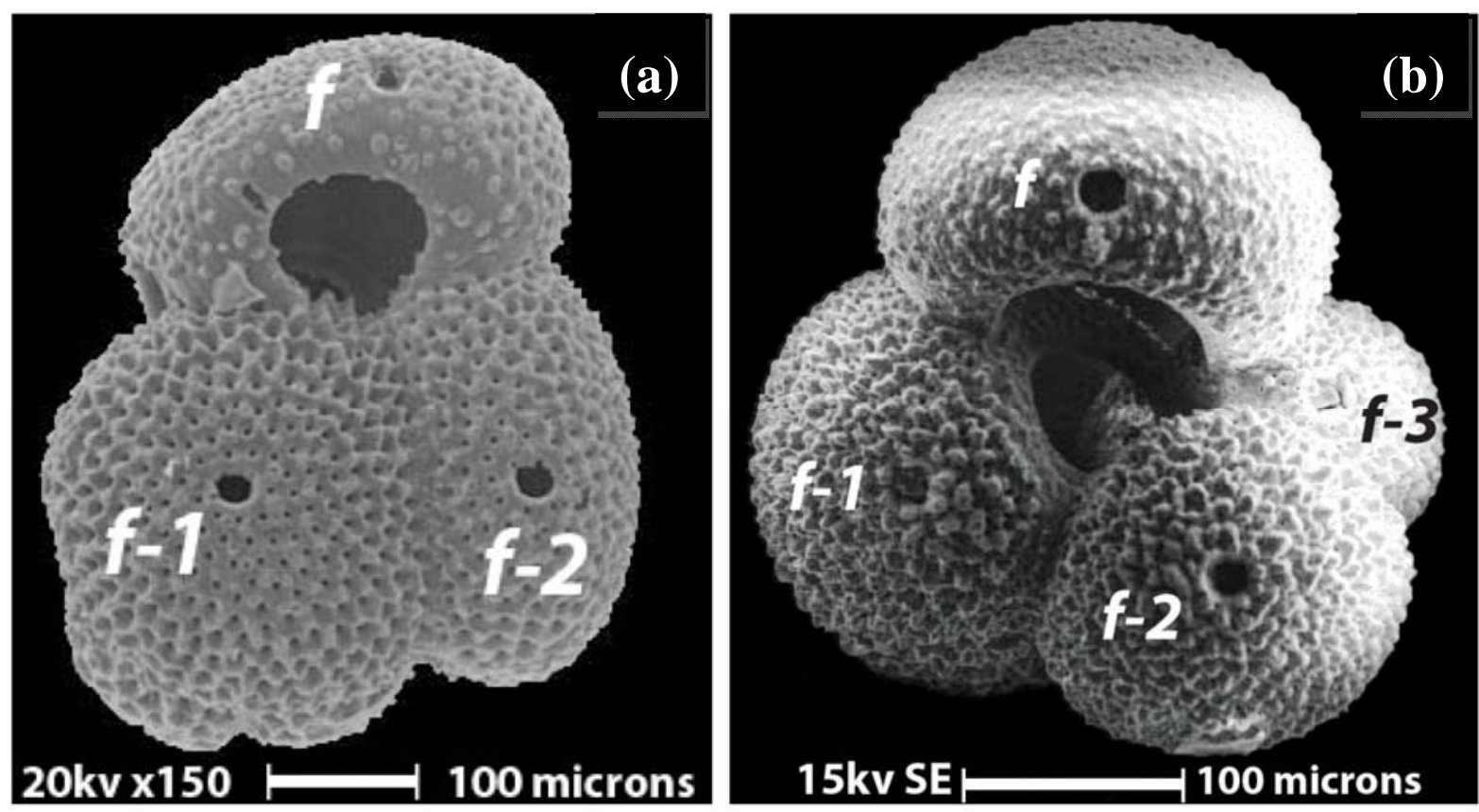

Figure 3. Scanning electron microscope images of G. ruber (a) and G. bulloides (b) analysed using laser ablation inductively coupled plasma mass spectrometry (LA-ICPMS) in this study. The chambers are labelled such that $f$ represents the final (youngest) chamber, $f-1$ is the penultimate chamber, $f-2$ is the antepenultimate chamber and $f-3$ the oldest chamber analysed. Circular laser ablation pits are shown in each G. bulloides chamber.

When assessing how foraminiferal species trace metal geochemistry reflects paleocean conditions there are two types of depth that need to be taken into account: 1) the natural depth habitat of the species and known migrations within its lifecycle, 2) the depth that a particular proxy has been calibrated for. It is best practice to develop modern calibrations specific to the depth and species targeted for paleoceanographic analysis due to variations in surface water trace metal concentrations and wider environmental conditions such as light or nutrient levels. These factors, in addition to other species specific biology, such as the microhabitat created by algal symboints associated with some species, may affect the kinetic or metabolic fractionations of an element and therefore its sensitivity to changing environmental conditions (Fig. 4) (Kucera et al., 2005; Lea et al., 1999; Rosenthal, 2007). For example, while $G$. ruber is restricted to the upper photic zone $(0-50 \mathrm{~m})$ due to its symbiotic activity, it also has a slightly lower $\mathrm{Mg} / \mathrm{Ca}$ sensitivity to temperature change than $\mathrm{G}$. bulloides, which 
tends to dwell between 50-200 m depending on lifecycle stage (Bé, 1977; Condie and Dunn, 2006; Hemleben et al., 1989; Mortyn and Charles, 2003; Wilke et al., 2009b).

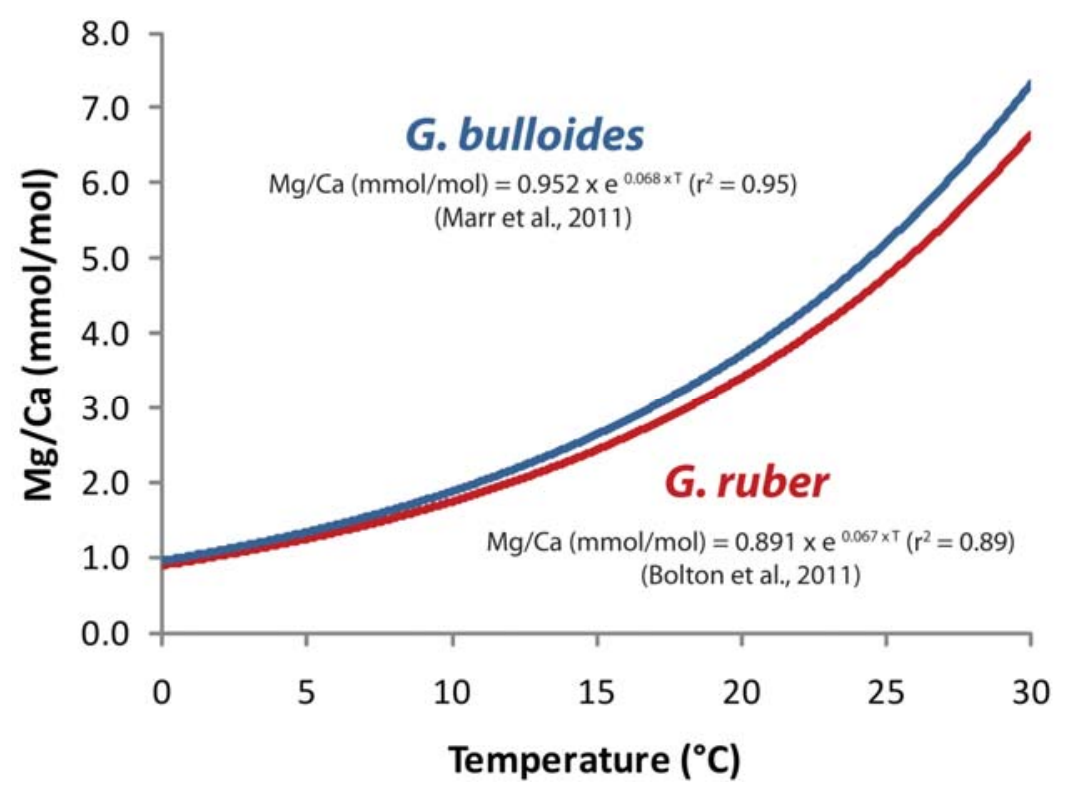

Figure 4. Species specific $\mathrm{Mg} / \mathrm{Ca}$-temperature calibrations for G. bulloides (blue) and G. ruber (red) from the Southwest Pacific Ocean (Bolton et al., 2011; Marr et al., 2011). Temperature curves extend beyond the species temperature tolerance levels to assist in the illustration of the calibration offset. The calibrations converge at lower temperatures and diverge at higher temperatures, illustrating the increased importance of species specific calibrations in warmer modern or paleoclimates. Note, calibrations have been extended beyond the typical species temperature ranges to better illustrate the calibration relationships.

\subsubsection{Seasonality and depth habitat}

Like physical proxies, geochemical proxies can only be applied as far back in time as the relationship between species ecology and the target chemical process are the same. Even if the metabolic or biochemical pathway responsible for incorporation of the chemical signal remains the same, any change in calcification depth or season(s) of peak productivity will alter the meaning of the reconstructed record (Kucera, 2007).

Species-specific stratification can be useful for the determination of stratified paleo surface water conditions. However, it can also lead to offsets between paleothermometry records with depth dependant variance in seasonal temperature range, as recorded in physical oceanographic data (e.g. Heath, 1985b; Locarnini et al., 2006). Organisms which have a specific surface water niche such as coccolithophores (ca. 0-20 m depth) experience a far greater seasonal range of temperatures at mid-latitudes of ca. $3-5^{\circ} \mathrm{C}$ than for example, sub- 
surface dwelling G. bulloides, which has a depth range of approximately 50-200 m (e.g. Condie and Dunn, 2006) and associated seasonal temperature range of $<1{ }^{\circ} \mathrm{C}$ (Heath, 1985b; Locarnini et al., 2006). As a consequence, change in seasonal peak productivity for surface dwelling species will have an impact on any paleotemperature record. Seasonally specific productivity peaks vary between marine organisms depending on species-specific optimal conditions, e.g. nutrient and light availability, temperature for surface dwelling species, level of competition and physical mixing (e.g. Hemleben et al., 1989; Smyth et al., 2002). Modern ocean planktic foraminifera generally have a spring bloom productivity cycle when high nutrient levels are present following winter mixing, coupled with warmer temperatures, and higher light levels for those species with symboints (King and Howard, 2001; Kuroyanagi et al., 2002; Thunell and Reynolds, 1984). However, this foraminiferal spring productivity peak is offset from that of coccolithophores, which tend to peak in summer owing to increased light levels and surface water stratification accompanied by reduced competition (Sikes et al., 2005; Tyrrell and Merico, 2004). Furthermore, these productivity generalisations can change on a regional and inter-annual basis, and therefore as surface water conditions change through time, so too may the timing of species-specific productivity peaks (King and Howard, 2001; Murphy et al., 2001; Neil et al., 2004; Nodder and Northcote, 2001; Sikes et al., 2005).

\subsubsection{Planktic foraminifera genotypes}

Planktic foraminiferal species have a limited diversity compared to benthic forms, numbering at around fifty extant species, traditionally identified based on test shape (Hemleben et al., 1989). Diversity typically peaks in the sub-tropics and decreases steeply towards the poles (Rutherford et al., 1999). Recent genetic studies, however, show that individual species such as G. bulloides are actually comprised of several discrete genetic types (genotypes) (Darling and Wade, 2008; Kucera and Darling, 2002). Many of these genotypes have distinct ecologies and novel adaptations leading to distinctive biogeographies.

G. bulloides has seven distinct genotype groups ranging from tropical to polar latitudinal provinces (Fig. 5) (Darling et al., 2007; Darling et al., 2003; Darling and Wade, 2008; Darling et al., 1999; Darling et al., 2000). The G. bulloides genotypes are split principally into two groups (Type I and Type II), which have distinct ecologies. Two Type I genotypes are found in subtropical/tropical waters: Type Ia has been found in the Coral Sea and Arabian Sea (Darling and Wade, 2008; Darling et al., 1999) and Type Ib in the Mediterranean and off the Canary Islands (Darling and Wade, 2008; de Vargas et al., 1997). 


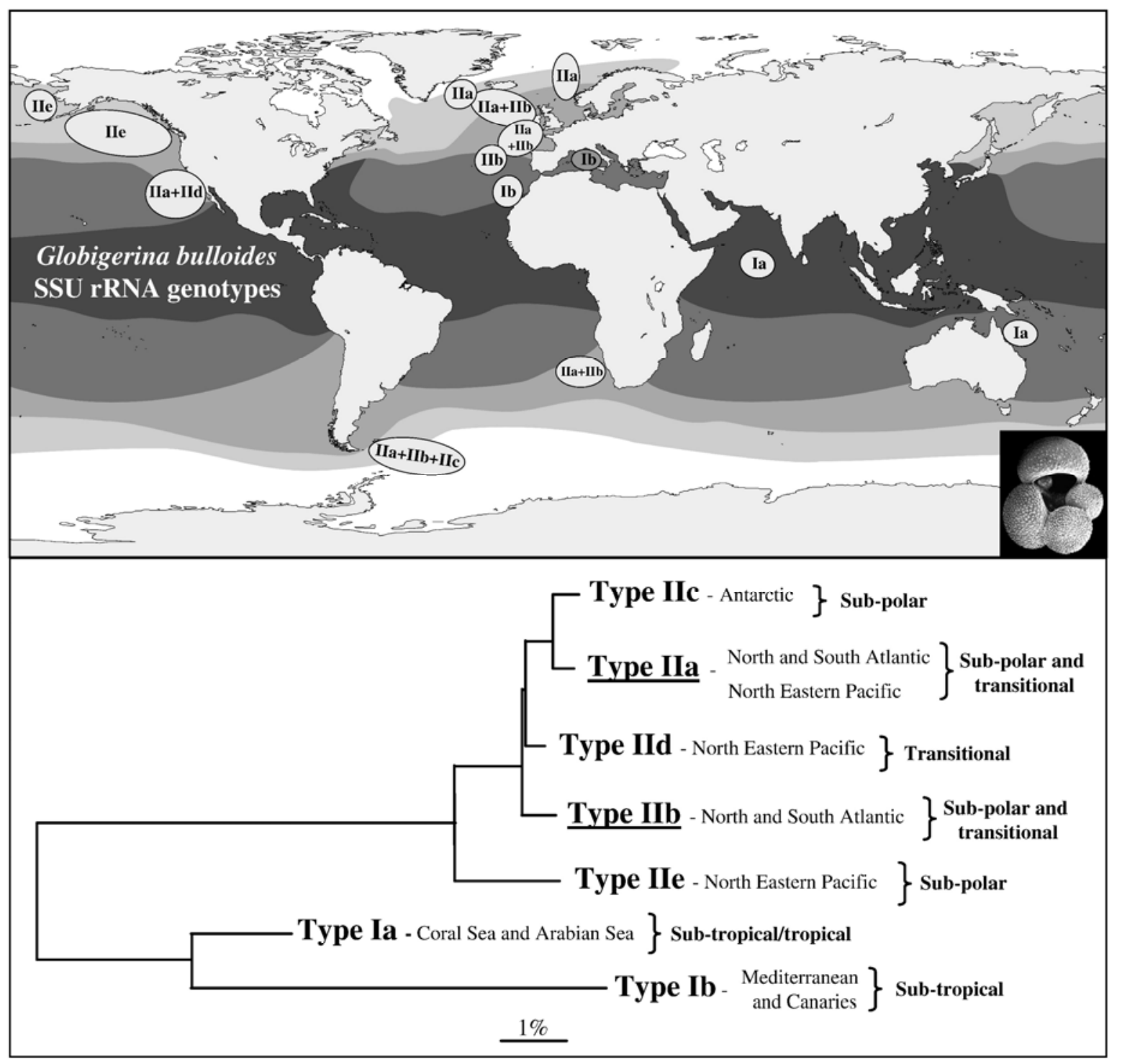

Figure 5. The biogeographical distribution (shaded) and evolutionary relationships for genotypes of $G$. bulloides. Bipolar genotypes are underlined (from Darling et al., 2008).

The Type II genotypes are typically found in cooler waters in the subpolar and transitional zones. Five Type II genotypes have been identified (Types IIa-IIe). Type IIa and Type IIb are bipolar genotypes, also found in the subpolar Arctic and Antarctic (Darling et al., 2007; Darling et al., 2000). However, while Type IIa and IIb occur together they have distinct ecological preferences. Type IIa is found in greatest abundance in the coldest subpolar waters, where Type IIb is absent (Darling and Wade, 2008). Seasonality studies also indicate that Type IIa advances ahead of Type IIb with the spring plankton bloom (Darling and Wade, 2008). Type IIc has currently only been identified in the subpolar Antarctic (Darling et al., 2000). 
The picture of genotype distribution of G. bulloides in the North Pacific, however, is entirely different from other ocean basins with distinctly different genotypes. Type IId is most commonly identified in subtropical regions while type IIe is only identified in subpolar waters (Darling et al., 2007).

The implications of this genetic diversity on trace metal incorporation or test development for G. bulloides has not been studied to date. However, the similarity of trace metal results from a number of ocean basins for G. bulloides (Marr et al., 2011) suggests that $\mathrm{Mg} / \mathrm{Ca}$ paleothermometry at least is unlikely to be significantly affected by species genotype.

There are four distinct genotypes for the G. ruber species, increasing in diversity towards the tropical regions (Fig. 6) (Darling and Wade, 2008). There are two main genotype groups for this species, Type I and Type II with Type IIa likely to represent a species level distinction. A high degree of genetic distinction also exists between the two morphotypes of G. ruber pink and white which both fall within Type I. The difference in test morphotype between these genotypes is also clearly evident. The tests of the G. ruber (white) morphospecies exhibit extensive morphological variation aligned to the genotype groupings and may be indicative of unique species adaptations. G. ruber $\mathrm{Mg} / \mathrm{Ca}$ ratios are also known to vary with the morphotype analysed, suggesting that geonotype differences for this species may have a significant effect on its use as a paleothermometer (Steinke et al., 2005). In this study only G. ruber white was analysed and results assessed using regionally derived calibrations (Bolton et al., 2011), which have the advantage of naturally accounting for any $\mathrm{Mg} / \mathrm{Ca}$ variation caused as a result of glacial-interglacial changes in regional genetic variability. 


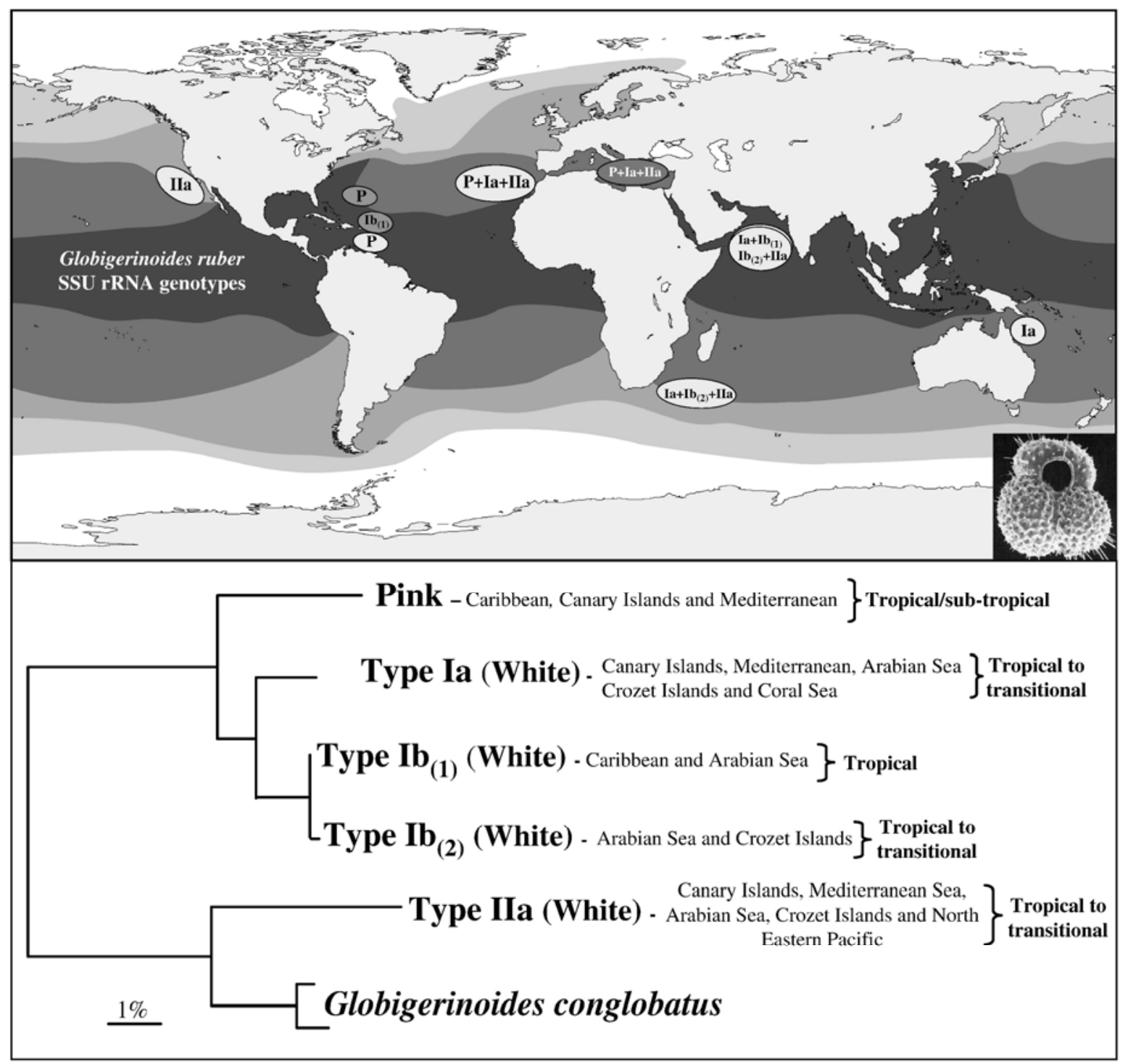

Figure 6. The biogeographical distribution (shaded) and evolutionary relationships for genotypes of the species G. ruber (from Darling et al., 2008).

\subsubsection{Other controls on foraminifera calcification - The carbonate ion effect}

Most of the surface ocean is supersaturated with respect to both the calcite and aragonite forms of calcium carbonate. Therefore, it is possible that small changes in surface-ocean carbonate chemistry would not have a significant effect on marine calcification (Fig. 7). For example, an increase in carbonate ion availability in the surface water may make it easier for foraminifera to produce the calcium carbonate required for chamber formation, potentially leads to an increase in the amount of calcite deposited (e.g. Spero et al., 1997). However, a range of studies have shown a strong dependence of carbonate production rates on the degree of supersaturation, concluding that the rate of carbonate production was positively correlated 
with the carbonate saturation state of seawater (e.g. Kleypas et al., 1999; Langdon et al., 2000; Riebesell et al., 2000). Similar results have also been identified for planktic foraminiferal calcification and thus foraminiferal test weights (Barker, 2002b; Moy et al., 2009; Spero et al., 1997).

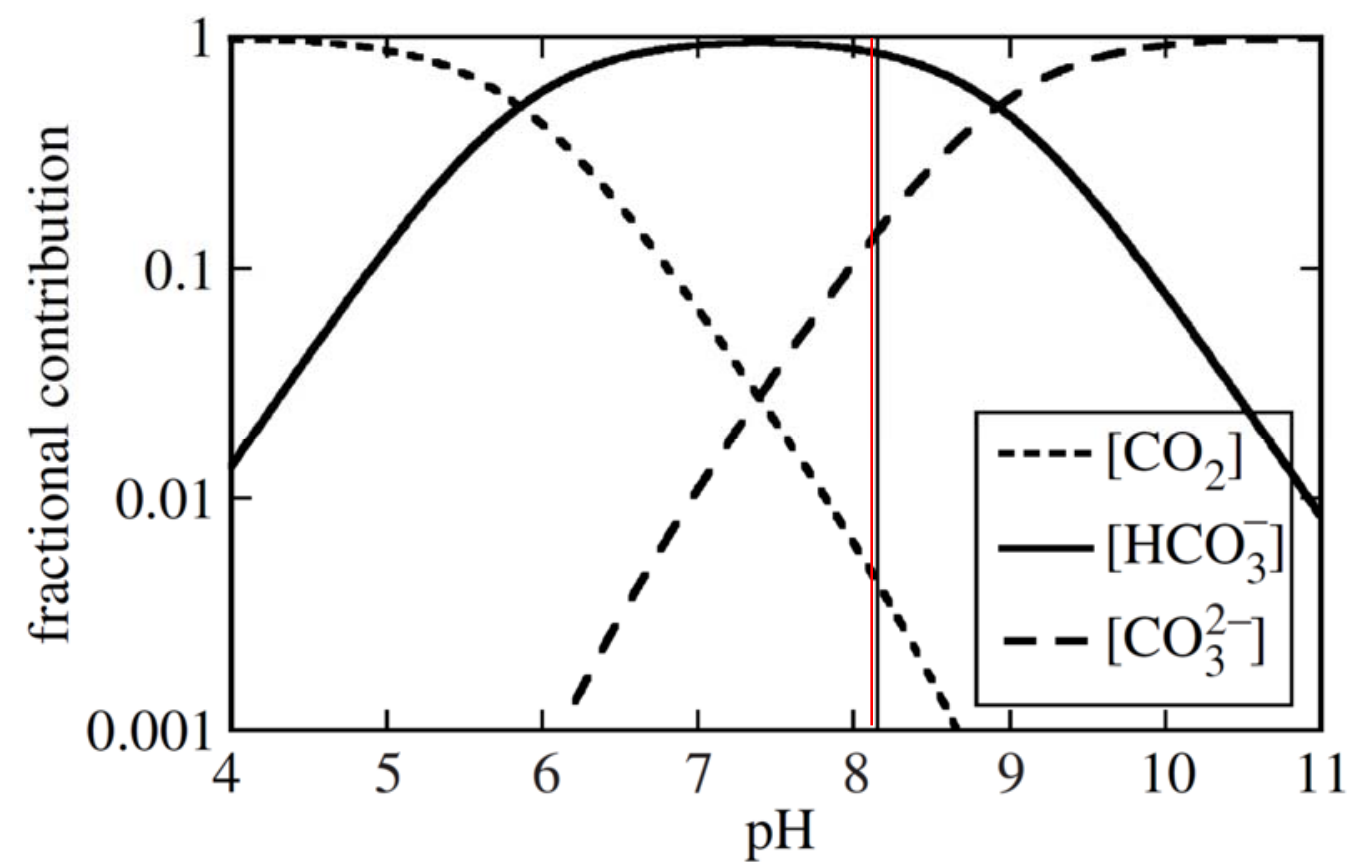

Figure 7. Bjerrum plot showing the relative contributions of $\mathrm{CO}_{2}$, bicarbonate $\left(\mathrm{HCO}_{3}^{-}\right)$and carbonate $\left(\mathrm{CO}_{3}^{2-}\right)$ ions to total dissolved inorganic carbon as a function of $\mathrm{pH}$. Typical surface seawater $\mathrm{pH}$ is indicated by the vertical red line i.e. $\mathrm{pH}=c a .8 .2$, and is therefore dominated by $\mathrm{HCO}_{3}{ }^{-}$(modified from Barker et al., 2003b).

It is difficult to quantify how calcifying foraminifera have responded to changes in the surface ocean $\left[\mathrm{CO}_{3}{ }^{2-}\right]$ levels, or if in fact change in open ocean test weights are a direct result surface water $\left[\mathrm{CO}_{3}{ }^{2-}\right]$. However, recent modern observational and modelling studies have made significant inroads into establishing what variations might occur (Barker and Elderfield, 2002; Flynn et al., 2012; Moy et al., 2009). Spero et al. (1997) laboratory experiments suggested that higher rates of calcification in the symbiont-bearing species Orbulina universa, induced by increased carbonate ion concentrations $\left(\left[\mathrm{CO}_{3}{ }^{2-}\right]>600 \mu \mathrm{mol} / \mathrm{kg}\right)$, resulted in tests $37 \%$ heavier than those grown in ambient seawater. In addition, Moy et al. (2009) also found that post-industrial modern G. bulloides test weights were 30-35\% lower than pre-industrial sediment samples in the Southern Ocean, linking this result to a decrease in modern ocean $\mathrm{pH}$ and carbonate saturation levels. 
Other factors that may affect calcification include sea surface stratification, by reducing the available nutrients necessary for primary production in the euphotic zone (Barker et al., 2003b). Increasing vertical stratification also affects the $\mathrm{CO}_{2}$ draw down by, in effect, reducing the oceanic volume available to $\mathrm{CO}_{2}$ absorption from the atmosphere. Foraminiferal calcification also relies upon temperature, light (if symbiont-bearing) and potentially 'food' availability for grazing zooplankton species, which varies as a function of surface water nutrient levels (e.g. Gonzalez-Mora et al., 2008; Hemleben et al., 1989; Lombard et al., 2011; Lombard et al., 2009).

\subsubsection{Regional Setting}

The Southwest Pacific, east of New Zealand, is a challenging environment to undertake paleoceanographic studies because of the varying water masses and dynamic current and frontal systems. To the north of the subtropical front (STF) lies the South Pacific Gyre (SPG) (Fig. 8). The East Australian Current (EAC) flows south along eastern Australia, with a component detaching to form the eastward flowing Tasman Front (TF) (Ridgway and Dunn, 2007). This frontal flow attaches to northern New Zealand as the East Auckland Current (EAUC) and its southward continuation as the East Coast Current (ECC) continues to Chatham Rise before being steered eastward (Ridgway and Hill, 2009; Tilburg et al., 2001). Seaward of the ECC is the anticyclonic, warm-core Wairarapa Eddy (WE) associated with the East Cape Eddy system. Eddies shed near East Cape propagate southwest along the continental margin to Hawke Bay where they may stall or merge with a previous perturbation to form the Wairarapa Eddy (Chiswell, 2005; Roemmich and Sutton, 1998).

South of the STF, the inflow is dominated by the Antarctic Circumpolar Current (ACC) whose leading edge is the Subantarctic Front (SAF). The SAF is forced south around the bathymetric barrier of Campbell Plateau and then northeast separating Subantarctic Surface Water (SAW) from colder Circumpolar Surface Water (CSW) to the east and south (Fig. 8) (Heath, 1985a; Morris et al., 2001).

These subtropical and subantarctic inflows create a dynamically-driven modern upper ocean (Fig. 8). The boundary between the two inflows is the STF positioned along the east-west crest of Chatham Rise (Chiswell, 2002a). The front separates warm, saline, micronutrientrich, macronutrient-poor subtropical surface water (STW) in the north from cold, less saline, 
micronutrient-poor, macronutrient-rich SAW to the south (Boyd et al., 1999; Ellwood et al., 2008; Locarnini et al., 2006).

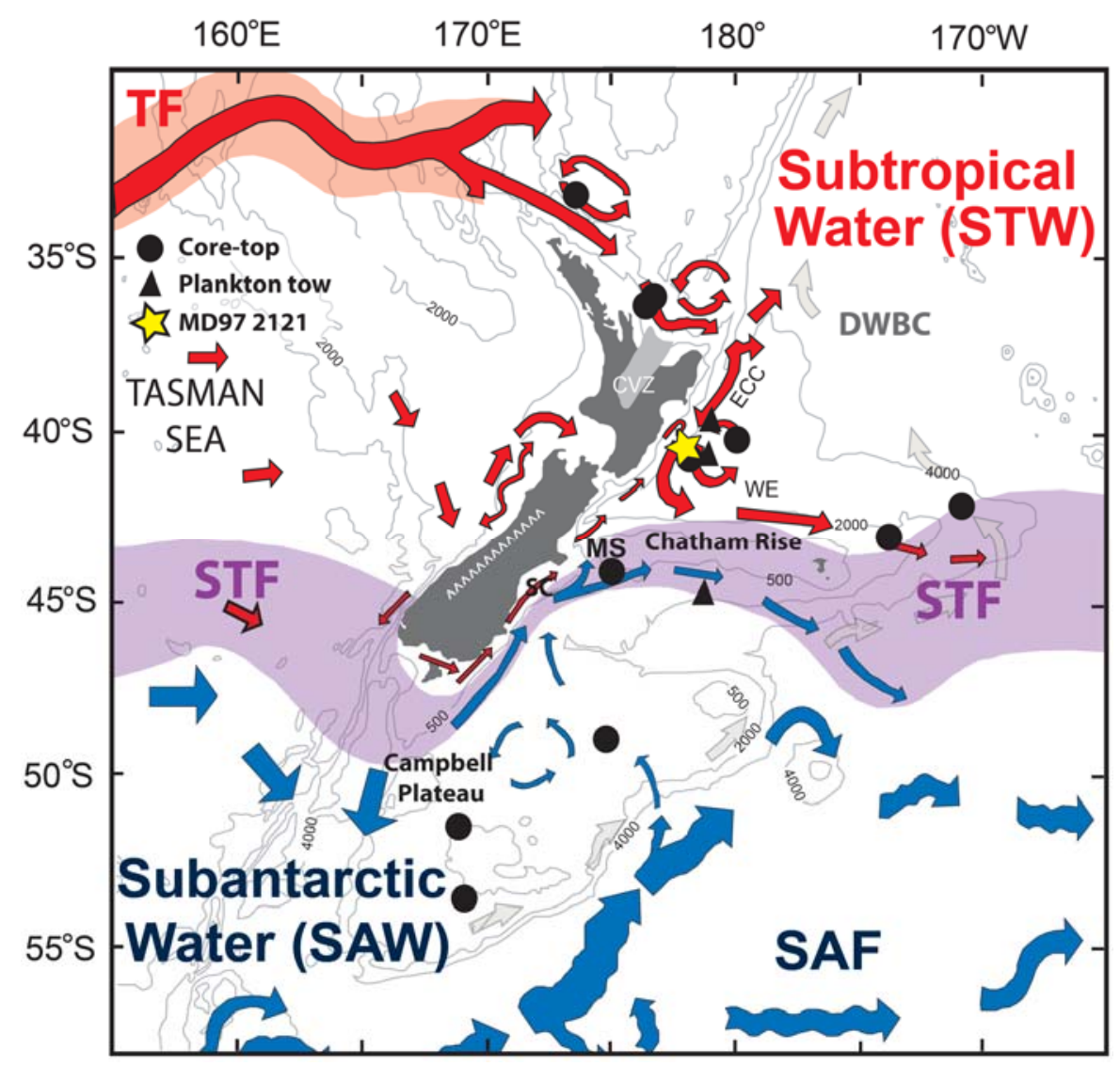

Figure 8. Generalised modern surface ocean currents and bathymetry surrounding New Zealand (modified from Carter et al., 1998). Black circles and triangles mark the core-top and plankton tow sites respectively where original modern data used in this thesis is derived from. Yellow star indicates core site MD97 2121 from which the 0-25ka paleoceanographic records contained in this thesis are derived. TF-Tasman Front; STF-Subtropical Front; SAF-Subantarctic Front; ECC-East Cape Current; STW-Subtropical Surface Water; SAW-Subantarctic Surface Water; MS-Mernoo Saddle; WE-Wairarapa Eddy; CVZ-Central volcanic zone; ^^Southern Alps. Isobaths are in metres.

\subsubsection{Glacial-Interglacial Oceanography}

During the LGM changes in the dominance and influence of the specific currents occurs near the MD97 2121 site. At the sea surface, temperatures were $5^{\circ} \mathrm{C}$ colder than present (Pahnke and Sachs, 2006; Carter et al., 2008) and microfaunas contained Neogloboquadrina pachyderma with subtropical forms being either rare or absent (Weaver et al., 1998; Northcote et al., 2007) suggesting the region was dominated by SAW from the south. In part, this reflects an increase in strength of the ACC, forcing more water through Pukaki Saddle, 
increasing the speed of the Bounty Gyre and forcing more SAW northwards through Mernoo Saddle (MS) onto the MD97 2121 site (Neil et al., 2004). In addition, the Southland Current (SC) had a more expansive role off southeastern North Island, carrying ca. 90\% SAW, and an increased SC flow through the MS acted to force the subtropical waters of the East Cape Current and the Wairarapa Eddy further offshore along the northern side of the Chatham Rise (Sutton, 2003; Carter and Manighetti, 2006; Nelson et al., 2000).

The STF is today semi-locked into place by the bathymetric influence of the Chatham Rise. The currents that flow along the northern and southern flanks of the rise and dynamically position the STF to the rise crest (Heath, 1972 and Heath, 1981). Paleoceanographic studies suggest that, in the Chatham Rise region, the STF has remained in this position through recent glacial-interglacial cycles (Fenner et al., 1992; Nelson et al., 1993; Weaver et al., 1998; Sikes et al., 2002). However, during the glacial there was an increase in upwelling due to strengthening in zonal westerly winds (Nelson et al., 2000).

In Antarctica and the Southern Hemisphere an event referred to as the "Antarctic Cold Reversal' (ACR) occurred at approximately $14.5 \mathrm{ka}$ and lasted for two millennia. It is recognized in both terrestrial and marine settings and brought an average cooling of ca. 2$3{ }^{\circ}$ C. (e.g. Carter et al., 2008; Putnam et al., 2010; Vandergoes et al., 2008). The Mystery Interval (MI) - a period of rapid and often contradictory change in the Northern Hemisphere (Denton et al., 2006). Millennial-scale MI events may be manifested in the Southern Hemisphere by the southward forcing of the Intertropical Convergence Zone (ITCZ) (Denton et al., 2010). In the Southern Hemisphere, the MI was accompanied by a poleward shift of zonal westerly winds, a general warming of the upper ocean (Barrows et al., 2007; Calvo et al., 2007), and increased Southern Ocean upwelling (Anderson et al., 2009).

Foraminiferal stable isotope, assemblage and trace metal values have been used extensively to understand hydrological and climatological changes (e.g.Carter et al., 2008; CLIMAP, 1976; Elderfield and Ganssen, 2000; Fenner et al., 1992; MARGO et al., 2009). Other techniques such as the use of alkenone undersaturation values as a paleothermometer compliment understandings derived from foraminifera (e.g. Pahnke and Sachs, 2006; Pahnke et al., 2003). The relative strengths and weaknesses of using foraminiferal trace metal values and alkenone values as paleoproxies and how they may assist us to understand changes which occurred during the last glacial maximum and subsequent transition will be explored in this thesis. 
Chapter 2 


\section{DIFFERENTIAL EFFECTS OF CLEANING PROCEDURES ON THE TRACE ELEMENT CHEMISTRY OF PLANKTIC FORAMINIFERA}

Marr, J. P., H. C. Bostock, L. Carter, A. Bolton and E. Smith, 2013. Differential effects of contrasting cleaning procedures on the trace element chemistry of planktic foraminifera. Chemical Geology, http://dx.doi.org/10.1016/j.chemgeo.2013.05.019

\section{Author Contributions:}

Julene Marr; data collection, interpretation, manuscript writing

Lionel Carter, Helen Bostock; general supervision

Monica Handler; general supervision; assistance with geochemical analysis

Annette Bolton; general discussion.

Euan Smith; assistance with statistical analysis and interpretation.

\section{Abstract}

We have investigated the effects of different sample cleaning procedures on six trace element/Ca ratios in Globigerina bulloides, a planktic species widely used in paleoenvironmental reconstructions. Foraminifera from core-top and down-core sediments were cleaned using seven different methods. Individual foraminifera were analysed before and after cleaning using laser ablation inductively coupled plasma mass spectrometry (LAICPMS). We present a comparison between oxidative and reductive cleaning, and an analysis of the effect of using laser ablation verses solution-based ICPMS methods. Measurements of $\mathrm{Mg} / \mathrm{Ca}$ and $\mathrm{Sr} / \mathrm{Ca}$ values were identical whether samples were subjected to oxidative, 
reductive treatments, two-four acid leach treatments or a combination thereof. However, ultra trace element ratios $\mathrm{Al} / \mathrm{Ca}, \mathrm{Mn} / \mathrm{Ca}, \mathrm{Zn} / \mathrm{Ca}$ and $\mathrm{Ba} / \mathrm{Ca}$ are much more sensitive to the cleaning method, with up to an order of magnitude difference between techniques. $\mathrm{Al} / \mathrm{Ca}$ was progressively removed with more intensive cleaning, but six or more acid leach treatments were required for full removal of this contaminant phase. $\mathrm{Mn} / \mathrm{Ca}$ and $\mathrm{Ba} / \mathrm{Ca}$ required a combination of oxidative and reductive and/or acid leaching for contaminant phase removal. By contrast, $\mathrm{Zn} / \mathrm{Ca}$ values increased after acid leaching cleaning procedures. This may be a reflection of preferential dissolution of low- $\mathrm{Zn}$ calcite. Accurate measurement of $\mathrm{Zn} / \mathrm{Ca}$ in planktic foraminifera by solution methods requires oxidative and reductive treatment without acid leaching or alternatively, the use of an in situ method such as laser ablation ICPMS. Careful data processing following laser ablation ICPMS analysis appears to be the most effective method to ensure elimination of ultra trace metal TE/Ca contaminant phases.

\subsection{Introduction}

The use of the $\mathrm{Mg} / \mathrm{Ca}$ compositions of planktic foraminifera test calcite as a paleothermometer is now well-established (e.g. Anand et al., 2003; Cléroux et al., 2008; Pahnke et al., 2003) and has stimulated further interest in the use of other trace metals as geochemical proxies to track paleo-productivity, nutrient, fluvial input and ocean front migration through time (Hall and Chan, 2004; Hönisch et al., 2011; Lea and Boyle, 1991; Marchitto et al., 2000; Marr et al., in press-b). However, while our understanding of how foraminiferal trace elements reflect the natural environment is rapidly developing and these elements are more commonly being measured, there has not yet been a clear study on the effects of pre-cleaning protocols, especially pertinent as different analytical methods commonly employ different cleaning techniques. This is especially critical for elements such 
as $\mathrm{Zn}$ or $\mathrm{Mn}$, for example, which have much lower concentrations in the test calcite than $\mathrm{Mg}$ or Sr, and are highly susceptible to contamination from organic matter, clays and ferromanganese oxide coatings.

Three main methods of analysing foraminiferal calcite have been established for determining trace element/Ca (TE/Ca) values. Two involve test calcite dissolution; either the complete dissolution prior to analysis (e.g. Barker et al., 2003a; Rosenthal et al., 2004) or progressive dissolution during analysis ('flow-through' method) (Haley and Klinkhammer, 2002; Klinkhammer et al., 2004). The third approach employs in situ analyses to target individual tests using electron microprobe, secondary ion mass spectrometry, or laser ablation inductively coupled plasma mass spectrometry (LA-ICPMS). Such techniques enable repeat analyses of individual tests at a high spatial resolution $(2-35 \mu \mathrm{m})$ with minimal sample destruction (e.g. Eggins et al., 2003b; Sadekov et al., 2010). Due to the nature of the different techniques, a range of strategies are employed for mitigating the potential impact of contamination. Pre-cleaning procedures vary for dissolution-based analyses depending on the trace element ratio(s) being targeted and level of test calcite contamination (e.g. Barker et al., 2003a; Boyle, 1981). The suite of chemicals used may affect the trace element chemistry of the primary calcite, depending on how the solution and its constituents interact with test calcite. It is now well established that partial test dissolution can artificially lower $\mathrm{Mg} / \mathrm{Ca}$ values of test calcite both in the natural and laboratory environments in response to preferential dissolution of Mg-rich portions of the calcite (Barker et al., 2003a; Benway et al., 2003; Dekens et al., 2002; Rosenthal and Lohmann, 2002). For example, Barker et al. (2003) showed that the combined effect of chemical-based cleaning techniques can reduce $\mathrm{Mg} / \mathrm{Ca}$ values by as much $25 \%$. The most affected elements however, are likely to be those that occur in ultra-low concentrations in formaminiferal calcite and are most susceptible to 
contamination and the inefficient removal of contaminant phases. As an example, Lea and Boyle (1991) found that levels of $\mathrm{Ba} / \mathrm{Ca}$ were reduced by up to $53 \%$ when different precleaning methods were employed (Lea and Boyle, 1991). In addition, there has been recent speculation that the early loss of the fragile final chamber of planktic foraminifera during cleaning may produce offsets between the results of laser ablation and solution based methods (Marr et al., 2011). However, as traditional solution-based methods require complete dissolution of the tests prior to analysis, the mechanism(s) by which these cleaning techniques reduce sample TE/Ca cannot be readily resolved.

The more recently developed in situ LA-ICPMS technique takes a different approach, initially removing test surface contamination via ablation and later discriminating between contaminated or primary TE/Ca values during data processing (e.g. Eggins et al., 2003). As in situ methods have the ability to discriminate between foraminiferal samples after analysis it has been assumed that extensive pre-treatment is not required (Sadekov et al., 2009).

In this study we examine the differential effects of various cleaning methods on the measurement of trace element ratios in the planktic foraminifera, G. bulloides. The key benefit to using laser ablation for this study is that we are able to undergo one particular treatment on an individual foraminifera, analyse by LA-ICPMS, then chemically treat the same specimen before geochemical reanalysis and imaging. Using this technique we are able to build a progressive picture of how the different cleaning methods affect the test through different stages of the cleaning process. 


\subsection{Methods}

\subsection{Samples and sample preparation}

Globigerina bulloides is a shallow dwelling ( $\sim 60 \mathrm{~m}$ water depth) spinose, planktic foraminifera that calcifies multiple chambers, progressively adding calcite layers to older chambers with each new chamber addition (Fig. 9). The G. bulloides examined here were picked from sieved core-top sediment samples (size fraction 250-400 $\mu \mathrm{m}$ ) from site D178, Southwest Pacific Ocean at $51.72^{\circ} \mathrm{S}, 169.83^{\circ} \mathrm{E}$ and water depth $629 \mathrm{~m}$ (Marr et al., 2011) with the antepenultimate or chamber $f-2$ targeted for analysis. Surface waters overlying D178 are characterised as cold, micronutrient-depleted, Subantarctic Water (Bowie et al., 2009; Boyd et al., 2001) and the radiocarbon age of the sediment is $4835 \pm 33$ yrs (Marr et al., 2011). G. bulloides samples previously investigated from this site (Marr et al., 2011) were determined to have experienced negligible post-depositional alteration as informed by examination under scanning electron microscopy (SEM).

A summary of the sample preparation procedures is given in figure 2, with further detail in Auxiliary information 1-3. All foraminifera were first treated with cleaning procedures typically used in LA-ICPMS analytical studies (e.g. Eggins et al., 2003; Sadekov et al., 2005). These are designed to remove clay contaminants and involve three ultrasonication washes in ultrapure water for 2-3 seconds, replacing the water after each ultrasonication. This was followed by two rinses in AR-grade methanol (AI. 1). Individual specimens were then mounted on a NIST610 silicate glass standard ready for LA-ICPMS analysis (analytical details described below). After this initial analysis of each test, individual foraminifera were then cleaned using various steps modified from common solution-based methods (Barker et al., 2003a; Boyle and Keigwin, 1985). Individual foraminifera were subjected to each 
cleaning step separately so that each specific individual could be traced throughout the entire study ensuring all data presented are co-related.

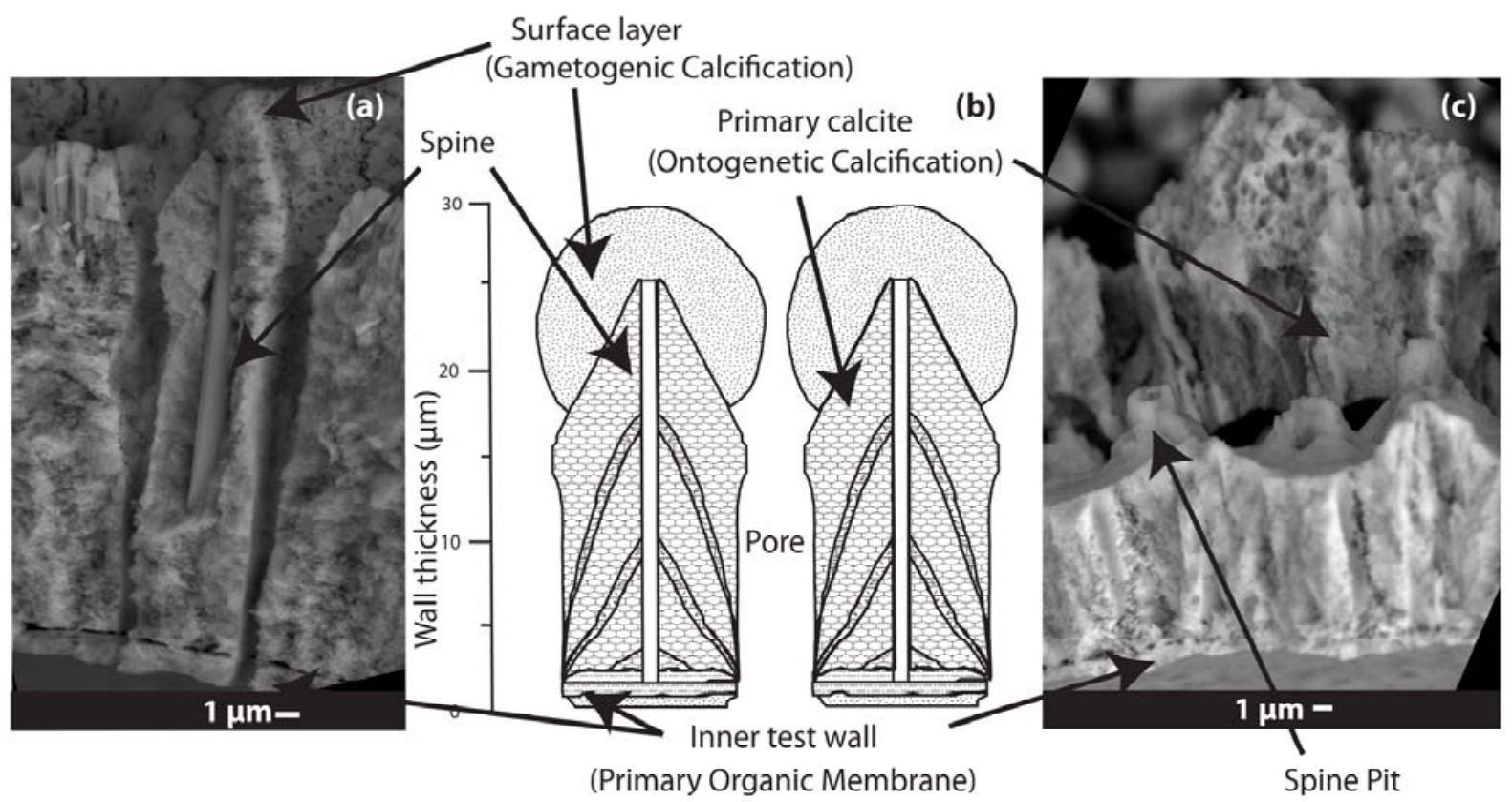

Figure 9. Calcification of the foraminifera test wall. (a) Electron backscattered image of foraminifera-29 chamber $f-1$, which has undergone oxidative and $1 \mathrm{x}$ acid leach cleaning. Spines of the foraminifera have had incomplete resorbtion, leaving the remnant spine in the test wall the top of which was subsequently covered with gametogenic calcite. (b) Schematic diagram illustrating wall and pore structure of an adult G. bulloides showing successive growth stages of ontogenetic calcification. Successive primary calcite/ontogenetic calcification layers are indicated by 'bricks' with the thin layers between chamber formation indicated by blocks with 'crescents', inner test wall/primary organic membrane is indicated by dashed lines. Gametogenic calcification/surface layer is indicated by stippling. (Bé, 1980; Erez, 2003; Sadekov et al., 2005). (c) Crosssection through the test wall of foraminifera- 18 , chamber $f-1$ which has undergone oxidative and reductive treatments. Complete resorbtion of spines has occurred, with remnants of the outer spine wall clearly visible after primary calcite layer separation. Also illustrated is the relationship between stronger calcite formed in the inner test wall and immediately around the spines, and primary calcite layers. No distinctive dark or light banding was observed in these or other samples to indicate the presence of organic layers (Erez, 2003).

Seven different chemical and physical cleaning techniques were used on seven subsets of tests prior to them being re-mounted for LA-ICPMS (Fig. 10). Foraminiferal tests were left whole during the cleaning process so that chamber specific variability could be assessed. This meant that any detritus located inside the test could only be removed via the test aperture. 
While this would be an issue for dissolution analysis, it does not impact upon in-situ LAICPMS analyses. Inner test calcite has different crystallography to the primary test layers and typically acts as a barrier to dissolution (Sadekov et al., 2010). It is therefore likely to remain unaffected by the cleaning process.

The recommended sample cleaning method of Barker et al. (2003a) for solution-based $\mathrm{Mg} / \mathrm{Ca}$ studies involves rinsing foraminifera fragments in ultraclean water and methanol, oxidative cleaning with hydrogen peroxide, followed by acid leaching in dilute nitric acid (AI 3). For measurement of other trace elements, including $\mathrm{Cd}$, which is found in much lower concentrations than $\mathrm{Mg}$, Boyle and Keigwin (1985) recommended the addition of a reductive cleaning step (AI. 5). 


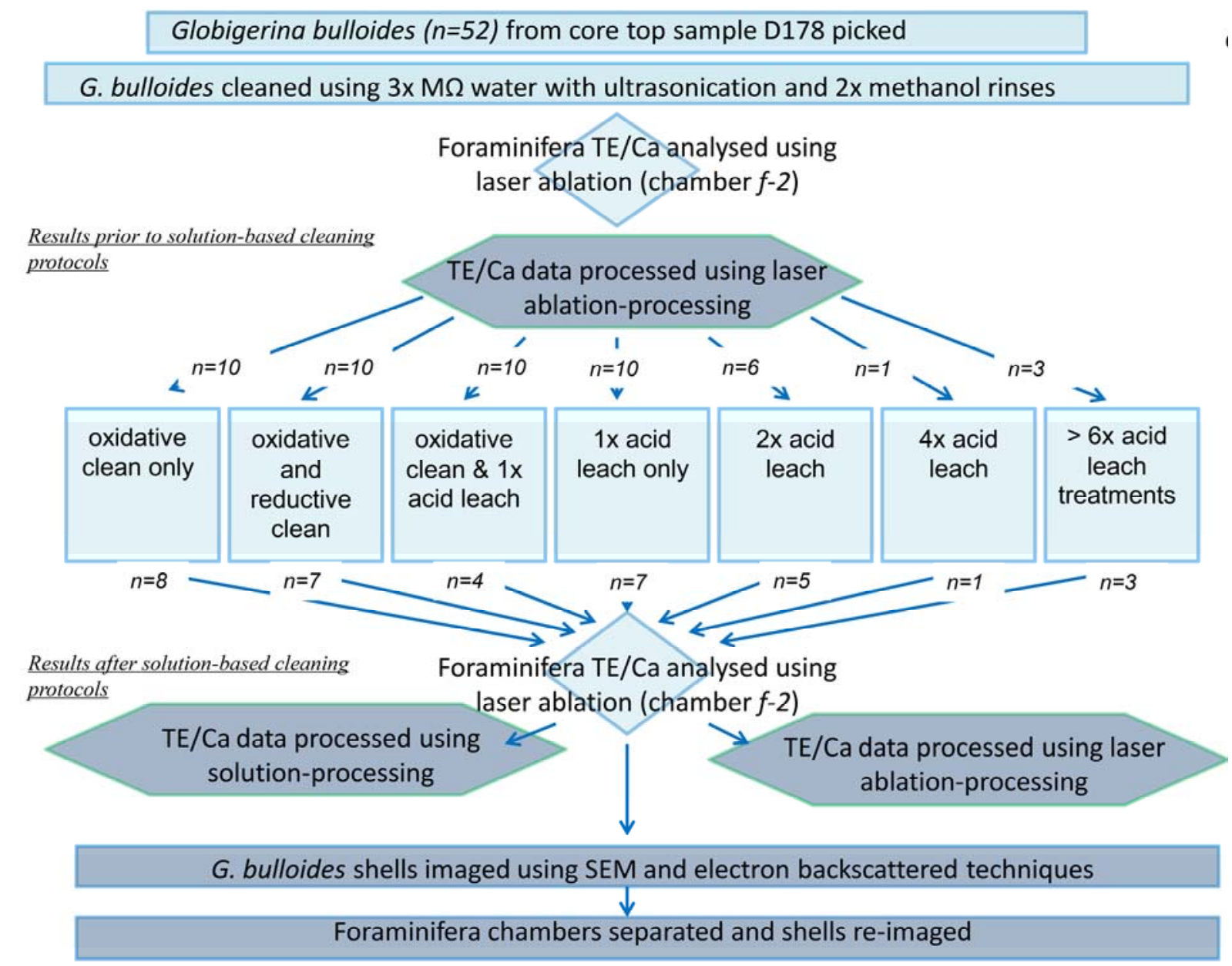

Figure 10. Flow diagram summary of the sample preparation and analytical procedures used during this study. Numbers in italics indicate the number of foraminifera involved in that particular experimental step e.g. $n=35$. See text for further details.

To evaluate the effects of these methods, 3-10 foraminifera with varying initial TE/Ca contents were treated individually using combinations of these cleaning steps with ultrasonication washes limited to 2-3 seconds, the steps are (Fig. 10):
(1) oxidative clean only, (7) $>6 x$ acid leach treatments
(2) oxidative and reductive clean only,
(3) oxidative clean and $1 \mathrm{x}$ acid leach,
(4) 1x acid leach only,
(5) $2 x$ acid leach,
(6) $4 \mathrm{x}$ acid leach, 
After the final treatment, the foraminifera were rinsed in ultrapure water and placed in an oven at $40^{\circ} \mathrm{C}$ overnight to dry. When a foraminifera test fragmented during cleaning it was removed from the study. Whole specimens were then re-analysed using LA-ICPMS (Table 1, Fig. 10, 11).

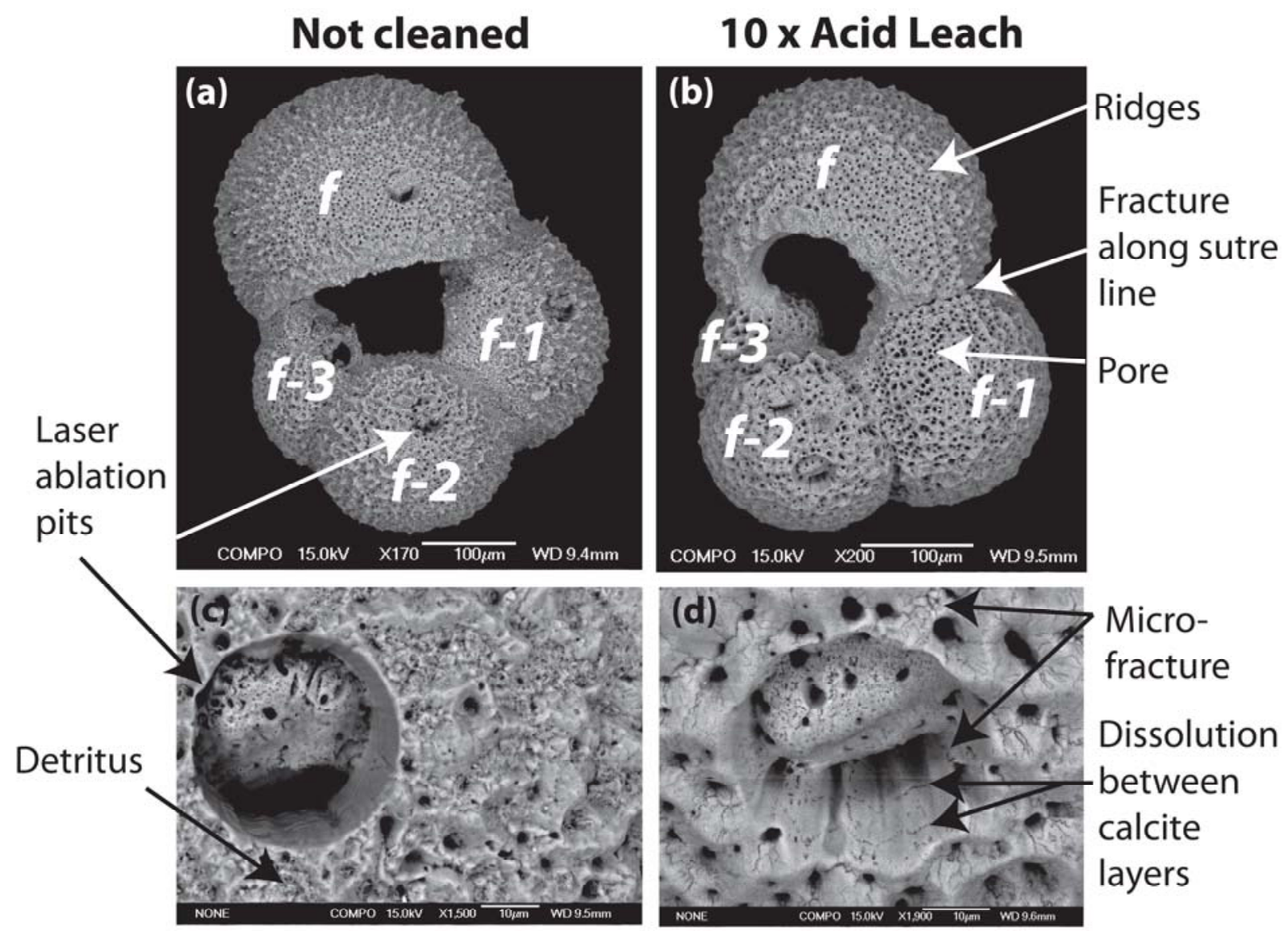

Figure 11. Electron backscattered images of two adult G. bulloides which have undergone (a) no cleaning and (b) 10x acid leach cleaning treatments to assess changes to the surface texture prior to chamber separation. Larger circular holes in chamber test walls are ablation pits of $35 \mu \mathrm{m}$ diameter. (c) and (d) are images of ablation pits from the foraminifera in (a) and (b) respectively, magnified $1500 \mathrm{x}$. Successive layers of calcite through the test wall are visible as lines in (c) and (d). Dark lines indicate where there has been increased dissolution at calcite layer boundaries. (a) and (c) have pore spaces that are smaller where visible, or loosely infilled with detritus such as nannofossils or clay. Detritus has been removed from pore spaces in (b) and (d), and pore spaces are generally larger. Fracturing between chambers and micro-fracturing on the surface of and through the test wall of (b) and (d) are also visible. 


\begin{tabular}{|c|c|c|c|c|c|c|}
\hline & \multicolumn{6}{|c|}{ 'LA processed' - before chemical cleaning ( $\mathrm{mmol} / \mathrm{mol})$} \\
\hline Cleaning protocol & $\mathrm{Mg} / \mathrm{Ca}$ & $\mathrm{Al} / \mathrm{Ca}$ & $\mathrm{Mn} / \mathrm{Ca}$ & $\mathrm{Zn} / \mathrm{Ca}$ & $\mathrm{Sr} / \mathrm{Ca}$ & $\mathrm{Ba} / \mathrm{Ca}$ \\
\hline Oxidative & 1.81 & 0.06 & 0.003 & 0.003 & 1.34 & 0.002 \\
\hline Oxidative-Reductive & 1.60 & 0.01 & 0.002 & 0.004 & 1.30 & 0.002 \\
\hline Oxidative-1x Leach & 1.46 & 0.02 & 0.004 & 0.003 & 1.30 & 0.002 \\
\hline $1 \mathrm{x}$ Leach & 1.33 & 0.06 & 0.004 & 0.003 & 1.32 & 0.003 \\
\hline $2 \times$ Leach & 1.71 & 0.07 & 0.005 & 0.003 & 1.32 & 0.003 \\
\hline $4 \times$ Leach & 1.23 & 0.02 & 0.001 & 0.000 & 1.36 & 0.001 \\
\hline $6 x$ Leach & 2.22 & 0.02 & 0.008 & 0.002 & 1.32 & 0.006 \\
\hline \multirow[t]{2}{*}{ 10x Leach } & 2.32 & 0.03 & 0.003 & 0.002 & 1.22 & 0.001 \\
\hline & \multicolumn{6}{|c|}{ 'LA processed'- after chemical cleaning (mmol/mol) } \\
\hline Oxidative & 1.64 & 0.03 & 0.004 & 0.022 & 1.31 & 0.003 \\
\hline Oxidative-Reductive & 1.45 & 0.01 & 0.001 & 0.006 & 1.31 & 0.001 \\
\hline Oxidative-1x Leach & 1.26 & 0.01 & 0.002 & 0.006 & 1.29 & 0.002 \\
\hline $1 \mathrm{x}$ Leach & 1.38 & 0.03 & 0.004 & 0.006 & 1.32 & 0.003 \\
\hline $2 x$ Leach & 1.41 & 0.02 & 0.003 & 0.005 & 1.33 & 0.003 \\
\hline $4 \times$ Leach & 1.17 & 0.00 & 0.000 & 0.001 & 1.37 & 0.001 \\
\hline 6x Leach & 2.61 & 0.01 & 0.007 & 0.002 & 1.33 & 0.004 \\
\hline \multirow[t]{2}{*}{ 10x Leach } & 1.33 & 0.00 & 0.000 & 0.000 & 1.28 & 0.001 \\
\hline & \multicolumn{6}{|c|}{ 'Solution processed'- before chemical cleaning (mmol/mol) } \\
\hline Oxidative & 2.68 & 0.81 & 0.018 & 0.033 & 1.45 & 0.010 \\
\hline Oxidative-Reductive & 2.27 & 0.39 & 0.009 & 0.013 & 1.39 & 0.008 \\
\hline Oxidative-1x Leach & 2.13 & 0.98 & 0.010 & 0.012 & 1.37 & 0.009 \\
\hline $1 \times$ Leach & 2.17 & 0.49 & 0.014 & 0.015 & 1.38 & 0.009 \\
\hline $2 x$ Leach & 2.25 & 0.42 & 0.013 & 0.010 & 1.38 & 0.004 \\
\hline $4 \times$ Leach & 1.93 & 0.39 & 0.007 & 0.008 & 1.40 & 0.021 \\
\hline $6 x$ Leach & 2.57 & 0.39 & 0.342 & 0.013 & 1.37 & 0.008 \\
\hline \multirow[t]{2}{*}{ 10x Leach } & 2.24 & 0.24 & 0.007 & 0.007 & 1.30 & 0.010 \\
\hline & \multicolumn{6}{|c|}{ 'Solution processed'- after chemical cleaning ( $\mathrm{mmol} / \mathrm{mol})$} \\
\hline Oxidative & 1.96 & 0.31 & 0.008 & 0.049 & 1.34 & 0.006 \\
\hline Oxidative-Reductive & 1.72 & 0.07 & 0.001 & 0.002 & 1.32 & 0.002 \\
\hline Oxidative-1x Leach & 1.55 & 0.12 & 0.004 & 0.021 & 1.32 & 0.004 \\
\hline $1 \mathrm{x}$ Leach & 1.84 & 0.42 & 0.016 & 0.027 & 1.37 & 0.022 \\
\hline $2 \times$ Leach & 1.74 & 0.24 & 0.011 & 0.032 & 1.35 & 0.009 \\
\hline $4 \times$ Leach & 1.38 & 0.05 & 0.003 & 0.044 & 1.61 & 0.003 \\
\hline $6 x$ Leach & 2.48 & 0.02 & 0.010 & 0.011 & 1.34 & 0.004 \\
\hline 10x Leach & 1.40 & 0.02 & 0.004 & 0.006 & 1.34 & 0.001 \\
\hline
\end{tabular}

Table 1. Mean TE/Ca values in primary test calcite calculated prior and subsequent to chemical cleaning using LA and solution data processing.

Following both LA-ICPMS analytical steps, pre- and post- cleaning, intact foraminifera tests were carbon coated and imaged using a Jeol JSM 6500F SEM at Victoria University of Wellington. After the second geochemical analysis, post-cleaning, tests were then broken 
open (chamber separation), re-coated with carbon and re-imaged on the SEM to reveal internal structures.

\subsection{Geochemical analysis}

Trace element/Ca $(\mathrm{TE} / \mathrm{Ca})$ ratios of foraminiferal tests were carried out using a New Wave deep-UV (193 nm) solid-state laser ablation (LA) system coupled to an Agilent 7500CS ICPMS at Victoria University of Wellington. Laser ablation analyses were of $60 \mathrm{~s}$ duration. For each analysis, after subtraction of background signals, TE/Ca ratios were calculated by reference to TE/Ca ratios obtained from bracketing analyses of the NIST610 glass standard, and normalised to the preferred trace element values in this standard: $\mathrm{Mg}=465, \mathrm{Al}=10798$, $\mathrm{Ca}=82191, \mathrm{Mn}=485, \mathrm{Zn}=456, \mathrm{Sr}=516, \mathrm{Ba}=435$ ppm (Pearce et al., 1997). Analyses of NIST610 bracketed 5-20 analyses of foraminifera and showed no significant drift in TE/Ca ratios beyond the internal precision of the analyses. Eight analyses of chamber $f-2$ on a single G. bulloides from D178 were conducted to evaluate reproducibility during the course of an analytical run. The $95 \%$ confidence intervals for the single chamber analysis based on the mean TE/Ca chamber values are $\mathrm{Mg} / \mathrm{Ca} 2.01 \pm 0.27(13 \%) \mathrm{mmol} / \mathrm{mol}, \mathrm{Al} / \mathrm{Ca} 0.11 \pm 0.06(50 \%)$ $\mathrm{mmol} / \mathrm{mol}, \mathrm{Mn} / \mathrm{Ca} 0.002 \pm 0.001(51 \%) \mathrm{mmol} / \mathrm{mol}, \mathrm{Zn} / \mathrm{Ca} 0.002 \pm 0.001(41 \%) \mathrm{mmol} / \mathrm{mol}$, $\mathrm{Sr} / \mathrm{Ca} 1.34 \pm 0.02(2 \%) \mathrm{mmol} / \mathrm{mol}, \mathrm{Ba} / \mathrm{Ca} 0.002 \pm 0.001(28 \%) \mathrm{mmol} / \mathrm{mol}($ all $\mathrm{n}=8)$. We use the calculated $95 \%$ confidence intervals to assess intra-chamber variability due to the small sample size. While still assuming a Gaussian normal distribution similar to standard practice, this approach uses a t-statistic with the appropriate degrees of freedom to assess the probability that true values lie outside the $95 \%$ limits for the mean. Limits of detection for each of the measured elements are given in AI 1 and were calculated using Iolite data reduction software and assuming a stoichiometric value of $40.04 \mathrm{wt} \%$ Ca content of the test

and monitoring ${ }^{43} \mathrm{Ca}$ as an internal standard (Paton et al., 2011). Typical concentrations of 
$\mathrm{Mg}, \mathrm{Al}, \mathrm{Sr}$ and $\mathrm{Ba}$ are all well above detection limits. However, the background levels of $\mathrm{Mn}$ and $\mathrm{Zn}$ comprise a significant percentage of the total signal for a typical analysis of foraminiferal calcite ( $\sim 29$ and $\sim 43 \%$, respectively). Analytical profiles of these elements are therefore carefully scrutinised to ensure that TE/Ca values reflect test calcite (AI. 2).

\subsection{Data processing}

Trace element data obtained from the individual foraminifera after solution cleaning were processed in two ways. First, using a typical LA analysis procedure ("LA processing”), for which the integrated portion of the time-resolved compositional profile through the test is carefully screened to exclude any contamination adhering to the outer test wall (AI. 2) (Eggins et al., 2003a; Marr et al., 2011; Sadekov et al., 2008). When calculated in this manner, any offset in an individual foraminifer's test chemistry as determined before and after solution cleaning protocols, reflect changes to the chemistry of the primary calcite test that have been induced by various the solution cleaning techniques. Secondly, the data were also processed by integrating the entire time-resolved signal including the outermost layer(s) to approximate the composition that would be obtained if the full test was dissolved for solution-based ICPMS analysis. Data processed this way are hereafter referred to as "solution-processed". Trends in data processed this way for example, contamination reduction, appear to closely match those previously published for solution-ICPMS analysis in Barker et al. (2003a) and Hathorne et al. (2009). As opposed to crushing and dissolving the tests for true solution analysis this approach, importantly, leaves the foraminifera tests intact for SEM and backscattered electron (BS) imaging. Note trace element data was processed before and after chemical cleaning using both the solution and LA processing techniques, however, all samples processed 'before chemical cleaning' had still undergone the 'Laser Ablation Clean, Clay Removal' cleaning protocol (AI. 1.1). 


\subsection{Results}

\subsection{Prior to solution-based cleaning protocols}

The range in test $\mathrm{TE} / \mathrm{Ca}$ values analysed before application of solution-based cleaning techniques follows a normal Gaussian distribution (Fig. 12). The range in data for individual foraminifera is typical for a core-top sample (e.g. Bolton et al., 2011; Marr et al., 2011; Sadekov et al., 2008) and mean values fall within previous published ranges for $\mathrm{Mn} / \mathrm{Ca}$ and $\mathrm{Zn} / \mathrm{Ca}<0.3 \mathrm{mmol} / \mathrm{mol}$ and $\mathrm{Ba} / \mathrm{Ca}<0.01 \mathrm{mmol} / \mathrm{mol}$ (Hathorne et al., 2003; Lea and Boyle, 1991; Pena et al., 2005; Rosenthal et al., 1999). However as core-top D178 is located in Subantarctic Water, low TE/Ca reflect low concentrations in the ambient water mass and a mean annual temperature of $7.4^{\circ} \mathrm{C}$ at $60 \mathrm{~m}$ water depth (Bowie et al., 2009; M. Ellwood pers. comm., 2011; Neil et al., 2004).

\subsection{After solution-based cleaning protocols}

\subsubsection{Test attrition rates}

Of the initial 52 foraminifera, 36 remained whole after cleaning treatments. Comparison of test chemistry before cleaning shows that tests with elevated $\mathrm{Mg} / \mathrm{Ca}$ values $(4.6 \mathrm{mmol} / \mathrm{mol})$ also had high $\mathrm{Zn} / \mathrm{Ca}$ and $\mathrm{Ba} / \mathrm{Ca}$ values of 0.012 and $0.011 \mathrm{mmol} / \mathrm{mol}$ respectively, and were lost due to fragmentation during the oxidative and leaching cleaning processes. Of the tests with $<0.004 \mathrm{mmol} / \mathrm{mol}$ of $\mathrm{Mn} / \mathrm{Ca}$ and/or $\mathrm{Zn} / \mathrm{Ca}$, more than $70 \%$ remained whole during the cleaning process, whereas the attrition rate for tests with $>0.004 \mathrm{mmol} / \mathrm{mol}$ of $\mathrm{Mn} / \mathrm{Ca}$ or $\mathrm{Zn} / \mathrm{Ca}$ was $50 \%$. The greatest loss in foraminifera tests was observed after oxidative and acid leach treatments, when $60 \%$ of the individuals fragmented. However, no unusual TE/Ca values were recorded prior to treatment with subsample means of $\mathrm{Mg} / \mathrm{Ca}, 2.0 \mathrm{mmol} / \mathrm{mol}$; $\mathrm{Sr} / \mathrm{Ca}, 1.33 \mathrm{mmol} / \mathrm{mol} ; \mathrm{Al} / \mathrm{Ca}, 0.044 \mathrm{mmol} / \mathrm{mol} ; \mathrm{Mn} / \mathrm{Ca}, 0.005 \mathrm{mmol} / \mathrm{mol} ; \mathrm{Zn} / \mathrm{Ca}, 0.006$ 
$\mathrm{mmol} / \mathrm{mol} ; \mathrm{Ba} / \mathrm{Ca}, 0.005 \mathrm{mmol} / \mathrm{mol}$ in the tests selected for oxidative and acid leach treatment.
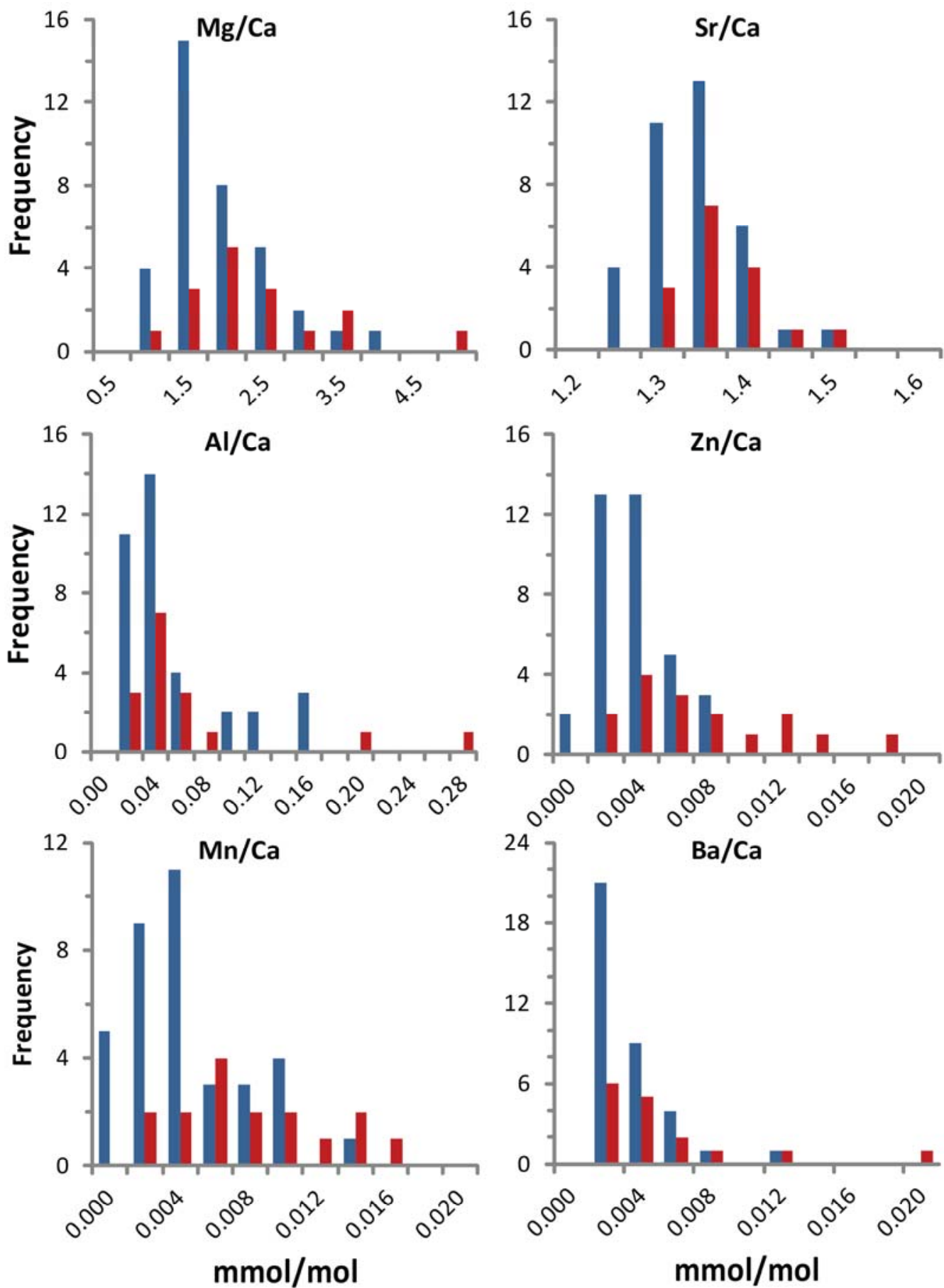

Figure 12. Histograms showing initial range in $G$. bulloides chamber $f-2 \mathrm{TE} / \mathrm{Ca}$ values prior to chemical cleaning treatment. Blue bars indicate those foraminifera that remained whole after chemical treatment and were used for further TE/Ca analysis and imaging, and red bars are the initial TE/Ca values of those foraminifera that fragmented during cleaning. 


\subsection{2 'LA processing'}

Here we present the TE/Ca data attained before and after chemical cleaning using only "LA processing" (Fig. 13-16, AI, 2). While a limited number of specimens remained after oxidative and $1 \mathrm{x}$ acid leach treatment $(\mathrm{n}=4), \mathrm{ag} / \mathrm{Ca}$ decrease of $c a .15 \%$ was observed, markedly higher than the $c a .3 \%$ decrease after 'a single' ( $1 \mathrm{x})$ acid leach or $c a .10 \%$ decrease after oxidative treatment alone. $\mathrm{A}>40 \%$ and $4 \%$ decrease in $\mathrm{Mg} / \mathrm{Ca}$ and $\mathrm{Sr} / \mathrm{Ca}$, respectively, was observed after 10 acid leaching treatments. Mean $\mathrm{Sr} / \mathrm{Ca}$ did not vary compared to the pre-cleaning measurements by more than $2 \%$ in all other treatments. The variability in $\mathrm{Mg} / \mathrm{Ca}$ after up to 4 acid leach treatments was not significantly different to the pre-treatment values with a mean difference of $\pm 9.5 \%$, which is less than natural heterogeneity ( $\pm 13 \%$ ) (Fig. 13). Distinctive $\mathrm{Mg} / \mathrm{Ca}$ peaks in the laser profiles through individual tests of up to $1.5 \mathrm{mmol} / \mathrm{mol}$ higher than the surrounding portions of the profiles, were apparent in the analyses both before and after chemical cleaning (Fig. 16). These $\mathrm{Mg} / \mathrm{Ca}$ peaks were not consistently associated with distinct layers identified in the test wall (e.g. Fig. 16). Published $\mathrm{Mg} / \mathrm{Ca}$ and $\mathrm{Sr} / \mathrm{Ca}$ values typically range between $c a .0 .5-4 \mathrm{mmol} / \mathrm{mol}$ and ultra trace elements (ultra TE/Ca) $\mathrm{Mn} / \mathrm{Ca}, \mathrm{Al} / \mathrm{Ca}, \mathrm{Ba} / \mathrm{Ca}$ and $\mathrm{Zn} / \mathrm{Ca}$ have values typically between $0.00-0.04 \mathrm{mmol} / \mathrm{mol}$ (e.g. Marr et al., 2011; Sadekov et al., 2009).

Our results show no resolvable differences in primary test $\mathrm{Mn} / \mathrm{Ca}$ and $\mathrm{Ba} / \mathrm{Ca}$ values measured before and after the standard oxidative and acid leach techniques recommended by Barker et al. (2003) (Fig. 13). This is similar to findings on Late Pleistocene planktic foraminifera from Panama Basin, where $\mathrm{Mn} / \mathrm{Ca}$ was identified as not being effectively removed by oxidative or oxidative $+1 \mathrm{x}$ acid leach treatments (Pena et al., 2005). For the D178 samples, a combination of oxidative and reductive cleanings, or multiple $(>2)$ acid leaches were required before primary calcite $\mathrm{Mn} / \mathrm{Ca}$ levels were measurably reduced (Fig. 14, 15). 
While $\mathrm{Mn} / \mathrm{Ca}$ oscillations of up to $0.009 \mathrm{mmol} / \mathrm{mol}$ were present through some test walls, the magnitude of these oscillations was generally unchanged by the cleaning treatments (Fig. 16). These high/low $\mathrm{Mn} / \mathrm{Ca}$ bands could not be identified as visually distinct calcite layers through the test wall (Fig. 16). Ba/Ca levels were not statistically different before and after solution-based cleaning treatments using LA processing (Fig. 10, 14, 15).

Mean test $\mathrm{Zn} / \mathrm{Ca}$ values increased by $>60 \%$ of their measured pre-treatment values following chemical cleaning treatments, but not with tests subject to oxidative and reductive treatments or 10x acid leach treatment (Fig. 13-15). Patterns of high and low Zn/Ca banding through the test were also enhanced by chemical cleaning treatments. For example, prior to oxidative cleaning, bands in one foraminifera specimen had a maximum oscillation up to \pm 0.003 $\mathrm{mmol} / \mathrm{mol}$ with a mean value of $0.004 \mathrm{mmol} / \mathrm{mol}$ in the primary calcite (Fig. 16). However after cleaning, the oscillations increased to $\pm 0.009 \mathrm{mmol} / \mathrm{mol}$ around a central mean value of $0.017 \mathrm{mmol} / \mathrm{mol}$ (AI. 2). An increase in oscillations of this magnitude was not evident in the other elements measured. $\mathrm{Al} / \mathrm{Ca}$ showed the strongest reduction following cleaning treatments, with values reduced from the pre-cleaning LA-ICPMS measurements by up to $90 \%$ (Table 1). 

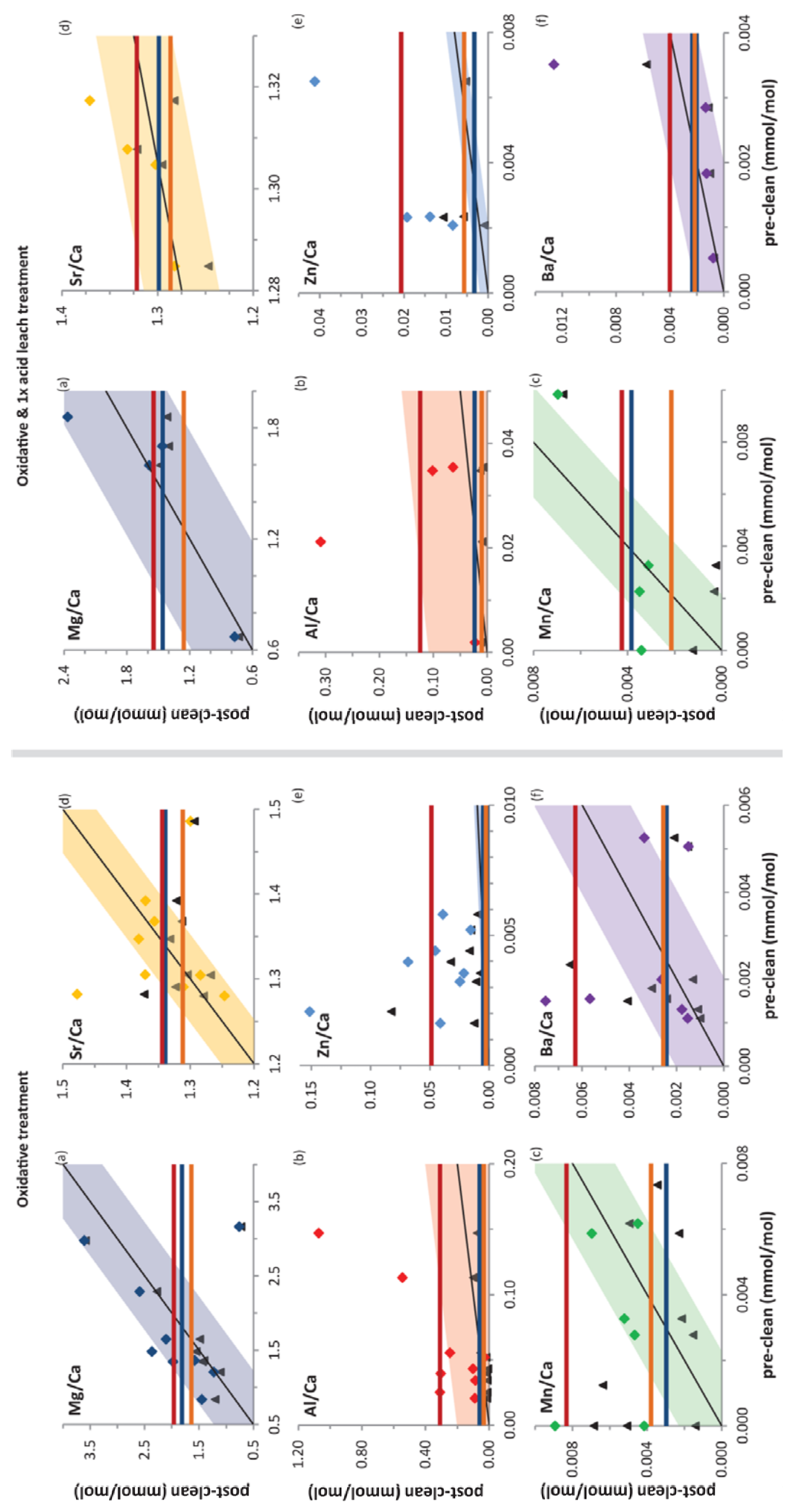
Figure 13. Comparison of TE/Ca for individual foraminifera prior and subsequent to oxidative only, and oxidative $+1 \mathrm{x}$ acid leach treatments. Coloured diamonds indicate individual foraminiferal values calculated using LA processing before and solution processing after cleaning (see text). Black triangles indicate samples processed using the LA processing before and after cleaning. Black line indicates a 1:1 relationship, shaded bar indicates the TE/Ca 95\% confidence interval (CI) for natural heterogeneity within an individual foraminifera chamber. Overall sample means are indicated by horizontal lines on the graphs; blue -before chemical cleaning (LA processing), orange -after chemical cleaning (LA processing), red - sample mean derived using solution processing after chemical cleaning.
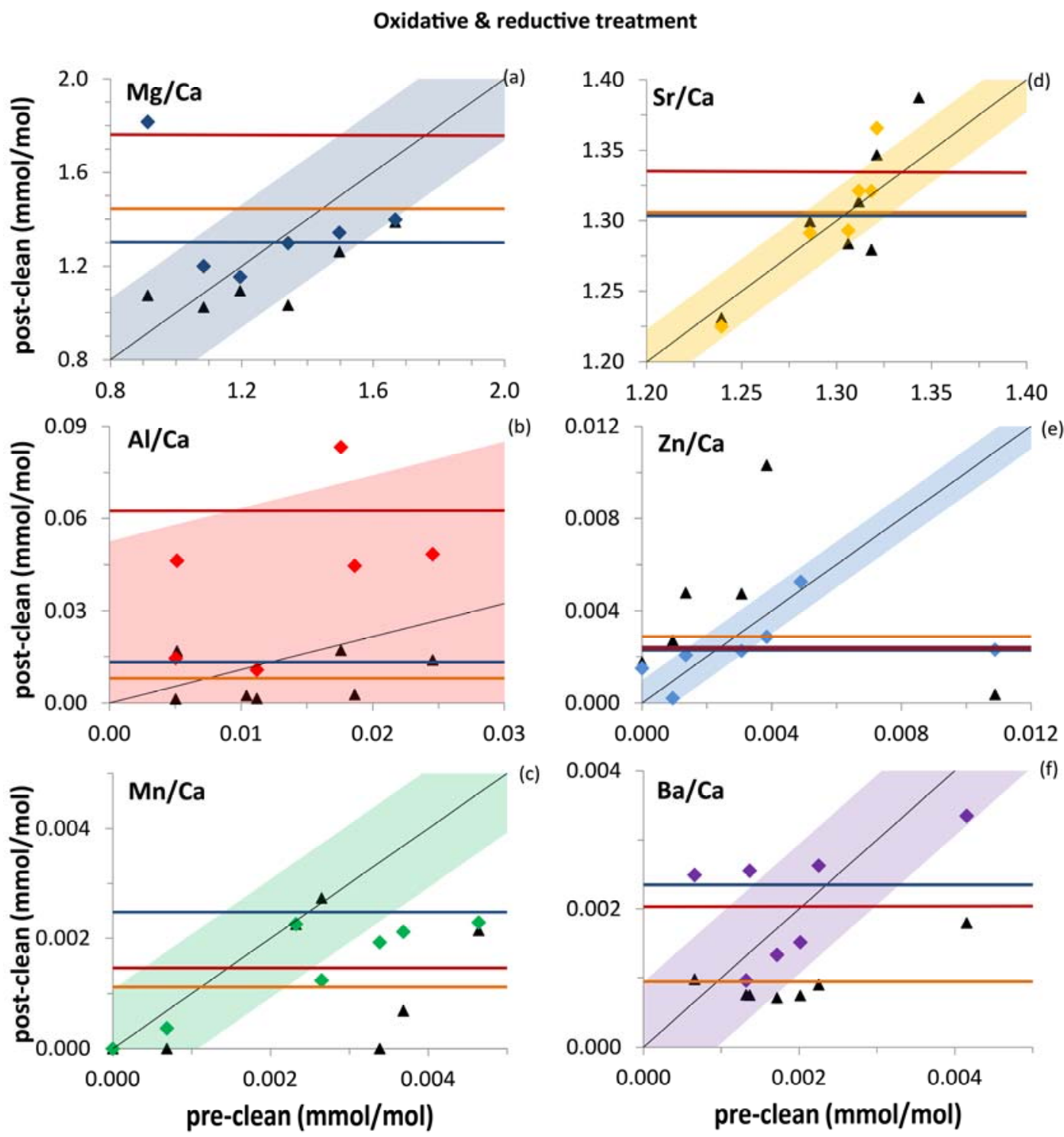

(b)

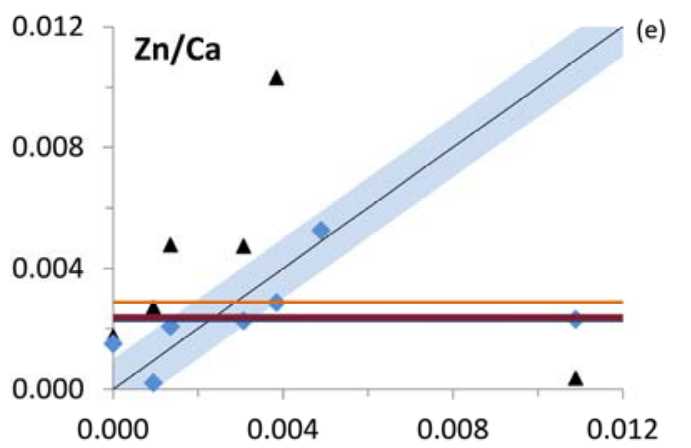

(c) 0.004

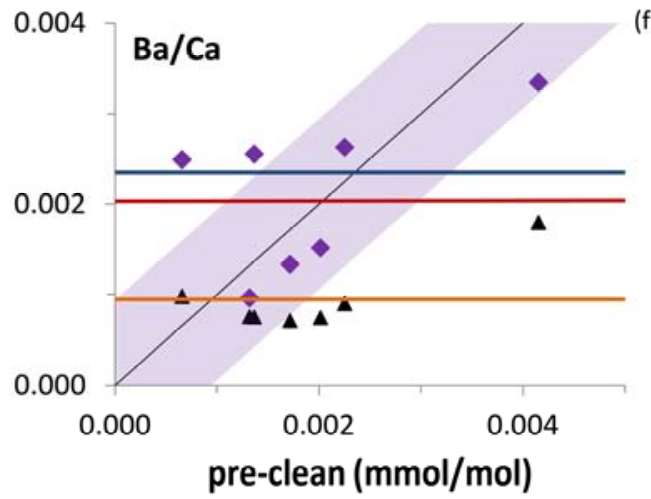

Figure 14. Comparison of $\mathrm{TE} / \mathrm{Ca}$ for individual foraminifera prior and subsequent to oxidative and reductive cleaning treatments. Symbols as for Fig. 13. Black line indicates a 1:1 relationship, shaded bar indicates the $\mathrm{TE} / \mathrm{Ca}$ 95\% CI for natural heterogeneity within an individual foraminifera chamber. 

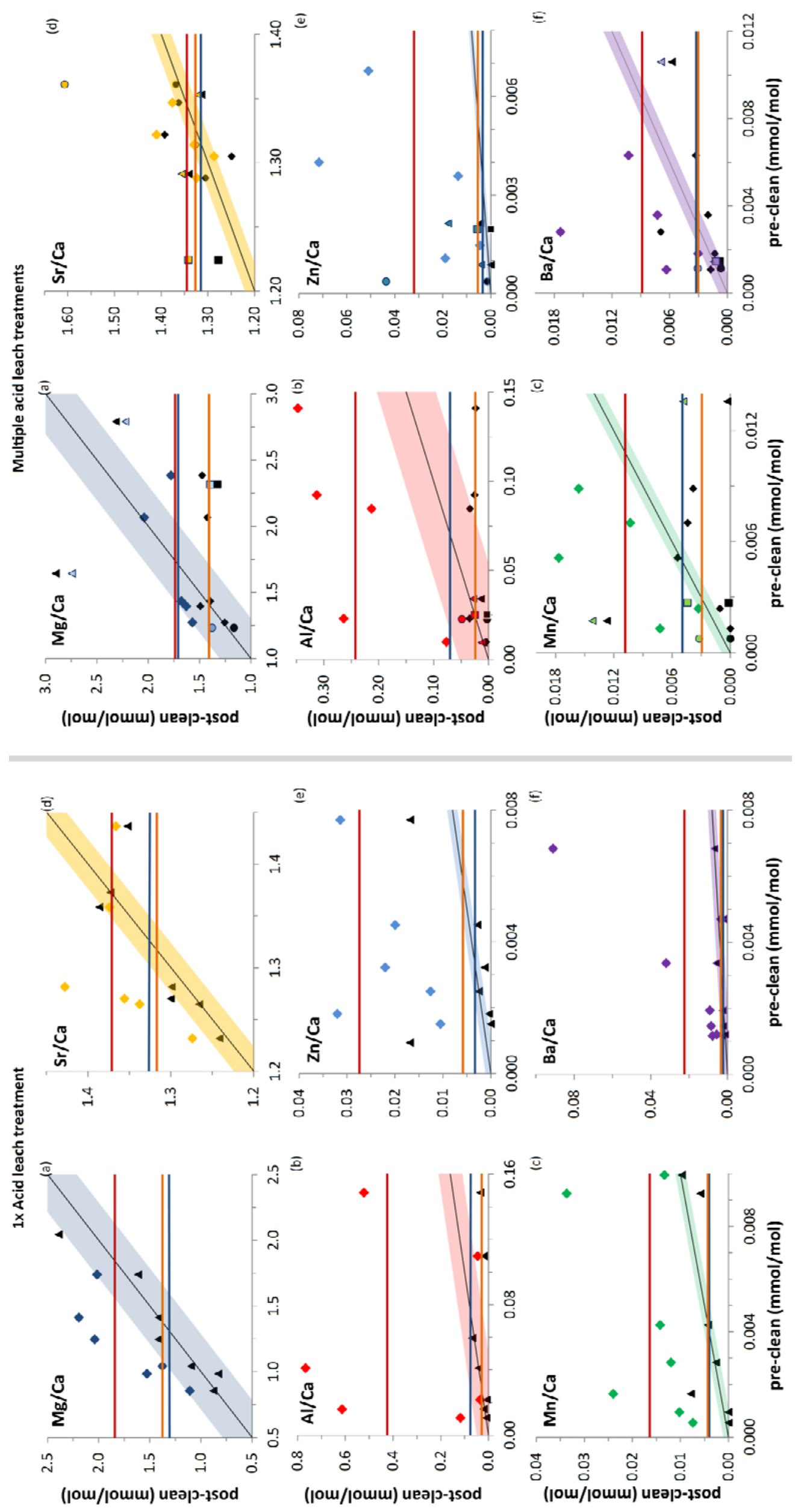
Figure 15. Comparison of TE/Ca for individual foraminifera prior and subsequent to single and multiple acid leach treatments. Multiple leach treatments key: coloured diamonds $=2 \mathrm{x}$ acid leach), circles (6x acid leach), triangles (4x acid leach) and squares (10x acid leach) indicate sample mean values calculated using LA processing before and solution processing after cleaning for 1x acid leach. Black triangles indicate samples processed using the LA processing before and after cleaning. LA and solution processing before and after cleaning. Multiple leach treatments black symbol key: diamonds (2x acid leach), circles (6x acid leach), triangles (4x acid leach) and squares (10x acid leach) indicate samples processed using the LA technique before and after cleaning. Single acid leach treatment: all black diamonds indicate the use of LA processing technique before and after chemical pre-treatment. Black line indicates a 1:1 relationship, shaded bar indicates the TE/Ca 95\% CI for natural heterogeneity within an individual foraminifera chamber. Overall sample means are indicated by horizontal lines for $1 \mathrm{x}$ acid leach, and 2x acid leach samples on the multi acid leach treatment graphs; blue -before chemical cleaning (LA processing), orange -after chemical cleaning (LA processing), red derived using solution processing after chemical cleaning.

\subsubsection{Solution- vs LA- Processing}

Here we compare results obtained using 'solution' and 'LA' processing (Fig. 13-15, 17, AI. 2). The largest offset in $\mathrm{Mg} / \mathrm{Ca}$ between solution and LA methods is following a single acid leach treatm ent where $\mathrm{Mg} / \mathrm{Ca}$ solution values are 1.4 times higher than the $\mathrm{LA}$. However, after 10 acid leach treatments, solution $\mathrm{Mg} / \mathrm{Ca}$ values are $0.99 \mathrm{mmol} / \mathrm{mol}$ lower (or a $40 \%$ decreased) than that recorded using LA prior to chemical cleaning (Fig. 17d). There is no significant difference between $\mathrm{Mg} / \mathrm{Ca}$ values in test calcite that has been LA- and solutionprocessed after foraminifera were treated using oxidative \pm reductive and oxidative $\pm 1 \mathrm{x}$ acid leach treatments, and foraminifera subject to 2-6x acid leach treatments (Fig. 17). Mean $\mathrm{Sr} / \mathrm{Ca}$ values are the same within error, regardless of data processing method (Fig. 17d). 

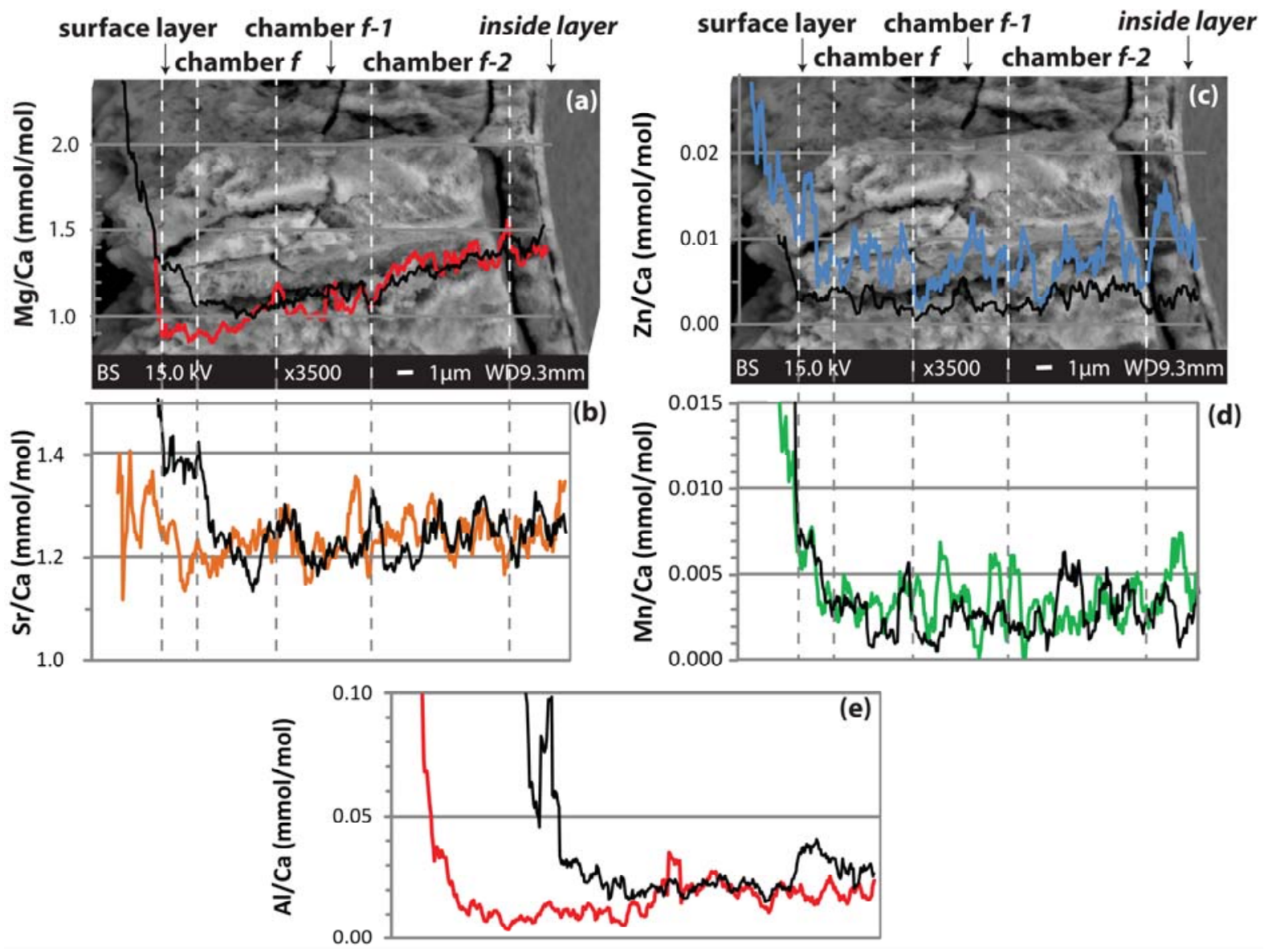

Figure 16. $\mathrm{TE} / \mathrm{Ca}$ ablation profiles of foraminifera-20, as measured by laser ablation analysis through chamber $f-2$ before and after oxidative and reductive cleaning. Black and coloured lines indicate TE/Ca profiles before and after cleaning, respectively. Dashed lines indicate boundaries of progressive calcite layers through the test wall, as identified from the electron backscattered image images after cleaning. Note micro-fracturing and calcite dissolution through the test wall. The thin membrane of calcite deposited during gametogenic calcification is clearly visible on the inner-most test wall. $\mathrm{Mg} / \mathrm{Ca}, \mathrm{Sr} / \mathrm{Ca}$ and $\mathrm{Mn} / \mathrm{Ca}$ surface layer enrichment present prior to cleaning treatments is significantly reduced in $\mathrm{Mg} / \mathrm{Ca}$ and $\mathrm{Sr} / \mathrm{Ca}$ after cleaning, while $\mathrm{Mn} / \mathrm{Ca}$ remains relatively unchanged. $\mathrm{Zn} / \mathrm{Ca}$ levels increase in the surface layer after cleaning. 


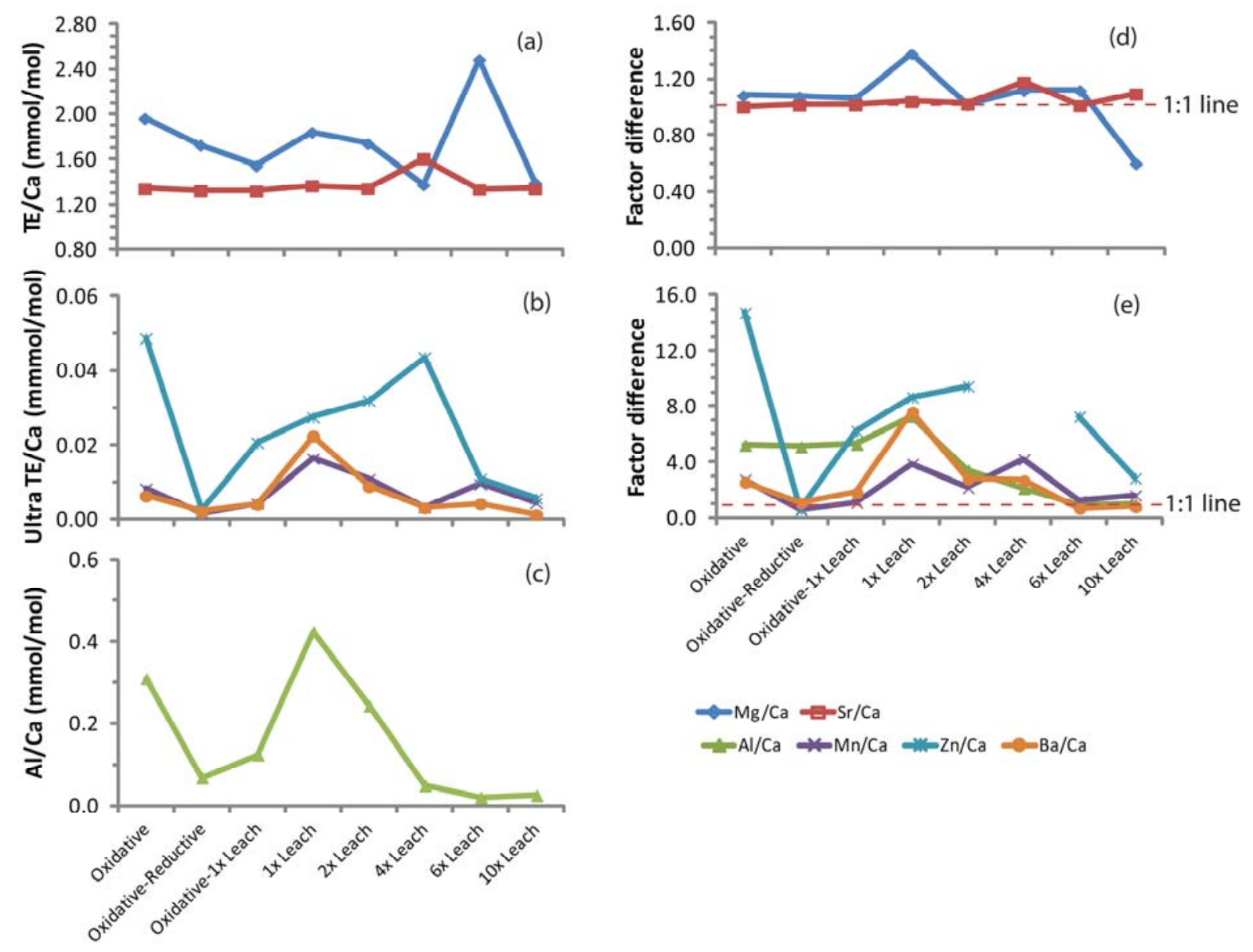

Figure 17. Comparison of sample means using the two different types of data acquisition. Graphs (a)-(c) give TE/Ca sample means from solution based data acquisition. Graphs (d) and (e) illustrate the factor of difference between $\mathrm{TE} / \mathrm{Ca}(\mathrm{d})$ and ultra-TE/Ca (e) values derived using solution methods and values calculated by laser ablation data processing. The dashed line indicates a factor of 1 difference, or where there is no difference between solution or laser ablation results. The factor difference between solution and laser ablation methods for $\mathrm{Zn} / \mathrm{Ca}$ after four acid leaches has been omitted as it was ca. 120 higher after chemical cleaning and therefore obscured other results.

Ultra TE/Ca values show the most sensitivity to the use of solution or LA processing methods (Fig. 16). Mean $\mathrm{Mn} / \mathrm{Ca}$ and $\mathrm{Ba} / \mathrm{Ca}$ values were 0.016 and $0.022 \mathrm{mmol} / \mathrm{mol}$ after using oxidative and reductive treatments followed by solution processing. However, if the same foraminiferal TE profiles used for solution processing are re-processed using LA processing methods those values were significantly reduced to 0.001 and $0.002 \mathrm{mmol} / \mathrm{mol}$ (Fig. 17). Comparison of samples processed using solution processing before and after chemical 
cleaning indicated that there were some significant trends in TE/Ca values. After chemical cleaning, those foraminifera processed using solution processing indicated a significant increase in $\mathrm{Zn} / \mathrm{Ca}$ values increase after using oxidative, oxidative and acid leach, and up to four acid leach only treatments (Table 1). Generally, all other TE/Ca values were reduced after using chemical treatments and solution processing (Table 1). $\mathrm{Zn} / \mathrm{Ca}$ values were ca. 2$5 \mathrm{x}$ higher using solution processing compared to LA processing values before chemical cleaning treatment (Table 1; Fig. 16). Solution processed Al/Ca values were generally 2 times higher than LA processed values, only showing comparable values after 6x acid leaches (Fig. $17 \mathrm{e})$.

\subsection{Test imaging}

All foraminifera tests for which chemical data are reported were imaged using SEM and BS imaging (Figs 1, 14, 16 and 17). The brightness of the SEM images reflect calcite density which in turn reflects an interplay of several factors including growth rate, nutrient levels and biological functions (e.g. Aldridge et al., 2012; Bé, 1980; Bentov and Erez, 2006; de Nooijer et al., 2009) (Fig. 11, 18). For example, the inner test wall, surface layer and spine appear brighter under BS imaging, indicating a higher density calcite (Fig. 11, 18). Detailed SEM images of the chamber wall indicate that calcite crystals on the inner and outer surface are different to those in the middle of the test wall (Fig. 19), similar to that previously identified in Orbulina universa (Allan et al., 1973).

The difference in inter-layer calcite density is most distinctive in samples that have undergone oxidative and reductive cleaning, or extensive acid leaching, where a 'patchy' appearance is suggestive of uneven test wall dissolution (Fig. 16, 18). Dissolution is most distinctive in surface layer calcite and adjacent to micro-fractures through the test wall. In these samples, etching into the outer calcite surface is evident and pore spaces are enlarged 
(Fig. 11, 18). After 1-2x acid leach treatments the foraminifera test surface layer showed signs of dissolution, for example etching on the test surface, and after more than $2 \mathrm{x}$ acid treatments the final chamber calcite $(f)$ appeared visibly more dissolved than the older chambers (Fig. 11).
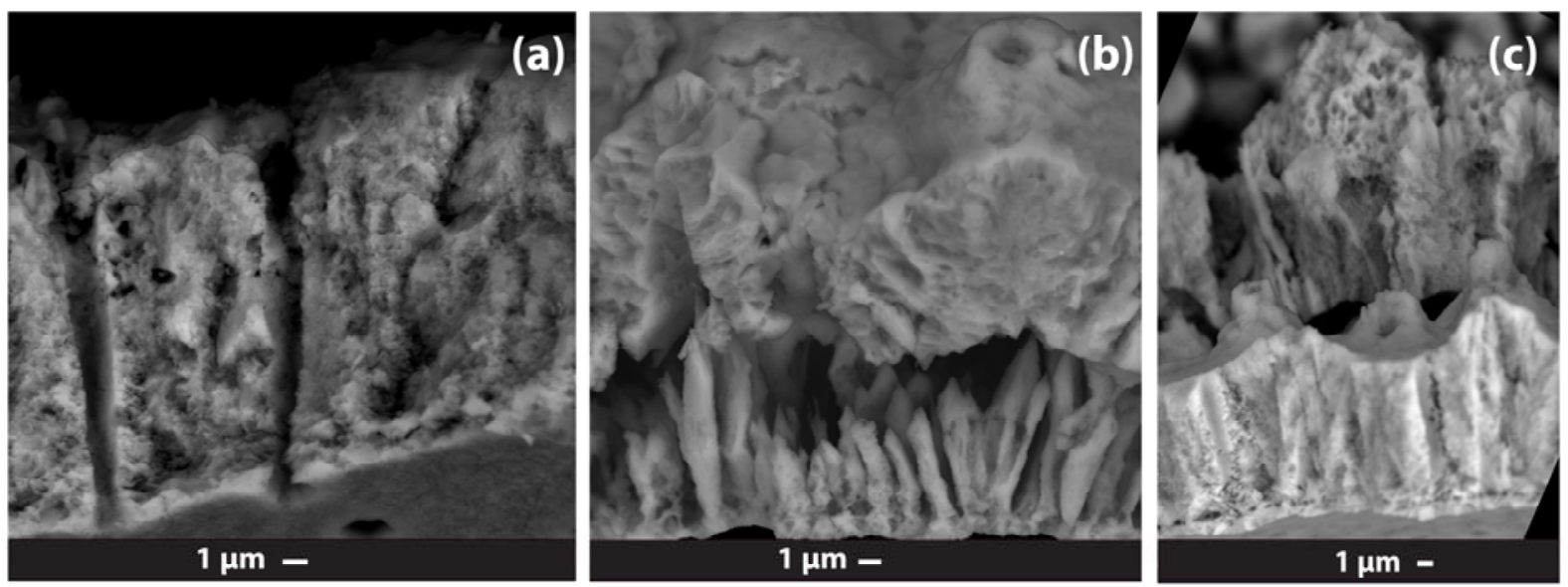

Figure 18. SEM backscatter images through foraminifera test walls showing various signs of dissolution. (a) Patchy dissolution of $G$. bulloides middle test wall while the outer calcite shows minimal dissolution after oxidative and 1x acid leach cleaning. (b) G. ruber test ca. 14 ka from SW Pacific Ocean core site (MD97 2121, ca. $2000 \mathrm{~m}$ water depth) showing signs of natural preferential dissolution of the middle of the test wall. (c) $G$. bulloides spine not fully re-adsorbed prior to gametogenesis. Pitting/etching on surface layer calcite indicates where a single acid leach has begun to dissolve the outer test, while a lack of micro-fracturing leaves the inner test free from dissolution effects. Etching of the test surface can be clearly observed while dissolution of the inner test is limited.

Backscattered imaging of the ablation pit prior to chamber separation shows preferential dissolution of thin, distinctive layers in the middle test wall (Fig. 11). In addition, all samples imaged after chemical cleaning with ultrasonication have micro-fractures or cracking through the test wall (Fig. 11, 18). The extent of test wall micro-fractures increased with progressive chemical cleaning treatments (Fig. 11, 18). Fracturing along suture lines was evident after 2x or more acid leaches (e.g. Fig. 11). After the oxidative and reductive, and multiple acid leaches, chambers were readily divided into their component 'layers' once the chambers had been separated (Fig. 9, 10, 17). 


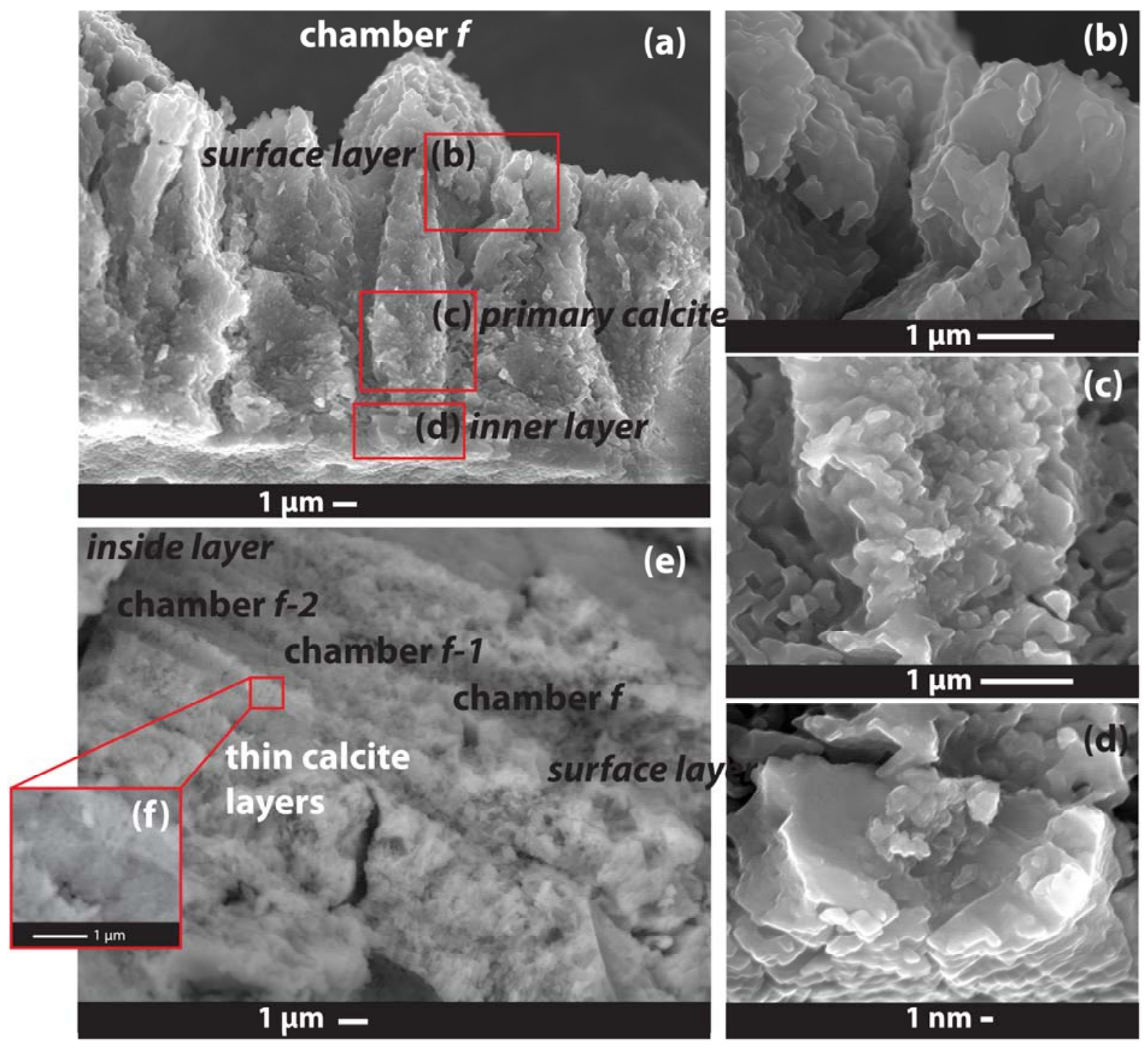

Figure 19. SEM back scattered imaging images of calcite crystals through the test wall of foraminifera -18 chamber $f$ which has undergone both oxidative and reductive treatments. (a) overview through the test wall (b) and (d) show the surface and inner layers magnified $22000 x$ and $35000 x$, respectively. Both show a different arrangement of calcite platelets to (c), which is from a ridge section of test wall primary calcite, magnified 27 000x. (e) View through chamber $f$-2 wall to illustrate the layering of calcite as chambers are added. A thin calcite band ca. 0.1-0.2 $\mu \mathrm{m}$ width is evident between chamber $f-2$ and $f-1$, but absent between chamber $f-1$ and $f$ where the chamber layers are separating. (f) Thin layer of calcite which appears to have been deposited between significant chamber calcification(s). 


\subsection{Discussion}

\subsection{Variability of $\mathrm{Mg} / \mathrm{Ca}$ and $\mathrm{Sr} / \mathrm{Ca}$ in test calcite}

Neither $\mathrm{Mg} / \mathrm{Ca}$, nor $\mathrm{Sr} / \mathrm{Ca}$, values measured after chemical cleaning reveal a significant response to oxidative and $1 \mathrm{x}$ acid leach, or the combination of oxidative and reductive cleaning (Figs. 11, 13-14). The difference between oxidative and reductively cleaned samples after solution processing was $<0.15 \mathrm{mmol} / \mathrm{mol}$ or $<10 \%$ lower, on an equivalent scale to natural inter-test variability (Table 1, SI. 1) (Barker, 2002a; Bolton et al., 2011; Marr et al., 2011; Sadekov et al., 2008). When converted to temperature range this represents an offset of ca. $1.0-1.5^{\circ} \mathrm{C}$, similar to the difference between G. bulloides calibrations (e.g. Anand et al., 2003; Marr et al., 2011; McConnell and Thunell, 2005). This confirms that $\mathrm{Mg} / \mathrm{Ca}$ data for planktic foraminifera such as G. bulloides attained via LA or solution protocols are comparable regardless of whether so-called solution 'Mg-cleaning' (oxidative only) or ' $\mathrm{Cd}$ cleaning' (oxidative and reductive cleaning) -without acid leaching or LA methods with minimal pre-cleaning are used.

We found that $\mathrm{Sr} / \mathrm{Ca}$ did not significantly respond to any of the cleaning protocols, similar to the findings of Barker et al. (2003a) (Fig. 13-15). Therefore, while unable to be used as a measure of test contamination beyond a first order assessment, $\mathrm{Sr} / \mathrm{Ca}$ data are highly comparable between solution and LA ICPMS analytical techniques.

Before and after chemical cleaning, distinctive peaks in $\mathrm{Mg} / \mathrm{Ca}$ of $\mathrm{LA}$ profiles through the test wall were identified in some specimens, suggesting possible Mg-rich and Mg-poor calcite banding (Fig. 17) similar to that previously observed for other species such as Orbulina universa and Globorotalia inflata in previous studies (e.g. Eggins et al., 2003b; Hathorne et al., 2003; Hathorne et al., 2009; Sadekov et al., 2005). However, when $\mathrm{Mg} / \mathrm{Ca}$ 
TE/Ca profiles were compared to structural layers through the test wall (as visible in SEM images), peaks were not generally associated with calcite layering (Fig. 16). This differs from previous studies using electron microprobe mapping that associated oscillations between thin high-Mg and thick low-Mg bands with different episodes of calcite deposition during the lifecycle of spinose planktic foraminifera with symboints (e.g. Globigerinoides ruber), and non-spinose deep-dwelling species (e.g. G. inflata) (Hathorne et al., 2009; Sadekov et al., 2005). High-low $\mathrm{Mg} / \mathrm{Ca}$ banding in G. bulloides may simply be less pronounced than $G$. inflata, similar to Globigerinoides sacculifer (Sadekov et al., 2010) so that identification of structural layers is not evident. Regardless, whether the high-low Mg banding is muted or absent, this, combined with the results showing no bias introduced by dissolution methods, indicates that any preferential dissolution of high $\mathrm{Mg} / \mathrm{Ca}$ layers associated with other species (e.g. Brown and Elderfield, 1996; Dekens et al., 2002; Rosenthal and Lohmann, 2002), would not have a significant effect on G. bulloides $\mathrm{Mg} / \mathrm{Ca}$ values. G. bulloides is therefore likely to provide reliable paleothermometry even where dissolution may be present.

\subsection{Sensitivity of ultra-trace element values to cleaning and analytical protocols}

In contrast to $\mathrm{Mg} / \mathrm{Ca}$ and $\mathrm{Sr} / \mathrm{Ca}$, ultra-trace element values investigated here, $\mathrm{Mn} / \mathrm{Ca}, \mathrm{Ba} / \mathrm{Ca}$, $\mathrm{Zn} / \mathrm{Ca}$ and $\mathrm{Al} / \mathrm{Ca}$, are sensitive to the type of cleaning protocol/s employed and the method used for analysis. As these elements have particularly low concentrations in test calcite, any enrichment or depletion caused by adhering clays, re-crystallisation or laboratory cleaning protocols, are likely to generate offsets, beyond that expected from natural heterogeneity within a population.

Similar to previous studies (Barker et al., 2003a), we found that oxidative treatment alone was unable to significantly reduce $\mathrm{Al} / \mathrm{Ca}$, requiring a combination of oxidative and reductive and/or acid leach treatments (Fig. 17). However, even after oxidative and 1x acid leach ('Mg 
cleaning'), $\mathrm{Al} / \mathrm{Ca}$ values were still four times greater than that recorded in primary calcite, as determined using LA processing, and 5 times higher than those achieved using LA processing prior to cleaning (Fig. 17). Only after $>4 \mathrm{x}$ acid leach are $\mathrm{Al} / \mathrm{Ca}$ levels reduced to values comparable to those obtained by LA processing (Fig. 15). However, elevated Al/Ca values after chemical cleaning did not necessarily indicate or reflect contamination in other trace and ultra trace elements measured.

In contrast to other trace and ultra trace elements measured, $\mathrm{Zn} / \mathrm{Ca}$ values generally increased with more intensive chemical cleaning procedures, regardless of whether LA or solution processing were used (Fig. 13-15). Similar to $\mathrm{Yu}$ (2007), we found that levels of $\mathrm{Zn} / \mathrm{Ca}$ remained high after the application of oxidative treatments. For example, a combination of oxidative and acid leaching increased $\mathrm{Zn} / \mathrm{Ca}$ levels by five times compared to primary calcite values measured prior to chemical cleaning (Fig. 13). Only the use of oxidative and reductive cleaning (without acid leaching) or $>10 \mathrm{x}$ acid leaching were we able to replicate values identified prior to chemical treatment (Fig. 14, 15) and result in the same values regardless of analytical technique. As this enrichment was evident regardless of solution or LA processing, but was not present in the samples that had undergone the most handling during preparation (oxidative + reductive treatment), this suggests that it may be an indication of low-Zn calcite preferential removal rather than laboratory contamination (Table 1, Fig. 13-15) (Wasylenki et al., 2011). Another explanation may be preferential dissolution of low-Zn/Ca calcite bands observed in the LA profiles during the leaching process (Fig. 16), which would suggest that enrichment of $\mathrm{Zn} / \mathrm{Ca}$ values in specimens that have undergone natural dissolution on the sea floor (e.g. Sadekov et al., 2010) may also be an issue.

We found that while oxidative cleaning and multiple acid leaches yield comparable results between LA- and solution-based methods for $\mathrm{Mg} / \mathrm{Ca}$, only the combination of oxidative and 
reductive treatments (without acid leaching) yield comparable results between methods for all TE/Ca measured, except Al/Ca (Fig. 17).

\subsection{Impact of cleaning protocols on test calcite}

Ultrasonication used during the cleaning processes resulted in both physical damage to the test wall (micro-fracturing), and the destruction of $c a .30 \%$ of whole tests in our study (Fig. 9, 17). Based on SEM imaging undertaken after chemical treatment and before chamber separation, a correlation appears to exist between the level of damage to the test wall and the number of ultrasonications. While 'large scale' fracturing occurred at junctions between chambers, or within chambers, 'micro-fracturing' also became increasingly pervasive through the test wall as the number of repeat ultrasonications increased (Fig. 11). Test wall micro-fracturing increases the surface area for chemical interaction during cleaning. This enhances the effect of chemical cleaning procedures, not only on the outer test surface, but also allowing the chemicals to penetrate through to primary test calcite. Therefore, acid leaching after oxidative and/or reductive cleaning and ultrasonification has a greater impact on test calcite as it is effectively able to dissolve both at the surface, and through the foraminifera test wall. The consequence of test wall micro-fracturing prior to acid leaching is indicated by the greater effect of TE/Ca removal by oxidative + acid leaching treatments than can be achieved by either treatment in isolation (Fig. 17). In contrast to Barker (2003a) and $\mathrm{Yu}$ (2007), we found that it was not the specific use of reductive chemicals \pm citric acid during cleaning that lowered trace metal content. Rather, we suggest that the dramatic reduction in trace element concentration was likely the result of acid leach treatments, which utilise nitric acid following the reductive step (AI. 3). After $>17$ ultrasonification treatments ranging from $3 \mathrm{~s}$ to $10 \mathrm{~min}$ long used during the full reductive cleaning protocol, the dilute 
nitric acid used during final leaching process would have had larger surface area from which to dissolve both surface and primary test calcite, enhancing any preferential leaching effects.

SEM imaging after various cleaning protocols shows that etching was present on the surface wall of specimens that had undergone as little as 1x acid leaching (Fig. 18), while specimens, which had undergone $>4 \mathrm{x}$ acid or oxidative $+1 \mathrm{x}$ acid treatments indicated preferential dissolution of layers within the test wall. The dissolution of thin primary calcite layers within the test wall resulted in a breakup of remaining layers, which otherwise had a marked prismatic structure (Fig. 19). This process was not observed during chamber separation for samples that had not been acid treated. It is likely that these foraminifera, that separated into distinct primary calcite layers, did not fragment during cleaning \pm analysis due to the higher density inner calcite layer supporting the outer layers (Fig. 19). In addition, after extensive chemical treatment the test wall primary calcite appeared to be dissolving at a faster rate than the outer surface. This effect was especially notable where the primary calcite surface had been exposed by LA (Fig. 11). Tests were also more fragile after treatment with nitric acid. Up to 3 out of 10 tests fragmented after oxidative \pm reductive treatment or a single acid leach. However, after oxidative + acid leach treatments the number of tests that fragmented doubled to 6 out of 10, indicative of the increased ability of even a single acid treatment following oxidative \pm reductive treatments to corrode the test calcite after extensive micro-fracturing (AI. 2).

Preferential dissolution of calcite from the middle of the test wall is similar to the effects of natural dissolution previously reported for planktic species by Johnstone et al. (2010) using X-ray computed tomography on core-top samples. The effects of chemical pre-cleaning found in this study range between that defined by Johnstone et al. (2010) as Dissolution Stage XDX 1, with only the first signs of dissolution present e.g. surface etching, to Dissolution 
stage XDX 2-3 after multiple acid leaches or oxidative + reductive treatment, characterised by the distinctive density differences between the middle and outer test wall of the largest chambers (Fig. 11, 18) (e.g. Johnstone et al., 2010; Petrizzo et al., 2008). The SEM and optical microscopy images of the test outer surfaces offered little visual indication as to the degree of primary calcite dissolution until after the tests were broken open.

\subsection{Effects of cleaning techniques on laser ablation results}

The efficacy of different 'cleaning' protocols for LA analysis was assessed via comparison of LA results before and after each chemical cleaning method. Potentially, remnants of contaminant material in a foraminifer's pore space (Fig. 11) may remain after use of standard ultrapure water and methanol LA cleaning, introducing bias during progressive ablation through the test wall. While pre-ablation may remove contaminants from the outer test surface (Sadekov et al., 2008) it will not remove material that may be lodged within pore spaces (Fig. 12c). Modified chemical cleaning methods otherwise used for solution based analyses (partially) remove the outer test surface layer, penetrating the pore spaces, removing potential contaminants (AI. 1). Whether these cleaning methods therefore yield improved accuracy for foraminifera trace and ultra-trace element LA-ICPMS analysis is evaluated below.

This study indicates little change in either the mean or precision of $\mathrm{Mg} / \mathrm{Ca}$ foraminiferal sample means following the use of oxidative \pm reductive, \pm acid leach treatments prior to LA analysis and using LA processing (Fig. 13-15, AI. 4). Thus, no change from the typical LA$\mathrm{Mg} / \mathrm{Ca}$ cleaning protocol is recommended for samples that have not undergone extensive post-depositional alteration, such as those reported from the Panama Basin (Pena et al., 2005).

$\mathrm{Sr} / \mathrm{Ca}$ changed little regardless of the degree of treatment and is therefore not suitable as either a contamination or dissolution indicator. Pre-cleaning treatments however had a more 
significant impact on ultra-trace element TE/Ca values (Fig. 13-15, 17). Zn/Ca test results indicate a strong response to intensive cleaning techniques, particularly those involving acid leaching, increasing the $\mathrm{Zn} / \mathrm{Ca}$ after treatment (Fig. 17).

$\mathrm{Al} / \mathrm{Ca}$ values are commonly used as an indicator of contamination, rather than as a paleoceanographic proxy. Intensive chemical pre-treatments were effective in their removal of contaminants such as $\mathrm{Al}$. However, $\mathrm{Al} / \mathrm{Ca}$ levels were using solution processing after chemical treatment still higher than those otherwise recorded using LA processing before chemical treatment (Table 1, Fig. 16). Despite persistent $\mathrm{Al} / \mathrm{Ca}$ contamination, elevated $\mathrm{Al} / \mathrm{Ca}$ levels were not linked to elevated levels of other $\mathrm{TE} / \mathrm{Ca}$ measured and consequently $\mathrm{Al} / \mathrm{Ca}$ was a poor indicator of overall $\mathrm{TE} / \mathrm{Ca}$ contamination. Therefore, the application of more aggressive cleaning treatments such as acid leaching targeted at Al removal for LA analysis is not warranted, and may in fact act to inadvertently enrich other TE/Ca values.

Careful post-analysis processing of the ca. 400 data points collected across a test profile for individual foraminifera to isolate the most representative $\mathrm{TE} / \mathrm{Ca}$ profile had the most significant impact on trace and ultra-trace element/Ca values. Careful data processing (AI. 4) can ensure that the integrated profile does not include TE-enriched calcite from the inner or outer test surfaces, reducing sample $\mathrm{TE} / \mathrm{Ca}$ values by up to $400 \%$ (e.g. $\mathrm{Al} / \mathrm{Ca}$ ). Use of any chemical cleaning treatments for LA-ICPMS analysis 1) did not effectively remove $\mathrm{Al} / \mathrm{Ca}, 2$ ) enriched $\mathrm{Zn} / \mathrm{Ca}$, and 3) did not alter sample values in a statistically significant way $(\mathrm{Mg} / \mathrm{Ca}$, $\mathrm{Sr} / \mathrm{Ca}, \mathrm{Ba} / \mathrm{Ca}, \mathrm{Mn} / \mathrm{Ca}$ ). The highest levels of contamination introduced into foraminifera test samples originate from the inner- and outer-most calcite layers and may be incorporated into the solution-based samples. However, these layers are excluded using LA-techniques where post-analytical processing allows the effective 'cleaning' of foraminifera via the selection of only primary calcite TE/Ca values for integrated means without the use of chemicals. 


\subsection{Conclusions}

Various approaches have been used to study the effectiveness of foraminiferal cleaning techniques, including a comparison between foraminifera analysed using solution and LAbased techniques. $\mathrm{Mg} / \mathrm{Ca}$ and $\mathrm{Sr} / \mathrm{Ca}$ values for the commonly used species, G. bulloides, demonstrate the resilience of test calcite to alteration as a result of oxidative \pm reductive cleaning methods, despite the extensive test micro-fracturing otherwise identified on acid leached samples. Minimal, if any discernible dissolution effects on sample $\mathrm{Mg} / \mathrm{Ca}$ compositions were identified for up to $6 \mathrm{x}$ acid leach treatments, including little evidence of selective Mg-rich calcite dissolution. G. bulloides from down-core samples with suspected dissolution may also provide a superior paleothermometer as this species' $\mathrm{Mg} / \mathrm{Ca}$ values remain relatively unchanged after induced dissolution by repeated acid leaching treatments. Foraminifera cleaned using 'Mg-cleaning' for solution analysis and ultrapure water and methanol for LA analysis yield reassuringly compatible results for $\mathrm{Mg} / \mathrm{Ca}$ and $\mathrm{Sr} / \mathrm{Ca}$ between techniques.

Ultra-trace element values (TE/Ca of $<0.15 \mathrm{mmol} / \mathrm{mol}$ ) are more susceptible to the effects of insufficient cleaning/differential cleaning methods. $\mathrm{Zn} / \mathrm{Ca}$ values increase with progressive dissolution of test calcite using dilute nitric acid suggesting preferential low-Zn calcite dissolution. Elevated $\mathrm{Al} / \mathrm{Ca}$ persists after extensive cleaning, however values of this $\mathrm{TE} / \mathrm{Ca}$ does not generally reflect contamination of other elements including $\mathrm{Mg} / \mathrm{Ca}, \mathrm{Zn} / \mathrm{Ca}, \mathrm{Sr} / \mathrm{Ca}$, $\mathrm{Ba} / \mathrm{Ca}$ or $\mathrm{Mn} / \mathrm{Ca}$ and therefore is not an effective contamination indicator. Likewise, $\mathrm{Sr} / \mathrm{Ca}$ values do not reflect other TE/Ca contamination or depletion and therefore should not be used as an indicator of post-depositional test alteration. 
We conclude that analysis of ultra-trace elements $(\mathrm{Mn} / \mathrm{Ca}, \mathrm{Zn} / \mathrm{Ca}, \mathrm{Ba} / \mathrm{Ca})$ via solution techniques require oxidative and reductive cleaning steps, without acid leaching to avoid artificial $\mathrm{Zn} / \mathrm{Ca}$ elevation. Laser ablation analysis of trace and ultra-trace elements do not require additional cleaning steps beyond those typically used, however careful data processing of individual specimens to exclude inner- and outer-most test calcite (highest TE contamination) is vital for reliable results. 


\section{Auxiliary Information}

\section{AI. 1.0. Stepwise cleaning procedure for the preparation of foraminiferal calcite for elemental analysis using laser ablation}

Procedures in part modified after Boyle (1981), Boyle and Keigwin (2000) and Barker et al. (2003a).

\section{AI . 1.1. Laser Ablation Clean, Clay Removal}

Only steps 1.1 and 1.2 were necessary for laser ablation analysis.

During this stage, samples were treated individually in order to maximize cleaning effectiveness, although ultrasonication was conducted in batches. Separate pipettes were used for adding and removing reagents.

1. $1 / 4$ fill deep sided petri dish with $>18.3 \mathrm{M} \Omega \mathrm{H}_{2} \mathrm{O}$ (ultrapure water) to, ca. $8 \mathrm{~mL}$.

2. Placed lid on petri dish, suspended foraminifera in the water and ultrasonicated for 3-10 seconds, depending on test fragility and the volume of adhering material. Samples with a large amount of material on the outer surface required ultrasonication for up to 1 minute, provided the tests did not fragment. This encouraged separation of more tightly bound clays and nano-fossils from the test surfaces.

3. Sample were allowed to settle for 30 seconds or so. The side of dish was flicked to encourage foraminifer to settle.

4. The dish was placed on an angle and the overlying solution (supernatant) was removed using a separate pipette, taking care not to inadvertently remove foraminifera which floated on the liquid surface or stuck to the sides of the dish. A $2 \mathrm{~mL}$ disposable pipette was found to be suitable for removing most of the overlying liquid from the dish without risk of sample loss.

5. Steps (1) to (4) were repeated a further 3 times.

9. $10 \mathrm{~mL}$ of Aristar methanol was squirted into each dish. 
10. Dishes were ultrasonicated for 3-10 seconds.

11. The sample was allowed to settle for a few seconds, before the methanol was removed. Foraminifera tend to be more buoyant in methanol and additional care was taken not to inadvertently remove foraminifera from the sample.

12. The sample was placed in the oven at $40^{\circ} \mathrm{C}$ overnight or for at least $6 \mathrm{hrs}$ to ensure it was dry for mounting or weighing.

13. Foraminifera were checked under a microscope to assess effectiveness of clay removal from the outer test. If clay and/or nannofossils were still visible in the outer test or within the test aperture, steps (1)-(13) were repeated and the length of time the sample was ultrasonicated was increased.

More repetitions were necessary if clay or nano-fossil material was found to be still visible on the outer test.

\section{AI. 1.2. Mounting for Laser Ablation Analysis}

The foraminifera were mounted directly onto a carefully polished and cleaned disk of NIST silicate glass standard.

In studies where foraminifera were to be weighed, this was done prior to mounting using the following procedure; Using a dry brush, foraminifera were either weighed individually or as a group Mettler Toledo (MX/UMX 2) ultramicro-balance (precision=0.1 $\mu \mathrm{g}$ ). As the weights of foraminifera were very low (e.g. $8.7 \mu \mathrm{g}$ ), the machine was zeroed between samples, and regular calibrations were performed to account for changes in environmental conditions. Reproducibility was assessed via by repeated weighing of the same sample.

1. Adhesive material was placed over $3 / 4$ of the NIST glass. In this study we used the sticky side of a post-it note, adhered to the silicate glass with double sided tape. The back of a postit note was used so that foraminifera were able to be easily removed without fragmentation.

2. Using methanol or a dry brush under an optical microscope, foraminifera were placed individually onto the sticky surface whorl side down with the chamber surface selected for ablation is as close to horizontal as possible for ablation. Care was taken to ensure minimal manipulation of the foraminifera on the post-it note Any foraminifera that fragmented during 
cleaning, strongly discoloured or had persistent adhering material were removed from the sample at this stage.

\section{AI. 1.3. Oxidative Clean- Oxidative treatment is design to remove organic matter.}

Equipment preparation:

1. Using a moistened brush, the foraminifera were transferred to an acid cleaned $2000 \mu 1$ micro-centrifuge tube. Foraminifera were treated individually so that the same foraminifera could be identified and TE/Ca values matched throughout the study. However, if foraminifera were to be analysed in batched, no more that 5 foraminifera were added to each tube to minimise the effects of fragmentation during ultrasonication.

\section{Oxidative clean:}

1. $250 \mu \mathrm{l}$ of alkali buffered $1 \% \mathrm{H}_{2} \mathrm{O}_{2}$ solution was added to each tube and the rack secured with a lid to prevent tubes popping open while under pressure.

2. The sample rack was placed into a boiling water bath for 10 minutes.

a) At 2.5 and 7.5 minutes the rack was removed momentarily and rapped on the bench top to release any gaseous build-up.

b) At 5 minutes the rack was placed in an ultrasonic bath for a few seconds and returned to the water bath after rapping on the bench.

3. The oxidizing reagent was removed using a pipette.

4. Steps (1) to (3) were repeated.

5. Any remaining oxidizing reagent was removed by filling the tube with ultrapure water and removing. The side of the tube was tapped to encourage foraminifera to settle to the bottom thereby ensuring that they were not inadvertently removed during this process. This step was repeated three times. 
AI. 1.4. Reductive Clean - Reductive cleaning is designed to remove any Mn-rich oxide or Mn-rich carbonate coatings (Boyle, 1983)

1. $100 \mu \mathrm{L}$ of reducing cleaning solution (see AI 3.0) was placed in each sample tube containing the foraminifera just prior to cleaning and the rack secured with a lid to prevent tubes popping open while under pressure.

2. The sample rack was placed in a boiling water bath for 30 minutes. After every 2 minutes the rack was placed in an ultrasonic tank for a few seconds and returned to the water bath after rapping on the bench.

3. Reducing agents were removed using a pipette.

4. Foraminifera were heated in two ultrapure water rinses ( 5 minutes each) and followed with a final rinse with room temperature ultrapure water.

AI. 1.5. Dilute Acid Leach - the acid leach is designed to remove adsorbed contaminants and further leaching may be used to dissolve a Mn-carbonate coating where necessary

1. $250 \mu \mathrm{l}$ of $0.001 \mathrm{M} \mathrm{HNO}_{3}$ were added to individual sample tubes.

2. Each sample was ultrasonicated for 3 seconds.

3. Acid was then removed from samples.

4. Ultrapure water was added to each tube.

It was important to replace the leach acid with $\mathrm{H}_{2} \mathrm{O}$ as soon as possible for all samples in order to prevent excess dissolution. This was best achieved by only undertaking this step with a few samples at a time.

5. Overlying $\mathrm{H}_{2} \mathrm{O}$ was removed.

6. Steps (4) and (5) were repeated once.

7. Using a $2 \mathrm{~mL}$ disposable pipette, any remaining solution was carefully removed from each sample.

8. The sample was placed in the oven at $40{ }^{\circ} \mathrm{C}$ overnight (or for at least $6 \mathrm{hrs}$ ) with the tube only loosely covered to ensure the sample was dry for sample mounting or weighing. 
9. Step AI. 1.2. Mounting for Laser Ablation Analysis was followed. 


\section{AI. 2.0. Stepwise procedure for laser ablation data processing}

\section{AI. 2.1 Individual foraminifera}

1. The raw counts of $\mathrm{Mg}$ and $\mathrm{Ca}$ vs. time were plotted on a xy line graph. This showed when the machine had ablated through the test wall.

2. The raw counts were used to assess at what times test wall ablation had taken place. As the laser had not been set for progressive depth correction as it ablated through the test wall, a small natural decay in the raw count signal was evident; however there was a significant decline in the signal after the test wall was penetrated.

3. All elements ratioed to $\mathrm{Ca}$ were plotted after background and standard correction on a log graph. This enabled all TE/Ca to be viewed at the same time despite the wide range in values.

4. The corrected TE/Ca data within the test ablation time frame indicated by the raw counts was assessed. A stable signal through all $\mathrm{TE} / \mathrm{Ca}$ was optimal for the 'integrated profile'. If there was any enrichment in the outer test from adsorbed contaminants for example, this part of the profile was not selected for inclusion in the integrated profile. Likewise, any inner test enrichment was also excluded.

5. 'Fliers' or spurious data generated during analysis were removed from the ca. 100-300 data points for each element included in the integrated profile. There were typically 1-3 measurements on a single $\mathrm{TE} / \mathrm{Ca}$ which generated values that were orders of magnitude higher than sample TE/Ca mean values.

5. Once the part of the foraminifera TE/Ca profile was selected for integration, values within the integrated section were averaged to generate the mean values.

6. The percent standard error was calculated for the integrated profiles. $\mathrm{Mg} / \mathrm{Ca}$ generally had a $\%$ SE of 1-3 \%, any individuals with $\mathrm{Mg} / \mathrm{Ca}>5 \% \mathrm{SE}$ were excluded. Low levels of natural $\mathrm{TE} / \mathrm{Ca}$ variability through the test wall was expected due to the progressive ablation through calcite layers deposited at different water depths during the species lifecycle. 


\section{AI. 2.2. Sample processing}

Once individual foraminifera integrated profiles were assessed, and mean TE/Ca values for individual foraminifera calculated; the individual G. bulloides values from the same sample (e.g. same cleaning method) were pooled to generate sample means.

1. Individual foraminiferal $\mathrm{TE} / \mathrm{Ca}$ values were collated for a sample.

Note, for studies which used more than one core top sample for example, which may cover a range of environmental variables (e.g. Marr et al., 2011) the following procedures would also be added:

2. Threshold values appropriate for the regional environment e.g. water mass, temperature, fluvial input, were used to assess individual $\mathrm{TE} / \mathrm{Ca}$ measurements and ensure that foraminifera which have undergone post-depositional alternation were not included in the sample mean. For example, foraminifera which had undergone post-depositional alteration of primary test calcite via clay contamination typically had elevated TE/Ca at least $200 \%$ higher than sample mean values. Alternatively, samples which have undergone calcite recrystallisation produced $\mathrm{Mg} / \mathrm{Ca}$ values up to $50 \%$ lower than sample mean values.

3. After individual values were pooled to generate sample means, the number of foraminifera remaining within the sample was scrutinised. Natural heterogeneity within a population caused by biological factors or 'vital effects' (Marr et al., 2011; Sadekov et al., 2008) meant that samples needed to have a statistically significant number of foraminifera to ensure an environmentally representative value was attained. While the number of foraminifera required for sample values to reach statistical significance varies between species and location, it is typically $>10$ foraminifera. 


\section{AI. 3.0. Reagents used for chemical cleaning, sufficient for a 20 samples}

\section{Oxidising Reagent}

Alkali buffered $1 \% \mathrm{H}_{2} \mathrm{O}_{2}$ solution. $250 \mathrm{ml}$ oxidising solution used per sample.

Prepare fresh mixture for each batch of samples.

Prepared from:-

Hydrogen peroxide 30\% w/v (Aristar grade).

$0.1 \mathrm{M}$ sodium hydroxide (Aristar grade)

\section{Reducing Reagent}

$0.25 \mathrm{M}$ citric acid in $16 \mathrm{M}$ ammonia. Prepared fresh mixture made up to $1 \mathrm{M}$ in hydrazine $\left(\mathrm{NH}_{2} \mathrm{NH}_{2}\right)$ immediately before cleaning step.

Prepared from:-

$100 \mathrm{ml}$ ammonia

$5.254 \mathrm{~g}$ citric acid (if using powdered citric acid)

Hydrazine step preparation:

To $146 \mu \mathrm{l}$ of ammonia/citric mix, add $1314 \mu \mathrm{l}$ of hydrazine

\section{Dilute Acid Leach}

Optima $^{\mathrm{TM}}$ ultra trace grade $0.001 \mathrm{M}$

Made up using conc. $\mathrm{HNO}_{3}(15 \mathrm{M})$ and ultra pure water 


\section{Auxiliary 4.0. Individual foraminifera TE/Ca data before and after chemical cleaning.}

Stars indicate where a foraminifera has fragmented during cleaning and there been removed from the study.

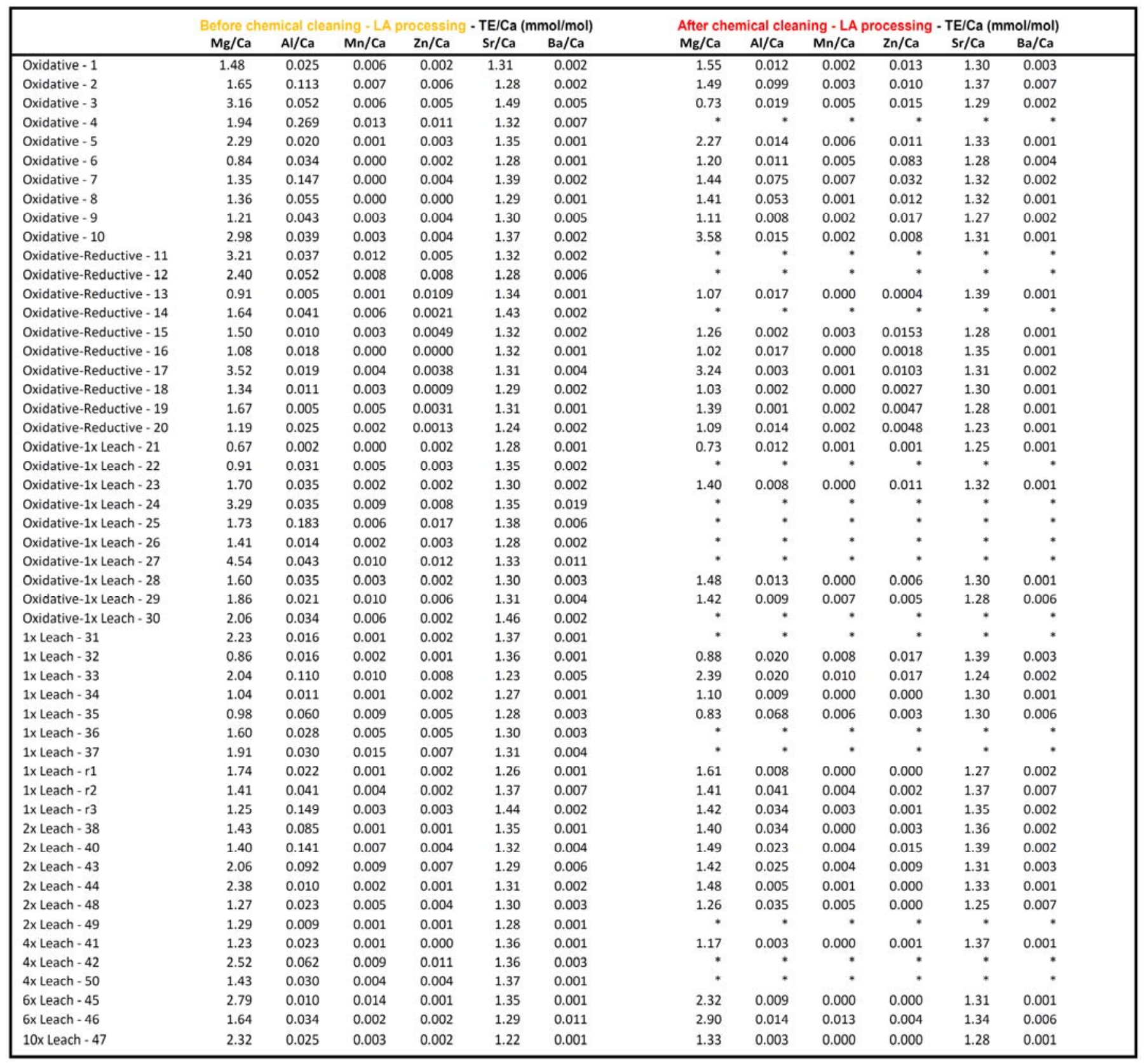

C2-AI - Table 1. Individual foraminifera TE/Ca data before and after chemical cleaning with laser ablation processing. Stars indicate where a foraminifera has fragmented during cleaning and there been removed from the study. 


\begin{tabular}{|c|c|c|c|c|c|c|c|c|c|c|c|c|}
\hline \multirow{3}{*}{ Oxidative - 1} & \multicolumn{6}{|c|}{ Before chemical cleaning - solution processing - TE/Ca $(\mathrm{mmol} / \mathrm{mol})$} & \multicolumn{6}{|c|}{ After chemical cleaning - solution processing - $\mathrm{TE} / \mathrm{Ca}(\mathrm{mmol} / \mathrm{mol})$} \\
\hline & $\mathrm{Mg} / \mathrm{Ca}$ & $\mathrm{Al} / \mathrm{Ca}$ & $\mathrm{Mn} / \mathrm{Ca}$ & $\mathrm{Zn} / \mathrm{Ca}$ & $\mathrm{Sr} / \mathrm{Ca}$ & $\mathrm{Ba} / \mathrm{Ca}$ & $\mathrm{Mg} / \mathrm{Ca}$ & $\mathrm{Al} / \mathrm{Ca}$ & $\mathrm{Mn} / \mathrm{Ca}$ & $\mathrm{Zn} / \mathrm{Ca}$ & $\mathrm{Sr} / \mathrm{Ca}$ & $\mathrm{Ba} / \mathrm{Ca}$ \\
\hline & 3.30 & 1.76 & 0.042 & 0.076 & 1.44 & 0.022 & 2.37 & 0.309 & 0.007 & 0.041 & 1.37 & 0.013 \\
\hline Oxidative -2 & 2.41 & 0.72 & 0.024 & 0.030 & 1.40 & 0.009 & 2.11 & 0.545 & 0.011 & 0.039 & 1.48 & 0.020 \\
\hline Oxidative -3 & 3.92 & 1.11 & 0.022 & 0.022 & 1.66 & 0.020 & 0.76 & 0.029 & 0.004 & 0.016 & 1.30 & 0.002 \\
\hline Oxidative -4 & * & * & * & * & * & * & * & * & * & * & - & * \\
\hline Oxidative -5 & 2.84 & 0.35 & 0.023 & 0.018 & 1.41 & 0.005 & 2.59 & 0.090 & 0.014 & 0.025 & 1.38 & 0.002 \\
\hline Oxidative -6 & 2.00 & 0.81 & 0.015 & 0.042 & 1.35 & 0.019 & 1.45 & 0.086 & 0.009 & 0.152 & 1.25 & 0.008 \\
\hline Oxidative -7 & 2.08 & 0.83 & 0.012 & 0.032 & 1.48 & 0.005 & 1.98 & 1.072 & 0.016 & 0.068 & 1.37 & 0.006 \\
\hline Oxidative -8 & 2.12 & 0.54 & 0.005 & 0.028 & 1.41 & 0.013 & 1.58 & 0.247 & 0.004 & 0.031 & 1.31 & 0.002 \\
\hline Oxidative - 9 & 2.09 & 0.62 & 0.012 & 0.024 & 1.44 & 0.091 & 1.23 & 0.101 & 0.005 & 0.045 & 1.28 & 0.003 \\
\hline Oxidative -10 & 3.39 & 0.52 & 0.011 & 0.026 & 1.44 & 0.006 & 3.61 & 0.304 & 0.005 & 0.021 & 1.36 & 0.003 \\
\hline Oxidative-Reductive - 11 & * & * & $*$ & $*$ & * & * & $\cdot$ & * & * & • & • & ${ }^{*}$ \\
\hline Oxidative-Reductive - 12 & $*$ & $*$ & $*$ & * & * & * & * & * & * & * & $*$ & * \\
\hline Oxidative-Reductive - 13 & 2.47 & 0.32 & 0.005 & 0.010 & 1.46 & 0.006 & 1.82 & 0.046 & 0.000 & 0.0023 & 1.46 & 0.002 \\
\hline Oxidative-Reductive - 14 & * & * & * & * & * & * & * & * & * & * & - & * \\
\hline Oxidative-Reductive - 15 & 2.08 & 0.69 & 0.016 & 0.028 & 1.40 & 0.013 & 1.34 & 0.228 & 0.001 & 0.0053 & 1.32 & 0.003 \\
\hline Oxidative-Reductive - 16 & 2.13 & 0.89 & 0.010 & 0.024 & 1.48 & 0.017 & 1.20 & 0.083 & 0.000 & 0.0015 & 1.37 & 0.003 \\
\hline Oxidative-Reductive - 17 & 3.61 & 0.34 & 0.009 & 0.009 & 1.34 & 0.012 & 3.86 & 0.045 & 0.002 & 0.0029 & 1.32 & 0.003 \\
\hline Oxidative-Reductive - 18 & 1.85 & 0.06 & 0.004 & 0.003 & 1.33 & 0.003 & 1.30 & 0.011 & 0.002 & 0.0002 & 1.29 & 0.001 \\
\hline Oxidative-Reductive - 19 & 1.77 & 0.01 & 0.002 & 0.002 & 1.29 & 0.001 & 1.40 & 0.015 & 0.002 & 0.0023 & 1.29 & 0.001 \\
\hline Oxidative-Reductive - 20 & 1.94 & 0.41 & 0.012 & 0.013 & 1.45 & 0.006 & 1.15 & 0.048 & 0.002 & 0.0021 & 1.22 & 0.002 \\
\hline Oxidative- 1 x Leach - 21 & 0.88 & 0.11 & 0.004 & 0.006 & 1.27 & 0.002 & 0.77 & 0.023 & 0.003 & 0.008 & 1.28 & 0.001 \\
\hline Oxidative- $1 \times$ Leach - 22 & $*$ & $\cdot$ & $\cdot$ & $*$ & $*$ & * & • & $*$ & * & • & $\cdot$ & * \\
\hline Oxidative $-1 \times$ Leach - 23 & 2.19 & 1.69 & 0.010 & 0.011 & 1.41 & 0.008 & 1.46 & 0.063 & 0.003 & 0.019 & 1.33 & 0.001 \\
\hline Oxidative- $1 x$ Leach - 24 & $\cdot$ & $\cdot$ & $*$ & $*$ & $\cdot$ & $*$ & $\cdot$ & * & * & $\cdot$ & $\cdot$ & * \\
\hline Oxidative- $1 \times$ Leach - 25 & * & * & * & * & * & * & * & * & * & * & * & * \\
\hline Oxidative- $1 \times$ Leach - 26 & * & • & * & * & • & $*$ & • & * & * & $\cdot$ & $\cdot$ & * \\
\hline Oxidative- 1 x Leach - 27 & $*$ & * & $*$ & * & * & * & * & * & * & * & * & * \\
\hline Oxidative- 1 x Leach - 28 & 2.11 & 0.38 & 0.008 & 0.008 & 1.33 & 0.008 & 1.59 & 0.102 & 0.003 & 0.014 & 1.30 & 0.001 \\
\hline Oxidative- $1 \times$ Leach - 29 & 3.34 & 1.74 & 0.019 & 0.024 & 1.46 & 0.022 & 2.37 & 0.309 & 0.007 & 0.041 & 1.37 & 0.013 \\
\hline Oxidative- $1 \times$ Leach - 30 & $\cdot$ & - & $\cdot$ & $\cdot$ & $\cdot$ & * & • & $\cdot$ & $*$ & $\cdot$ & $\cdot$ & $\cdot$ \\
\hline $1 \times$ Leach -31 & $*$ & * & $*$ & * & $*$ & $*$ & $*$ & $*$ & * & $*$ & • & * \\
\hline $1 \times$ Leach -32 & 1.52 & 0.22 & 0.006 & 0.006 & 1.37 & 0.004 & 1.11 & 0.613 & 0.024 & 0.063 & 1.37 & 0.008 \\
\hline $1 \times$ Leach - 33 & 2.15 & 0.38 & 0.014 & 0.012 & 1.26 & 0.007 & 2.62 & 0.046 & 0.013 & 0.031 & 1.27 & 0.003 \\
\hline $1 \times$ Leach -34 & 1.77 & 0.57 & 0.009 & 0.021 & 1.37 & 0.008 & 1.38 & 0.118 & 0.007 & 0.032 & 1.36 & 0.006 \\
\hline $1 \times$ Leach -35 & 2.72 & 0.57 & 0.025 & 0.014 & 1.35 & 0.011 & 1.53 & 0.870 & 0.034 & 0.020 & 1.43 & 0.032 \\
\hline $1 \times$ Leach - 36 & $*$ & $*$ & * & * & $*$ & $*$ & * & * & * & * & * & * \\
\hline $1 \times$ Leach - 37 & $*$ & * & $*$ & * & * & * & $*$ & * & * & * & * & * \\
\hline $1 \times$ Leach $-r 1$ & 2.06 & 0.32 & 0.008 & 0.008 & 1.30 & 0.004 & 2.02 & 0.035 & 0.010 & 0.011 & 1.34 & 0.008 \\
\hline $1 \times$ Leach $-r 2$ & 2.76 & 0.45 & 0.009 & 0.018 & 1.39 & 0.026 & 2.19 & 0.766 & 0.014 & 0.013 & 1.46 & 0.091 \\
\hline $1 \times$ Leach $-r 3$ & 2.21 & 0.89 & 0.025 & 0.026 & 1.65 & 0.012 & 2.04 & 0.522 & 0.012 & 0.022 & 1.37 & 0.009 \\
\hline $2 \times$ Leach - 38 & 2.04 & 0.49 & 0.008 & 0.009 & 1.38 & 0.004 & 1.68 & 0.213 & 0.007 & 0.019 & 1.38 & 0.006 \\
\hline $2 \times$ Leach - 40 & 2.07 & 0.46 & 0.012 & 0.008 & 1.40 & 0.006 & 1.63 & 0.347 & 0.010 & 0.072 & 1.41 & 0.007 \\
\hline $2 \times$ Leach - 43 & 2.59 & 0.68 & 0.012 & 0.013 & 1.41 & 0.013 & 2.04 & 0.313 & 0.016 & 0.051 & 1.32 & 0.010 \\
\hline $2 \times$ Leach - 44 & 2.39 & 0.20 & 0.006 & 0.007 & 1.35 & 0.005 & 1.78 & 0.077 & 0.003 & 0.005 & 1.33 & 0.003 \\
\hline $2 \times$ Leach - 48 & 2.16 & 0.27 & 0.026 & 0.013 & 1.33 & 0.009 & 1.57 & 0.264 & 0.018 & 0.014 & 1.29 & 0.017 \\
\hline $2 \times$ Leach - 49 & * & - & $\cdot$ & $*$ & $*$ & $*$ & - & * & * & ? & . & * \\
\hline $4 x$ Leach - 41 & 1.93 & 0.39 & 0.007 & 0.008 & 1.40 & 0.009 & 1.38 & 0.049 & 0.003 & 0.044 & 1.61 & 0.003 \\
\hline $4 \times$ Leach - 42 & $*$ & $\cdot$ & $*$ & $*$ & $\cdot$ & * & • & * & * & * & • & * \\
\hline $4 \times$ Leach - 50 & * & $\cdot$ & $\cdot$ & * & $\cdot$ & $*$ & $\cdot$ & $*$ & $*$ & $\cdot$ & $\cdot$ & * \\
\hline $6 x$ Leach - 45 & 3.28 & 0.45 & 0.678 & 0.016 & 1.38 & 0.010 & 2.22 & 0.013 & 0.005 & 0.004 & 1.32 & 0.001 \\
\hline $6 x$ Leach - 46 & 1.87 & 0.33 & 0.007 & 0.010 & 1.35 & 0.011 & 2.74 & 0.028 & 0.014 & 0.018 & 1.36 & 0.007 \\
\hline $10 x$ Leach - 47 & 2.24 & 0.24 & 0.007 & 0.007 & 1.30 & 0.004 & 1.40 & 0.025 & 0.004 & 0.006 & 1.34 & 0.001 \\
\hline
\end{tabular}

C2-AI - Table 2. Individual foraminifera TE/Ca data before and after chemical cleaning with solution processing. Stars indicate where a foraminifera has fragmented during cleaning and there been removed from the study. 
Chapter 3 


\section{Southwest Pacific Ocean response to a warming world: using $\mathrm{Mg} / \mathrm{Ca}, \mathrm{Zn} / \mathrm{Ca}$ and $\mathrm{Mn} / \mathrm{Ca}$ in foraminifera to track surface ocean water masses during the last deglaciation}

Marr, J. P., L. Carter, H. C. Bostock, Euan Smith and A. Bolton, 2013. Southwest Pacific Ocean response to a warming world: using $\mathrm{Mg} / \mathrm{Ca}, \mathrm{Zn} / \mathrm{Ca}$ and $\mathrm{Mn} / \mathrm{Ca}$ in foraminifera to track surface ocean water masses during the last deglaciation. Paleoceanography, DOI: $10.1002 /$ palo. 20032

\section{Author Contributions:}

Julene Marr; data collection, interpretation, manuscript writing

Lionel Carter, Helen Bostock; general supervision

Monica Handler; general supervision

Annette Bolton; data contribution (modern G. ruber); general discussion.

Euan Smith; assistance with statistical analysis and interpretation.

\section{Abstract}

In situ measurements of $\mathrm{Mg} / \mathrm{Ca}, \mathrm{Zn} / \mathrm{Ca}, \mathrm{Mn} / \mathrm{Ca}$ and $\mathrm{Ba} / \mathrm{Ca}$ in Globigerinoides bulloides and Globigerina ruber from Southwest Pacific core top sites and plankton tow are reported and their potential as paleo-proxies explored. The modern samples cover $20^{\circ}$ of latitude from $34-$ $54^{\circ} \mathrm{S}, 7-19{ }^{\circ} \mathrm{C}$ water temperature, and variable influence of subantarctic (SAW) and subtropical (STW) surface waters. Trace element signatures recorded in core top and plankton tow planktic foraminifera are examined in the context of the chemistry and nutrient profiles of their modern water masses. Our observations suggest that $\mathrm{Zn} / \mathrm{Ca}$ and $\mathrm{Mn} / \mathrm{Ca}$ may have potential to trace SAW and STW. Intra- and inter-species offsets identified by in situ measurements of $\mathrm{Mg} / \mathrm{Ca}$ and $\mathrm{Zn} / \mathrm{Ca}$ indicate these ratios may also record changes in thermal and nutrient stratification in the upper ocean. 
We apply these potential proxies to fossilised foraminifera from the high resolution core MD97-2121. At the Last Glacial Maximum, mean surface water temperatures from $\mathrm{Mg} / \mathrm{Ca}$ were ca. $6-7^{\circ} \mathrm{C}$ lower than present, accompanied by low levels of $\mathrm{Mn} / \mathrm{Ca}$ and $\mathrm{Zn} / \mathrm{Ca}$, with minimal thermal and nutrient stratification. This is consistent with regional dominance of SAW and reduced STW inflow associated with a reduced South Pacific Gyre (SPG). Upper ocean thermal and nutrient stratification collapsed during the Antarctic Cold Reversal, before poleward migration of the zonal winds and ocean fronts invigorated the SPG and increased STW inflow in the early Holocene.Together with reduced winds, this favoured a stratified upper ocean from $c a .10 \mathrm{ka}$ to present.

\subsection{Introduction}

The South Pacific Gyre (SPG) plays a dominant role in heat transportation, with surface currents transporting heat from the tropics to the subtropics. The SPG is also globally important as it links with other Southern Hemisphere mid-latitude gyres in the Indian and Atlantic oceans via the Tasman Leakage (Ridgway and Dunn, 2007; Roemmich, 2007). Recent climatic warming has been accompanied by increased wind stress curl over the South Pacific. This has resulted in a 'spin up' of the SPG, causing the poleward advance of the extended East Australian Current (Ridgway and Hill, 2009). However, the degree to which traditional paleoceanographic methods can investigate past SPG change, as reflected in the surface oceans, is limited restricting our understanding of the dynamic Southwest Pacific Ocean environment.

Previous work has indicated that the SPG contracted during the glacial, with a northward shift of the STF (Passlow et al., 1997; Sikes et al., 2009). The exception to this is along the Chatham Rise, east of New Zealand, where the STF is constrained by the topography and confined within $1-2^{\circ}$ of latitude (Sikes et al., 2002). Evidence from eastern New Zealand suggests, however, that there may have been some flow through of cold subantarctic surface 
waters (SAW) across the western end of Chatham Rise through the Mernoo Saddle (Fig. 1; Weaver et al., 1998; Nelson et al., 2000).

This paper firstly endeavours to develop new paleoceanographic proxies using trace element geochemistry of planktic foraminifers, which may aid in our understanding of surface water masses. In situ measurements of $\mathrm{Mg} / \mathrm{Ca}, \mathrm{Ba} / \mathrm{Ca}, \mathrm{Zn} / \mathrm{Ca}$ and $\mathrm{Mn} / \mathrm{Ca}$ in Globigerina bulloides (G. bulloides) and Globigerinoides ruber (G. ruber) were obtained using laser ablation inductively coupled plasma mass spectrometry (LA-ICPMS). Modern variations in foraminiferal core top and plankton tow trace metal concentrations are initially used to determine whether any distinctive chemical signatures could be used to distinguish between water masses (e.g. Lea and Boyle, 1991; Marchitto et al., 2000). These modern samples span a wide range of temperature and nutrient concentrations, and build on previous work that established regional calibration curves for foraminiferal $\mathrm{Mg} / \mathrm{Ca}$ and ocean temperatures (Bolton et al., 2011; Marr et al., 2011).

In situ trace element measurements are then presented for foraminifera from the last $25 \mathrm{ka}$ of core MD97 2121 in the Southwest Pacific Ocean (Fig. 1) located north of the modern STF, at the southern boundary of the SPG. We used this record to assess whether any changes in the water mass, including surface water thermal and nutrient stratification at the MD97 2121 site were recorded and preserved in the foraminiferal geochemistry. These novel geochemical water mass tracers are then used help enhance our understanding of how frontal surface waters of the SPG - in this case subtropical (STW) and subantarctic (SAW) surface waters near the STF - responded, expanding upon the findings of previous studies in the region. 


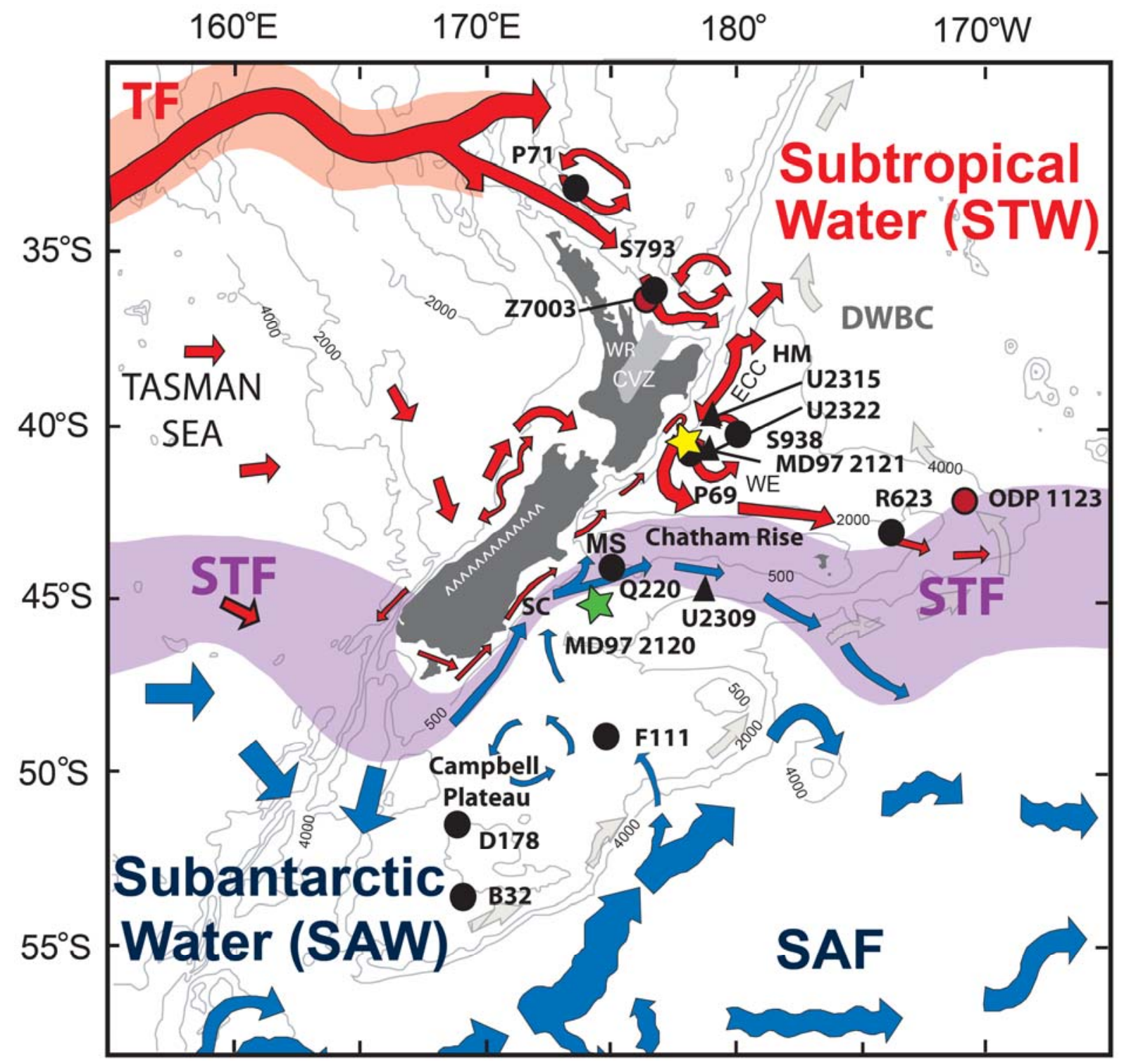

Figure 20. Generalised modern surface ocean currents and bathymetry surrounding New Zealand (modified from Carter et al., 1998). Black and red circles mark the core-top sites, with red sites denoting those used for $G$. ruber only. Black triangle - plankton tow locations; yellow star - MD97 2121, green star - MD97 2120. TFTasman Front; STF-Subtropical Front; SAF-Subantarctic Front; ECC-East Cape Current; STW-Subtropical Surface Water; SAW-Subantarctic Surface Water; MS-Mernoo Saddle; WE-Wairarapa Eddy; CVZ-Central volcanic zone; WR-Waihou River; ${ }^{\wedge}{ }^{\wedge}$-Southern Alps. Isobaths are in metres.

In situ trace element measurements are then presented for foraminifera from the last $25 \mathrm{ka}$ of core MD97 2121 in the Southwest Pacific Ocean (Fig. 20) located north of the modern STF, at the southern boundary of the SPG. We used this record to assess whether any changes in the water mass, including surface water thermal and nutrient stratification at the MD97 2121 site were recorded and preserved in the foraminiferal geochemistry. These novel geochemical 
water mass tracers are then used help enhance our understanding of how frontal surface waters of the SPG - in this case subtropical (STW) and subantarctic (SAW) surface waters near the STF - responded, expanding upon the findings of previous studies in the region.

\subsection{Background}

\subsection{Trace metal signatures in foraminiferal calcite}

The incorporation of trace metals into foraminiferal calcite is likely to be influenced by the waters from which the organisms calcify (e.g. Hönisch et al., 2011). Here we focus on $\mathrm{Mg} / \mathrm{Ca}$, which is now well established as a temperature proxy (e.g. Anand et al., 2003; Cléroux et al., 2008), and $\mathrm{Zn} / \mathrm{Ca}, \mathrm{Mn} / \mathrm{Ca}$ and $\mathrm{Ba} / \mathrm{Ca}$ as potential paleo water mass and environmental tracers.

Previously, $\mathrm{Zn} / \mathrm{Ca}$ and $\mathrm{Ba} / \mathrm{Ca}$ have been used as paleo tracers in benthic foraminifera (Lea and Boyle, 1990; Marchitto et al., 2000) and $\mathrm{Ba} / \mathrm{Ca}$ in planktic foraminifera to track surface water changes in trace metal composition caused by changing fluvial input or upwelling (Hall and Chan, 2004; Lea and Boyle, 1991). However, values of $\mathrm{Ba} / \mathrm{Ca}$ in planktic foraminifera are typically low (ca. 1-15 $\mu \mathrm{mol} / \mathrm{mol}$ ) making it challenging to measure statistically significant offsets in test calcite where a Ba-enriched fluvial source is absent (Hall and Chan, 2004; Lea and Spero, 1994; Weldeab et al., 2007). Also, the use of oxidative or reductive cleaning procedures prior to the measurements of $\mathrm{Zn} / \mathrm{Ca}, \mathrm{Mn} / \mathrm{Ca}$ and $\mathrm{Ba} / \mathrm{Ca}$ via solutionbased analytical techniques can lead to marked differences in measurements (Marr et al., in press-a).

Zinc and Mn have roles similar to Fe, and are essential to biological processes associated with the primary productivity and enzymatic activity of phytoplankton (Bruland and Lohan, 2003; Croot and Hunter, 1998; Lea and Boyle, 1991; Morel and Price, 2003; Price and Morel, 1990). They are collectively referred to as 'bioactive trace metals' (Bruland and Lohan, 2003). The mechanisms by which planktic foraminifera incorporate and biologically mediate $\mathrm{Mn}, \mathrm{Zn}$ or $\mathrm{Ba}$ into test calcite are, however, unclear.

There are various factors known to influence $\mathrm{Mg}$ incorporation, and which may also affect the other trace metals. Studies using in situ analytical techniques highlight the effect of daynight, high-low $\mathrm{Mg} / \mathrm{Ca}$ banding through foraminifera test wall caused by light on symbiotic species (Eggins et al., 2004; Sadekov et al., 2005; Spero et al., 2008). While this can cause $\mathrm{Mg} / \mathrm{Ca}$ offsets between calcite layers of up to $8 \mathrm{mmol} / \mathrm{mol}$ in species such as Orbulina 
universa, which precipitates ca. 30\% of its shell as high $\mathrm{Mg} / \mathrm{Ca}$ calcite (Spero et al., 2008), high-Mg calcite precipitation is significantly less in other species such as G. ruber (Sadekov et al., 2008; Sadekov et al., 2005). G. bulloides is asymbiotic and there is no apparent highlow banding of $\mathrm{Mg} / \mathrm{Ca}, \mathrm{Mn} / \mathrm{Ca}, \mathrm{Ba} / \mathrm{Ca}$ or $\mathrm{Zn} / \mathrm{Ca}$ through test walls associated with ontogenic growth as revealed by LA-ICPMS profiles through test walls (Marr et al., 2011; Marr et al., in press-a). LA-ICPMS also enables the direct targeting of specific chambers for trace metal analysis, and thus allows assessment of changes in trace metal concentrations of different chambers during the foraminifera's lifecycle.

\subsection{Surface ocean trace metal concentrations}

Differences in concentrations of $\mathrm{Zn}$ and $\mathrm{Mn}$ in the surface waters have been observed across the modern STF in the South Pacific Ocean. Mean dissolved Zn levels of $0.22 \mathrm{nmol} / \mathrm{kg}$ in STW are higher than a mean of $0.04 \mathrm{nmol} / \mathrm{kg}$ in SAW (M. Ellwood pers. comm., 2011). STW Mn concentrations are ca. $1.2 \mathrm{nmol} / \mathrm{kg}$, while those from SAW generally range from 0.3 to $0.7 \mathrm{nmol} / \mathrm{kg}$ (Klinkhammer and Bender, 1980). Thus, an increasing influence of nutrient-rich STW may potentially be indicated by elevated $\mathrm{Zn} / \mathrm{Ca}$ or $\mathrm{Mn} / \mathrm{Ca}$ in foraminifera.

Dissolved $\mathrm{Ba}$ concentrations, however, are relatively homogenous with as little as $10-20 \%$ difference between SAW and STW off southern Australia (Jacquet et al., 2004). While there is no major upwelling in this region to enhance $\mathrm{Ba}$ concentrations, there are many rivers that discharge along the lower eastern North Island, annually carrying ca. $83 \mathrm{Mt}$ of suspended load to the continental shelf (Hicks and Shankar, 2003). The Waihou River, where the Mn and $\mathrm{Zn}$ concentrations have been measured, is the closest river to the core site MD97 2121, over $300 \mathrm{~km}$ to the northwest (Fig. 20). The Waihou, does however, drain a similar catchment to rivers discharging into Hawke Bay (Fig. 20). The Waihou River has dissolved Mn levels of $1.4-8.8 \mu \mathrm{g} / \mathrm{kg}$ and $\mathrm{Zn}$ of $<0.1 \mu \mathrm{g} / \mathrm{kg}$ (Webster, 1995), lower than the global averages of $34 \mu \mathrm{g} / 1$ and $0.6 \mu \mathrm{g} / \mathrm{l}$, respectively (Gaillardet et al., 2003). Unfortunately no dissolved $\mathrm{Ba}$ concentrations from rivers are available for the North Island (see Auxiliary Information).

\subsection{Physical Oceanography}

The East Australian Current (EAC) is the main western boundary current of the SPG (Ridgway and Hill, 2009). The EAC flows south along eastern Australia, with a component detaching to form the eastward flowing Tasman Front (TF) (Ridgway and Dunn, 2007). This 
frontal flow attaches to northern New Zealand as the East Auckland Current (EAUC) and its southward continuation as the East Coast Current (ECC) continues to Chatham Rise before being steered eastward (Ridgway and Hill, 2009; Tilburg et al., 2001). Seaward of the ECC is the anticyclonic, warm-core Wairarapa Eddy (WE) associated with the East Cape Eddy system. Eddies shed near East Cape, and propagate southwest along the continental margin to Hawke Bay where they may stall or merge with a previous perturbation to form the WE (Chiswell, 2005; Roemmich and Sutton, 1998).

South of Chatham Rise, the inflow to southern New Zealand is dominated by the Antarctic Circumpolar Current (ACC) whose leading edge is the Subantarctic Front (SAF). The SAF separates Subantarctic Water (SAW) from colder Circumpolar Surface Water (CSW) and is forced south around the bathymetric barrier of Campbell Plateau (Fig. 20) (Heath, 1985a; Morris et al., 2001).

These subtropical and subantarctic inflows create a dynamically-driven modern surface ocean east of New Zealand (Fig. 20). The boundary between the two inflows is the STF positioned along the east-west crest of Chatham Rise (Chiswell, 2002a). The front separates warm, saline, micronutrient-rich, macronutrient-poor subtropical water (STW) in the north from cold, less saline, micronutrient-poor, macronutrient-rich SAW to the south (Boyd et al., 1999; Ellwood et al., 2008; Locarnini et al., 2006).

Off the eastern South island, the STF is represented by the northward flowing Southland Current. At Chatham Rise, a branch of the Southland Current extends east to the STF whereas another branch continues north through Mernoo Saddle (Fig. 20). On its passage north through the Mernoo Saddle, cool $\left(\sim 7^{\circ} \mathrm{C}\right)$, low salinity ( $\left.\sim 34.6 \mathrm{psu}\right)$ Subantarctic Mode Water is forced from $580-800 \mathrm{~m}$ water depth to at least $275 \mathrm{~m}$, and probably to the surface, via episodic wind-induced upwelling (Heath 1972a,b; Heath 1985; Morris et al., 2001).

\subsection{Samples and Methods}

\subsection{Samples}

Modern foraminifera were sampled from eleven core-top sites and three plankton tows spanning 20 degrees of latitude, three water masses, and water depths from 580-3003 m (Fig. 20). The deepest sites are close to the calcite saturation horizon, which locally lies at 2800$3100 \mathrm{~m}$ (Bostock et al., 2011). Accordingly, individual foraminifera from core-top sites $>2500 \mathrm{~m}$ depth were examined visually and via scanning electron microscopy for signs 
of test dissolution, which can indicate that preferential leaching of trace elements (e.g. Brown and Elderfield, 1996). Any individuals that were potentially compromised by dissolution were removed from the dataset.

Ancient foraminifera were sampled from the upper $9.15 \mathrm{~m}$, corresponding to the last ca. 25 kyr of giant piston core, MD97 2121, situated north of the modern STF $\left(40^{\circ} 22.935^{\prime} \mathrm{S}\right.$, $\left.177^{\circ} 59.68^{\prime} \mathrm{E}\right)$ at a water depth of $2314 \mathrm{~m}$ (Carter et al., 2008). The oceanographic setting, high sedimentation rate $(29-42 \mathrm{~cm} / \mathrm{kyr}$ ) and well constrained chronology (Carter et al., 2008) make this an optimal site to test these new geochemical proxies and learn more about the SPG over the last glacial/interglacial cycle.

Samples were taken in ca. 5-10 cm intervals yielding a ca. 300-600 year resolution (e.g. Carter et al., 2008). G. ruber and G. bulloides from core-tops and MD97 2121, were handpicked from the $250-450 \mu \mathrm{m}$ sieved fraction (Fig. 21). G. bulloides is present continuously throughout the glacial-interglacial record, however, G. ruber, which favours warmer waters, is rare during the cooler intervals and is only present in sufficient abundance for analysis from ca. $15.5 \mathrm{ka}$ through the late Holocene. 

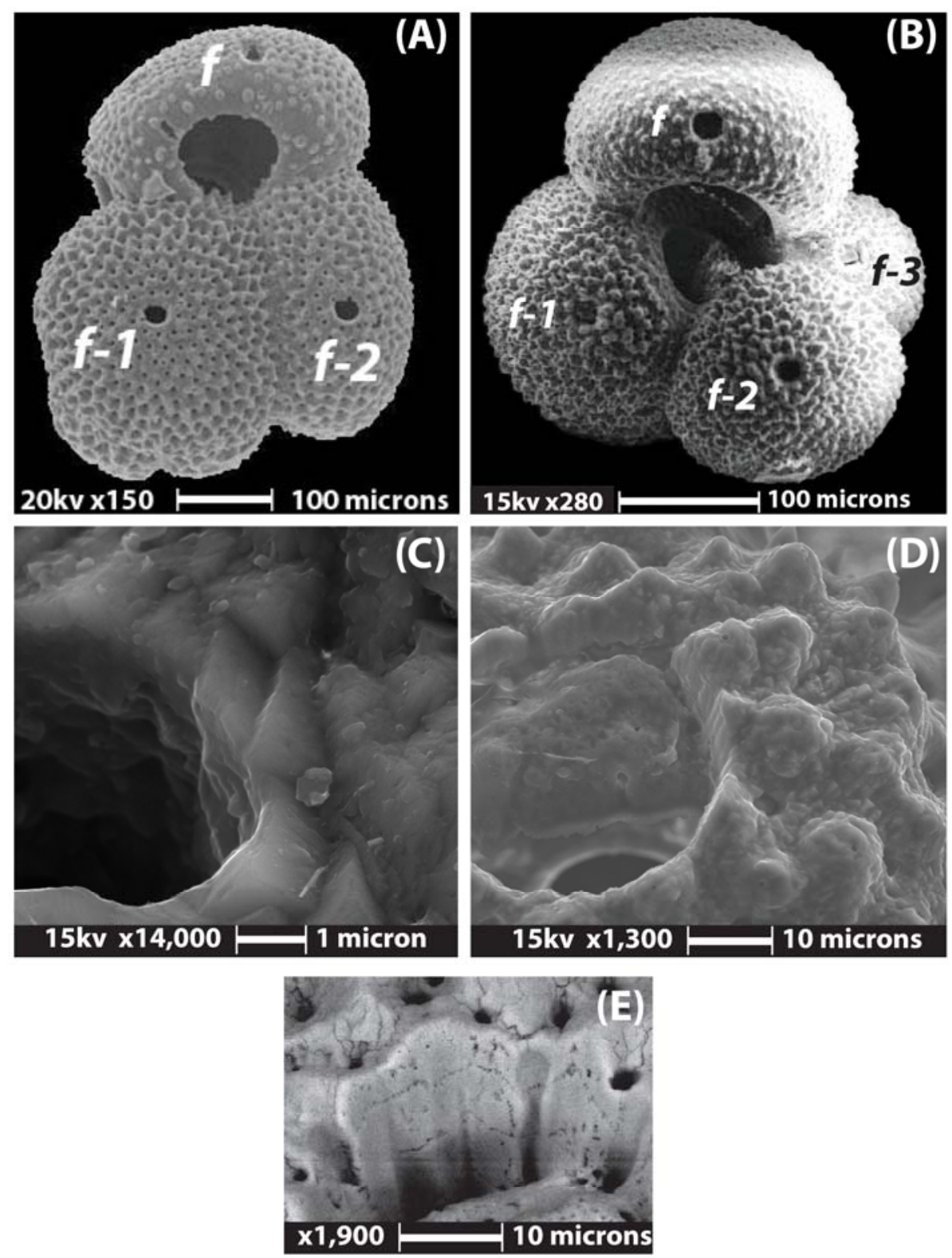

Figure 21. Scanning electron microscopy image of Globigerinoides ruber (A) and Globigerina bulloides (B). The chambers are labelled such that $f$ represents the final (youngest) chamber, $f-1$ is the penultimate chamber, $f$ 2 is the antepenultimate chamber and $f-3$ the oldest chamber analysed. Core-top study results for mean STW and SAW trace element/Ca values are based on the mean of $G$. bulloides chamber $f-3, f-2$ and $f-1$ values as this species present in both STW and SAW. For the down core MD97 2121 record, only chambers $f$-2 and $f$ were analysed for $G$. bulloides and chamber $f-2$ for $G$. ruber. Laser ablation pits measuring $25 \mu \mathrm{m}$ in diameter are visible. High magnification images of pore space and surrounding calcite in a glacial (C) and, Holocene ablation pit (D) G. bulloides shows no change in calcification through the test wall which indicates little to no dissolution and/or re-crystallisation has taken place. Image (E) is of an ablation pit through a G. bulloides from another Southwest Pacific location on which dissolution is clearly evident by the absence of thin calcite layers through the test wall. 


\subsection{Analytical Techniques}

Foraminifera were cleaned and mounted on a NIST 610 silicate glass standard for trace element analysis by LA-ICPMS following the protocols outlined in Marr et al. (2011). Trace element/Ca ratios of foraminiferal tests were analysed using a New Wave deep-UV (193 nm) solid-state laser ablation system coupled to an Agilent 7500CS ICPMS at Victoria University of Wellington, New Zealand. Monitored isotopes were ${ }^{24} \mathrm{Mg},{ }^{27} \mathrm{Al},{ }^{43} \mathrm{Ca},{ }^{55} \mathrm{Mn},{ }^{66} \mathrm{Zn},{ }^{88} \mathrm{Sr}$ and ${ }^{138} \mathrm{Ba}$. Laser ablation analyses were between $60 \mathrm{~s}$ and $120 \mathrm{~s}$ in duration depending on test wall thickness and/or density, to ensure consistent penetration of the G. bulloides and G. ruber test wall (e.g. Marr et al., 2011). After subtraction of background signals, trace element/Ca ratios were calculated by reference to bracketing LA-ICPMS analyses of the NIST610 glass standard, and normalisation to the preferred trace element values in this standard: $\mathrm{Mg}-465$ ppm, Al-10798 ppm, Ca-82191 ppm, Mn-485 ppm, Zn-456 ppm, Sr-516 ppm, Ba-435 ppm (Pearce et al., 1997). Analyses of NIST610 bracketed every 5-20 analyses of foraminifera and showed no significant drift in trace element/Ca ratios beyond the internal precision of the analyses over the course of the analytical sessions. The internal precisions (\% 2 standard error) of trace element/Ca ratios for a single foraminiferal analysis are typically: $\mathrm{Mg} / \mathrm{Ca} \pm 1.0$ $2.5 \%, \mathrm{Al} / \mathrm{Ca} \pm 5-20 \%, \mathrm{Mn} / \mathrm{Ca} \pm 3-15 \%, \mathrm{Zn} / \mathrm{Ca} \pm 6-23 \%, \mathrm{Sr} / \mathrm{Ca} \pm 1.0-2.0 \%, \mathrm{Ba} / \mathrm{Ca} \pm 3-30 \%$.

Previous LA-ICPMS studies of foraminifera demonstrated that trace element-depth profiles through a test wall are typically variable with a 'surface veneer' enriched in $\mathrm{Mg}$ and other trace elements (except $\mathrm{Sr}$ ) and similar, highly localised, enrichment in $\mathrm{Mg}$ and other trace elements as the laser penetrates the inner test wall (e.g. Eggins et al., 2003b). This is especially true of $\mathrm{Mn} / \mathrm{Ca}$ levels in foraminiferal calcite, which is known to be susceptible to post-deposition alteration (e.g. Boiteau et al., 2012; Boyle, 1983). Careful scrutiny of the time-resolved trace element depth profiles during processing, with exclusion of high $\mathrm{Mn} / \mathrm{Ca}$ phases potentially representing post-depositional contamination or diagenesis (e.g. Boyle, 1983), ensures that only primary calcite is represented in sample means (Marr et al., 2011).

For the modern core-tops all four visible chambers of $G$. bulloides and chamber $f-2$ of $G$. ruber were analysed (Bolton et al., 2011). However, only data from G. bulloides older three visible chambers ( $f-3$ to $f-1)$ were used to determine the mean for the water mass, as final chamber ( $f$ ) values show a large offset (Marr et al., 2011). Individual foraminifera values are grouped and presented as sample means for core-top and plankton tows $(n=10-37)$ to allow comparison with studies that use solution techniques (e.g. Anand et al., 2003; Pahnke and Sachs, 2006; Pahnke et al., 2003). 
For the MD97 2121 down core samples only the anti-penultimate $(f-2)$ and final $(f)$ chambers of $G$. bulloides were analysed, because chamber $f-2$ yielded better within-chamber reproducibility than older $f-3$ or younger $f-1$ chambers and avoids issues associated with the kummerform chambers (Fig. 2) (Berger, 1971). Each sample mean (using chambers $f-2$ or $f$ ) were composed of measurements from 10-46 individual specimens with the $95 \%$ confidence interval describing the distribution of the data about the sample mean given in Auxiliary Information 1. The variance of values in each sample was also calculated. Paleo-temperature estimates were determined as follows:

G. bulloides $-\mathrm{Mg} / \mathrm{Ca}(\mathrm{mmol} / \mathrm{mol})=0.952[ \pm 0.041] \times \mathrm{e}^{0.068[ \pm 0.002] \times \mathrm{T}}\left(\mathrm{r}^{2}=0.95\right)$

Calibrated temperature range - ca. $7.0-31.0^{\circ} \mathrm{C}$ (Marr et al., 2011)

G. ruber $-\mathrm{Mg} / \mathrm{Ca}(\mathrm{mmol} / \mathrm{mol})=0.798[ \pm 0.133] \times \mathrm{e}^{0.070[ \pm 0.005] \times \mathrm{T}}\left(\mathrm{r}^{2}=0.89\right)$

Calibrated temperature range - ca. $14.0-29.0^{\circ} \mathrm{C}$ (Bolton et al., 2011)

\subsection{Results}

\section{1. $\mathrm{Mn} / \mathrm{Ca}, \mathrm{Zn} / \mathrm{Ca}$ and $\mathrm{Ba} / \mathrm{Ca}$ ratios in the modern ocean}

$\mathrm{Mn} / \mathrm{Ca}$ and $\mathrm{Zn} / \mathrm{Ca}$ typically occur in low $(<300 \mu \mathrm{mol} / \mathrm{mol})$ and $\mathrm{Ba} / \mathrm{Ca}$ in ultra low $(<10$ $\mu \mathrm{mol} / \mathrm{mol}$ ) levels in the modern and ancient foraminifera studied here (Fig. 23-25, Table 2) (e.g. Lea and Boyle, 1991; Rosenthal et al., 1999). Individual LA-ICPMS analyses of these elemental ratios can have large uncertainties, due to low concentrations of $\mathrm{Mn}, \mathrm{Zn}$ and $\mathrm{Ba}$ and heterogeneity of the foraminiferal test wall. Multiple analyses $(n=3-5)$ of single chambers of an individual foraminifera show that the external reproducibility $(2 \mathrm{sd})$ of trace element/Ca ratios for a single foraminifera analysis are better than: $\mathrm{Mn} / \mathrm{Ca} \pm 15-60 \%( \pm 9-33$ $\mu \mathrm{mol} / \mathrm{mol}), \mathrm{Zn} / \mathrm{Ca} \pm 14-52 \%$ ( $\pm 4-19 \mu \mathrm{mol} / \mathrm{mol}), \mathrm{Ba} / \mathrm{Ca} \pm 27-157 \%$ ( $\pm 2-14 \mu \mathrm{mol} / \mathrm{mol})$. Some of this variability represents real heterogeneity within the foraminiferal test chambers and overestimates the analytical external reproducibility (Marr et al., 2011). Nevertheless, $\mathrm{Mn} / \mathrm{Ca}$ and $\mathrm{Zn} / \mathrm{Ca}$ mean values of $\mathrm{G}$. bulloides from STW core-top sites are statistically different from SAW core-top sites, $(\mathrm{Mn} / \mathrm{Ca}$ STw $=23.7-120.2 \mathrm{vs} \mathrm{Mn} / \mathrm{Ca} \mathrm{SAw}=1.8-7.6 \mu \mathrm{mol} / \mathrm{mol}$ and $\mathrm{Zn} / \mathrm{Ca} \mathrm{sTw}=19.7-65.6 \mathrm{vs} \mathrm{Zn} / \mathrm{Ca} \mathrm{sAw}=7.5-14.1 \mu \mathrm{mol} / \mathrm{mol})$. The relative differences of these mean elemental ratios from G. bulloides between STW and SAW core-top sites, ca. 1700\% for $\mathrm{Mn}$ and $400 \% \mathrm{Zn}$, are larger than analytically, or known biologically induced uncertainties (Fig. 22). 
G. bulloides and G. ruber mean $\mathrm{Zn} / \mathrm{Ca}$ and $\mathrm{Ba} / \mathrm{Ca}$ values from individual core-top and plankton tow samples are in good agreement, suggesting that any post-depositional alteration of tests is not significant (Fig. 22, Table 2; AI 2). However, mean $\mathrm{Mn} / \mathrm{Ca}$ of $0.6 \mu \mathrm{mol} / \mathrm{mol}$ measured on the G. bulloides from U2309 plankton tow is 4-12 times lower than that of nearby core tops. Likewise, the mean $\mathrm{Mn} / \mathrm{Ca}$ of $7.6 \mu \mathrm{mol} / \mathrm{mol}$ measured on G. ruber from plankton tow $\mathrm{U} 2315 / \mathrm{U} 2322$ from STW is 5 times less than adjacent core top ratios (Table 2; AI 2).

Mean $\mathrm{Mn} / \mathrm{Ca}$ and $\mathrm{Zn} / \mathrm{Ca}$ ratios for modern G. bulloides compared across all core-top and plankton tow samples show approximately an order of magnitude variation, with the largest difference evident across the STF (Fig. 20, 22, Table 2). G. bulloides $\mathrm{Zn} / \mathrm{Ca}$ values from STW sites are four times greater than their SAW counterparts (Fig. 22). This broadly mirrors modern water chemistry, where mean STW Zn levels are $>5$ times higher than in SAW (Fig. 22g) (M. Ellwood pers. comm., 2011). G. bulloides STW and SAW foraminiferal $\mathrm{Mn} / \mathrm{Ca}$ values also mimic the distinctive water mass trace metal concentrations, where particulate STW Mn is two to four times higher than that found in SAW south of Australia (Fig. 22d) (Bowie et al., 2009). G. bulloides $\mathrm{Ba} / \mathrm{Ca}$ from SAW and STW does not vary significantly between samples, which are very low $(0.5-5 \mu \mathrm{mol} / \mathrm{mol})$ for distal sites P71, B32, D178, F111, dominated by carbonate-rich sediments (Fig. 22c). However, core-top and plankton tow $\mathrm{Ba} / \mathrm{Ca}$ results from S938, R623, $\mathrm{U} 2309$ have values of up to $8.7 \mu \mathrm{mol} / \mathrm{mol}$, and S793 up to 14 $\mu \mathrm{mol} / \mathrm{mol}$ or $400 \%$ higher (Fig. 22c). Corresponding enrichments or depletions in foraminiferal $\mathrm{Zn} / \mathrm{Ca}, \mathrm{Mn} / \mathrm{Ca}$ or $\mathrm{Mg} / \mathrm{Ca}$ are not apparent. 

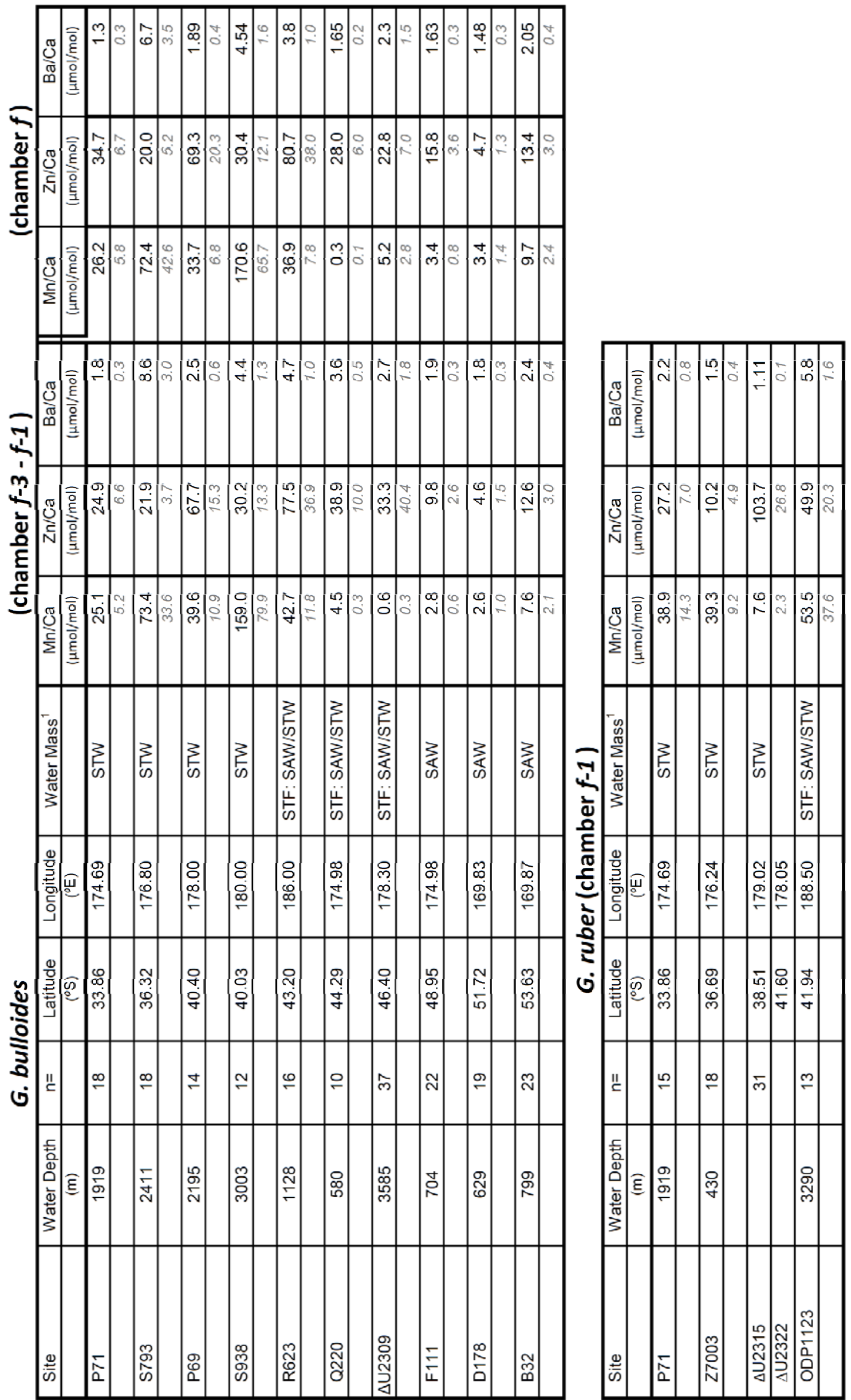
Table 2. Details of core-top and ${ }^{\Delta}$ plankton tow locations, water depth and number of foraminifera analysed from 10 core-top and one plankton tow site in the Southwest Pacific Ocean, east of New Zealand used for calibrating the planktic foraminifera water mass proxies (Fig. 20). Also presented is a summary of trace element chemistry for $G$. bulloides three oldest chambers $(f 1, f 2, f 3)$, final chamber $(f)$ and $G$. ruber outlined here as sample means with $95 \%$ confidence interval in italics. Note, where subtropical mean or subantarctic water means have been presented only those sites solely labelled STW or SAW have been used. For additional details about core-top sites see Marr et al. (2011).

${ }^{1} \mathrm{STW}=$ Subtropical Water; SAW = Subantarctic Water; STF = Subtropical Front, Stanton (1973).

G. ruber samples are restricted to the warmer STW, however, their mean $\mathrm{Mn} / \mathrm{Ca}, \mathrm{Zn} / \mathrm{Ca}$ and $\mathrm{Ba} / \mathrm{Ca}$ values are similar to the mean for $G$. bulloides older chambers $f-3, f-2$ and $f-1$ from the same or nearby sites (ODP1123:R623, Z7003:S973, P71) (Fig. 22, Table 2).

Modern G. bulloides chamber $f$ values tend to be more enriched in $\mathrm{Zn} / \mathrm{Ca}$ than either $G$. bulloides chambers $f-1$ to $f-3$ by up to $40 \%$ or in $G$. ruber (chamber $f-2$ ) by up to $50 \%$ (Table 2). While the difference between G. bulloides chamber $f$ and $G$. ruber chamber $f-2$ is up to $50 \%$, except the data from plankton tow sites U2322 and U2315, where G. ruber $\mathrm{Zn} / \mathrm{Ca}$ values are more than $50 \%$ higher than core top sites suggesting these samples may contain some remnant $\mathrm{Zn}$-enriched organic material (Fig. 22). The relationship between G. bulloides chamber $f$ and $G$. ruber chamber $f-2 \mathrm{Zn} / \mathrm{Ca}$ may replicate the modern surface water concentration gradients, where $\mathrm{Zn} / \mathrm{Ca}$ is $c a .50 \%$ higher at $100 \mathrm{~m}$ depth than at $30-40 \mathrm{~m}$ (Fig. 22H,I) (Martin et al., 1989).

All G. bulloides chambers and G. ruber $\mathrm{Mn} / \mathrm{Ca}$ values from the same sample are indistinguishable (P71; Table 2). $\mathrm{Ba} / \mathrm{Ca}$ is present in ultra low concentrations, and any interchamber variations are close to uncertainty; however the general trend is for G. bulloides older chambers $f-3, f-2$ and $f-1$ and $G$. ruber to be more enriched in $\mathrm{Ba} / \mathrm{Ca}$ than $G$. bulloides chamber $f$ (Table, 2). 

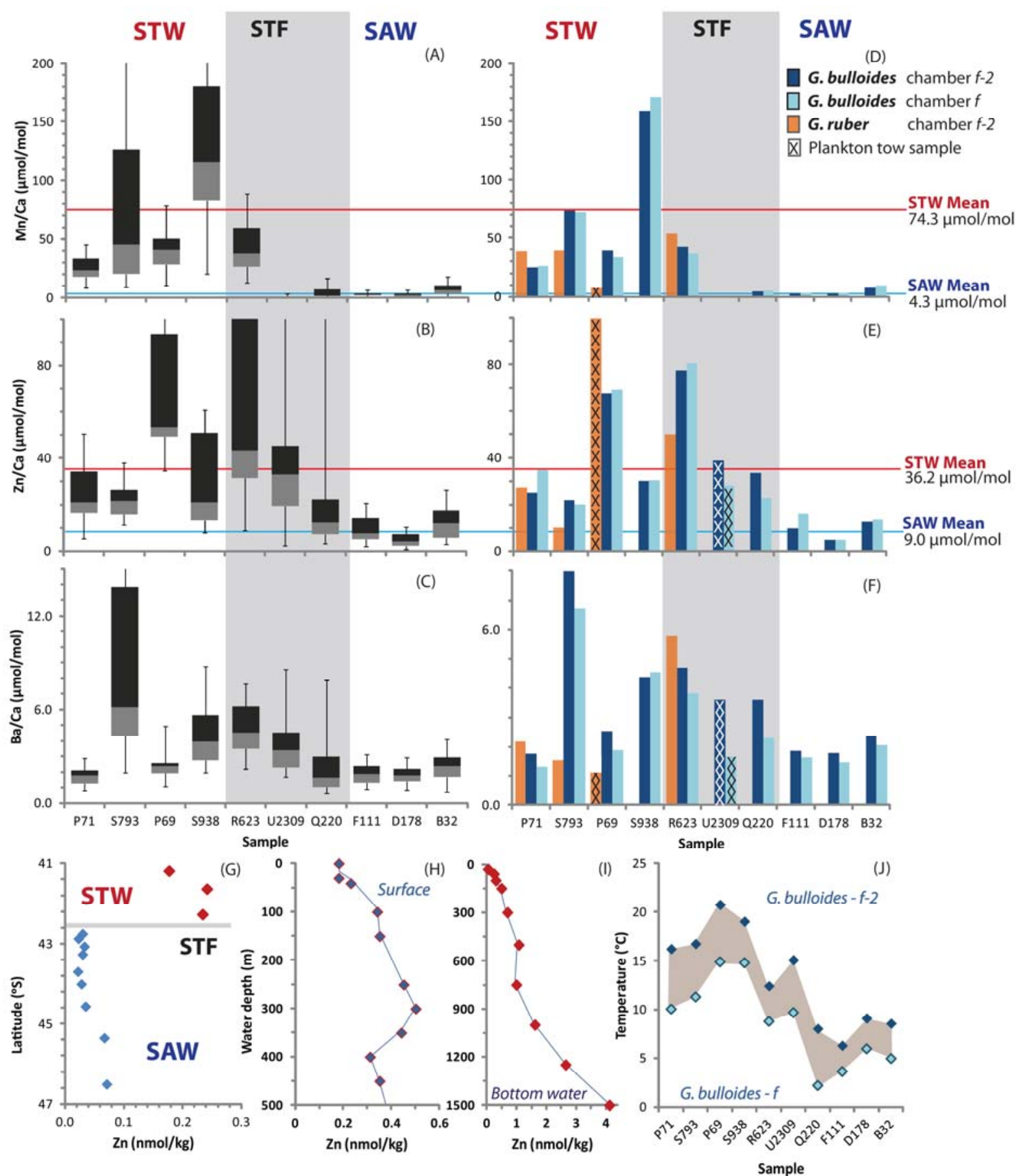

Figure 22. Comparison of sample trace element/Ca ratios for modern $G$. bulloides chambers $f-1$ to $f-3$ (inclusive) and $G$. ruber chamber $f-2$ with each sample mean comprised of measurements from multiple individual specimens. Core sites are presented according to their respective latitudes (Table 2) from north to south with those sites from the STW and SAW indicated either side of the STF sites (grey shaded box). "Box and whisker" plots in panels $(\mathrm{A}-\mathrm{C})$ illustrate values of all $G$. bulloides $f-2$ analyses at a given site. Bar graphs in panels (D-F) represents G. ruber (orange) and G. bulloides (chambers $f-3-1$ - dark blue; chamber $f$ - light blue). Note $G$. ruber site Z7003 has been incorporated into S793 and ODP1123 into R623 due to their close proximity. The bar graph indicates mean site values for G. bulloides chambers $f-1-f-3$ (dark blue) and $f$ (light blue). The $\mathrm{Zn} / \mathrm{Ca}$ and 
Mn/Ca solid lines represent the mean values for the STW (red - P71, P81, S793, P69, S938) and SAW (blue F111, D178, B32) sites. Site means are for G. bulloides chambers $f-1$ to $f-3$ only. Plankton tow values from U2309 (G. bulloides) and U2315 and U2322 (G. ruber) are indicated by hashed lines, note, G. ruber plankton tow values have been appended to site P69 due to location proximity. (G) STW and SAW water mass Zn concentrations sampled in October, 2000 (Elwood, unpub. data 2012) ca.41.2-46.5 ${ }^{\circ} \mathrm{S} ; 178.5-178.6^{\circ} \mathrm{E}$, (H) $\mathrm{Zn}$ surface water concentrations from $0-500 \mathrm{~m}$ and (I) surface-deep water from $0-1500 \mathrm{~m}, 39.47^{\circ} \mathrm{S} ; 179.35^{\circ} \mathrm{E}$ (Elwood, unpub. data 2012). (J) Modern surface ocean thermal stratification as measured by $\mathrm{Mg} / \mathrm{Ca}$ thermometry of $G$. bulloides chamber $f-2$ (dark blue diamonds) and $f$.

\subsection{Glacial-interglacial $\mathrm{Mg} / \mathrm{Ca}, \mathrm{Zn} / \mathrm{Ca}, \mathrm{Mn} / \mathrm{Ca}$ and $\mathrm{Ba} / \mathrm{Ca}$}

MD97 2121 core data (Fig. 22, 23 and AI 1) show mean glacial Mg/Ca temperatures for $G$. bulloides (chamber $f$-2) and G. ruber (chamber $f$-2) are 10.4 and $12.4{ }^{\circ} \mathrm{C}$, respectively from 25-21 ka. G. bulloides records an initial temperature increase of ca. $4{ }^{\circ} \mathrm{C}$ from ca. 22-18 ka followed by an equivalent decrease in temperature from 18 to15 ka. From $c a$. 17 to $14 \mathrm{ka}$ there is an apparent decoupling of $G$. bulloides and G. ruber temperature trends, while $G$. ruber indicates warming, G. bulloides displays continued, but highly variable, cooling (Fig. 23). Significant, but erratic, warming of $c a .6-7{ }^{\circ} \mathrm{C}$ is only indicated by G. bulloides after ca.14 ka, during the Antarctic Cold Reversal (ACR- ca. 14.2-12.4 ka) (Fig. 23). Meanwhile G. ruber temperatures cool by ca. $4{ }^{\circ} \mathrm{C}$ during the ACR. Mean Holocene G. ruber and G. bulloides surface ocean temperatures (17.9 and $17.8^{\circ} \mathrm{C}$, respectively) are within error of each other and of modern regional surface ocean temperatures (Carter, unpublished report, 2000). However, ca. 9-6.5 ka and again in the late Holocene ( $<3 \mathrm{ka})$ G. bulloides (chamber $f-2$ ) records higher temperatures by up to $3{ }^{\circ} \mathrm{C}$ than G. ruber, the opposite of normal species stratification.

Previous laser ablation measurements of core-top and plankton tow G. bulloides show chamber $f \mathrm{Mg} / \mathrm{Ca}$ values are ca. 20-30\% lower than those of chamber $f$-2 (Marr et al., 2011). Down core $G$. bulloides chamber $f-2-f$ offset varies markedly during the glacial period, including times when chamber $f$ temperatures are similar to, or occasionally higher than the older chambers (Fig. 23). During the ACR there is little significant difference in $\mathrm{Mg} / \mathrm{Ca}$ values between chambers. Following the ACR, the offset between chambers is relatively consistent, equivalent to $3-4{ }^{\circ} \mathrm{C}$ throughout the Holocene (Fig. 23). 


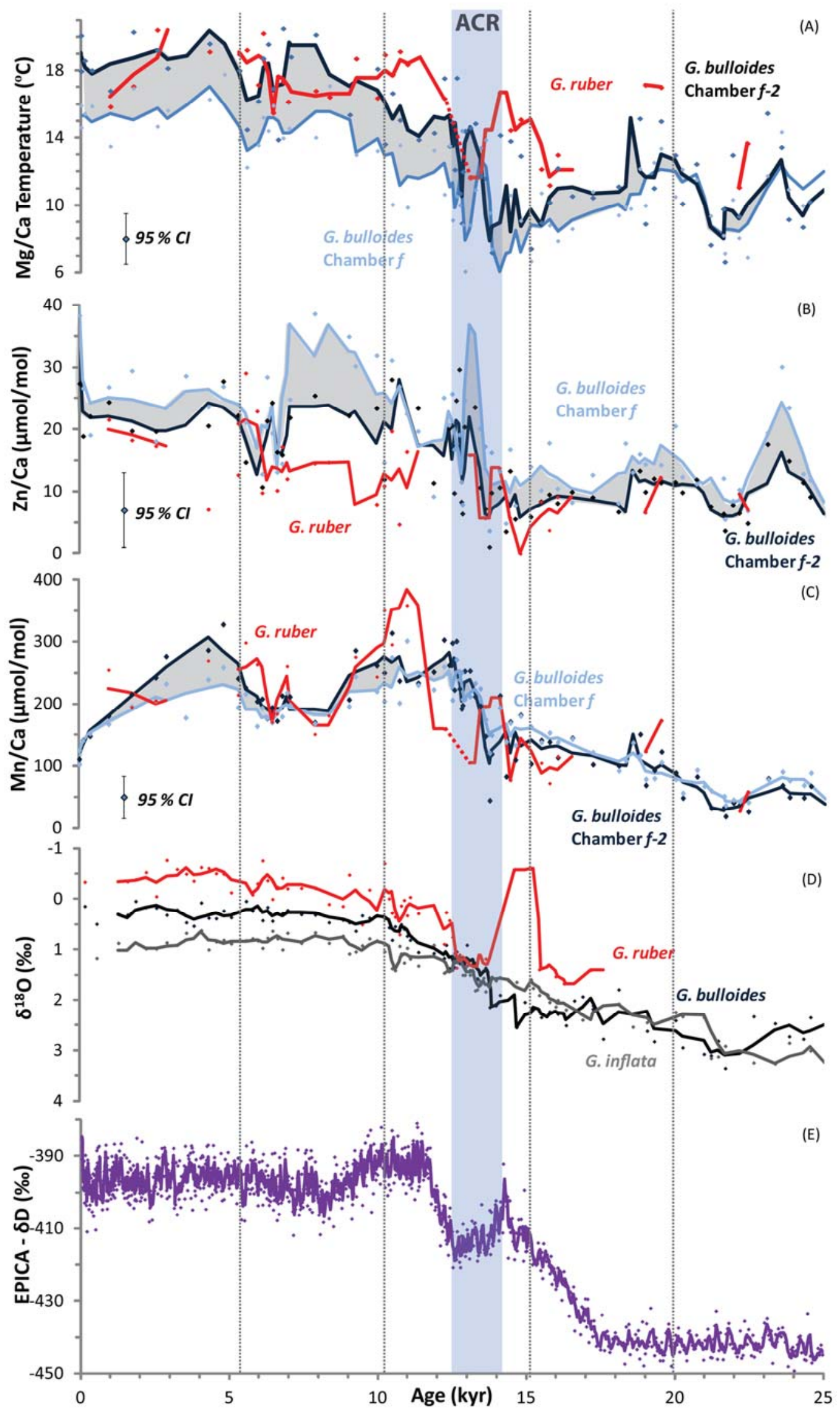


Figure 23. Geochemical and isotopic proxy data from MD97 2121 (A - D) and Antarctica (E) for the last 25 kyr. Laser ablation ICPMS data (this study, A - C) are shown for 2 chambers of $G$. bulloides as the dark blue line- $f-2$ (anti-penultimate chamber) and light blue line-f (final chamber) with each sample mean comprised of measurements from multiple individual specimens. Data for G. ruber (red line) are from laser ablation analyses of chamber $f$-2. (A) $\mathrm{Mg} / \mathrm{Ca}$ - temperatures using the calibrations of Marr et al. (2011) and Bolton et al. (2011) (B) $\mathrm{Zn} / \mathrm{Ca}$ - nutrient stratification, (C) $\mathrm{Mn} / \mathrm{Ca}$ - productivity, (D) $\delta^{18} \mathrm{O}$ profiles of three planktic foraminiferal species from the MD97 2121 record (Carter et al., 2008), (E) EPICA Dome C deuterium record (Jouzel et al., 2007). The Antarctic Cold Reversal (ACR) is indicated by the blue shaded bar. Grey shaded area highlights the difference in trace metal values between $G$. bulloides chambers $f$ and $f-2$. Geochemical data are presented using a three point moving mean for trend comparison with typical 95\% confidence interval (CI) about the moving mean shown as error bars to simplify the graph. Individual sample values are represented as points on the graph. Where the density of data is less than 2 samples/3ka no trend line has been drawn. Red dashed line from 13.5$12.5 \mathrm{kyr}$ indicates a period of clear, appreciable variability evident in G. bulloides data for which a G. ruber record is absent, likely due to an influx of SAW water which is also evident in the faunal assemblage record (E).

Glacial to Holocene $\mathrm{Zn} / \mathrm{Ca}, \mathrm{Mn} / \mathrm{Ca}$ and $\mathrm{Ba} / \mathrm{Ca}$ trends of $\mathrm{G}$. bulloides and G. ruber generally follow that of $\mathrm{Mg} / \mathrm{Ca}$ (Fig. 22, 23) (Carter et al., 2008; Weaver et al., 1997). In the glacial the $\mathrm{Zn} / \mathrm{Ca}$ values are similar to that from modern SAW core tops, while during the deglaciation, including the ACR, $\mathrm{Zn} / \mathrm{Ca}$ values of $G$. bulloides $f-2$ increase dramatically from 9.3-24.4 $\mu \mathrm{mol} / \mathrm{mol}$ and $\mathrm{Ba} / \mathrm{Ca}$ from 2.8-5.3 $\mu \mathrm{mol} / \mathrm{mol}$. G. bulloides $\mathrm{f}-2 \mathrm{Mn} / \mathrm{Ca}$ values are lowest during peak glacial conditions at $c a .40 \mu \mathrm{mol} / \mathrm{mol} c a .23-22 \mathrm{ka}$, gradually increasing until the ACR when they peak at $c a .300 \mu \mathrm{mol} / \mathrm{mol}$, and maintain a range of $c a \cdot 100-300 \mu \mathrm{mol} / \mathrm{mol}$ throughout the Holocene. Holocene mean G. bulloides $f-2 \mathrm{Zn} / \mathrm{Ca}$ values of $24.4 \mu \mathrm{mol} / \mathrm{mol}$ are similar to those of STW from core-tops.

Shallow dwelling G. ruber records the lowest $\mathrm{Zn} / \mathrm{Ca}$ values, whereas deeper living $G$. bulloides has higher values, especially in chamber $f$ (Fig. 23). Glacial G. ruber and G. bulloides $f-2 \mathrm{Zn} / \mathrm{Ca}$ offsets and G. bulloides inter-chamber $(f-2-f) \mathrm{Zn} / \mathrm{Ca}$ offsets are relatively consistent with $G$. bulloides chamber $f$ more enriched in $\mathrm{Zn} / \mathrm{Ca}$ by $c a .45 \%$ than chamber $f-2$ (Fig. 23). At the ACR, however, there is no offset in $\mathrm{Zn} / \mathrm{Ca}$ values between chambers $\mathrm{f}-2$ and $f$ in G. bulloides, or G. bulloides-G. ruber. During the Holocene, the $\mathrm{Zn} / \mathrm{Ca}$ offset between $G$. bulloides-G. ruber is variable, reaching a peak difference between ca. 10 and $6.5 \mathrm{ka}$ when $G$. bulloides chamber $f$ values are double those of $G$. ruber.

The variance of the trace element/Ca data within individual samples was also calculated. $\mathrm{Mg} / \mathrm{Ca}$ variance of $G$. bulloides chamber $f-2$ averaged $0.92 \mathrm{mmol} / \mathrm{mol}$ from $25-18 \mathrm{ka}$, and $0.86 \mathrm{mmol} / \mathrm{mol}$ from $18-10 \mathrm{ka}$. From ca. $10 \mathrm{ka}$ there is a $c a .50 \%$ increased $\mathrm{Mg} / \mathrm{Ca}$ variance 
increasing to $1.37 \mathrm{mmol} / \mathrm{mol}$, with a similar result for chamber $f$. The scatter was further tested over the delineated periods to ascertain if the difference in population variance was significant by application of the 'F-test' (Dixon and Massey, 1969). A value of $F=1.09$ (Finv $=1.74, d f=48)$ confirmed that the difference is significant. Similar variance trends were also found for $\mathrm{Zn} / \mathrm{Ca}$ and $\mathrm{Mn} / \mathrm{Ca}$. T-test values of 17.6 between the periods $25-14 \mathrm{ka}$ and 17.1 between $12.5 \mathrm{ka}$ to present $(\mathrm{p}<0.05, d f=48)$ clearly indicate a significant difference.

\subsection{Discussion}

\subsection{Zn/Ca, Mn/Ca and Ba/Ca as tracers of ocean change}

The evidence from the modern core tops and plankton tows suggests that these trace elements show distinct offsets between STW and SAW in the Southwest Pacific. If modern $\mathrm{Zn} / \mathrm{Ca}$ concentrations in surface waters (Results 4.1 and Fig. 22) hold for the paleocean record, $\mathrm{Zn} / \mathrm{Ca}$ concentrations in G. bulloides and G. ruber chambers potentially can track surface water masses. Zinc is also essential for phytoplankton photosynthesis, and has a spatial and vertical distribution similar to other micronutrients (Fig. 22H). The results from modern core tops in this study suggest that $\mathrm{Zn} / \mathrm{Ca}$ in fossilised foraminiferal calcite may also be a paleonutrient proxy.

Manganese, after Fe, is the most important trace element for marine phytoplankton growth, and is ca. 10 times more abundant in seawater than Zn (Fig. 23, 24) (Ho et al., 2003; Morel et al., 2003). However, $\mathrm{Mn} / \mathrm{Ca}$ ratios in foraminiferal test calcite are a conundrum. Core-top data reveal a clear distinction between sites underlying SAW (mean $4.3 \mu \mathrm{mol} / \mathrm{mol}$ ) and STW (mean $74.3 \mu \mathrm{mol} / \mathrm{mol}$ ), suggesting a link with those water masses. Such low SAW values are confirmed by a plankton tow from the STF (U2309) where there is a strong SAW influence via the subantarctic-dominant Southland Current (Fig. 20) (Sutton, 2003). The down-core variability suggests that change in measured $\mathrm{Mn} / \mathrm{Ca}$ values is primarily a response to changing water masses. Minimum $\mathrm{Mn} / \mathrm{Ca}$ values occur during the glacial, which is consistent with the dominance of SAW, as evinced by $\mathrm{Mg} / \mathrm{Ca}, \mathrm{Zn} / \mathrm{Ca}$, stable isotopes and foraminiferal assemblages (Fig. 23; Carter et al. 2008). We discount any possibility of $\mathrm{Mn} / \mathrm{Ca}$ being influenced by terrigenous input, as terrigenous flux increased in the glaciation when $\mathrm{Mn} / \mathrm{Ca}$ is low at MD97 2121 (Fig. 25) (Carter and Manighetti, 2006). During the Holocene, Mn/Ca is generally higher than glacial values, again consistent with STW dominance as identified by aforementioned proxies (e.g. Weaver et al., 1998). However, Holocene G. bulloides and G. ruber $\mathrm{Mn} / \mathrm{Ca}$ is significantly elevated above the modern STW and while the cause of this 
offset remains unknown, it raises the possibility of other influences (Fig. 25; Auxiliary Information-Chapter 3). Several peaks in $\mathrm{Mn} / \mathrm{Ca}$ occur during the Holocene, including a distinct peak in $G$ ruber $\mathrm{Mn} / \mathrm{Ca}$ centred on $11 \mathrm{ka}$. This coincides with a time of elevated carbonate and silicate MAR, and warmer SSTs from the subtropics suggesting some influence of increase STW inflow and potentially productivity.

In contrast to $\mathrm{Zn} / \mathrm{Ca}$ and $\mathrm{Mn} / \mathrm{Ca}$, levels of $\mathrm{Ba} / \mathrm{Ca}$ in the modern $G$. ruber and $G$. bulloides samples do not distinguish between STW and SAW. Core-top S793 has elevated $\mathrm{Ba} / \mathrm{Ca}$ levels, which may reflect locally high fluvial input (Hicks and Shankar, 2003). However, foraminifera from other high fluvial inputs $(\mathrm{P} 69$, S938) do not have elevated $\mathrm{Ba} / \mathrm{Ca}$ values (Fig. 22), suggesting that fluvial discharge is not a primary control on local Ba concentrations (Fig. 22). The higher $\mathrm{Ba} / \mathrm{Ca}$ at $\mathrm{S} 793$ may also be due to the proximity to the volcanichydrothermally active White Island (Fig. 20), which produces rocks and hydrothermal fluids with high levels of $\mathrm{Ba}$ (rocks $>1000 \mathrm{~g} / \mathrm{m}^{3}$ ) (Hedenquist et al., 1993). The MD97 2121 record reveals a small offset between glacial and interglacial $\mathrm{Ba} / \mathrm{Ca}$ values suggesting a change in $\mathrm{Ba}$ concentrations in the ambient water mass (Fig. 24). However, as fluctuations of $\mathrm{Ba} / \mathrm{Ca}$ are unlikely to reflect terrestrial sources as seen in the core-top material, the reason for the offset is unresolved (Fig. 22).

Figure 24. $\mathrm{Mg} / \mathrm{Ca}(\mathrm{A}), \mathrm{Zn} / \mathrm{Ca}(\mathrm{B})$ and $\mathrm{Ba} / \mathrm{Ca}(\mathrm{C})$ records of core MD97 2121 for the past $25 \mathrm{ka}$ for G. ruber (red) and G. bulloides (blue) with each sample mean comprised of measurements from multiple individual specimens. Horizontal blue and red lines on the graph define SAW and STW water mass modern trace element /Ca means as determined from modern core-top analyses (from Fig. 22). Also presented is the $\delta^{13} \mathrm{C}$ record for G. bulloides (blue) (D) (Carter et al., 2008) together with mean values of 0.51 and -0.95 for SAW and STW respectively are from repeat core-top G. bulloides analyses undertaken at NIWA and (E) the foraminiferal assemblages of species with known environmental preferences (Imbrie and Kipp, 1973), based on samples of $>100$ individuals (Northcote et al., 2007). The Antarctic Cold Reversal (ACR) is indicated by the blue shaded bar. See Fig. 23 for details on data presentation. 


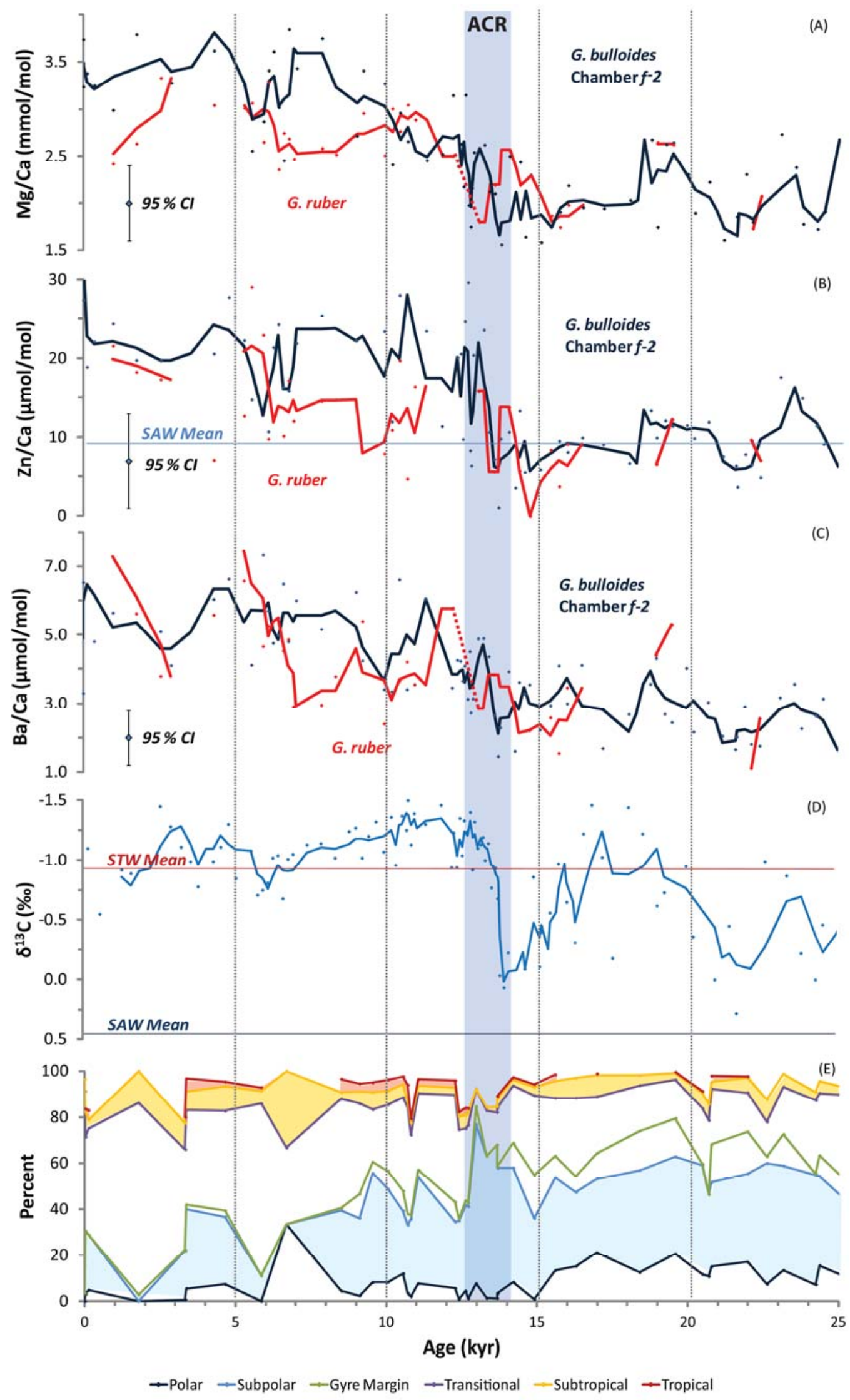




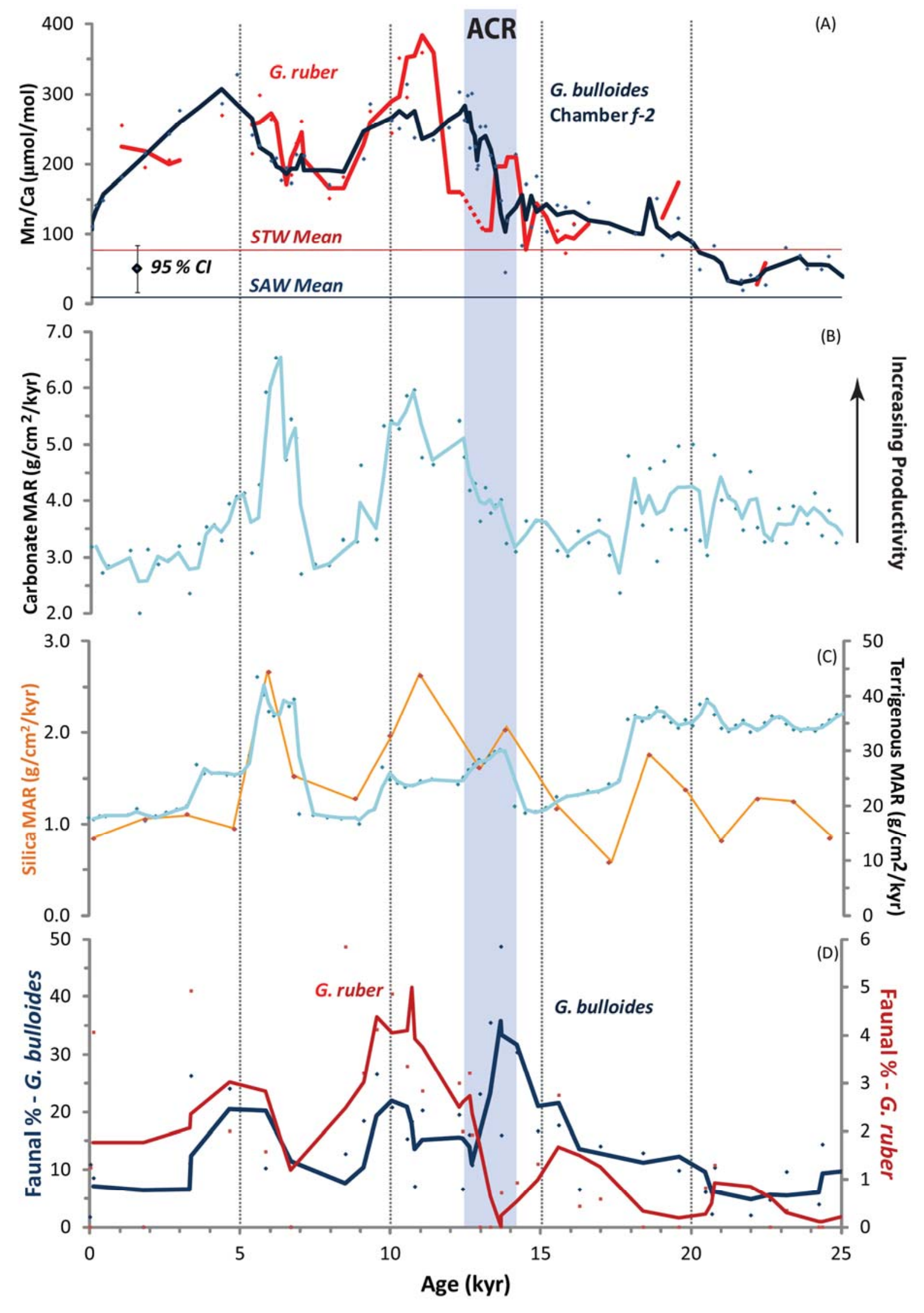


Figure 25. Geochemical, biogenic sediment based productivity indicators for the MD97 2121 paleo record and abundance of key faunal taxa. (A) $\mathrm{Mn} / \mathrm{Ca}$ for G. bulloides (blue) and G. ruber (red). (B) Carbonate mass accumulation rate (MAR) and (C) terrigenous sediment and silica MARs for MD97 2121 (Carter et al., 2008). (D) Percentage of G. ruber (red) and G. bulloides (blue) from the total planktonic foraminifera species abundance, based on samples of $>100$ individuals (Northcote et al., 2007). The Antarctic Cold Reversal (ACR) is indicated by the blue shaded bar. See Fig. 23 for details on data presentation.

\subsection{Thermal and nutrient stratification}

Modern G. bulloides chamber $f$ is lower in $\mathrm{Mg} / \mathrm{Ca}$ compared to the previous chambers. This is likely to reflect a lower temperature at the time the chamber was calcified, an interpretation consistent with this species migrating to deeper depths near the end of its lifecycle (Fig. 22I) (Hemleben et al., 1989; Marr et al., 2011). Alternative reasons for offsets in $\mathrm{Mg} / \mathrm{Ca}$ and other trace metal values between chambers may include diagenesis disproportionally affecting the thinner chamber $f$. However, diagenesis seems unlikely as $\mathrm{Mg} / \mathrm{Ca}$ values (and therefore $\mathrm{Mg} / \mathrm{Ca}$ paleotemperatures) decrease in chamber $f$ relative to chamber $f$ - 2 , while $\mathrm{Zn} / \mathrm{Ca}$ values increase and $\mathrm{Mn} / \mathrm{Ca}$ remains relatively unchanged (Fig. 23). G. bulloides $\mathrm{Mg} / \mathrm{Ca}$ mean and chamber $f$ values for core tops adjacent to the plankton tows are also consistent with the change in trace metal values originating from primary calcite (Fig. 22).

Core-top $\mathrm{Mg} / \mathrm{Ca}$-temperature data for $\mathrm{G}$. bulloides reveal a systematic offset with final chamber ( $f$ ) consistently yielding cooler temperatures (Fig. 22). The final chamber temperatures are ca. $5.5{ }^{\circ} \mathrm{C}$ (STW core tops) and $3{ }^{\circ} \mathrm{C}$ (SAW core tops) colder than corresponding chamber $f-2$ estimates for G. bulloides (Fig. 22I) (Marr et al., 2011). This temperature offset is comparable to the difference between the bottom of the mixed layer and base of the thermocline in modern surface waters off eastern New Zealand (Garner, 1961; Heath, 1975; Locarnini et al., 2006).

$\mathrm{Zn} / \mathrm{Ca}$ offsets between chambers $f-2$ and $f$ in core tops and plankton tows are also consistent with increasing $\mathrm{Zn}$ concentrations with water depth, following a nutrient-like distribution similar to Cd (Fig. 22) (Boyle, 1981). This indicates for the first time that inter-chamber differences in $G$. bulloides $\mathrm{Zn} / \mathrm{Ca}$ could be used to elucidate nutrient stratification in the upper water column. The down core $\mathrm{Zn} / \mathrm{Ca}$ offset between chambers $f-2$ and $f$ shows a similar pattern to the $\mathrm{Mg} / \mathrm{Ca}$ with reduced nutrient stratification in the glacial and no stratification/complete mixing of the upper water column during the ACR. Nutrient stratification appears to re-establish initially in the upper surface waters from $c a .11 .5 \mathrm{ka}$, prior to the stabilisation of the mixed layer/thermocline after ca. $10.5 \mathrm{ka}$ (Nelson et al., 2000). 


\subsection{Glacial/Interglacial Changes in the SPG}

Changes in the wind fields across glacial-interglacial cycles probably affected the ancestral SPG, judging by the dependency of its modern counterpart on the wind stress curl (e.g. Ridgway and Dunn, 2007; Tilburg et al., 2001). Here we evaluate the glacial/interglacial changes in the SPG from the presence of STW sourced from the gyre via the TF - the transTasman component of the SPG (Fig. 20). We combine the evidence from our new geochemical proxies, with previously published paleoceanographic data (Fig. 26, 27).

\subsubsection{Glaciation}

During the glacial period, SAW dominated the MD97 2121 site as reflected by $\mathrm{Mg} / \mathrm{Ca} G$. bulloides temperatures, typically $<11^{\circ} \mathrm{C}$ (Fig. 23, 27), and supported by a planktonic foraminiferal assemblage, which includes the polar species Neogloboquadrina pachyderma (Fig. 24) (Nelson et al., 2000; Weaver et al., 1998). The concomitant low $\mathrm{Zn} / \mathrm{Ca}$ and $\mathrm{Mn} / \mathrm{Ca}$ also supports the presence of SAW north of the Chatham Rise (Fig. 22). This is the result of a strengthened branch of the ACC forced SAW northwards through Mernoo Saddle thus circumventing the STF that is constrained by Chatham Rise (Sikes et al., 2002; Sutton and Roemmich, 2001) (Fig. 20).

Between 25 and $15 \mathrm{ka}, \mathrm{Mg} / \mathrm{Ca}$ and $\mathrm{Zn} / \mathrm{Ca}$ data from different chambers (chamber $f-2$ minus $f$ ) of $G$. bulloides suggest reduced thermal (offset of $<3^{\circ} \mathrm{C}$ ) and nutrient stratification of the upper ocean (Fig. 23, 27). This coincides with a reduction in the offset between G. bulloides and G. inflata $\delta^{18} \mathrm{O}$ data as well (Carter et al., 2008; Fig. 23) and indicates that the upper water column was well mixed by the strong westerly winds during the glacial (Shulmeister et al., 2004). The variance in the $\mathrm{Mg} / \mathrm{Ca}, \mathrm{Zn} / \mathrm{Ca}$ and $\mathrm{Mn} / \mathrm{Ca}$ data from individual samples was also at its lowest during the glacial, suggesting that there may have been fewer or muted short term fluctuations such as that caused by ENSO activity (also modulated by the Southern Annular Mode) which affects storminess and ocean temperatures in the Hawke Bay region (Gomez et al., 2012). However, this lower glacial $\mathrm{Mg} / \mathrm{Ca}$ variance may also reflect a more limited calcification depth range for G. bulloides owing to diminished upper ocean thermal stratification than during the interglacial period. 


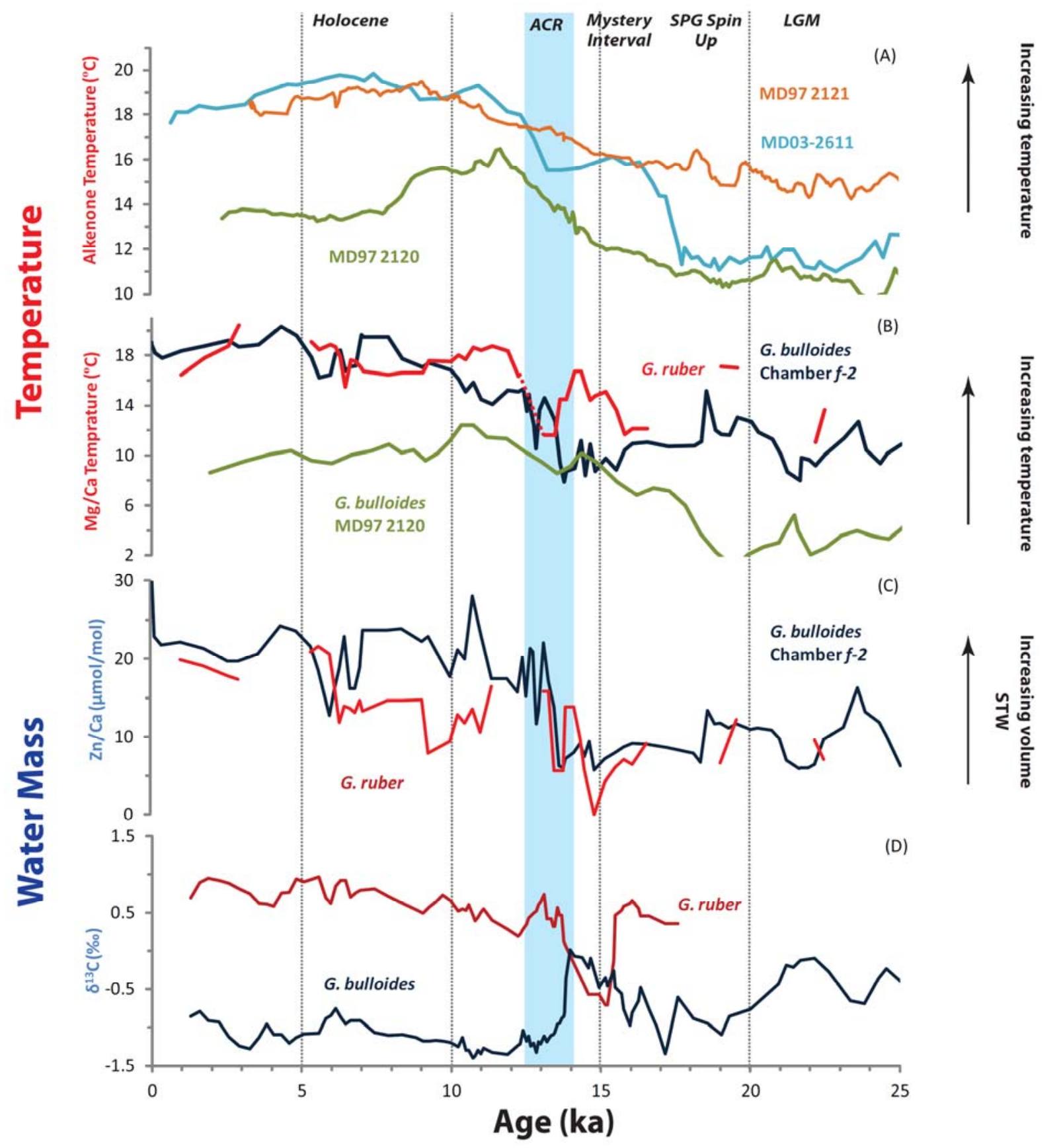

Figure 26. Compilation of regional water mass proxy data with global deglaciation trends. Temperature proxy data includes (A) regional high resolution alkenone data for site MD97 2121 (Pahnke and Sachs, 2006), for site MD03 2611, South Australia (Calvo et al., 2007), and site MD97 2120 -off the South Island, New Zealand (Pahnke et al., 2003); (B) Mg/Ca temperature data G. ruber (red), G. bulloides (blue) - this study, MD97 2121 and for site MD97 2120:G. bulloides (green) (Mg/Ca data from Pahnke et al., 2003 converted to temperature using calibration from Marr et al., 2011). Water mass proxies (C) Zn/Ca G. bulloides (blue), G. ruber (red) this study, (D) $\delta^{13}$ C G. bulloides (blue), G. ruber (red) (Carter et al., 2008). All geochemical data are presented using a three point moving mean for trend comparison, except for MD97 $2120 \mathrm{Mg} / \mathrm{Ca}$ and MD03 2611 alkenone data which are at a lower temporal resolution and therefore individual data points have been joined. The Antarctic Cold Reversal (ACR) is indicated by the blue shaded bar. 
Warmer $\mathrm{Mg} / \mathrm{Ca}$ SSTs at ca. 22-18 ka, accompanied by elevated $\mathrm{Zn} / \mathrm{Ca}$, lightened planktic $\delta^{18} \mathrm{O}$ and warmer water foraminiferal assemblages point to an incursion of STW that is also present at ODP 1123, downstream of MD97 2121, (Fig. 23, 26) (Crundwell et al., 2008). No clear temperature change is recorded in Antarctica at this time period (Fig. 23) (Jouzel et al., 2007), but there is a coeval warming in the Greenland (NGRIP et al., 2004). We suggest that the perturbation may reflect Northern Hemispheric forcing of the equatorial region and midlatitude winds that spin up the SPG under increased wind stress curl (cf. Denton et al., 2010; Roemmich, 2007).

\subsubsection{7-14.5 ka or Mystery Interval, early deglacial}

The Mystery Interval (MI) - a period of rapid and often contradictory change in the Northern Hemisphere (Denton et al., 2006) coincides with rapid change in MD97 2121 (Fig. 26, 27). Millennial-scale MI events may be manifested in the Southern Hemisphere by the southward forcing of the Intertropical Convergence Zone (ITCZ) (Denton et al., 2010). In the Southern Hemisphere, the MI was accompanied by a poleward shift of zonal westerly winds, a general warming of the upper ocean (Barrows et al., 2007; Calvo et al., 2007), and increased Southern Ocean upwelling (Anderson et al., 2009).

In contrast, G. bulloides $\mathrm{Mg} / \mathrm{Ca}$-temperatures at MD97 2121cooled to the point that they converged on those of subantarctic site MD97 2120 (Pahnke et al., 2003). G. bulloides Zn/Ca and $\mathrm{Mn} / \mathrm{Ca}$ levels increased slightly and subpolar and polar planktic species reached a maximum (Fig. 24, 25). G. bulloides $\mathrm{Mg} / \mathrm{Ca}$ cooling coupled with high nutrient levels ( $\mathrm{Zn} / \mathrm{Ca})$ and high $\delta^{13} \mathrm{C}$, appear to confirm regional upwelling of cooler nutrient-rich water similar to, but on a much smaller scale than, that previously associated with diatom productivity blooms in the Southern Ocean (Anderson et al., 2009).

However, the alkenone temperatures from MD97 2121 maintained a consistent warming trend of ca. $0.4{ }^{\circ} \mathrm{C} / \mathrm{ka}$ (Pahnke and Sachs, 2006), similar to SSTs from the eastern equatorial Pacific Ocean (e.g. Koutavas et al., 2002; Rosenthal et al., 2003) and consistent with an incursion of STW resulting from a spin up of the SPG. The decoupling of G. bulloides $\mathrm{Mg} / \mathrm{Ca}$ from alkenone and later $G$. ruber temperatures may reflect changes in the species seasonality/ecological niches across this interval (Leduc et al., 2010; Marr et al., in-prep). 


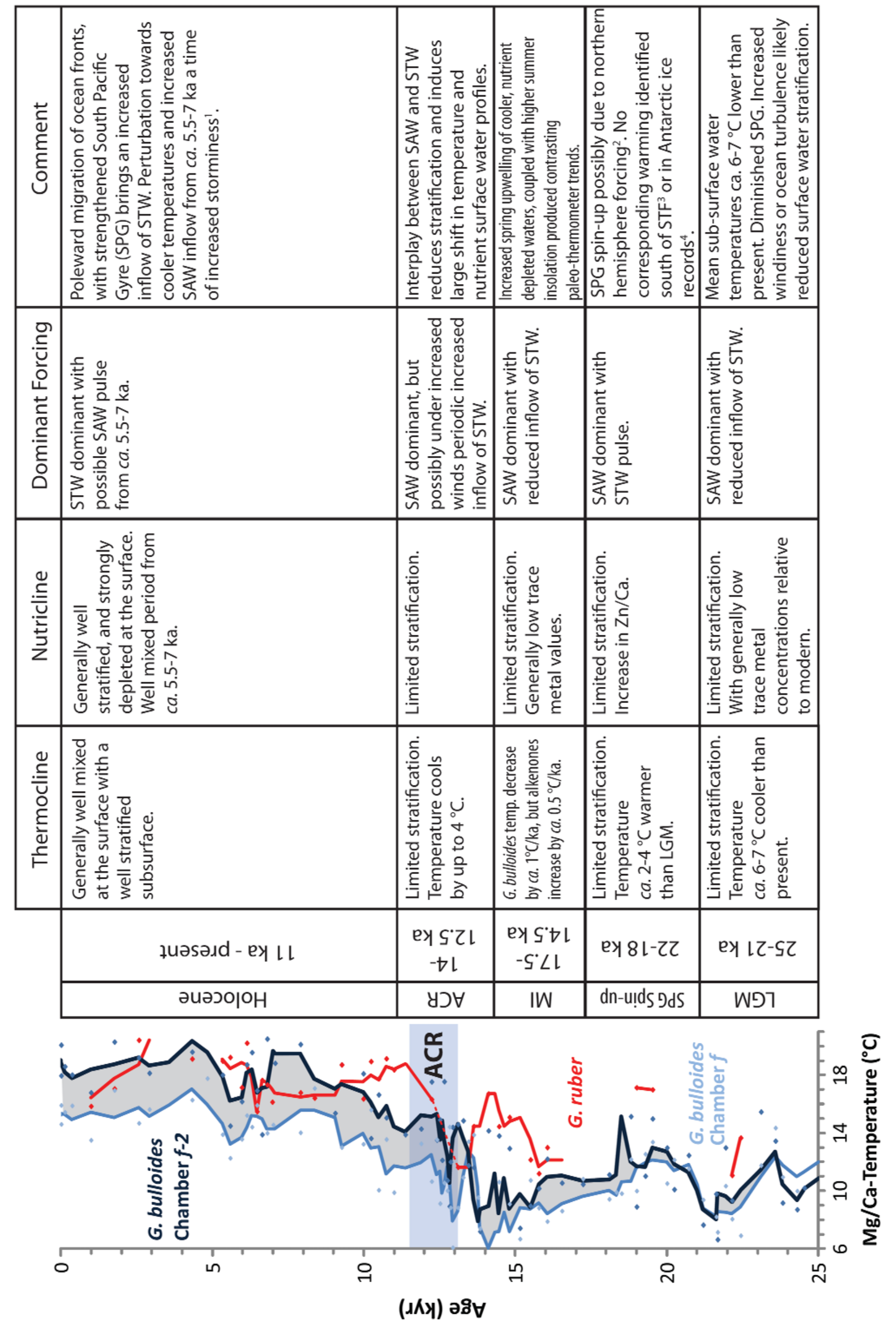


Figure 27. Summary of surface water changes in the thermocline, nutricline and dominant forcing from $25 \mathrm{ka}$ present. MI= Mystery Interval, or period from 17.5-14.5 ka ${ }^{1}$ Gomez et al. (2012), ${ }^{2}$ Stuiver (1997), ${ }^{3}$ Lorrey et al. (2012), ${ }^{4}$ EPICA et al. (2004).

\subsubsection{ACR- late deglaciation}

Large variability in foraminiferal $\mathrm{Mg} / \mathrm{Ca}$ temperature and $\mathrm{Zn} / \mathrm{Ca}$ from $14-11.5 \mathrm{ka}$ is representative of a dynamically mixed upper ocean with competing SAW and STW during the ACR (Fig. 27). The ACR is bookended by peaks in G. bulloides and G. ruber abundance (Fig. 25) as water masses over MD97 2121 shifted dominance from SAW to STW. Large swings in foraminifera SSTs of $c a .7^{\circ} \mathrm{C}$ are similar to other Southern Hemisphere cores which switch from SAW to STW (Barrows et al., 2007; Calvo et al., 2007; Passlow et al., 1997; Sikes et al., 2009). These swings are accompanied here by marked changes in subsurface trace metal levels and an offset in planktic $\delta^{13} \mathrm{C}$ (Fig. 23, 26). Thermal and nutrient surface water stratification during this time were also highly variable. There is a shift from moderate stratification during the early ACR, before stratification collapse during ca. 13.5-12.5 ka (Fig. 23) (Carter et al., 2008). This was followed by a decline in surface water productivity, before a gradual recovery and increase in thermal stratification by the late deglaciation (Fig. 23, 25). This condensed stratification during the ACR is likely the result of enhanced winds (Carter et al., 2008), either causing (i) increased physical mixing of the surface waters (Carter et al., 2008; Shulmeister et al., 2004) and/or (ii) regional upwelling along the nearby continental margin as seen in the modern ocean (e.g. Heath, 1972a; 1985).

This intense ACR variability is representative of the competing equatorial-southern forcing; the latter driving SAW northward through the Mernoo Saddle during the last glaciation and ACR, and the former forcing STW southward during the late deglaciation/early Holocene.

\subsubsection{Holocene}

At $c a$. 11.5 ka peak STW conditions were reached with a thermal maxima from G. ruber $\mathrm{Mg} / \mathrm{Ca} \mathrm{SST}$. The TF shifted south, and likely found gaps in the Norfolk Ridge system that maximised the subtropical inflow to eastern New Zealand (Carter et al., 2008) (Fig. 27). Surface water thermal and nutrient stratification are strongest during the Holocene. Stratification is most prominent in the uppermost surface waters at $11.5 \mathrm{ka}$ accompanied by a peak in biogenic siliceous and carbonate MAR/productivity (Fig. 25). For the remainder of the Holocene, upper ocean temperature stratification was consistent, as shown by the offset between $G$. bulloides chambers $f-2$ and $f$ temperatures. However, isothermal conditions from 
0 to $c a .75 \mathrm{~m}$ depth likely prevailed, as indicated by similarity between G. bulloides chamber $f-2$ and G. ruber temperatures (Fig. 23). Between 7 and $5.5 \mathrm{ka}$, G. bulloides $\mathrm{Zn} / \mathrm{Ca}$ declines rapidly and merges with G. ruber. This convergence may represent a phase of reduced nutrient stratification in the mid-Holocene that is coeval with a period of high storm activity recorded in nearby onshore Lake Tutira (Gomez et al., 2012). A $50 \%$ increase in the variance of the trace element/Ca data during the Holocene may suggest increased decadal or ENSO activity (Koutavas et al., 2006; Koutavas et al., 2002).

\subsection{Conclusions}

In situ measurements on modern foraminifera from a wide range of environmental settings indicate that $\mathrm{Zn} / \mathrm{Ca}, \mathrm{Mn} / \mathrm{Ca}$ and $\mathrm{Mg} / \mathrm{Ca}$ can act as proxies for the water masses and structure of the upper ocean. We show that $\mathrm{Zn} / \mathrm{Ca}$ and $\mathrm{Mn} / \mathrm{Ca}$ measurements in G. bulloides and $\mathrm{G}$. ruber have the potential to trace SAW and STW surface water masses. Offsets between the $\mathrm{Mg} / \mathrm{Ca}$ and $\mathrm{Zn} / \mathrm{Ca}$ from chamber $f$ and $f-2$ data may also function as a proxy for thermal and nutrient stratification of the upper ocean.

By applying these new proxies to down-core data from MD97 2121 we show that the ocean off eastern New Zealand underwent significant changes over the past $25 \mathrm{kyr}$. At the last glacial maximum, mean SSTs were ca.6-7 ${ }^{\circ} \mathrm{C}$ colder than present, foraminiferal $\mathrm{Mn} / \mathrm{Ca}$ and $\mathrm{Zn} / \mathrm{Ca}$ were low, and ocean thermal and nutrient stratification were minimal. Such conditions reflect regional dominance of SAW under a strengthened ACC, and a reduced STW inflow associated with a weakened SPG. Warm SST perturbations from ca. 22-18 ka were likely due to early deglacial equatorial forcing that increased the STW inflow, raising $\mathrm{Zn} / \mathrm{Ca}$ levels briefly. From 17.5-14.5ka an anomalous period occurred that coincides with the Northern Hemisphere 'Mystery Interval'. During this period G. bulloides SSTs cooled by ca. $1^{\circ} \mathrm{C} / \mathrm{ka}$, while alkenone temperatures indicate continued warming. Upper ocean thermal and nutrient stratification collapsed during the ACR when large swings in temperature and nutrient concentrations resulted from the interplay between polar forced SAW and equatorial derived STW. After the ACR, the continued poleward migration of strong zonal westerly winds strengthened the SPG and its STW inflow to eastern New Zealand. With this southward shift of strong winds, the upper ocean at core site MD97 2121 was dominated by generally well stratified STW from ca. 10ka to present. 


\section{Auxiliary information}

\section{AI 1.0. Table of $\mathrm{Mg}, \mathrm{Al}, \mathrm{Mn}, \mathrm{Zn}, \mathrm{Sr}$ and $\mathrm{Ba} / \mathrm{Ca}$ ratios and sample means}

C3-AI. Table 1. Table of $\mathrm{Mg}, \mathrm{Al}, \mathrm{Mn}, \mathrm{Zn}, \mathrm{Sr}$ and $\mathrm{Ba} / \mathrm{Ca}$ ratios and sample mean, $95 \%$ confidence interval, of G. bulloides (chamber $f-2$ and $f$ ) and G. ruber (chamber $f$-2) from MD97 2121, with sample depth and age. 


\begin{tabular}{|c|c|c|c|c|c|c|c|c|c|c|c|c|c|c|}
\hline $\begin{array}{l}\text { G. bulloides - } \\
\text { chamber } f-2 \\
\text { (n) }\end{array}$ & $\begin{array}{l}\text { Age } \\
\text { (kyr) }\end{array}$ & $\begin{array}{c}\text { Sediment } \\
\text { sample depth } \\
\text { (m) }\end{array}$ & $\begin{array}{c}\mathrm{Mg} / \mathrm{Ca} \\
(\mathrm{mmol} / \mathrm{mol})\end{array}$ & $\mathrm{Cl}$ & $\begin{array}{c}\mathrm{Al} / \mathrm{Ca} \\
(\mu \mathrm{mol} / \mathrm{mol})\end{array}$ & $\mathrm{Cl}$ & $\begin{array}{c}\mathrm{Mn} / \mathrm{Ca} \\
(\mu \mathrm{mol} / \mathrm{mol})\end{array}$ & a & $\begin{array}{c}\mathrm{Zn} / \mathrm{Ca} \\
(\mu \mathrm{mol} / \mathrm{mol})\end{array}$ & $\mathrm{Cl}$ & $\begin{array}{c}\mathrm{Sr} / \mathrm{Ca} \\
(\mathrm{mmol} / \mathrm{mol})\end{array}$ & $a$ & $\begin{array}{c}\mathrm{Ba} / \mathrm{Ca} \\
(\mu \mathrm{mol} / \mathrm{mol})\end{array}$ & $\mathrm{Cl}$ \\
\hline 13 & 0.0 & $0.00-0.01$ & 3.74 & 0.8 & 322.7 & 190.0 & 102.8 & 50.2 & 55.6 & 22.4 & 1.41 & 0.03 & 3.3 & 0.9 \\
\hline 18 & 0.0 & $0.01-0.02$ & 3.24 & 0.6 & 100.8 & 43.6 & 111.1 & 33.6 & 27.4 & 8.4 & 1.43 & 0.06 & 6.5 & 1.6 \\
\hline 16 & 0.1 & $0.08-0.09$ & 3.38 & 0.8 & 235.8 & 92.2 & 141.3 & 38.4 & 18.9 & 4.9 & 1.37 & 0.03 & 8.1 & 2.4 \\
\hline 12 & 0.4 & $0.20-0.21$ & 3.25 & 0.9 & 49.7 & 26.1 & 148.2 & 46.7 & 22.1 & 6.3 & 1.73 & 0.24 & 4.8 & 1.2 \\
\hline 32 & 1.0 & $0.38-0.39$ & 2.99 & 0.4 & 124.8 & 40.0 & 180.6 & 28.6 & 24.4 & 4.7 & 1.37 & 0.02 & 5.6 & 1.5 \\
\hline 23 & 1.8 & $0.56-0.57$ & 3.80 & 0.7 & 247.3 & 106.5 & 215.4 & 30.8 & 19.8 & 5.9 & 1.33 & 0.03 & & \\
\hline 16 & 2.6 & $0.80-0.81$ & 3.52 & 0.7 & 125.0 & 50.1 & 242.6 & 43.3 & 19.7 & 8.0 & 1.36 & 0.02 & 5.1 & 1.6 \\
\hline 12 & 2.9 & $0.90-0.91$ & 3.28 & 0.8 & 72.2 & 40.4 & 276.5 & 56.2 & 66.3 & 35.5 & 1.39 & 0.05 & 4.1 & 2.0 \\
\hline 13 & 4.3 & $1.40-1.41$ & 3.62 & 1.2 & 132.6 & 63.5 & 286.4 & 80.1 & 20.6 & 11.3 & 1.39 & 0.05 & 6.0 & 1.6 \\
\hline 21 & 4.8 & $1.60-1.61$ & 4.01 & 0.9 & 146.0 & 50.4 & 328.0 & 49.3 & 27.8 & 10.8 & 1.42 & 0.04 & 6.6 & 1.1 \\
\hline 17 & 5.3 & $1.80-1.81$ & 3.25 & 0.7 & 168.2 & 132.0 & 241.2 & 102.3 & 22.3 & 10.5 & 1.41 & 0.09 & & \\
\hline 10 & 5.6 & $1.90-1.91$ & 2.56 & 0.4 & 68.4 & 32.7 & 226.2 & 55.5 & 14.7 & 9.7 & 1.34 & 0.05 & 4.1 & 1.1 \\
\hline 19 & 6.0 & $2.10-2.11$ & 2.87 & 0.5 & 93.2 & 39.1 & 204.2 & 46.6 & & & 1.37 & 0.04 & 7.3 & 2.5 \\
\hline 17 & 6.1 & $2.20-2.21$ & 3.41 & 0.8 & 103.3 & 62.8 & 208.1 & 39.0 & 10.7 & 5.3 & 1.37 & 0.03 & 5.7 & 1.7 \\
\hline 23 & 6.3 & $2.30-2.31$ & 3.61 & 0.7 & 158.5 & 54.2 & 176.5 & 33.6 & 21.4 & 6.1 & 1.38 & 0.03 & 4.8 & 1.0 \\
\hline 12 & 6.5 & $2.40-2.41$ & 3.02 & 0.9 & 107.7 & 58.5 & 194.1 & 68.2 & 24.3 & 14.8 & 1.40 & 0.10 & 5.0 & 1.6 \\
\hline 12 & 6.6 & $2.50-2.51$ & 2.46 & 0.4 & 34.2 & 16.9 & 172.6 & 71.1 & 16.4 & 9.1 & 1.35 & 0.03 & 6.5 & 2.9 \\
\hline 19 & 6.8 & $2.60-2.61$ & 3.85 & 1.0 & 107.8 & 63.0 & 213.2 & 35.4 & 15.9 & 4.4 & 1.33 & 0.02 & 4.8 & 1.7 \\
\hline 20 & 7.1 & $2.72-2.73$ & 3.43 & 0.7 & 179.6 & 54.3 & 211.6 & 46.7 & 21.9 & 6.0 & 1.37 & 0.04 & 6.0 & 1.1 \\
\hline 12 & 7.9 & $2.90-2.91$ & 3.75 & 1.1 & 158.5 & 75.0 & 170.2 & 56.4 & 25.5 & 11.1 & 1.35 & 0.06 & 5.2 & 2.2 \\
\hline 20 & 9.0 & $3.20-3.21$ & 2.72 & 0.6 & 300.0 & 113.7 & 206.9 & 55.4 & 22.2 & 11.1 & 1.43 & 0.07 & 6.2 & 1.8 \\
\hline 16 & 9.3 & $3.30-3.31$ & 3.41 & 0.9 & 344.0 & 131.8 & 285.9 & 77.5 & & & 1.37 & 0.04 & 4.2 & 1.4 \\
\hline 16 & 10.0 & $3.60-3.61$ & 3.27 & 0.8 & 247.1 & 160.1 & 262.2 & 55.1 & 23.4 & 16.2 & 1.44 & 0.04 & 3.4 & 0.8 \\
\hline 10 & 10.2 & $3.70-3.71$ & 2.41 & 0.4 & 169.8 & 74.8 & 250.4 & 86.6 & 12.0 & 7.3 & 1.34 & 0.03 & 3.3 & 0.9 \\
\hline 16 & 10.5 & $3.80-3.81$ & 2.96 & 0.7 & 180.8 & 139.8 & 314.1 & 73.0 & 28.0 & 20.7 & 1.36 & 0.06 & 6.6 & 2.8 \\
\hline 16 & 10.7 & $3.90-3.91$ & 2.66 & 0.4 & 128.4 & 69.9 & 237.3 & 66.7 & & & 1.36 & 0.03 & 3.4 & 1.4 \\
\hline 14 & 11.4 & $4.10-4.11$ & 2.46 & 0.4 & 749.7 & 322.5 & 233.8 & 49.3 & 23.5 & 5.9 & 1.36 & 0.02 & 6.0 & 1.9 \\
\hline 18 & 11.9 & $4.16-4.17$ & 2.52 & 0.4 & 776.9 & 373.9 & 251.9 & 49.8 & 11.4 & 3.4 & 1.39 & 0.05 & & \\
\hline 12 & 12.2 & $4.20-4.21$ & 3.15 & 0.8 & 229.2 & 92.9 & 303.1 & 121.1 & & & 1.37 & 0.02 & 3.4 & 1.0 \\
\hline 19 & 12.4 & $4.30-4.31$ & 2.39 & 0.3 & 448.3 & 155.1 & 262.7 & 45.8 & 20.2 & 5.2 & 1.41 & 0.04 & 4.3 & 1.5 \\
\hline 10 & 12.5 & $4.36-4.37$ & 2.63 & 0.6 & 194.9 & 85.4 & 298.0 & 91.5 & 20.6 & 15.0 & 1.31 & 0.04 & 4.2 & 0.7 \\
\hline 11 & 12.6 & $4.40-4.41$ & 2.18 & 0.6 & 159.1 & 96.0 & 222.6 & 74.3 & 9.8 & 5.8 & 1.34 & 0.04 & 3.6 & 1.9 \\
\hline 15 & 12.6 & $4.44-4.45$ & 3.15 & 0.9 & 209.2 & 85.1 & 301.0 & 70.2 & 24.7 & 13.4 & 1.39 & 0.03 & 4.1 & 1.6 \\
\hline 12 & 12.8 & $4.50-4.51$ & 1.98 & 0.3 & 154.7 & 93.0 & 224.5 & 80.0 & 29.7 & 21.2 & 1.32 & 0.05 & 3.1 & 0.7 \\
\hline 15 & 12.8 & $4.54-4.55$ & 1.75 & 0.3 & 390.5 & 223.0 & 192.4 & 58.5 & 8.3 & 8.7 & 1.31 & 0.05 & 4.5 & 1.1 \\
\hline 15 & 12.9 & $4.56-4.57$ & 2.16 & 0.4 & 97.0 & 31.6 & 197.7 & 56.4 & 6.4 & 2.3 & 1.39 & 0.02 & 2.7 & 0.7 \\
\hline 18 & 12.9 & $4.60-4.61$ & 2.54 & 0.5 & 106.7 & 49.7 & 253.0 & 97.9 & 20.4 & 11.7 & 1.38 & 0.04 & 3.1 & 0.6 \\
\hline 15 & 13.1 & $4.70-4.71$ & 2.57 & 0.5 & 215.0 & 102.9 & 253.6 & 55.8 & & & 1.38 & 0.03 & 4.9 & 2.0 \\
\hline 15 & 13.3 & $4.80-4.81$ & 2.62 & 0.9 & 198.1 & 93.9 & 211.9 & 88.2 & 23.6 & 12.4 & 1.41 & 0.05 & 4.9 & 1.5 \\
\hline 14 & 13.4 & $4.90-4.91$ & 2.12 & 0.4 & 359.7 & 176.8 & 196.7 & 63.0 & 10.7 & 4.9 & 1.32 & 0.04 & 4.4 & 1.9 \\
\hline 10 & 13.6 & $5.04-5.05$ & 2.10 & 0.5 & 157.1 & 94.6 & 148.0 & 62.6 & 7.2 & 6.3 & 1.36 & 0.04 & 2.6 & 0.7 \\
\hline 13 & 13.8 & $5.08-5.09$ & 1.33 & 0.2 & 83.9 & 57.0 & 44.6 & 23.3 & 1.1 & 2.9 & 1.33 & 0.05 & 1.5 & 0.3 \\
\hline 10 & 13.8 & $5.12-5.13$ & 1.56 & 0.5 & 97.3 & 31.0 & 119.3 & 61.9 & 9.8 & 12.5 & 1.37 & 0.07 & 2.3 & 0.6 \\
\hline 18 & 14.1 & $5.20-5.21$ & 2.50 & 0.5 & 320.2 & 149.6 & 213.5 & 90.7 & 10.7 & 6.6 & 1.36 & 0.02 & 3.9 & 1.4 \\
\hline 21 & 14.3 & $5.26-5.27$ & 1.39 & 0.2 & 101.6 & 40.1 & 83.1 & 38.8 & 3.6 & 1.3 & 1.34 & 0.02 & 1.6 & 0.7 \\
\hline 15 & 14.5 & $5.30-5.31$ & 2.44 & 0.5 & 264.4 & 97.1 & 171.2 & 60.8 & 13.3 & 7.5 & 1.36 & 0.03 & 3.6 & 1.1 \\
\hline 19 & 14.6 & $5.35-5.36$ & 1.68 & 0.4 & 201.9 & 109.8 & 110.8 & 50.3 & 5.6 & 6.6 & 1.41 & 0.03 & 3.3 & 0.8 \\
\hline 16 & 14.8 & $5.40-5.41$ & 2.30 & 0.4 & 306.3 & 114.4 & 182.2 & 57.6 & & & 1.36 & 0.03 & 3.5 & 1.5 \\
\hline 21 & 15.1 & $5.50-5.51$ & 1.58 & 0.3 & 129.4 & 87.9 & 103.7 & 54.3 & 5.9 & 3.0 & 1.37 & 0.03 & 2.2 & 0.7 \\
\hline 15 & 15.5 & $5.60-5.61$ & 1.76 & 0.6 & 129.3 & 68.6 & 141.5 & 55.3 & 8.4 & 4.2 & 1.33 & 0.04 & 2.9 & 1.1 \\
\hline 12 & 15.8 & $5.68-5.69$ & 1.91 & 0.3 & 312.1 & 174.4 & 138.7 & 46.9 & 9.5 & 4.2 & 1.41 & 0.10 & 4.1 & 1.4 \\
\hline 17 & 16.0 & $5.76-5.77$ & 2.19 & 0.8 & 198.8 & 93.8 & 113.7 & 59.7 & 8.1 & 5.0 & 1.35 & 0.03 & 3.0 & 1.0 \\
\hline 18 & 16.5 & $5.90-5.91$ & 1.96 & 0.4 & 264.6 & 143.8 & 145.1 & 50.2 & 10.0 & 4.7 & 1.41 & 0.03 & 4.1 & 1.4 \\
\hline 16 & 17.2 & $6.10-6.11$ & 1.94 & 0.5 & 185.9 & 90.2 & 102.7 & 43.9 & 9.1 & 4.1 & 1.36 & 0.04 & 1.7 & 0.5 \\
\hline 12 & 18.1 & $6.40-6.41$ & 2.03 & 0.6 & 73.5 & 46.3 & 100.5 & 63.3 & 6.7 & 4.8 & 1.33 & 0.04 & 2.7 & 0.8 \\
\hline 16 & 18.8 & $6.70-6.71$ & 2.67 & 0.6 & 127.7 & 51.7 & 151.0 & 56.8 & 13.4 & 8.7 & 1.36 & 0.04 & 3.6 & 0.8 \\
\hline 14 & 19.0 & $6.78-6.79$ & 1.75 & 0.4 & 173.3 & 99.6 & 69.1 & 36.5 & 9.9 & 7.0 & 1.42 & 0.04 & 4.3 & 1.3 \\
\hline 21 & 19.3 & $6.90-6.91$ & 2.57 & 0.8 & 140.2 & 75.7 & 89.4 & 38.2 & 12.1 & 6.6 & 1.38 & 0.03 & 2.6 & 1.0 \\
\hline 21 & 19.5 & $7.00-7.01$ & 2.64 & 0.5 & 88.9 & 33.1 & 123.0 & 47.5 & 11.4 & 5.6 & 1.39 & 0.03 & 2.4 & 0.9 \\
\hline 15 & 20.0 & $7.20-7.21$ & 2.31 & 0.6 & 151.0 & 54.0 & 89.3 & 43.5 & 11.5 & 6.1 & 1.39 & 0.04 & 4.0 & 1.0 \\
\hline 21 & 20.2 & $7.30-7.30$ & 1.90 & 0.3 & 179.9 & 94.8 & 48.6 & 27.2 & 9.9 & 5.7 & 1.37 & 0.03 & 2.2 & 0.8 \\
\hline 14 & 20.7 & $7.50-7.50$ & 2.23 & 0.7 & 63.8 & 24.7 & 82.9 & 51.2 & 11.9 & 12.7 & 1.28 & 0.04 & 3.0 & 1.1 \\
\hline 15 & 21.2 & $7.70-7.71$ & 1.61 & 0.4 & 126.0 & 58.2 & 32.2 & 18.5 & 7.6 & 4.1 & 1.36 & 0.03 & 2.0 & 0.7 \\
\hline 13 & 21.6 & $7.88-7.89$ & 1.86 & 0.6 & 134.9 & 68.8 & 33.4 & 24.0 & 6.4 & 4.2 & 1.39 & 0.03 & 1.7 & 0.5 \\
\hline 12 & 21.7 & $7.90-7.91$ & 1.50 & 0.2 & 187.4 & 102.4 & 19.1 & 18.9 & 3.7 & 3.4 & 1.42 & 0.04 & 2.0 & 0.7 \\
\hline 16 & 21.7 & $8.01-8.02$ & 2.31 & 0.8 & 265.7 & 138.2 & 40.8 & 15.4 & 7.9 & 4.0 & 1.39 & 0.04 & 2.9 & 1.3 \\
\hline 15 & 22.1 & $8.10-8.11$ & 1.80 & 0.2 & 93.5 & 45.5 & 38.1 & 19.6 & 6.5 & 4.4 & 1.35 & 0.03 & 1.8 & 0.6 \\
\hline 24 & 22.4 & $8.22-8.23$ & 1.37 & 0.2 & 93.0 & 47.7 & 26.6 & 8.3 & 4.9 & 2.6 & 1.35 & 0.02 & 1.8 & 0.5 \\
\hline 19 & 23.1 & $8.50-8.51$ & 2.73 & 10 & 105.9 & 52.6 & 80.2 & 32.0 & 17.6 & 10.6 & 1.36 & 0.03 & 3.2 & 0.8 \\
\hline 19 & 23.6 & $8.70-8.71$ & 2.38 & 0.5 & 150.8 & 70.7 & 68.9 & 20.2 & & & 1.39 & 0.03 & 3.6 & 1.2 \\
\hline 18 & 23.8 & $8.80-8.81$ & 1.78 & 0.3 & 115.9 & 61.8 & 49.8 & 13.5 & 14.9 & 6.8 & 1.36 & 0.02 & 2.3 & 0.6 \\
\hline 21 & 24.3 & $9.00-9.01$ & 1.73 & 0.2 & 120.1 & 49.6 & 48.9 & 15.0 & 11.5 & 5.8 & 1.34 & 0.03 & 2.6 & 0.6 \\
\hline 17 & 24.5 & $9.10-9.11$ & 1.91 & 0.3 & 88.3 & 33.6 & 67.7 & 18.9 & 9.2 & 4.4 & 1.36 & 0.03 & 3.1 & 1.0 \\
\hline 10 & 25.0 & $9.30-9.31$ & 2.10 & 0.6 & 63.6 & 32.1 & 48.0 & 36.2 & 9.7 & 6.9 & 1.42 & 0.05 & 1.8 & 0.5 \\
\hline
\end{tabular}




\begin{tabular}{|c|c|c|c|c|c|c|c|c|c|c|c|c|c|c|}
\hline $\begin{array}{l}\text { G. bulloides - } \\
\text { chamber } f \\
\text { (n) }\end{array}$ & $\begin{array}{l}\text { Age } \\
(\mathrm{kyr})\end{array}$ & $\begin{array}{l}\text { Sediment sample } \\
\text { depth } \\
\text { (m) }\end{array}$ & $\begin{array}{c}\mathrm{Mg} / \mathrm{Ca} \\
(\mathrm{mmol} / \mathrm{mol})\end{array}$ & $\mathrm{Cl}$ & $\begin{array}{c}\mathrm{Al} / \mathrm{Ca} \\
(\mu \mathrm{mol} / \mathrm{mol})\end{array}$ & a & $\begin{array}{c}\mathrm{Mn} / \mathrm{Ca} \\
(\mu \mathrm{mol} / \mathrm{mol})\end{array}$ & $\mathrm{Cl}$ & $\begin{array}{c}\mathrm{Zn} / \mathrm{Ca} \\
(\mu \mathrm{mol} / \mathrm{mol})\end{array}$ & $\mathrm{Cl}$ & $\begin{array}{c}\mathrm{Sr} / \mathrm{Ca} \\
(\mathrm{mmol} / \mathrm{mol})\end{array}$ & Cl & $\begin{array}{c}\mathrm{Ba} / \mathrm{Ca} \\
(\mu \mathrm{mol} / \mathrm{mol})\end{array}$ & a \\
\hline 13 & 0.0 & $0.00-0.01$ & 3.74 & 0.8 & 322.7 & 233.0 & 102.8 & 31.9 & 55.6 & 23.4 & 1.41 & 0.03 & 3.3 & 0.9 \\
\hline 24 & 0.0 & $0.01-0.02$ & 2.58 & 0.4 & 46.0 & 20.5 & 125.7 & 18.6 & 38.4 & 8.4 & 1.41 & 0.05 & 6.3 & 1.2 \\
\hline 24 & 0.1 & $0.08-0.09$ & 2.73 & 0.5 & 129.5 & 59.9 & 140.6 & 21.4 & 26.7 & 5.7 & 1.37 & 0.04 & 7.4 & 1.3 \\
\hline 16 & 0.4 & $0.20-0.21$ & 2.81 & 0.9 & 32.0 & 18.2 & 152.2 & 21.2 & 19.1 & 4.3 & 1.61 & 0.14 & 5.0 & 1.0 \\
\hline 46 & 1.0 & $0.38-0.39$ & 2.39 & 0.3 & 86.1 & 27.7 & 167.3 & 15.4 & 26.8 & 3.9 & 1.36 & 0.02 & 5.6 & 1.2 \\
\hline 25 & 1.8 & $0.56-0.57$ & 3.02 & 0.7 & 251.7 & 138.8 & 196.2 & 25.6 & 29.5 & 15.1 & 1.34 & 0.02 & 10.0 & 2.2 \\
\hline 21 & 2.6 & $0.80-0.81$ & 2.59 & 0.4 & 73.1 & 42.3 & 205.6 & 29.3 & 18.1 & 5.6 & 1.35 & 0.02 & 4.7 & 1.2 \\
\hline 15 & 2.9 & $0.90-0.91$ & 2.76 & 0.6 & 55.9 & 39.3 & 232.5 & 39.9 & 87.4 & 35.7 & 1.39 & 0.02 & 3.4 & 1.3 \\
\hline 9 & 3.6 & $1.10-1.11$ & 2.17 & 0.3 & 196.9 & 117.5 & 177.8 & 36.5 & 28.6 & 13.6 & 1.39 & 0.06 & 6.3 & 2.6 \\
\hline 16 & 4.3 & $1.40-1.41$ & 2.89 & 0.7 & 109.7 & 53.6 & 239.3 & 54.7 & 23.7 & 11.6 & 1.39 & 0.04 & 5.6 & 1.9 \\
\hline 23 & 4.8 & $1.60-1.61$ & 3.20 & 0.6 & 117.7 & 61.5 & 259.0 & 44.6 & 26.9 & 10.5 & 1.41 & 0.02 & 5.3 & 1.0 \\
\hline 27 & 5.3 & $1.80-1.81$ & 2.46 & 0.4 & 88.3 & 44.8 & 194.3 & 36.9 & 24.0 & 12.3 & 1.39 & 0.06 & 7.6 & 3.4 \\
\hline 13 & 5.6 & $1.90-1.91$ & 2.20 & 0.4 & 27.1 & 18.4 & 216.0 & 34.8 & 21.2 & 8.6 & 1.36 & 0.04 & 5.6 & 1.5 \\
\hline 22 & 6.0 & $2.10-2.11$ & 2.40 & 0.3 & 84.7 & 35.6 & 164.2 & 17.3 & 55.6 & 16.3 & 1.37 & 0.03 & 4.6 & 0.7 \\
\hline 19 & 6.1 & $2.20-2.21$ & 2.69 & 0.6 & 19.8 & 12.3 & 193.5 & 30.7 & 12.8 & 4.4 & 1.36 & 0.03 & 4.5 & 1.3 \\
\hline 27 & 6.3 & $2.30-2.31$ & 2.54 & 0.4 & 98.3 & 38.5 & 177.2 & 30.2 & 28.5 & 6.7 & 1.36 & 0.03 & 4.6 & 0.7 \\
\hline 16 & 6.5 & $2.40-2.41$ & 2.82 & 0.7 & 67.2 & 56.9 & 170.0 & 29.1 & 19.4 & 9.4 & 1.38 & 0.03 & 4.1 & 1.0 \\
\hline 14 & 6.6 & $2.50-2.51$ & 2.47 & 0.4 & 33.5 & 23.0 & 187.7 & 77.3 & 13.2 & 6.6 & 1.38 & 0.05 & 5.7 & 1.8 \\
\hline 21 & 6.8 & $2.60-2.61$ & 2.57 & 0.8 & 80.8 & 55.2 & 179.7 & 34.9 & 14.5 & 5.5 & 1.36 & 0.03 & 3.0 & 1.1 \\
\hline 14 & 7.0 & $2.69-2.70$ & 2.18 & 0.4 & 159.0 & 42.8 & 218.3 & 43.9 & 47.4 & 17.8 & 1.78 & 0.17 & 3.8 & 0.9 \\
\hline 21 & 7.1 & $2.72-2.73$ & 2.48 & 0.4 & 132.8 & 48.1 & 198.4 & 34.4 & 24.9 & 6.5 & 1.34 & 0.03 & 5.7 & 1.5 \\
\hline 15 & 7.9 & $2.90-2.91$ & 3.05 & 0.9 & 124.5 & 67.9 & 168.3 & 24.4 & 38.6 & 18.5 & 1.34 & 0.06 & 4.7 & 1.9 \\
\hline 25 & 8.4 & $3.20-3.21$ & 2.31 & 0.4 & 147.8 & 88.7 & 196.0 & 30.7 & 35.0 & 20.2 & 1.47 & 0.05 & 4.9 & 1.2 \\
\hline 21 & 9.0 & $3.30-3.31$ & 2.35 & 0.4 & 61.5 & 25.4 & 244.3 & 48.3 & 30.2 & 15.1 & 1.39 & 0.04 & 3.8 & 1.5 \\
\hline 20 & 9.3 & $3.60-3.61$ & 2.76 & 0.6 & 131.0 & 71.1 & 220.2 & 37.6 & 31.9 & 17.3 & 1.44 & 0.04 & 2.9 & 0.7 \\
\hline 14 & 10.0 & $3.70-3.71$ & 1.89 & 0.5 & 77.7 & 58.5 & 204.3 & 49.4 & 14.7 & 7.6 & 1.36 & 0.03 & 2.2 & 0.5 \\
\hline 22 & 10.2 & $3.80-3.81$ & 2.40 & 0.5 & 81.6 & 42.7 & 274.7 & 40.2 & 31.2 & 16.4 & 1.38 & 0.03 & 4.5 & 1.1 \\
\hline 19 & 10.5 & $3.90-3.91$ & 1.87 & 0.5 & 80.1 & 46.4 & 201.5 & 62.7 & 26.9 & 23.7 & 1.39 & 0.02 & 2.0 & 0.5 \\
\hline 22 & 10.7 & $4.00-4.01$ & 2.62 & 0.5 & 149.4 & 71.0 & 301.4 & 52.6 & 22.6 & 5.8 & 1.38 & 0.04 & 4.5 & 1.3 \\
\hline 23 & 11.4 & $4.10-4.11$ & 2.35 & 0.4 & 343.8 & 148.9 & 230.6 & 31.7 & 19.7 & 4.2 & 1.38 & 0.03 & 5.2 & 1.2 \\
\hline 16 & 11.9 & $4.16-4.17$ & 1.97 & 0.2 & 785.0 & 480.1 & 223.0 & 54.9 & 9.2 & 2.4 & 1.41 & 0.04 & 6.6 & 1.4 \\
\hline 16 & 12.2 & $4.20-4.21$ & 2.40 & 0.4 & 69.0 & 34.9 & 260.1 & 50.2 & 25.1 & 8.5 & 1.40 & 0.03 & 3.7 & 1.6 \\
\hline 17 & 12.4 & $4.30-4.31$ & 1.78 & 0.3 & 472.2 & 273.2 & 247.6 & 33.4 & 20.7 & 4.3 & 1.39 & 0.04 & 3.7 & 1.0 \\
\hline 12 & 12.5 & $4.36-4.37$ & 1.96 & 0.6 & 112.1 & 66.4 & 206.2 & 58.8 & 25.7 & 12.9 & 1.36 & 0.04 & 4.1 & 0.7 \\
\hline 14 & 12.6 & $4.40-4.41$ & 1.89 & 0.4 & 177.7 & 76.5 & 243.4 & 52.9 & 16.8 & 6.0 & 1.33 & 0.04 & 4.9 & 1.6 \\
\hline 14 & 12.6 & $4.44-4.45$ & 2.55 & 0.9 & 115.5 & 104.0 & 271.3 & 33.1 & 17.7 & 8.8 & 1.42 & 0.03 & 4.1 & 1.3 \\
\hline 17 & 12.8 & $4.50-4.51$ & 1.74 & 0.2 & 97.4 & 57.5 & 239.7 & 40.7 & 19.1 & 7.9 & 1.33 & 0.04 & 3.7 & 1.0 \\
\hline 21 & 12.8 & $4.54-4.55$ & 1.44 & 0.2 & 364.7 & 179.4 & 250.9 & 41.0 & 11.6 & 5.6 & 1.31 & 0.04 & 4.1 & 1.3 \\
\hline 12 & 12.9 & $4.56-4.57$ & 1.74 & 0.6 & 77.9 & 43.5 & 207.6 & 61.1 & 7.9 & 3.0 & 1.39 & 0.03 & 2.2 & 0.5 \\
\hline 21 & 12.9 & $4.60-4.61$ & 2.01 & 0.3 & 35.8 & 21.8 & 207.8 & 47.3 & 24.8 & 13.6 & 1.39 & 0.04 & 2.6 & 0.8 \\
\hline 18 & 13.1 & $4.70-4.71$ & 2.38 & 0.4 & 237.5 & 124.3 & 212.1 & 47.4 & 45.6 & 21.7 & 1.40 & 0.04 & 4.7 & 1.4 \\
\hline 18 & 13.3 & $4.80-4.81$ & 2.45 & 0.6 & 173.6 & 71.9 & 233.5 & 46.1 & 40.2 & 18.2 & 1.41 & 0.03 & 5.4 & 1.2 \\
\hline 20 & 13.4 & $4.90-4.91$ & 1.83 & 0.3 & 156.6 & 60.3 & 224.8 & 47.2 & 20.2 & 8.8 & 1.37 & 0.03 & 4.9 & 1.4 \\
\hline 19 & 13.6 & $5.04-5.05$ & 1.58 & 0.2 & 82.8 & 50.7 & 174.9 & 33.8 & 17.3 & 10.8 & 1.36 & 0.03 & 3.1 & 0.9 \\
\hline 17 & 13.8 & $5.08-5.09$ & 1.40 & 0.1 & 98.2 & 39.7 & 121.0 & 36.7 & 3.7 & 1.6 & 1.32 & 0.05 & 1.9 & 0.4 \\
\hline 12 & 13.8 & $5.12-5.13$ & 1.36 & 0.2 & 86.5 & 41.6 & 149.6 & 52.4 & 16.3 & 9.7 & 1.39 & 0.04 & 2.8 & 0.6 \\
\hline 19 & 14.1 & $5.20-5.21$ & 1.96 & 0.4 & 166.7 & 77.7 & 193.8 & 52.6 & 13.3 & 6.4 & 1.39 & 0.03 & 3.3 & 1.0 \\
\hline 20 & 14.3 & $5.26-5.27$ & 1.42 & 0.2 & 89.2 & 38.4 & 139.1 & 51.8 & 4.9 & 2.1 & 1.39 & 0.03 & 2.5 & 0.8 \\
\hline 23 & 14.5 & $5.30-5.31$ & 1.77 & 0.3 & 95.8 & 55.5 & 169.1 & 35.7 & 16.8 & 7.0 & 1.38 & 0.03 & 3.3 & 1.4 \\
\hline 19 & 14.6 & $5.35-5.36$ & 1.50 & 0.2 & 209.6 & 89.6 & 133.4 & 33.5 & 7.8 & 3.5 & 1.42 & 0.03 & 4.9 & 1.2 \\
\hline 21 & 14.8 & $5.40-5.41$ & 1.98 & 0.3 & 270.0 & 84.6 & 180.5 & 45.8 & 40.5 & 18.2 & 1.38 & 0.03 & 3.2 & 0.9 \\
\hline 25 & 15.1 & $5.50-5.51$ & 1.74 & 0.3 & 147.8 & 59.1 & 163.3 & 41.9 & 14.0 & 6.1 & 1.39 & 0.04 & 3.5 & 0.8 \\
\hline 18 & 15.5 & $5.60-5.61$ & 1.63 & 0.3 & 130.7 & 66.4 & 138.0 & 35.6 & 10.2 & 3.7 & 1.34 & 0.03 & 2.5 & 0.5 \\
\hline 19 & 15.8 & $5.68-5.69$ & 1.71 & 0.2 & 302.7 & 128.2 & 153.6 & 27.5 & 17.8 & 6.6 & 1.39 & 0.05 & 4.1 & 0.9 \\
\hline 26 & 16.0 & $5.76-5.77$ & 1.99 & 0.4 & 179.5 & 66.4 & 138.3 & 30.3 & 10.5 & 3.4 & 1.37 & 0.03 & 3.9 & 0.8 \\
\hline 24 & 16.5 & $5.90-5.91$ & 1.81 & 0.3 & 168.0 & 75.4 & 143.7 & 29.3 & 8.3 & 3.0 & 1.41 & 0.02 & 3.2 & 0.6 \\
\hline 22 & 17.2 & $6.10-6.11$ & 1.87 & 0.3 & 53.0 & 28.0 & 122.0 & 28.6 & 12.7 & 5.8 & 1.38 & 0.04 & 1.7 & 0.4 \\
\hline 17 & 18.1 & $6.40-6.41$ & 1.86 & 0.4 & 65.6 & 39.8 & 92.6 & 39.6 & 8.2 & 4.1 & 1.33 & 0.04 & 2.8 & 0.6 \\
\hline 10 & 18.3 & $6.50-6.51$ & 2.47 & 0.6 & 22.5 & 13.2 & 108.6 & 41.4 & 17.8 & 8.0 & 1.39 & 0.04 & 2.0 & 0.7 \\
\hline 22 & 18.6 & $6.60-6.61$ & 2.80 & 0.6 & 61.6 & 42.2 & 137.5 & 33.2 & 13.1 & 3.7 & 1.37 & 0.04 & 2.5 & 1.0 \\
\hline 22 & 18.8 & $6.70-6.71$ & 2.19 & 0.3 & 101.1 & 53.2 & 117.6 & 31.0 & 16.0 & 7.9 & 1.39 & 0.04 & 3.4 & 0.7 \\
\hline 11 & 19.0 & $6.78-6.79$ & 1.88 & 0.5 & 132.5 & 86.3 & 79.0 & 28.5 & 14.4 & 8.6 & 1.38 & 0.04 & 3.7 & 0.9 \\
\hline 19 & 19.3 & $6.90-6.91$ & 2.24 & 0.7 & 110.3 & 80.5 & 80.3 & 30.4 & 27.6 & 18.1 & 1.41 & 0.04 & 3.3 & 1.4 \\
\hline 27 & 19.5 & $7.00-7.01$ & 2.37 & 0.4 & 71.1 & 25.3 & 106.1 & 24.1 & 14.3 & 3.9 & 1.41 & 0.03 & 2.4 & 1.2 \\
\hline 14 & 20.0 & $7.20-7.21$ & 1.95 & 0.5 & 109.4 & 41.6 & 78.8 & 26.7 & 20.6 & 9.0 & 1.40 & 0.05 & 2.9 & 0.6 \\
\hline 26 & 20.2 & $7.30-7.30$ & 2.18 & 0.5 & 176.0 & 63.7 & 56.5 & 18.2 & 12.4 & 5.2 & 1.38 & 0.04 & 2.7 & 0.4 \\
\hline 13 & 20.7 & $7.50-7.50$ & 2.09 & 0.5 & 99.2 & 59.9 & 93.8 & 45.7 & 11.3 & 6.3 & 1.37 & 0.05 & 2.9 & 0.8 \\
\hline 17 & 21.0 & $7.60-7.61$ & 2.31 & 0.5 & 76.1 & 36.9 & 67.5 & 22.5 & 28.1 & 14.1 & 1.39 & 0.03 & 2.7 & 0.8 \\
\hline 20 & 21.2 & $7.70-7.71$ & 1.81 & 0.2 & 141.3 & 62.1 & 60.1 & 15.0 & 32.5 & 10.3 & 1.42 & 0.03 & 3.3 & 1.1 \\
\hline 14 & 21.6 & $7.88-7.89$ & 1.67 & 0.5 & 120.4 & 64.9 & 51.2 & 29.1 & 12.2 & 6.6 & 1.40 & 0.05 & 2.4 & 0.5 \\
\hline 15 & 21.7 & $7.90-7.91$ & 1.55 & 0.2 & 255.0 & 112.2 & 36.5 & 15.3 & 5.5 & 2.6 & 1.43 & 0.04 & 3.1 & 0.9 \\
\hline 19 & 21.7 & $8.01-8.02$ & 1.93 & 0.4 & 129.8 & 84.9 & 45.5 & 14.7 & 8.5 & 3.2 & 1.43 & 0.04 & 3.7 & 0.9 \\
\hline 18 & 22.1 & $8.10-8.11$ & 1.65 & 0.2 & 56.6 & 36.1 & 43.3 & 10.8 & 10.3 & 4.6 & 1.36 & 0.04 & 1.8 & 0.5 \\
\hline 27 & 22.4 & $8.22-8.23$ & 1.53 & 0.2 & 97.5 & 44.0 & 41.5 & 11.0 & 6.9 & 2.5 & 1.37 & 0.03 & 2.4 & 0.6 \\
\hline 22 & 23.1 & $8.50-8.51$ & 2.12 & 0.5 & 107.9 & 45.0 & 78.4 & 20.3 & 19.5 & 11.0 & 1.36 & 0.03 & 3.2 & 0.7 \\
\hline 21 & 23.6 & $8.70-8.71$ & 2.53 & 0.4 & 107.5 & 37.5 & 90.9 & 16.9 & 30.1 & 11.6 & 1.39 & 0.03 & 4.3 & 1.2 \\
\hline 16 & 23.8 & $8.80-8.81$ & 2.01 & 0.3 & 75.2 & 42.0 & 76.8 & 10.8 & 23.5 & 6.9 & 1.37 & 0.03 & 3.7 & 0.6 \\
\hline 21 & 24.3 & $9.00-9.01$ & 1.88 & 0.2 & 72.1 & 28.7 & 69.2 & 18.4 & 12.9 & 6.2 & 1.35 & 0.03 & 3.1 & 0.7 \\
\hline 23 & 24.5 & $9.10-9.11$ & 2.16 & 0.2 & 65.1 & 29.5 & 89.2 & 14.5 & 11.9 & 3.3 & 1.37 & 0.03 & 4.0 & 0.7 \\
\hline 12 & 25.0 & $9.30-9.31$ & 2.16 & 0.6 & 33.8 & 22.3 & 50.6 & 15.2 & 12.8 & 7.7 & 1.40 & 0.04 & 2.1 & 0.3 \\
\hline
\end{tabular}




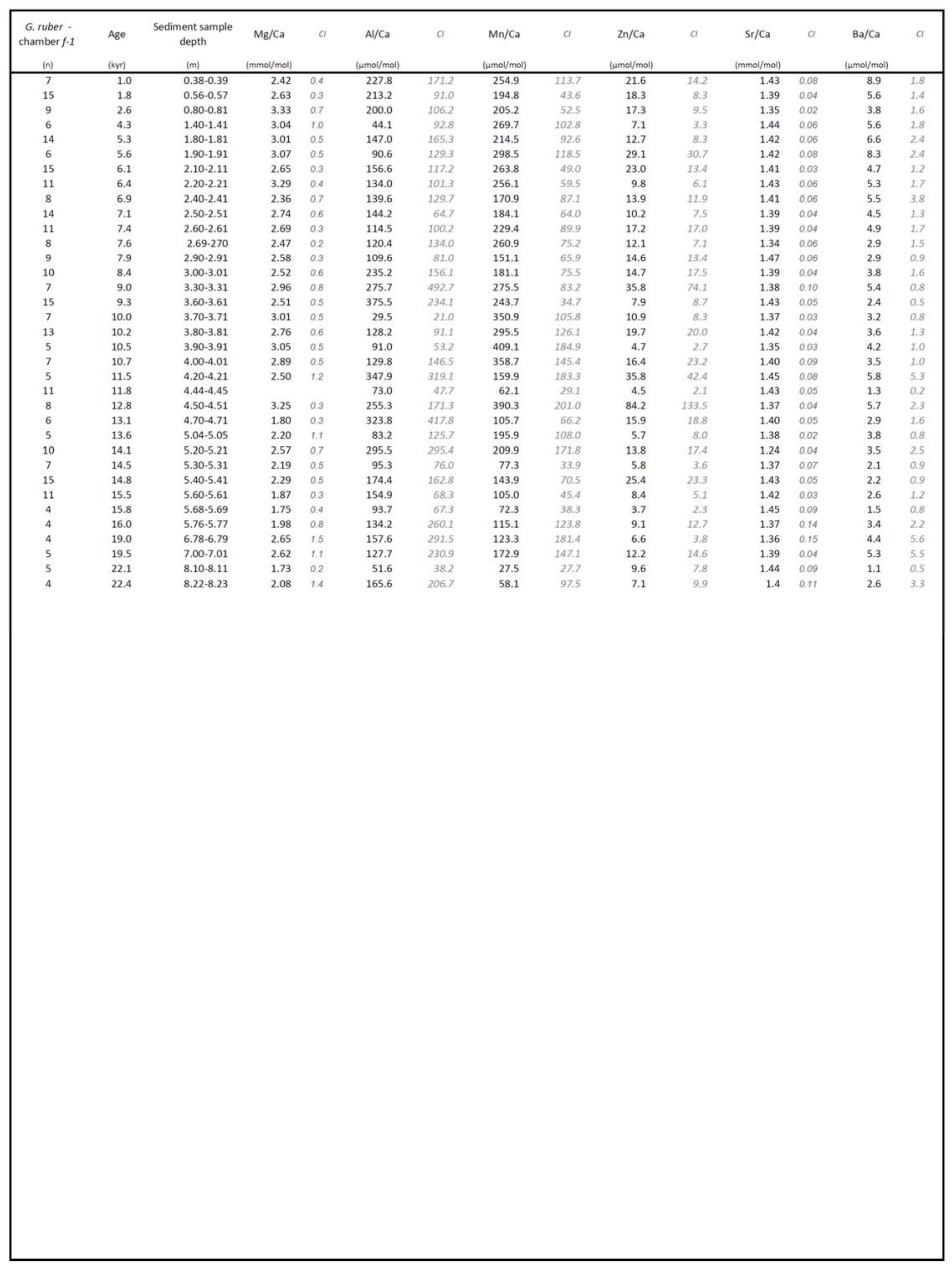




\section{AI 2.0. Trace metal concentrations in the surface ocean and foraminiferal test calcite}

\section{AI 2.1. Surface ocean trace metal concentrations}

Differences in the modern water mass concentrations of $\mathrm{Zn}$ and $\mathrm{Mn}$ have been observed across the modern STF. Mean dissolved Zn levels of $0.22 \mathrm{nmol} / \mathrm{kg}$ in STW are higher than a mean of $0.04 \mathrm{nmol} / \mathrm{kg}$ in SAW (M. Ellwood pers. comm., 2011). Subtropical surface water Mn concentrations from the Southwest Pacific Ocean are ca. $1.2 \mathrm{nmol} / \mathrm{kg}$ while those from the subantarctic waters generally range from 0.3 to $0.7 \mathrm{nmol} / \mathrm{kg}$ (Klinkhammer and Bender, 1980). Dissolved Ba concentrations, however, are relatively homogenous with as little as 10$20 \%$ difference between SAW and STW off southern Australia (Jacquet et al., 2004). The closest river record of $\mathrm{Mn}, \mathrm{Zn}$ or Ba levels to the core sites of this study is from the Waihou River, located $300 \mathrm{~km}$ west of Hawke Bay (Fig. 20). The river drains a greywacke/volcanic catchment similar to that of rivers discharging off Hawke Bay near MD97 2121. The Waihou River has dissolved Mn levels of 1.4-8.8 $\mu \mathrm{g} / \mathrm{kg}$ and $\mathrm{Zn}$ of $<0.1 \mu \mathrm{g} / \mathrm{kg}$ (Webster, 1995), lower than the global averages of $34 \mu \mathrm{g} / 1$ and $0.6 \mu \mathrm{g} / \mathrm{l}$, respectively (Gaillardet et al., 2003). No dissolved $\mathrm{Ba}$ concentrations are available for the North Island. Rivers draining the lower eastern North Island annually carry ca. $83 \mathrm{Mt}$ of suspended load to the continental shelf (Hicks and Shankar, 2003). Modern core-top and plankton-tow sites in STW or SAW, which are adjacent to high-input rivers (P69, S938, U2309, Q220) are then compared to sites that are more distal from major fluvial point sources (P71, S793, F111, D178, B32, R623 or ODP1123).

\section{AI 2.2 Trace metal values in foraminifera}

Zinc follows a nutrient-like profile in the water column similar to that of cadmium and phosphate. Zinc is depleted in surface waters, becoming increasingly replete with depth (Ellwood, 2004; Frew and Hunter, 1995; Hunter and Boyd, 1999; Morel et al., 1991). Variable concentrations of $\mathrm{Zn} / \mathrm{Ca}$ in foraminifera may therefore offer insights into nutrient depletion/repletion in surface waters. Diatom blooms may potentially affect $\mathrm{Zn} / \mathrm{Ca}$ concentrations, as $\mathrm{Zn}$ is an essential element for many diatom enzymatic processes. However, even after diatom blooms in Southern Ocean, surface water $\mathrm{Zn}$ levels reduced by only ca. 50\% (Frew et al., 2001), which is likely to only affect surface dwelling G. ruber.

Although vital for phytoplankton growth, the relatively low uptake of $\mathrm{Mn}$ by marine phytoplankton results in high ambient Mn surface water concentrations (Learman et al., 2011; 
Morel et al., 2003; Sunda and Huntsman, 1988). Manganese concentrations are in excess of those that would otherwise limit growth and/or productivity and are therefore generally higher in surface than deep waters (Morel et al., 2003). Fluctuations in the Mn excess may be regulated by terrestrial or volcanic inputs relative to a background concentration in the ambient water mass (Bruland and Lohan, 2003).

Barium is incorporated into foraminifera via passive substitution for $\mathrm{Ca}$ either in a biologically mediated process and/or by adhering to the test (Bruland and Lohan, 2003; Lea and Boyle, 1991). Accordingly, depletion of $\mathrm{Ba}$ in surface waters (as low as $20 \%$ of the highest deep water values) is smaller than observed for bio-active trace metals that can limit productivity (Bacon and Edmond, 1972; Chan et al., 1977; Lea and Boyle, 1989). Laboratory foraminifera culturing experiments have established that $\mathrm{Ba}$ is incorporated into test calcite in equilibrium with ambient water concentrations (Hönisch et al., 2011; Lea and Spero, 1992) with $\mathrm{Ba} / \mathrm{Ca}$ levels homogeneous across the test wall regardless of diurnal cycles (Spero et al., 2008). Previously, links between foraminiferal $\mathrm{Ba} / \mathrm{Ca}$ and fluvial discharge and upwelling have been made (Hall and Chan, 2004; Lea and Boyle, 1990; Weldeab et al., 2007). In addition, a relationship between marine sediment $\mathrm{Ba} / \mathrm{Al}$ values and diatom productivity in the Southwest Pacific Ocean has been proposed (Weedon and Hall, 2004). A core-top validation of $\mathrm{Ba} / \mathrm{Ca}$ in planktic foraminifera as a water mass tracer proxy has not previously been established. Plankton tow and core-top material utilised in this study span zones of high-low productivity (e.g. King and Howard, 2001; Murphy et al., 2001) and variable fluvial input (see Hicks and Shankar, 2003) thereby providing the opportunity to evaluate any modern relationship between trace metal levels in foraminiferal test calcite and the environment.

\section{AI 3.0. Complexity in interpretation of test trace metal values as paleo-ocean proxies}

\section{AI 3.1. Core-top diagenesis}

Southern core-tops are mainly from the carbonate-mantled Campbell Plateau (e.g. Neil et al., 2004) whereas the northern core-tops come from the high terrigenous input, Hikurangi Margin and Plateau (Hicks and Shankar, 2003; Orpin et al., 2008). This raises the possibility that the high terrigenous fluvial flux may contribute to the elevated northern $\mathrm{Mn} / \mathrm{Ca}$ values in contrast to the terrigenous-starved Campbell Plateau and its minimal Mn/Ca ratios (Fig. 24). However, northern plankton tows, in particular U2322 from near MD97 2121, captured G. ruber with $\mathrm{Mn} / \mathrm{Ca}$ of $c a .8 \mu \mathrm{mol} / \mathrm{mol}$, similar to SAW values (Fig. 24). Bearing in mind that 
this tow data are a single "snapshot" of the austral autumn water conditions of 2001, it raises the following possibilities; namely, the $\mathrm{Mn} / \mathrm{Ca}$ ratio is low because of (i) the presence of SAW-bearing water, which can extend to MD97 2121, but is unlikely because under the modern conditions, SAW modified water is confined mainly to the continental shelf and MD97 2121, which is located off the continental slope, is overlain by STW (Chiswell, 2000), (ii) low fluvial input as reflected by the low precipitation at the time of the plankton tows (NIWA, 2012), and/or (iii) it is the normal dissolved Mn level for the surface waters. If the last point is valid, it implies that the elevated $\mathrm{Mn} / \mathrm{Ca}$ of the core tops and down-core section of MD97 2121 may be affected by post-depositional processes.

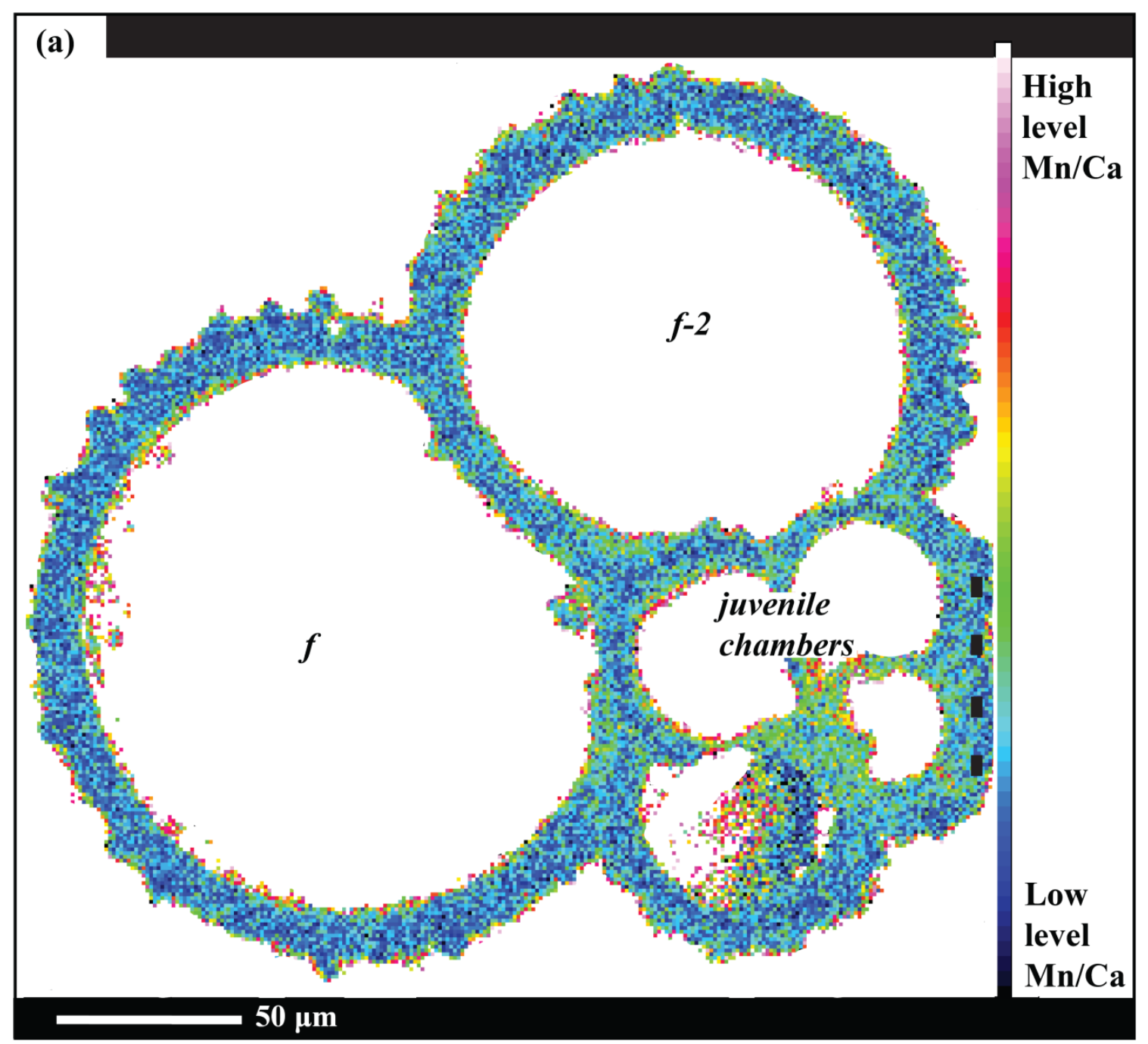




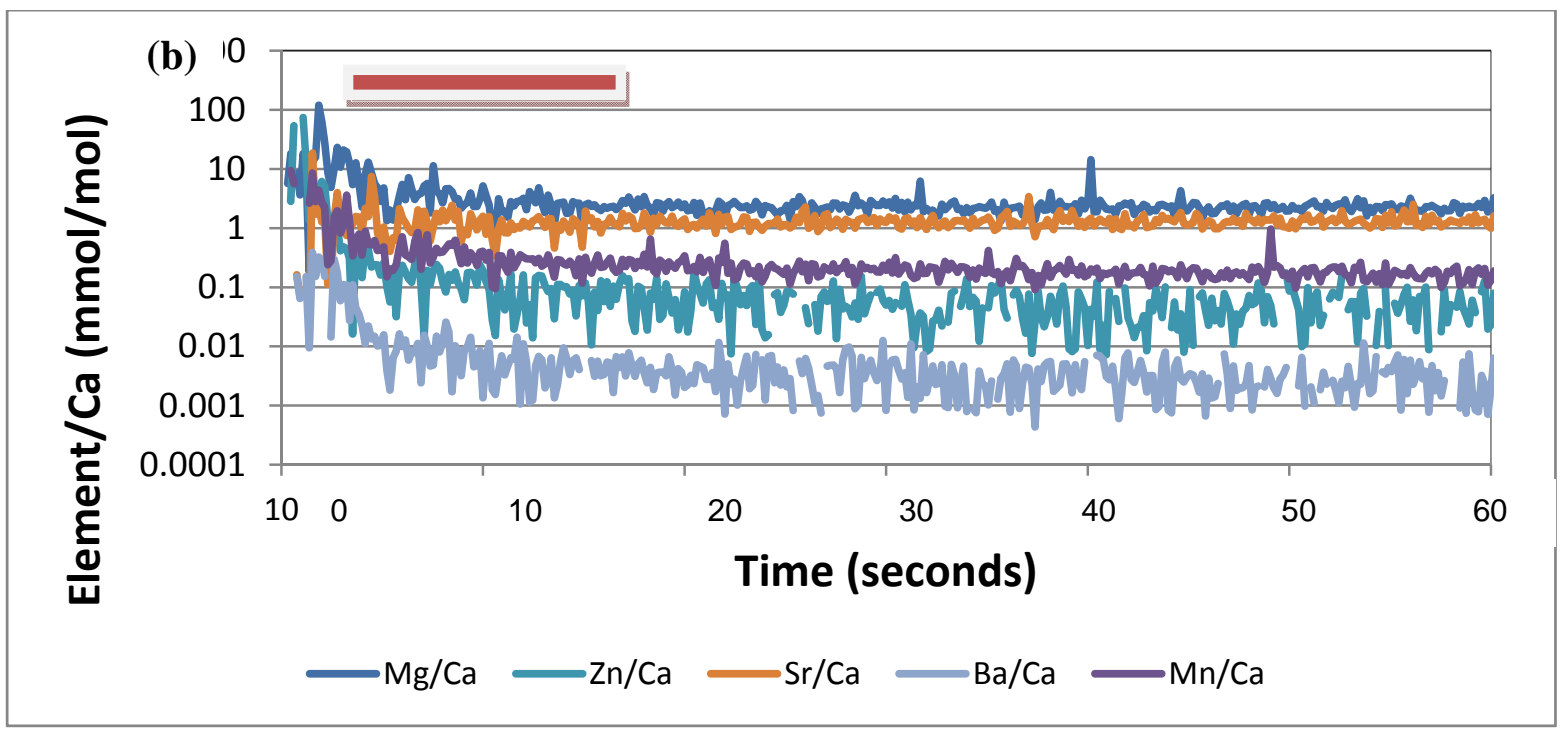

C3-AI. Fig. 1. (a) X-ray map of $\mathrm{Mn} / \mathrm{Ca}$ relative intensity of a single G. bulloides test as measured by WDS electron microprobe with two adult and juvenile chambers indicated. (b) Time-resolved laser ablation profile for G. bulloides chamber $f$ from MD97 2121, $2.4 \mathrm{~m}$ depth (6.5 ka). The colour spectrum on (a) has been linearly scaled to enable distinction between the inner and outer test compositions. Values of $\mathrm{Mn} / \mathrm{Ca}$ above $c a .1$ $\mathrm{mmol} / \mathrm{mol}$ are coloured pink or higher on this intensity scale. The spatial resolution of the WDS map is ca. 1 $\mu \mathrm{m}^{2}$. Contaminant phases are indicated in red/pink on the outer test surface in the elemental map with very high relative amounts of $\mathrm{Mn} / \mathrm{Ca}(\mathrm{ca} .>1 \mathrm{mmol} / \mathrm{mol})$ compared to the inner test coloured in blue/green (ca. 0.3 $\mathrm{mmol} / \mathrm{mol}$ ). The contaminant phase on the outer test can also be clearly identified on the laser ablation profile (indicated by the red bar). This section is completed removed during the first 10-15 seconds of ablation and the test trace metal profile indicated by the red bar is excluded when calculating individual foraminifera and sample mean elemental ratios.

Any post-depositional contamination of foraminiferal tests has the potential to affect trace element concentrations, for example, Boyle $(1981 ; 1983)$ highlighted enrichment in Mn due to the formation of manganese carbonate outgrowths and ferromanganese coatings on test surfaces. In addition, as noted in the Methods, any surface enrichment seen in the trace element maps are detectable in the laser ablation profiles (C3-AI. Fig. 1). Hence trace element measurements are restricted to the test's primary calcite layer. Element maps of the test wall also confirm a lack of obvious $\mathrm{Mn} / \mathrm{Ca}$ contamination within test pore spaces (C3-AI. Fig. 1) and the primary test calcite (C3-AI. Fig. 1). Our LA-ICPMS analyses and EPMA element mapping can only resolve Mn contamination within the acknowledged spatial and analytical capabilities of those instruments, and we cannot discount the potential presence of pervasive sub-micron films of Mn precipitation within the pores, a feature which would likely only be resolvable using NanoSIMS methods (e.g. Kunioka et al., 2006). Given low 
concentrations of $\mathrm{Mn}$ in the test calcite of plankton tow samples, any film may act leverage the analysis. Nonetheless, clearly resolvable differences exist between core top foraminifera underlying SAW and STW.

\section{AI 3.2 Measurement of trace element data}

Trace metal data was measured here using laser ablation ICP-MS. This technique involves the removal of a very small volume of material from the formainiferal shell, associated with a circular laser beam of $35 \mu \mathrm{m}$ diameter. Any foraminiferal shell spot likely only represents data from up to one month which the foraminifera takes to undergo its full life cycle (Hemleben et al., 1989) and thus only offers a 'snap shot' of environmental conditions at the time and depth at which the shell was calcified. As such, a spot analysis of a single foraminifera is unlikely to be representative of annual conditions prevailing at (for example) $60 \mathrm{~m}$ water depth. However, spot analyses of multiple foraminifera reduces the uncertainty (see discussion of uncertainty in the methods section 3.2) of a single spot and generates results which, in their totality, offer an insight into conditions over a time span for which the age of the foraminifera range. For example, in a high sedimentation region a core top sample of 30 foraminifera may provide the average conditions over a 200 year time span for spring conditions under a regional spring dominated productivity cycle.

Uncertainty of individual data points (\% 2 standard error) of trace element/Ca ratios for a single foraminiferal analysis are typically: $\mathrm{Mg} / \mathrm{Ca} \pm 1.0-2.5 \%, \mathrm{Al} / \mathrm{Ca} \pm 5-20 \%, \mathrm{Mn} / \mathrm{Ca} \pm 3-15 \%$, $\mathrm{Zn} / \mathrm{Ca} \pm 6-23 \%, \mathrm{Sr} / \mathrm{Ca} \pm 1.0-2.0 \%, \mathrm{Ba} / \mathrm{Ca} \pm 3-30 \%$. This level of uncertainty on an individualby-individual basis affects the uncertainty of a sample mean at a given horizon within a down-core record. The use of multiple foraminifera in a sample is therefore vital to ensure that uncertainty associated an individual measurement is reduced. Uncertainty is reduced by the increase in the number of foraminifera in a sample, this can be clearly illustrated using tstatistics. For example, by going from 30 to 10 foraminifera in a sample would increase the 'degrees of freedom' from 2.04 to 2.6 or an inflation of the uncertainty of approximately $10 \%$. This variability will introduce uncertainty into the sample. However, inter-sample variability varies from $10-30 \%$, therefore this is far more significant than for an individual data point. 


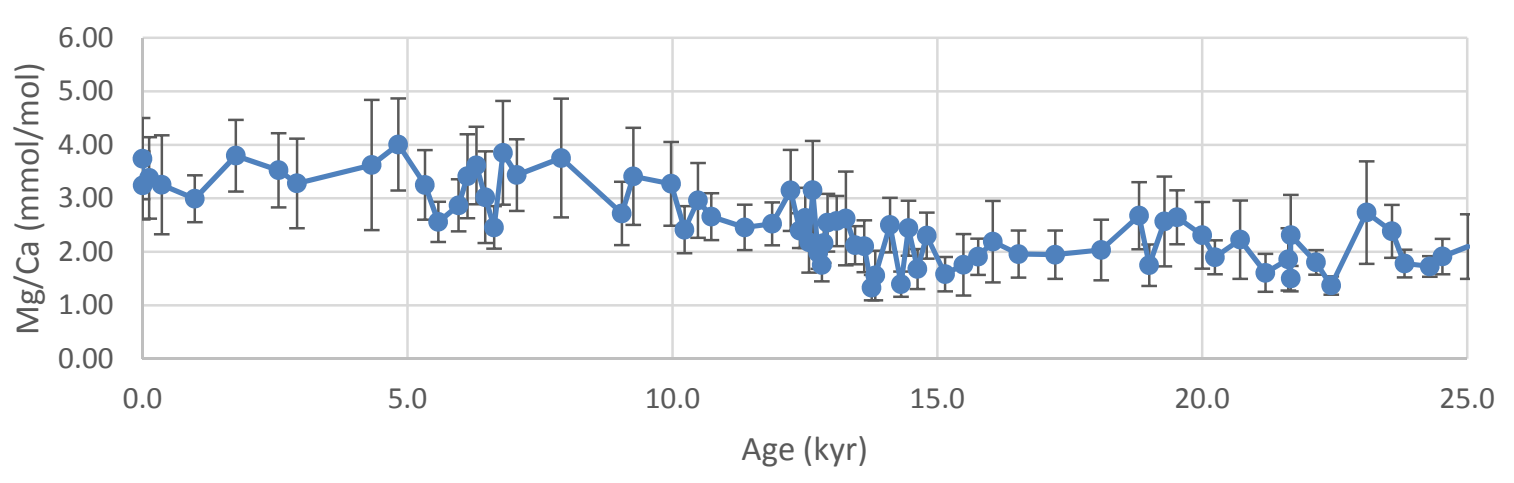

$\mathrm{Zn} / \mathrm{Ca}$

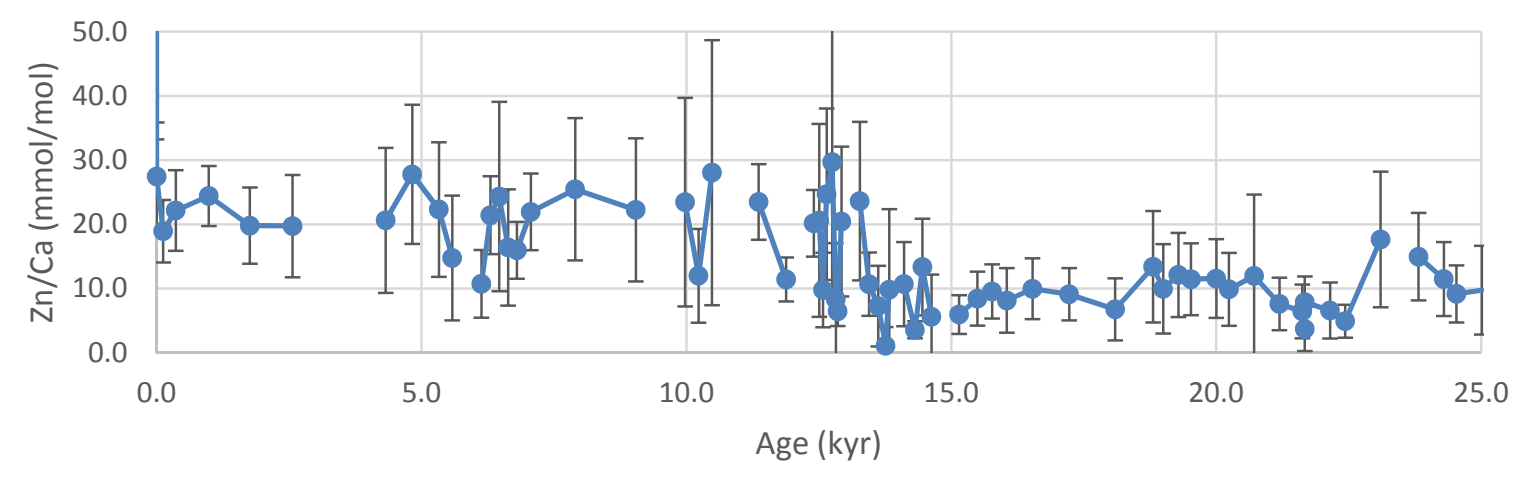

C3-AI. Fig. 2. (a) $\mathrm{Mg} / \mathrm{Ca}$ and (b) $\mathrm{Zn} / \mathrm{Ca}$ sample values with individual sample $95 \%$ confidence intervals.

Inter sample variability like those above represent natural heterogeneity within the sample (Fig. C3-AI. Fig. 2). This natural heterogeneity is a result of the different depths at which the foraminifera dwell (e.g. Mortyn and Charles, 2003), the different season(s) of productivity and related surface water trace metal concentrations (e.g. Neil and Northcote, 2004; GaultRingold et al. 2012) and natural differences in the biological incorporation of trace metals between individuals (pers. comm. Spero, 2012). Using laser ablation we are able to further investigate this variability. In the text of chapter 3 we use the intra-sample variability to investigate if this may act as a potential proxy for changes in ENSO following the work of Koutavas et al. (2006). However this intra-sample variability, which is only resolvable using in situ geochemcial techniques, also emphasises the need to use the smoothing technique to highlight trends through time, rather than be reliant on a single sample. In addition, it also emphasises the need to look for similar trends in other independent proxy records e.g. foraminifera assemblages or key indicator species indicating a cooling trend at a similar time 
thus supporting the interpretation and clearly distinguish between natural background 'noise' and changes reflecting wider environmental conditions.

\section{AI 3.3 Benthic Conditions}

Trace element ratios over a glacial-interglacial cycle may be affected by changing benthic conditions. In the case of ODP 1123, ca. $900 \mathrm{~km}$ east of MD97 2121, glacial to interglacial changes from (i) terrigenous-dominant to carbonate-dominant sedimentation, (ii) a reduced the organic carbon flux (Lean and McCave, 1998) and (iii) relatively fast flowing Antarcticsourced Circumpolar Deep Water to relatively slower North Atlantic Deep Water (Hall et al., 2001), all have the potential to change the trace element supply and benthic geochemical conditions. In contrast, sedimentation at MD97 2121 is continually rapid $(30-40 \mathrm{~cm} / \mathrm{kyr}$ compared to $4 \mathrm{~cm} / \mathrm{kyr}$ at ODP 1123), and the terrigenous input remained high and carbonate low $(<20 \%)$ over the last glacial/interglacial cycle without major changes in the benthic water mass compared to the marked changes in the surface ocean (Carter and Manighetti, 2006). Thus the trace element/Ca ratios, in particular $\mathrm{Zn} / \mathrm{Ca}$, potentially reflect the concentrations of trace elements at the time of calcification at MD97 2121.

\section{AI 3.4 Water column concentrations}

Interpretations of $\mathrm{Zn} / \mathrm{Ca}$ trace metal values in foraminifera require consideration of the $\mathrm{Zn}$ water-column profile at the time of calcification. G. bulloides mainly calcifies in the New Zealand spring (King and Howard, 2001) when strong seasonal winds affect deep mixing and local upwelling at the continental margin (Chang et al., 2003; Sutton and Roemmich, 2001). Such conditions, in particular upwelling, are liable to bring Zn-enriched deeper waters to the surface and so disrupt the $\mathrm{Zn}$ nutrient profile causing calcifying tests to have an elevated $\mathrm{Zn} / \mathrm{Ca}$ ratio compared to the profile data available to us (Fig. 23). This situation would be reversed for Mn, which is enriched in surface waters and declines with depth. 
Chapter 4 


\section{IMPACT OF SEASONALITY AND CHANGING OCEANOGRAPHY ON PALEOTHERMOMETRY RECORDS}

Marr, J. P., H. C. Bostock, L. Carter, in review. Impact of seasonality on paleothermometry records: implications for paleothermometry records derived from frontal regions, Paleoceanography Paleoclimatology Paleoecology

\section{Author Contributions:}

Julene Marr; interpretation, manuscript writing

Lionel Carter, Helen Bostock; general supervision

\section{Abstract}

Modern sediment trap studies have illustrated a distinct seasonal offset in foraminiferal and alkenone flux to the sea floor between the subantarctic and subtropical water masses. However, the potential effect of a change in species seasonality on paleothermometry records where there has been a change in dominant water mass is yet to be illustrated. Here we present a comparison between temperature records of two independent paleothermometers, alkenone and $\mathrm{Mg} / \mathrm{Ca}$ analysed on planktonic foraminifera, from a high-resolution core situated close to a subtropical frontal region. The long term temperature trends in alkenone and Globigerina bulloides (G. bulloides) $\mathrm{Mg} / \mathrm{Ca}$-based estimates generally agree. The offset between G. bulloides and alkenone temperatures varies between ca. 3-7 ${ }^{\circ} \mathrm{C}$ during the glacial period and the subsequent transition to the Holocene. During the last glacial to early deglaciation (25-16 ka) the study site was bathed by SAW and alkenone production was most likely limited to summer, as favourable conditions for coccolithophore productivity including stratified surface waters and optimal light levels is unlikely to be achieved at other time during the year. This has the effect of producing warmer glacial alkenone temperatures, dampening glacial-interglacial variability. However, during the glacial period G. bulloides is likely to have followed a spring bloom cycle, similar to modern subantarctic sites with temperature further dampened by wind induced upwelling or mixing of the upper ocean. This resulted in cooler $\mathrm{Mg} / \mathrm{Ca}-\mathrm{G}$. bulloides glacial temperature estimates and a greater offset with 
between alkenone and $\mathrm{Mg} / \mathrm{Ca}$ temperature records as compared to the Holocene. Holocene based alkenone-G. bulloides temperatures are generally the same within error, signalling a return to modern surface water conditions and a common season(s) (spring and summer) of productivity. This study highlights the susceptibility of foraminiferal $\mathrm{Mg} / \mathrm{Ca}$ and alkenonebased temperature estimates to the effects of seasonality and changing regional hydrology.

\subsection{Introduction}

Global temperature has been warming since 1880 s, and the more recent acceleration of this increase since the late 1970s has alarmed scientists (e.g. Cole and McCarthy, 2012; Root et al., 2003; IPCC 4th Assessment). However, it is also known that global temperature naturally fluctuates, thus it is important to establish a base line for natural temperature variability in order to identify any anthropogenic impact on global climate (e.g. Mayewski et al., 2004). Paleotemperature reconstructions largely rely on geochemical measurements or floral/faunal assemblages (e.g. Otto-Bliesner et al., 2009). However, when data from different proxies are compared discrepancies commonly arise as identified previously in the CLIMAP (Climate Long-Range Investigation, Mapping and Prediction) (e.g. CLIMAP, 1976; CLIMAP, 1981; Rind and Peteet, 1985), or more recently the MARGO projects (Multiproxy Approach for the Reconstruction of the Glacial Ocean surface) (Kucera et al., 2005; MARGO et al., 2009). From these global research projects it has become clear that a greater understanding is required of what temperatures these proxies are actually recording. In this study we tackle this issue by comparing multiple paleothermometer analyses which use different planktic organisms/species preserved in well-dated, well-preserved marine sediment cores.

Geochemical proxies can only be applied as far back in time as the relationship between species ecology and biology, and the target chemical process remain stable (Kucera, 2007; MARGO et al., 2009; Sikes et al., 2009). Even if the metabolic or biochemical pathway responsible for incorporation of the chemical signal remains the same, any change in the season of production, or the environmental niche, can alter the reconstructed record (Bemis et al., 2002; Kucera, 2007). Depending on the environmental preference/s of a particular species and its adaptive capacity, this may result in an attenuated record as an organism attempts to maintain optimal habitat conditions by ceasing productivity in specific region(s) (Kucera et al., 2005; Tyrrell and Merico, 2004). Previously, it was suggested that a change in species seasonality may be affecting paleoceanographic records, however details regarding the 
degree to which seasonality impacts upon the paleotemperature record are currently unknown (Barrows et al., 2007; Leduc et al., 2010; Sikes et al., 2009).

Here we present a comparison between paleotemperature records of two independent paleothermometers; alkenones and $\mathrm{Mg} / \mathrm{Ca}$ measured on planktonic foraminifera, Globigerina bulloides, from a high-resolution core MD97 2121 from north of the Chatham Rise, east of New Zealand (Carter et al., 2002). The core sits just north of the Subtropical Front (STF; Fig. 28) and while the surface waters currently bathing the core site are subtropical water (STW), the region was overlain by subantarctic water (SAW) during the glacial period (Carter et al., 2008; Marr et al., in press-b; Weaver et al., 1998). Therefore this site provides the ideal opportunity to investigate how changes in the dominant water mass(es), both of which have distinctive temperature and nutrient profiles, have affected the ecological response of coccolithophores and foraminifers and thus the paleotemperature records derived from these organisms.

\subsection{Background}

\subsection{Paleothermometry tools}

There are two sources of paleotemperature records used in this study; alkenone records and $\mathrm{Mg} / \mathrm{Ca}$ ratios measured on planktic foraminifera Globigerina bulloides (G. bulloides). Alkenone-based surface water temperatures are determined from the organic remnants of the phytoplankton coccolithophores in sediment, using the alkenone undersaturation index. This index uses the degree of unsaturation of the $\mathrm{C}_{37}$ alkenones, which increases with decreasing temperature of the water in which the microalgae grow (Brassell et al., 1986; Prahl and Wakeham, 1987). For temperature estimation, this unsaturation is generally expressed as the $U_{37}^{K^{\prime}}$ ratio, which is the ratio of the amount of di-unsaturated to the total di-plus triunsaturated $\mathrm{C}_{37}$ alkenones in the sample ([37:2]/[37:2+37:3]). Emiliania huxleyi (E. huxleyi) and Gephyrocapsa oceanica (G. oceanica) are the two species of coccolithophore, which are the principal alkenone synthesizers in the modern ocean (Conte et al., 1994; Volkman et al., 1995) and both are commonly found in the New Zealand region (Rhodes et al., 1995; Hoe Chang, pers. comm.).

$\mathrm{Mg} / \mathrm{Ca}$-based thermometry uses the geochemical trace element composition of foraminiferal shells (tests), which reflect i) the chemistry of the ambient seawater, and ii) in the case of the $\mathrm{Mg}$ incorporation into test calcite, the thermodynamic relationship between $\mathrm{Mg}$ and $\mathrm{Ca}$, 
which leads to an exponential increase in the level of $\mathrm{Mg}$ relative to $\mathrm{Ca}$ with increasing temperature (e.g. Bender et al., 1975; Lea et al., 1999). While multiple species of planktic foraminifera have been calibrated for $\mathrm{Mg} / \mathrm{Ca}$ paleothermometry, here we use the temperate species, G. bulloides due to its wide geographic distribution at southern mid-latitudes (Hemleben et al., 1989) and continuous presence in Quaternary cores from the eastern New Zealand region (Hayward et al., 2008; Marr et al., in press-b; Pahnke et al., 2003).

\section{Modern}

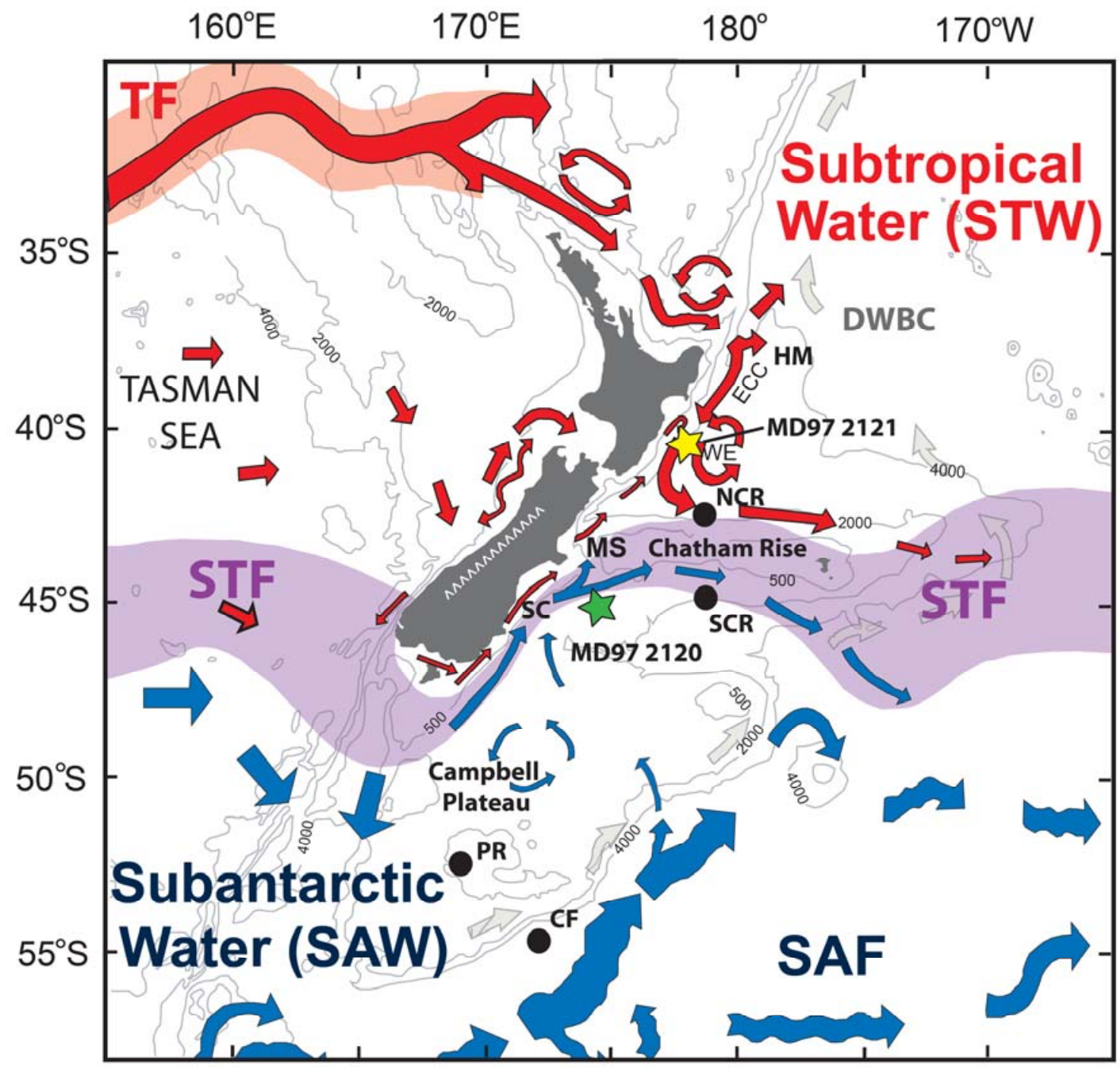

Figure 28. Generalised modern surface ocean currents and bathymetry surrounding New Zealand (modified from Carter et al., 1998). Yellow star marks the core site MD97 2121 used in this study. Circles mark location of $G$. bulloides and alkenone sediment trap studies, NCR=North of Chatham Rise, SCR=South of Chatham Rise: King and Howard (2001), Sikes et al. (Sikes et al., 2005); PR=Pukaki Rise, $C F=$ Campbell Flank: Northcote and Neil (2005); TF $=$ Tasman Front; STF $=$ Subtropical Front; SAF $=$ Subantarctic Front; STW $=$ Subtropical 
Surface Water; SAW = Subantarctic Surface Water; MS = Mernoo Saddle; DWBC=Deep western boundary current; ECC=East Coast Current; WE=Wairarapa Eddy. Isobaths are in metres.

\subsection{Ecological niches}

Coccolithophore are distributed in the upper mixed layer, while planktonic foraminifera are present throughout the whole water column. Particular species are restricted in their vertical and spatial distribution by species-specific ecological requirements (e.g. Hemleben et al., 1989; Kuroyanagi and Kawahata, 2004; Tyrrell and Merico, 2004). Phytoplankton E. huxleyi and G. oceanica are recognised as being relatively cosmopolitan living north and south of the STF. However, G. oceanica tends to be more dominant in STW, while E. huxleyi is more prominent in SAW (Duncan, 2012; Rhodes et al., 1995). There are a number of potential constraints on coccolithophore depth habitat, including the key physiological requirement of light for the photosynthesis (Tyrrell and Merico, 2004). Light requirements generally restrict coccolithophore to the upper $30 \mathrm{~m}$ of the water column (Nanninga and Tyrrell, 1996; Tyrrell and Merico, 2004).

Foraminifera are zooplankton. The foraminifera G. bulloides is asymbiotic and thus its depth habitats are not constrained by light levels. North and south of the STF the distribution of $G$. bulloides through the water column, as identified by stratified plankton tows, does not significantly change (NIWA, Cruise Report TAN 9814, unpublished report, 1998) despite the significant differences in water mass properties including temperature and seasonal surface water mixing (Heath, 1985b; Morris et al., 2001; Sutton, 2001). The highest concentrations of G. bulloides are typically found between 50-100 m depth (Mortyn and Charles, 2003; Wilke et al., 2009a), however they have also been recovered alive from depths of $400 \mathrm{~m}$ in the New Zealand region (NIWA, Voyage Report TAN 9814, unpublished report, 1998).

\subsection{Oceanography}

Modern surface waters east of New Zealand feature a suite of dynamically-driven water masses (e.g. Chiswell, 2002a; Heath, 1985b; Morris et al., 2001). Off eastern Australia, the East Australian Current (EAC) flows south, with a component detaching to form the eastward flowing Tasman Front (TF) (Fig. 28) (Ridgway and Dunn, 2007). The Tasman Front flows across the Tasman Basin and re-attaches to northern New Zealand as the East Auckland Current (EAUC) and its southward continuation, the East Coast Current (ECC) (Ridgway and 
Hill, 2009; Tilburg et al., 2001). Seaward of the ECC is the anticyclonic, warm-core Wairarapa Eddy (WE) associated with the East Cape Eddy system. Eddies shed near East Cape and propagate southwest along the continental margin to Hawke Bay where they may stall or merge with a previous perturbation to form the Wairarapa Eddy, which is proximal to our core site MD97 2121 (Chiswell, 2005; Roemmich and Sutton, 1998).

East of New Zealand the STF is situated approximately along the east-west crest of Chatham Rise (Fig. 28). This front separates the warm, micronutrient-rich, saline STW which have flowed in to the region via the TF from Australia, from micronutrient poor, cool, fresher SAW (e.g. Bowie et al., 2009; Chiswell, 2002a; Hamilton, 2006) (Fig. 28). Modern sea surface temperatures (SSTs) north of the Chatham Rise vary by $c a .3 .5-4^{\circ} \mathrm{C}$ at the ocean surface between spring and summer (Locarnini et al., 2006).

South of Chatham Rise, the inflow to southern New Zealand is dominated by the Antarctic Circumpolar Current (ACC) whose leading edge is the Subantarctic Front (SAF). The SAF separates the SAW from colder Circumpolar Surface Water (CSW) is forced south around the bathymetric barrier of Campbell Plateau (Fig. 28) (Heath, 1985a; Morris et al., 2001).

\subsection{Modern seasonality of coccolithophores and G. bulloides production}

Timing of coccolithophore, and thus alkenone, production varies north and south of the STF (Sikes et al., 2005). Evidence from sediment traps show that to the north of the STF in STW, alkenone flux peaks in late December, during the Austral summer, with smaller peaks approximately half the size in spring and autumn (Fig. 29). Alkenone STW temperatures from sediment traps generally agreed with the satellite derived SST throughout the year, but gave cooler than predicted temperatures by up to $4{ }^{\circ} \mathrm{C}$ during late summer to early autumnpossibly due to reduced nutrients (Sikes et al., 2005). South of the STF in SAW, a more sustained, but single peak in alkenone flux occurs from September-November, Austral spring (Fig. 29), with warmer alkenone derived temperatures than expected found during late summer to early winter - possibly due to light limitation (Sikes et al., 2005).

In STW, north of the STF, G. bulloides mainly blooms in spring to early summer, with smaller peaks in productivity (approximately half the flux) in spring and autumn, similar to alkenones (Fig. 29) (King and Howard, 2001). South of the STF, in SAW, G. bulloides peak flux occurs during spring, also at the same time as the alkenones (Fig. 29) (King and Howard, 2001; Northcote and Neil, 2005). 


\subsection{Methods}

Paleotemperatures used in this study have been derived from the marine sediment core MD97 2121. The top $9.15 \mathrm{~m}$ of the giant piston core covers the period from $25 \mathrm{ka}$-present giving a mean sedimentation rate of $c a .40 \mathrm{~cm} / \mathrm{ka}$. The core site is located just north of the Chatham Rise $\left(40^{\circ} 22^{\prime} \mathrm{S} ; 177^{\circ} 60^{\prime} \mathrm{E}\right.$, water depth $\left.2314 \mathrm{~m}\right)$. A robust chronology is based on 20 Accelerator Mass Spectrometry (AMS) ${ }^{14} \mathrm{C}$ and nine tephra dates (Carter et al., 2008).

\subsection{Alkenone temperature estimates}

Alkenone-based SSTs for core MD97 2121 were published by Pahnke and Sachs (2006). We have calibrated the temperatures using the Sikes and Volkman (1993) calibration due to the regional dominance of SAW at this site during the glacial period (Marr et al., in press-b; Nelson et al., 2000; Weaver et al., 1998). The Sikes and Volkmann (1993) calibration was developed for the Southern Ocean, but in modern subtropical waters can lead to temperature estimates $1-2{ }^{\circ} \mathrm{C}$ warmer than expected from satellite temperature measurements (Sikes et al., 2005; Sikes and Volkman, 1993). Errors of $\pm 1.5{ }^{\circ} \mathrm{C}$ are associated with alkenone temperatures derived from the Southern Ocean (Sikes et al., 2009), comparable to the errors associated with $\mathrm{Mg} / \mathrm{Ca}$ SST estimates. The Sikes and Volkman (1993) alkenone calibrations are based on alkenone concentrations of both E. huxleyi and G. oceanica whereas the Prahl et al. (1988), calibration is based only on E. huxleyi. Neither calibration is likely to be suitable for samples containing only G. oceanica (Volkman et al., 1995), and the performance of both alkenone calibrations is poor below $6{ }^{\circ} \mathrm{C}$ (Sikes et al., 1997).

Previously, the use of either the global (Prahl et al., (1988) or SW Pacific regional (Sikes and Volkman, (1993) alkenone calibrations for marine sediment cores MD97 2121 and MD97 2120 (south of the Chatham Rise) have been discussed in Pahnke and Sachs (2006). Typically, the Sikes and Volkman (1993) temperature calibration generates warmer temperatures by $1-4{ }^{\circ} \mathrm{C}$, equivalent to summer SST estimates. While the global Prahl et al. (1988) calibration reflects annual mean SST. The difference between Prahl et al. (1988) and Sikes and Volkman (1993) temperature estimates are more pronounced at the MD97 2120 site. At MD97 2121 the difference between the calibrations is typically $1-2{ }^{\circ} \mathrm{C}$, only exceeding the calibration error of $\pm 1.5^{\circ} \mathrm{C}$ during the glacial period (AI. 1). During the glacial period the difference between the Sikes and Prahl calibrations at MD97 2121 increases to between $1.5-2{ }^{\circ} \mathrm{C}$, with the Prahl calibration producing cooler temperatures. The increased 
glacial offset is likely the effect of increased SAW influence at the MD97 2121 site during the glacial period (Marr et al., in press-b; Nelson et al., 2000; Weaver et al., 1998). As the Sikes and Volkman (1993) calibration was developed for SAW we use this for comparison, noting that during times of peak alkenone production this calibration may produce warmer SSTs by $1-2{ }^{\circ} \mathrm{C}$ in subtropical water and will provide summer rather than annual SSTs (Prahl et al., 1988; Sikes et al., 2005; Sikes and Volkman, 1993). 


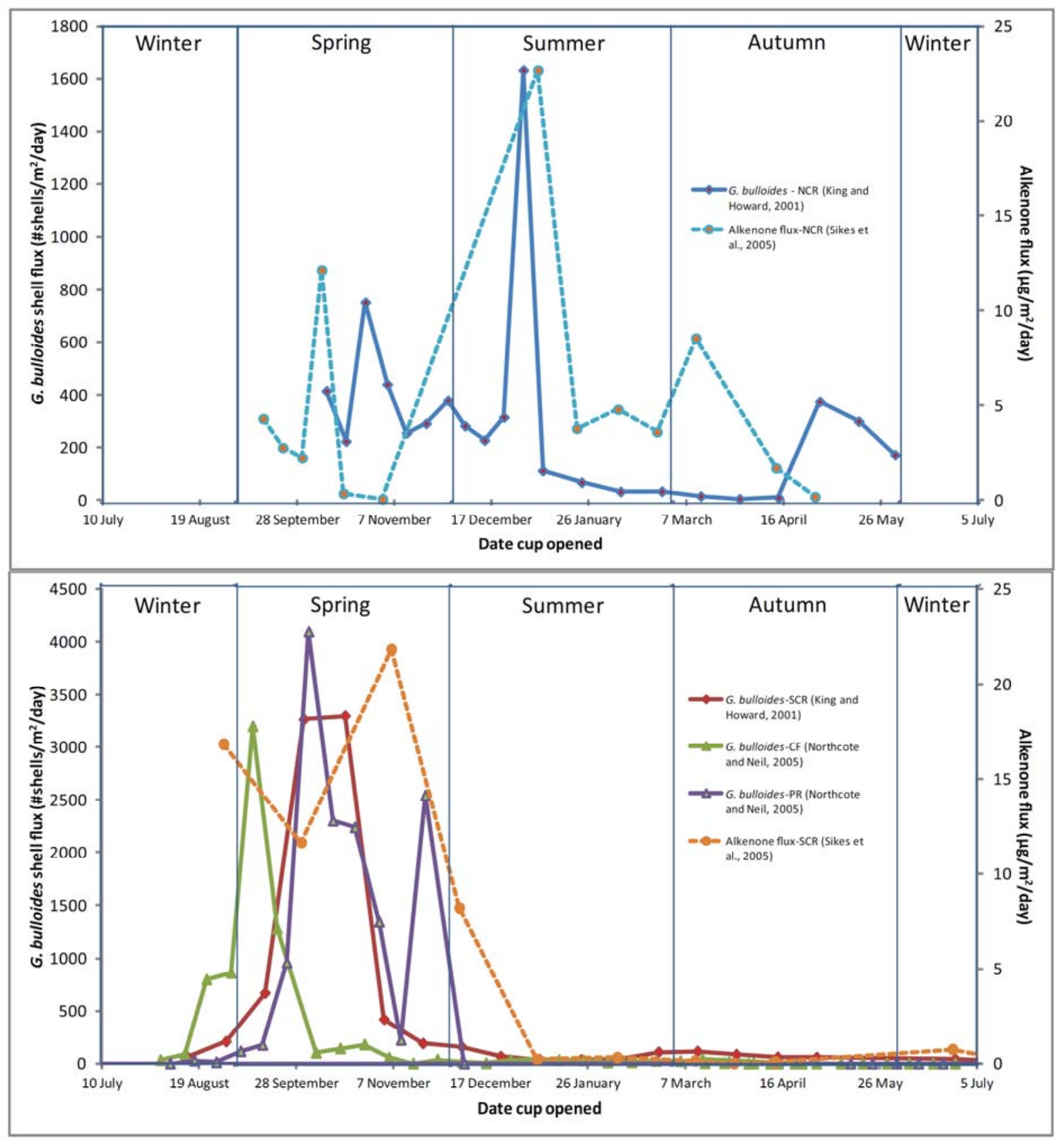

Figure 29. Alkenone and foraminiferal seasonal productivity fluxes north (a) and south (b) of the Subtropical Front. NCR-North Chatham Rise, SCR-South Chatham (G. bulloides-King and Howard, 2001; Alkenone-Sikes et al., 2005), CF-Campbell Flank, PR-Pukaki Rise (Northcote and Neil, 2005). Note, the Sikes et al. (2005) data is presented as the non-normalised total daily fluxes as this is more likely to represent alkenone accumulation in the marine sediment core record.

\subsection{Mg/Ca temperature estimates}

$\mathrm{Mg} / \mathrm{Ca}$-temperatures from MD97 2121 G. bulloides anti-penultimate chamber $(f-2)$ has previously been published (Marr et al., in press-b) using a regional SW Pacific species- 
specific calibration (Marr et al., 2011). While there are small errors associated with the specific calibrations (Anand et al., 2003; Marr et al., 2011), the errors on the $\mathrm{Mg} / \mathrm{Ca}$ paleotemperatures used in this study are $c a . \pm 1.5^{\circ} \mathrm{C}$ (Marr et al., in press-b).

\subsection{SEM identification of coccolithophore species}

Seven $1 \mathrm{~cm}$ sections interspersed throughout marine isotope stages (MIS) 1 and 2 were selected for SEM imaging. This was carried out on the $<40 \mu \mathrm{m}$ grain size fraction to determine the dominant species of alkenone producing coccolithophore (Fig. 30). SEM images were taken using Jeol JSM 6500F at Victoria University of Wellington. Carbon tape was attached to an SEM stub, with a silicon wafer placed on top. A drop of sediment, diluted in MilliQ water, was placed on to a stub. Stubs were then dried under a heat lamp before being carbon coated.

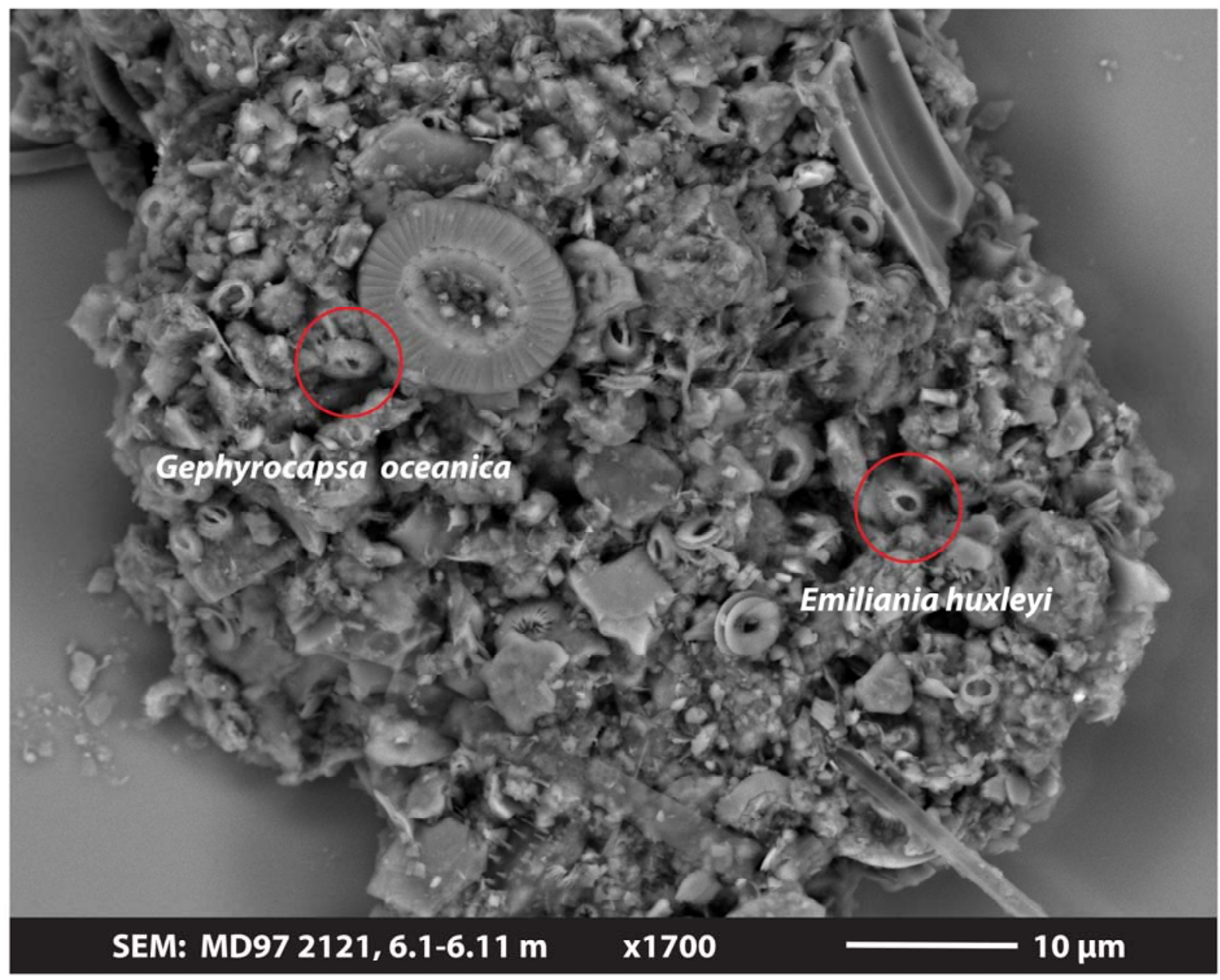

Figure 30. Example of an SEM image of coccolithophore and terrigenous material from sample 6.10-6.11 m. Favourable sample preservation has allowed for species level identification of G. oceanica and E. huxleyi (red 
circles). However, all G. oceanica were included in the category Gephyrocapsa spp. as identification to species level was not always possible.

For each sample, images were taken from random fields of view (FOV) at 1500-3000x magnification and used to identify coccolithophore specimens. The total number of specimens identified for each sample varied from 11 to 85 (AI. 2). These data were turned into percentages to look at major changes in the assemblage over the last $25 \mathrm{ka}$ (Fig. 31). This is a semi-quantitative approach, since the total numbers of coccolithophore per gram of sediment were not determined, but the method highlights significant changes that could be evaluated with a more quantitative approach in the future. The use of the SEM rather than a light microscope had benefits and limitations. Very small specimens of E. huxleyi and Gephyrocapsa spp. are easier to identify with a SEM. However, the traditional data collection method of counting a specific number of coccolithophore per sample (e.g., 300 to 500) takes significantly longer. In addition, coccolithophore in SEM images are occasionally obscured from view by terrigenous sediment. Poor preservation of some samples also made species identification difficult. For this reason, gephyrocapsids were grouped into Gephyrocapsa spp.. However, in samples where preservation permitted specimens to be identified to species level, most gephyrocapsids were identified as being G. oceanica.

\subsection{Determination of the difference between alkenone and $\mathrm{Mg} / \mathrm{Ca}$ temperature proxies}

The difference in temperature between the proxies has been determined by measuring the difference between the proxies temperature estimates after a three point moving mean was applied to the data. Smoothing of the data is an attempt to find better representation over time, reducing the scatter point by point by assuming that the general background conditions are fairly constant over a period of time - in the case of $\mathrm{Mg} / \mathrm{Ca}$ this is $c a .700 \mathrm{yr}$. The statistical basis for this is the reduction in the uncertainty of the mean of $\mathrm{N}$ numbers by $1 / \sqrt{ } \mathrm{N}$. We note that after a 3 point moving mean is used every $3^{\text {rd }}$ point will be independent. 


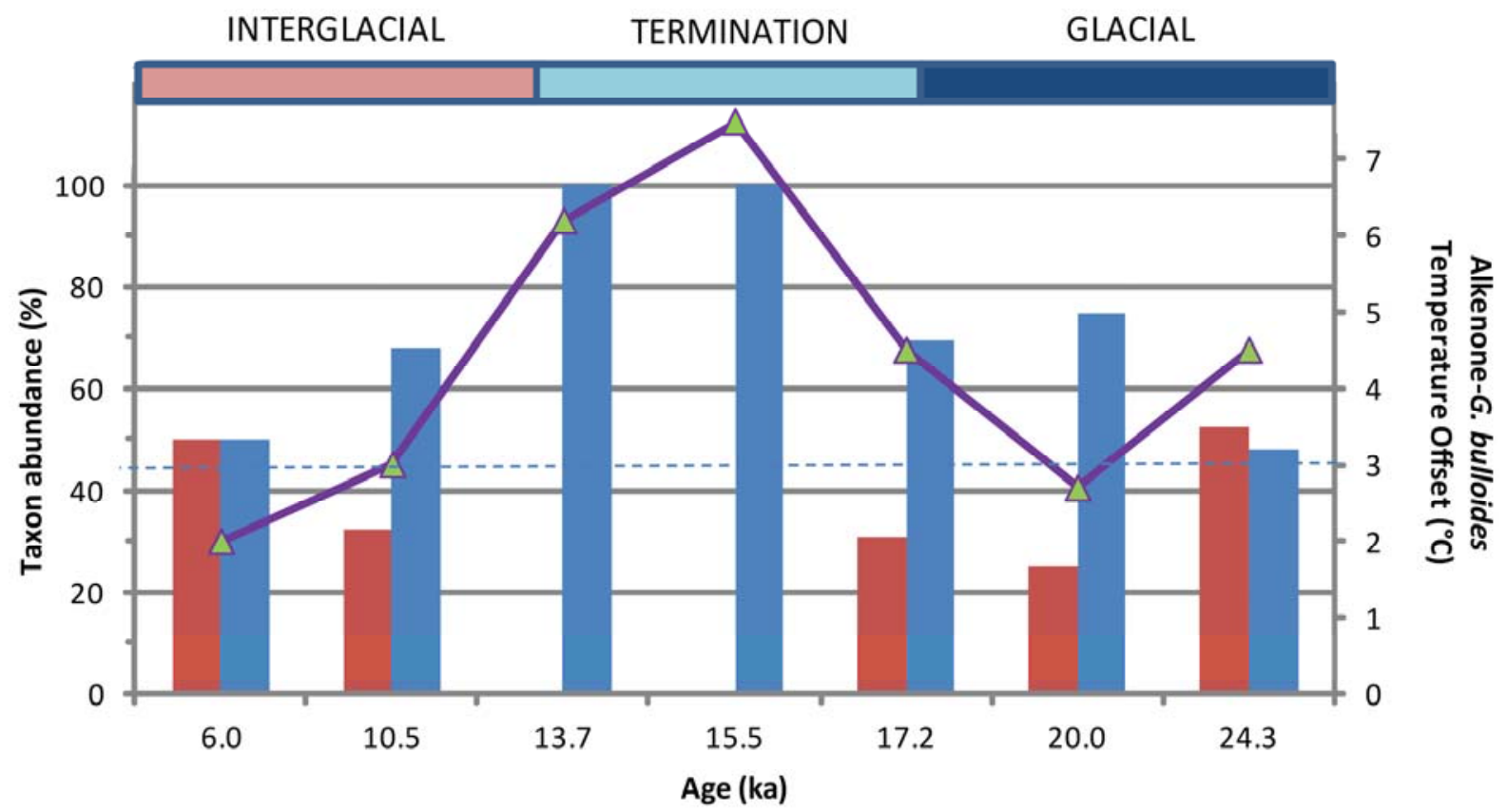

Gephyrocapsa spp. Inc oceanica

Emiliania huxleyi

$\triangle$ Temperature offset

Figure 31. Relative abundances of alkenone producing coccolithophore identified under SEM from the $<40 \mu \mathrm{m}$ sediment size fraction, and relative temperature offset between alkenone and G. bulloides paleotemperatures for the selected time slices (Marr et al., in press-b; Pahnke and Sachs, 2006).

\subsection{Results}

\subsection{Difference between alkenone and Mg/Ca temperature proxies}

There are two distinct periods of temperature difference between alkenone and G. bulloides $\mathrm{Mg} / \mathrm{Ca}$ paleotemperatures at the MD97 2121 site (Fig. 32). From $25 \mathrm{ka}$ to the initiation of the Antarctic Cold Reversal (ACR) at $14.2 \mathrm{ka}$, alkenone SSTs were 3 to $7{ }^{\circ} \mathrm{C}$ warmer than their $\mathrm{Mg} / \mathrm{Ca}$ counterparts (Marr et al., in press-b; Pahnke and Sachs, 2006). The largest offset(s) occurred during the early ACR, from ca. 14.2-13.7 ka reaching up to $10{ }^{\circ} \mathrm{C}$ (Fig. 32). However, during the late deglaciation from $c a$. $13.5 \mathrm{ka}$, the difference between the two paleotemperature estimates declines. From $c a .10 \mathrm{ka}$ the alkenone- $\mathrm{Mg} / \mathrm{Ca}$ temperature estimates are indistinguishable based on the associated proxy errors of $\pm 1.5{ }^{\circ} \mathrm{C}$ (Marr et al., in press-b; Pahnke and Sachs, 2006; Sikes et al., 2009). 


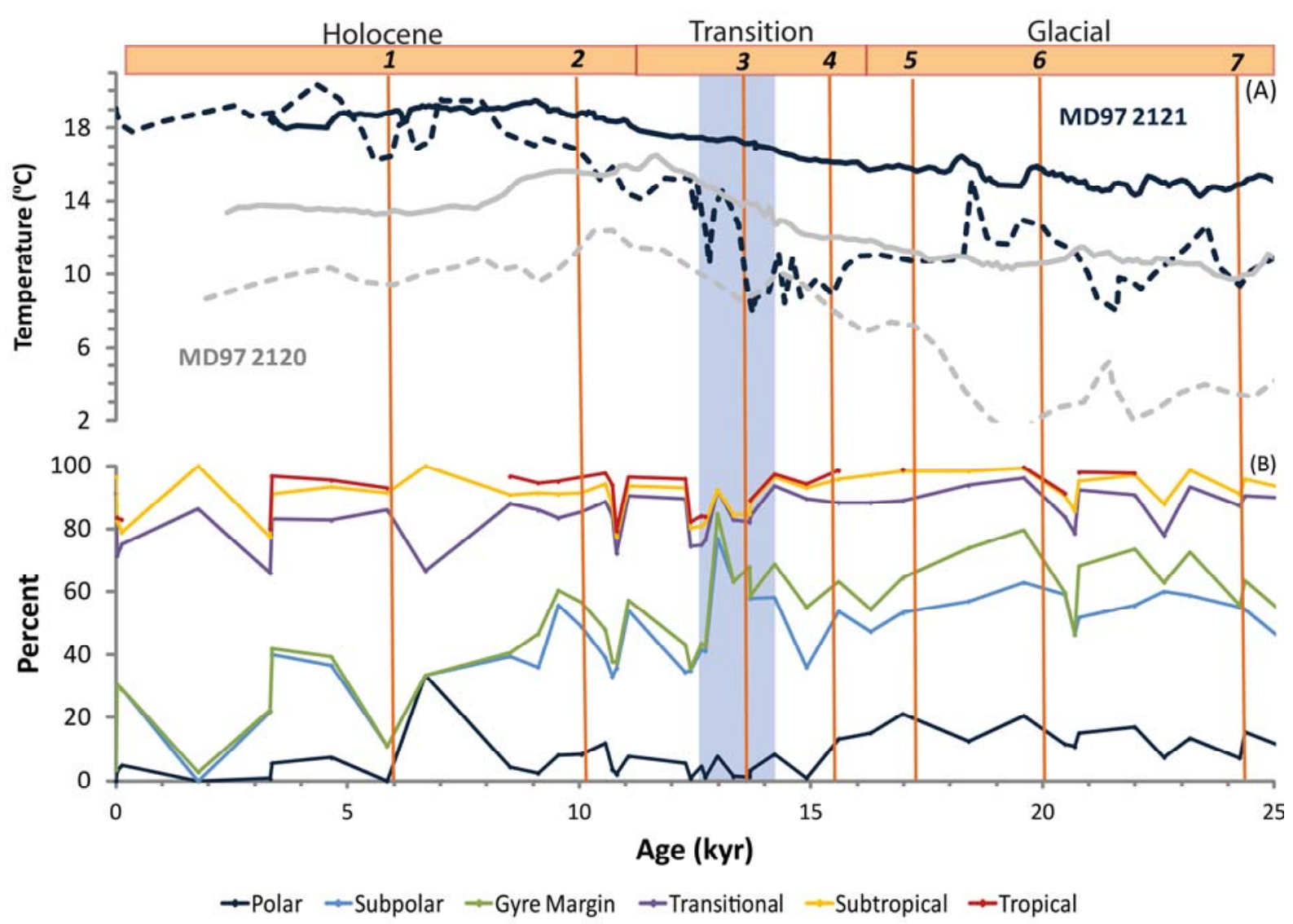

Figure 32. 25 ka-present faunal and paleotemperature records from MD97 2121 and MD97 2120. (a) paleotemperature data in blue derived from MD97 2121 alkenones-solid line (Pahnke and Sachs, 2006) and G. bulloides chamber $f-2$-dashed line $\mathrm{Mg} / \mathrm{Ca}$ (Marr et al., in press-b), and in grey MD97 2120 derived from alkenones-solid line and G. bulloides-dashed line (Pahnke et al., 2003) (b) foraminiferal assemblages of species with known environmental preferences (Imbrie and Kipp, 1973), based on samples of $>100$ individuals (Northcote et al., 2007). Geochemical data are presented using a three point moving mean for trend comparison. For consistency, the Sikes and Volkman (1993) calibration is used for alkenone data, and Marr et al. (2011) calibration for G. bulloides $\mathrm{Mg} / \mathrm{Ca}$. The Antarctic Cold Reversal (ACR) is indicated by the blue shaded bar. Vertical orange lines indicate the timing of the seven $1 \mathrm{~cm}$ core sections selected for further analysis via SEM and $\mathrm{x}$-ray imaging.

\subsection{Identification of alkenone producing coccolithophore species}

Both Gephyrocapsa spp. and E. huxleyi were able to be identified in SEM images (Fig. 30). During the glacial-interglacial period the total number of Gephyrocapsa spp. and E. huxleyi identified fluctuated depending on the amount of clay in the sample (which obscured lith view) and sample preservation (AI. 2). Gephyrocapsa spp. was typically identified in greater numbers than E. huxleyi, which likely reflects the wider range of species morphology included in this category (AI. 2). However during the transition period, including the ACR, E. 
huxleyi was absent from both 15.5 and $13.7 \mathrm{ka}$ samples despite a strong presence of Gephyrocapsa spp. (Fig. 31).

\subsection{Discussion}

Paleothermometry records derived from foraminiferal and coccolithophore based material can be affected by a number of issues; 1) transport or post-depositional alteration to the record after the organism has completed its lifecycle and the material is deposited in the sediment (e.g. Boyle, 1995; Mollenhauer et al., 2003; Pena et al., 2005), 2) the organisms' environmental preferences or niches (depth in the water column), and 3) the season of their peak productivity and thus highest flux to the sea floor (Northcote and Neil, 2005; Sikes et al., 2005).

\subsection{Alteration to samples following completion of its life cycle}

Previous work has shown that the carbonate proxy records from MD97 2121 have not been affected by post-depositional alteration/diagenesis (Carter et al., 2008; Marr et al., in press-b; Pahnke and Sachs, 2006; Weaver et al., 1998), as it sits above the modern calcite saturation horizon (Bostock et al., 2011), which would have only deepened during the glacial period (Marchitto et al., 2005). In addition, there was little change in the sediment flux to the seabed (Holocene $=30 \mathrm{~g} / \mathrm{cm}^{2} / \mathrm{kyr}$; Glacial $=37 \mathrm{~g} / \mathrm{cm}^{2} / \mathrm{kyr}$; Carter and Manighetti, 2006) and minimal bottom water currents in the region (Carter and Manighetti, 2006; Carter et al., 2002). Thus re-working and re-distribution of sediment is unlikely. Significant changes between glacial and interglacial sedimentary structures were also not identified in core x-ray images (AI. 3).

During the interglacial period the dominant inflow at the MD97 2121 site was from the north, while during the glacial period it was from the south (Marr et al., in press-b; Nelson et al., 2000). Transportation of the fine sediment size fraction had been previously highlighted as a source of error for alkenone thermometry (Mollenhauer et al., 2003; Ohkouchi et al., 2002). The alkenone-based glacial SSTs at MD97 2121 are $c a .15^{\circ} \mathrm{C}$, which is only $4{ }^{\circ} \mathrm{C}$ colder than those for the Holocene (Marr et al., in press-b; Pahnke and Sachs, 2006), however this is greater than proxy uncertainty $\pm 1.5^{\circ} \mathrm{C}$. Such temperatures would preclude alkenones being swept to the site from the south where alkenone based SSTs are ca. $8{ }^{\circ} \mathrm{C}$ during the glacial period(Pahnke et al., 2003). Such a preclusion is counter to the documented northward transport of SAW to MD97 2121 as supported by the presence of subpolar/polar foraminifera 
assemblages (Carter et al., 2008; Weaver et al., 1998) and to a lesser extent by the modern physical oceanography (e.g. Chiswell, 2000; Orpin et al., 2008). Therefore we believe that the most likely reasons for the differences between the two paleotemperature estimates in this core are due to changes in the foraminifera or coccolithophore ecological niche, or season of productivity.

\subsection{Change in the organisms' environmental preferences or niches}

Coccolithophore dependence on light for photosynthesis means that it is unlikely to significantly change its depth of maximum production between the glacial-Holocene periods (Nanninga and Tyrrell, 1996; Tyrrell and Merico, 2004). However, asymboint G. bulloides is not constrained by light limitation and therefore depth of greatest production may change. There is no direct evidence to indicate that $G$. bulloides productivity depth changed during the glacial period, or, that it remained stable. Inter-species $\mathrm{Mg} / \mathrm{Ca}$ and oxygen isotope records from MD97 2121 indicate that inter-species stratification was present during the glacial period with G. bulloides dwelling at lower depths than Globigerinoides ruber and higher than Globorotalia inflata, similar to the modern period (Carter et al., 2008; Marr et al., in press-a). However, it should be noted that during the ACR this inter-species stratification relationship changed as previously noted in Marr et al., (submitted a) and Carter et al., (2008), with little to no stratification present at times. As the temperature and environmental information derived from this species is consistent with our current understanding of the MD97 2121 region (e.g. Nelson et al., 2000; Weaver et al., 1998), there is little evidence to suggest any significant change in the G. bulloides habitat depth.

\subsection{Changes in the seasonality of productivity}

If alkenone and G. bulloides season's of maximum flux responded in a similar way to the glacial presence of SAW at MD97 2121, then based on modern conditions, it may be expected both species would bloom during spring. This would result in a consistent temperature offset between the paleothermometry records throughout the glacial-Holocene record. The change in alkenone and G. bulloides $\mathrm{Mg} / \mathrm{Ca}$ temperature offset between the

glacial and Holocene periods indicates that, 1) the species response to the changing environmental conditions were different, and 2) there were factors beyond a change in water mass properties which influenced species' ecology. As coccolithophore are photosynthesisers a change in glacial-Holocene light levels is likely to have been a significant additional factor, 
in addition to nutrient levels, and stratification, affecting the timing of species productivity and water column depth (e.g. Nanninga and Tyrrell, 1996).

In the modern ocean wind intensity at southern mid-latitudes affects regional upwelling and depth of the mixed layer, following a seasonal cycle; peaking during winter, subsiding during spring, before reaching a summer minima (Sallée et al., 2010b; Young, 1999). This seasonal wind cycle has a significant effect on the surface water stratification and upwelling and mixing (e.g. Pollard et al., 1972; Sallée et al., 2010a). In the Southern Ocean under modern conditions, maximum surface water stratification typically occurs during summer (Morris et al., 2001; Sallée et al., 2010b). Optimal bloom conditions for coccolithophore requires relatively stable surface water stratification, especially for species such as E. huxleyi (Tyrrell and Merico, 2004).

\subsubsection{Glacial-early deglacial (25-16 ka)}

During the glacial period, wind intensity increased (Shulmeister et al., 2004) and thus it is likely that this delayed the establishment of stable surface water stratification and thus coccolithophore blooms. At MD97 2121 well mixed winter surface water conditions prevailed at least until spring (Marr et al., in press-b) creating more turbid surface water conditions and filtering light levels. Thus, during the glacial period it is likely that coccolithophore peak productivity was restricted to summer when there was maximum surface ocean stratification and increased levels of light transmitted to the surface waters (Fig. 33). Asymbiotic G. bulloides, however, was likely able to maintain a spring bloom cycle, consistent with modern SAW (Fig. 32) (King and Howard, 2001; Northcote and Neil, 2005). This offset in seasonal bloom times likely contributed to $c a .3-4{ }^{\circ} \mathrm{C}$ of the total temperature offset between alkenone-G. bulloides paleotemperature estimates.

The increased wind intensity during the glacial period (Shulmeister et al., 2004) is also likely to have encouraged the upwelling of cooler, deeper Antarctic Intermediate and/or Subantarctic Mode Waters (AAIW/SAMW) over the Mernoo Saddle, in an intensification of the modern processes (Carter et al., 2000; Chiswell, 2000; Heath, 1975). Mixing with overlying SAW, the cooler upwelled waters may have contributed to the appearance of several polar planktic foraminiferal species in the MD97 2121 region, including Neogloboquadrina pachyderma, which formed up to $20 \%$ of the faunal abundance during the glacial period (Nelson et al., 2000; Northcote et al., 2007; Weaver et al., 1998). Thus, if G. 
bulloides maintained a spring bloom cycle it is likely that temperature estimates would be further cooled due to this upwelling phenomenon by at least another $2{ }^{\circ} \mathrm{C}$ (Sutton, 2003).

South of the STF at MD97 2120, glacial period G. bulloides-Mg/Ca and alkenone temperature offsets were also larger during the glacial period, similar to MD97 2121 (Pahnke et al., 2003). However, between 25-18 ka, temperature offsets at MD97 2120 averaged 7-8 ${ }^{\circ} \mathrm{C}$, greater than that of MD97 2121, narrowing to a 3-4 ${ }^{\circ} \mathrm{C}$ offset during the Holocene. The difference in alkenone-G. bulloides- $\mathrm{Mg} / \mathrm{Ca}$ temperature relationship between the sites indicates that there are likely to be different factors affecting the MD97 2120 region (Fig. 32).

Compounding factors during the glacial period at MD97 2120 for alkenone-G. bulloides$\mathrm{Mg} / \mathrm{Ca}$ temperature offsets include, 1) the poor performance of the alkenone paleothermometer at temperatures at or below $6{ }^{\circ} \mathrm{C}$ (Sikes et al., 1997), which depending on which temperature calibration is used, surface ocean temperatures at the MD97 2120 may have been close to this threshold (Pahnke and Sachs, 2006); 2) The influx of very cold CSW into the Bounty Trough with more intense winds, changes in the SAF and intensification of the ACC around Campbell Plateau (Hayward et al., 2008; Neil et al., 2004), significantly lowering $G$. bulloides temperatures, also taking them outside the calibrated range of the $G$. bulloides Mg/Ca paleothermometer(s) (Fig. 32) (Anand et al., 2003; Hayward et al., 2008; Marr et al., 2011). We suggest the seasons of maximum flux during the glacial period at MD97 2120 are similar to MD97 2121, with alkenones during the summer and G. bulloides in the spring, due to similar insolation and seasonality in surface water mixing conditions (Berger and Loutre, 1992; Sallée et al., 2010b; Shulmeister et al., 2004).

\subsection{Deglacial (16-11 ka)}

During the transition from glacial to Holocene conditions there was significant variability in surface water temperature recorded by both G. bulloides and G. ruber $\mathrm{Mg} / \mathrm{Ca}$ which are absent from the alkenone record (Fig. 32). (Marr et al., in press-b; Pahnke and Sachs, 2006). The difference between G. bulloides and alkenone paleotemperature records during this period is up to $10{ }^{\circ} \mathrm{C}$ (Fig. 32), which is greater than the proxy associated uncertainity of $\pm 1.5^{\circ} \mathrm{C}$. Such a difference cannot be accounted for solely by species seasonality or regional upwelling, thus they are likely to be other contributing factors. It is known that SSTs during this period reflected the dynamic interplay between SAW and STW as the region shifted from glacial-SAW dominated to interglacial-STW dominated conditions (Carter et al., 2008; Marr et al., in press-b; Nelson et al., 2000; Northcote et al., 2007). 


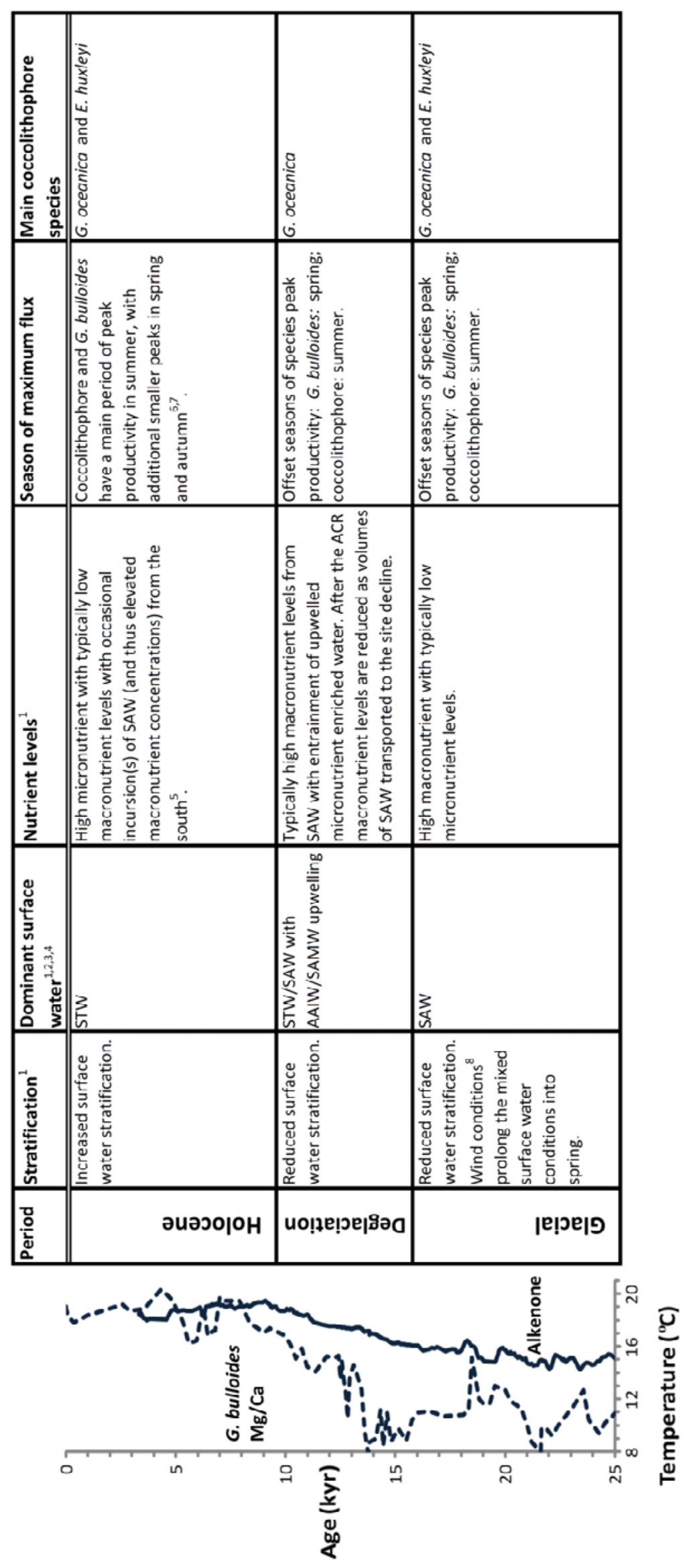


Figure 33. Summary of surface water stratification, nutrient, seasonality, and species changes from $25 \mathrm{ka}$ present. ${ }^{1}$ Marr et al., (in press-b); ${ }^{2}$ Nelson et al., (2000); ${ }^{3}$ Weaver et al., (1998); ${ }^{4}$ Carter et al., (2008); ${ }^{5}$ Boyd et al., (1999); ${ }^{6}$ King and Howard, (2001); ${ }^{7}$ Sikes et al. (2005); ${ }^{8}$ Shulmeister et al., (2004); ${ }^{9}$ Northcote and Neil (2005).

During the glacial-Holocene transitional SAW flow through Mernoo saddle is likely to have increased initially as sea level rose, reducing the bathymetric constraints. However, at $c a .14$ ka the glacial land bridge between the New Zealand North and South islands opened, swamping the region with STW (Carter et al., 2000). While clearly evident in the $G$. bulloides $\mathrm{Mg} / \mathrm{Ca}$ record, neither of these events are captured in the alkenone record. This suggests that there may have been other factors which affected the MD97 2121 alkenone record during this time, which in effect acted to smooth out the dynamic glacial-Holocene changes in this region (Fig. 32) (Pahnke and Sachs, 2006). SEM imaging of the $<40 \mu \mathrm{m}$ size fraction of the sediment revealed that a change in the alkenone-producing coccolithophore species also occurred during the transition period. Whereas Gephyrocapsa spp. and E. huxleyi were typically present throughout the glacial-interglacial period, the two samples taken immediately preceding and during the Antarctic Cold Reversal, revealed that E. huxleyi may have been absent (Fig. 31).

Reasons for the absence of the 'cosmopolitan' E. huxleyi are unknown, as they are typically identified throughout the modern surface waters north and south of the STF (Rhodes et al., 1995). Previously, G. oceanica blooms were observed in Jervis Bay, Australia, after eddy induced continental slope water upwelling increased nutrient supply (Blackburn and Cresswell, 1993). Northern sourced AAIW currently bathes the continental slope adjacent to core site MD97 2121, similar to that in the Jervis Bay region (Bostock et al., 2013; Chiswell, 2000; Stanton, 2002). Thus, it is possible that a shift in the wind (and/or eddy regime) to favour the regional upwelling of AAIW (Chiswell, 2002b) during the ACR may have favoured a similar dominance of large-scale, monospecific G. oceanica blooms, whilst the cool water upwelling resulted in depressed G. bulloides temperatures (Fig. 33, Fig. 32) (Weaver et al., 1998). Furthermore, the lack of surface water stratification (Marr et al., in press-b) during this transition period is likely to have further inhibited the growth of $E$. huxleyi (Nanninga and Tyrrell, 1996; Tyrrell and Merico, 2004). Thus neither the Sikes and Volkman (1993) nor Prahl et al. (1988) alkenone calibrations may be appropriate for this 
interval and application of these calibrations may have contributed to the apparently muted alkenone temperature record.

During the deglacial period (16-13.5 ka) the G. bulloides $\mathrm{Mg} / \mathrm{Ca}$ temperatures from MD97 2121 and MD97 2120 converge following a period of sustained warming as indicated by $G$. bulloides at MD97 2120 from ca. 19-16 ka (Fig. 32). The increase in G. bulloides temperature at MD97 2120 is likely a reflection of reduced CSW inflow to the region (Hayward et al., 2008). This is consistent with nearby DSDP 594 faunal assemblage records which also indicate the diminished presence of polar planktic species (Neogloboquadrina pachyderma (s), and Globigerina quinqueloba) (Nelson et al., 1993). After the reduction of CSW inflow it is likely that a very similar mix of SAW and AAIW/SAMW bathed both the MD97 2121 and MD97 2120 sites, causing the G. bulloides temperatures to converge (Fig. $32)$.

\subsection{Holocene (ca. 11 ka-present)}

Throughout the Holocene and in the modern ocean, STW has dominated surface waters above MD97 2121 (Marr et al., in press-b; Nelson et al., 2000). Under Holocene conditions, deeper surface water stratification at MD97 2121 relative to the glacial period allowed increased light penetration (Marr et al., in press-b). Coupled with higher summer insolation and influx of micro-nutrient rich STW, coccolithophore are able to bloom multiple times throughout the year similar to modern G. bulloides flux(s) (Sikes et al., 2005). As a result, the temperature relationship between alkenone and G. bulloides paleothermometry records is largely consistent from $\mathrm{ca}$. $11 \mathrm{ka}$ to present bearing in mind $\pm 1.5{ }^{\circ} \mathrm{C}$ errors for the two proxies.

In the early Holocene alkenone temperatures from both MD97 2121 and MD97 2120 converge ca. 12.5-11 ka, suggesting an increased influence of STW at both sites (Fig. 32). The increased volume of STW is consistent with a peak in the faunal abundance of G. ruber at MD97 2121 (Northcote et al., 2007). The increased volume of STW and thus micronutrient concentrations at MD97 2120 may have also influenced the seasonality of peak alkenone productivity in the region, bringing the alkenone temperatures closer to MD97 2121. Thus, in the early Holocene due to the STW influence alkenone temperatures at MD97 2120 were recording an annual average temperature which was warmer than in the mid-late Holocene. 
The mid-late Holocene (ca. 9-3 ka) 3-4 ${ }^{\circ} \mathrm{C}$ offset between alkenone and G. bulloides temperature estimates at MD97 2120 suggests a sustained seasonal offset in peak flux, however this is contradictory to modern observations of similar seasons of alkenone- $G$. bulloides peak flux in SAW (Fig. 29) (King and Howard, 2001; Sikes et al., 2005). Modern stratified plankton tow records also do not indicate that G. bulloides dwell significantly deeper in MD97 2120 region (NIWA, Cruise Report TAN 0103, unpublished report, 2001). Therefore, why there appears to be a clear discrepancy between modern observed and seasonality inferred from the MD97 2120 Holocene temperature records is unknown. However, the apparently clear changes in alkenone seasonal flux between the glacial and Holocene periods does suggest that it may be appropriate to alternate the use of the Sikes and Volkman (1993) and Prahl et al. (1988) calibrations within paleocean records depending on the dominant timing of regional seasonal alkenone production, or new calibrations are required.

\subsection{Conclusions}

Understanding how environmental changes affect species ecology is vital for an improved interpretation of the paleotemperature record. At site MD97 2121 the relationship between alkenone and $\mathrm{Mg} / \mathrm{Ca}$ G. bulloides derived paleotemperatures changed over the last $25 \mathrm{ka}$. Glacial temperature estimate offsets of $c a .3-7^{\circ} \mathrm{C}$ are all but eliminated during the Holocene, suggesting that the planktic species' ecology and the local hydrology changed. We suggest the organisms' season of maximum productivity, and thus the annual timing of the temperature records, changed between glacial-interglacial periods. This was in response to variations in surface water conditions with SAW dominating the region during the glacial period and STW during the Holocene. Glacial-Holocene environmental changes such as wind and light conditions also altered surface water stratification and insolation levels. As a consequence of the change in the environmental conditions and changes in the surface waters, alkenone production at MD97 2121 shifted from glacial-summer to Holocene-annual and $G$. bulloides from glacial-spring to Holocene-annual productivity peak. For surface dwelling coccolithophore, changes to the season of maximum production had a significant impact on the associated paleotemperature record, offsetting glacial temperature estimates toward warmer values and dampening the apparent glacial-interglacial temperature change. However, G. bulloides is a sub-surface species and thus the (limited) effect of seasonality productivity 
changes on the paleotemperature records was unable to be resolved within the errors associated with $\mathrm{Mg} / \mathrm{Ca}$ paleothermometry, and therefore more likely affected by regional upwelling. The findings of the study suggest that paleotemperature records from regions where a change in surface water mass are likely to have occurred between glacial-interglacial periods should be carefully assessed. 


\section{Auxiliary Information}

AI 1.0. Difference in alkenone based temperature estimates from $25 \mathrm{ka}$-present at MD97 2121-blue and MD97 2120-grey using two different temperature calibrations.

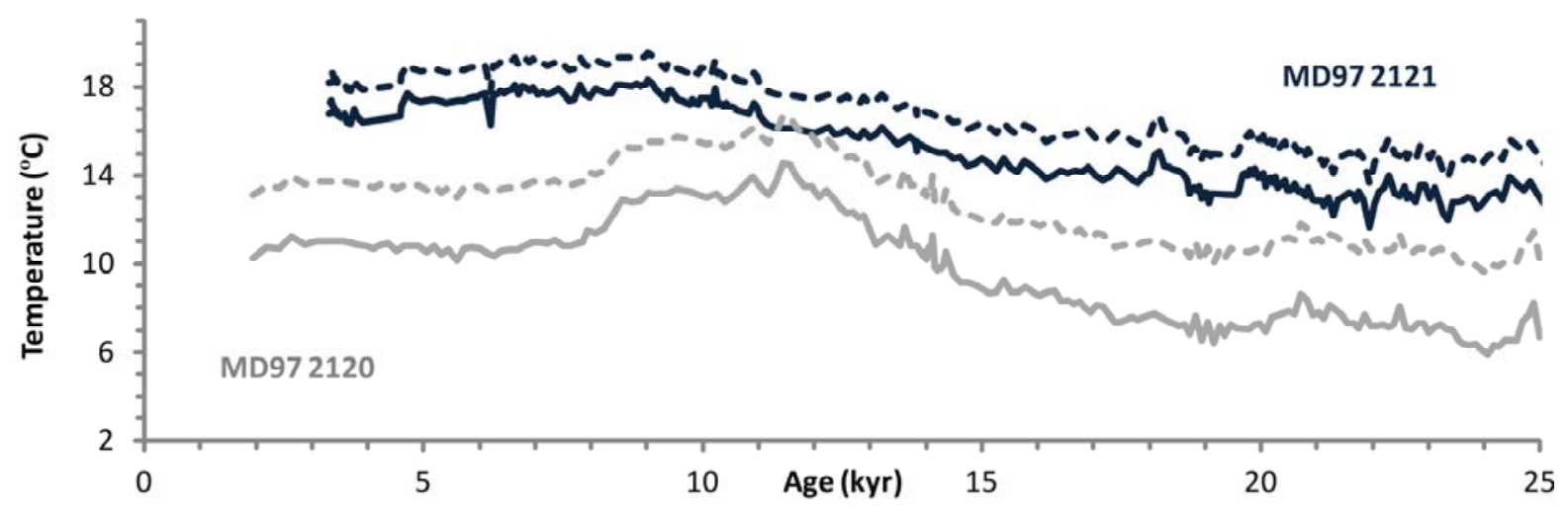

C4-AI. Fig. 1. Difference in alkenone based temperature estimates from 25ka-present at MD97 2121-blue (Pahnke and Sachs, 2006) and MD97 2120-grey (Sachs et al., 2003) using two different temperature calibrations. The global derived Prahl et al. (1988) is indicated by the dashed line and regionally derived Sikes and Volkman (1993) by the solid line. Note, the calibration error of $\pm 1.5^{\circ} \mathrm{C}$ is only exceeded at MD97 2121 during the glacial period, with a mean offset $1.7^{\circ} \mathrm{C}$ towards cooler temperatures using the Prahl et al. (1988) calibration. 
AI 2.0. Total number of Gephyrocapsa spp. and E. huxleyi identified in SEM images.

\begin{tabular}{|c|c|c|c|c|c|c|c|}
\hline & \multicolumn{3}{|c|}{ Glacial } & \multicolumn{2}{|c|}{ Termination (ACR) } & \multicolumn{2}{|c|}{ Interglacial } \\
\hline & \multicolumn{7}{|c|}{ Depth $(m)$} \\
\hline & $9.01-9.02$ & 7.21-7.22 & 6.10-6.11 & 5.60-5.61 & 5.04-5.05 & $3.79-3.80$ & $2.10-2.11$ \\
\hline & \multicolumn{7}{|c|}{ Age (ka) } \\
\hline Species & 24.3 & 20.0 & 17.2 & 15.5 & 13.7 & 10.5 & 6.0 \\
\hline Coccolithus palagicus & 9 & 4 & 7 & 17 & 15 & 7 & 1 \\
\hline Calcidiscus leptoporus & 25 & 13 & 12 & 7 & & 1 & 8 \\
\hline Gephyrocapsa spp. & 22 & 27 & 43 & 37 & 5 & 19 & 1 \\
\hline Emiliania huxleyi & 24 & 9 & 19 & & & 9 & 1 \\
\hline Umbilicosphaera & 1 & 2 & 4 & 1 & & & \\
\hline Helicosphaera carteri & & 1 & & 1 & 1 & 1 & \\
\hline Oolithotus antillarum & & & & 1 & & & \\
\hline Total identified & 81 & 56 & 85 & 64 & 21 & 37 & 11 \\
\hline
\end{tabular}

C4-AI. Fig. 2. Total number of Gephyrocapsa spp. and E. huxleyi identified in SEM images of MD97 2121 samples. 
AI 2.0. Core $X$-Ray imaging

X-radiographs of longitudinally split sediment cores, approximately $5.75 \mathrm{~cm}$ max thickness, were made using a Varian PaxScan 4030E flat panel digital imaging system and an Ecotron EPX-F2800 portable veterinary X-ray generator at NIWA, Wellington (C4-AI. Fig. 3). Exposures were compensated on the core edges by placing the half-core into a milled PVC cradle, ensuring consistent cross-sectional thickness. Exposure, grey-level mapping and window/level were controlled via proprietary Varian software (ViVA 2.0, Revision L.04), and typical energy settings for this study were [60] kV and [20] $\mathrm{mA}$. The X-radiographs are displayed herein as negatives; low densities in dark shades and the highest density as white, and the area outside the core of zero density as black.

X-ray images help identify features from density differences, which cannot be seen by visual examination. In addition, these images help identify bioturbation structures especially where different lithologies are involved, e.g. if a burrow fill is different from the ambient sediment. Where the core appears featureless, this may indicate that only one lithology is dominant, or there has been significant bioturbation which has homogenised the sediment (e.g. Pouderoux et al., 2012). 


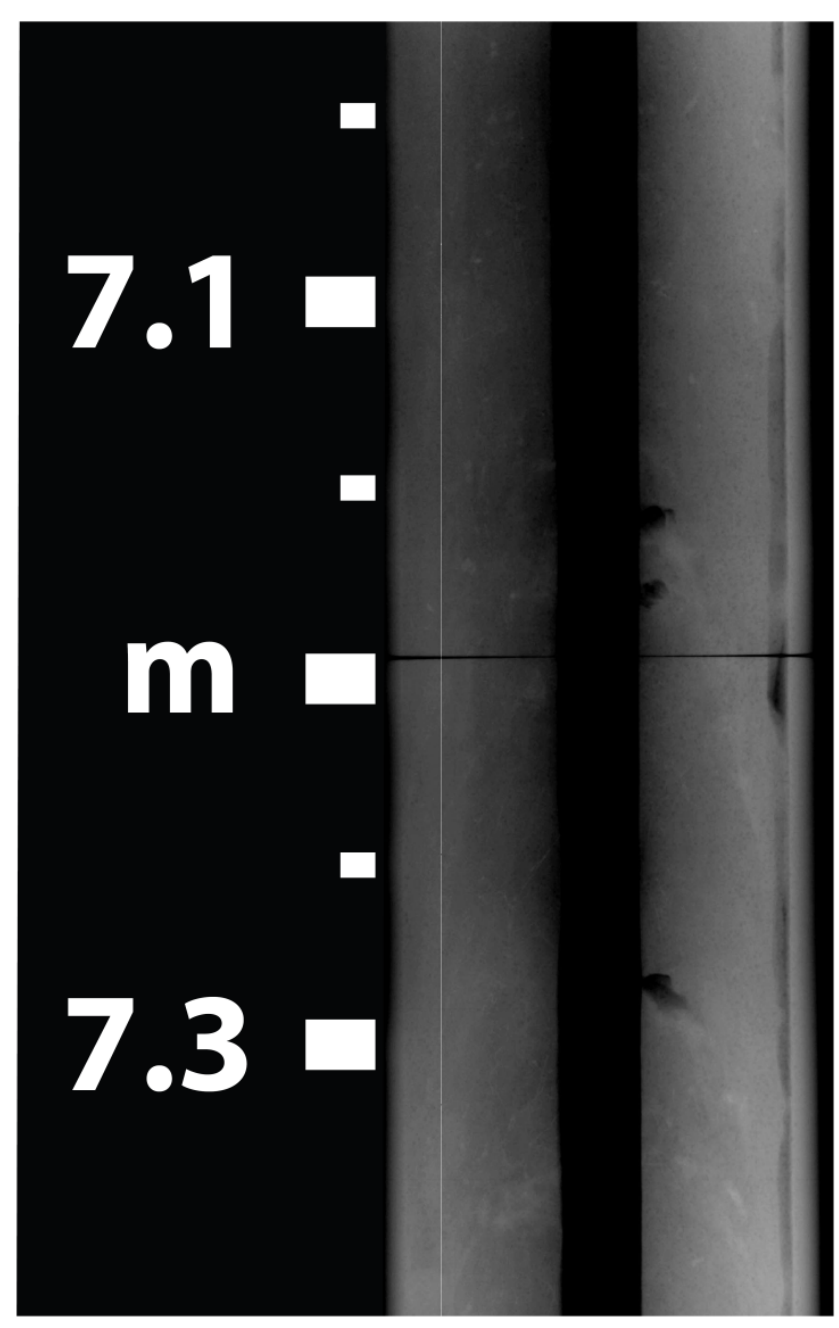

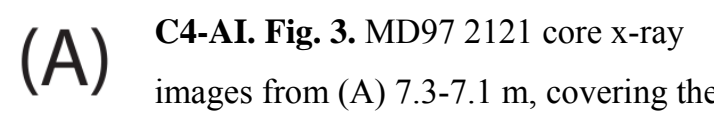
7.2-7.21 $\mathrm{m}$ or $20.0 \mathrm{ka}$ interval, (B) 9.09.2 m, covering the $9.01-9.02 \mathrm{~m}$ or 24.3 ka interval. X-ray images of the MD97 2121 sediment core were largely featureless possibly reflecting limited bioturbation and the high volume of terrigenous material deposited at this site (Carter et al., 2002). However, two sections from 20.0 and $24.3 \mathrm{ka}$ had visible burrows.

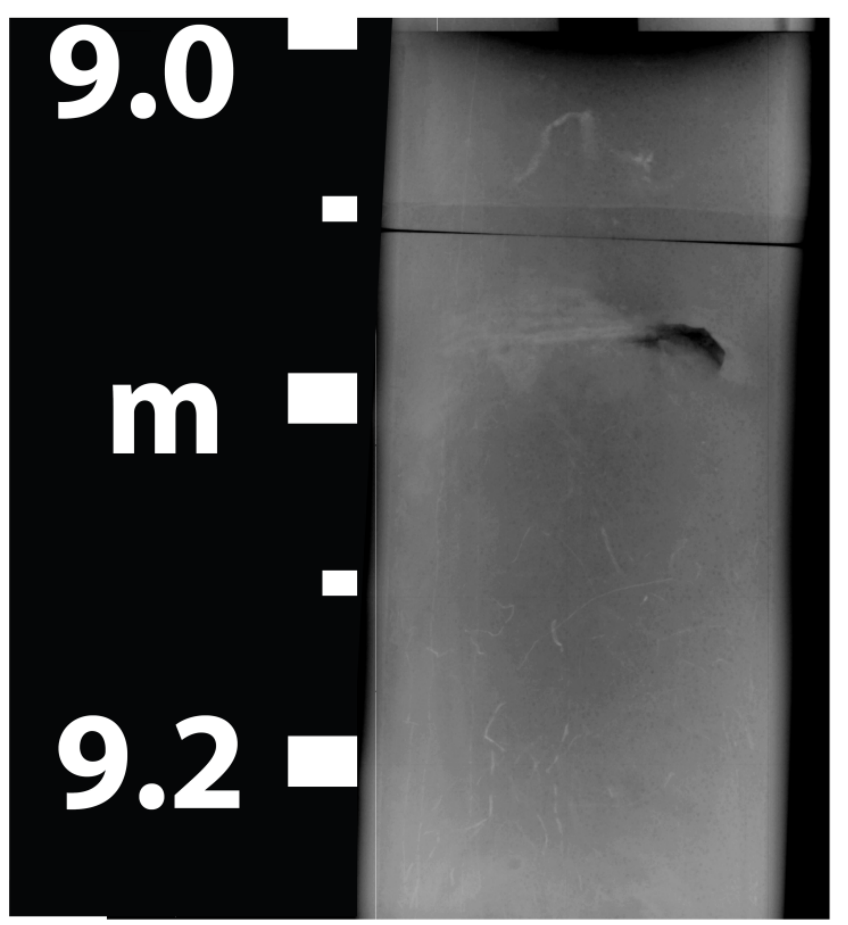

(B) 
Chapter 5 


\section{WEIGHING IN: ARE SIZE-NORMALISED FORAMINIFERA WEIGHTS A PROXY FOR SURFACE WATER CARBONATE ION CONCENTRATIONS?}

Marr, J. P., H. C. Bostock, L. Carter and E. Smith, in review. Weighing in: are sizenormalised foraminifera weights a proxy for surface water carbonate ion concentrations? Marine Micropaleontology.

\section{Author Contributions:}

Julene Marr; data collection/collation, interpretation, manuscript writing, Lionel Carter, Helen Bostock; general supervision

Euan Smith; assistance with statistical analysis and interpretation.

\section{Abstract}

Studies in the North Atlantic have suggested that higher calcium carbonate ion concentrations $\left(\left[\mathrm{CO}_{3}{ }^{-}\right]\right)$are the primary cause of increased calcification of the planktic foraminifer, Globigerina bulloides. However, G. bulloides in the Southern Ocean calcify heavier shells, in a region which has low surface water $\left[\mathrm{CO}_{3}{ }^{-}\right]$relative to the North Atlantic. Such ocean differences have been largely overlooked. Here we assess differences in calcification, as expressed by shell size normalised weight (SNW), of modern G. bulloides shells from five ocean regions. Comparison of trends between different modern water masses showed no consistent relationship between any single environmental factor and shell calcification. Instead linear models suggest that SNW responds to an "ocean effect," that is a combination of various environmental variables such as temperature, nutrients, or $\left[\mathrm{CO}_{3}{ }^{-}\right]$. The differences between the oceans/regions appear to be consistent with previously identified spatial patterns of genetic variability. Comparison of environmental proxy and SNW data from the last glacial maximum to the Holocene from the North Atlantic and SW Pacific Oceans confirms that at mid-latitudes, regardless of ocean region, G. bulloides shell SNW increased during the glacial period. We suggest that this may reflect multiple factors including increased surface 
ocean $\left[\mathrm{CO}_{3}{ }^{=}\right]$, possibly combined with changes in primary productivity. There is no apparent relationship in the SW Pacific between G. bulloides SNW and down core productivity or G. bulloides abundance. We conclude that calcification of $G$. bulloides appears to be region specific; therefore, proxy calibrations based on shell SNW for one ocean will not be applicable to other settings.

\subsection{Introduction}

Carbonate-bearing marine organisms play a critical role in the global carbon cycle, transferring carbon dioxide from the atmosphere and depositing it as calcium carbonate $\left(\mathrm{CaCO}_{3}\right)$ on the sea floor (Archer and Maier-Reimer, 1994; Broecker and Clark, 2002; Milliman, 1993). A significant reduction in this carbon removal mechanism through ocean acidification and reduced shell calcification would likely have a large impact on the global carbon cycle. However, to strengthen the link between atmospheric carbon dioxide levels and shell calcification requires a greater understanding of the controls of modern calcification in order to interpret changes in the past (Caldeira and Wickett, 2003). The notion that surface water carbonate ion concentration $\left(\left[\mathrm{CO}_{3}{ }^{-}\right]\right)$controls planktic foraminiferal shell weight, derives from the idea that additional ions in the surface water are likely to reduce the energy required for, and thus increase the rate of calcification (Barker and Elderfield, 2002; Lohmann, 1995).

Previous studies have generally focused either on a single oceanic region, weighing and measuring G. bulloides shells on samples derived from core-top, down core, sediment trap, plankton tow, or on laboratory cultured material. They have then linked the shell weight or size normalised weight (SNW) to changes in a variety of environmental variables including, species optimal environment (e.g. de Villiers, 2004; Hecht, 1976), temperature (e.g. Lombard et al., 2009), $\left[\mathrm{CO}_{3}{ }^{-}\right]$(e.g. Barker and Elderfield, 2002; Spero et al., 1997) and nutrient concentration (Aldridge et al., 2012).

In this study we combine previously published data from 5 different ocean regions to see if any one environmental variable can explain the changes in SNW. We then compare down core data from the North Atlantic (Barker et al., 2002) and SW Pacific to see if past changes can provide more information about what causes the changes in SNW. 


\subsection{Background}

\subsection{G. bulloides}

Globigerina bulloides is generally described as most productive at warmer temperatures (10$18^{\circ} \mathrm{C}$ ) with higher salinity, and lower nutrient levels (Bé, 1977; Bé and Hutson, 1977; Hemleben et al., 1989). It is also associated with weak and shallow thermocline environments with highest faunal abundances in subtropical waters (Bé, 1977; Bé and Hutson, 1977; Hemleben et al., 1989). This species has no symbiotic algae, being a heterotroph that feeds off phyto- and other zooplankton (Hemleben et al., 1989).

\subsection{Shell calcification}

In foraminifera, the shell's function is to protect the organism, and in the case of spinose species, such as G. bulloides, the shell also serves as base for the spines (Erez, 2003). The spines then allow for the construction of a wide pseudopodial "spider web" to help catch algal prey, move, build their shell, respire and extract waste (Hemleben et al., 1989). Thus, maintenance of these networks is especially critical for planktic species such as G. bulloides which dwells in turbulent, shallow water (ter Kuile and Erez, 1984).

There is a large discrepancy between $\left[\mathrm{Ca}^{2+}\right]$ and $\left[\mathrm{CO}_{3}{ }^{-}\right]$, in seawater. In the modern ocean $\left[\mathrm{Ca}^{2+}\right]$ is between 10 and $11 \mathrm{mM}$ while $\left[\mathrm{CO}_{3}{ }^{-}\right]$is only $100-300 \mu \mathrm{M}, c a .50$ times lower then $\left[\mathrm{Ca}^{2+}\right]$ (Tyrrell and Zeebe, 2004). Thus, it is $\left[\mathrm{CO}_{3}{ }^{-}\right]$and not $\left[\mathrm{Ca}^{2+}\right]$ which is the limiting factor for $\mathrm{CaCO}_{3}$ precipitation (Erez, 2003). Foraminifera also raise their internal $\mathrm{pH}$ to $c a .8 .5$ to 9 to increase the internal $\left[\mathrm{CO}_{3}{ }^{-}\right]$levels (de Nooijer et al., 2009; Erez, 2003). This provides enough $\left[\mathrm{CO}_{3}{ }^{-}\right]$to match the amount of $\left[\mathrm{Ca}^{2+}\right]$ in the seawater vacuoles.

\subsection{Regional SW Pacific setting}

The giant piston core, MD97 2121, was recovered off the east coast of New Zealand, in the SW Pacific Ocean $\left(40^{\circ} 22.935^{\prime}\right.$ S, $\left.177^{\circ} 59.68^{\prime} \mathrm{E}\right)$ from a water depth of $2314 \mathrm{~m}$ (Carter et al., 2002; Carter et al., 2008) (Fig. 34). The modern site is overlain by warm, saline, micronutrient-rich, macronutrient-poor subtropical surface waters (STW) (Boyd et al., 1999; Ellwood et al., 2008; Frew et al., 2001; Locarnini et al., 2006). During the LGM, cold, less saline, micronutrient-poor, macronutrient-rich subantarctic water (SAW) from the south (Boyd et al., 1999; Ellwood et al., 2008; Frew et al., 2001; Locarnini et al., 2006) flowed north over the core site (Marr et al., in press-b; Nelson et al., 2000). 

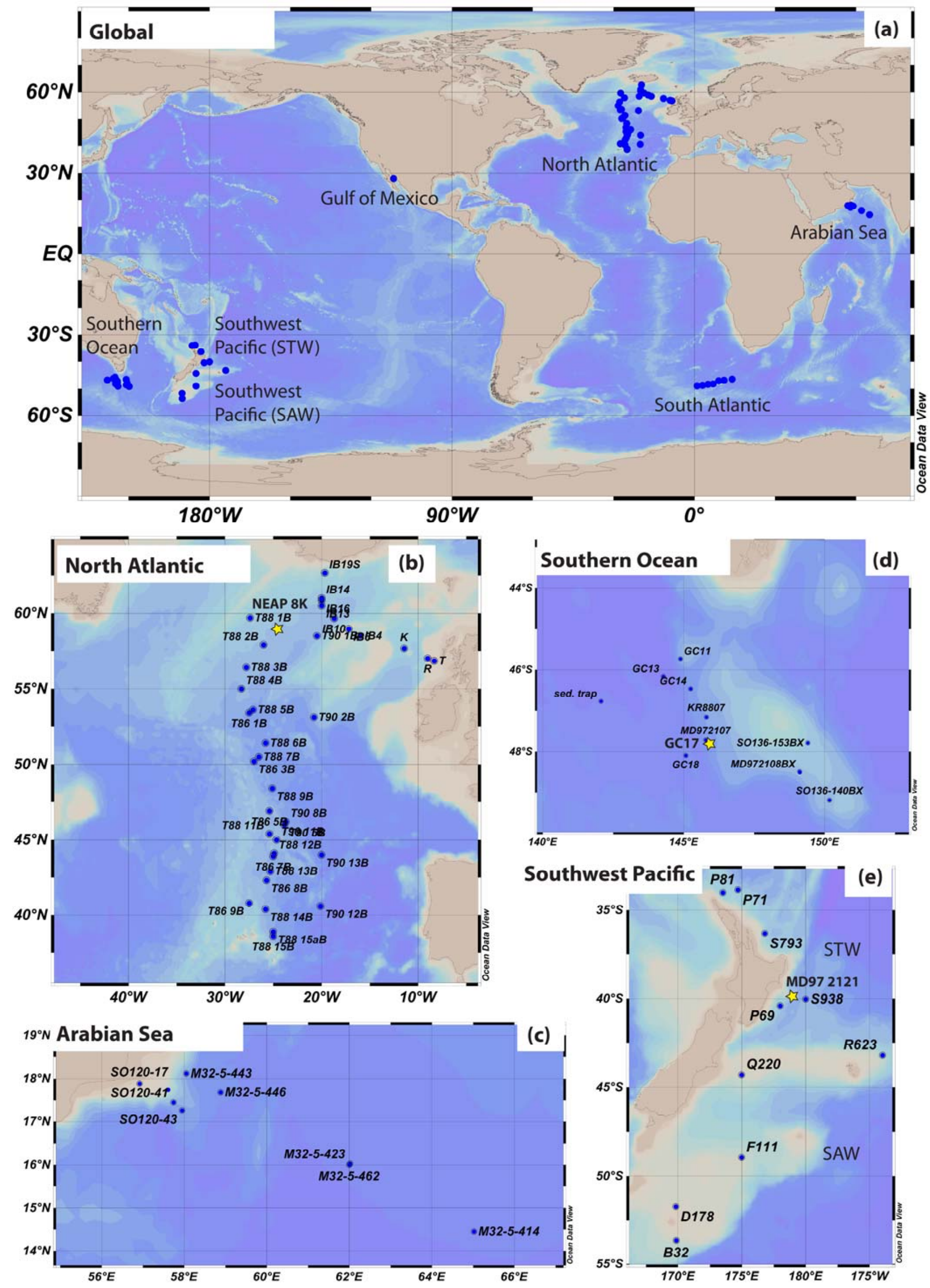
Figure 34. Global (a) location map of core-top, plankton tow, sediment trap and down core locations referred to in this study. Regional maps are provided for sites used in linear regression models: (b) North Atlantic: Barker and Elderfield (2002b); Aldridge et al. (2012); (c) Arabian Sea: Beer et al. (2010b); (d) SW Pacific: this study and Marr et al. (2011); (e) Southern Ocean: Moy et al. (2009). Note, individual core site longitudes were not provided for South Atlantic sites, thus for illustrative purposes only core sites have been evenly spaced within the stated $14^{\circ}$ range at their given latitudes (figures generated using Schlitzer, 2011). Stars indicate the location of down core sites referred to in text.

At $2314 \mathrm{~m}$ depth, the core site is situated above the modern day calcite saturation horizon which in the SW Pacific Ocean lies at $2800 \mathrm{~m}$ depth (Bostock et al., 2011). The site is bathed by low- $\delta^{13} \mathrm{C}$, oxygen, macronutrient-rich North Pacific Deep Water (NPDW) (Broecker and Maier-Reimer, 1992; McCave et al., 2008). During the glacial period, MD97 2121 was bathed in upper Circumpolar Deep Water (UCDW) of similar origin and nutrient content to NPDW (Gordon, 1975; McCave et al., 2008). While the change in bottom water mass may potentially enhance post-depositional alteration at MD97 2121, there is little evidence by way of fragmentation indices to suggest that foraminifera preservation was adversely affected by the change in bottom water during the glacial (Northcote et al., 2007; Weaver et al., 1998).

\subsection{Data and Methods}

We combine the results from previous studies using core-top and plankton-tow data from the North Atlantic (Aldridge et al., 2012; Barker and Elderfield, 2002) and South Atlantic (de Villiers, 2004), Southern Ocean (Moy et al., 2009), SW Pacific Ocean (Marr et al., 2011) and Arabian Sea (Beer et al., 2010b), as well as culturing studies (Lombard et al., 2010; Lombard et al., 2009). The core-top, sediment trap and plankton tow data collated here cover a range of environmental gradients including mean annual sea-surface temperature (SST) ranges from ca. 5 to $28{ }^{\circ} \mathrm{C}$ (Locarnini et al., 2010), surface water $\left[\mathrm{CO}_{3}{ }^{-}\right]$from ca. 120 to $250 \mu \mathrm{mol} / \mathrm{kg}$, nutrient phosphate and nitrate concentrations from ca. 0.1-2.3 $\mu \mathrm{mol} / \mathrm{L}$ and $0.01-18 \mu \mathrm{mol} / \mathrm{L}$ respectively (Garcia et al., 2010), and six of the seven genotypes (genetic variations within the same species) recognised for G. bulloides by Darling and Wade (2008).

New down core G. bulloides SNW data were generated from core MD97 2121 for the last 25 ka. Systematic samplings at ca. $12 \mathrm{~cm}$ intervals of the upper $9.15 \mathrm{~m}$ of the core were made. Measured shell weights, and lengths (diameter) for the planktonic foraminiferal species $G$. bulloides were determined for all samples. The species $G$. bulloides was selected as it was 
continuously present throughout the Late Pleistocene and thus able to be compared to previous core-top, plankton tow and down core studies in other regions (e.g. Aldridge et al., 2012; Barker and Elderfield, 2002; de Villiers, 2004). Shell-weight values presented for MD97 2121 represent the mean specimen weight based on a sample size of 10-32 specimens from a size range of 250-400 $\mu \mathrm{m}$, avoiding ones with kummerform chambers. All foraminiferal shells were cleaned to removing loosely adhering clay and other detrital material via 2-3 ultrasonication rinses for $2-3 \mathrm{~s}$ in $>18.2 \mathrm{M} \Omega$ ultra-clean water, followed by two AR-grade methanol rinses. Samples were subsequently examined under a binocular microscope and any individuals with visible adhering material were treated to a further one or two ultrasonic cycles in $\mathrm{M} \Omega$ ultra-clean water. Foraminifera were then dried in an oven at 40 ${ }^{\circ} \mathrm{C}$ for $24 \mathrm{hr}$. Any shells broken during the cleaning process were discarded. Shells were then batch weighed using a Mettler Toledo (MX/UMX 2) ultramicro-balance (precision=0.1 $\mu \mathrm{g}$ ). Analytical uncertainty on these weight measurements is $< \pm 5 \%$ ( 2 sd relative) based upon 15 replicate measurements of a single G. bulloides shell weighing $8.7 \mu \mathrm{g}$. Foraminifera lengths were then individually measured prior to laser ablation using the laser ablation systems optical microscopy.

The same foraminifera samples used for weighing were analysed for their $\mathrm{Mg} / \mathrm{Ca}$ values using a New Wave deep-UV (193 nm) solid-state laser ablation system coupled to an Agilent 7500CS ICP-MS at Victoria University of Wellington. The anti-penultimate $(f-2)$ chamber of G. bulloides was analysed as chamber $f-2$ generally shows better within-chamber reproducibility than older $f-3$ or younger $f-1$ chambers (Marr et al., 2011; Marr et al., in pressa).

\subsection{Size normalisation}

Shell weights used in this study were normalised to shell size (maximum diameter) so that the results may be compared between ocean regions. Previously it has been shown that the use of shell area or length does not make a significant difference to normalisation data with an $\mathrm{r}^{2}$ correlation of $>0.95$ (Aldridge et al., 2012; Barker, 2002b; Beer et al., 2010a; Beer et al., 2010b). However, the method of shell weight 'size normalisation' has varied between studies,

typically concluding with multiplication of the final value by an arbitrary amount, normally the average shell size of a number of foraminifera from the region (e.g. Aldridge et al., 2012; Barker, 2002b). In addition, some studies which measured shell weights elected not to 
measure shell size, instead choosing to confine sample selection to a narrow sieved size range instead (e.g. Moy et al., 2009). Issues associated with sieving foraminifera are fully discussed in Beer et al. (2010a), with the primary problem being that sieving alone does not always guarantee a narrow size range due to the irregular shape of the foraminifera.

In cases where measured shell lengths are not available, the sieved size range midpoint has been used for size normalisation so the data may be compared to other sites. As the samples used in this study were from a number of regions, and data for foraminiferal surface area not available for all samples, the simplest approach to size normalisation has been applied. Shell weight measured in micrograms was divided by the shell length or midpoint of the sieved size range measured in microns and the final result given in $\mathrm{g} / \mathrm{m}$. SW Pacific individual core top weight and length measurements of G. bulloides from STW $(n=13)$ and SAW $(n=18)$ samples indicate that the $95 \%$ confidence intervals for a sample weight/length measurements based on the mean values are: $0.020 \mathrm{~g} / \mathrm{m} \pm 0.003 \mathrm{~g} / \mathrm{m}(\mathrm{STW})$, or $0.045 \mathrm{~g} / \mathrm{m} \pm 0.007 \mathrm{~g} / \mathrm{m}$ (SAW).

\subsection{Modern oceanographic data}

Core-top temperature and nutrient data were obtained from the World Ocean Atlas, 2009 (Garcia et al., 2010; Locarnini et al., 2010). Annual mean data from $60 \mathrm{~m}$ depth was used as G. bulloides is a subsurface species, and seasonality effects at this depth are limited (e.g. Kuroyanagi and Kawahata, 2004; Wilke et al., 2009a). Sixty meters water depth is also within the range of plankton tow depths for samples presented here and thus depth of measured environmental values (Aldridge et al., 2012; Beer et al., 2010b). However, it should be noted plankton tow environmental variable values will only provide a 'snapshot' of conditions at the time of the tow. These values depend on the season and ocean hydrology in the days immediately preceding data collection. As the $G$. bulloides lifecycle is at least one month long (Hemleben et al., 1989) these measurements provide a limited impression of sample growth conditions. Thus, an offset between 'instantaneous' measured plankton tow values from the annual averages calculated for core-top values are expected.

Core-top carbonate ion values are derived from Global Ocean Data Analysis Project (GLODAP) and CLIVAR databases. Barker and Elderfield (2002) had previously converted this data to preindustrial values. However, we have avoided this approach due to the number 
of assumptions required, including the need to estimate anthropogenic $\mathrm{CO}_{2}$ contribution according to the region and water depth. The difference between post- and pre-industrial values is on the order of $c a .20$ to $50 \mu \mathrm{mol} / \mathrm{kg}$ decrease in $\left[\mathrm{CO}_{3}{ }^{-}\right]$depending on a number of oceanographic factors including regional surface water temperature, hydrology and productivity. Therefore, direct comparison between $\left[\mathrm{CO}_{3}{ }^{-}\right]$in the pre-industrial oceans is not possible where the difference in concentration is less than $50 \mu \mathrm{mol} / \mathrm{kg}$. Chlorophyll- $a$ data is derived from the Giovanni NASA online database (Acker and Leptoukh, 2007). As depth stratified chlorophyll- $a$ data are sparse, surface ocean measurements have been used. Longitudes for South Atlantic core sites were not able to be sourced, however core-tops were identified as spanning a $14^{\circ}$ longitudinal range (de Villiers, 2004). Therefore only the information previously presented in de Villiers (2004) is presented here including: temperature, $\left[\mathrm{CO}_{3}{ }^{-}\right]$and latitude oceanographic data, limiting its use for inter-ocean comparison. All hydrographic information for the sites discussed is listed in the auxiliary material (AI. 1).

\subsection{Regression of SNW against environmental variables and temperature}

Simple linear regression between SNW and one environmental variable were initially undertaken to assess any common trends within ocean regions (Fig. 35). Subsequently, multiple linear regression models were constructed using more than one environmental variable. The latter included the observed data for five environmental variables, and also an "ocean effect", described below. SW Pacific data are presented two ways; firstly as a combined regional dataset for simple regressions, and secondly by dividing sites by the dominant water mass, and thus presenting the information in a similar way to other regions a single dominant surface water mass.

This has the effect of creating two SW Pacific 'oceans' denoted as SW Pacific - Subantarctic waters (SAW) and SW Pacific - Subtropical waters (STW). Plankton tow data have also been treated separately to core-top data. Thus, North Atlantic core-top and plankton tow data have been divided to form two North Atlantic 'oceans' denoted North Atlantic - plankton tow (P) and North Atlantic - core-top (C). Arabian Sea data which were also included as an 'ocean' was derived from plankton tow material. This gives a total of six modelled 'oceans', excluding the South Atlantic and Gulf of Mexico for which limited datasets were available. 

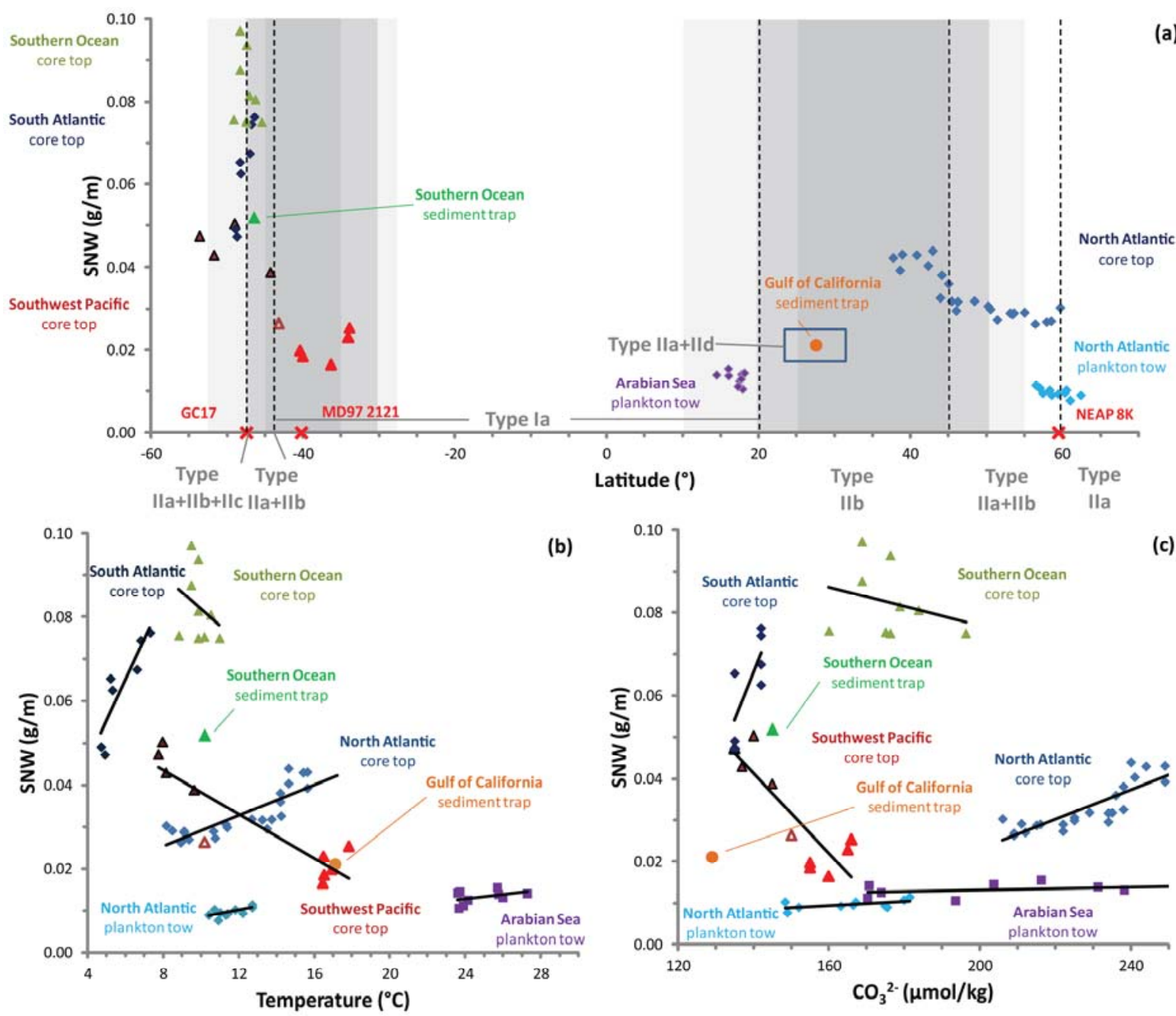

(a)
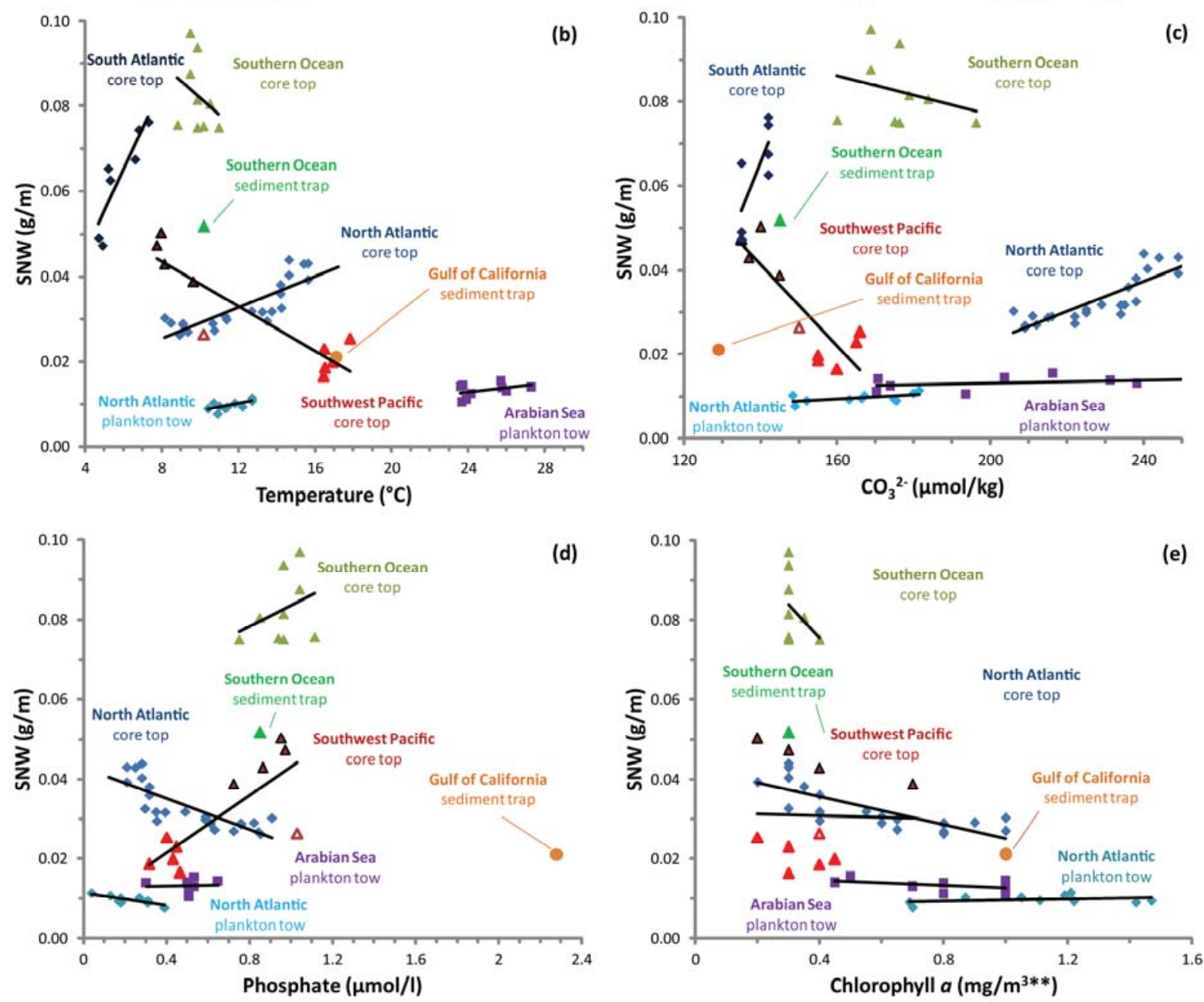

Figure 35. G. bulloides SNW-environmental variable comparison between water mass: North Atlantic core-topdark blue (Barker and Elderfield, 2002) and plankton tow-light blue (Aldridge et al., 2012); South Atlantic-dark blue (de Villiers, 2004); SW Pacific-red (Marr et al., 2011), note: SW Pacific (STW) sites are in filled with a lighter red colour, while results from site R623 are unfilled as it has not been included in the water mass specific relationships due to its location within the subtropical front, SAW dark red in-filled triangle with a black outline; Southern Ocean-green (Moy et al., 2009); Arabian Sea-purple (Beer et al., 2010b) locations. 
Within panel (a): Vertical grey lines indicate species ecological niches as calculated from G. bulloides relative sedimentary abundances by latitude, dark grey (>20\%), medium grey (10-20\%), light grey (5-10\%), white (< $5 \%$ ) (from Bé, 1977). Ecological preferences as indicated by dashed vertical black lines with species genotypes written in grey after Darling and Wade (2008). Latitudes of down core sites from NEAP 8K-Barker and Elderfield (2002), MD97 2121-this study, and GC17-Moy et al. (2009) are indicated by red crosses..

Panels (b-e): G. bulloides shell SNWs plotted against (b) temperature; (c) $\left[\mathrm{CO}_{3}{ }^{*}\right]$; (d) phosphate; (e) chlorophyll- $a$ data, see in text for details regarding data acquisition and AI. 1 for data sources. Black lines within panels (b)-(e) indicate data linear regressions with $\mathrm{r}^{2}$ values given in Table 4 .

Here we use the term "ocean effect" to describe where data has been grouped by water mass or "ocean" and pre- or post-industrial age. Grouped by 'ocean', the data reflect a combination of factors which contribute to a specific ocean environment which may, or may not, be measured here, including seasonality, terrestrial input, regional hydrology and any anthropogenic changes. The term 'environmental variable' is used to describe different ocean parameters used for the multiple linear regression model for example; temperature, $\left[\mathrm{CO}_{3}{ }^{=}\right]$, concentration of nutrients phosphate and nitrate, and chlorophyll- $a$ concentration.

The linear models are in the form:

$$
\mathrm{y}=\mathrm{X} \beta
$$

where $\mathrm{y}$ is the pooled vector of SNW for the six oceans, $\mathrm{X}$ is the model matrix of dimensions (number of data) $\mathrm{x}$ (number of parameters) and $\beta$ is the vector of parameters to be solved.

For a simple regression of SNW against one environmental variable, $\mathrm{X}$ would have the structure that the first column would be all 1 , and the second would be the observed values of the variable. The two components of $\beta$ are then the intercept $(\beta(1))$ and slope $(\beta(2))$ of the regression.

The following is the set of models considered.

1) Multiple regression of SNW on all five measurement variables ( $\beta$ comprises five slope parameters plus a constant);

2) An "ocean effect" only model, being a separate constant for each ocean without additional variables ( $\beta$ comprises six parameters); 
3) An "ocean effect" plus measurement variables model, being a separate constant for each ocean plus a slope parameter for each measurement variable $(\beta$ comprises six ocean parameters plus five slope parameters);

4) Five models consisting of a separate parameter for each ocean plus one slope parameter for each measurement variable in turn $(\beta$ comprises six ocean parameters plus one slope parameter);

Each model was solved by least squares, in which all SNW data had the same weight and no allowance was made for the covariance between the measurement variables. The relative regression parameters have been obtained by subtracting the column means ( $\mathrm{X}$ and $\mathrm{y}=\mathrm{SNW}$ ), from that column and then dividing by the column standard deviation. This has the effect of shifting the origin for the variable (subtracted mean) in the model and rescaling the variables to make then of comparable size (in the approximate range -2 to 2), but not changing the relationship between variables. This re-scaling enables the relative contributions of the different environmental variables to be compared visually. After rescaling, the null model is zero, so the significance of each individual parameter can be assessed according to whether its $95 \%$ confidence interval includes zero. For example, if the environmental parameter crosses the null model or zero line then this indicates that it has no significant contribution to shell SNW changes. The results, discussed below, show that the "ocean effect" is dominant. We conclude that alternative approaches to least squares, such as canonical correlation analysis (Hair et al., 2005) will not be successful unless an "ocean effect" is included, and so has not been attempted.

\subsection{Results}

\subsection{Modern ocean}

\subsubsection{Inter-ocean parameter comparison}

Firstly, environmental and temperature data were correlated, as shown in Table 3a. From this it is clear that the different environmental variables are moderate-highly correlated (Table 3a). This indicates that these variables are not independent, and thus highlights the difficultly in isolating the effect of any single variable on shell SNW. 
In addition, this relationship becomes distinctly stronger if the 'ocean' environmental variable mean value is subtracted (Table $3 b$ ). This is evidence for what we have termed the "ocean effect".

\begin{tabular}{|l|r|r|r|r|r|}
\hline (a) & Temperature & Phosphate & Nitrate & Carbonate ion & Chlorophyll- $a$ \\
\hline Temperature & 1 & -0.44 & -0.77 & 0.36 & 0.17 \\
\hline Phosphate & -0.44 & 1 & 0.79 & -0.52 & -0.10 \\
\hline Nitrate & -0.77 & 0.79 & 1 & -0.64 & -0.02 \\
\hline Carbonate ion & 0.36 & -0.52 & -0.64 & 1 & 0.05 \\
\hline Chlorophyll- $a$ & 0.17 & -0.10 & -0.02 & 0.05 & 1 \\
\hline
\end{tabular}

\begin{tabular}{|l|r|r|r|r|r|}
\hline (b) & Temperature & Phosphate & Nitrate & Carbonate ion & Chlorophyll- $a$ \\
\hline Temperature & 1 & -0.75 & -0.91 & 0.90 & -0.32 \\
\hline Phosphate & -0.75 & 1 & 0.83 & -0.68 & 0.20 \\
\hline Nitrate & -0.91 & 0.83 & 1 & -0.89 & 0.33 \\
\hline Carbonate ion & 0.90 & -0.68 & -0.89 & 1 & -0.39 \\
\hline Chlorophyll- $a$ & -0.32 & 0.20 & 0.33 & -0.39 & 1 \\
\hline
\end{tabular}

Table 3. Environmental variable correlation coefficients from linear regressions shown to illustrate the close relationship between environmental data. Negative values indicate a negative correlation between variables. A: original data; B: with 'ocean' environmental variable mean value subtracted. Note, the relationship becomes distinctly stronger after the 'ocean' mean value is subtracted.

\subsubsection{Shell SNW and environmental variables}

To further illustrate the difficulty in isolating the influence of a single environmental control on shell SNW, a series of SNW-environmental variable relationships have been calculated (Fig. 35, Table 4). From this it is clear that no single parameter appears to consistently covary with shell SNW between ocean regions. For example, the Southern and SW Pacific (SAW) have the inverse relationship between temperature and nutrient concentrations and SNW relative to the other oceans (Table 4). The strengths of global SNW-surface ocean linear relationships were not improved by exclusion of the two plankton tow data sets from the North Atlantic and Arabian Sea which may have been affected by anthropogenic changes and thus offset from core top sample values (Fig. 35). 


\begin{tabular}{|c|c|c|c|c|c|c|c|c|}
\hline & $\begin{array}{l}\text { North Atlantic } \\
\text { (C) }\end{array}$ & $\begin{array}{c}\text { North Atlantic } \\
\text { (P) }\end{array}$ & South Atlantic & $\begin{array}{l}\text { Southwest } \\
\text { Pacific }\end{array}$ & $\begin{array}{c}\text { Southwest } \\
\text { Pacific (STW) }\end{array}$ & $\begin{array}{c}\text { Southwest } \\
\text { Pacific (SAW) }\end{array}$ & Southrn Ocean & Arabian Sea \\
\hline Temperature & 0.69 & 0.44 & 0.79 & 0.81 & 0.55 & -0.71 & -0.08 & 0.18 \\
\hline Phosphate & -0.65 & -0.61 & $\mathrm{n} / \mathrm{a}$ & 0.62 & 0.00 & 0.88 & 0.11 & 0.00 \\
\hline Nitrate & -0.68 & -0.42 & $\mathrm{n} / \mathrm{a}$ & 0.71 & -0.80 & 0.93 & 0.07 & -0.20 \\
\hline Carbonate ion & 0.73 & 0.33 & 0.59 & -0.74 & -0.31 & 0.53 & -0.08 & 0.16 \\
\hline Chlorophyll- $a$ & -0.60 & 0.11 & $n / a$ & 0.00 & -0.34 & -0.93 & -0.12 & -0.18 \\
\hline
\end{tabular}

Table 4. Correlation coefficient table of single environmental variables with G. bulloides shell SNW. SW Pacific STW includes core-tops: P71, P81, S793, P69, S938 and SAW includes core-tops: Q220, F111, D178 and B32. Negative values indicate a negative correlation between variables.

Model results for the relative regression parameters and their $95 \%$ confidence intervals are shown in Figure 3a and Table 4. Multi-parameter models have been used in two different ways, firstly to look at the five environmental variables in isolation which are then compared to the "ocean effect" (Fig. 36a). Secondly, the "ocean effect" has been combined with a single environmental variable (Fig. 36b). The $\mathrm{r}^{2}$ values for each of these models are given in Table 4. Based on the models, the following are evident: 1) the contribution of the "ocean effect" is much larger than the environmental variables, in all models which include them (Fig. 36a) and $r^{2}$ is distinctly better for models that include the "ocean effect" $\left(r^{2}>0.9\right.$ compared to a maximum of 0.75 for environmental variables only).

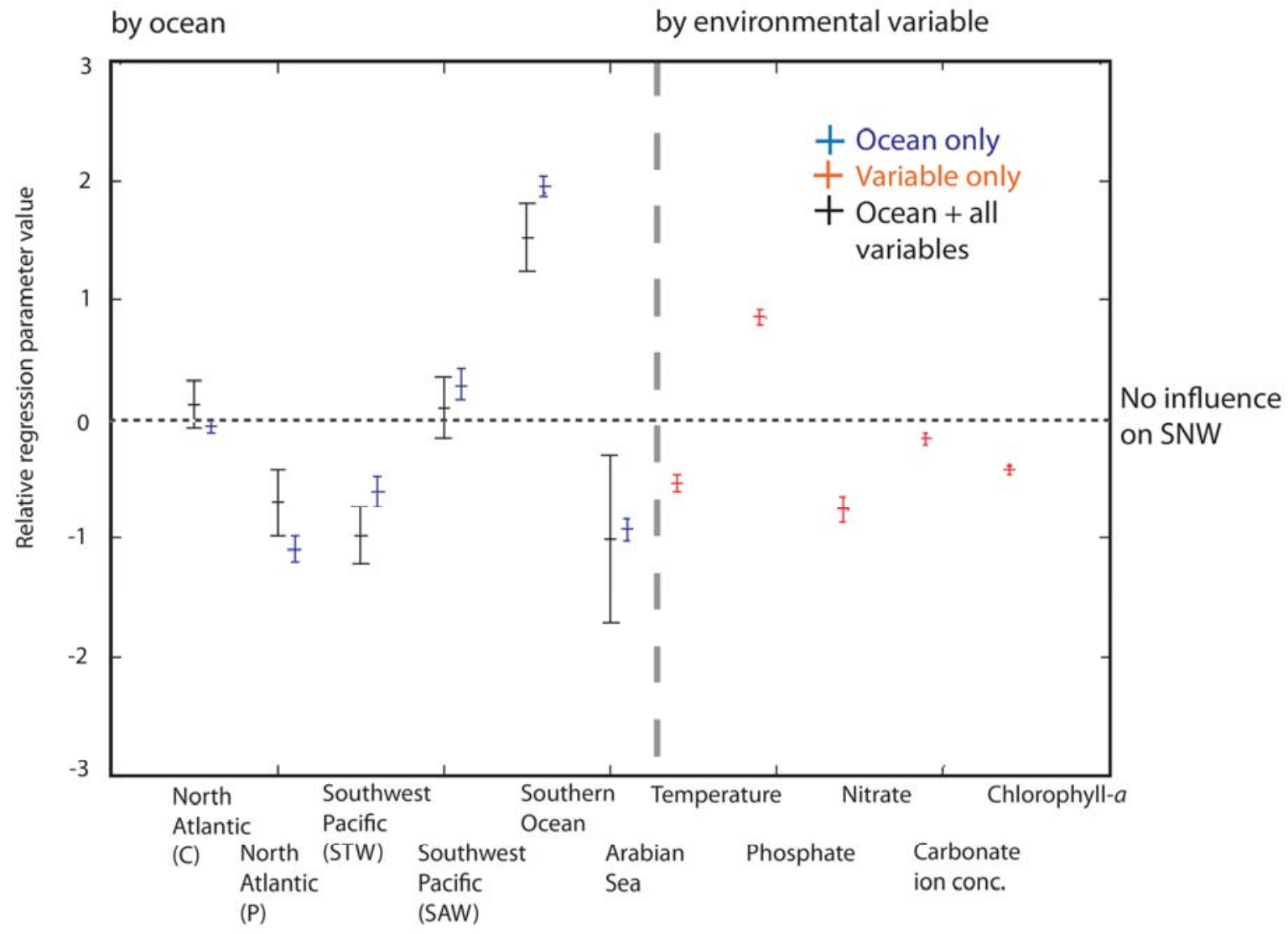


Figure 36. An illustration of the relative environmental and 'ocean' significance in controlling shell SNW, as determined by multiple linear regression modelling. The relative distance from the 0 -fit line indicates the relative influence of the variable on shell SNW. Model results have been separated into ocean and environmental variable categories. The apparent ocean influence or "ocean effect" is significantly larger than that of the environmental variables, highlighting its importance in determining G. bulloides shell SNW. In addition, the model fit is little improved with addition of the environmental variables and model error is increased. Model $\mathrm{r}^{2}$ values are given in Table 5. Error bars indicate 95\% confidence intervals for the regression values.

\begin{tabular}{|l|r|}
\hline Model & $r^{2}$ value \\
\hline $\begin{array}{l}\text { Five environmental variables } \\
\text { only }\end{array}$ & 0.75 \\
\hline Six 'oceans' only & 0.91 \\
\hline $\begin{array}{l}\text { Six 'oceans' \& five } \\
\text { environmental variables }\end{array}$ & 0.92 \\
\hline Six 'oceans' \& temperature & 0.918 \\
\hline Six 'oceans' \& phosphate & 0.914 \\
\hline Six 'oceans' \& nitrate & 0.916 \\
\hline Six 'oceans' \& carbonate ion & 0.911 \\
\hline Six 'oceans' \& chlorophyll- $a$ & 0.923 \\
\hline
\end{tabular}

Table 5. The $\mathrm{r}^{2}$ values for models illustrated in Figure 36 with addition values for model + a single environmental variable to indicate how well change in environmental conditions are able to explain the $G$. bulloides shell SNWs.

Generally, there is very little difference between the modelled significance of different environmental variable estimates (Fig. 36). This suggests that these estimates are stable and not model dependent. Inclusion of some, or all parameters, produces an insignificant improvement in $r^{2}$ compared to the "ocean effect" only model $\left(r^{2}=0.911\right.$ to 0.923 compared to 0.909 for ocean effects only). Large error-bars for the six 'oceans' plus five environmental variables arise from the close variable correlation (Fig. 36b). This has the effect of inflating the covariance matrix even though the root-mean-square residual is reduced. Thus, inclusion of all environmental variables is statistically no better than a model which includes only the best single variable (chlorophyll-a), a conclusion confirmed by the $r^{2}$ values (Table 4 ). 
Therefore, it appears that the SNW values of G. bulloides are dominated by an effect which is 'ocean' specific.

\subsection{Paleoceanography}

Shell SNW of G. bulloides from 25 ka to present in MD97 2121 (Fig. 37; AI. 2) range from 4 to $20 \mu \mathrm{g}$ and length between 263 to $434 \mu \mathrm{m}$. Shell SNW is highest during the last glacial and early termination period, peaking twice at ca. 22.0 and $14.5 \mathrm{ka}$ respectively before a decrease in size of $c a .50 \%$ by the early Holocene at ca. $11.0 \mathrm{ka}$. Heavier weights during the glacial period relative to the interglacial are also seen at other sites including the Southern Ocean (29.3 (glacial) vs. 24.7 (interglacial) $\mu$ g) (Moy et al., 2009), Indian Ocean (13 vs. $6 \mu \mathrm{g}$ ) (Naik et al., 2010) and North Atlantic (20 vs. 11 $\mu$ g) (Barker and Elderfield, 2002). Previous studies using modern core-tops from the SW Pacific region suggested that foraminifera weights may be strongly linked to SSTs (Marr et al., 2011), with cooler temperatures predicted to produce heavier shell weights during the glacial period. MD97 2121 G. bulloides SNWs have a good relationship $\left(r^{2}=0.58\right)$ with temperature, significantly greater than the $r^{2}=0.10$ in the North Atlantic. However, G. bulloides SNW from the SW Pacific Ocean are consistently lower than those from the North Atlantic for the same temperature range (Fig. 38). Shell SNW in the SW Pacific decreases by $c a .0 .002 \mathrm{~m} / \mathrm{g} /{ }^{\circ} \mathrm{C}$, significantly less than the $0.015 \mathrm{~m} / \mathrm{g} /{ }^{\circ} \mathrm{C}$ which occurs between the LGM and Holocene in the North Atlantic (Barker and Elderfield, 2002).

There is little relationship between shell SNW and $\mathrm{Zn} / \mathrm{Ca}$ (representative of nutrients; Marr et al., submitted) or G. bulloides abundance (Fig. 37f). A weak relationship between $G$. bulloides SNW and foraminiferal fragmentation index at the SW Pacific core site is present (Fig. 37d), indicating that while dissolution may have occurred it was not the major factor controlling shell weight (Northcote et al., 2007). Moreover, scanning electron micrograph (SEM) imaging of foraminifera down core did not identify any changes consistent with dissolution. SEM images also did not show any calcite overgrowths and thus we do not believe that that post-depositional alteration has added or reduced mass to foraminiferal shells in the MD97 2121 record (Marr et al., in press-b). There is also no apparent relationship between G. bulloides SNW and biosiliceous or carbonate mass accumulation rates at MD97 2121 (Fig. 37e; AI. 3) (Carter and Manighetti, 2006). 

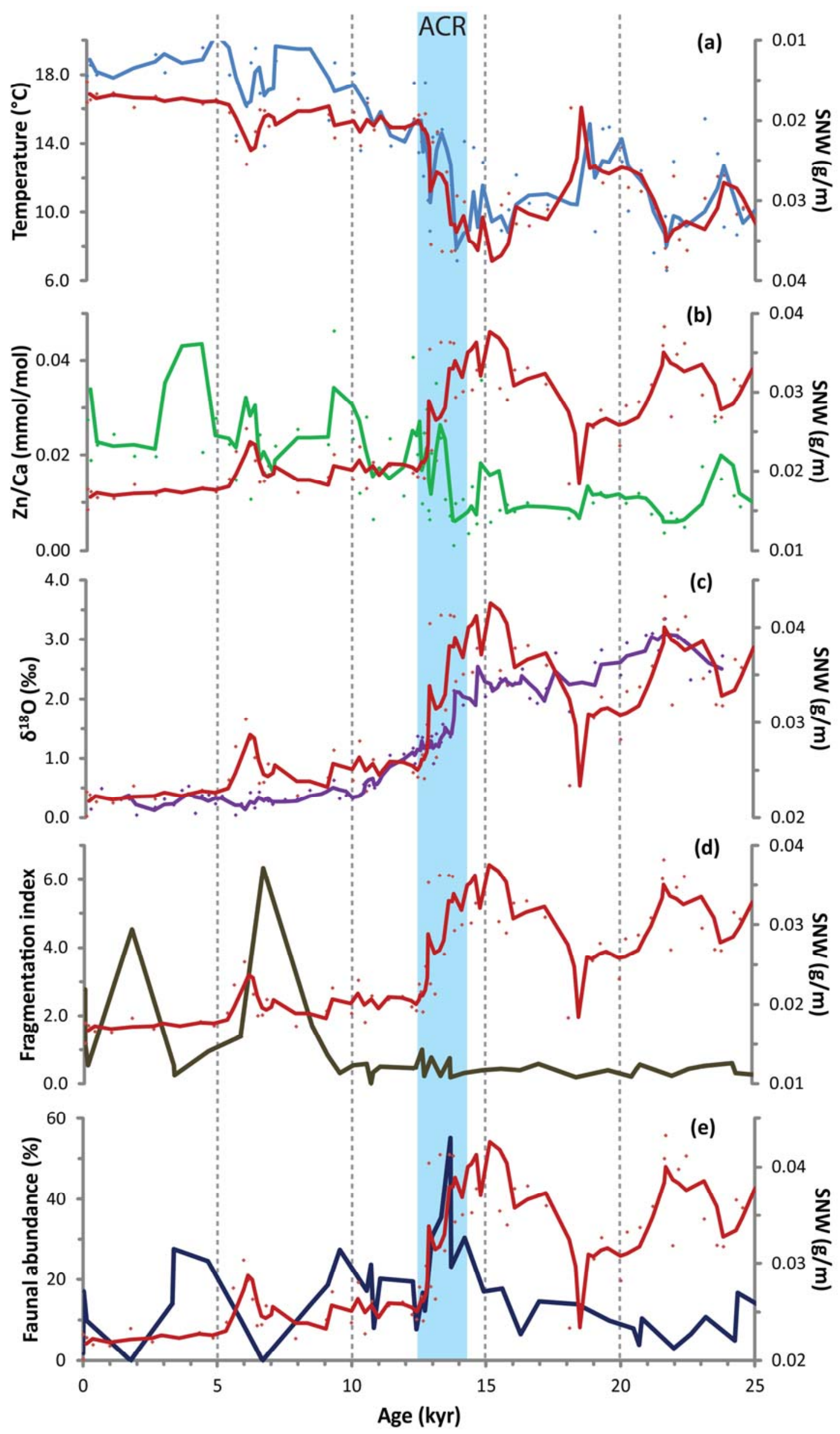
Figure 37. Summary of G. bulloides data from SW Pacific core site, MD97 2121 from 25 ka-present. SNW data is indicate in red, and compared to; (a) temperature, (b) $\mathrm{Zn} / \mathrm{Ca}$ derived using G. bulloides chamber $f-2$ trace metal values (see Marr et al., in press-b), (c) $\delta^{18} \mathrm{O}$ (Carter et al., 2008), (d) faunal fragmentation (Northcote et al., 2007), (e) carbonate mass accumulation rate (Carter and Manighetti, 2006), and (f) G. bulloides abundance (Northcote et al., 2007). Note, individual geochemical and SNW measurements are shown as dots, while the solid line indicates the three point moving mean shown for trend comparison. Antarctic cold reversal (ACR) is indicated by the blue bar.

\subsection{Discussion}

Surface water conditions, which may lead to optimal G. bulloides growth, have been discussed extensively (e.g. Barker and Elderfield, 2002; Gonzalez-Mora et al., 2008; Kucera, 2007; Moy et al., 2009). Yet, there is still no agreement on what controls the shell weight of modern tests in different ocean regions (Fig. 35). The foraminifers' location, e.g. the water mass from which it hails, is likely to dictate its shell weight. However, what environmental variable(s) cause changes within water masses remains unclear (Fig. 36). In addition, G. bulloides shell SNW generally increases from the last glacial period to Holocene independent of ocean location, despite the records at MD97 2121 being punctuated by a brief midHolocene period of shell SNW lightening (Fig. 38). This suggests that there is an environmental variable which changes over a glacial-interglacial cycle which universally affects calcification (Fig. 38) (e.g. Barker and Elderfield, 2002; Gonzalez-Mora et al., 2008).

Development of a G. bulloides SNW proxy for an oceanic variable(s) is desirable as shell weight and size measurements are arguably easier to obtain than geochemical proxy data. However, significant changes in regional shell development may preclude the use of this proxy in certain water masses, or demand basin-specific calibrations. In the first part of the discussion we evaluate each of the leading theories on G. bulloides shell calcification against the modern environmental variables. Secondly, these findings are compared with data from high resolution cores from the North Atlantic and SW Pacific Ocean for the last $25 \mathrm{ka}$ to ascertain if a single parameter can be identified as a control of G. bulloides SNW over glacial/interglacial timescales (Fig. 38) (Barker, 2002b; Kucera, 2007; Moy et al., 2009). 

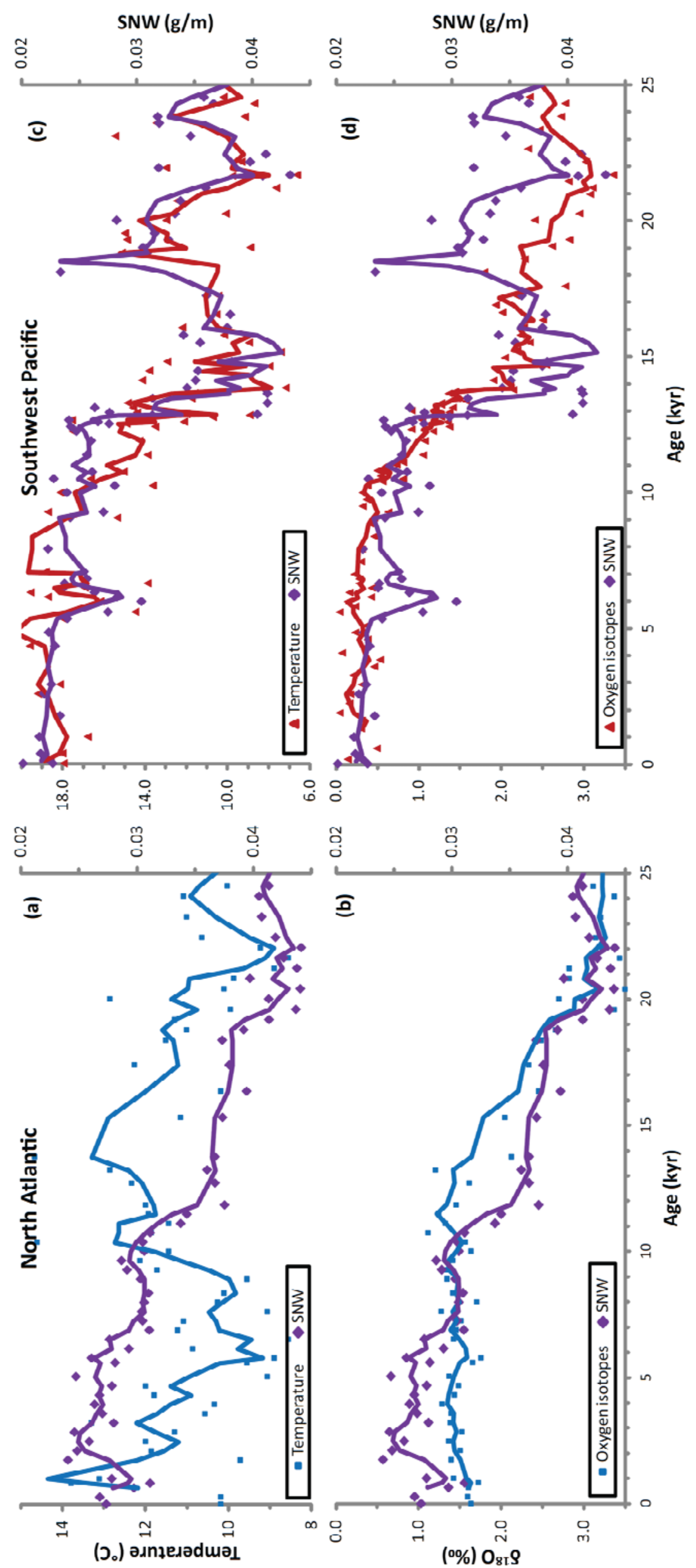
Figure 38. Comparison between G. bulloides North Atlantic NEAP 8K (Barker and Elderfield, 2002) (blue) and SW Pacific MD97 2121 (Marr et al., 2011) (red); temperature, oxygen isotopes and SNW (purple) values.

Temperature values $(\mathrm{a}, \mathrm{c})$ were derived from $\mathrm{G}$. bulloides $\mathrm{Mg} / \mathrm{Ca}$ values and converted to temperature using the calibration from Marr et al., (2011). Oxygen isotope values (b,d) are from Barker and Elderfield (2002) -North Atlantic and Carter et al. (2008) -SW Pacific. Note, individual geochemical and SNW measurements are shown as dots, while the solid line indicates the sample 3 point moving mean shown for trend for comparison.

\subsection{Modern Observations}

\subsubsection{Optimal growth conditions}

The theory of optimal growth conditions was proposed initially from down-core relationship between larger shell size during glacial periods, and has been used to explain modern and ancient changes in G. bulloides shell calcification (e.g. Hecht, 1976; Malmgren and Kennett, 1978). De Villiers (2004) noted that the heaviest planktic foraminifera weights occurred at the latitude of 'optimal growth conditions' as defined by the highest abundances of the particular species. In addition, higher G. bulloides abundances have been suggested as a productivity and upwelling indicator (e.g. Clemens et al., 1991; Clemens and Prell, 2003; Weaver et al., 1998). Modelling has also linked increased foraminiferal abundance to elevated shell growth (Lombard et al., 2011). However, while the modelled growthabundance relationship was strong for symbiotic species like Globigerinoides ruber $\left(\mathrm{r}^{2}=0.4\right)$, the relationship for the asymbiotic G. bulloides, at $\mathrm{r}^{2}=0.19$, is tenuous at best (Lombard et al., 2011). No single environmental variable has yet been isolated which reflects G. bulloides 'optimal conditions'.

While modern North Atlantic SNWs plotted against G. bulloides abundance in core tops (Bé, 1977) indicate a possible relationship (Fig. 35a), this is not consistent for the Southern Hemisphere where heavier SNWs occur outside the latitudes of high abundance as defined by Bé (1977). Plankton tow samples from the North Atlantic also indicated a weak link between species abundance and shell SNW (Aldridge et al., 2012; Beer et al., 2010b). Therefore species abundance and/or 'optimal conditions' are unlikely to control G. bulloides SNW (Fig. 35a). However, elements of whatever comprises this species 'optimal growth conditions' are potentially incorporated into the "ocean effect" recognised here. 


\subsubsection{Temperature}

Previously it was recognised that temperature may control shell size in planktonic foraminifera (Hecht, 1976; Malmgren and Kennett, 1976). Temperature is likely to be an important environmental factor in shell growth as foraminifera do not regulate their own temperature (Kooijman, 2000). Thus a change in temperature may affect foraminiferal feeding processes such as the speed of prey capture and digestion (Kooijman, 2000), which may in turn affect shell calcification. Recent computer modelling using temperature coupled with foraminiferal enzyme activity indicated that the simple combination of these factors could effectively model species growth patterns. Modelled and observed peak shell growth in the laboratory for G. bulloides occurred between ca. $23-27^{\circ} \mathrm{C}$ (Lombard et al., 2009).

These temperatures of peak growth rate for G. bulloides fall within the temperature range of Arabian Sea plankton tow samples (Beer et al., 2010b). However, even though mean shell length $(290-330 \mu \mathrm{m})$ was comparable with other samples presented here, Arabian Sea samples had significantly lower shell SNWs. In addition, these samples indicated little relationship between SNW and temperature (Table 4). Thus, while temperature may limit a species biogeographical range, within its biogeographical range temperature does not appear to be a primary control on G. bulloides shell SNW. Linear relationships between SNWtemperature indicate a normally positive relationship between the parameters including SW Pacific (STW). However, SW Pacific (SAW) and Southern Ocean samples indicate a weak negative relationship (Table 4, Fig. 35b). Coupled with the "ocean effect", temperature alone produced an insignificant improvement to the modelled relationship (Table 5). This suggests that temperature may only co-vary with other controlling environmental factor(s).

\subsubsection{Surface water carbonate ion concentration}

Changing surface water $\left[\mathrm{CO}_{3}{ }^{-}\right]$between different water masses is illustrated in the North Atlantic-SW Pacific/Southern Ocean comparison (Fig. 39). Foraminifera use $\left[\mathrm{CO}_{3}{ }^{-}\right]$to construct their shell, therefore changes in surface water concentrations may have a direct impact on their calcification (e.g. Barker et al., 2003b; Spero et al., 1997). However, surface ocean $\left[\mathrm{CO}_{3}{ }^{-}\right]$varies as a function of temperature and atmospheric $\mathrm{CO}_{2}$ levels, thus making it difficult to distinguish between the relative effects of those three variables (Lynch-Stieglitz et al., 1995). 
North Atlantic core-top samples have a strong positive relationship between surface ocean $\left[\mathrm{CO}_{3}{ }^{=}\right]$and shell SNW (Table 4, Fig. 35c) (Barker and Elderfield, 2002). In the SW Pacific, however, if (SAW) and (STW) samples are combined, shell SNW progressively decreases with increased surface ocean $\left[\mathrm{CO}_{3}{ }^{=}\right]$concentrations (Table 4, Fig. 35c) (Marr et al., 2011). However, if SW Pacific (SAW) samples are isolated, these exhibit a weak negative relationship with $\left[\mathrm{CO}_{3}{ }^{=}\right]$(Table 4). Inter-ocean comparison indicates that the heaviest $G$. bulloides SNWs occur in surface waters with the lowest $\left[\mathrm{CO}_{3}{ }^{-}\right]$and lowest temperatures in the South Atlantic and Southern Ocean (Fig. 35c) (de Villiers, 2004; Moy et al., 2009). Coupled with the "ocean effect", $\left[\mathrm{CO}_{3}{ }^{=}\right]$did not significantly improve upon the "ocean effect" only fit (Table 5, Fig. 36). $\left[\mathrm{CO}_{3}{ }^{-}\right]$therefore does not appear to be the primary control over modern shell size and/or weight globally, a finding consistent with Orbulina universa and Globigerinoides sacculifer laboratory results (Lombard et al., 2010).

All post-industrial G. bulloides SNWs derived from sediment trap and plankton tow samples, except that from the Southern Ocean (Moy et al., 2009), have SNWs at or below $0.02 \mathrm{~g} / \mathrm{m}$ (Fig. 35). This is lower than $95 \%$ of core-top sample SNWs measured. The Southern Ocean sediment trap sample is ca. $40 \%$ lighter than mean Holocene weights from core tops in the same water mass (Fig. 35) (Moy et al., 2009). Low plankton tow SNWs may suggest that those specimens had not undergone the full foraminiferal lifecycle and therefore lacked calcification that may otherwise be associated with the core-top samples. However, Arabian Sea G. bulloides plankton net samples obtained from $2200 \mathrm{~m}$ water column depth did not suggest any significant change in SNW compared to samples from shallower depths (Beer, 2010). The cause of the reduced post-industrial calcification of G. bulloides is uncertain and does not appear to have a direct relationship with temperature or carbonate ion concentration. It may, instead, be associated with the modern response of the phytoplankton algal prey to environmental change (see below).

Figure 39. Surface water $\left[\mathrm{CO}_{3}{ }^{-}\right]$in (a) the North Atlantic core-tops-solid line (Barker and Elderfield, 2002) and plankton tow samples-dashed lines (Aldridge et al., 2012), (b) SW Pacific core-top samples (Marr et al., 2011) and (c) Southern Ocean core-top-solid lines and sediment trap-dashed line samples (Moy et al., 2009). Colour scale indicates modern $\left[\mathrm{CO}_{3}{ }^{=}\right]$in $\mu \mathrm{mol} / \mathrm{kg}$ (CLIVAR data set). Site line length corresponds to the deepest site at or above the calcite saturation horizon $(\mathrm{CSH})$. Stars above core sites indicate locations where core falls below the $\mathrm{CSH}$, the line length for these sites correspond to actual site depth. Sites which fell below the CSH were assessed in the original studies, however no signs of dissolution were indicated (Marr et al., 2011; Moy et al., 2009). Horizontal dashed line indicates regional calcite saturation horizons (Bostock et al., 2011). Figures constructed using Ocean Data View (Schlitzer, 2011). 

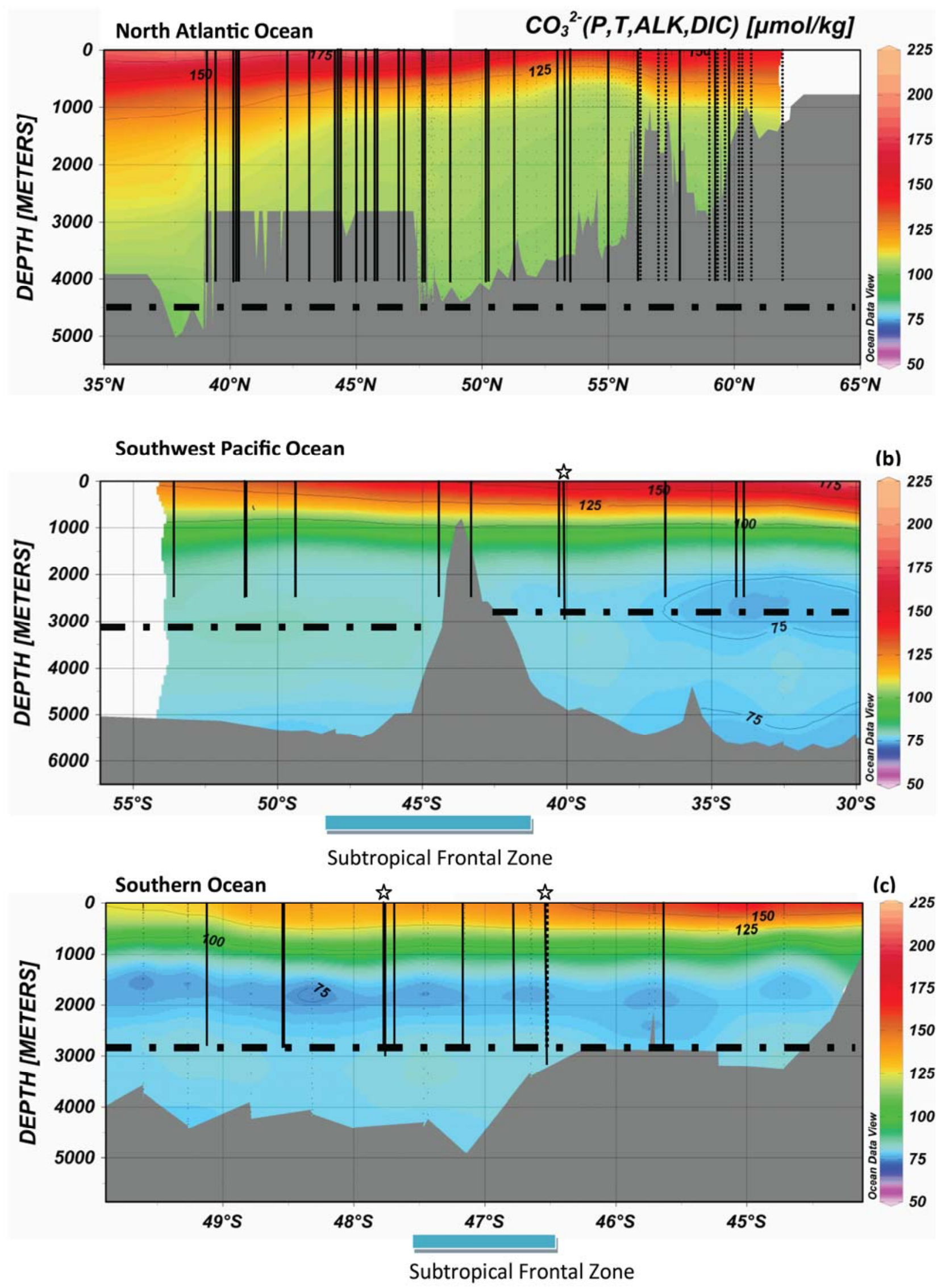


\subsubsection{Nutrients and chlorophyll-a}

A change in nutrient concentration is unlikely to have a direct effect on G. bulloides as it is a predatory species of zooplankton (Hemleben et al., 1989). However, G. bulloides graze on phyto- and other zooplankton algae, which directly respond to changes in nutrient levels (e.g. Carpenter et al., 1985; Frew et al., 2001). As some sites are situated in the Southern Ocean, which is the largest high-nutrient low-chlorophyll (HNLC) region of the global ocean (Trull et al., 2001). As high nutrient levels do not necessarily reflect high productivity both nutrient and chlorophyll- $a$ data are presented here.

North Atlantic sites have a negative relationship between phosphate, with G. bulloides shell SNW decreasing with increasing phosphate levels (Fig. 35d) (Aldridge et al., 2012; Barker and Elderfield, 2002). However, this is inconsistent with the other water masses: either there is no change in the case of Arabian Sea and SW Pacific (STW) (Beer et al., 2010b; Marr et al., 2011), or a positive relationship in the case of SW Pacific (SAW) and Southern Ocean (Fig. 35d) (Marr et al., 2011; Moy et al., 2009). The positive G. bulloides shell SNW-nutrient concentration relationship is consistent with faunal association data, which links higher $G$. bulloides abundance with nutrient-rich upwelling environments (e.g. deMenocal et al., 2000; Kipp, 1976; Weaver et al., 1997). However, at phosphate levels of $2.3 \mu \mathrm{mol}$, which is at least double those from the North Atlantic or SW Pacific, shells from the Gulf of California were still of comparable size/weight to the other locations, indicating that shell development in this water mass was not enhanced by the increased nutrient levels (Fig. 35d) (McConnell and Thunell, 2005). Addition of either nitrate or phosphate to the "ocean effects" model did not significantly improve the model fit (Table 5, Fig. 3). Therefore nutrient concentration does not appear to be a primary control over global G. bulloides shell SNW.

Planktonic foraminiferal shell calcification is dependent on feeding (Bé et al., 1982; Hemleben et al., 1989). An indicator of algal abundance, and thus G. bulloides food source is the concentration of surface water chlorophyll- $a$. Chlorophyll- $a$ is the only environmental variable presented here which appears to have a relatively consistent, albeit very weak trend, with G. bulloides SNW across all the global water masses (Table 4, Fig. 35e). The weak relationship indicates that as chlorophyll-a decreases G. bulloides SNW shows a subtle increase (Fig. 35e). However, Southern Ocean samples are still offset to heavier SNW values. 
Surface ocean chlorophyll- $a$ concentration also had the best relationship in the "ocean effect" plus variable model (Fig. 36). The negative relationship between chlorophyll-a and $G$. bulloides shell SNWs is somewhat contradictory to the observation that the highest species abundance usually co-varies positively with elevated chlorophyll-a concentrations (Kuroyanagi and Kawahata, 2004; Schiebel et al., 2001). This re-affirms that shell SNW does not appear to reflect species abundance. It is possible however, that in response to less favourable conditions for growth, including low chlorophyll-a concentrations G. bulloides may slow shell growth. In effect this would increase the time available for calcite formation in the internal Calcite-pool (Anderson and Faber, 1984; Bentov and Erez, 2005), thereby increasing the amount of calcite available for chamber calcification.

\subsubsection{Genotypes}

There are at least seven G. bulloides genotypes (Darling and Wade, 2008; Kucera and Darling, 2002), suggesting that discrepancies between observed and modelled data for growth rates may originate from the species genetic diversity (Fig. 35a). Previous plankton tow, coretop, sediment trap and culturing studies have been generally based on specimens from a narrow range of locations (e.g. Aldridge et al., 2012; Lombard et al., 2009), or did not cover a wide range of inter-basin surface ocean conditions (e.g. Marr et al., 2011). Here we explore a new idea that a change in genotype, may have a significant effect on shell calcite and its geochemical composition. For example, G. bulloides calcifying in highly saline Mediterranean waters are known to incorporate trace metals differently to other locations (Ferguson et al., 2008) and have a distinctive G. bulloides genotype (Darling and Wade, 2008). While the geographical conditions, which lead to the formation of the Mediterranean surface water environment are limited, the possibility remains that other G. bulloides genotypes with distinct ecological preferences, e.g. Type-IIc, may change their latitudinal, biogeographic range as the prevailing environmental conditions vary.

Darling and Wade (2008) noted that while genotypes may occur together, there was a distinct difference in their ecologies. Of the seven G. bulloides genotypes types Type-IIa and -IIb are characterised as bipolar, subpolar species (Darling and Wade, 2008). However, Type-IIa had the highest abundance in cooler subpolar waters, blooming first in spring (Darling and Wade, 2008). Type-Ia was a unique subtropical water genotype present in both the Coral and Arabian Seas (Darling and Wade, 2008). Type IIc is unique to Antarctic waters (Darling and 
Wade, 2008). Grouping G. bulloides samples by their genotypes may aid in explanation of the differences in SNW under relatively similar environmental conditions (Fig. 35a). Samples from the Southern Ocean (including SW Pacific (SAW)), which have much heavier SNW than the other water masses, fall within the regionally distinct Type-IIc boundaries, although the relative regional abundance of IIc compared to IIa or IIb is as yet unknown (Darling and Wade, 2008).

SW Pacific (STW) sites have some of the lightest shell modern core-top SNWs and appear distinctly offset from the geographically close SAW samples (Table 4, Fig. 35a). Darling and Wade (2008) genotype results suggest that this SW Pacific STW-SAW divide may be due to the presence of Type-Ia at STW sites, which is absent from SAW water. In addition, the SW Pacific STW SNWs are most similar to those from the Arabian Sea where this Type-Ia genotype has been previously identified (Fig. 35a). In the Southern Ocean, the ca. 3 sites north of the subtropical frontal zone tend towards lighter shell weights (Fig. 35). This may suggest the increased influence of other $G$. bulloides genotypes such as the subpolar/transitional Type IIa and IIb relative to Type IIc present in the circumpolar surface water masses, south of the subtropical frontal zone (Fig. 35a). The relative dominance of specific genotypes at any given site may aid in explanation of the large offsets between $G$. bulloides SNWs and the apparently strong "ocean effect" evident in the statistical modelling. However, it does not account for shell SNW variation within a specific genotype region (Fig. 35a) (Aldridge et al., 2012).

\subsubsection{Ocean Effect}

This work has identified an ocean effect on shell SNW not currently captured in these other environmental variables (Fig. 36). This "ocean effect" is most likely related to the different combination of environmental variables that exists within any one water mass (Table 3). Water mass specific SNW variation therefore may be a reflection of species' environmental adaptations, which optimise shell development and other life cycle properties to ensure the species' success in each region. This suggests that the "ocean effect" may actually reflect the evolutionary process evident in regional genetic variations (Fig. 35) (Darling and Wade, 2008). Based on the parameters measured here there does not appear to be any dominant environmental factor which causes the regional variation in weight (Fig. 36). The dominance of the "ocean effect" on G. bulloides shell calcification implies that any proxy calibrated to 
modern surface ocean condition which utilises shell SNW is unlikely to be applicable outside the localised water mass.

\subsection{LGM-Present}

The primary cause(s) of modern geospatial shell SNW variation remains unresolved, potentially due to the wide distribution of sample sites and therefore the increased number of potential environmental influences. Thus, down-core samples taken from a single location where changes in surface water conditions are geographically constrained, may reduce the number of variables, and narrow the possibilities for that site or local region.

\subsubsection{Environmental forcing of species ecological optimum}

The down-core variance of G. bulloides shell size with SST has long been recognized, with use of the size-temperature relationship as a SST proxy first pioneered by Malmgren and Kennett (1978) following the work of Kennett (1976) and Hecht (1976). In this work the systematic shift in mean shell size of G. bulloides was linked to isotopically and faunally defined glacial stages (marine isotope stages (MIS) 2-8) that displayed a negative relationship between size and temperature. However, as the Indian Ocean core on which these findings were based was located north of the present-day G. bulloides 'ecological optimum' or $c a .50^{\circ}$ latitude (Hecht, 1976), the possibility was raised that the change in shell size was merely an artefact of the species optimal growth conditions. During the glacial stages environmental forcing shifted the latitudinal range for optimal growth conditions northwards (Kucera, 2007; Schmidt et al., 2003), and closer to the Indian Ocean core site. Therefore by extension, if a core was analysed from a site located in waters within, or slightly cooler than, the ecological optimum, shell size should exhibit the opposite trend, decreasing in size during the glacial period.

Cores NEAP 8K and MD97 2121 provide an opportunity to test theories relating to the primary control over shell calcification with high resolution shell SNW weight, isotope and trace metal data available for G. bulloides from the LGM-present, in addition to regional core-top data to compare to (Fig. 34, 38) (Barker, 2002b; Carter et al., 2008; Marr et al., 2011; Marr et al., in press-b). North Atlantic core NEAP $8 \mathrm{~K}$ at $c a .60^{\circ} \mathrm{N}$ is located within waters which are cooler, or outside, the G. bulloides preferred modern 'ecological optimum'. At $40{ }^{\circ} \mathrm{S}$, MD97 2121 is located in SW Pacific STW, which are within the modern 'ecological 
optimum' (Fig. 35a) (Bé, 1977). Therefore these two core sites should show the inverse shell SNW trends from the LGM to present with latitudinal migration of the species optimum conditions. However, in MD97 2121 and NEAP 8K G. bulloides shell SNWs are heavier during the glacial period relative to the Holocene (Fig. 38) (Barker and Elderfield, 2002).

Further, G. bulloides from the Southern Ocean site GC17 at $47.5^{\circ} \mathrm{S}$, which are significantly heavier under modern ocean conditions relative to other global locations, also increased shell weight during the last glacial period (Fig. 34,b38) (Moy et al., 2009). The G. bulloides abundance at MD97 2121 indicates that optimal conditions occurred immediately preceding the Antarctic Cold Reversal (Northcote et al., 2007); but there is no corresponding peak in shell SNW during this period (Fig. 37f, AI 3) (Northcote et al., 2007). The lack of correlation between G. bulloides abundance, carbonate or biosiliceous mass accumulation rates and test SNW indicates that the G. bulloides abundance, or SNW, of this species is not a reliable paleo-productivity indicator in this region (Fig. 37 e,f, AI. 3) (Carter and Manighetti, 2006; Northcote et al., 2007). These data agree with core-top and plankton tow studies, which show little relationship between optimal growth conditions and shell SNW in the SW Pacific (Marr et al., 2011), and therefore support previous findings which suggest that changes in 'ecological optimum conditions' are unlikely to be the cause of glacial shell SNW increase (Fig. 35) (Beer et al., 2010b).

\subsubsection{SST and carbonate ion concentration}

Temperature alone, as described by the Marr et al. (2011) SNW-temperature calibration, is unable to fully explain the glacial SNWs, with ca. 30\% offset between those weights predicted from the down core $\mathrm{Mg} / \mathrm{Ca}$ G. bulloides estimated temperatures (Marr et al., submitted). When other MD97 2121 proxy data are matched to shell SNW records, it also becomes immediately apparent that shell weights do not appear to be responding to surface water micronutrient/nutrient content as suggested by $\mathrm{Zn} / \mathrm{Ca}$ (Marr et al., in press-b). Therefore, if it is not temperature or nutrient content which is the primary cause of increased shell calcification, other factors which are known to increase during the glacial period such as surface water $\left[\mathrm{CO}_{3}{ }^{-}\right]$and primary productivity need to be investigated.

During glacial periods surface water $\left[\mathrm{CO}_{3}{ }^{-}\right]$and $\mathrm{pH}$ were higher than the pre-industrial Holocene (e.g. Foster, 2008; Lynch-Stieglitz et al., 1995; Tyrrell and Zeebe, 2004). Glacial conditions may have assisted foraminifera in $\mathrm{CaCO}_{3}$ formation by reducing the amount of 
energy required to produce sufficient internal $\left[\mathrm{CO}_{3}{ }^{=}\right]$concentrations to match the $\left[\mathrm{Ca}^{2+}\right]$. Greater water turbulence is also been shown to increase test calcification, possibly to ensure the integrity of the spine network which is integral for this species survival (ter Kuile and Erez, 1984). As surface water turbulence is likely to have increased during the glacial period (e.g. Carter et al., 2008; Mulitza et al., 1997), this possibly also contributed to higher shell SNWs (Fig. 38). Elevated glacial primary productivity increased the G. bulloides food source (Hayward et al., 2012; Kumar et al., 1995; Sarnthein et al., 1988), reducing the energy needed for prey capture and increasing the energy able to be allocated to calcification.

In summary, during the glacial period colder, more turbulent surface waters may have increased the foraminifera's shell calcification requirements so that the spine network was maintained. The increased demand for calcification was made easier as there was higher surface water $\left[\mathrm{CO}_{3}{ }^{-}\right]$. Despite the negative relationship between increased food abundance and calcification in the modern ocean, during the glacial period the increased ease of prey capture may have actually provided the foraminifera with the additional energy required. This may then have enabled the foraminifera to create larger internal $\mathrm{CaCO}_{3}$-pools for shell calcification thus creating larger, heavier shells to be calcified regardless of the species genotype (Fig. 38).

\subsection{Conclusions}

These results suggest that there is an "ocean effect" not captured by the environmental variables, which may explain variations in SNW. We suggest that this "ocean effect" likely reflects G. bulloides genetic variations. However, this cannot account for the variations within the same water mass. Shell SNW appears to vary as a function of several environmental factors, including; temperature, surface water $\left[\mathrm{CO}_{3}{ }^{3}\right]$, nutrient concentrations, chlorophyll- $a$ levels and genotype. As shell calcification tends towards heavier weights during the last glacial period, this study supports the theory that changes in foraminiferal shell weight are potentially related to changes in ambient $\left[\mathrm{CO}_{3}{ }^{*}\right]$, however changes in other environmental factors over glacial/interglacial cycles, such as food availability could also be significant. However, due to regional variation in shell calcification any modern proxy calibrations based on shell SNW are unlikely to be widely applicable. Modern (postindustrial) shell calcification is significantly lighter than Holocene samples from core-top 
locations, even within the same genotype groupings. However, as there appears to be no consistent relationship between $\left[\mathrm{CO}_{3}{ }^{-}\right]$and shell SNW, these post-industrial changes may reflect changes in foraminifera's food source and/or quantity. The quality and/or abundance of food may then in turn be affecting modern, post-industrial shell calcification. 


\section{Auxiliary Information}

AI 1.0. Modern environmental, core-top and plankton tow data used in this study.

C5-AI. Table 1. Modern environmental, core-top and plankton tow data used in this study. Core top and sediment trap data: world ocean atlas (WOA)- temperature (Locarnini et al., 2010), nutrients (Garcia et al., 2010). Core-top and sediment trap carbonate ion values for SW Pacific and Southern Ocean core sites are derived from Global Ocean Data Analysis Project (GLODAP) and CLIVAR databases. Chlorophyll- $a$ data is from the Giovanni NASA online database (Acker and Leptoukh, 2007) for all sites except $\mathrm{R}$ and $\mathrm{T}$ from Aldridge et al. (2012), due to their proximity to the coast. Unless otherwise stated, plankton tow data is that from the original Beer et al., (2010b) and Aldridge et al. (2012) papers, and North Atlantic pre-industrial core top carbonate ion values from Barker et al. (2003). South Atlantic temperature and carbonate ion values from de Villiers (2004). 


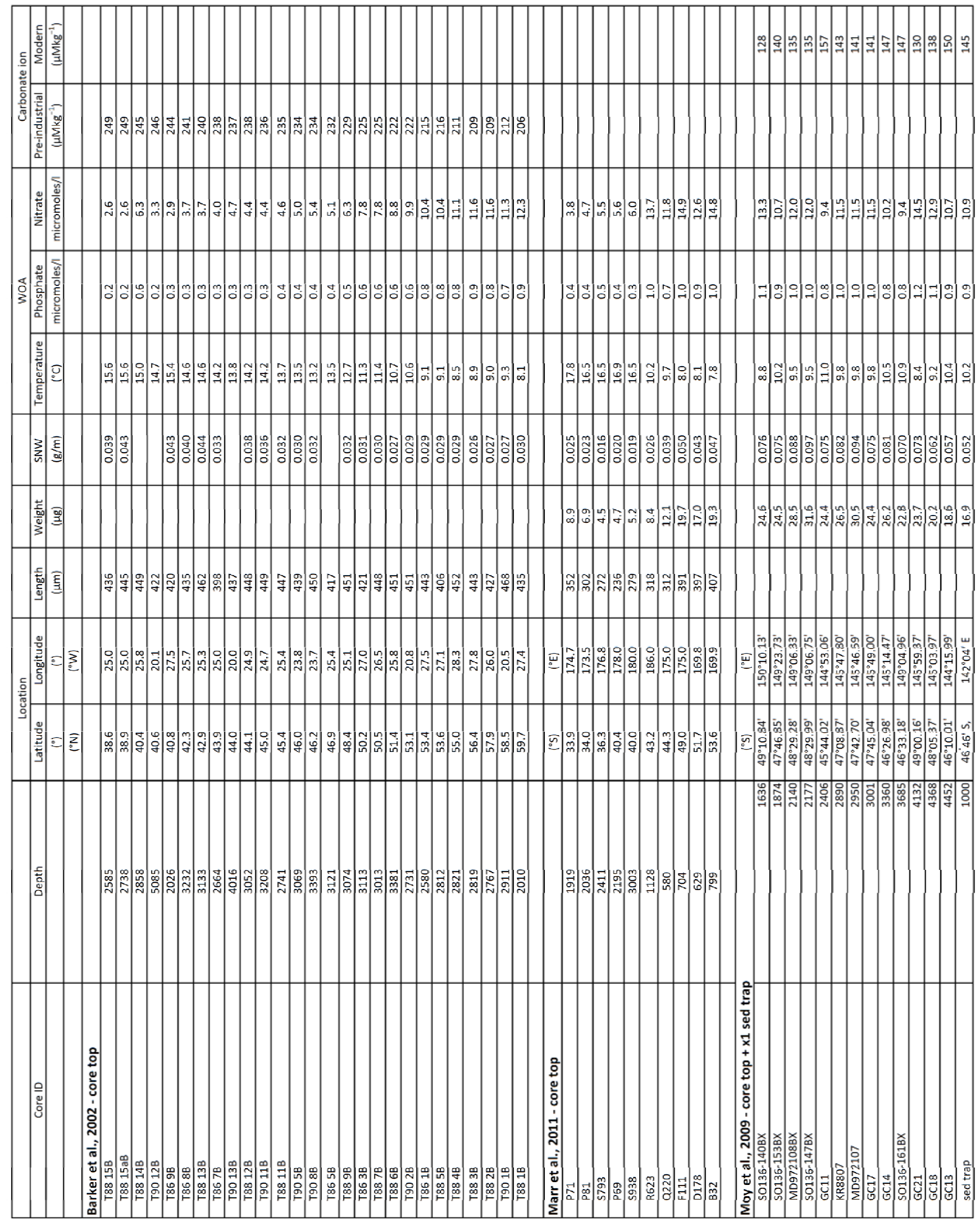




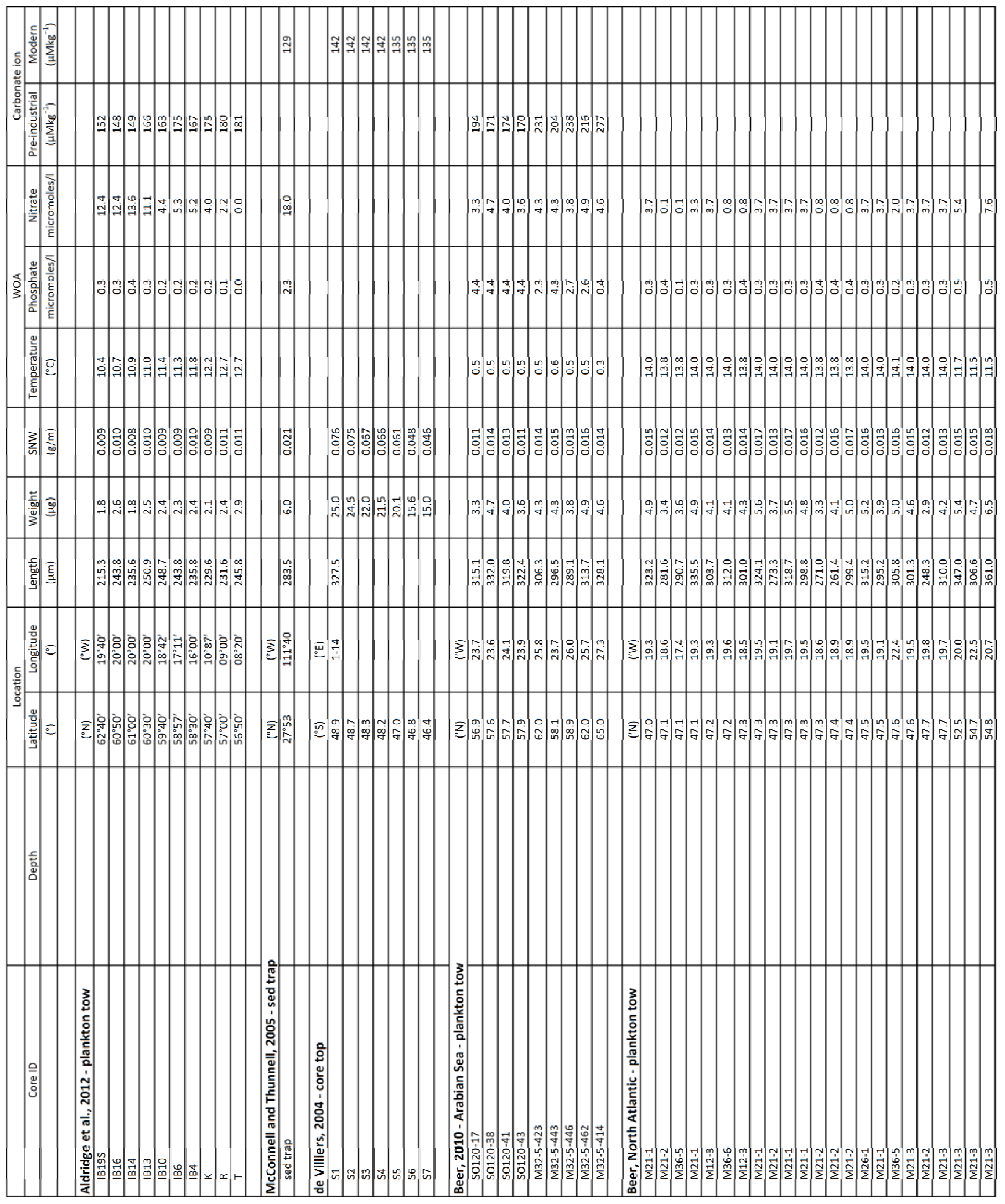


AI 2.0. 25ka-present data used in this study.

C5-AI. Table 2. 25ka-present data used in this study.

\begin{tabular}{|c|c|c|c|c|c|}
\hline \multirow[b]{2}{*}{$\begin{array}{l}\text { Number of } \\
\text { foraminifera } \\
\text { in sample }\end{array}$} & \multirow[b]{2}{*}{$\begin{array}{l}\text { Age } \\
\text { (kyrs) }\end{array}$} & \multirow[b]{2}{*}{ Depth } & \multicolumn{3}{|c|}{ G. bulloides } \\
\hline & & & $\mathrm{T}^{\circ} \mathrm{C}$ & 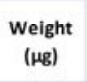 & $\begin{array}{l}\text { Length } \\
(\mu \mathrm{m})\end{array}$ \\
\hline 13 & 0.0 & $0.00-0.01 \mathrm{~m}$ & 20.1 & 4.05 & 263.3 \\
\hline 18 & 0.0 & $0.01-0.02 \mathrm{~m}$ & 18.0 & 5.50 & 310.7 \\
\hline 16 & 0.1 & $0.08-0.09 \mathrm{~m}$ & 18.6 & 5.24 & 301.6 \\
\hline 12 & 0.4 & $0.20-0.21 \mathrm{~m}$ & 18.0 & 4.56 & 274.1 \\
\hline 32 & 1.0 & $0.38-0.39 \mathrm{~m}$ & 16.8 & 4.99 & 301.6 \\
\hline 23 & 1.8 & $0.56-0.57 \mathrm{~m}$ & 20.3 & 5.67 & 309.2 \\
\hline 16 & 2.6 & $0.80-0.81 \mathrm{~m}$ & 19.2 & 5.14 & 303.5 \\
\hline 12 & 2.9 & $0.90-0.91 \mathrm{~m}$ & 18.1 & 5.20 & 295.8 \\
\hline 13 & 3.6 & $1.40-1.41 \mathrm{~m}$ & 19.6 & 5.51 & 307.8 \\
\hline 21 & 4.3 & $1.60-1.61 \mathrm{~m}$ & 21.1 & 5.33 & 307.4 \\
\hline 17 & 4.8 & $1.80-1.81 \mathrm{~m}$ & 18.0 & 5.76 & 294.5 \\
\hline 10 & 5.3 & $1.90-1.91 \mathrm{~m}$ & 14.5 & 7.73 & 343.7 \\
\hline 19 & 5.6 & $2.10-2.11 \mathrm{~m}$ & 16.2 & 7.41 & 292.0 \\
\hline 17 & 6.0 & $2.20-2.21 \mathrm{~m}$ & 18.7 & 7.41 & 318.5 \\
\hline 23 & 6.1 & $2.30-2.31 \mathrm{~m}$ & 19.6 & 6.67 & 313.0 \\
\hline 12 & 6.3 & $2.40-2.41 \mathrm{~m}$ & 16.9 & 5.25 & 282.1 \\
\hline 12 & 6.5 & $2.50-2.51 \mathrm{~m}$ & 13.9 & 5.70 & 304.4 \\
\hline 19 & 6.6 & $2.60-2.61 \mathrm{~m}$ & 20.5 & 6.30 & 304.9 \\
\hline 11 & 6.8 & $2.69-270 \mathrm{~m}$ & 11.0 & 9.53 & 362.3 \\
\hline 20 & 7.0 & $2.72-2.73 \mathrm{~m}$ & 18.8 & 6.17 & 302.6 \\
\hline 12 & 7.1 & $2.90-2.91 \mathrm{~m}$ & 20.1 & 4.98 & 288.3 \\
\hline 20 & 7.9 & $3.20-3.21 \mathrm{~m}$ & 15.4 & 5.53 & 288.0 \\
\hline 16 & 8.4 & $3.30-3.31 \mathrm{~m}$ & 18.7 & 7.68 & 347.4 \\
\hline 16 & 9.0 & $3.60-3.61 \mathrm{~m}$ & 18.1 & 6.04 & 319.2 \\
\hline 10 & 9.3 & $3.70-3.71 \mathrm{~m}$ & 13.6 & 8.46 & 366.5 \\
\hline 16 & 10.0 & $3.80-3.81 \mathrm{~m}$ & 16.6 & 5.62 & 315.9 \\
\hline 16 & 10.2 & $3.90-3.91 \mathrm{~m}$ & 15.0 & 7.60 & 360.0 \\
\hline 14 & 10.5 & $4.10-4.11 \mathrm{~m}$ & 13.9 & 6.27 & 303.3 \\
\hline 18 & 10.7 & $4.16-4.17 \mathrm{~m}$ & 14.3 & 7.04 & 334.9 \\
\hline 12 & 11.0 & $4.20-4.21 \mathrm{~m}$ & 17.5 & 5.89 & 298.1 \\
\hline 19 & 11.4 & $4.30-4.31 \mathrm{~m}$ & 13.5 & 5.98 & 310.4 \\
\hline 10 & 11.9 & $4.36-4.37 \mathrm{~m}$ & 14.9 & 7.16 & 317.0 \\
\hline 11 & 12.2 & $4.40-4.41 \mathrm{~m}$ & 12.1 & 7.09 & 328.0 \\
\hline 15 & 12.4 & $4.44-4.45 \mathrm{~m}$ & 17.6 & 6.00 & 314.0 \\
\hline 12 & 12.5 & $4.50-4.51 \mathrm{~m}$ & 10.7 & 8.62 & 347.6 \\
\hline 15 & 12.6 & $4.54-4.55 \mathrm{~m}$ & 8.9 & 9.65 & 366.4 \\
\hline 15 & 12.6 & $4.56-4.57 \mathrm{~m}$ & 12.0 & 12.70 & 358.5 \\
\hline 18 & 12.8 & $4.60-4.61 \mathrm{~m}$ & 14.4 & 7.50 & 331.7 \\
\hline 15 & 12.8 & $4.70-4.71 \mathrm{~m}$ & 14.6 & 6.92 & 324.1 \\
\hline 15 & 12.9 & $4.80-4.81 \mathrm{~m}$ & 14.8 & 13.64 & 375.7 \\
\hline 14 & 12.9 & $4.90-4.91 \mathrm{~m}$ & 11.7 & 10.06 & 381.6 \\
\hline 10 & 13.1 & $5.04-5.05 \mathrm{~m}$ & 11.6 & 13.64 & 375.7 \\
\hline 13 & 13.3 & $5.08-5.09 \mathrm{~m}$ & 4.9 & 15.10 & 417.4 \\
\hline 10 & 13.4 & $5.12-5.13 \mathrm{~m}$ & 7.2 & 11.02 & 375.7 \\
\hline 18 & 13.6 & $5.20-5.21 \mathrm{~m}$ & 14.2 & 11.10 & 369.1 \\
\hline 21 & 13.8 & $5.26-5.27 \mathrm{~m}$ & 5.6 & 19.80 & 434.0 \\
\hline 15 & 13.8 & $5.30-5.31 \mathrm{~m}$ & 13.8 & 11.69 & 385.8 \\
\hline 19 & 14.1 & $5.35-5.36 \mathrm{~m}$ & 8.3 & 12.23 & 372.8 \\
\hline 16 & 14.3 & $5.40-5.41 \mathrm{~m}$ & 12.9 & 12.45 & 366.7 \\
\hline 21 & 14.5 & $5.50-5.51 \mathrm{~m}$ & 7.4 & 17.47 & 374.0 \\
\hline 15 & 14.6 & $5.60-5.61 \mathrm{~m}$ & 9.0 & 11.40 & 374.0 \\
\hline 12 & 14.8 & $5.68-5.69 \mathrm{~m}$ & 10.2 & 11.05 & 380.7 \\
\hline 17 & 15.1 & $5.76-5.77 \mathrm{~m}$ & 12.2 & 12.57 & 383.1 \\
\hline 18 & 15.5 & $5.90-5.91 \mathrm{~m}$ & 10.5 & 12.66 & 382.5 \\
\hline 16 & 15.8 & $6.10-6.11 \mathrm{~m}$ & 10.5 & 12.22 & 393.9 \\
\hline 12 & 16.0 & $6.40-6.41 \mathrm{~m}$ & 11.1 & 5.70 & 310.5 \\
\hline 16 & 16.5 & $6.60-6.61 \mathrm{~m}$ & 19.4 & 6.88 & 340.5 \\
\hline 16 & 17.2 & $6.70-6.71 \mathrm{~m}$ & 15.1 & 8.83 & 341.1 \\
\hline 14 & 18.1 & $6.78-6.79 \mathrm{~m}$ & 8.9 & 7.93 & 310.8 \\
\hline 21 & 18.3 & $6.90-6.91 \mathrm{~m}$ & 14.5 & 8.96 & 323.4 \\
\hline 21 & 18.5 & $7.00-7.01 \mathrm{~m}$ & 15.0 & 9.25 & 348.6 \\
\hline 15 & 18.8 & $7.20-7.21 \mathrm{~m}$ & 13.0 & 8.94 & 384.9 \\
\hline 21 & 19.0 & $7.30-7.30 \mathrm{~m}$ & 10.1 & 10.02 & 354.2 \\
\hline 14 & 19.3 & $7.50-7.50 \mathrm{~m}$ & 12.5 & 10.07 & 349.9 \\
\hline 15 & 19.5 & $7.60-7.61 \mathrm{~m}$ & 19.8 & 12.69 & 345.5 \\
\hline 15 & 20.0 & $7.70-7.71 \mathrm{~m}$ & 7.6 & 12.72 & 366.7 \\
\hline 13 & 20.2 & $7.88-7.89 \mathrm{~m}$ & 9.8 & 13.19 & 367.4 \\
\hline 12 & 20.7 & $7.90-7.91 \mathrm{~m}$ & 6.6 & 13.63 & 356.2 \\
\hline 16 & 21.0 & $8.01-8.02 \mathrm{~m}$ & 13.0 & 0.94 & 301.9 \\
\hline 15 & 21.2 & $8.10-8.11 \mathrm{~m}$ & 9.3 & 12.67 & 352.4 \\
\hline 24 & 21.6 & $8.22-8.23 \mathrm{~m}$ & 5.3 & 13.62 & 376.5 \\
\hline 19 & 21.7 & $8.50-8.51 \mathrm{~m}$ & 15.5 & 10.89 & 367.3 \\
\hline 19 & 21.9 & $8.70-8.71 \mathrm{~m}$ & 13.4 & 9.45 & 351.2 \\
\hline 18 & 22.1 & $8.80-8.81 \mathrm{~m}$ & 9.2 & 9.41 & 351.1 \\
\hline 21 & 22.4 & $9.00-9.01 \mathrm{~m}$ & 8.7 & 11.27 & 356.4 \\
\hline 17 & 23.1 & $9.10-9.11 \mathrm{~m}$ & 10.2 & 11.27 & 366.1 \\
\hline 10 & 23.6 & $9.30-9.31 \mathrm{~m}$ & 11.6 & 12.88 & 352.2 \\
\hline
\end{tabular}


AI 3.0. MD97 2121 G. bulloides SNW compared to biogenic carbonate and silica mass accumulation rates.
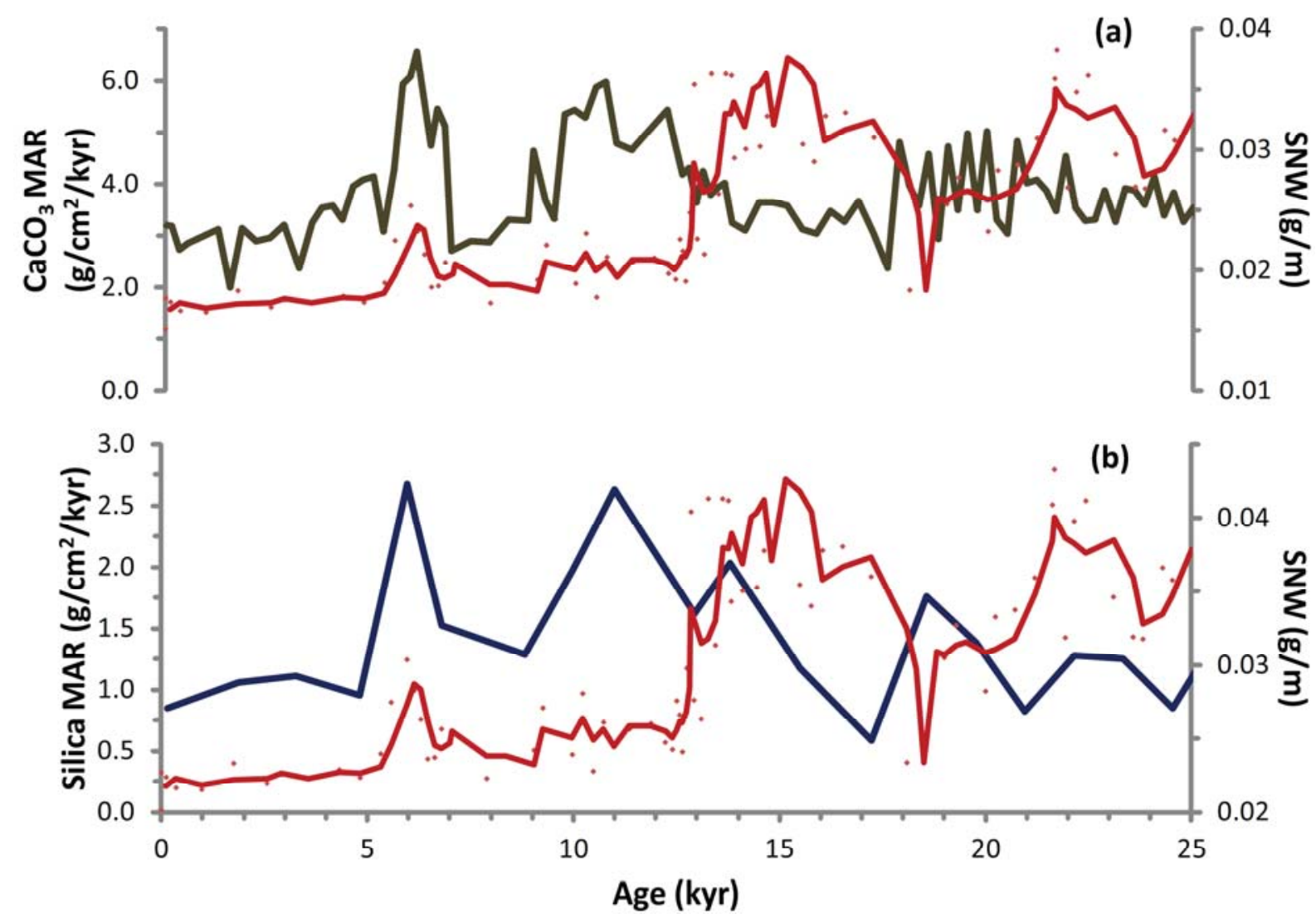

C5-AI. Fig. 1. MD97 2121 G. bulloides SNW (red) compared to biogenic carbonate (a-brown-repeated from Fig. 37) and silica (b-blue) mass accumulation rates (MAR) (Carter and Manighetti, 2006). There is no apparent relationship between the variables. Note, the relationship between surface ocean production and particulate export to the sea floor can be decoupled (Buesseler, 1998). In addition, productivity as measured by carbonate MARs are limited to organisms which produce a calcium carbonate shell, and are bias towards larger zooplankton organisms such as foraminifera (200-700 $\mu \mathrm{m})$. Therefore phytoplankton productivity from organisms such as coccolithophore (ca. 4-7 $\mu \mathrm{m})$ which are vital to the 'biological pump' are not well represented in carbonate MARs (Frenz et al., 2005; Legendre and Le Fevre, 1995). Carbonate and silicate MAR records at MD 972121 confirm that; 1) silica MARs are low compared to carbonate. There is a small increase in silica MARs of $0.38 \mathrm{~g} / \mathrm{cm}^{2} / \mathrm{kyr}$ and therefore an increase in production and/or preservation in the Holocene; 2) Mean carbonate MAR values between the last glacial and Holocene periods change little (3.74 vs. $3.96 \mathrm{~g} / \mathrm{cm}^{2} / \mathrm{kyr}$ ), however, carbonate MAR are more consistent during the glacial periods as compared to the Holocene. 
Chapter 6 


\section{Conclusions and Future Work}

\section{Conclusions}

This thesis has generated a high resolution data set from off the eastern North Island of New Zealand that identifies changes in the regional climate and ocean over the last 25 kyr. Highlighted is the dynamic interaction between STW and SAW, which has led to a new understanding of how foraminiferal geochemical and physical paleoceanographic proxies reflect their environment. Each of the six central objectives of this thesis, set out in Chapter 1, are summarized here.

Determine the reliability of the laser ablation technique for $\mathrm{Mg} / \mathrm{Ca}$ and other trace elements ratioed to calcium $(\mathrm{TE} / \mathrm{Ca})$ in foraminifera, and

* Compare geochemical techniques for measuring TE/Ca.

The second chapter in this thesis presents an investigation into the effects of different sample cleaning procedures on six trace element/Ca ratios in G. bulloides, a planktic species widely used in paleoenvironmental reconstructions. Foraminifera from coretop and down-core sediments were cleaned using seven different methods. Individual foraminifera were analysed before and after cleaning using laser ablation inductively coupled plasma mass spectrometry (LA-ICPMS). Oxidative and reductive cleaning and subsequent analyses using laser ablation and "pseudo" solution-based ICPMS methods were compared. Measurements of $\mathrm{Mg} / \mathrm{Ca}$ and $\mathrm{Sr} / \mathrm{Ca}$ values were identical whether samples were subjected to oxidative and reductive treatments, or 2-4 acid leach treatments. However, ultra trace elements $\mathrm{Al} / \mathrm{Ca}, \mathrm{Mn} / \mathrm{Ca}, \mathrm{Zn} / \mathrm{Ca}$ and $\mathrm{Ba} / \mathrm{Ca}$ are much more sensitive to the cleaning method, with up to an order-of-magnitude difference between techniques depending on the cleaning employed. Al/Ca was progressively removed with more intense cleaning, but six or more acid leach treatments were required for full removal of this contaminant. $\mathrm{Mn} / \mathrm{Ca}$ and $\mathrm{Ba} / \mathrm{Ca}$ required a combination of oxidative and reductive and/or acid leaching for contaminant phase removal. By contrast, $\mathrm{Zn} / \mathrm{Ca}$ values increased after acid leaching cleaning procedures, potentially indicating the preferential dissolution of low-Zn calcite. Accurate measurement of $\mathrm{Zn} / \mathrm{Ca}$ in planktic foraminifera by solution methods 
was found to require oxidative and reductive treatment without acid leaching or alternatively, the use of an in situ method such as laser LA- ICPMS. Careful data processing following LA- ICPMS analysis was found to be as the most effective method to ensure ultra trace metal contaminant phases were eliminated.

* Develop foraminiferal $\mathrm{Mg} / \mathrm{Ca}$ and other 'trace elements' $(\mathrm{TE} / \mathrm{Ca}$ ) as proxies for thermal and nutrient concentration and thus determine upper ocean stratification and,

* Test these proxies against modern core top and plankton tow samples before applying them to a paleoceanographic record that reveals major shifts the oceanography and climate over the last $25 \mathrm{kyr}$.

The third chapter presents data from SW Pacific core tops and down-core data from the high resolution sediment core, MD97 2121. Core-top data showed that $\mathrm{Zn} / \mathrm{Ca}$ and $\mathrm{Mn} / \mathrm{Ca}$ measurements in G. ruber and G. bulloides have the potential to trace SAW and STW surface waters, the latter tending to be elevated in these trace elements. In addition, intra-chamber offsets between chambers $f$ and $f-2$ of $G$. bulloides and interspecies offsets of the 0-50m dwelling G. ruber and deeper dwelling G. bulloides showed potential to reveal upper ocean nutrient and thermal stratification via $\mathrm{Zn} / \mathrm{Ca}$ and $\mathrm{Mg} / \mathrm{Ca}$ ratios, respectively. Furthermore, $\mathrm{Zn} / \mathrm{Ca}$ and $\mathrm{Mn} / \mathrm{Ca}$ data analysed from MD97 2121, paired with $\mathrm{Mg} / \mathrm{Ca}$ paleothermometry, alkenones, foraminiferal assemblages, carbonate and silicate contents, and stable isotopes, revealed major changes in the ocean over the past $25 \mathrm{kyr}$ as follows. At the Last Glacial Maximum, mean surface water temperatures were ca. $6-7^{\circ} \mathrm{C}$ lower than present, accompanied by low levels of $\mathrm{Mn} / \mathrm{Ca}$ and $\mathrm{Zn} / \mathrm{Ca}$, and minimal thermal and nutrient stratification. These findings are consistent with a regional dominance of SAW and reduced STW inflow associated with a reduced South Pacific Gyre. From 17.5-14.5 ka an anomalous period occurred, coinciding with the previously recognised 'Mystery Interval' when G. bulloides paleotemperatures cooled by ca. $1{ }^{\circ} \mathrm{C} / \mathrm{ka}$, accompanied by an increase in polar species faunal abundance, whereas alkenone temperatures continued to warm. It is likely that this offset was caused by seasonal upwelling, which due to the sub-surface position of G. bulloides in the water column and its tendency to bloom in spring in the subantarctic waters, was significantly affected relative to the summer blooming, surface dwelling coccolithophores. Upper ocean 
thermal and nutrient stratification appeared to collapse during the Antarctic Cold Reversal. After this, the poleward migration of zonal winds and ocean fronts increased the STW inflow, and together with reduced winds, favoured a predominently stratified upper ocean from ca.10 ka to present.

* Evaluate the reason(s) behind differences between various proxies used to determine sea surface temperatures.

In Chapter Five a comparison between two independent paleothermometry records from the LGM to modern is presented. The broad, long term trends in alkenone and $G$. bulloides $\mathrm{Mg} / \mathrm{Ca}$ based temperature estimates generally agree. There was, however, an inconsistent offset between G. bulloides and alkenone temperature records up to $6{ }^{\circ} \mathrm{C}$ during the glacial period. The relative influence of the STW and SAW waters that overlay MD97 2121 had a significant influence on paleo-temperature estimates. During the glacial period (25-16 ka), when the study site was bathed by SAW, the alkenones production was probably limited to summer. However, during this same period, G. bulloides most likely followed a spring bloom cycle. During the Holocene, alkenones and G. bulloides peak fluxes are likely closely aligned with the modern accumulation periods during summer north of and spring south of the Subtropical Front. Therefore, the lack of offset between the paleothermometer temperature estimates is consistent with a return to modern ocean conditions. The findings of this study highlighted the susceptibility of foraminiferal and alkenone-based paleothermometry records to the influence of changing regional hydrology and highlights the complimentary nature of combining different proxies (from a single site).

* Investigate the potential use of G. bulloides test weights as a paleoceanographic proxy.

Chapter Six investigates published hypotheses that higher surface water carbonate ion concentrations are the primary cause of an increased G. bulloides shell calcification during glacial periods. This hypothesis is largely based on studies from a North Atlantic setting. However, this chapter takes a novel approach by comparing data from the SW Pacific with previously published data from around to world to assess any inter-basin ocean differences in species calcification. Modern ocean general linear 
models indicated that an 'ocean effect,' which reflects a combination of factors that contribute to a specific ocean environment, was the most significant factor in determining shell size normalised weight $(\mathrm{SNW})\left(\mathrm{r}^{2}>0.90\right)$. This effect is likely reflected in the various combinations of environmental parameters by the geographic distribution of species genotypes. However, comparison of linear regional trends between oceans showed no consistent relationship between temperature, nutrient or carbonate ion concentrations and shell calcification. A weak negative inter-basin correlation between shell SNW and chlorophyll- $a$ concentration was identified, highlighting the importance of food in the dynamics of foraminiferal calcification. Comparison of geochemical and SNW data back to the LGM from the North Atlantic and SW Pacific Oceans confirmed that at mid-latitudes G. bulloides shell SNW increased during the glacial period, regardless of ocean region. This may reflect multiple factors including increased surface ocean carbonate ion concentration and $\mathrm{pH}$ and elevated levels of primary productivity. However, as calcification of G. bulloides appears to be region specific, shell SNW proxy is limited to the local environment it was developed for.

Overall, the work presented in this thesis demonstrates that trace metals in foraminiferal test calcite as measured using LA-ICPMS are potentially reliable paleoenvironmental recorders. Furthermore, the offset in $\mathrm{Mg} / \mathrm{Ca}$ and $\mathrm{Zn} / \mathrm{Ca}$ between the chambers of $G$. bulloides can respectively reconstruct the thermal and nutrient surface water stratification of the paleocean. This information, combined with regional paleoceanographic data, enabled the reconstruction of dynamics of the SW Pacific surface ocean under polar and subtropical forcing from the LGM to present. Moreover, the impact of the interaction between these competing water masses on the seasonality of plankton species, and thus their paleotemperature estimates, highlighted the need for caution when interpreting multi-proxy records. Finally, Darwinian Theory of species evolution was born out when looking at G. bulloides SNW after it was found that shell calcification appears to reflect species specific adaptations to regional environments. However, the universal trend towards heavier SNW during glacial periods suggests that an increase in surface water carbonate ion concentrations, higher $\mathrm{pH}$ and a change to more turbulent surface water likely encouraged 
calcification in all genotypes. As these parameters are likely to be region specific, a universal SNW based paleo-proxy is unlikely.

\section{Future Work}

Foraminifera shells act as time capsules, in essence capturing and preserving information about their environment and thus the wider ocean climate in which they grew. If both the geochemical and physical information contained within the calcite shells is able to be understood, this can provide key insights about how climate may change in the future. Work in this thesis raises several exciting possibilities that can be further advanced along the following lines;

* Analyse multiple core tops from the SW Pacific Ocean, first using laser ablation-ICPMS, and then using solution-ICPMS on the same foraminifera samples to enable a direct comparison between the two techniques for trace and ultra-trace element measurements.

* Conduct trials on the use of $\mathrm{Zn} / \mathrm{Ca}$ as a water mass/micronutrient tracer in different ocean regions using laser ablation techniques on plankton tow samples concomitant with water mass chemistry and physical oceanography for selected sites around NZ including use of long term sediment trap data to assess any inter-annual variability.

* Investigate multiple high resolution paleothermometry multi-proxy records to assess the offset between thermometers to see if there is a consistent trend, e.g. change in frontal movements, and therefore water mass influence, seasonal variability in algal and foraminiferal blooms. This investigation could be extended to compare to other types of paleotemperature proxies such as TEX86.

* Conduct systematic sampling of G. bulloides from different ocean regions with distinctive genotypes. Those samples would be the basis for further research including, size normalised weight, trace metal and isotope analysis to assess any systematic offset which may be a function of genotype-specific trait. 


\section{Reference List}

Acker, J.G., Leptoukh, G., 2007. Online analysis enhances use of NASA earth science data. Eos. Trans. AGU, 88(2): 14, 17.

Aldridge, D., Beer, C.J., Purdie, D.A., 2012. Calcification in the planktonic foraminifera Globigerina bulloides linked to phosphate concentrations in surface waters of the North Atlantic Ocean. Biogeosciences, 9(5): 1725-1739.

Allan, W., Harrison, S.M., Lott, L., 1973. Orbulina universa d'Orbigny in the Indian Ocean. Micropaleontology, 19(2): 150-192.

Allen, K.A. et al., 2011. Controls on boron incorporation in cultured tests of the planktic foraminifer Orbulina universa. Earth and Planetary Science Letters, 309(3-4): 291-301.

Anand, P., Elderfield, H., Conte, M.H., 2003. Calibration of $\mathrm{Mg} / \mathrm{Ca}$ thermometry in planktonic foraminifera from a sediment trap time series. Paleoceanography, 18(2): 1050.

Anderson, O.R., Faber, W.W., 1984. An estimation of calcium carbonate deposition rate in a planktonic foraminifer Globigerinoides sacculifer using ${ }^{45} \mathrm{Ca}$ as a tracer; a recommended procedure for improved accuracy. The Journal of Foraminiferal Research, 14(4): 303-308.

Anderson, R.F. et al., 2009. Wind-driven upwelling in the Southern Ocean and the deglacial rise in atmospheric $\mathrm{CO}_{2}$. Science, 323(5920): 1443-1448.

Archer, D., Maier-Reimer, E., 1994. Effect of deep-sea sedimentary calcite preservation on atmospheric $\mathrm{CO}_{2}$ concentration. Nature, 367(6460): 260-263.

Bacon, M.P., Edmond, J.M., 1972. Barium at Geosecs III in the southwest Pacific. Earth and Planetary Science Letters, 16(1): 66-74.

Barker, S., 2002a. Planktonic foraminiferal proxies for temperature and $\mathrm{pCO}_{2}$, University of Cambridge, Cambridge, UK, 135 pp.

Barker, S., 2002b. Planktonic foraminiferal proxies for temperature and $p \mathrm{CO}_{2}$, University of Cambridge.

Barker, S., Elderfield, H., 2002. Foraminiferal calcification response to glacial-interglacial changes in atmospheric $\mathrm{CO}_{2}$. Science, 297(5582): 833-836.

Barker, S., Greaves, M., Elderfield, H., 2003a. A study of cleaning procedures used for foraminiferal $\mathrm{Mg} / \mathrm{Ca}$ paleothermometry. Geochem. Geophys. Geosyst., 4(9).

Barker, S., Higgins, J.A., Elderfield, H., 2003b. The future of the carbon cycle: review, calcification response, ballast and feedback on atmospheric $\mathrm{CO}_{2}$. Philosophical Transactions of the Royal Society of London. Series A: Mathematical, Physical and Engineering Sciences, 361(1810): 1977-1999.

Barrows, T.T., Juggins, S., De Deckker, P., Calvo, E., Pelejero, C., 2007. Long-term sea surface temperature and climate change in the Australian-New Zealand region. Paleoceanography, 22(2): PA2215.

Bé, A.W.H., 1977. An Ecological, Zoogeographic and Taxonomic Review of Recent Planktonic Foraminifera, 1. Academic, San Diego, Calif.

Bé, A.W.H., 1980. Gametogenic calcification in a spinose planktonic foraminifer, Globigerinoides sacculifer (Brady). Marine Micropaleontology, 5: 283-310.

Bé, A.W.H., Hemleben, C., Anderson, O.R., Spindler, M., 1979. Chamber formation in planktonic foraminifera. Micropaleontology, 25(3): 294-307.

Bé, A.W.H., Hemleben, C., Anderson, O.R., Spindler, M., 1980. Pore structures in planktonic foraminifera. The Journal of Foraminiferal Research, 10(2): 117-128.

Bé, A.W.H., Hutson, W.H., 1977. Ecology of Planktonic Foraminifera and Biogeographic Patterns of Life and Fossil Assemblages in the Indian Ocean. Micropaleontology, 23(4): 369-414.

Bé, A.W.H., Spero, H.J., Anderson, O.R., 1982. Effects of symbiont elimination and reinfection on the life processes of the planktonic foraminifer Globigerinoides sacculifer. Marine Biology, 70(1): 73-86.

Beer, C.J., 2010. Planktic foraminifera, ocean sediments and the palaeo-marine carbonate system. Doctoral Thesis, University of Southampton, $144 \mathrm{pp}$. 
Beer, C.J., Schiebel, R., Wilson, P.A., 2010a. Technical Note: Determining the size-normalised weight of planktic foraminifera. Biogeosciences, 7: 2193-2198.

Beer, C.J., Schiebel, R., Wilson, P.A., 2010b. Testing planktic foraminiferal shell weight as a surface water $\left[\mathrm{CO}_{3}{ }^{2-}\right]$ proxy using plankton net samples. Geology, 38(2): 103-106.

Bemis, B.E., Spero, H.J., Thunell, R.C., 2002. Using species-specific paleotemperature equations with foraminifera: a case study in the Southern California Bight. Marine Micropaleontology, 46(34): 405-430.

Bender, M.L., Lorens, R.B., Williams, D.F., 1975. Sodium, magnesium and strontium in the tests of planktonic foraminifera. Micropaleontology, 21(4): 448-459.

Bentov, S., Erez, J., 2005. Novel observations on biomineralization processes in foraminifera and implications for $\mathrm{Mg} / \mathrm{Ca}$ ratio in the shells. Geology, 33(11): 841-844.

Bentov, S., Erez, J., 2006. Impact of biomineralization processes on the Mg content of foraminiferal shells: A biological perspective. Geochem. Geophys. Geosyst., 7(1): Q01P08.

Benway, H.M., Haley, B.A., Klinkhammer, G.P., Mix, A.C., 2003. Adaptation of a flow-through leaching procedure for $\mathrm{Mg} / \mathrm{Ca}$ paleothermometry. Geochem. Geophys. Geosyst., 4(2): 8403.

Berger, A., Loutre, M.F., 1992. Astronomical solutions for paleoclimate studies over the last 3 million years. Earth and Planetary Science Letters, 111(2-4): 369-382.

Berger, W.H., 1971. Sedimentation of planktonic foraminifera. Marine Geology, 11(5): 325-358.

Blackburn, S.I., Cresswell, G.R., 1993. A coccolithophorid bloom in Jervis Bay, Australia. Marine and Freshwater Research, 44(2): 253-260.

Boiteau, R., Greaves, M., Elderfield, H., 2012. Authigenic uranium in foraminiferal coatings: A proxy for ocean redox chemistry. Paleoceanography, 27(3): PA3227.

Bolton, A. et al., 2011. Environmental versus biological controls on $\mathrm{Mg} / \mathrm{Ca}$ variability in Globigerinoides ruber (white) from core top and plankton tow samples in the southwest Pacific Ocean. Paleoceanography, 26(2): PA2219.

Bostock, H.C., Hayward, B.W., Neil, H.L., Currie, K.I., Dunbar, G.B., 2011. Deep-water carbonate concentrations in the southwest Pacific. Deep Sea Research Part I: Oceanographic Research Papers, 58(1): 72-85.

Bostock, H.C., Sutton, P.J., Williams, M.J.M., Opdyke, B.N., 2013. Reviewing the circulation and mixing of Antarctic Intermediate Water in the South Pacific using evidence from geochemical tracers and Argo float trajectories. Deep Sea Research Part I: Oceanographic Research Papers, 73(0): 84-98.

Bowie, A.R. et al., 2009. Biogeochemical iron budgets of the Southern Ocean south of Australia: Decoupling of iron and nutrient cycles in the subantarctic zone by the summertime supply. Global Biogeochem. Cycles, 23(4): GB4034.

Boyd, P., LaRoche, J., Gall, M., Frew, R., McKay, R.M.L., 1999. Role of iron, light, and silicate in controlling algal biomass in subantarctic waters SE of New Zealand. J. Geophys. Res., 104(C6): 13395-13408.

Boyd, P.W. et al., 2001. Control of phytoplankton growth by iron supply and irradiance in the subantarctic Southern Ocean: Experimental results from the SAZ Project. J. Geophys. Res., 106(C12): 31573-31583.

Boyle, E.A., 1981. Cadmium, zinc, copper, and barium in foraminifera tests. Earth and Planetary Science Letters, 53(1): 11-35.

Boyle, E.A., 1983. Manganese carbonate overgrowths on foraminifera tests. Geochimica et Cosmochimica Acta, 47(10): 1815-1819.

Boyle, E.A., 1995. Limits on benthic foraminiferal chemical analyses as precise measures of environmental properties. The Journal of Foraminiferal Research, 25(1): 4-13.

Boyle, E.A., Keigwin, L.D., 1985. Comparison of Atlantic and Pacific paleochemical records for the last 215,000 years: changes in deep ocean circulation and chemical inventories. Earth and Planetary Science Letters, 76(1-2): 135-150.

Brady, H.B., 1876. A monograph of Carboniferous and Permian Foraminifera (the genus Fusilina excepted). printed for the Palaeontological Society, London.

Brady, H.B., 1884. Report on the foraminifera dredged by H.M.S. Challenger during the years 18731876. 
Brassell, S.C., Eglinton, G., Marlowe, I.T., Pflaumann, U., Sarnthein, M., 1986. Molecular stratigraphy: a new tool for climatic assessment. Nature, 320(6058): 129-133.

Broecker, W.S., Clark, E., 2002. Carbonate ion concentration in glacial-age deep waters of the Caribbean Sea. Geochem. Geophys. Geosyst., 3(3): 1021.

Broecker, W.S., Maier-Reimer, E., 1992. The influence of air and sea exchange on the carbon isotope distribution in the sea. Global Biogeochemical Cycles, 6(3): 315-320.

Broecker, W.S., Peng, T.H., 1982. Tracers in the Sea. Eldigio Press, New York.

Brown, S.J., Elderfield, H., 1996. Variations in $\mathrm{Mg} / \mathrm{Ca}$ and $\mathrm{Sr} / \mathrm{Ca}$ Ratios of Planktonic Foraminifera Caused by Postdepositional Dissolution: Evidence of Shallow Mg-Dependent Dissolution. Paleoceanography, 11(5): 543-551.

Bruland, K.W., Lohan, M.C., 2003. 6.02 - Controls of trace metals in seawater. In: Heinrich, D.H., Karl, K.T. (Eds.), Treatise on Geochemistry. Pergamon, Oxford, pp. 23-47.

Buesseler, K.O., 1998. The decoupling of production and particulate export in the surface ocean. Global Biogeochemical Cycles, 12(2): 297-310.

Caldeira, K., Wickett, M.E., 2003. Oceanography: Anthropogenic carbon and ocean pH. Nature, 425(6956): 365-365.

Calvo, E., Pelejero, C., De Deckker, P., Logan, G.A., 2007. Antarctic deglacial pattern in a 30 kyr record of sea surface temperature offshore South Australia. Geophys. Res. Lett., 34(13): L13707.

Carpenter, S.R., Kitchell, J.F., Hodgson, J.R., 1985. Cascading Trophic Interactions and Lake Productivity. BioScience, 35(10): 634-639.

Carter, L., Manighetti, B., 2006. Glacial/interglacial control of terrigenous and biogenic fluxes in the deep ocean off a high input, collisional margin: A 139 kyr-record from New Zealand. Marine Geology, 226(3-4): 307-322.

Carter, L., Manighetti, B., Elliot, M., Trustrum, N., Gomez, B., 2002. Source, sea level and circulation effects on the sediment flux to the deep ocean over the past $15 \mathrm{ka}$ off eastern New Zealand. Global and Planetary Change, 33(3-4): 339-355.

Carter, L., Manighetti, B., Ganssen, G., Northcote, L., 2008. Southwest Pacific modulation of abrupt climate change during the Antarctic Cold Reversal-Younger Dryas. Palaeogeography, Palaeoclimatology, Palaeoecology, 260(1-2): 284-298.

Carter, L., Neil, H.L., McCave, I.N., 2000. Glacial to interglacial changes in non-carbonate and carbonate accumulation in the SW Pacific Ocean, New Zealand. Palaeogeography, Palaeoclimatology, Palaeoecology, 162(3-4): 333-356.

Chan, L.H., Drummond, D., Edmond, J.M., Grant, B., 1977. On the barium data from the Atlantic GEOSECS expedition. Deep Sea Research, 24(7): 613-649.

Chan, L.H. et al., 1976. Radium and barium at GEOSECS stations in the Atlantic and Pacific. Earth and Planetary Science Letters, 32(2): 258-267.

Chang, G.C., Dickey, T.D., Mobley, C.D., Boss, E., Pegau, W.S., 2003. Toward closure of upwelling radiance in coastal waters. Appl. Opt., 42(9): 1574-1582.

Chiswell, S.M., 2000. The Wairarapa Coastal Current. New Zealand Journal of Marine and Freshwater Research, 34(2): 303-315.

Chiswell, S.M., 2002a. Temperature and salinity mean and variability within the subtropical front over the Chatham rise, New Zealand. New Zealand Journal of Marine and Freshwater Research, 36(2): 281-298.

Chiswell, S.M., 2002b. Wairarapa coastal current inflence on sea surface temperature in Hawke Bay, New Zealand. New Zealand Journal of Marine and Freshwater Research, 36(2): 267-279.

Chiswell, S.M., 2005. Mean and variability in the Wairarapa and Hikurangi Eddies, New Zealand. N. Z. J. Mar. Freshwater Res., 39: 121-134.

Clemens, S., Prell, W., Murray, D., Shimmield, G., Weedon, G., 1991. Forcing mechanisms of the Indian Ocean monsoon. Nature, 353(6346): 720-725.

Clemens, S.C., Prell, W.L., 2003. A 350,000 year summer-monsoon multi-proxy stack from the Owen Ridge, Northern Arabian Sea. Marine Geology, 201(1-3): 35-51.

Cléroux, C. et al., 2008. $\mathrm{Mg} / \mathrm{Ca}$ and $\mathrm{Sr} / \mathrm{Ca}$ ratios in planktonic foraminifera: Proxies for upper water column temperature reconstruction. Paleoceanography, 23(3): PA3214. 
CLIMAP, 1976. The Surface of the Ice-Age Earth. Science, 191(4232): 1131-1137.

CLIMAP, 1981. Seasonal reconstruction of the Earth's surface at the last glacial maximum, Map and Chart Series. Geological Society of America.

Cole, S., McCarthy, L., 2012. NASA Finds 2011 Ninth-Warmest Year on Record. NASA Headquarters release, No. 12-020.

Condie, S.A., Dunn, J.R., 2006. Seasonal characteristics of the surface mixed layer in the Australasian region: implications for primary production regimes and biogeography. Marine and Freshwater Research, 57(6): 569-590.

Conte, M., Volkman, J.K., Eglinton, G. (Eds.), 1994. Lipid biomarkers of the Haptophyta. The Haptophyte Algae. Clarendon Press, Oxford, 351-377 pp.

Croot, P.L., Hunter, K.A., 1998. Trace metal distributions across the continental shelf near Otago Peninsula, New Zealand. Marine Chemistry, 62(3-4): 185-201.

Crundwell, M., Scott, G.H., Naish, T.R., Carter, L., 2008. Glacial-interglacial ocean climate variability from planktonic foraminifera during the Mid-Pleistocene transition in the temperate Southwest Pacific, ODP Site 1123. Palaeogeography, Palaeoclimatology, Palaeoecology, 260(1-2): 202-229.

d'Orbigny, A., 1826. Tableau methodique de la classe des Cephalopodes. Ann. Sci. Nat., 1(7): 245314.

d'Orbigny, A., 1839. Histoire physique, politique et naturelle de l'ille de Cuba. Part 2: Natural History Foraminiferes. A. Bertrand, Paris, pp. 1-224.

Darling, K.F., Kucera, M., Wade, C.M., 2007. Global molecular phylogeography reveals persistent Arctic circumpolar isolation in a marine planktonic protist. Proceedings of the National Academy of Sciences, 104(12): 5002-5007.

Darling, K.F., Kucera, M., Wade, C.M., von Langen, P., Pak, D., 2003. Seasonal distribution of genetic types of planktonic foraminifer morphospecies in the Santa Barbara Channel and its paleoceanographic implications. Paleoceanography, 18(2): 1032.

Darling, K.F., Wade, C.M., 2008. The genetic diversity of planktic foraminifera and the global distribution of ribosomal RNA genotypes. Marine Micropaleontology, 67(3-4): 216-238.

Darling, K.F., Wade, C.M., Kroon, D., Brown, A.J.L., Bijma, J., 1999. The diversity and distribution of modern planktic foraminiferal small subunit ribosomal RNA genotypes and their potential as tracers of present and past ocean circulations. Paleoceanography, 14(1): 3-12.

Darling, K.F. et al., 2000. Molecular evidence for genetic mixing of Arctic and Antarctic subpolar populations of planktonic foraminifers. Nature, 405(6782): 43-47.

de Nooijer, L.J., Toyofuku, T., Kitazato, H., 2009. Foraminifera promote calcification by elevating their intracellular $\mathrm{pH}$. Proceedings of the National Academy of Sciences, 106(36): 1537415378.

de Vargas, C., Zaninetti, L., Hilbrecht, H., Pawlowski, J., 1997. Phylogeny and rates of molecular evolution of planktonic foraminifera: SSU rDNA sequences compared to the fossil record. Journal of Molecular Evolution, 45(3): 285-294.

de Villiers, S., 1999. Seawater strontium and $\mathrm{Sr} / \mathrm{Ca}$ variability in the Atlantic and Pacific oceans. Earth and Planetary Science Letters, 171(4): 623-634.

de Villiers, S., 2004. Optimum growth conditions as opposed to calcite saturation as a control on the calcification rate and shell-weight of marine foraminifera. Marine Biology, 144(1): 45-49.

Dekens, P.S., Lea, D.W., Pak, D.K., Spero, H.J., 2002. Core top calibration of $\mathrm{Mg} / \mathrm{Ca}$ in tropical foraminifera: Refining paleotemperature estimation. Geochem. Geophys. Geosyst., 3(4): 1022.

Delaney, M.L., 1989. Uptake of cadmium into calcite shells by planktonic foraminifera. Chemical Geology, 78(2): 159-165.

Delaney, M.L., Bé, A.W.H., Boyle, E.A., 1985. Li, Sr, Mg, and $\mathrm{Na}$ in foraminiferal calcite shells from laboratory culture, sediment traps, and sediment cores. Geochimica et Cosmoschimica Acta, 49(6): 1327-1341.

deMenocal, P., Ortiz, J., Guilderson, T., Sarnthein, M., 2000. Coherent High- and Low-Latitude Climate Variability During the Holocene Warm Period. Science, 288(5474): 2198-2202.

Denton, G.H. et al., 2010. The last glacial termination. Science, 328(5986): 1652-1656. 
Dixon, W.J., Massey, F.J., 1969. Introduction to statistical analysis. McGraw-Hill Book Company, Tokyo.

Duncan, B., 2012. Environmental controls on coccolithophore blooms in the southwest Pacific Ocean during marine isotope stages $5 \mathrm{e}(125 \mathrm{Ka})$ and $7 \mathrm{a}(210 \mathrm{Ka})$, Victoria University of Wellington, Wellington.

Eggins, S., De Deckker, P., Marshall, J., 2003a. Mg/Ca variation in planktonic foraminifera tests: implications for reconstructing palaeo-seawater temperature and habitat migration. Earth and Planetary Science Letters, 212(3-4): 291-306.

Eggins, S., De Deckker, P., Marshall, J., 2003b. $\mathrm{Mg} / \mathrm{Ca}$ variation in planktonic foraminifera tests: Implications for reconstructing palaeo-seawater temperature and habitat migration. Earth Planet. Sci. Lett., 212(3-4): 291-306.

Eggins, S.M., Sadekov, A., De Deckker, P., 2004. Modulation and daily banding of $\mathrm{Mg} / \mathrm{Ca}$ in Orbulina universa tests by symbiont photosynthesis and respiration: a complication for seawater thermometry? Earth and Planetary Science Letters, 225(3-4): 411-419.

Elderfield, H., Ganssen, G., 2000. Past temperature and $\delta^{18} \mathrm{O}$ of surface ocean waters inferred from foraminiferal $\mathrm{Mg} / \mathrm{Ca}$ ratios. Nature, 405(6785): 442-445.

Ellwood, M.J., 2004. Zinc and cadmium speciation in subantarctic waters east of New Zealand. Marine Chemistry, 87(1-2): 37-58.

Ellwood, M.J., Boyd, P.W., Sutton, P., 2008. Winter-time dissolved iron and nutrient distributions in the Subantarctic Zone from 40-52S; 155-160E. Geophys. Res. Lett., 35(11): L11604.

EPICA et al., 2004. Eight glacial cycles from an Antarctic ice core. Nature, 429(6992): 623-628.

Erez, J., 2003. The source of ions for biomineralization in foraminifera and their implications for paleoceanographic proxies. Reviews in Mineralogy and Geochemistry, 54(1): 115-149.

Erez, J., Almogi-Labin, A., Avraham, S., 1991. On the life history of planktonic foraminifera: lunar reproduction cycle in Globigerinoides Sacculifer (Brady). Paleoceanography, 6(3): 295-306.

Fenner, J., Carter, L., Stewart, R., 1992. Late Quaternary paleoclimatic and paleoceanographic change over northern Chatham Rise, New Zealand. Marine Geology, 108(3-4): 383-404.

Ferguson, J.E., Henderson, G.M., Kucera, M., Rickaby, R.E.M., 2008. Systematic change of foraminiferal $\mathrm{Mg} / \mathrm{Ca}$ ratios across a strong salinity gradient. Earth and Planetary Science Letters, 265(1-2): 153-166.

Flynn, K.J. et al., 2012. Changes in $\mathrm{pH}$ at the exterior surface of plankton with ocean acidification. Nature Climate Change, advance online publication.

Foster, G.L., 2008. Seawater pH, pCO2 and [CO2-3] variations in the Caribbean Sea over the last 130 kyr: A boron isotope and B/Ca study of planktic foraminifera. Earth and Planetary Science Letters, 271(1-4): 254-266.

Frenz, M., Baumann, K.-H., Boeckel, B., Höppner, R., Henrich, R., 2005. Quantification of foraminifer and coccolith carbonate in South Atlantic surface sediments by means of carbonate grain-size distributions. Journal of Sedimentary Research, 75(3): 464-475.

Frew, R., Bowie, A., Croot, P., Pickmere, S., 2001. Macronutrient and trace-metal geochemistry of an in situ iron-induced Southern Ocean bloom. Deep Sea Research Part II: Topical Studies in Oceanography, 48(11-12): 2467-2481.

Frew, R.D., Hunter, K.A., 1995. Cadmium-phosphorus cycling at the subtropical convergence south of New Zealand. Marine Chemistry, 51(3): 223-237.

Gaillardet, J., Viers, J., Dupré, B., 2003. 5.09 - Trace Elements in River Waters. In: Heinrich, D.H., Karl, K.T. (Eds.), Treatise on Geochemistry. Pergamon, Oxford, pp. 225-272.

Garcia, H.E., Locarnini, R.A., Boyer, T.P., Antonov, J.I., 2010. Volume 4: Nutrients (phosphate, nitrate, silicate). In: Levitus, S. (Editor), World Ocean Atlas 2009. NOAA Atlas NESDIS 71, U.S. Government Printing Office, Washington, D.C., pp. 398.

Garner, D.M., 1961. Hydrology of New Zealand coastal waters, 1955. New Zealand Oceanographic Institute, Wellington.

Gomez, B. et al., 2012. ENSO/SAM interactions during the middle and late Holocene. The Holocene, 22(1): 23-30.

Gonzalez-Mora, B., Sierro, F.J., Flores, J.A., 2008. Controls of shell calcification in planktonic foraminifers. Quaternary Science Reviews, 27(9-10): 956-961. 
Gordon, A.L., 1975. An Antarctic oceanographic section along $170^{\circ}$ E. Deep Sea Research and Oceanographic Abstracts, 22(6): 357-377.

Hair, J.F., Anderson, R.E., Tatham, R.L., Black, W.C., 2005. Multivariate data analysis. Prentice-Hall, New Jersey.

Haley, B.A., Klinkhammer, G.P., 2002. Development of a flow-through system for cleaning and dissolving foraminiferal tests. Chemical Geology, 185(1-2): 51-69.

Hall, I.R., McCave, I.N., Shackleton, N.J., Weedon, G.P., Harris, S.E., 2001. Intensified deep Pacific inflow and ventilation in Pleistocene glacial times. Nature, 412(6849): 809-812.

Hall, J.M., Chan, L.H., 2004. Ba/Ca in Neogloboquadrina pachyderma as an indicator of deglacial meltwater discharge into the western Arctic Ocean. Paleoceanography, 19(1): PA1017.

Hamilton, L.J., 2006. Structure of the Subtropical Front in the Tasman Sea. Deep Sea Research Part I: Oceanographic Research Papers, 53(12): 1989-2009.

Hathorne, E.C., Alard, O., James, R.H., Rogers, N.W., 2003. Determination of intratest variability of trace elements in foraminifera by laser ablation inductively coupled plasma-mass spectrometry. Geochem. Geophys. Geosyst., 4(12): 8408.

Hathorne, E.C., James, R.H., Lampitt, R.S., 2009. Environmental versus biomineralization controls on the intratest variation in the trace element composition of the planktonic foraminifera $G$. inflata and G. scitula. Paleoceanography, 24(4): PA4204.

Hayward, B.W. et al., 2012. Planktic foraminifera-based sea-surface temperature record in the Tasman Sea and history of the Subtropical Front around New Zealand, over the last one million years. Marine Micropaleontology, 82-83(0): 13-27.

Hayward, B.W. et al., 2008. The effect of submerged plateaux on Pleistocene gyral circulation and sea-surface temperatures in the Southwest Pacific. Global and Planetary Change, 63(4): 309316.

Heath, R., 1985a. A review of the physical oceanography of the seas around New Zealand-1982. N. Z. J. Mar. Freshwater Res., 19(79): 124.

Heath, R.A., 1975. Oceanic circulation and hydrology off the southern half of South Island, New Zealand. New Zealand Oceanographic Institute, Wellington, $36 \mathrm{pp}$.

Heath, R.A., 1985b. A review of the physical oceanography of the seas around New Zealand - 1982. New Zealand Journal of Marine and Freshwater Research, 19(1): 79-124.

Hecht, A.D., 1976. An ecologic model for test size variation in Recent planktonic foraminifera; applications to the fossil record. The Journal of Foraminiferal Research, 6(4): 295-311.

Hedenquist, J.W., Simmons, S.F., Giggenbach, W.F., Eldridge, C.S., 1993. White Island, New Zealand, volcanic-hydrothermal system represents the geochemical environment of highsulfidation $\mathrm{Cu}$ and $\mathrm{Au}$ ore deposition. Geology, 21(8): 731-734.

Hemleben, C., Spindler, M., Anderson, O.R., 1989. Modern Planktonic Foraminifera. Springer-Verlag Inc., New York.

Hicks, D.M., Shankar, U., 2003. Sediment from New Zealand Rivers. In: 236, N.M.C. (Editor). NIWA, Wellington.

Ho, T.-Y. et al., 2003. The elemental composition of some marine phytoplankton. Journal of Phycology, 39(6): 1145-1159.

Hönisch, B. et al., 2011. Planktic foraminifers as recorders of seawater $\mathrm{Ba} / \mathrm{Ca}$. Marine Micropaleontology, 79(1-2): 52-57.

Hunter, K.A., Boyd, P., 1999. Biogeochemistry of trace metals in the ocean. Marine and Freshwater Research, 50(8): 739-753.

Jacquet, S.H.M., Dehairs, F., Rintoul, S., 2004. A high resolution transect of dissolved barium in the Southern Ocean. Geophys. Res. Lett., 31(14): L14301.

Johnson, K., Johnson, B., Johnson, H., 1999. Periodic Table of Elements in the Ocean. Monterey Bay Aquarium Research Institute.

Johnson, K.S., Coale, K.H., Berelson, W.M., Michael Gordon, R., 1996. On the formation of the manganese maximum in the oxygen minimum. Geochimica et Cosmochimica Acta, 60(8): 1291-1299. 
Johnstone, H.J.H., Schulz, M., Barker, S., Elderfield, H., 2010. Inside story: An X-ray computed tomography method for assessing dissolution in the tests of planktonic foraminifera. Marine Micropaleontology, 77(1-2): 58-70.

Jouzel, J. et al., 2007. Orbital and Millennial Antarctic Climate Variability over the Past 800,000 Years. Science, 317(5839): 793-796.

Kennett, J.P., 1976. Phenotypic variation in some Recent and Late Cenozoic planktonic foraminifera. Foraminifera, 2(11): 1-170.

King, A.L., Howard, W.R., 2001. Seasonality of foraminiferal flux in sediment traps at Chatham Rise, SW Pacific: Implications for paleotemperature estimates. Deep-Sea Research Part IOceanographic Research Papers, 48(7): 1687-1708.

Kipp, N.G., 1976. In: Hays, R.M.C.a.J.D. (Ed.), Investigation of Late Quaternary Paleoceanography and Paleoclimatology. Geological Society of America, Boulder, CO, pp. 3-42.

Kleypas, J.A. et al., 1999. Geochemical consequences of increased atmospheric carbon dioxide on coral reefs. Science, 284(5411): 118-120.

Klinkhammer, G.P., Bender, M.L., 1980. The distribution of manganese in the Pacific Ocean. Earth and Planetary Science Letters, 46(3): 361-384.

Klinkhammer, G.P., Haley, B.A., Mix, A.C., Benway, H.M., Cheseby, M., 2004. Evaluation of automated flow-through time-resolved analysis of foraminifera for $\mathrm{Mg} / \mathrm{Ca}$ paleothermometry. Paleoceanography, 19(4): PA4030.

Kooijman, S., 2000. Dynamic Energy and Mass Budgets in Biological Systems. Cambridge University Press.

Koutavas, A., deMenocal, P.B., Olive, G.C., Lynch-Stieglitz, J., 2006. Mid-Holocene El NiñoSouthern Oscillation (ENSO) attenuation revealed by individual foraminifera in eastern tropical Pacific sediments. Geology, 34(12): 993-996.

Koutavas, A., Lynch-Stieglitz, J., Marchitto, T.M., Sachs, J.P., 2002. El Niño-like pattern in ice age tropical Pacific sea surface temperature. Science, 297(5579): 226-230.

Kucera, M., 2007. Chapter Six Planktonic Foraminifera as Tracers of Past Oceanic Environments. In: Claude, H.M., Anne De, V. (Eds.), Developments in Marine Geology. Elsevier, pp. 213-262.

Kucera, M., Darling, K.F., 2002. Cryptic species of planktonic foraminifera: their effect on palaeoceanographic reconstructions. Philosophical Transactions of the Royal Society of London, 360(1793): 695-718.

Kucera, M. et al., 2005. Reconstruction of sea-surface temperatures from assemblages of planktonic foraminifera: multi-technique approach based on geographically constrained calibration data sets and its application to glacial Atlantic and Pacific Oceans. Quaternary Science Reviews, 24(7-9): 951-998.

Kumar, N. et al., 1995. Increased biological productivity and export production in the glacial Southern Ocean. Nature, 378(6558): 675-680.

Kunioka, D. et al., 2006. Microdistribution of $\mathrm{Mg} / \mathrm{Ca}, \mathrm{Sr} / \mathrm{Ca}$, and $\mathrm{Ba} / \mathrm{Ca}$ ratios in Pulleniatina obliquiloculata test by using a NanoSIMS: Implication for the vital effect mechanism. Geochem. Geophys. Geosyst., 7(12): Q12P20.

Kuroyanagi, A., Kawahata, H., 2004. Vertical distribution of living planktonic foraminifera in the seas around Japan. Marine Micropaleontology, 53(1-2): 173-196.

Kuroyanagi, A., Kawahata, H., Nishi, H., Honda, M.C., 2002. Seasonal changes in planktonic foraminifera in the northwestern North Pacific Ocean: sediment trap experiments from subarctic and subtropical gyres. Deep Sea Research Part II: Topical Studies in Oceanography, 49(24-25): 5627-5645.

Langdon, C. et al., 2000. Effect of calcium carbonate saturation state on the calcification rate of an experimental coral reef. Global Biogeochemical Cycles, 14(2): 639-654.

Lea, D., Boyle, E., 1989. Barium content of benthic foraminifera controlled by bottom-water composition. Nature, 338(6218): 751-753.

Lea, D.W., 2003. 6.14 - Elemental and isotopic proxies of past ocean temperatures. In: Heinrich, D.H., Karl, K.T. (Eds.), Treatise on Geochemistry. Pergamon, Oxford, pp. 1-26.

Lea, D.W., Boyle, E.A., 1990. Foraminiferal reconstruction of barium distributions in water masses of the glacial oceans. Paleoceanography, 5(5): 719-742. 
Lea, D.W., Boyle, E.A., 1991. Barium in planktonic foraminifera. Geochimica et Cosmochimica Acta, 55(11): 3321-3331.

Lea, D.W., Mashiotta, T.A., Spero, H.J., 1999. Controls on magnesium and strontium uptake in planktonic foraminifera determined by live culturing. Geochimica et Cosmochimica Acta, 63(16): 2369-2379.

Lea, D.W., Spero, H.J., 1992. Experimental determination of barium uptake in shells of the planktonic foraminifera Orbulina universa at $22^{\circ} \mathrm{C}$. Geochimica et Cosmochimica Acta, 56(7): 26732680.

Lea, D.W., Spero, H.J., 1994. Assessing the reliability of paleochemical tracers: Barium uptake in the shells of planktonic foraminifera. Paleoceanography, 9(3): 445-452.

Lean, C.M.B., McCave, I.N., 1998. Glacial to interglacial mineral magnetic and palaeoceanographic changes at Chatham Rise, SW Pacific Ocean. Earth and Planetary Science Letters, 163(1-4): 247-260.

Lear, C.H., Elderfield, H., Wilson, P.A., 2000. Cenozoic deep-Sea temperatures and global ice volumes from $\mathrm{Mg} / \mathrm{Ca}$ in benthic foraminiferal calcitee. Science, 287(5451): 269-272.

Lear, C.H., Rosenthal, Y., Slowey, N., 2002. Benthic foraminiferal Mg/Ca-paleothermometry: a revised core-top calibration. Geochimica et Cosmochimica Acta, 66(19): 3375-3387.

Learman, D.R., Voelker, B.M., Vazquez-Rodriguez, A.I., Hansel, C.M., 2011. Formation of manganese oxides by bacterially generated superoxide. Nature Geosci, 4(2): 95-98.

Leduc, G., Schneider, R., Kim, J.H., Lohmann, G., 2010. Holocene and Eemian sea surface temperature trends as revealed by alkenone and $\mathrm{Mg} / \mathrm{Ca}$ paleothermometry. Quaternary Science Reviews, 29(7-8): 989-1004.

Legendre, L., Le Fevre, J., 1995. Microbial food webs and the export of biogenic carbon in oceans Aquatic Microbial Ecology 9(1): 69-77.

Locarnini, R.A., Mishonov, A.V., Antonov, J.I., Boyer, T.P., Garcia, H.E., 2006. Hydrographic data. In: Levitus, S. (Ed.), World Ocean Atlas 2005. NOAA Atlas NESDIS 61, U.S. Government Printing Office, Washington, D.C., pp. 182.

Locarnini, R.A., Mishonov, A.V., Antonov, J.I., Boyer, T.P., Garcia, H.E., 2010. World Ocean Atlas 2009. In: Levitus, S. (Editor), NOAA Atlas.

Lohmann, G.P., 1995. A model for variation in the chemistry of planktonic foraminifera due to secondary calcification and selective dissolution. Paleoceanography, 10(3): 445-457.

Lombard, F., da Rocha, R.E., Bijma, J., Gattuso, J.P., 2010. Effect of carbonate ion concentration and irradiance on calcification in planktonic foraminifera. Biogeosciences, 7(1): 247-255.

Lombard, F. et al., 2011. Modelling planktic foraminifer growth and distribution using an ecophysiological multi-species approach. Biogeosciences, 8(4): 853-873.

Lombard, F., Labeyrie, L., Michel, E., Spero, H.J., Lea, D.W., 2009. Modelling the temperature dependent growth rates of planktic foraminifera. Marine Micropaleontology, 70(1-2): 1-7.

Lorrey, A.M. et al., 2012. PalaeocirculationacrossNewZealand during the lastglacialmaximum at $\sim 21$ ka. Quaternary Science Reviews, 36: 189-213.

Lynch-Stieglitz, J., Stocker, T.F., Broecker, W.S., Fairbanks, R.G., 1995. The influence of air-sea exchange on the isotopic composition of oceanic carbon: Observations and modeling. Global Biogeochemical Cycles, 9(4): 653-665.

Malmgren, B.A., Kennett, J.P., 1978. Test size variation in Globigerina bulloides in response to Quaternary palaeoceanographic changes. Nature, 275(5676): 123-124.

Malmgren, B.r., Kennett, J.P., 1976. Biometric analysis of phenotypic variation in RecentGlobigerina bulloides d'Orbigny in the southern Indian Ocean. Marine Micropaleontology, 1(0): 3-25.

Marchitto, T.M., Jr., Curry, W.B., Oppo, D.W., 2000. Zinc concentrations in benthic foraminifera reflect seawater chemistry. Paleoceanography, 15(3): 299-306.

Marchitto, T.M., Lynch-Stieglitz, J., Hemming, S.R., 2005. Deep Pacific CaCO3 compensation and glacial-interglacial atmospheric CO2. Earth and Planetary Science Letters, 231(3-4): 317-336.

MARGO et al., 2009. Constraints on the magnitude and patterns of ocean cooling at the Last Glacial Maximum. Nature Geosci, 2(2): 127-132.

Marr, J.P. et al., 2011. Ecological and temperature controls on $\mathrm{Mg} / \mathrm{Ca}$ ratios of Globigerina bulloides from the southwest Pacific Ocean. Paleoceanography, 26(2): PA2209. 
Marr, J.P., Bostock, H.C., Carter, L., Bolton, A., Smith, E., in press-a. Differential effects of contrasting cleaning procedures on the trace element chemistry of planktic foraminifera. Chemical geology.

Marr, J.P., Carter, L., Bostock, H.C., in-prep. Impact of seasonality and changing oceanography on paleothermometry records.

Marr, J.P., Carter, L., Bostock, H.C., Bolton, A., in press-b. Southwest Pacific Ocean response to a warming world: using $\mathrm{Mg} / \mathrm{Ca}, \mathrm{Zn} / \mathrm{Ca}$ and $\mathrm{Mn} / \mathrm{Ca}$ in foraminifera to track surface ocean water masses during the last deglaciation. Paleoceanography.

Martin, J.H., Gordon, R.M., Fitzwater, S., Broenkow, W.W., 1989. Vertex: phytoplankton/iron studies in the Gulf of Alaska. Deep Sea Research Part A. Oceanographic Research Papers, 36(5): 649-680.

Martin, J.H., Knauer, G.A., 1980. Manganese cycling in northeast Pacific waters. Earth and Planetary Science Letters, 51(2): 266-274.

Mayewski, P.A. et al., 2004. Holocene climate variability. Quaternary Research, 62(3): 243-255.

McCave, I.N., Carter, L., Hall, I.R., 2008. Glacial-interglacial changes in water mass structure and flow in the SW Pacific Ocean. Quaternary Science Reviews, 27(19-20): 1886-1908.

McConnell, M.C., Thunell, R.C., 2005. Calibration of the planktonic foraminiferal $\mathrm{Mg} / \mathrm{Ca}$ paleothermometer: Sediment trap results from the Guaymas Basin, Gulf of California. Paleoceanography, 20(2): PA2016.

Milliman, J.D., 1993. Production and accumulation of calcium carbonate in the ocean: Budget of a nonsteady state. Global Biogeochemical Cycles, 7(4): 927-957.

Mollenhauer, G. et al., 2003. Asynchronous alkenone and foraminifera records from the Benguela Upwelling System. Geochimica et Cosmochimica Acta, 67(12): 2157-2171.

Morel, F.M.M., Hudson, R.J.M., Price, N.M., 1991. Limitation of productivity by trace metals in the sea. Limnology and Oceanography, 36(8): 1742-1755.

Morel, F.M.M., Milligan, A.J., Saito, M.A., 2003. 6.05 - Marine bioinorganic chemistry: The role of trace metals in the oceanic cycles of major nutrients. In: Heinrich, D.H., Karl, K.T. (Eds.), Treatise on Geochemistry. Pergamon, Oxford, pp. 113-143.

Morel, F.M.M., Price, N.M., 2003. The Biogeochemical Cycles of Trace Metals in the Oceans. Science, 300(5621): 944-947.

Morris, M., Stanton, B., Neil, H., 2001. Subantarctic oceanography around New Zealand: Preliminary results from an ongoing survey. New Zealand Journal of Marine and Freshwater Research, 35(3): 499-519.

Mortyn, P.G., Charles, C.D., 2003. Planktonic foraminiferal depth habitat and $\delta^{18} \mathrm{O}$ calibrations: Plankton tow results from the Atlantic sector of the Southern Ocean. Paleoceanography, 18(2): 1037.

Moy, A.D., Howard, W.R., Bray, S.G., Trull, T.W., 2009. Reduced calcification in modern Southern Ocean planktonic foraminifera. Nature Geoscience, 2(4): 276-280.

Mulitza, S., Dürkoop, A., Hale, W., Wefer, G., Stefan Niebler, H., 1997. Planktonic foraminifera as recorders of past surface-water stratification. Geology, 25(4): 335-338.

Murphy, R.J., Pinkerton, M.H., Richardson, K.M., Bradford-Grieve, J.M., Boyd, P.W., 2001. Phytoplankton distributions around New Zealand derived from SeaWiFS remotely-sensed ocean colour data. N. Z. J. Mar. Freshwater Res., 35(2): 343-362.

Naik, S.S., Naidu, P.D., Govil, P., Godad, S., 2010. Relationship between weights of planktonic foraminifer shell and surface water $\mathrm{CO}_{3}{ }^{=}$concentration during the Holocene and Last Glacial Period. Marine Geology, 275(1-4): 278-282.

Nanninga, H.J., Tyrrell, T., 1996. Importance of light for the formation of algal blooms by Emiliania huxleyi. Marine Ecology Progress Series, 136: 195-203.

Neil, H., Carter, L., Morris, M., 2004. Thermal isolation of Campbell Plateau, New Zealand, by the Antarctic Circumpolar Current over the past 130 kyr. Paleoceanography, 19(4): PA4008.

Nelson, C.S., Cooke, P.J., Hendy, C.H., Cuthbertson, A.M., 1993. Oceanographic and climatic changes over the past 160,000 years at deep sea drilling project site 594 off southeastern New Zealand, Southwest Pacific Ocean. Paleoceanography, 8(4): 435-458. 
Nelson, C.S., Hendy, I.L., Neil, H.L., Hendy, C.H., Weaver, P.P.E., 2000. Last glacial jetting of cold waters through the Subtropical Convergence zone in the Southwest Pacific off eastern New Zealand, and some geological implications. Palaeogeography, Palaeoclimatology, Palaeoecology, 156(1-2): 103-121.

NGRIP et al., 2004. High-resolution record of Northern Hemisphere climate extending into the last interglacial period. Nature, 431(7005): 147-151.

NIWA, 2012. The National Climate Database. CliFlo-NIWA.

Nodder, S.D., Northcote, L.C., 2001. Episodic particulate fluxes at southern temperate mid-latitudes $\left(42-45^{\circ} \mathrm{S}\right)$ in the Subtropical Front region, east of New Zealand. Deep Sea Research Part I: Oceanographic Research Papers, 48(3): 833-864.

Northcote, L., Neil, H., Manighetti, B., 2007. Global Change through Time, Objective 1, Quaternary Climate and Biota - Foraminiferal Census, National Institute of Water \& Atmospheric Research Ltd., Wellington.

Northcote, L.C., Neil, H.L., 2005. Seasonal variations in foraminiferal flux in the Southern Ocean, Campbell Plateau, New Zealand. Marine Micropaleontology, 56(3-4): 122-137.

Nürnberg, D., Bijma, J., Hemleben, C., 1996. Assessing the reliability of magnesium in foraminiferal calcite as a proxy for water mass temperatures. Geochimica et Cosmochimica Acta, 60(5): 803-814.

Ohkouchi, N., Eglinton, T.I., Keigwin, L.D., Hayes, J.M., 2002. Spatial and Temporal Offsets Between Proxy Records in a Sediment Drift. Science, 298(5596): 1224-1227.

Orians, K.J., Bruland, K.W., 1986. The biogeochemistry of aluminum in the Pacific Ocean. Earth and Planetary Science Letters, 78(4): 397-410.

Orpin, A. et al., 2008. New Zealand's diverse seafloor sediments, Miscellaneous Series 86. NIWA Chart.

Otto-Bliesner, B. et al., 2009. A comparison of PMIP2 model simulations and the MARGO proxy reconstruction for tropical sea surface temperatures at last glacial maximum. Climate Dynamics, 32(6): 799-815.

Pahnke, K., Sachs, J.P., 2006. Sea surface temperatures of southern midlatitudes 0-160 kyr BP. Paleoceanography, 21(2): PA2003.

Pahnke, K., Zahn, R., Elderfield, H., Schulz, M., 2003. 340,000-year centennial-scale marine record of Southern Hemisphere climatic oscillation. Science, 301(5635): 948-952.

Passlow, V., Pinxian, W., Chivas, A.R., 1997. Late Quaternary palaeoceanography near Tasmania, southern Australia. Palaeogeography, Palaeoclimatology, Palaeoecology, 131(3-4): 433-463.

Paton, C., Hellstrom, J., Paul, B., Woodhead, J., Hergt, J., 2011. Iolite: Freeware for the visualisation and processing of mass spectrometric data. Journal of Analytical Atomic Spectrometry, 26(12): 2508-2518.

Pearce, N. et al., 1997. New data for National Institute of Standards and Technology 610 and 612 glass reference materials. Geostandards Newsletter, 21: 115-44.

Pena, L.D., Calvo, E., Cacho, I., Eggins, S., Pelejero, C., 2005. Identification and removal of Mn-Mgrich contaminant phases on foraminiferal tests: Implications for $\mathrm{Mg} / \mathrm{Ca}$ past temperature reconstructions. Geochemistry Geophysics Geosystems, 6(9).

Petrizzo, M.R., Leoni, G., Speijer, R.P., De Bernardi, B., Felletti, F., 2008. Dissolution susceptibility of some Paleogene planktonic foraminifera from ODP site 1209 (Shatsky Rise, Pacific Ocean). The Journal of Foraminiferal Research, 38(4): 357-371.

Pollard, R.T., Rhines, P.B., Thompson, R.O.R.Y., 1972. The deepening of the wind-Mixed layer. Geophysical Fluid Dynamics, 4(1): 381-404.

Pouderoux, H., Proust, J.-N., Lamarche, G., Orpin, A., Neil, H., 2012. Postglacial (after 18 ka) deepsea sedimentation along the Hikurangi subduction margin (New Zealand): Characterisation, timing and origin of turbidites. Marine Geology, 295-298(0): 51-76.

Prahl, F.G., Muehlhausen, L.A., Zahnle, D.L., 1988. Further evaluation of long-chain alkenones as indicators of paleoceanographic conditions. Geochimica et Cosmochimica Acta, 52(9): 23032310.

Prahl, F.G., Wakeham, S.G., 1987. Calibration of unsaturation patterns in long-chain ketone compositions for palaeotemperature assessment. Nature, 330(6146): 367-369. 
Price, N.M., Morel, F.M.M., 1990. Cadmium and cobalt substitution for zinc in a marine diatom. Nature, 344(6267): 658-660.

Putnam, A.E. et al., 2010. Glacier advance in southern middle-latitudes during the Antarctic Cold Reversal. Nature Geosci, 3(10): 700-704.

Rhodes, L.L., Peake, B.M., MacKenzie, A.L., Marwick, S., 1995. Coccolithophores Gephyrocapsa oceanica and Emiliania huxleyi (Prymnesiophyceae = Haptophyceae) in New Zealand's coastal waters: Characteristics of blooms and growth in laboratory culture. New Zealand Journal of Marine and Freshwater Research, 29(3): 345-357.

Ridgway, K.R., Dunn, J.R., 2007. Observational evidence for a Southern Hemisphere oceanic supergyre. Geophys. Res. Lett., 34(13): L13612.

Ridgway, K.R., Hill, K., 2009. The East Australian Current.

Riebesell, U. et al., 2000. Reduced calcification of marine plankton in response to increased atmospheric CO2. Nature, 407(6802): 364-367.

Rind, D., Peteet, D., 1985. Terrestrial conditions at the Last Glacial Maximum and CLIMAP seasurface temperature estimates: Are they consistent? Quaternary Research, 24(1): 1-22.

Roemmich, D., 2007. Physical oceanography: super spin in the southern seas. Nature, 449(7158): 345.

Roemmich, D., Sutton, P., 1998. The mean and variability of ocean circulation past northern New Zealand: Determining the representativeness of hydrographic climatologies. J. Geophys. Res., [Oceans], 103(C6): 13041-13054.

Rohling, E.J. et al., 2004. Reconstructing past planktic foraminiferal habitats using stable isotope data: a case history for Mediterranean sapropel S5. Marine Micropaleontology, 50(1-2): 89-123.

Root, T.L. et al., 2003. Fingerprints of global warming on wild animals and plants. Nature, 421(6918): 57-60.

Rosenthal, Y., 2007. Elemental proxies for reconstructing Cenozoic seawater paleotemperatures. In: Hillaire-Marcel, C., De Vernal, A. (Eds.), Proxies in Late Cenozoic Paleoceanography. Elsevier Science, United States, pp. 765-793.

Rosenthal, Y., Boyle, E.A., Slowey, N., 1997. Temperature control on the incorporation of magnesium, strontium, fluorine, and cadmium into benthic foraminiferal shells from Little Bahama Bank: Prospects for thermocline paleoceanography. Geochimica et Cosmochimica Acta, 61(17): 3633-3643.

Rosenthal, Y., Field, M.P., Sherrell, R.M., 1999. Precise Determination of Element/Calcium Ratios in Calcareous Samples Using Sector Field Inductively Coupled Plasma Mass Spectrometry. Analytical Chemistry, 71(15): 3248-3253.

Rosenthal, Y., Lohmann, G.P., 2002. Accurate estimation of sea surface temperatures using dissolution-corrected calibrations for $\mathrm{Mg} / \mathrm{Ca}$ paleothermometry. Paleoceanography, 17(3): 1044.

Rosenthal, Y., Oppo, D.W., Linsley, B.K., 2003. The amplitude and phasing of climate change during the last deglaciation in the Sulu Sea, western equatorial Pacific. Geophysical Research Letters, $30(8)$.

Rosenthal, Y. et al., 2004. Interlaboratory comparison study of $\mathrm{Mg} / \mathrm{Ca}$ and $\mathrm{Sr} / \mathrm{Ca}$ measurements in planktonic foraminifera for paleoceanographic research. Geochem. Geophys. Geosyst., 5(4): Q04D09.

Rost, B., Riebesell, U., 2004. Coccolithophores and the biological pump: responses to environmental changes. In: Thierstein, H.R., Young, J.R. (Editors), Coccolithophores: From Molecular Processes to Global Impact. Springer, Berlin, pp. 99-125.

Rutherford, S., D'Hondt, S., Prell, W., 1999. Environmental controls on the geographic distribution of zooplankton diversity. Nature, 400(6746): 749-753.

Sadekov, A., Eggins, S.M., De Deckker, P., Kroon, D., 2008. Uncertainties in seawater thermometry deriving from intratest and intertest $\mathrm{Mg} / \mathrm{Ca}$ variability in Globigerinoides ruber. Paleoceanography, 23(1): PA1215

Sadekov, A. et al., 2009. Surface and subsurface seawater temperature reconstruction using $\mathrm{Mg} / \mathrm{Ca}$ microanalysis of planktonic foraminifera Globigerinoides ruber, Globigerinoides sacculifer, and Pulleniatina obliquiloculata. Paleoceanography, 24: PA3201. 
Sadekov, A.Y., Eggins, S.M., De Deckker, P., 2005. Characterization of Mg/Ca distributions in planktonic foraminifera species by electron microprobe mapping. Geochem. Geophys. Geosyst., 6(12): Q12P06.

Sadekov, A.Y., Eggins, S.M., Klinkhammer, G.P., Rosenthal, Y., 2010. Effects of seafloor and laboratory dissolution on the $\mathrm{Mg} / \mathrm{Ca}$ composition of Globigerinoides sacculifer and Orbulina universa tests - A laser ablation ICPMS microanalysis perspective. Earth and Planetary Science Letters, 292(3-4): 312-324.

Sallée, J.-B., Speer, K., Rintoul, S., Wijffels, S., 2010a. Southern Ocean Thermocline Ventilation. Journal of Physical Oceanography, 40(3): 509-529.

Sallée, J.B., Speer, K.G., Rintoul, S.R., 2010b. Zonally asymmetric response of the Southern Ocean mixed-layer depth to the Southern Annular Mode. Nature Geosci, 3(4): 273-279.

Sarnthein, M., Winn, K., Duplessy, J.-C., Fontugne, M.R., 1988. Global variations of surface ocean productivity in low and mid latitudes: Influence on $\mathrm{CO}_{2}$ reservoirs of the deep ocean and atmosphere during the last 21,000 years. Paleoceanography, 3(3): 361-399.

Savin, S.M., Douglas, R.G., 1973. Stable isotope and magnesium geochemistry of recent planktonic foraminifera from the South Pacific. Geol. Soc. Am. Bull., 84: 2327-2342.

Schiebel, R., Waniek, J., Bork, M., Hemleben, C., 2001. Planktic foraminiferal production stimulated by chlorophyll redistribution and entrainment of nutrients. Deep Sea Research Part I: Oceanographic Research Papers, 48(3): 721-740.

Schlitzer, R., 2011. Ocean Data Viewer

Schmidt, D.N., Renaud, S., Bollmann, J., 2003. Response of planktic foraminiferal size to late Quaternary climate change. Paleoceanography, 18(2): 1039.

Sen Gupta, B., Hansen, H., 2003. Shell construction in modern calcareous foraminifera Modern Foraminifera. Springer Netherlands, pp. 57-70.

Shiller, A.M., Boyle, E., 1985. Dissolved zinc in rivers. Nature, 317(6032): 49-52.

Shulmeister, J. et al., 2004. The Southern Hemisphere westerlies in the Australasian sector over the last glacial cycle: a synthesis. Quaternary International, 118-119(0): 23-53.

Sikes, E.L., Howard, W.R., Neil, H.L., Volkman, J.K., 2002. Glacial-interglacial sea surface temperature changes across the subtropical front east of New Zealand based on alkenone unsaturation ratios and foraminiferal assemblages. Paleoceanography, 17(2): 1012.

Sikes, E.L. et al., 2009. Southern Ocean seasonal temperature and Subtropical Front movement on the South Tasman Rise in the late Quaternary. Paleoceanography, 24(2): PA2201.

Sikes, E.L., O'Leary, T., Nodder, S.D., Volkman, J.K., 2005. Alkenone temperature records and biomarker flux at the subtropical front on the Chatham Rise, SW Pacific Ocean. Deep Sea Research Part I: Oceanographic Research Papers, 52(5): 721-748.

Sikes, E.L., Volkman, J.K., 1993. Calibration of alkenone unsaturation ratios (Uk'37) for paleotemperature estimation in cold polar waters. Geochimica et Cosmochimica Acta, 57(8): 1883-1889.

Sikes, E.L., Volkman, J.K., Robertson, L.G., Pichon, J.-J., 1997. Alkenones and alkenes in surface waters and sediments of the Southern Ocean: Implications for paleotemperature estimation in polar regions. Geochimica et Cosmochimica Acta, 61(7): 1495-1505.

Smyth, T.J., Moore, G.F., Groom, S.B., Land, P.E., Tyrrell, T., 2002. Optical modeling and measurements of a coccolithophore bloom. Appl. Opt., 41(36): 7679-7688.

Spero, H.J., Bijma, J., Lea, D.W., Bemis, B.E., 1997. Effect of seawater carbonate concentration on foraminiferal carbon and oxygen isotopes. Nature, 390(6659): 497-500.

Spero, H.J., Eggins, S., Russell, A., Vetter, L., Hoenisch, B., 2008. Experimental perspective on cause of planktonic foraminifera intrashell $\mathrm{Mg} / \mathrm{Ca}$ variability and impact on paleoceanographic applications, Fall Meeting 2008. American Geophysical Union, pp. abstract \#PP41F-01.

Stanton, B.R., 2002. Antarctic Intermediate Water variability in the northern New Zealand region. New Zealand Journal of Marine and Freshwater Research, 36(3): 645-654.

Steinke, S. et al., 2005. Mg/Ca ratios of two Globigerinoides ruber (white) morphotypes: Implications for reconstructing past tropical/subtropical surface water conditions. Geochem. Geophys. Geosyst., 6(11): Q11005. 
Stuiver, M., Braziunas, T.F., Grootes, P.M., Zielinski, G.A., 1997. Is there evidence for solar forcing of climate in the GISP2 oxygen isotope record? Quaternary Research, 48(3): 259-266.

Sunda, W.G., Huntsman, S.A., 1988. Effect of sunlight on redox cycles of manganese in the southwestern Sargasso Sea. Deep Sea Research Part A. Oceanographic Research Papers, 35(8): 1297-1317.

Sutton, P., 2001. The modern ocean hours to decades: the nature of variability and change Water and Atmosphere, 9(4): 22-23.

Sutton, P., Roemmich, D., 2001. Ocean temperature climate off north-east New Zealand. New Zealand Journal of Marine and Freshwater Research, 35(3): 553-566.

Sutton, P.J.H., 2003. The Southland Current: A subantarctic current. New Zealand Journal of Marine and Freshwater Research, 37(3): 645-652.

ter Kuile, B., Erez, J., 1984. In situ growth rate experiments on the symbiont-bearing foraminifera Amphistegina lobifera and Amphisorus hemprichii. The Journal of Foraminiferal Research, 14(4): 262-276.

Thunell, R.C., Reynolds, L.A., 1984. Sedimentation of Planktonic Foraminifera: Seasonal Changes in Species Flux in the Panama Basin. Micropaleontology, 30(3): 243-262.

Tilburg, C.E., Hurlburt, H.E., O'Brien, J.J., Shriver, J.F., 2001. The dynamics of the East Australian Current system: The Tasman Front, the East Auckland Current, and the East Cape Current. Journal of Physical Oceanography, 31(10): 2917-2943.

Trull, T., Rintoul, S.R., Hadfield, M., Abraham, E.R., 2001. Circulation and seasonal evolution of polar waters south of Australia: implications for iron fertilization of the Southern Ocean. Deep Sea Research Part II: Topical Studies in Oceanography, 48(11-12): 2439-2466.

Tyrrell, T., Merico, A., 2004. Emiliania huxleyi: bloom observations and the conditions that induce them. In: Thierstein, H.R., Young, J.R. (Eds.), Coccolithophores: from molecular processes to global impact. Springer, pp. 76-97.

Tyrrell, T., Zeebe, R.E., 2004. History of carbonate ion concentration over the last 100 million years. Geochimica et Cosmochimica Acta, 68(17): 3521-3530.

Vandergoes, M.J., Dieffenbacher-Krall, A.C., Newnham, R.M., Denton, G.H., Blaauw, M., 2008. Cooling and changing seasonality in the Southern Alps, New Zealand during the Antarctic Cold Reversal. Quaternary Science Reviews, 27(5-6): 589-601.

Volkman, J.K., Barrerr, S.M., Blackburn, S.I., Sikes, E.L., 1995. Alkenones in Gephyrocapsa oceanica: Implications for studies of paleoclimate. Geochimica et Cosmochimica Acta, 59(3): 513-520.

Wasylenki, L.E., Wilkes, E.B., Anbar, A.D., 2011. Is your clean lab full of zinc?, Goldschmidt, Prague, pp. 2135.

Weaver, P.P.E., Carter, L., Neil, H.L., 1998. Response of surface water masses and circulation to late Quaternary climate change east of New Zealand. Paleoceanography, 13(1): 70-83.

Weaver, P.P.E., Neil, H., Carter, L., 1997. Sea surface temperature estimates from the Southwest Pacific based on planktonic foraminifera and oxygen isotopes. Palaeogeography, Palaeoclimatology, Palaeoecology, 131(3-4): 241-256.

Webster, J.G., 1995. Chemical processes affecting trace metal transport in the Waihou River and estuary, New Zealand. New Zealand Journal of Marine and Freshwater Research, 29(4): 539553.

Weedon, G.P., Hall, I.R., 2004. Neogene palaeoceanography of Chatham Rise (Southwest Pacific) based on sediment geochemistry. Marine Geology, 205(1-4): 207-225.

Weldeab, S., Lea, D.W., Schneider, R.R., Andersen, N., 2007. 155,000 Years of West African Monsoon and Ocean Thermal Evolution. Science, 316(5829): 1303-1307.

Wilke, I., Meggers, H., Bickert, T., 2009a. Depth habitats and seasonal distributions of recent planktic foraminifers in the Canary Islands region $\left(29^{\circ} \mathrm{N}\right)$ based on oxygen isotopes. Deep Sea Research Part I: Oceanographic Research Papers, 56(1): 89-106.

Wilke, I., Meggers, H., Bickert, T., 2009b. Depth habitats and seasonal distributions of recent planktic foraminifers in the Canary Islands region $\left(29^{\circ} \mathrm{N}\right)$ based on oxygen isotopes. Deep Sea Res., Part A, 56(1): 89-106. 
Young, I.R., 1999. Seasonal variability of the global ocean wind and wave climate. International Journal of Climatology, 19(9): 931-950.

Yu, J., Elderfield, H., Greaves, M., Day, J., 2007. Preferential dissolution of benthic foraminiferal calcite during laboratory reductive cleaning. Geochem. Geophys. Geosyst., 8(6): Q06016. 

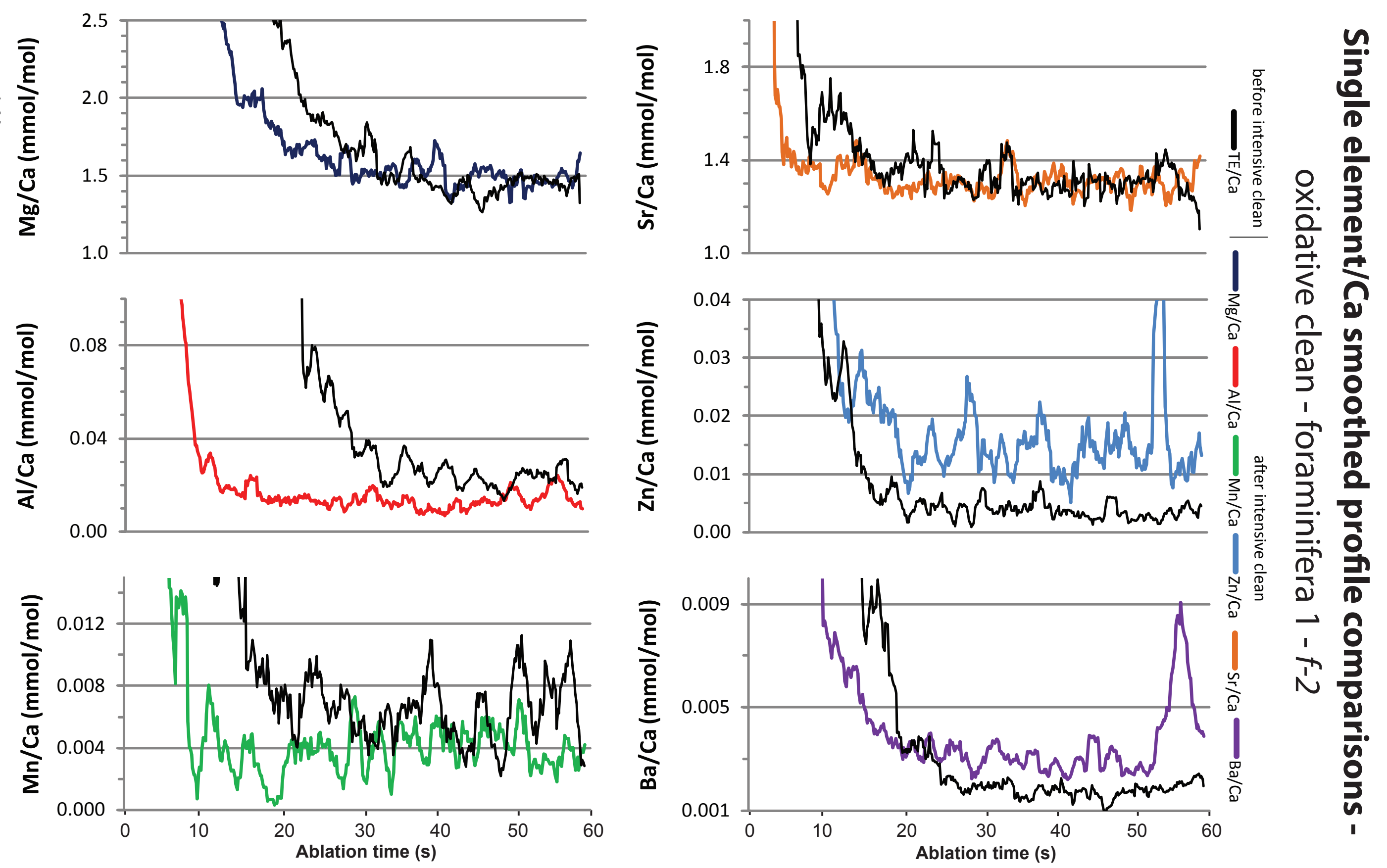

\begin{tabular}{|c|c|c|c|c|c|c|c|c|c|c|c|c|c|c|c|c|c|c|c|c|c|}
\hline & \multicolumn{6}{|c|}{ Before cleaning - LA processing - TE/Ca (mmol/mol) } & $n=$ & \multicolumn{6}{|c|}{ After cleaning - LA processing - TE/Ca $(\mathrm{mmol} / \mathrm{mol})$} & $n=$ & \multicolumn{6}{|c|}{ After cleaning - bulk processing - TE/Ca $(\mathrm{mmol} / \mathrm{mol})$} & $n=$ \\
\hline & $\mathrm{Mg} / \mathrm{Ca}$ & $\mathrm{Al} / \mathrm{Ca}$ & $\mathrm{Mn} / \mathrm{Ca}$ & $\mathrm{Zn} / \mathrm{Ca}$ & $\mathrm{Sr} / \mathrm{Ca}$ & $\mathrm{Ba} / \mathrm{Ca}$ & 200 & $\mathrm{Mg} / \mathrm{Ca}$ & $\mathrm{Al} / \mathrm{Ca}$ & $\mathrm{Mn} / \mathrm{Ca}$ & $\mathrm{Zn} / \mathrm{Ca}$ & $\mathrm{Sr} / \mathrm{Ca}$ & $\mathrm{Ba} / \mathrm{Ca}$ & 190 & $\mathrm{Mg} / \mathrm{Ca}$ & $\mathrm{Al} / \mathrm{Ca}$ & $\mathrm{Mn} / \mathrm{Ca}$ & $\mathrm{Zn} / \mathrm{Ca}$ & $\mathrm{Sr} / \mathrm{Ca}$ & $\mathrm{Ba} / \mathrm{Ca}$ & 390 \\
\hline mean & 1.482 & 0.025 & 0.006 & 0.002 & 1.305 & 0.002 & & 1.551 & 0.012 & 0.002 & 0.013 & 1.305 & 0.003 & & 2.366 & 0.309 & 0.007 & 0.041 & 1.371 & 0.013 & \\
\hline$\% 2 s e$ & 2.4 & 7.3 & 14.5 & 64.6 & 3.2 & 7.2 & & 2.3 & 12.3 & 46.1 & 18.0 & 1.9 & 7.0 & & 5.1 & 5.3 & 0.0 & 0.2 & 1.4 & 0.1 & \\
\hline
\end{tabular}



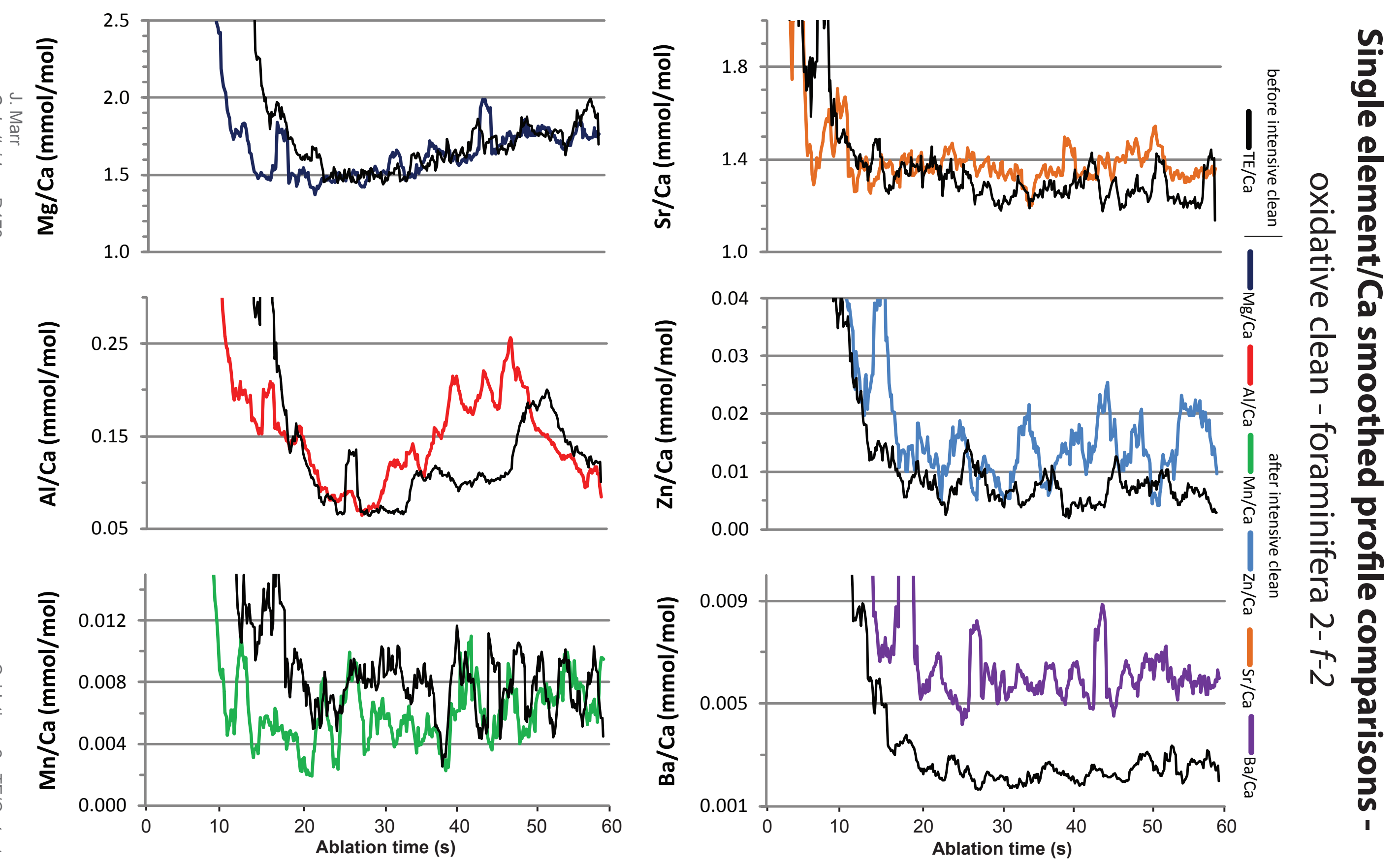

\begin{tabular}{|c|c|c|c|c|c|c|c|c|c|c|c|c|c|c|c|c|c|c|c|c|c|}
\hline & \multicolumn{6}{|c|}{ Before cleaning - LA processing - TE/Ca (mmol/mol) } & $n=$ & \multicolumn{6}{|c|}{ After cleaning - LA processing - TE/Ca (mmol/mol) } & \multirow{2}{*}{$\begin{array}{l}n= \\
90\end{array}$} & \multicolumn{6}{|c|}{ After cleaning - bulk processing - TE/Ca ( $\mathrm{mmol} / \mathrm{mol})$} & \multirow{2}{*}{$\begin{array}{l}n= \\
390\end{array}$} \\
\hline & $\mathrm{Mg} / \mathrm{Ca}$ & $\mathrm{Al} / \mathrm{Ca}$ & $\mathrm{Mn} / \mathrm{Ca}$ & $\mathrm{Zn} / \mathrm{Ca}$ & $\mathrm{Sr} / \mathrm{Ca}$ & $\mathrm{Ba} / \mathrm{Ca}$ & 300 & $\mathrm{Mg} / \mathrm{Ca}$ & $\mathrm{Al} / \mathrm{Ca}$ & $\mathrm{Mn} / \mathrm{Ca}$ & $\mathrm{Zn} / \mathrm{Ca}$ & $\mathrm{Sr} / \mathrm{Ca}$ & $\mathrm{Ba} / \mathrm{Ca}$ & & $\mathrm{Mg} / \mathrm{Ca}$ & $\mathrm{Al} / \mathrm{Ca}$ & $\mathrm{Mn} / \mathrm{Ca}$ & $\mathrm{Zn} / \mathrm{Ca}$ & $\mathrm{Sr} / \mathrm{Ca}$ & $\mathrm{Ba} / \mathrm{Ca}$ & \\
\hline mean & 1.648 & 0.113 & 0.007 & 0.006 & 1.282 & 0.002 & & 1.486 & 0.099 & 0.003 & 0.010 & 1.372 & 0.007 & & 2.106 & 0.545 & 0.011 & 0.039 & 1.478 & 0.020 & \\
\hline $62 \mathrm{se}$ & 2.1 & 5.8 & 11.7 & 17.5 & 2.2 & 5.7 & & 2.4 & 7.6 & 49.2 & 35.0 & 2.6 & 19.5 & & 10.4 & 28.6 & 21.4 & 35.2 & 6.6 & 27.5 & \\
\hline
\end{tabular}



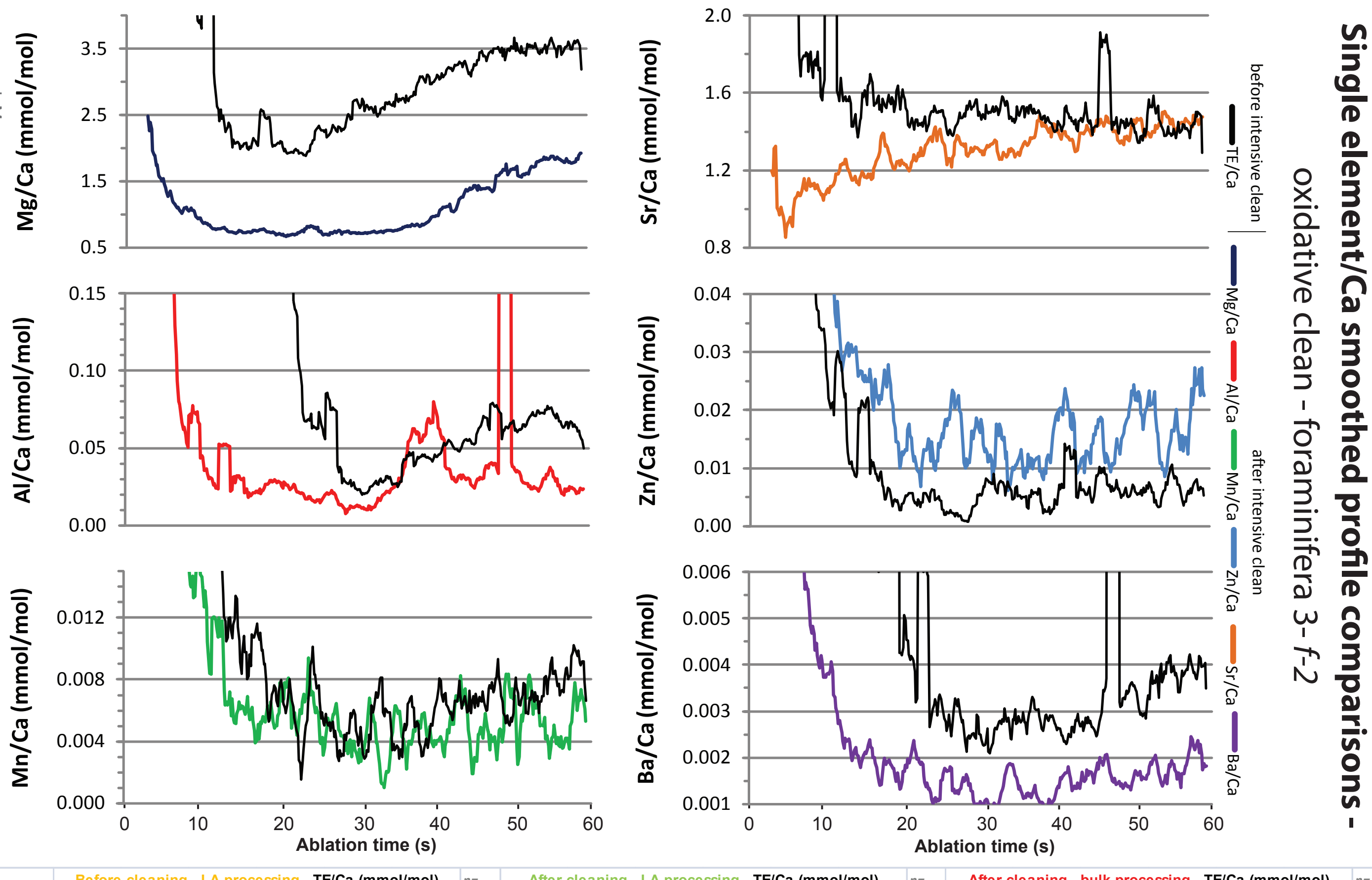

Before cleaning - LA processing - TE/Ca $\mathbf{( m m o l} / \mathbf{m o l}) \quad n=\quad$ After cleaning - LA processing - TE/Ca $(\mathbf{m m o l} / \mathbf{m o l})$ After cleaning - bulk processing - TE/Ca $(\mathrm{mmol} / \mathrm{mol})$

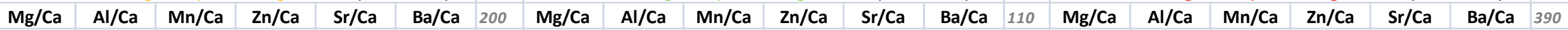

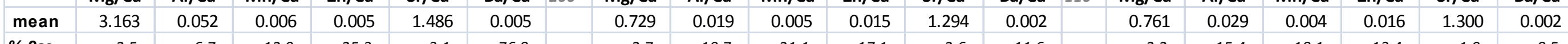

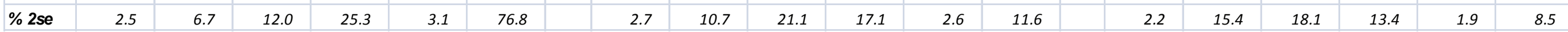



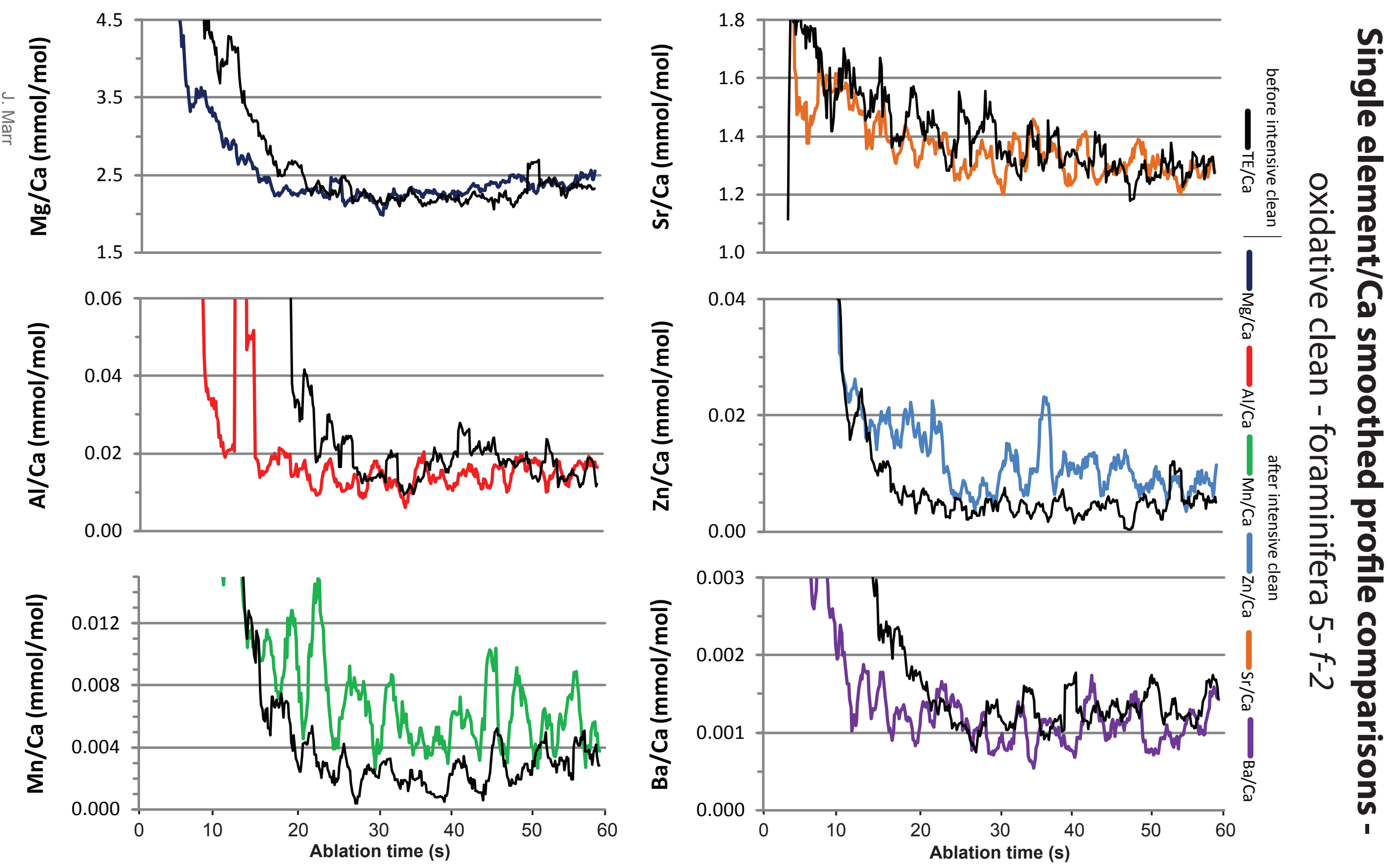

\begin{tabular}{|c|c|c|c|c|c|c|c|c|c|c|c|c|c|c|c|c|c|c|c|c|}
\hline & & & & & & \multicolumn{6}{|c|}{ (1...... } & & \multicolumn{6}{|c|}{ /Ca $(\mathrm{mm}$} \\
\hline mean & $\mathrm{Mg} / \mathrm{Ca}$ & $\mathrm{Al} / \mathrm{Ca}$ & $\mathrm{Mn} / \mathrm{Ca}$ & $\mathrm{Zn} / \mathrm{Ca}$ & $\mathrm{Sr} / \mathrm{Ca}$ & $\mathrm{Ba} / \mathrm{Ca}$ & 270 & $\mathrm{Mg} / \mathrm{Ca}$ & $\mathrm{Al} / \mathrm{Ca}$ & $\mathrm{Mn} / \mathrm{Ca}$ & $\mathrm{Zn} / \mathrm{Ca}$ & $\mathrm{Sr} / \mathrm{Ca}$ & $\mathrm{Ba} / \mathrm{Ca}$ & 210 & $\mathrm{Mg} / \mathrm{Ca}$ & $\mathrm{Al} / \mathrm{Ca}$ & $\mathrm{Mn} / \mathrm{Ca}$ & $\mathrm{Zn} / \mathrm{Ca}$ & $\mathrm{Sr} / \mathrm{Ca}$ & $\mathrm{Ba} / \mathrm{Ca}$ \\
\hline 2 se & 2.290 & 0.020 & 0.001 & 0.003 & 1.347 & 0.001 & & 2.274 & 0.014 & 0.006 & 0.011 & 1.332 & 0.001 & & 2.591 & 0.090 & 0.014 & 0.025 & 1.381 & 0.002 \\
\hline & 2.0 & 13.6 & 50.3 & 29.8 & 2.4 & 6.5 & & 1.8 & 9.7 & 15.4 & 16.5 & 1.7 & 8.5 & & 3.3 & 45.7 & 20.4 & 19.8 & 2.2 & 18.6 \\
\hline
\end{tabular}



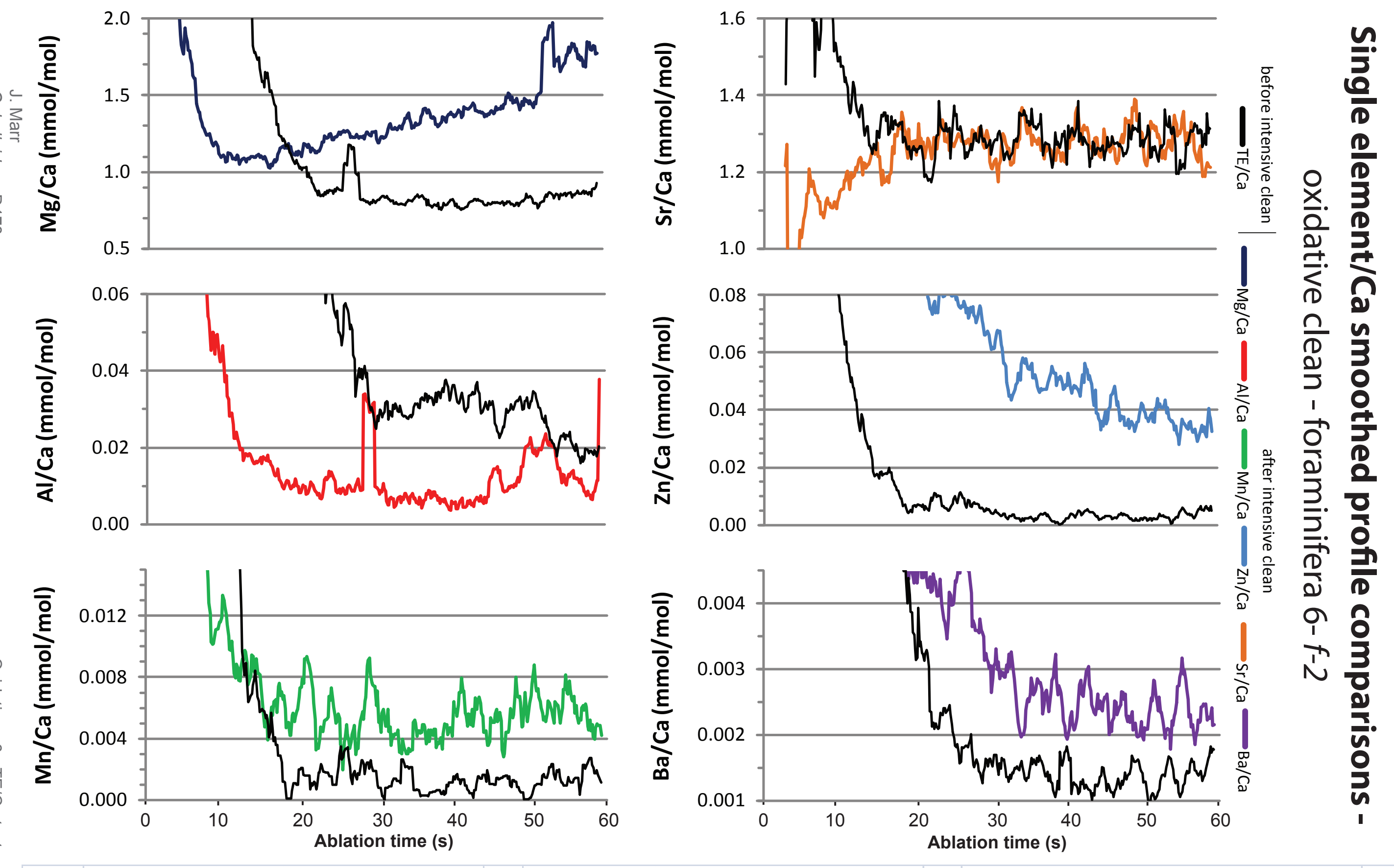

\begin{tabular}{|c|c|c|c|c|c|c|c|c|c|c|c|c|c|c|c|c|c|c|c|c|c|}
\hline & \multicolumn{6}{|c|}{ Before cleaning - LA processing - TE/Ca $(\mathbf{m m o l} / \mathbf{m o l})$} & $n=$ & \multicolumn{6}{|c|}{ After cleaning - LA processing - TE/Ca $(\mathrm{mmol} / \mathrm{mol})$} & $n=$ & \multicolumn{6}{|c|}{ After cleaning - bulk processing - TE/Ca $(\mathrm{mmol} / \mathrm{mol})$} & $n=$ \\
\hline & $\mathrm{Mg} / \mathrm{Ca}$ & $\mathrm{Al} / \mathrm{Ca}$ & $\mathrm{Mn} / \mathrm{Ca}$ & $\mathrm{Zn} / \mathrm{Ca}$ & $\mathrm{Sr} / \mathrm{Ca}$ & $\mathrm{Ba} / \mathrm{Ca}$ & 250 & $\mathrm{Mg} / \mathrm{Ca}$ & $\mathrm{Al} / \mathrm{Ca}$ & $\mathrm{Mn} / \mathrm{Ca}$ & $\mathrm{Zn} / \mathrm{Ca}$ & $\mathrm{Sr} / \mathrm{Ca}$ & $\mathrm{Ba} / \mathrm{Ca}$ & 100 & $\mathrm{Mg} / \mathrm{Ca}$ & $\mathrm{Al} / \mathrm{Ca}$ & $\mathrm{Mn} / \mathrm{Ca}$ & $\mathrm{Zn} / \mathrm{Ca}$ & $\mathrm{Sr} / \mathrm{Ca}$ & $\mathrm{Ba} / \mathrm{Ca}$ & 390 \\
\hline mean & 0.836 & 0.034 & 0.000 & 0.002 & 1.280 & 0.001 & & 1.203 & 0.011 & 0.005 & 0.083 & 1.279 & 0.004 & & 1.449 & 0.086 & 0.009 & 0.152 & 1.246 & 0.008 & \\
\hline$\% 2 s e$ & 2.7 & 7.1 & -39.0 & 44.6 & 1.7 & 6.0 & & 2.1 & 45.1 & 24.3 & 5.9 & 2.7 & 7.3 & & 5.3 & 60.6 & 17.3 & 18.0 & 1.9 & 18.2 & \\
\hline
\end{tabular}



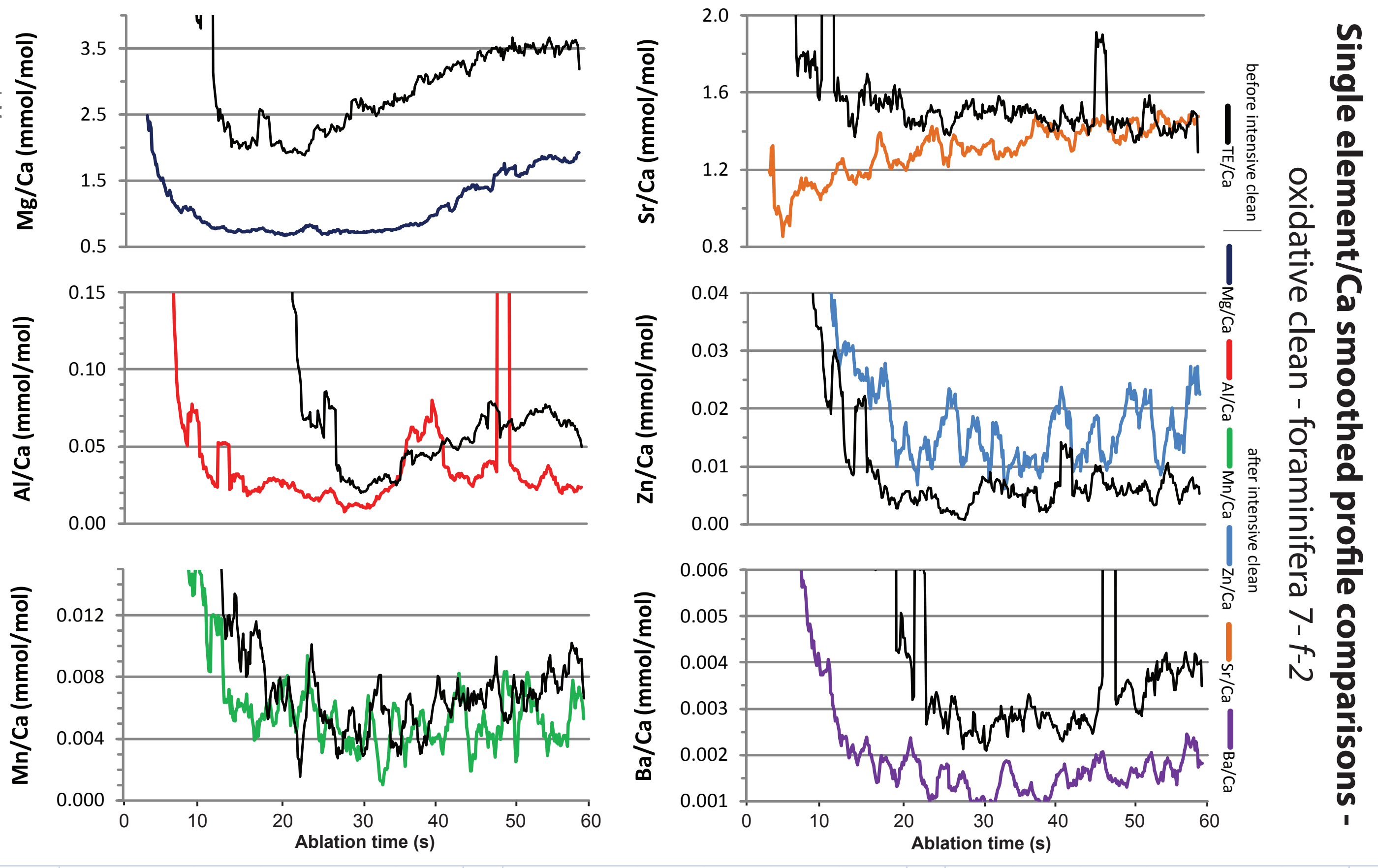

\begin{tabular}{|c|c|c|c|c|c|c|c|c|c|c|c|c|c|c|c|c|c|c|c|c|c|}
\hline & \multicolumn{6}{|c|}{ Before cleaning - LA processing - TE/Ca (mmol/mol) } & $n=$ & \multicolumn{6}{|c|}{ After cleaning - LA processing - TE/Ca $(\mathrm{mmol} / \mathrm{mol})$} & $n=$ & \multicolumn{6}{|c|}{ After cleaning - bulk processing - TE/Ca $(\mathrm{mmol} / \mathrm{mol})$} & $n=$ \\
\hline & $\mathrm{Mg} / \mathrm{Ca}$ & $\mathrm{Al} / \mathrm{Ca}$ & $\mathrm{Mn} / \mathrm{Ca}$ & $\mathrm{Zn} / \mathrm{Ca}$ & $\mathrm{Sr} / \mathrm{Ca}$ & $\mathrm{Ba} / \mathrm{Ca}$ & 180 & $\mathrm{Mg} / \mathrm{Ca}$ & $\mathrm{Al} / \mathrm{Ca}$ & $\mathrm{Mn} / \mathrm{Ca}$ & $\mathrm{Zn} / \mathrm{Ca}$ & $\mathrm{Sr} / \mathrm{Ca}$ & $\mathrm{Ba} / \mathrm{Ca}$ & 130 & $\mathrm{Mg} / \mathrm{Ca}$ & $\mathrm{Al} / \mathrm{Ca}$ & $\mathrm{Mn} / \mathrm{Ca}$ & $\mathrm{Zn} / \mathrm{Ca}$ & $\mathrm{Sr} / \mathrm{Ca}$ & $\mathrm{Ba} / \mathrm{Ca}$ & 390 \\
\hline mean & 1.345 & 0.147 & 0.000 & 0.004 & 1.392 & 0.002 & & 1.436 & 0.075 & 0.007 & 0.032 & 1.322 & 0.002 & & 1.978 & 1.072 & 0.016 & 0.068 & 1.370 & 0.006 & \\
\hline$\% 2$ se & 2.3 & 15.6 & 39.3 & 32.8 & 1.6 & 20.2 & & 2.6 & 6.3 & 16.2 & 10.8 & 2.0 & 9.0 & & 8.4 & 83.9 & 29.6 & 21.3 & 2.7 & 20.4 & \\
\hline
\end{tabular}



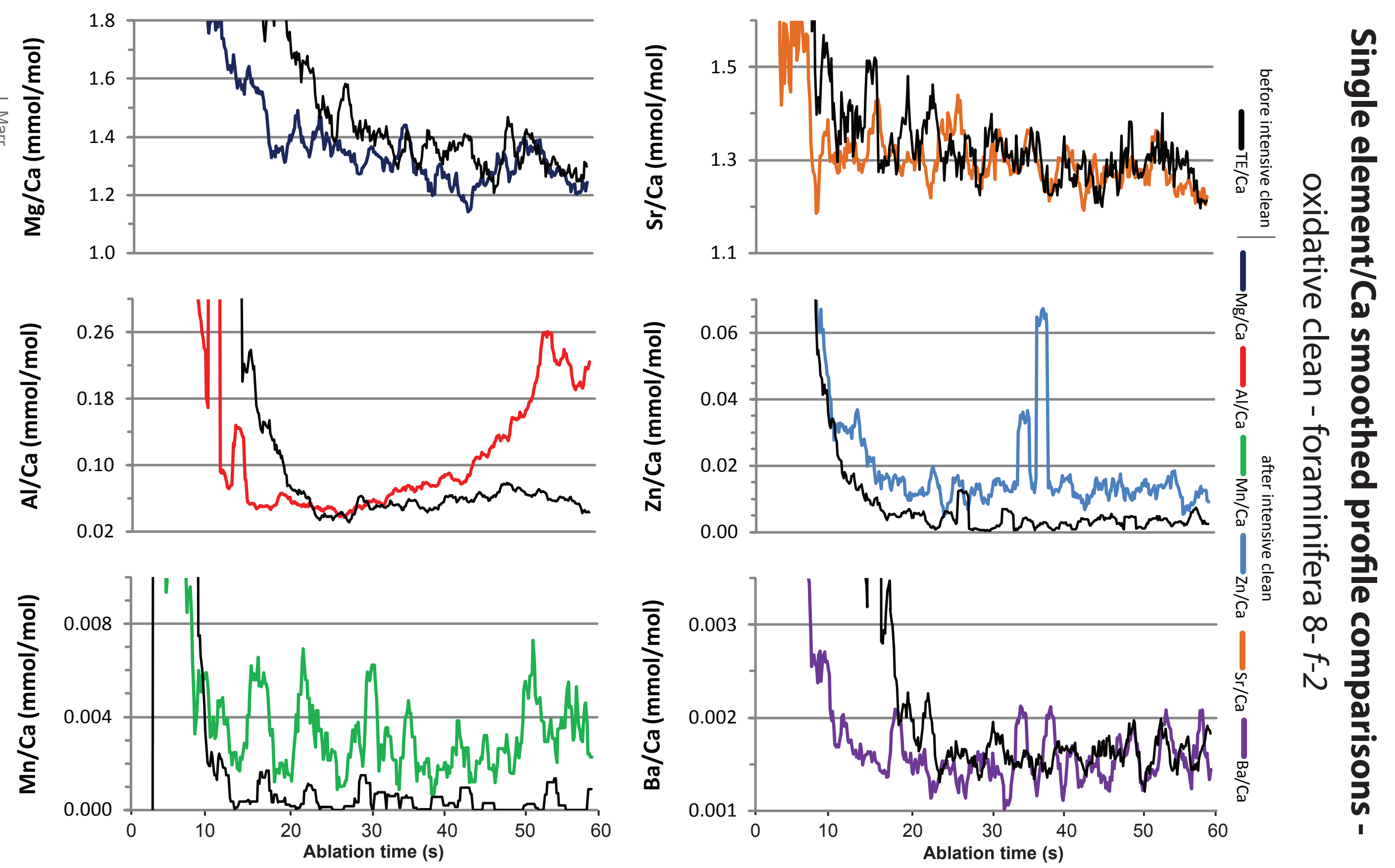

\begin{tabular}{|c|c|c|c|c|c|c|c|c|c|c|c|c|c|c|c|c|c|c|c|c|c|}
\hline & \multicolumn{6}{|c|}{ Before cleaning - LA processing - TE/Ca (mmol/mol) } & $n=$ & \multicolumn{6}{|c|}{ After cleaning - LA processing - TE/Ca $(\mathrm{mmol} / \mathrm{mol})$} & $n=$ & \multicolumn{6}{|c|}{ After cleaning - bulk processing - TE/Ca $(\mathrm{mmol} / \mathrm{mol})$} & $n=$ \\
\hline & $\mathrm{Mg} / \mathrm{Ca}$ & $\mathrm{Al} / \mathrm{Ca}$ & $\mathrm{Mn} / \mathrm{Ca}$ & $\mathrm{Zn} / \mathrm{Ca}$ & $\mathrm{Sr} / \mathrm{Ca}$ & $\mathrm{Ba} / \mathrm{Ca}$ & 230 & $\mathrm{Mg} / \mathrm{Ca}$ & $\mathrm{Al} / \mathrm{Ca}$ & $\mathrm{Mn} / \mathrm{Ca}$ & $\mathrm{Zn} / \mathrm{Ca}$ & $\mathrm{Sr} / \mathrm{Ca}$ & $\mathrm{Ba} / \mathrm{Ca}$ & 110 & $\mathrm{Mg} / \mathrm{Ca}$ & $\mathrm{Al} / \mathrm{Ca}$ & $\mathrm{Mn} / \mathrm{Ca}$ & $\mathrm{Zn} / \mathrm{Ca}$ & $\mathrm{Sr} / \mathrm{Ca}$ & $\mathrm{Ba} / \mathrm{Ca}$ & 390 \\
\hline mean & 1.362 & 0.055 & 0.000 & 0.000 & 1.291 & 0.001 & & 1.406 & 0.053 & 0.001 & 0.012 & 1.323 & 0.001 & & 1.580 & 0.247 & 0.004 & 0.031 & 1.311 & 0.002 & \\
\hline$\% 2 s e$ & 1.8 & 4.3 & 12.3 & -903.5 & 2.4 & 7.0 & & 2.4 & 10.8 & 82.5 & 20.8 & 2.4 & 12.3 & & 5.9 & 27.6 & 16.4 & 21.2 & 1.7 & 14.2 & \\
\hline
\end{tabular}



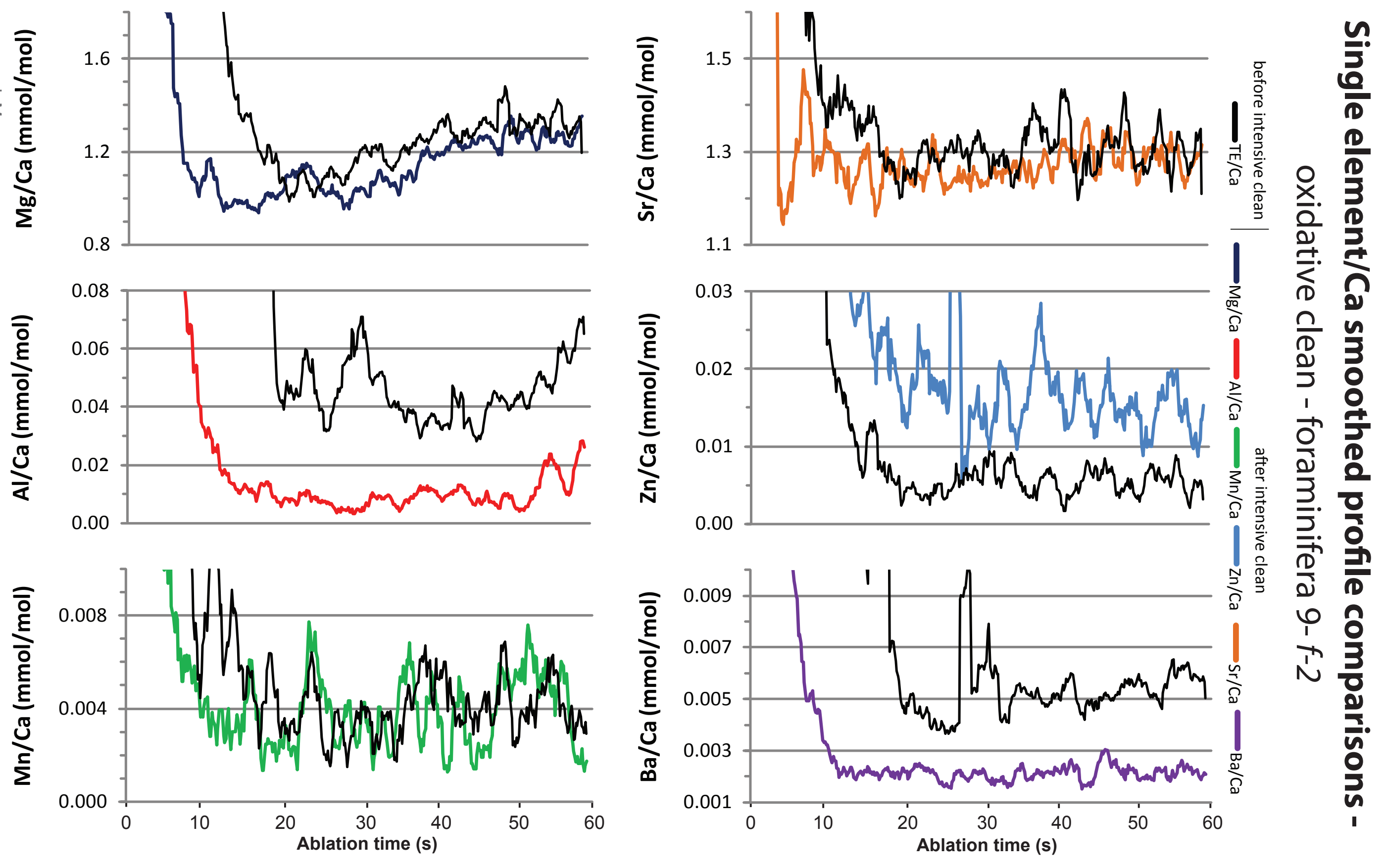

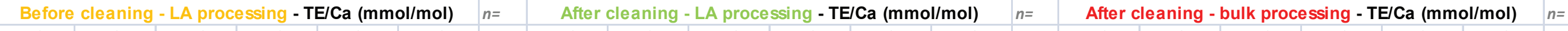

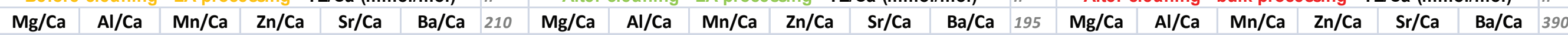

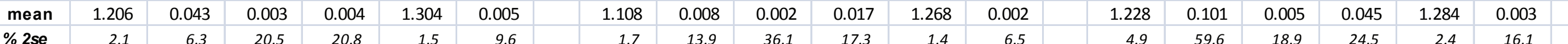

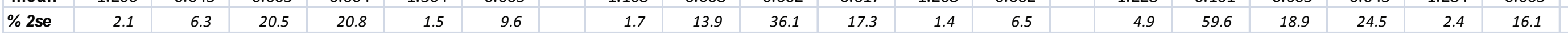



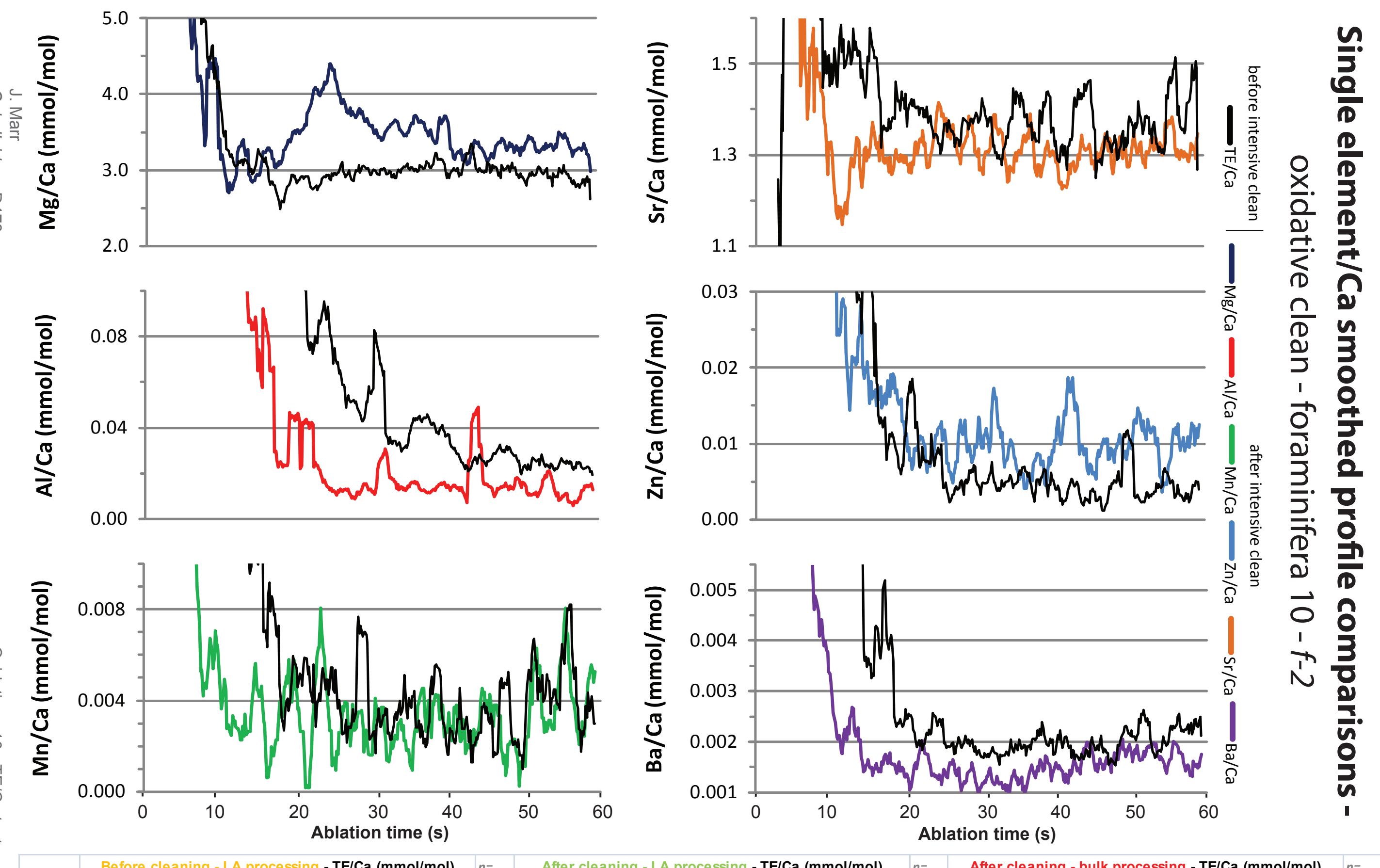

\begin{tabular}{|c|c|c|c|c|c|c|c|c|c|c|c|c|c|c|c|c|c|c|c|c|c|}
\hline & \multicolumn{6}{|c|}{ Before cleaning - LA processing - TE/Ca $(\mathrm{mmol} / \mathrm{mol})$} & $n=$ & \multicolumn{6}{|c|}{ After cleaning - LA processing - TE/Ca (mmol/mol) } & $n=$ & \multicolumn{6}{|c|}{ After cleaning - bulk processing - TE/Ca $(\mathrm{mmol} / \mathrm{mol})$} & $n=$ \\
\hline & $\mathrm{Mg} / \mathrm{Ca}$ & $\mathrm{Al} / \mathrm{Ca}$ & $\mathrm{Mn} / \mathrm{Ca}$ & $\mathrm{Zn} / \mathrm{Ca}$ & $\mathrm{Sr} / \mathrm{Ca}$ & $\mathrm{Ba} / \mathrm{Ca}$ & 250 & $\mathrm{Mg} / \mathrm{Ca}$ & $\mathrm{Al} / \mathrm{Ca}$ & $\mathrm{Mn} / \mathrm{Ca}$ & $\mathrm{Zn} / \mathrm{Ca}$ & $\mathrm{Sr} / \mathrm{Ca}$ & $\mathrm{Ba} / \mathrm{Ca}$ & 100 & $\mathrm{Mg} / \mathrm{Ca}$ & $\mathrm{Al} / \mathrm{Ca}$ & $\mathrm{Mn} / \mathrm{Ca}$ & $\mathrm{Zn} / \mathrm{Ca}$ & $\mathrm{Sr} / \mathrm{Ca}$ & $\mathrm{Ba} / \mathrm{Ca}$ & 390 \\
\hline mean & 2.975 & 0.039 & 0.003 & 0.004 & 1.368 & 0.002 & & 3.584 & 0.015 & 0.002 & 0.008 & 1.313 & 0.001 & & 3.609 & 0.304 & 0.005 & 0.021 & 1.356 & 0.003 & \\
\hline$\% 2 s e$ & 1.5 & 9.2 & 28.5 & 30.0 & 1.7 & 5.2 & & 2.2 & 13.1 & 69.9 & 29.9 & 2.1 & 12.6 & & 3.1 & 35.5 & 19.2 & 19.7 & 2.7 & 17.3 & \\
\hline
\end{tabular}



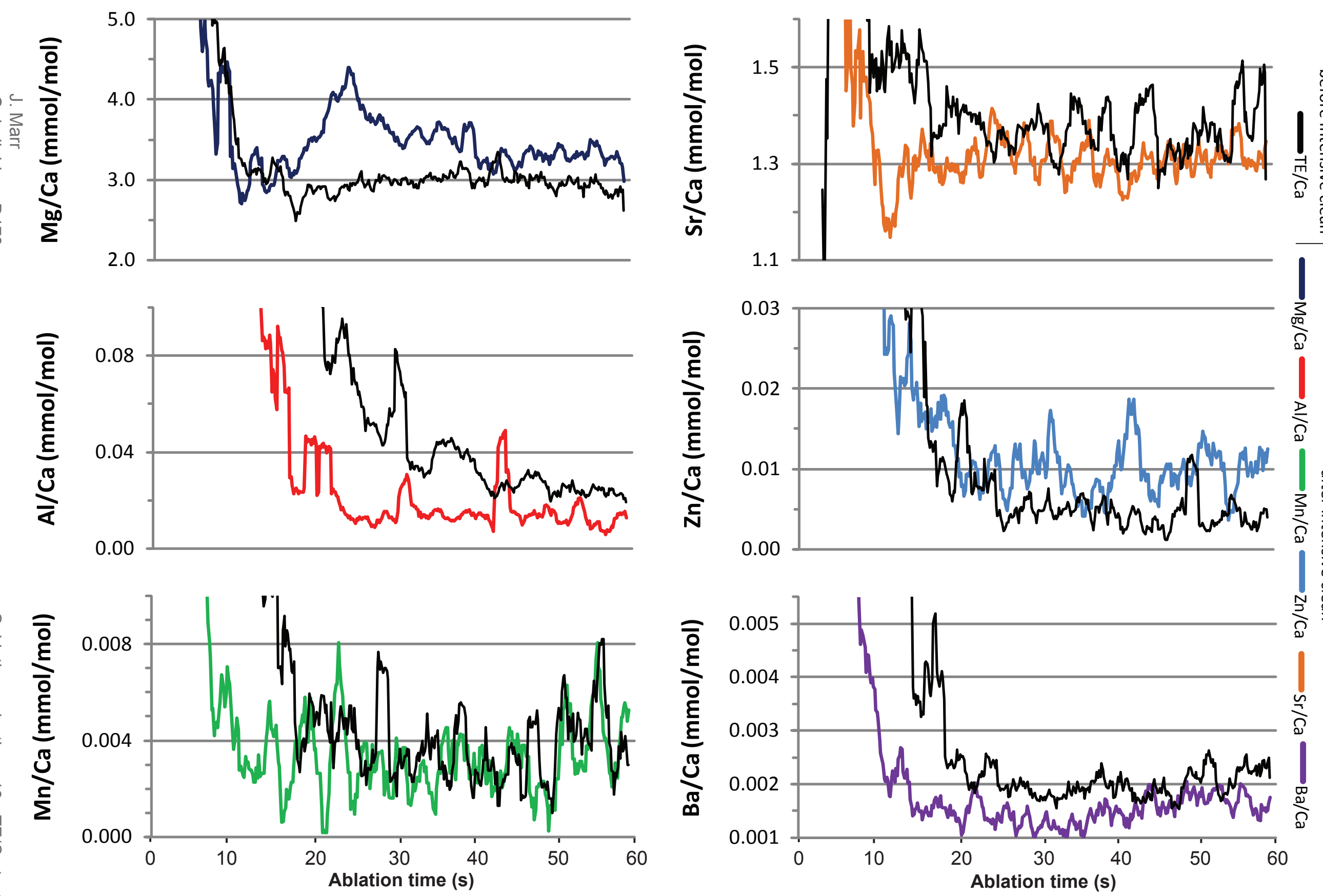

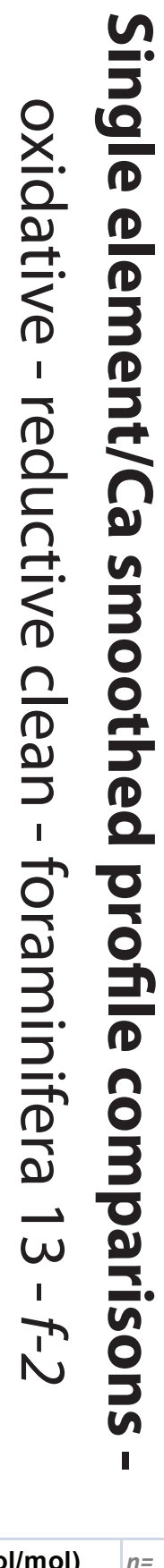

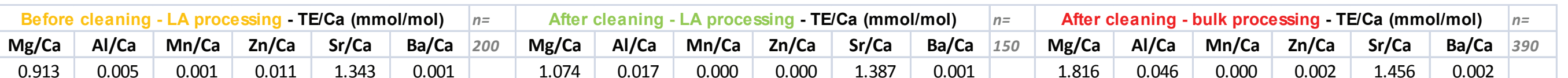
\begin{tabular}{|l|r|r|r|r|r|r|r|r|r|r|r|r|r|r|r|r|r|r|r|r|}
\hline mean & 0.913 & 0.005 & 0.001 & 0.011 & 1.343 & 0.001 & 1.074 & 0.017 & 0.000 & 0.000 & 1.387 & 0.001 & 1.816 & 0.046 & 0.000 & 0.002 & 1.456 & 0.002 \\
\hline
\end{tabular} 

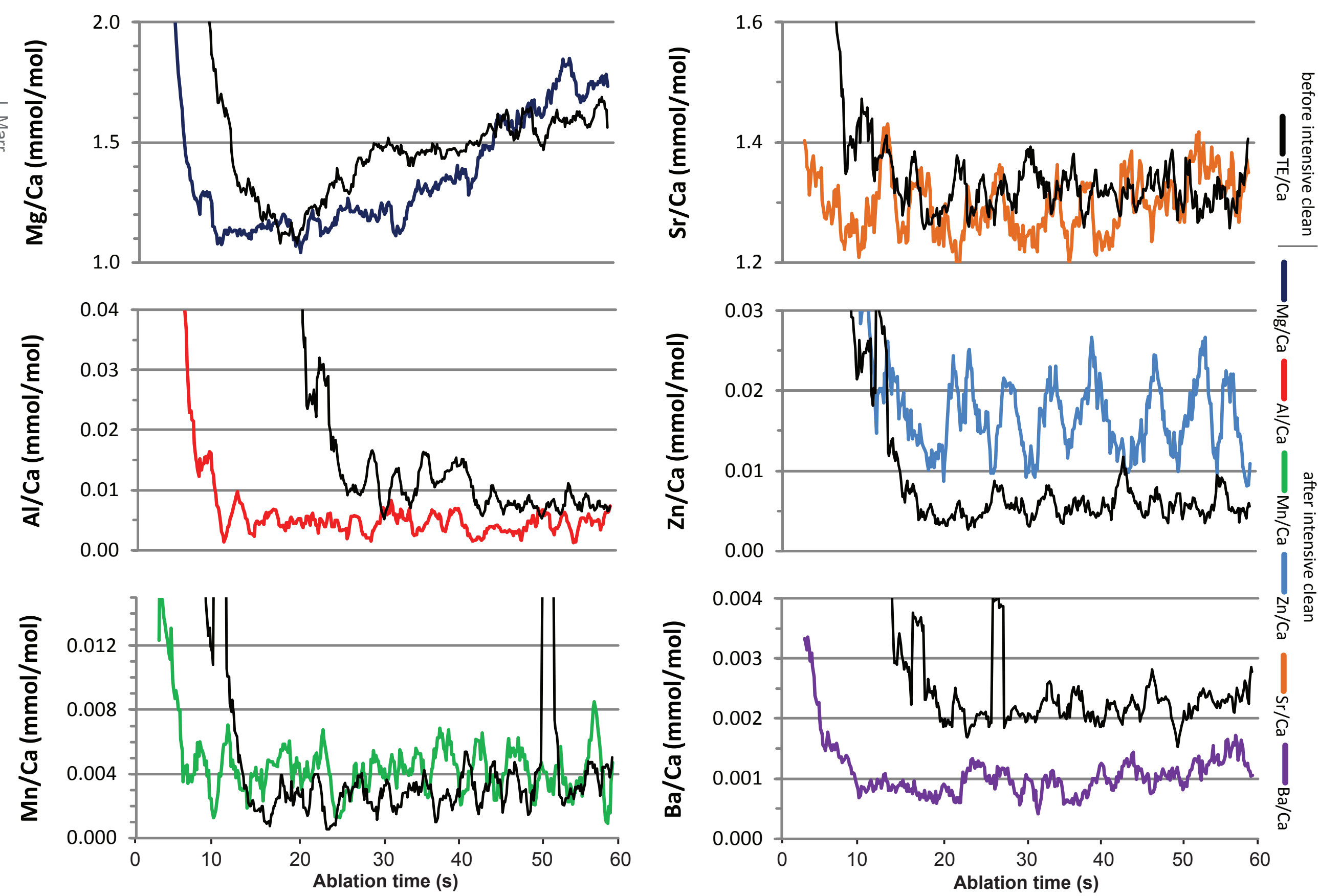

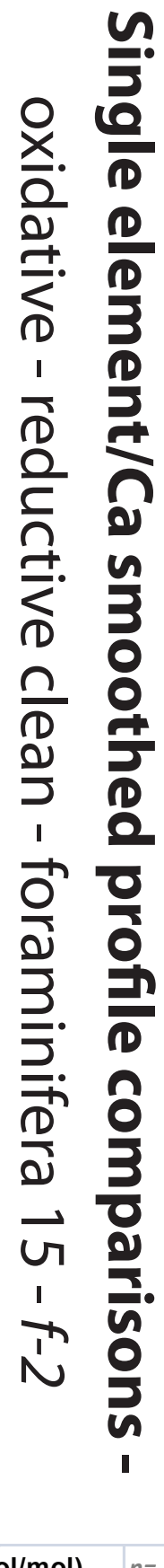

Before cleaning - LA processing - TE/Ca $(\mathrm{mmol} / \mathrm{mol}) \quad n=\quad$ After cleaning $-\mathrm{LA}$ processing $-\mathrm{TE} / \mathrm{Ca}(\mathrm{mmol} / \mathrm{mol}) \quad n=\quad$ After cleaning - bulk processing $-\mathrm{TE} / \mathrm{Ca}(\mathrm{mmol} / \mathrm{mol})$

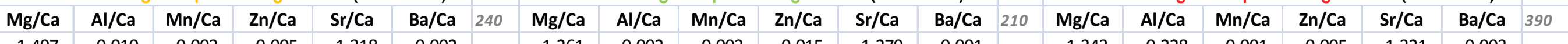
\begin{tabular}{|l|r|r|r|r|r|r|r|r|r|r|r|r|r|r|r|r|r|r|r|r|}
\hline mean & 1.497 & 0.010 & 0.003 & 0.005 & 1.318 & 0.002 & 1.261 & 0.002 & 0.003 & 0.015 & 1.279 & 0.001 & 1.343 & 0.228 & 0.001 & 0.005 & 1.321 & 0.003 \\
\hline
\end{tabular} \begin{tabular}{|l|l|l|l|l|l|l|l|l|l|l|l|l|l|l|l|l|l|l|}
\hline \% 2se & 1.5 & 11.7 & 48.0 & 17.7 & 1.3 & 8.6 & 2.2 & 42.4 & 32.9 & 12.9 & 1.8 & 11.0 & 2.0 & 148.9 & 56.0 & 17.6 & 1.4 & 15.4 \\
\hline
\end{tabular} 

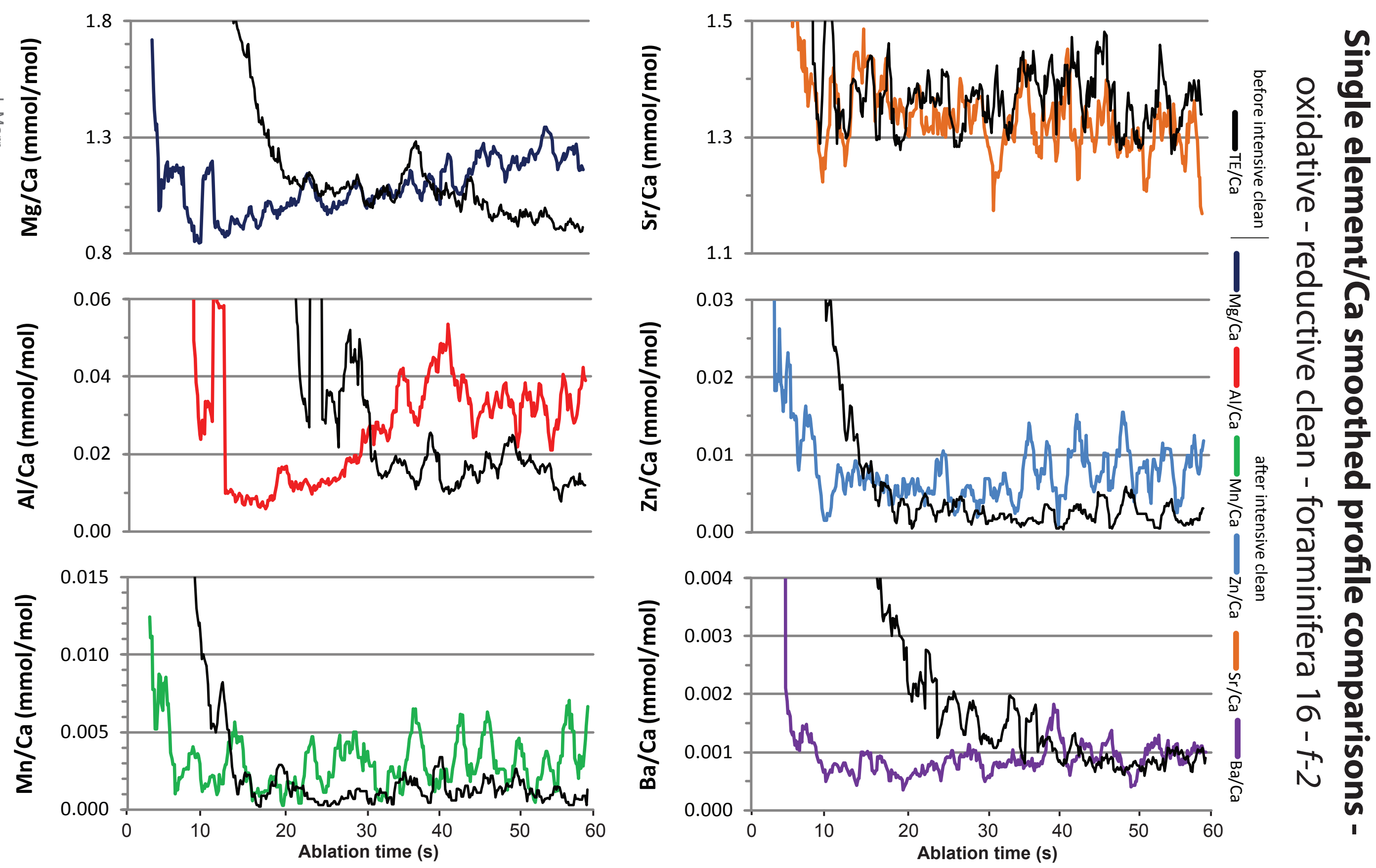

$$
\begin{aligned}
& \text { Before cleaning - LA processing - TE/Ca }(\mathbf{m m o l} / \mathbf{m o l}) \quad n=\quad \text { After cleaning }-\mathrm{LA} \text { processing }-\mathrm{TE} / \mathrm{Ca}(\mathbf{m m o l} / \mathbf{m o l}) \quad n=\quad \text { After cleaning }- \text { bulk processing }-\mathrm{TE} / \mathrm{Ca}(\mathbf{m m o l} / \mathbf{m o l}) \quad n=
\end{aligned}
$$

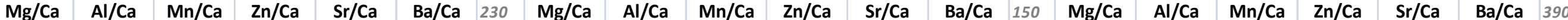



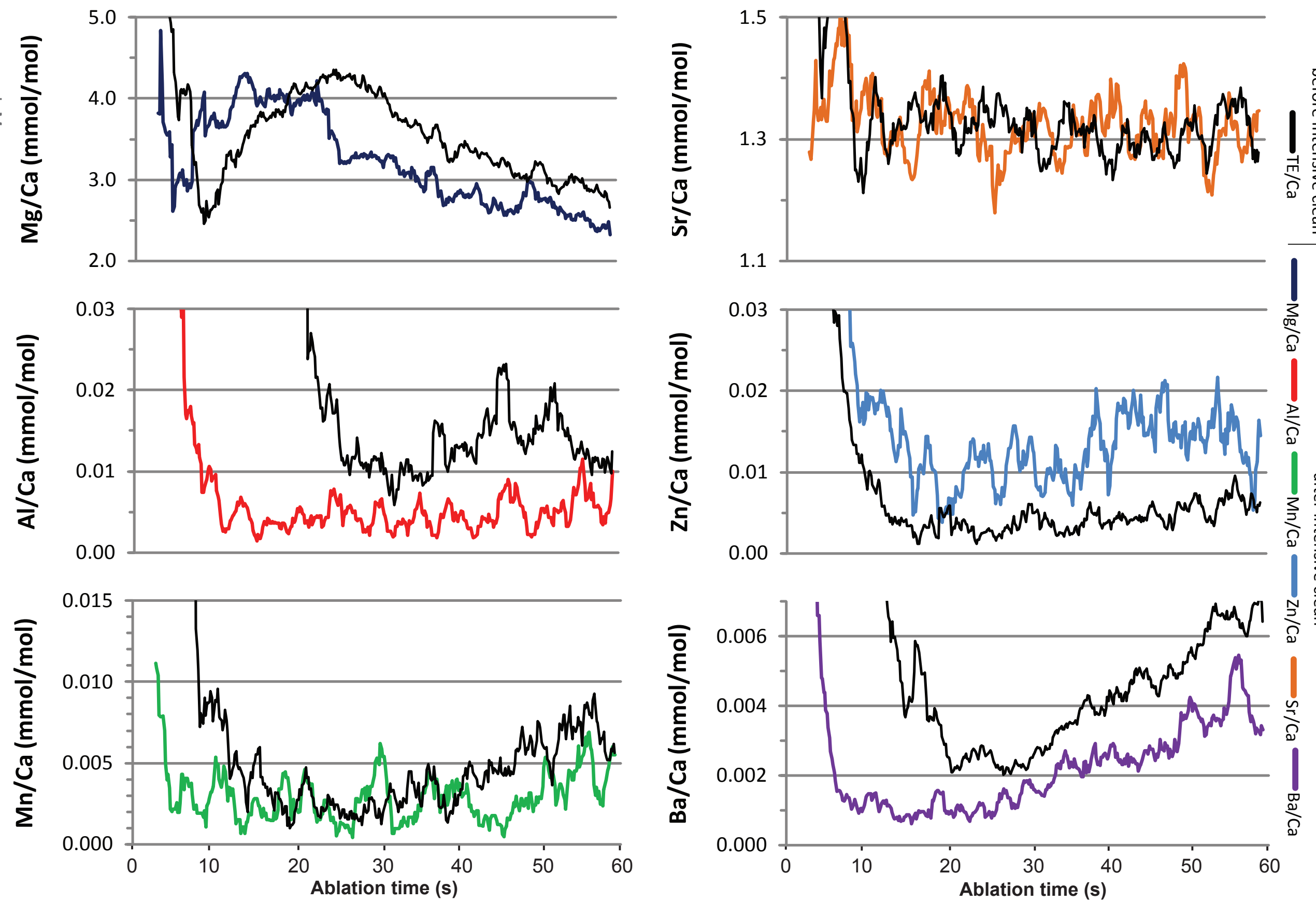

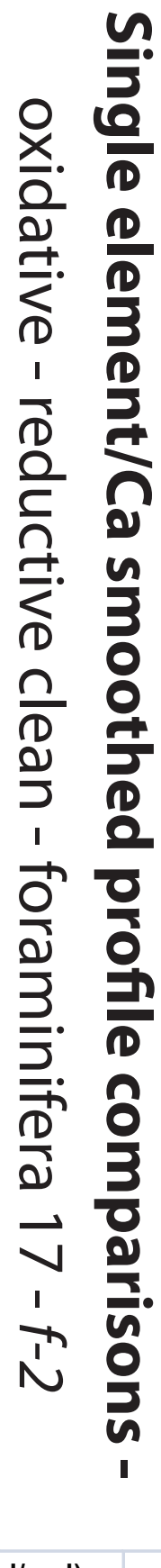

Before cleaning - LA processing - TE/Ca $(\mathbf{m m o l} / \mathbf{m o l}) \quad n=\quad$ After cleaning - LA processing $-\mathrm{TE} / \mathrm{Ca}(\mathbf{m m o l} / \mathbf{m o l})$ After cleaning - bulk processing - TE/Ca $(\mathrm{mmol} / \mathrm{mol})$

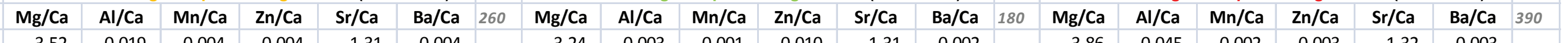
\begin{tabular}{|l|r|r|r|r|r|r|r|r|r|r|r|r|r|r|r|r|r|r|r|r|}
\hline mean & 3.52 & 0.019 & 0.004 & 0.004 & 1.31 & 0.004 & 3.24 & 0.003 & 0.001 & 0.010 & 1.31 & 0.002 & 3.86 & 0.045 & 0.002 & 0.003 & 1.32 & 0.003 \\
\hline
\end{tabular}

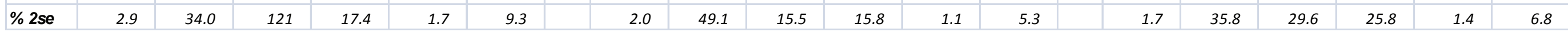



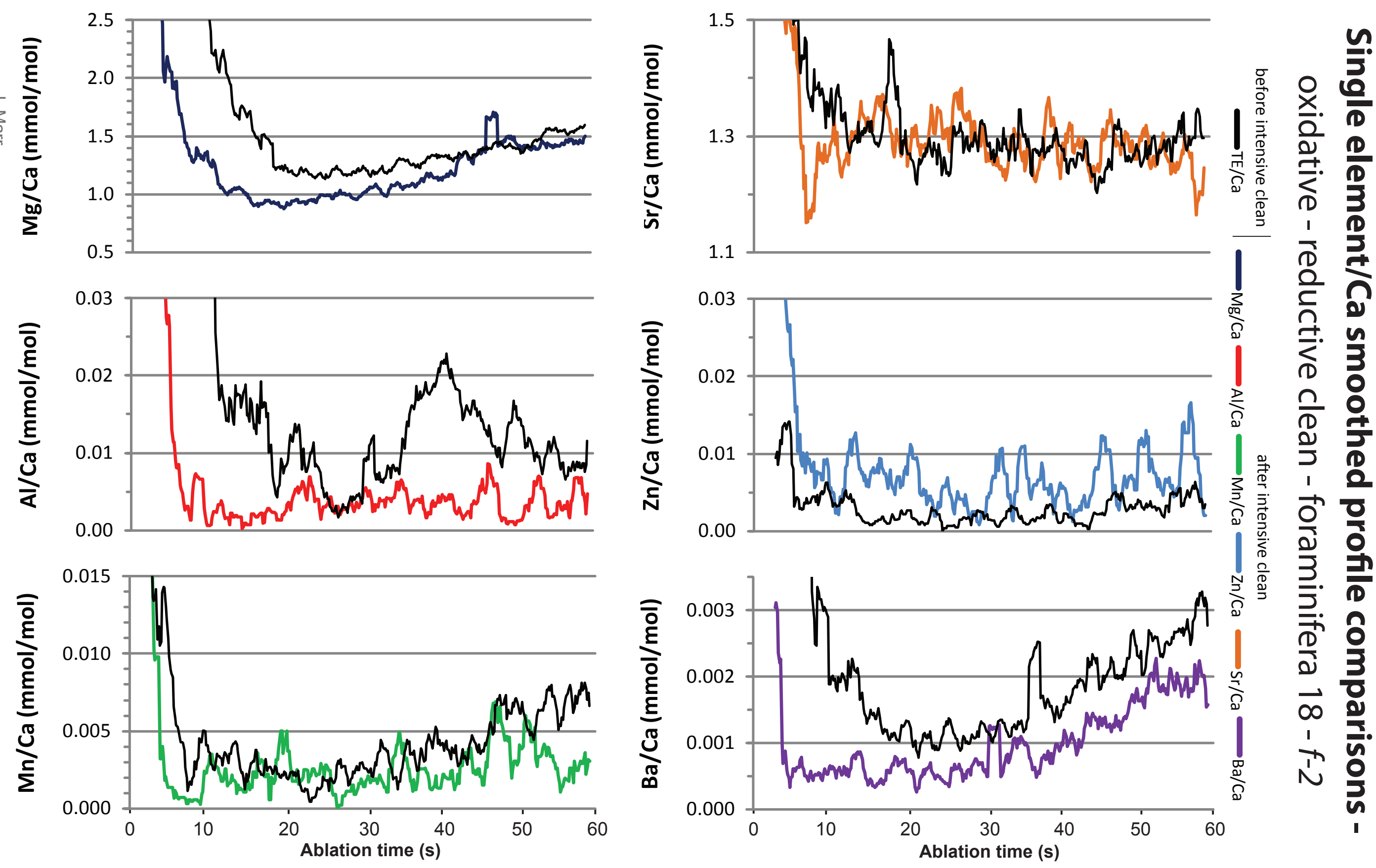

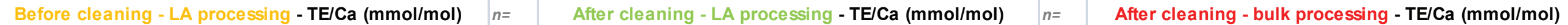

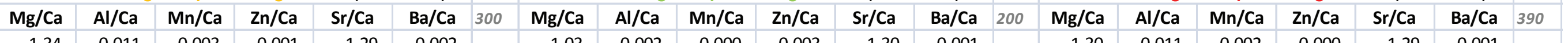

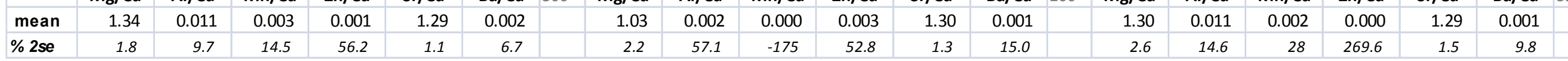



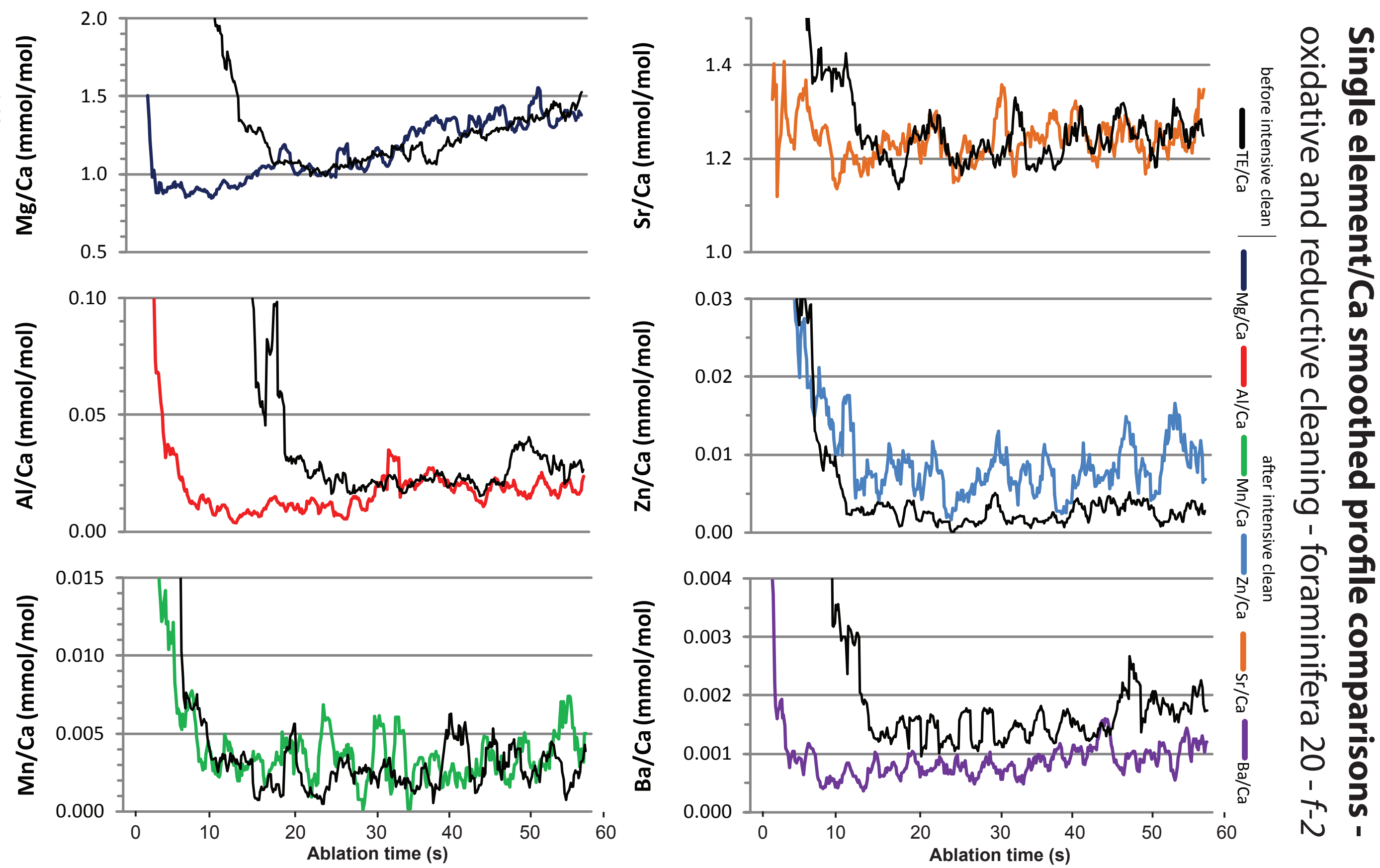

\begin{tabular}{|c|c|c|c|c|c|c|c|c|c|c|c|c|c|c|c|c|c|c|c|c|c|}
\hline & \multicolumn{6}{|c|}{ Before cleaning - LA processing - TE/Ca (mmol/mol) } & \multirow{2}{*}{$\begin{array}{l}n= \\
260\end{array}$} & \multicolumn{6}{|c|}{ After cleaning = LA processing - TE/Ca $(\mathbf{m m o l} / \mathbf{m o l})$} & \multirow{2}{*}{$\begin{array}{l}n= \\
190\end{array}$} & \multicolumn{6}{|c|}{ After cleaning - bulk processing - TE/Ca (mmol/mol) } & \multirow{2}{*}{$\begin{array}{l}n= \\
390\end{array}$} \\
\hline & $\mathrm{Mg} / \mathrm{Ca}$ & $\mathrm{Al} / \mathrm{Ca}$ & $\mathrm{Mn} / \mathrm{Ca}$ & $\mathrm{Zn} / \mathrm{Ca}$ & $\mathrm{Sr} / \mathrm{Ca}$ & $\mathrm{Ba} / \mathrm{Ca}$ & & $\mathrm{Mg} / \mathrm{Ca}$ & $\mathrm{Al} / \mathrm{Ca}$ & $\mathrm{Mn} / \mathrm{Ca}$ & $\mathrm{Zn} / \mathrm{Ca}$ & $\mathrm{Sr} / \mathrm{Ca}$ & $\mathrm{Ba} / \mathrm{Ca}$ & & $\mathrm{Mg} / \mathrm{Ca}$ & $\mathrm{Al} / \mathrm{Ca}$ & $\mathrm{Mn} / \mathrm{Ca}$ & $\mathrm{Zn} / \mathrm{Ca}$ & $\mathrm{Sr} / \mathrm{Ca}$ & $\mathrm{Ba} / \mathrm{Ca}$ & \\
\hline & 1. & $J \angle J$ & & 0.001 & 1.2 & 0.002 & & 1.09 & 4 & 0.002 & 0.005 & 1.23 & 0.001 & & 1.40 & 0.015 & 0.002 & 0.002 & 1.29 & 0.001 & \\
\hline$\%$ 2se & 1.9 & 6.3 & 47.5 & 41.4 & 1.3 & 44.6 & & 2.5 & 17.7 & 80.7 & 39.6 & 1.5 & 11.8 & & 2.5 & 85.2 & 22.2 & 27.8 & 1.5 & 6.5 & \\
\hline
\end{tabular}



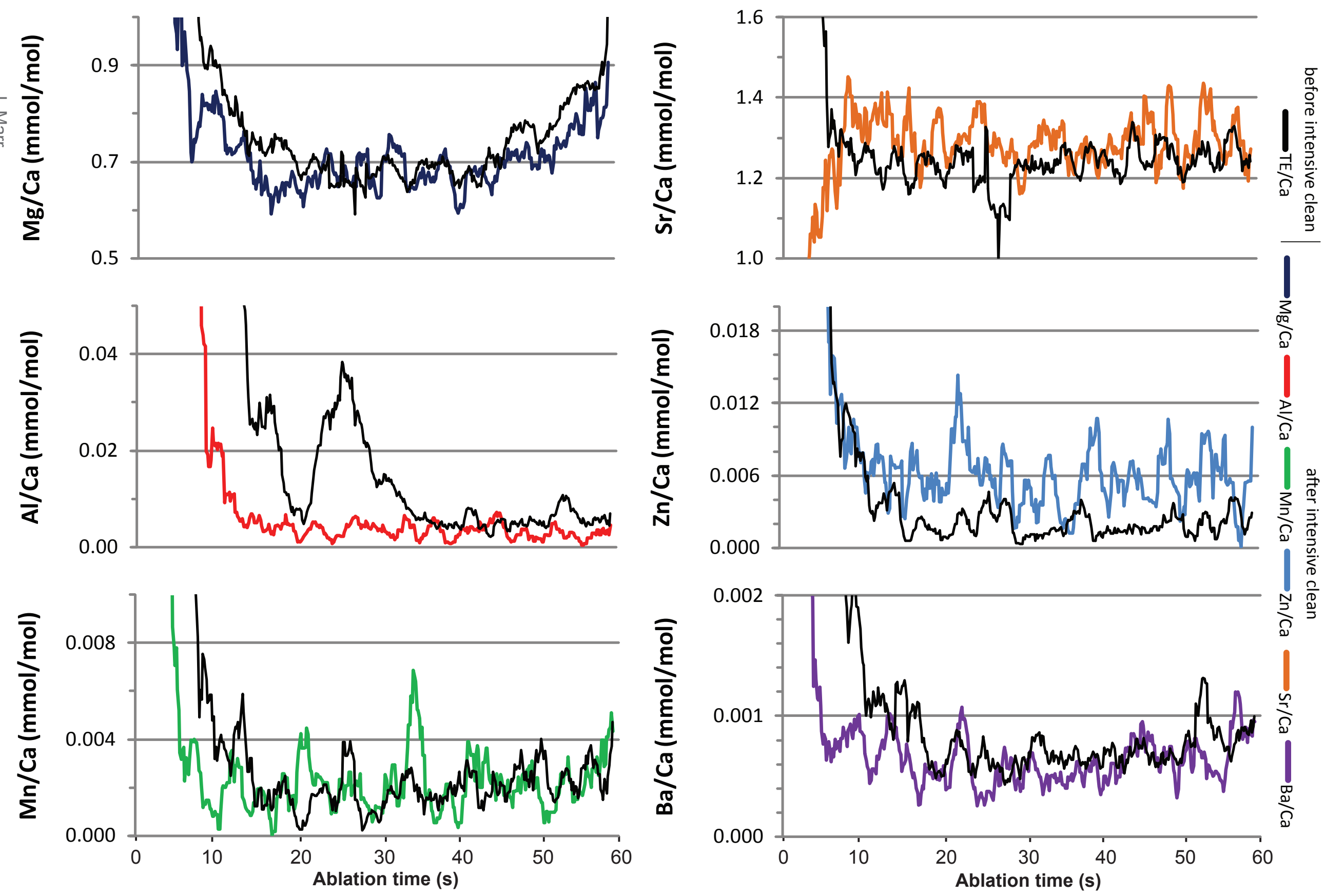

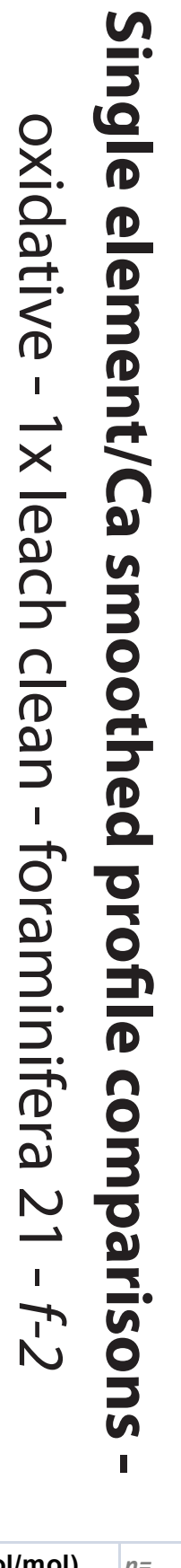
Before cleaning - LA processing $-\mathrm{TE} / \mathrm{Ca}(\mathbf{m m o l} / \mathbf{m o l}) \quad n=\quad$ After cleaning $-\mathrm{LA}$ processing $-\mathrm{TE} / \mathrm{Ca}(\mathbf{m m o l} / \mathbf{m o l})$ \begin{tabular}{|l|l|l|l|l|l|l|l|l|}
$\mathrm{Mg} / \mathrm{Ca}$ & $\mathrm{Al} / \mathrm{Ca}$ & $\mathrm{Mn} / \mathrm{Ca}$ & $\mathrm{Zn} / \mathrm{Ca}$ & $\mathrm{Sr} / \mathrm{Ca}$ & $\mathrm{Ba} / \mathrm{Ca}$ & 300 & $\mathrm{Mg} / \mathrm{Ca}$ & $\mathrm{Al} / \mathrm{Ca}$ \\
\hline
\end{tabular} \begin{tabular}{|c|c|c|c|c|c|c|c|c|c|c|c|}
$\mathrm{Mn} / \mathrm{Ca}$ & $\mathrm{Zn} / \mathrm{Ca}$ & $\mathrm{Sr} / \mathrm{Ca}$ & $\mathrm{Ba} / \mathrm{Ca}$ & 200 & $\mathrm{Mg} / \mathrm{Ca}$ & $\mathrm{Al} / \mathrm{Ca}$ & $\mathrm{Mn} / \mathrm{Ca}$ & $\mathrm{Zn} / \mathrm{Ca}$ & $\mathrm{Sr} / \mathrm{Ca}$ & $\mathrm{Ba} / \mathrm{Ca}$ & 390 \\
\hline
\end{tabular} 

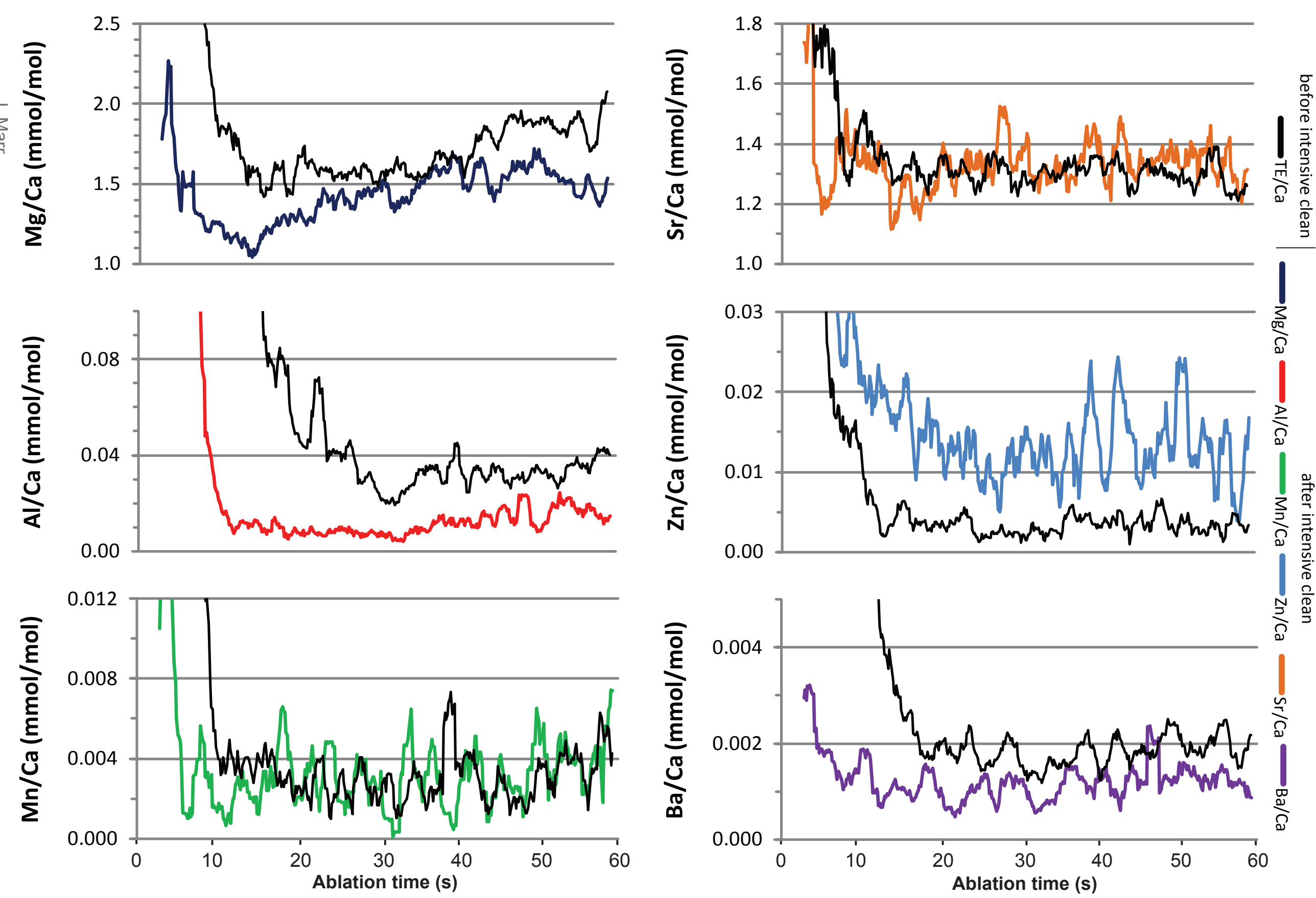

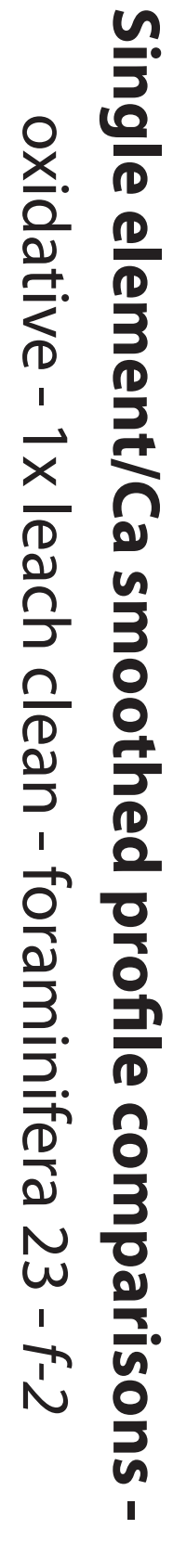

Before cleaning - LA processing $-\mathrm{TE} / \mathrm{Ca}(\mathbf{m m o l} / \mathrm{mol}) \quad n=\quad$ After cleaning $-\mathrm{LA}$ processing $-\mathrm{TE} / \mathrm{Ca}(\mathbf{m m o l} / \mathrm{mol})$

\begin{tabular}{|r|r|r|r|r|r|r|r|r|}
\hline $\mathrm{Mg} / \mathrm{Ca}$ & $\mathrm{Al} / \mathrm{Ca}$ & $\mathrm{Mn} / \mathrm{Ca}$ & $\mathrm{Zn} / \mathrm{Ca}$ & $\mathrm{Sr} / \mathrm{Ca}$ & $\mathrm{Ba} / \mathrm{Ca}$ & 270 & $\mathrm{Mg} / \mathrm{Ca}$ & $\mathrm{Al} / \mathrm{Ca}$ \\
\hline 1.70 & 0.035 & 0.002 & 0.002 & 1.30 & 0.002 & & 1.40 & 0.008 \\
\hline
\end{tabular}

After cleaning - bulk processing $-\mathrm{TE} / \mathrm{Ca}(\mathrm{mmol} / \mathrm{mol})$ 

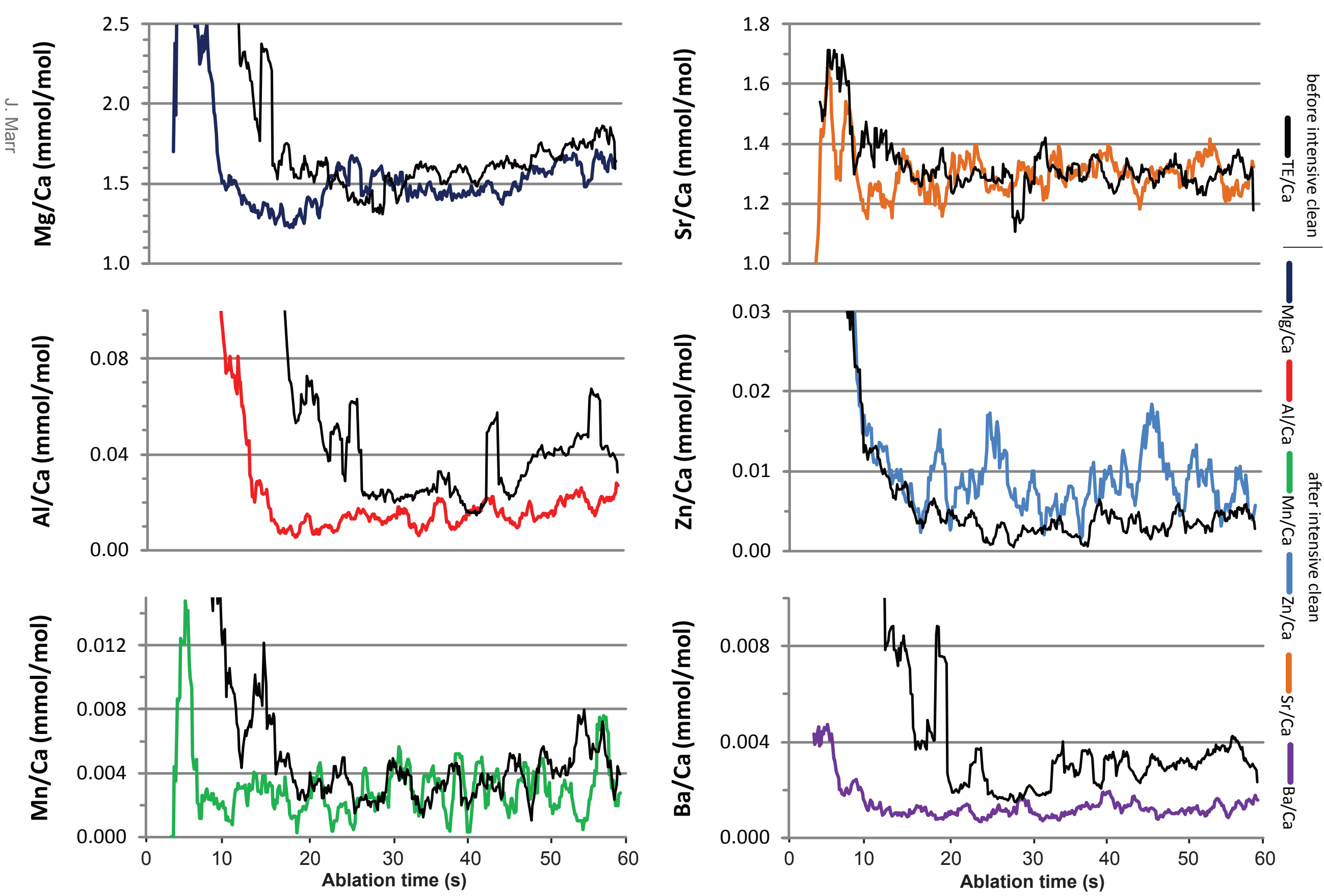

\begin{tabular}{|c|c|c|c|c|c|c|c|c|c|c|c|c|c|c|c|c|c|c|c|c|c|}
\hline & \multicolumn{6}{|c|}{ Before cleaning - LA processing - TE/Ca $(\mathrm{mmol} / \mathrm{mol})$} & $n=$ & \multicolumn{6}{|c|}{ After cleaning - LA processing - TE/Ca $(\mathrm{mmol} / \mathrm{mol})$} & $n=$ & \multicolumn{6}{|c|}{ After cleaning - bulk processing - TE/Ca $(\mathrm{mmol} / \mathrm{mol})$} & $n=$ \\
\hline & $\mathrm{Mg} / \mathrm{Ca}$ & $\mathrm{Al} / \mathrm{Ca}$ & $\mathrm{Mn} / \mathrm{Ca}$ & $\mathrm{Zn} / \mathrm{Ca}$ & $\mathrm{Sr} / \mathrm{Ca}$ & $\mathrm{Ba} / \mathrm{Ca}$ & 250 & $\mathrm{Mg} / \mathrm{Ca}$ & $\mathrm{Al} / \mathrm{Ca}$ & $\mathrm{Mn} / \mathrm{Ca}$ & $\mathrm{Zn} / \mathrm{Ca}$ & $\mathrm{Sr} / \mathrm{Ca}$ & $\mathrm{Ba} / \mathrm{Ca}$ & 210 & $\mathrm{Mg} / \mathrm{Ca}$ & $\mathrm{Al} / \mathrm{Ca}$ & $\mathrm{Mn} / \mathrm{Ca}$ & $\mathrm{Zn} / \mathrm{Ca}$ & $\mathrm{Sr} / \mathrm{Ca}$ & $\mathrm{Ba} / \mathrm{Ca}$ & 390 \\
\hline & 1.60 & כב & בנס & $z$ & 1.30 & .003 & & 1.48 & 3 & 0 & 06 & 1.30 & 0.001 & & 1.59 & 0.102 & 003 & 0.014 & 1.30 & 0.001 & \\
\hline & 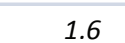 & 11.4 & 16.0 & & 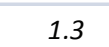 & 7.6 & & 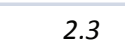 & 11.6 & 388 & 31.7 & 2.0 & 9.8 & & 3.3 & $2-$ & 17 & 19.2 & 18 & & \\
\hline
\end{tabular}



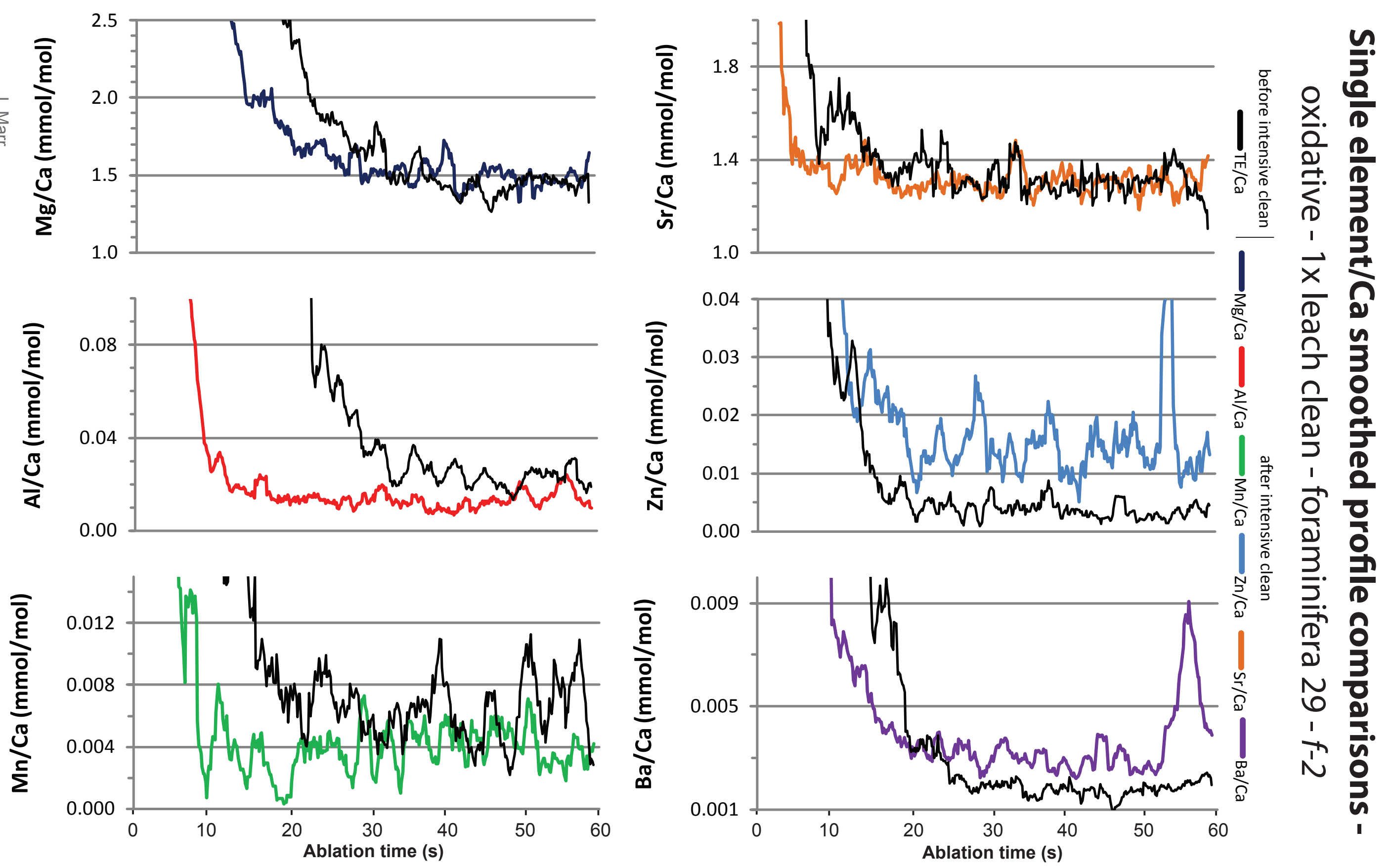

\begin{tabular}{|c|c|c|c|c|c|c|c|c|c|c|c|c|c|c|c|c|c|c|c|c|c|}
\hline & \multicolumn{6}{|c|}{ Before cleaning - LA processing - TE/Ca (mmol/mol) } & $n=$ & \multicolumn{6}{|c|}{ After cleaning - LA processing - TE/Ca $(\mathrm{mmol} / \mathrm{mol})$} & $n=$ & \multicolumn{6}{|c|}{ After cleaning - bulk processing - TE/Ca $(\mathrm{mmol} / \mathrm{mol})$} & $n=$ \\
\hline & $\mathrm{Mg} / \mathrm{Ca}$ & $\mathrm{Al} / \mathrm{Ca}$ & $\mathrm{Mn} / \mathrm{Ca}$ & $\mathrm{Zn} / \mathrm{Ca}$ & $\mathrm{Sr} / \mathrm{Ca}$ & $\mathrm{Ba} / \mathrm{Ca}$ & 300 & $\mathrm{Mg} / \mathrm{Ca}$ & $\mathrm{Al} / \mathrm{Ca}$ & $\mathrm{Mn} / \mathrm{Ca}$ & $\mathrm{Zn} / \mathrm{Ca}$ & $\mathrm{Sr} / \mathrm{Ca}$ & $\mathrm{Ba} / \mathrm{Ca}$ & 160 & $\mathrm{Mg} / \mathrm{Ca}$ & $\mathrm{Al} / \mathrm{Ca}$ & $\mathrm{Mn} / \mathrm{Ca}$ & $\mathrm{Zn} / \mathrm{Ca}$ & $\mathrm{Sr} / \mathrm{Ca}$ & $\mathrm{Ba} / \mathrm{Ca}$ & 390 \\
\hline mean & 1.86 & 0.021 & 0.010 & 0.006 & 1.31 & 0.004 & & 1.42 & 0.009 & 0.007 & 0.005 & 1.28 & 0.006 & & 2.37 & 0.309 & 0.007 & 0.041 & 1.37 & 0.013 & \\
\hline$\% 2 s e$ & 2.7 & 8.6 & 6.8 & 13.7 & 1.1 & 4.9 & & 2.6 & 23.5 & 18.6 & 48.0 & 2.7 & 6.2 & & 10.9 & 86.9 & 34.4 & 27.9 & 5.4 & 41.3 & \\
\hline
\end{tabular}



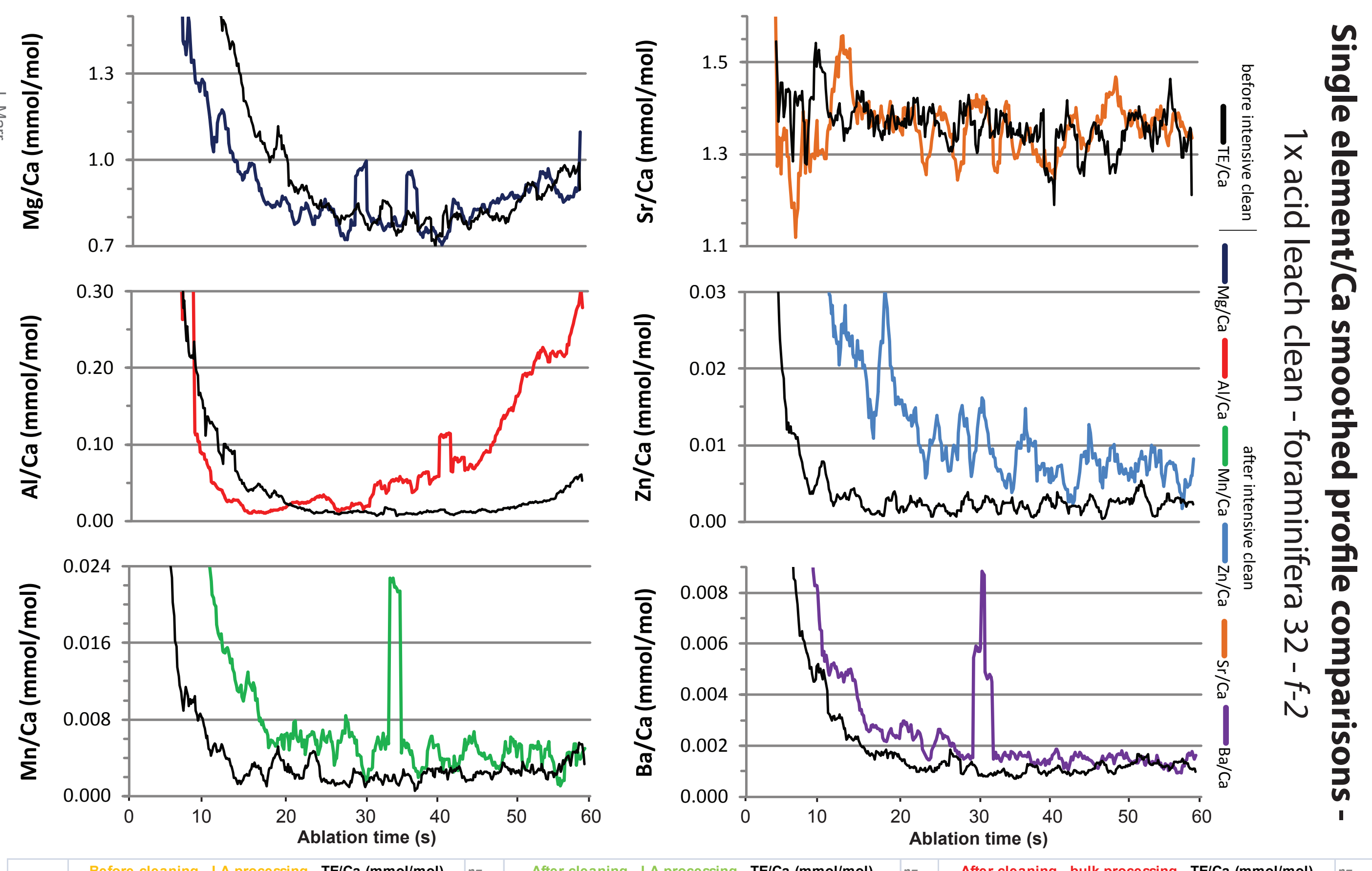

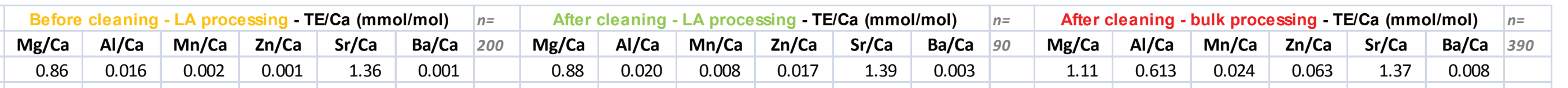
\begin{tabular}{|l|l|l|l|l|l|l|l|l|l|l|l|l|l|l|l|l|l|l|}
\hline \% 2se & 2.46 & 12.1 & 29.0 & 62.8 & 1.65 & 9.29 & 2.7 & 12.7 & 16.6 & 15.9 & 2.3 & 10.9 & 12.4 & 81.2 & 58.5 & 104.0 & 2.9 & 53.9 \\
\hline
\end{tabular} 

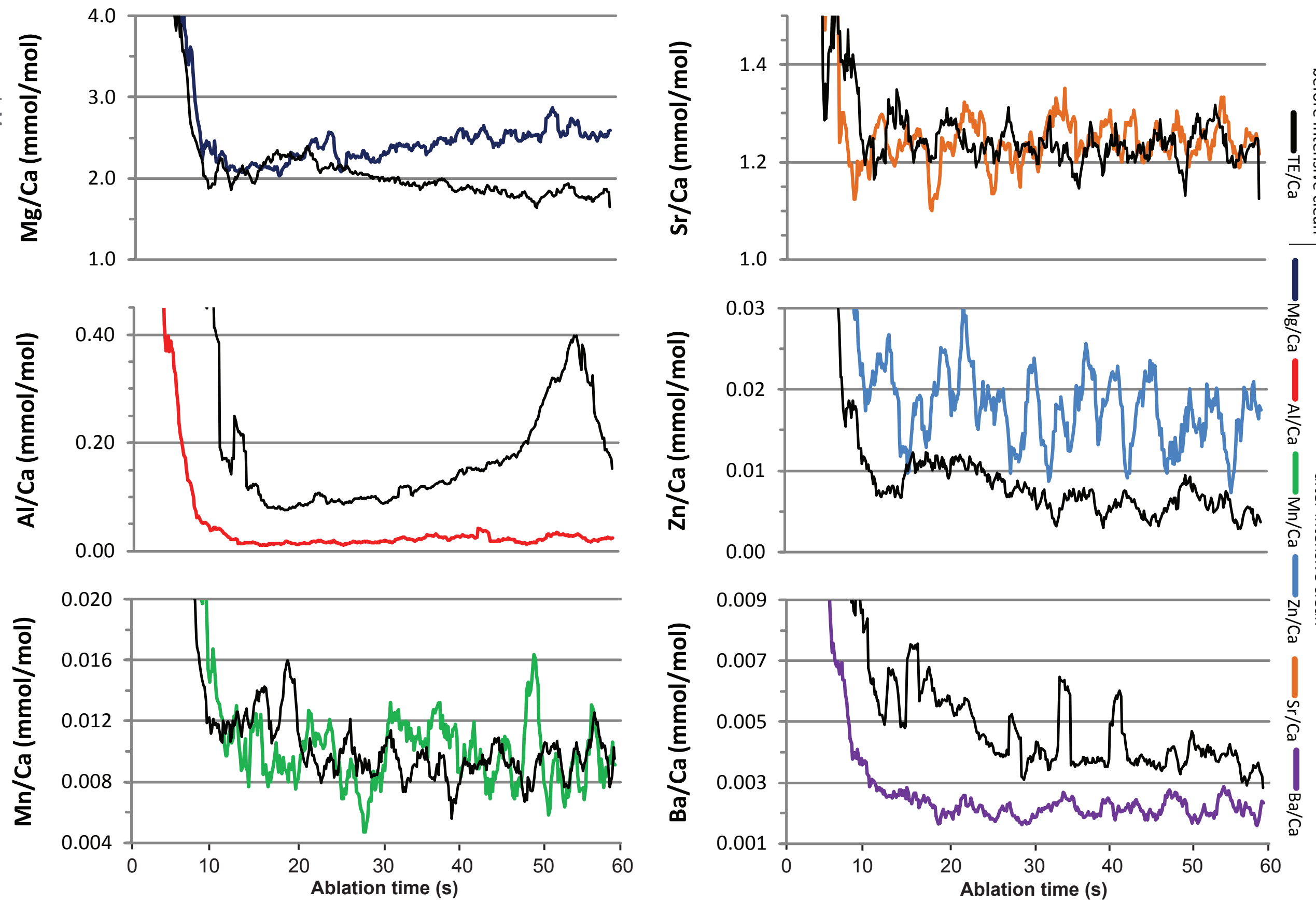

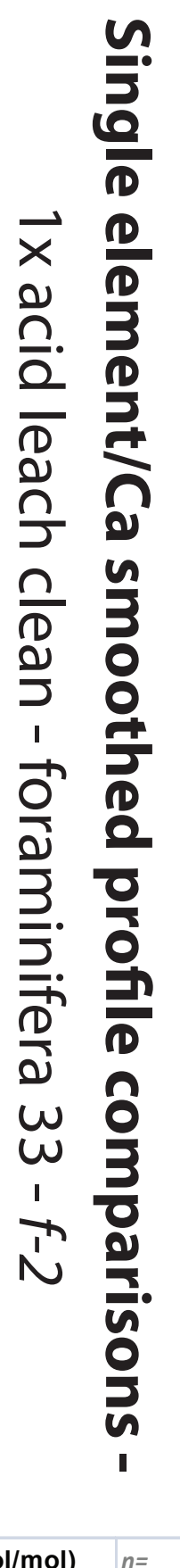

Before cleaning - LA processing - TE/Ca $(\mathbf{m m o l} / \mathbf{m o l}) \quad n=\quad$ After cleaning $-L A$ processing $-\mathrm{TE} / \mathrm{Ca}(\mathrm{mmol} / \mathbf{m o l}) \quad n=\quad$ After cleaning $-\mathrm{bulk} \mathrm{processing}-\mathrm{TE} / \mathrm{Ca}(\mathrm{mmol} / \mathrm{mol}) \quad n=$

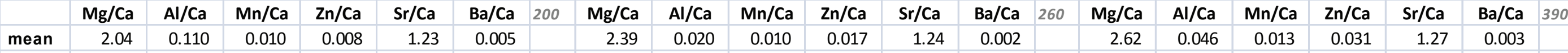
\begin{tabular}{|l|l|l|l|l|l|l|l|l|l|l|l|l|l|l|l|l|l|l|l|l|}
\hline$\% 2 \mathrm{se}$ & 1.6 & 4.2 & 5.9 & 9.2 & 1.3 & 8.3 & 1.6 & 9.3 & 8.3 & 9.7 & 1.4 & 5.3 & 5.8 & 22.8 & 11.4 & 24.7 & 2.4 & 18.9 \\
\hline
\end{tabular} 

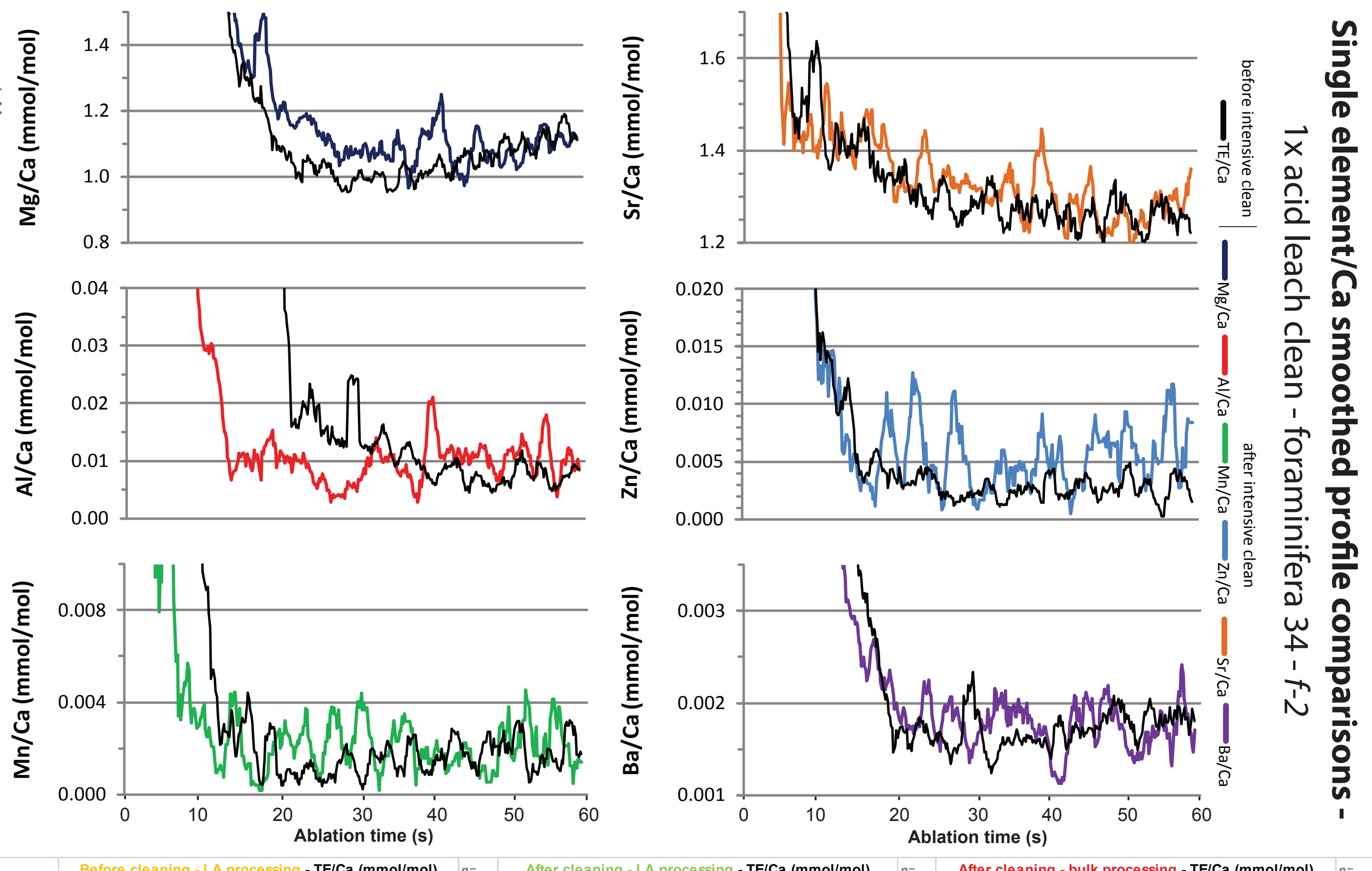

Before cleaning - LA processing - TE/Ca (mmol/mol) $n=\quad$ After cleaning - LA processing - TE/Ca (mmol/mol)

After cleaning - bulk processing - TE/Ca $(\mathrm{mmol} / \mathrm{mol})$

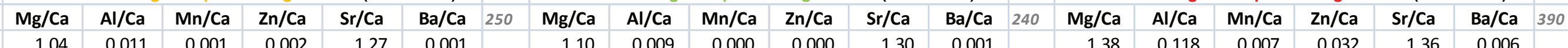

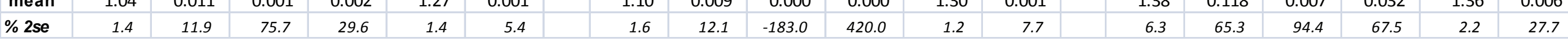



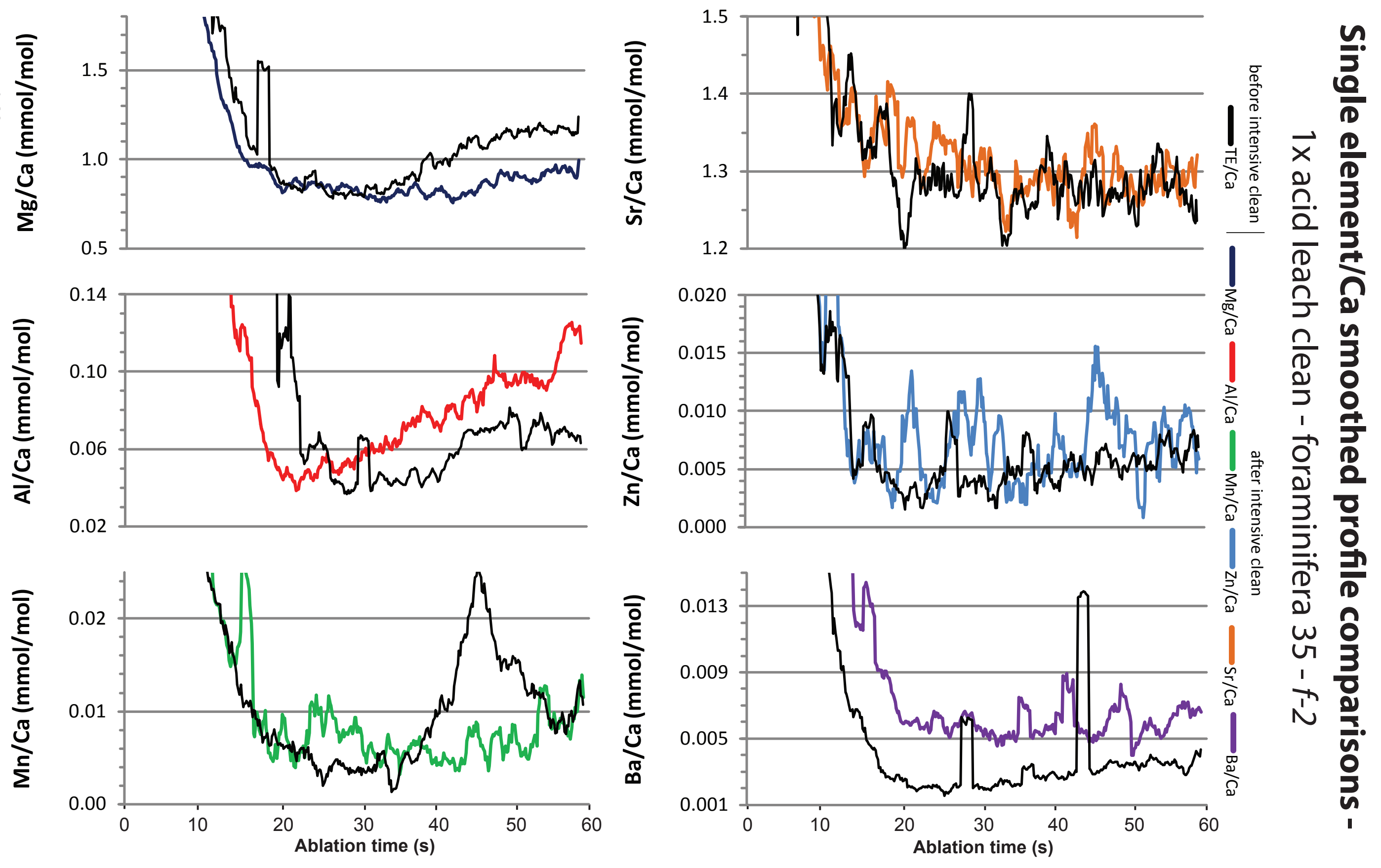

Before cleaning - LA processing - TE/Ca $(\mathbf{m m o l} / \mathrm{mol}) \quad n=\quad$ After cleaning - LA processing $-\mathrm{TE} / \mathrm{Ca}(\mathrm{mmol} / \mathrm{mol})$

After cleaning - bulk processing - TE/Ca $(\mathrm{mmol} / \mathrm{mol})$

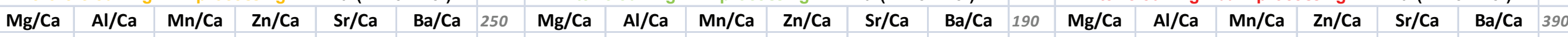

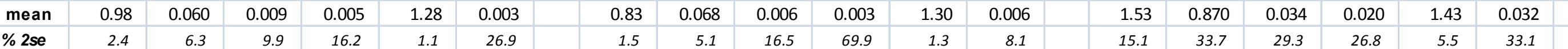



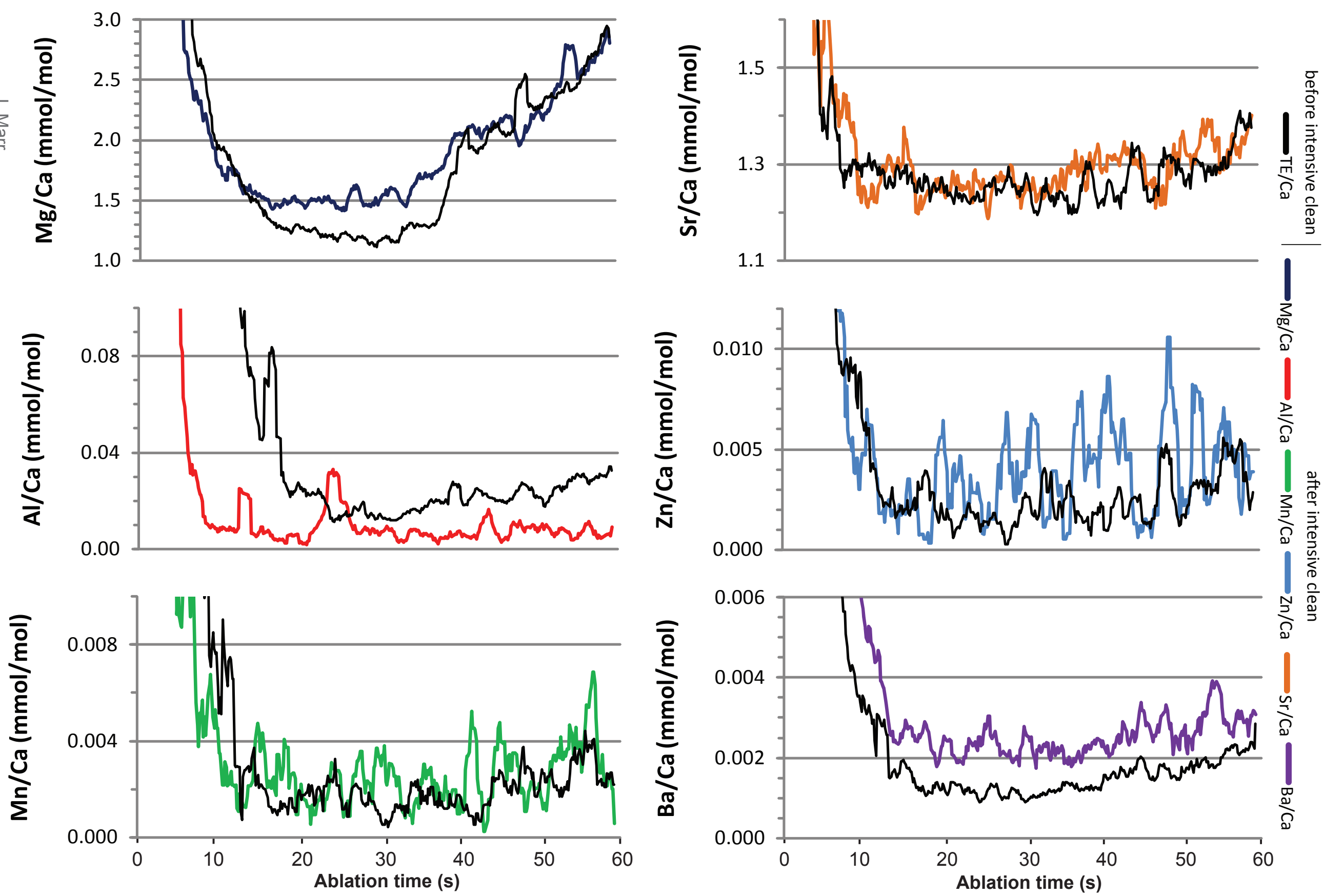

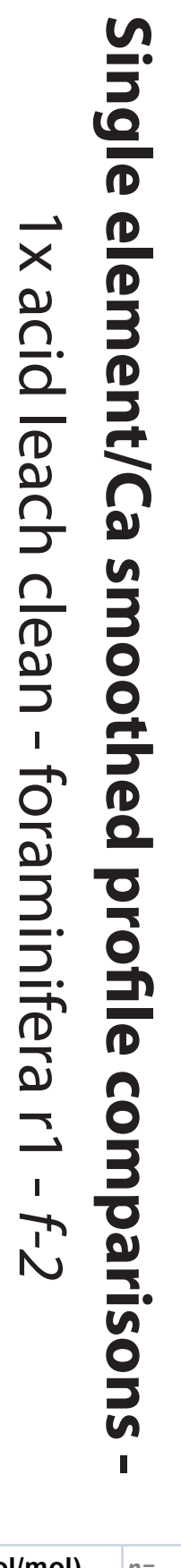

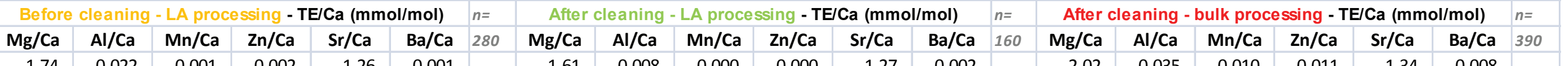

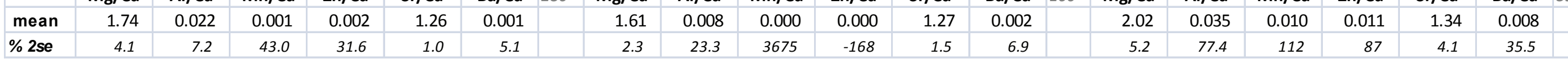



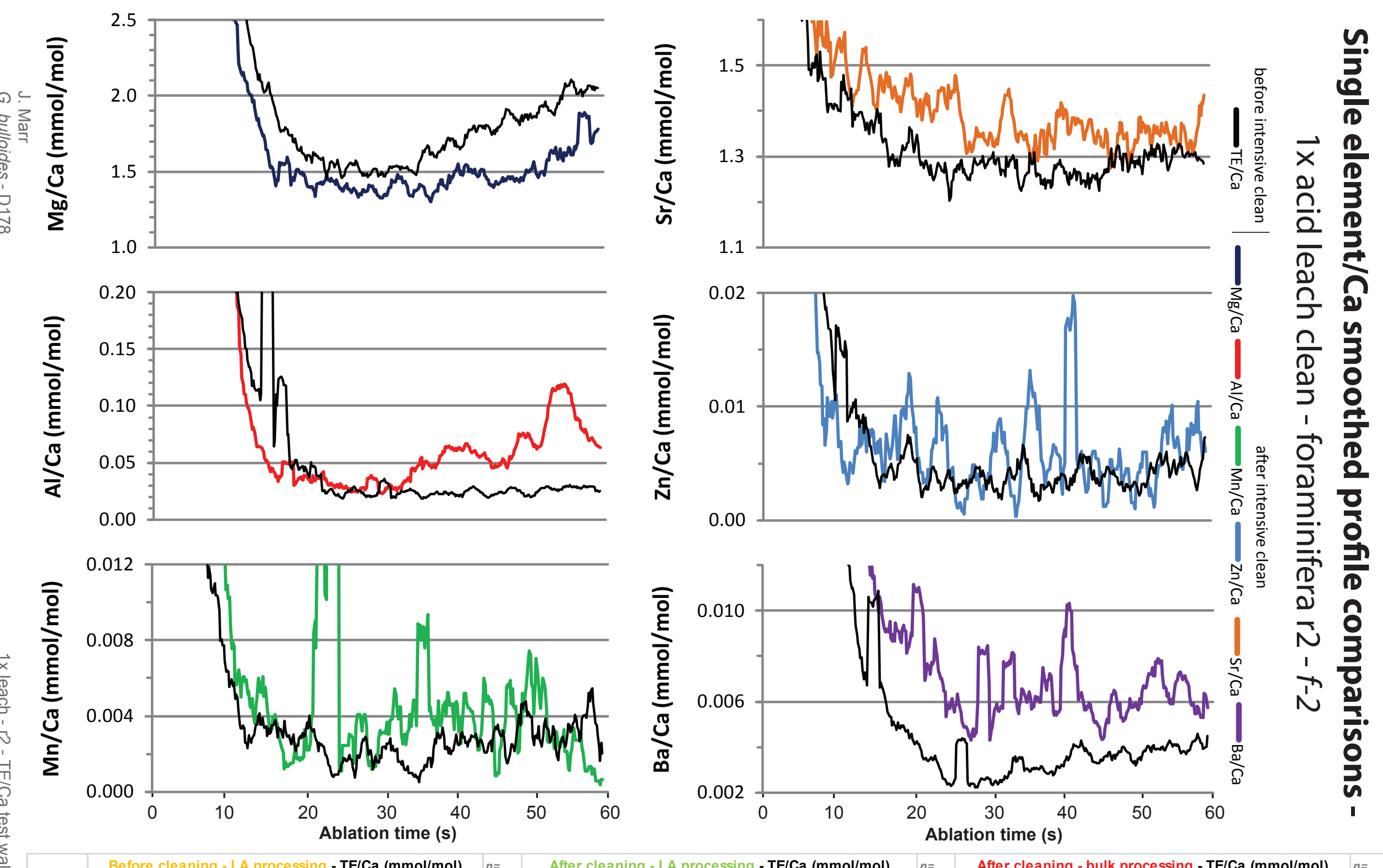

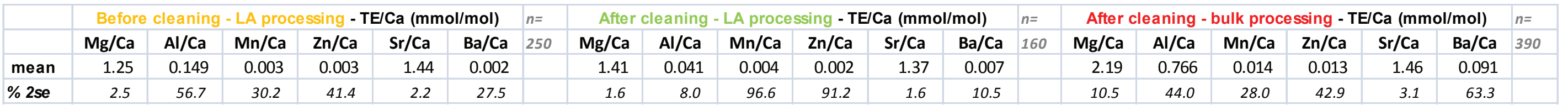



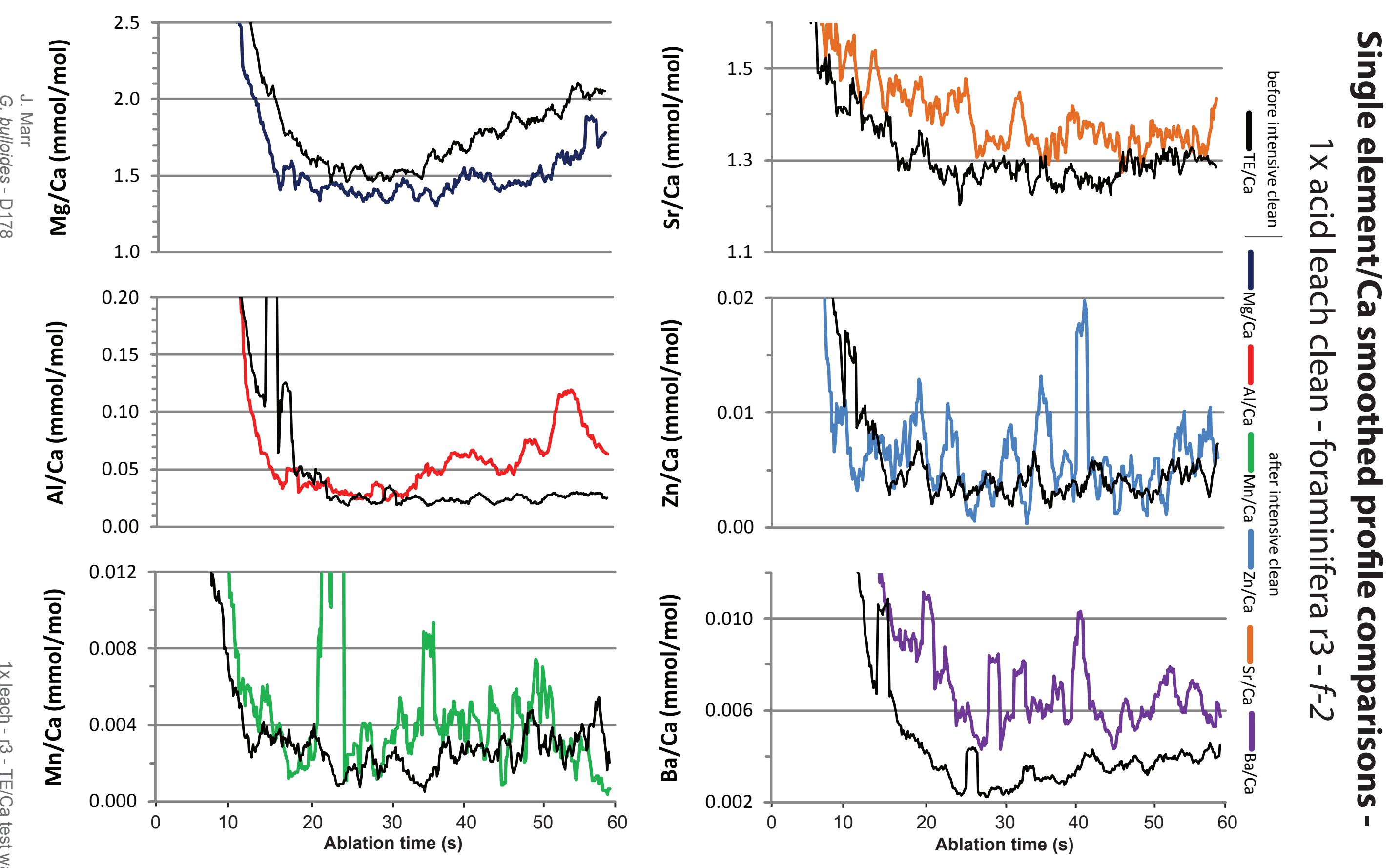

\begin{tabular}{|c|c|c|c|c|c|c|c|c|c|c|c|c|c|c|c|c|c|c|c|c|c|}
\hline & \multicolumn{6}{|c|}{ Before cleaning - LA processing - TE/Ca $(\mathrm{mmol} / \mathrm{mol})$} & $n=$ & \multicolumn{6}{|c|}{ After cleaning - LA processing - TE/Ca $(\mathrm{mmol} / \mathrm{mol})$} & $n=$ & \multicolumn{6}{|c|}{ After cleaning - bulk processing - TE/Ca $(\mathrm{mmol} / \mathrm{mol})$} & $n=$ \\
\hline & $\mathrm{Mg} / \mathrm{Ca}$ & $\mathrm{Al} / \mathrm{Ca}$ & $\mathrm{Mn} / \mathrm{Ca}$ & $\mathrm{Zn} / \mathrm{Ca}$ & $\mathrm{Sr} / \mathrm{Ca}$ & $\mathrm{Ba} / \mathrm{Ca}$ & 50 & $\mathrm{Mg} / \mathrm{Ca}$ & $\mathrm{Al} / \mathrm{Ca}$ & $\mathrm{Mn} / \mathrm{Ca}$ & $\mathrm{Zn} / \mathrm{Ca}$ & $\mathrm{Sr} / \mathrm{Ca}$ & $\mathrm{Ba} / \mathrm{Ca}$ & 180 & $\mathrm{Mg} / \mathrm{Ca}$ & $\mathrm{Al} / \mathrm{Ca}$ & $\mathrm{Mn} / \mathrm{Ca}$ & $\mathrm{Zn} / \mathrm{Ca}$ & $\mathrm{Sr} / \mathrm{Ca}$ & $\mathrm{Ba} / \mathrm{Ca}$ & 390 \\
\hline mean & 1.25 & 0.149 & 0.003 & 0.003 & 1.44 & 0.002 & & 1.42 & 0.034 & 0.003 & 0.001 & 1.35 & 0.002 & & 2.04 & 0.522 & 0.012 & 0.022 & 1.37 & 0.009 & \\
\hline$\% 2 s e$ & 2.5 & 56.7 & 30.2 & 41.4 & 2.2 & 27.5 & & 1.3 & 14.3 & 38.0 & 154 & 1.4 & 7.0 & & 9.4 & 51.0 & 20.4 & 33 & 1.6 & 24.3 & \\
\hline
\end{tabular}



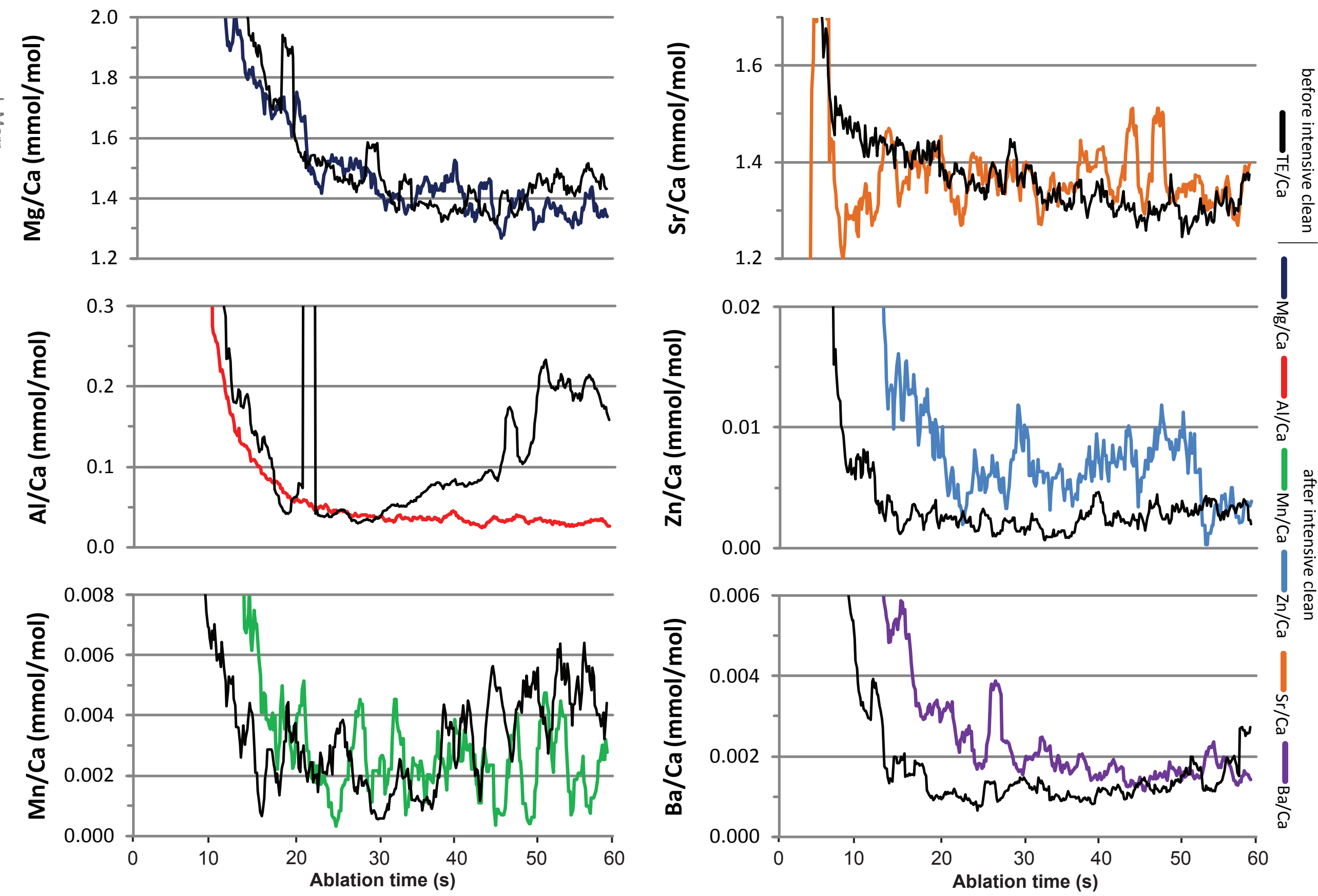

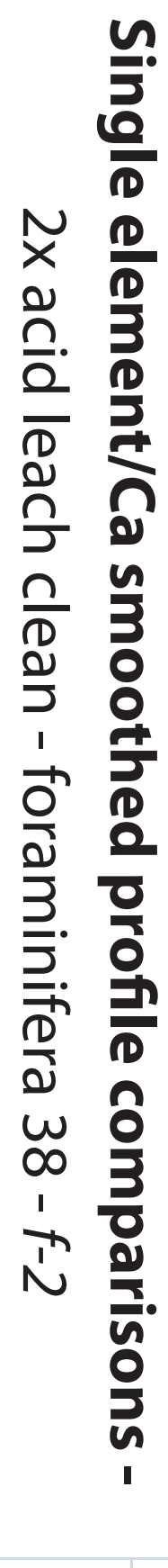

Before cleaning - LA processing - TE/Ca (mmol/mol) $n=\quad$ After cleaning - LA processing - TE/Ca $(\mathbf{m m o l} / \mathbf{m o l})$

\begin{tabular}{|l|l|l|l|l|l|l|l|l|l|l|l|l|}
$\mathrm{Mg} / \mathrm{Ca}$ & $\mathrm{Al} / \mathrm{Ca}$ & $\mathrm{Mn} / \mathrm{Ca}$ & $\mathrm{Zn} / \mathrm{Ca}$ & $\mathrm{Sr} / \mathrm{Ca}$ & $\mathrm{Ba} / \mathrm{Ca}$ & 150 & $\mathrm{Mg} / \mathrm{Ca}$ & $\mathrm{Al} / \mathrm{Ca}$ & $\mathrm{Mn} / \mathrm{Ca}$ & $\mathrm{Zn} / \mathrm{Ca}$ & $\mathrm{Sr} / \mathrm{Ca}$ & $\mathrm{Ba} / \mathrm{Ca}$
\end{tabular}

After cleaning - bulk processing - TE/Ca $(\mathrm{mmol} / \mathrm{mol})$

\begin{tabular}{|c|c|c|c|c|c|c|c|c|c|c|c|c|c|c|c|c|c|c|c|c|}
\hline & $\mathrm{Mg} / \mathrm{Ca}$ & $\mathrm{Al} / \mathrm{Ca}$ & $\mathrm{Mn} / \mathrm{Ca}$ & $\mathrm{Zn} / \mathrm{Ca}$ & $\mathrm{Sr} / \mathrm{Ca}$ & $\mathrm{Ba} / \mathrm{Ca}$ & 150 & $\mathrm{Mg} / \mathrm{Ca}$ & $\mathrm{Al} / \mathrm{Ca}$ & $\mathrm{Mn} / \mathrm{Ca}$ & $\mathrm{Zn} / \mathrm{Ca}$ & $\mathrm{Sr} / \mathrm{Ca}$ & $\mathrm{Ba} / \mathrm{Ca}$ & 200 & $\mathrm{Mg} / \mathrm{Ca}$ & $\mathrm{Al} / \mathrm{Ca}$ & $\mathrm{Mn} / \mathrm{Ca}$ & $\mathrm{Zn} / \mathrm{Ca}$ & $\mathrm{Sr} / \mathrm{Ca}$ & $\mathrm{Ba} / \mathrm{Ca}$ \\
\hline ean & 1.43 & 0.085 & 0.001 & 0.001 & 1.35 & 0.001 & & 1.40 & 0.034 & 0.000 & 0.003 & 1.36 & 0.002 & & 1.68 & 0.213 & 0.007 & 0.019 & 1.38 & 0.006 \\
\hline se & 0.32 & 0.7 & 0.007 & 0.007 & 0.24 & 0.001 & & 0.32 & 0.023 & 0.013 & 0.025 & 0.33 & 0.002 & & 4.14 & 31.5 & 20.5 & 23.1 & 1.96 & 24.0 \\
\hline
\end{tabular}



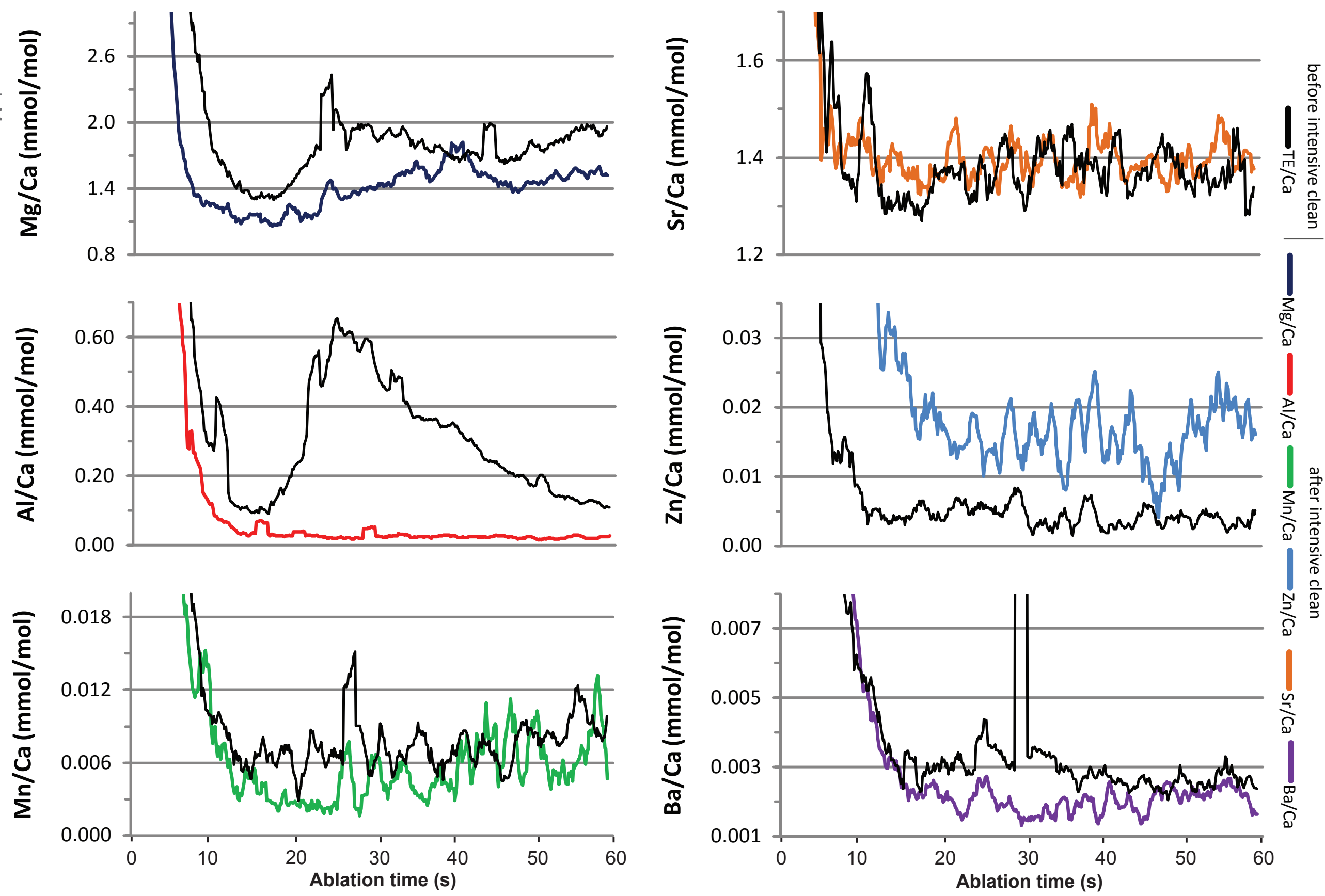

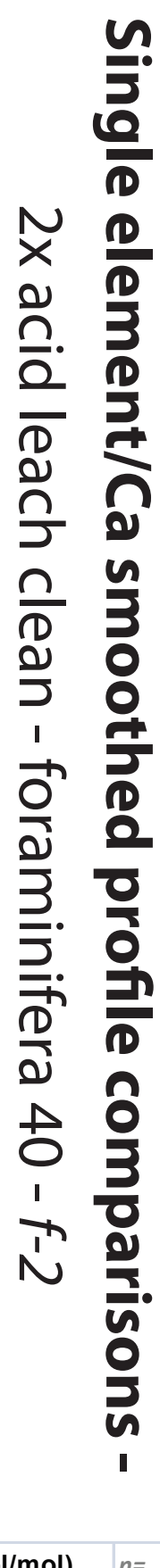

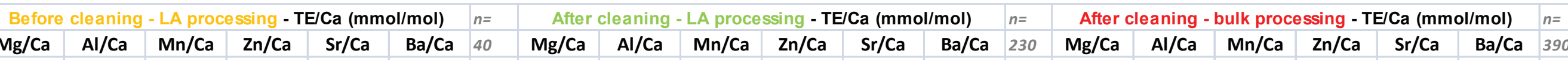
\begin{tabular}{|r|r|r|r|r|r|r|r|r|r|r|r|r|r|r|r|r|r|r|r|r|r|r|}
\hline mean & 1.40 & 0.141 & 0.007 & 0.004 & 1.32 & 0.004 & 1.49 & 0.023 & 0.004 & 0.015 & 1.39 & 0.002 & 1.63 & 0.347 & 0.010 & 0.072 & 1.41 & 0.007 \\
\hline
\end{tabular} \begin{tabular}{|l|l|l|l|l|l|l|l|l|l|l|l|l|l|l|l|l|l|l|l|}
\hline \% 2se & 4.7 & 41.8 & 18.9 & 32.5 & 3.6 & 18.9 & 1.7 & 11.6 & 21.8 & 11.1 & 1.2 & 6.2 & 7.5 & 56.9 & 25.6 & 35.4 & 1.4 & 30.5 \\
\hline
\end{tabular} 

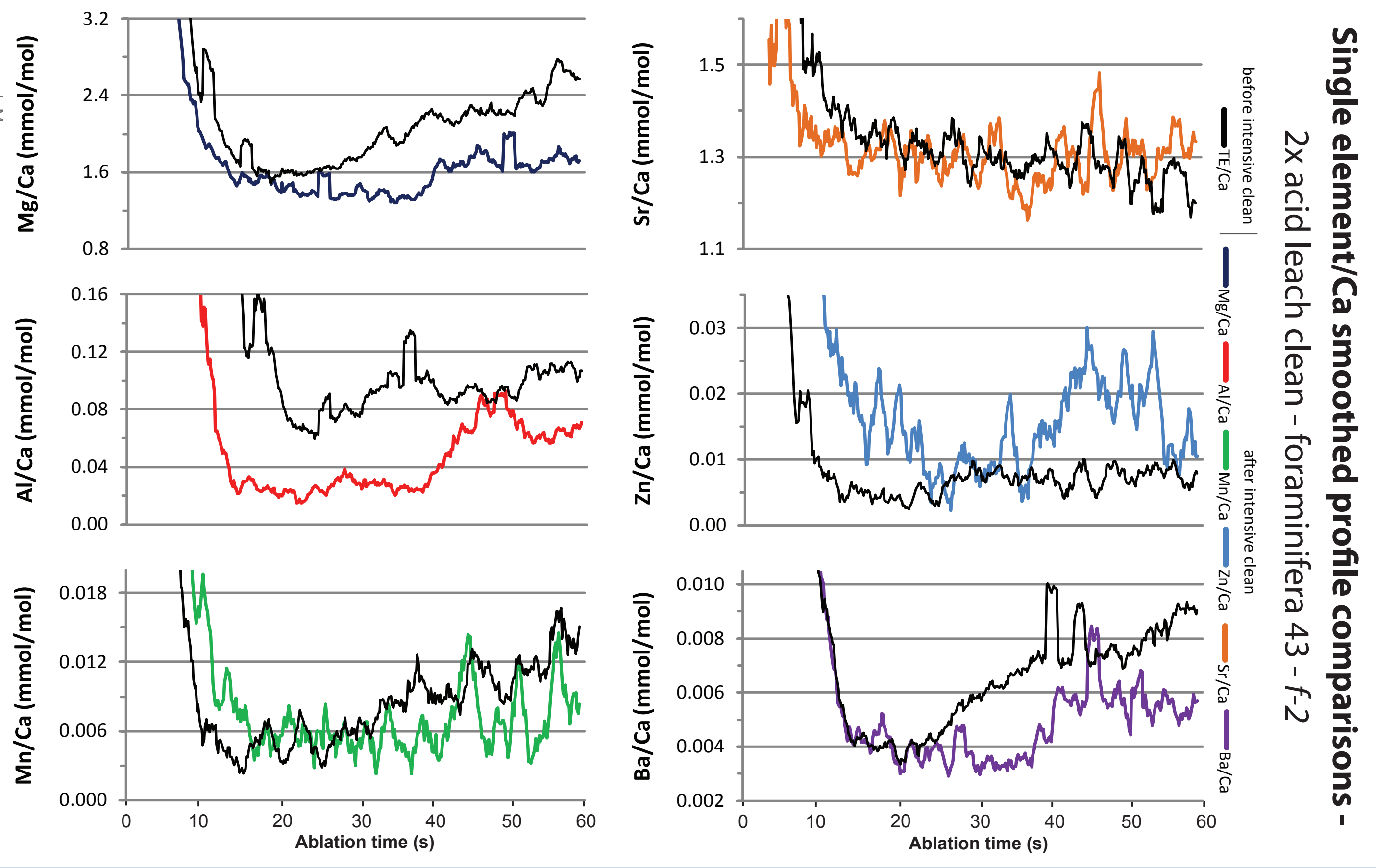

\begin{tabular}{|c|c|c|c|c|c|c|c|c|c|c|c|c|c|c|c|c|c|c|c|c|c|}
\hline & \multicolumn{6}{|c|}{ Before cleaning - LA processing - TE/Ca ( $\mathrm{mmol} / \mathrm{mol})$} & $n=$ & \multicolumn{6}{|c|}{ After cleaning - LA processing - TE/Ca (mmol/mol) } & $n=$ & \multicolumn{6}{|c|}{ After cleaning - bulk processing - TE/Ca (mmol/mol) } & $n=$ \\
\hline & $\mathrm{Mg} / \mathrm{Ca}$ & $\mathrm{Al} / \mathrm{Ca}$ & $\mathrm{Mn} / \mathrm{Ca}$ & $\mathrm{Zn} / \mathrm{Ca}$ & $\mathrm{Sr} / \mathrm{Ca}$ & $\mathrm{Ba} / \mathrm{Ca}$ & 260 & $\mathrm{Mg} / \mathrm{Ca}$ & $\mathrm{Al} / \mathrm{Ca}$ & $\mathrm{Mn} / \mathrm{Ca}$ & $\mathrm{Zn} / \mathrm{Ca}$ & $\mathrm{Sr} / \mathrm{Ca}$ & $\mathrm{Ba} / \mathrm{Ca}$ & 110 & $\mathrm{Mg} / \mathrm{Ca}$ & $\mathrm{Al} / \mathrm{Ca}$ & $\mathrm{Mn} / \mathrm{Ca}$ & $\mathrm{Zn} / \mathrm{Ca}$ & $\mathrm{Sr} / \mathrm{Ca}$ & $\mathrm{Ba} / \mathrm{Ca}$ & 390 \\
\hline ea & 2.06 & 0.092 & 0.009 & 0.007 & 1.29 & 0.006 & & 1.42 & 0.025 & 0.004 & 0.009 & 1.31 & 0.003 & & 2.04 & 0.313 & 0.016 & 0.051 & 1.32 & 0.010 & \\
\hline $2 s e$ & 2.3 & 3.9 & 7.3 & 8.2 & 1.2 & 5.2 & & 4.0 & 9.3 & 37.7 & 31.1 & 2.2 & 8.1 & & 10.5 & 49.9 & 28.5 & 39.6 & 1.8 & 26.7 & \\
\hline
\end{tabular}



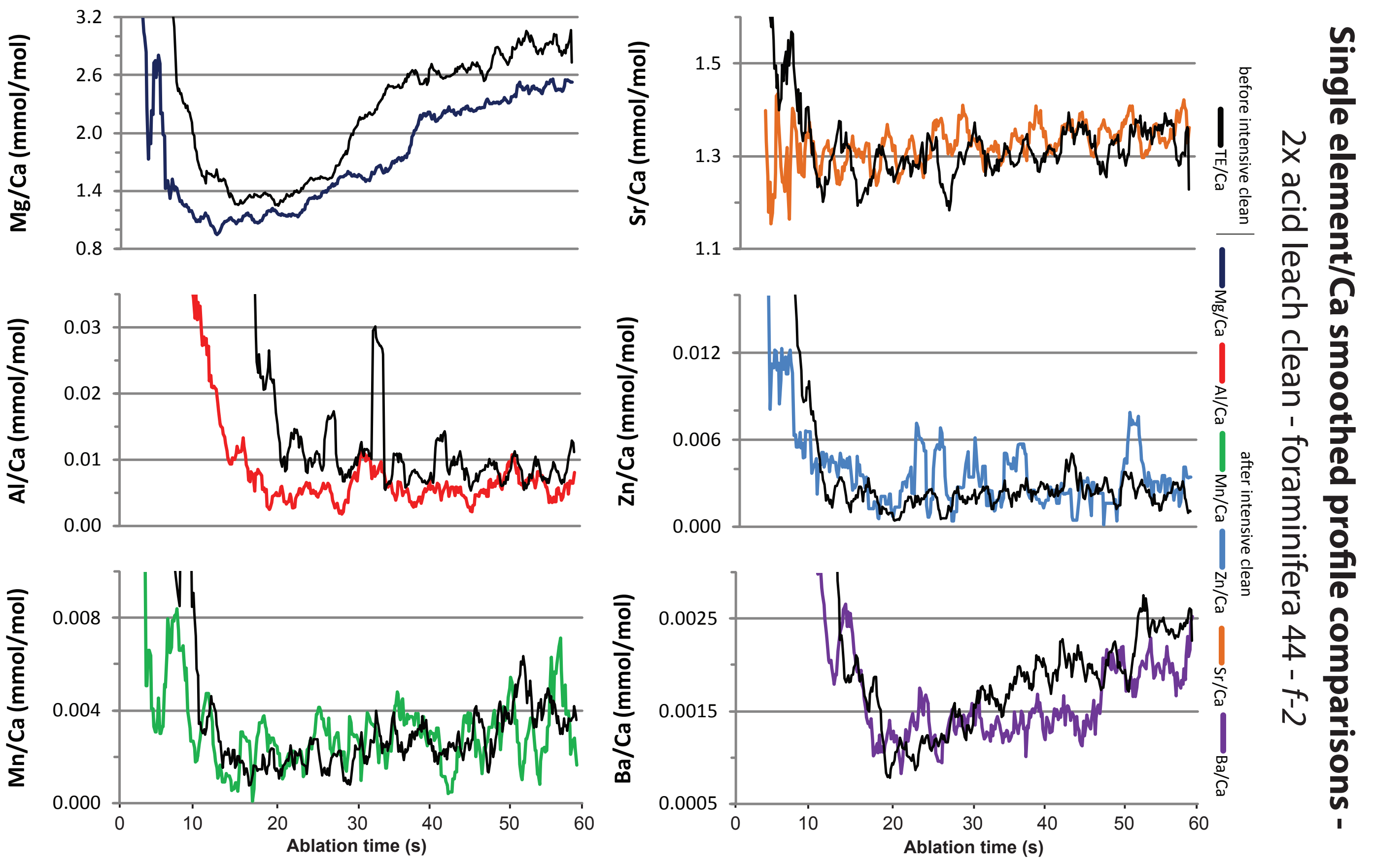

\begin{tabular}{|c|c|c|c|c|c|c|c|c|c|c|c|c|c|c|c|c|c|c|c|c|c|}
\hline & \multicolumn{6}{|c|}{ Before cleaning - LA processing - TE/Ca (mmol/mol) } & $n=$ & \multicolumn{6}{|c|}{ After cleaning - LA processing - TE/Ca (mmol/mol) } & $n=$ & \multicolumn{6}{|c|}{ After cleaning - bulk processing - TE/Ca $(\mathrm{mmol} / \mathrm{mol})$} & $n=$ \\
\hline & $\mathrm{Mg} / \mathrm{Ca}$ & $\mathrm{Al} / \mathrm{Ca}$ & $\mathrm{Mn} / \mathrm{Ca}$ & $\mathrm{Zn} / \mathrm{Ca}$ & $\mathrm{Sr} / \mathrm{Ca}$ & $\mathrm{Ba} / \mathrm{Ca}$ & 250 & $\mathrm{Mg} / \mathrm{Ca}$ & $\mathrm{Al} / \mathrm{Ca}$ & $\mathrm{Mn} / \mathrm{Ca}$ & $\mathrm{Zn} / \mathrm{Ca}$ & $\mathrm{Sr} / \mathrm{Ca}$ & $\mathrm{Ba} / \mathrm{Ca}$ & 140 & $\mathrm{Mg} / \mathrm{Ca}$ & $\mathrm{Al} / \mathrm{Ca}$ & $\mathrm{Mn} / \mathrm{Ca}$ & $\mathrm{Zn} / \mathrm{Ca}$ & $\mathrm{Sr} / \mathrm{Ca}$ & $\mathrm{Ba} / \mathrm{Ca}$ & 390 \\
\hline mean & 2.38 & 0.010 & 0.002 & 0.001 & 1.31 & 0.002 & & 1.48 & 0.005 & 0.001 & 0.000 & 1.33 & 0.001 & & 1.78 & 0.077 & 0.003 & 0.005 & 1.33 & 0.003 & \\
\hline$\% 2 s e$ & 3.0 & 18.4 & 18.3 & 31.8 & 1.1 & 4.9 & & 3.4 & 25.6 & 84.6 & 71.3 & 1.5 & 9.4 & & 4.4 & 93.9 & 18.2 & 24.0 & 1.4 & 20.6 & \\
\hline
\end{tabular}



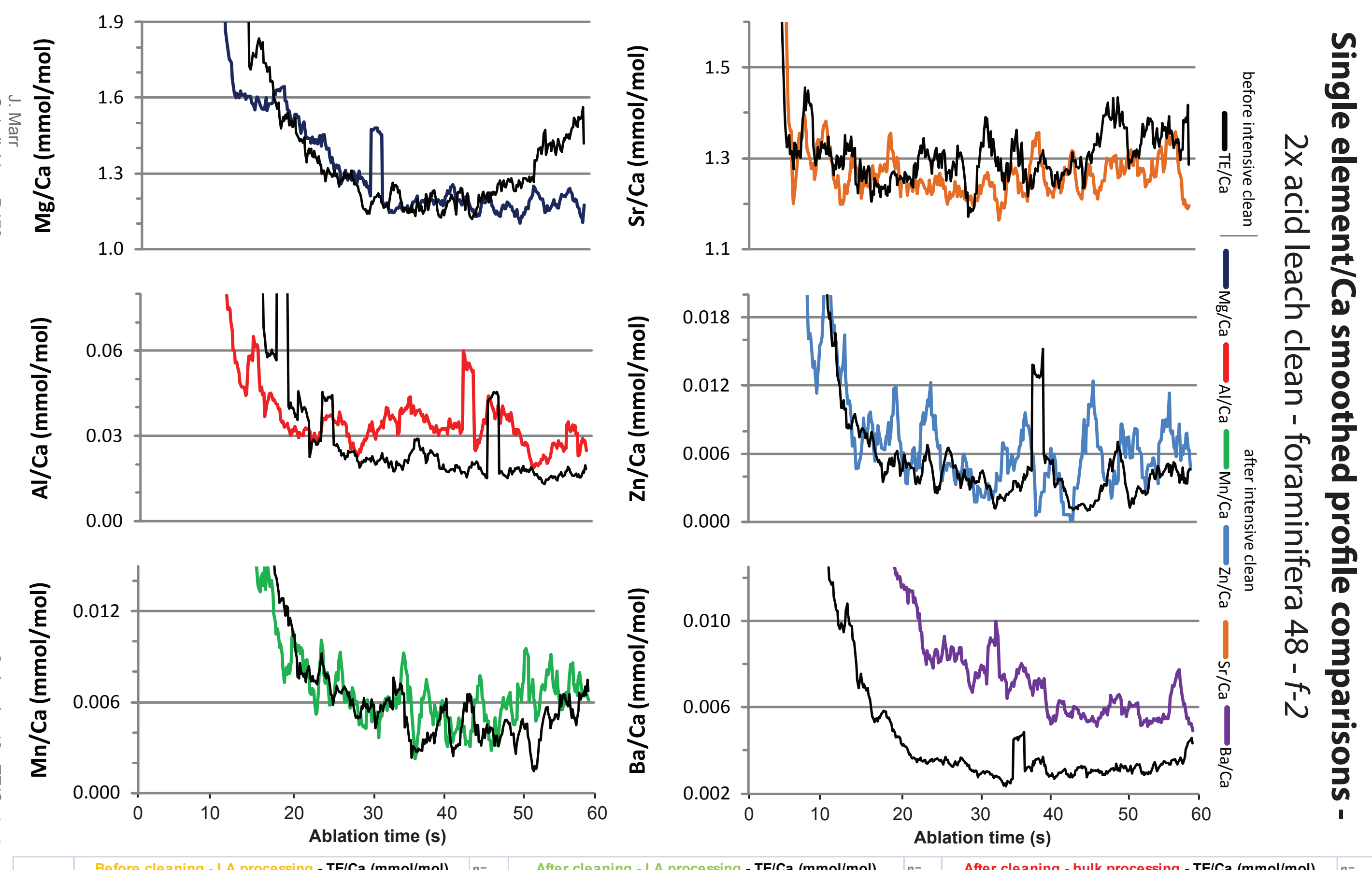

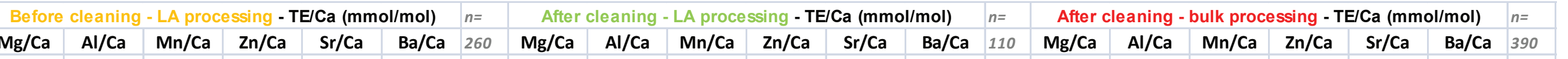
\begin{tabular}{|l|r|r|r|r|r|r|r|r|r|r|r|r|r|r|r|r|r|r|r|r|r|}
\hline mean & 1.27 & 0.023 & 0.005 & 0.004 & 1.30 & 0.003 & 1.26 & 0.035 & 0.005 & 0.000 & 1.25 & 0.007 & 1.57 & 0.264 & 0.018 & 0.014 & 1.29 & 0.017 \\
\hline
\end{tabular} \begin{tabular}{|l|l|l|l|l|l|l|l|l|l|l|l|l|l|l|l|l|l|l|}
\hline$\% 2 s e$ & 1.9 & 12.9 & 10.1 & 25.7 & 1.6 & 6.3 & 2.6 & 9.2 & 16.2 & 351 & 1.3 & 5.5 & 6.1 & 53.5 & 18.2 & 30 & 1.7 & 22.3 \\
\hline
\end{tabular} 

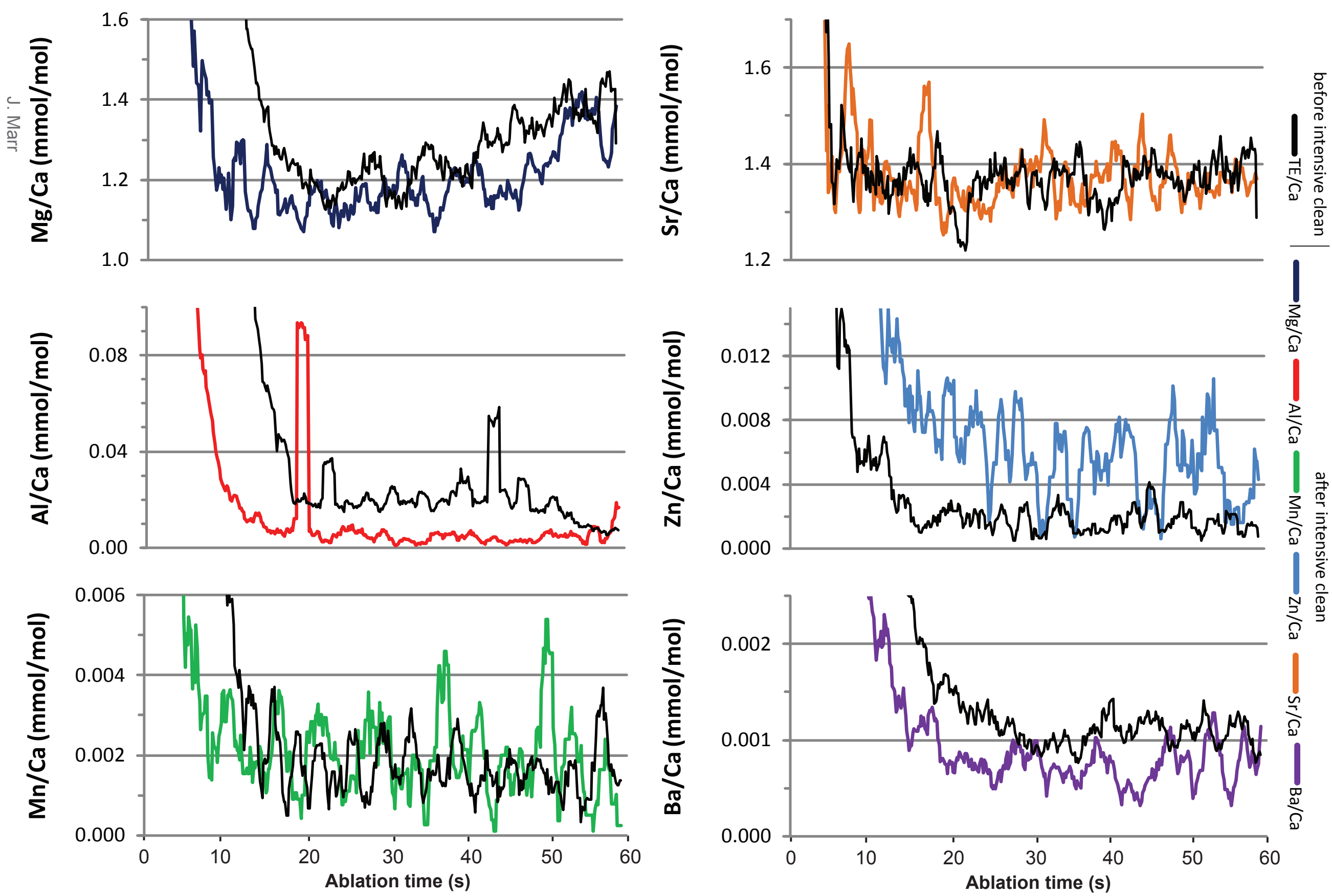

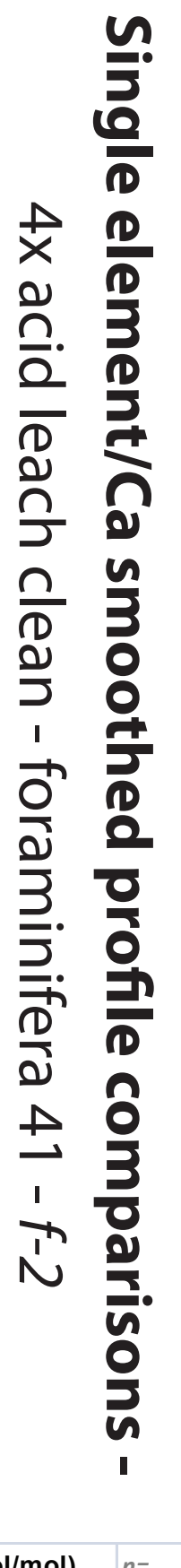

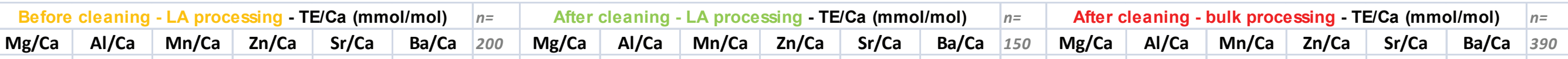



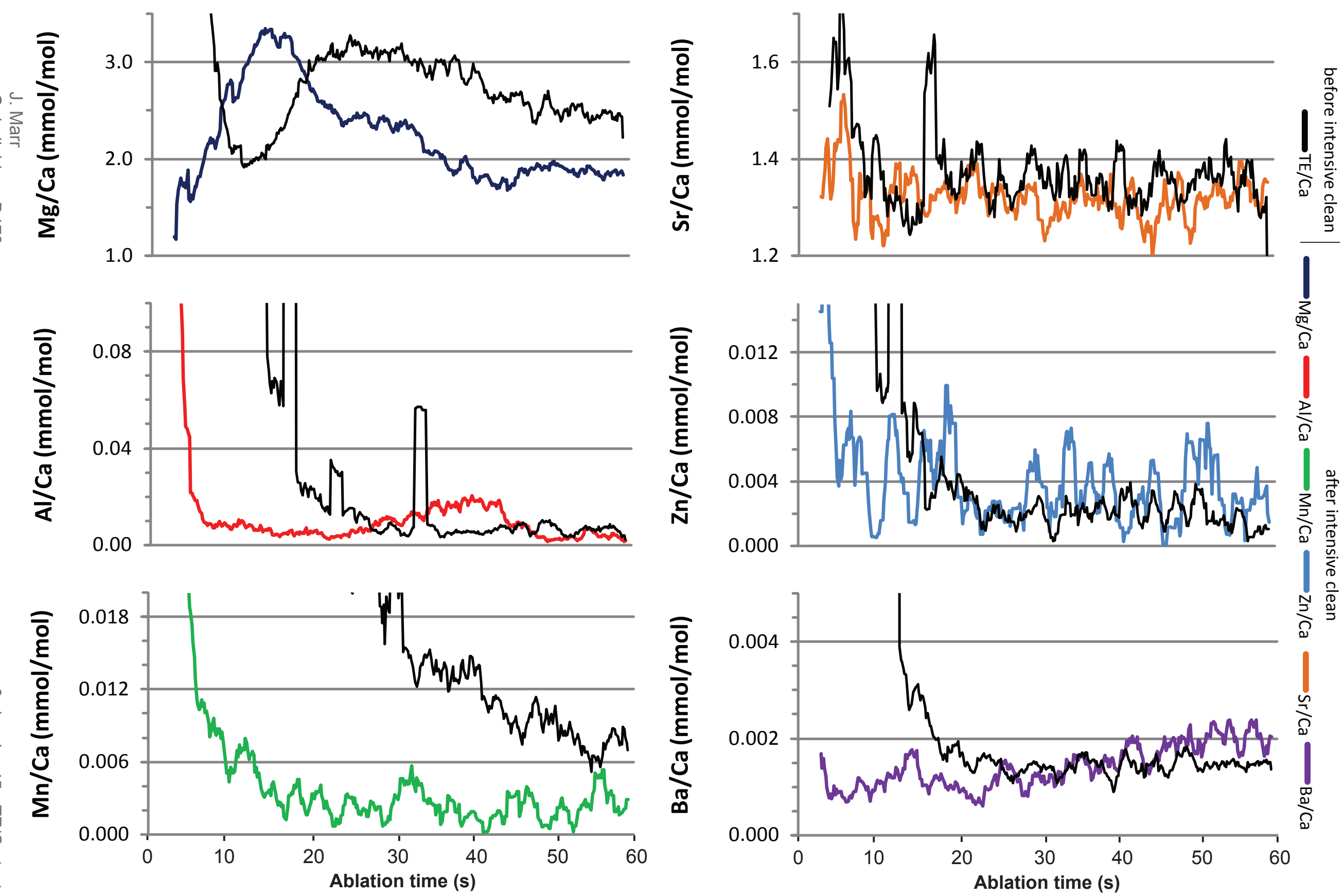

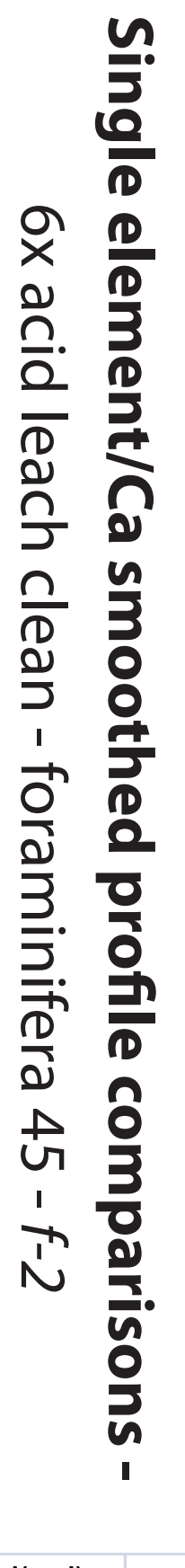

\begin{tabular}{|c|c|c|c|c|c|c|c|c|c|c|c|c|c|c|c|c|c|c|c|c|c|}
\hline & \multicolumn{6}{|c|}{ Before cleaning - LA processing - TE/Ca $(\mathbf{m m o l} / \mathbf{m o l})$} & $n=$ & \multicolumn{6}{|c|}{ After cleaning - LA processing - TE/Ca $(\mathrm{mmol} / \mathrm{mol})$} & $n=$ & \multicolumn{6}{|c|}{ After cleaning - bulk processing - TE/Ca $(\mathrm{mmol} / \mathrm{mol})$} & $n=$ \\
\hline & $\mathrm{Mg} / \mathrm{Ca}$ & $\mathrm{Al} / \mathrm{Ca}$ & $\mathrm{Mn} / \mathrm{Ca}$ & $\mathrm{Zn} / \mathrm{Ca}$ & $\mathrm{Sr} / \mathrm{Ca}$ & $\mathrm{Ba} / \mathrm{Ca}$ & 280 & $\mathrm{Mg} / \mathrm{Ca}$ & $\mathrm{Al} / \mathrm{Ca}$ & $\mathrm{Mn} / \mathrm{Ca}$ & $\mathrm{Zn} / \mathrm{Ca}$ & $\mathrm{Sr} / \mathrm{Ca}$ & $\mathrm{Ba} / \mathrm{Ca}$ & 230 & $\mathrm{Mg} / \mathrm{Ca}$ & $\mathrm{Al} / \mathrm{Ca}$ & $\mathrm{Mn} / \mathrm{Ca}$ & $\mathrm{Zn} / \mathrm{Ca}$ & $\mathrm{Sr} / \mathrm{Ca}$ & $\mathrm{Ba} / \mathrm{Ca}$ & 390 \\
\hline mean & 2.79 & 0.010 & 0.014 & 0.001 & 1.35 & 0.001 & & 2.32 & 0.009 & 0.000 & 0.000 & 1.31 & 0.001 & & 2.22 & 0.013 & 0.005 & 0.004 & 1.32 & 0.001 & \\
\hline$\%$ 2se & 1.8 & 47.3 & 9.8 & 54.1 & 1.6 & 4.6 & & 2.9 & 13.3 & 246 & -69.1 & 1.2 & 7.8 & & 2.6 & 21.3 & 19 & 17.9 & 1.2 & 6.2 & \\
\hline
\end{tabular}



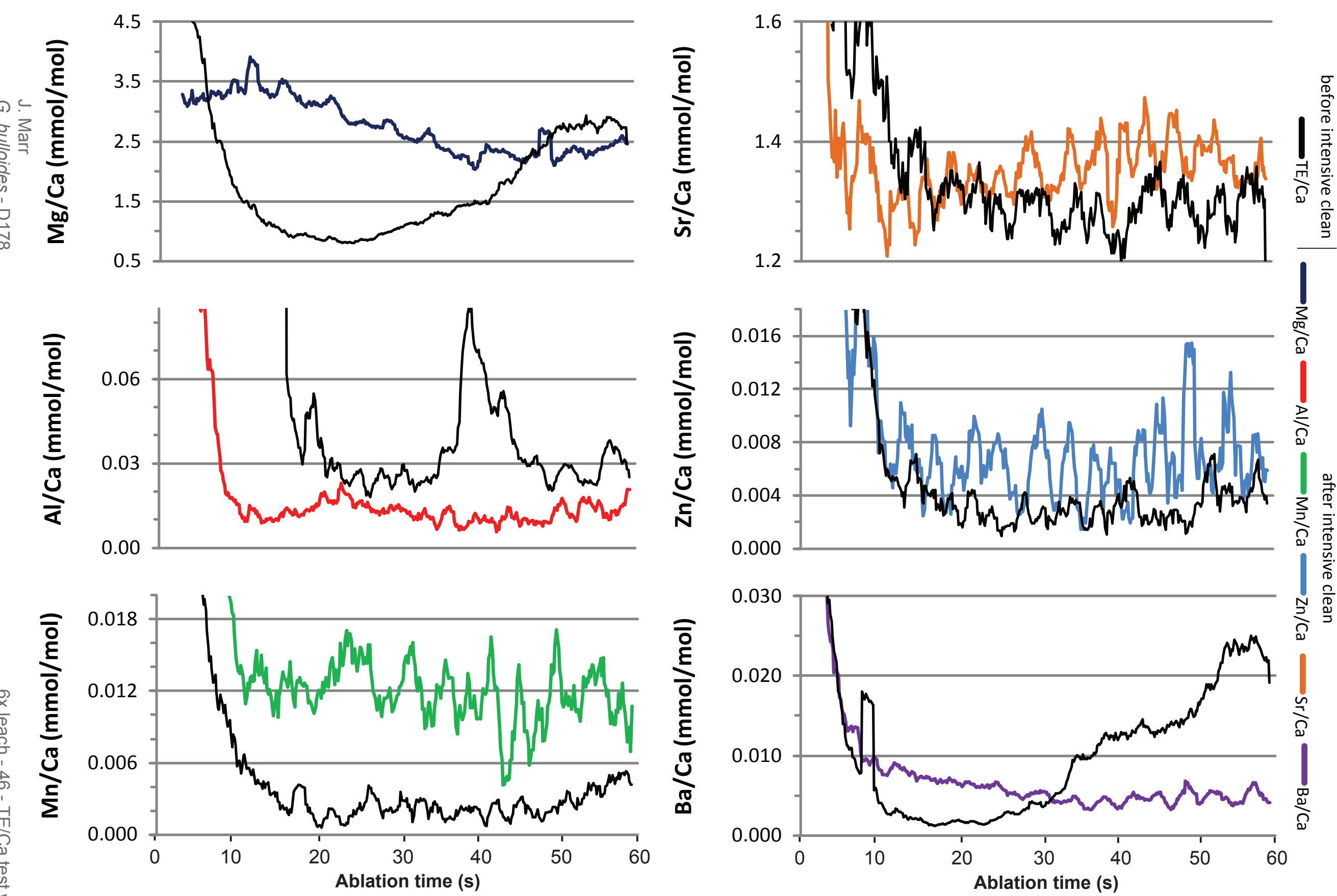

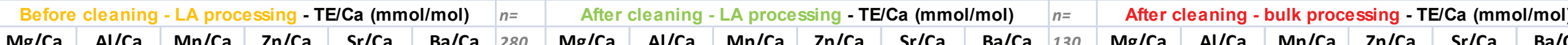

Ablation time (s)

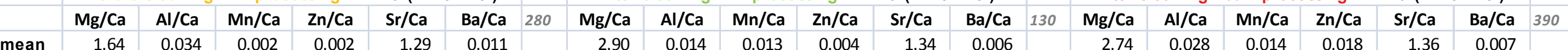

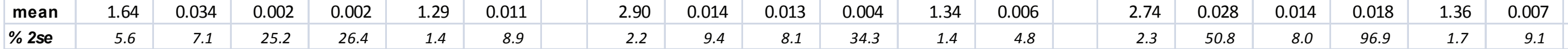



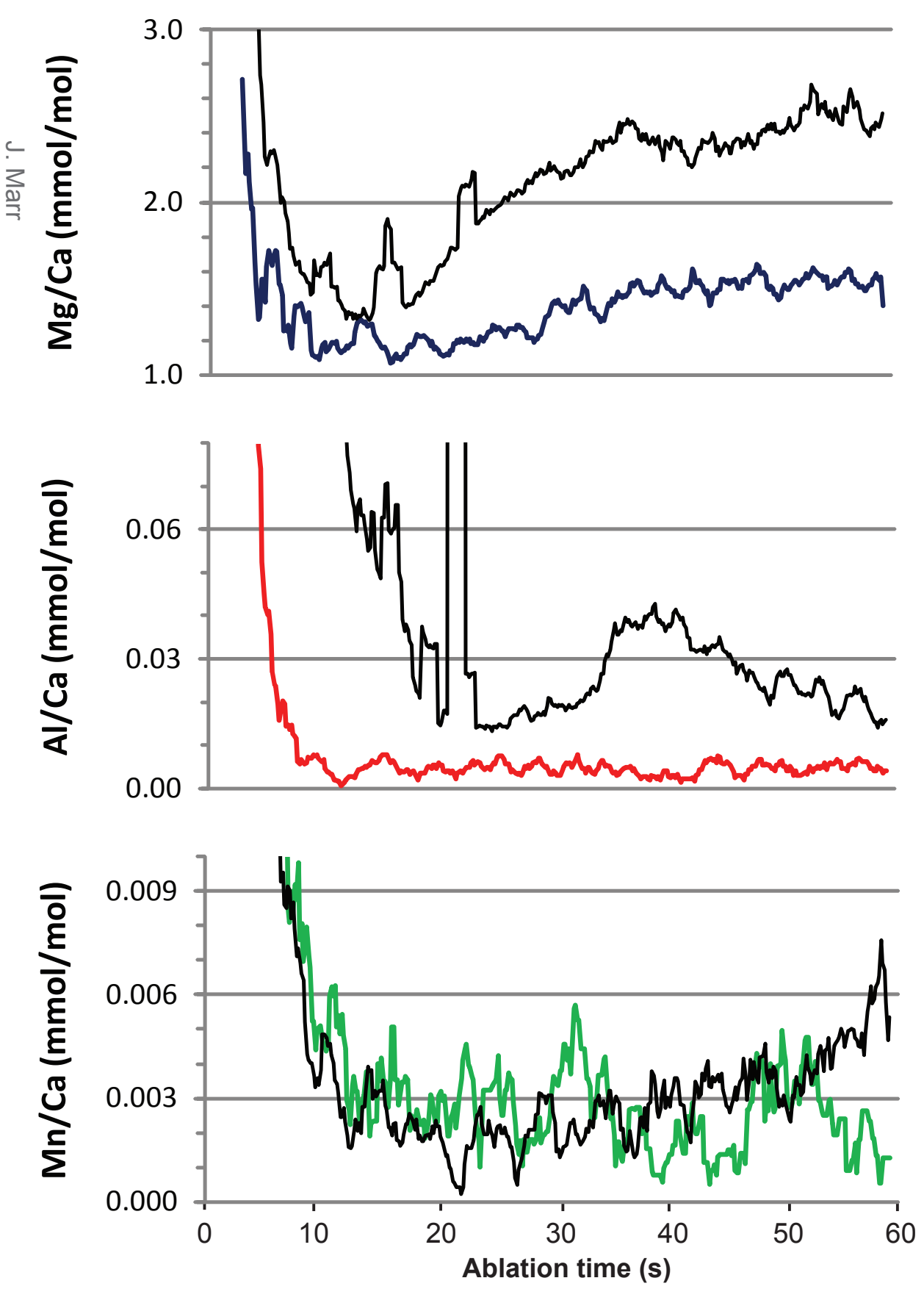

Before cleaning - LA processing - TE/Ca (mmol/mol)

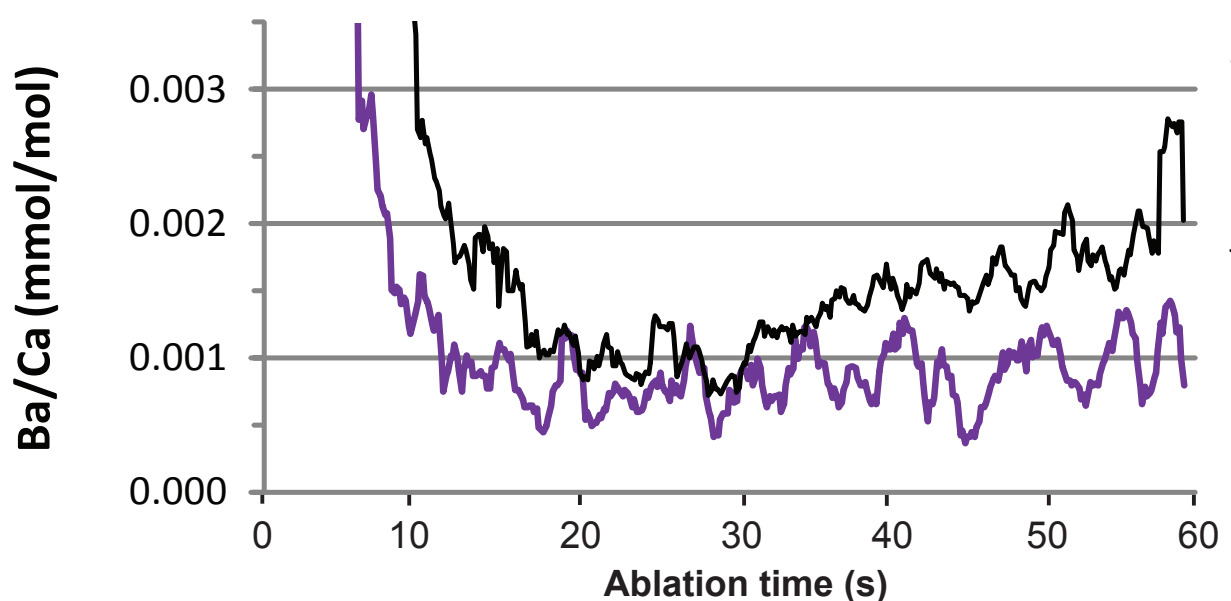

$\frac{\varrho}{\frac{6}{0}}$

1.1

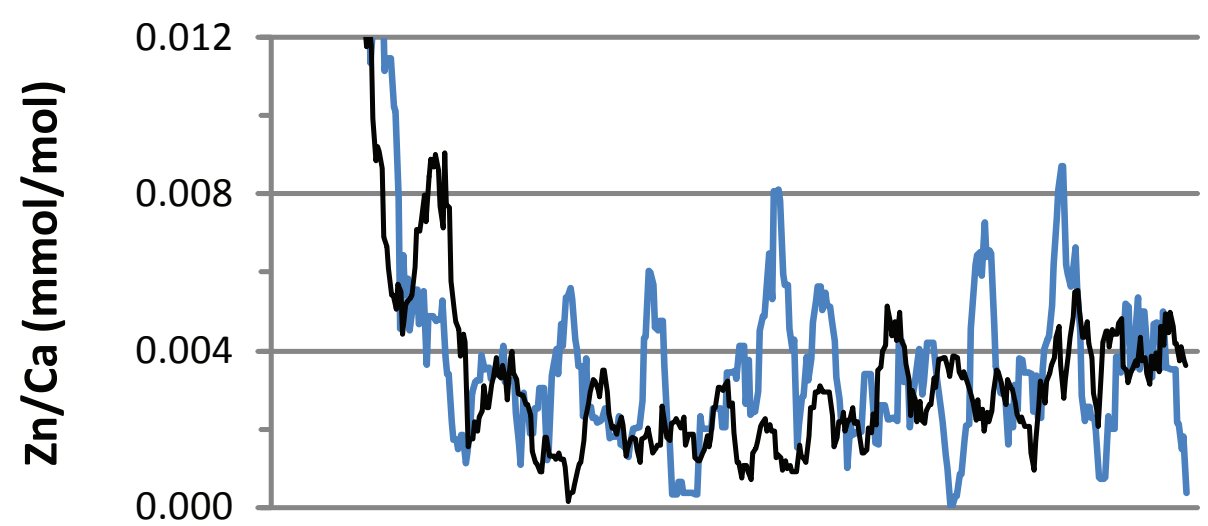

After cleaning - bulk processing - TE/Ca $(\mathrm{mmol} / \mathrm{mol})$

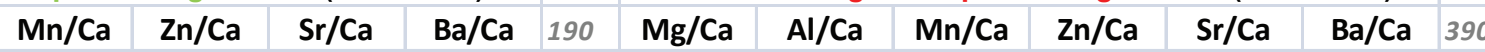
\begin{tabular}{|l|l|l|l|l|l|l|l|l|l|}
\hline 0.000 & 0.000 & 1.28 & 0.001 & 1.40 & 0.025 & 0.004 & 0.006 & 1.34 & 0.001 \\
\hline
\end{tabular} 

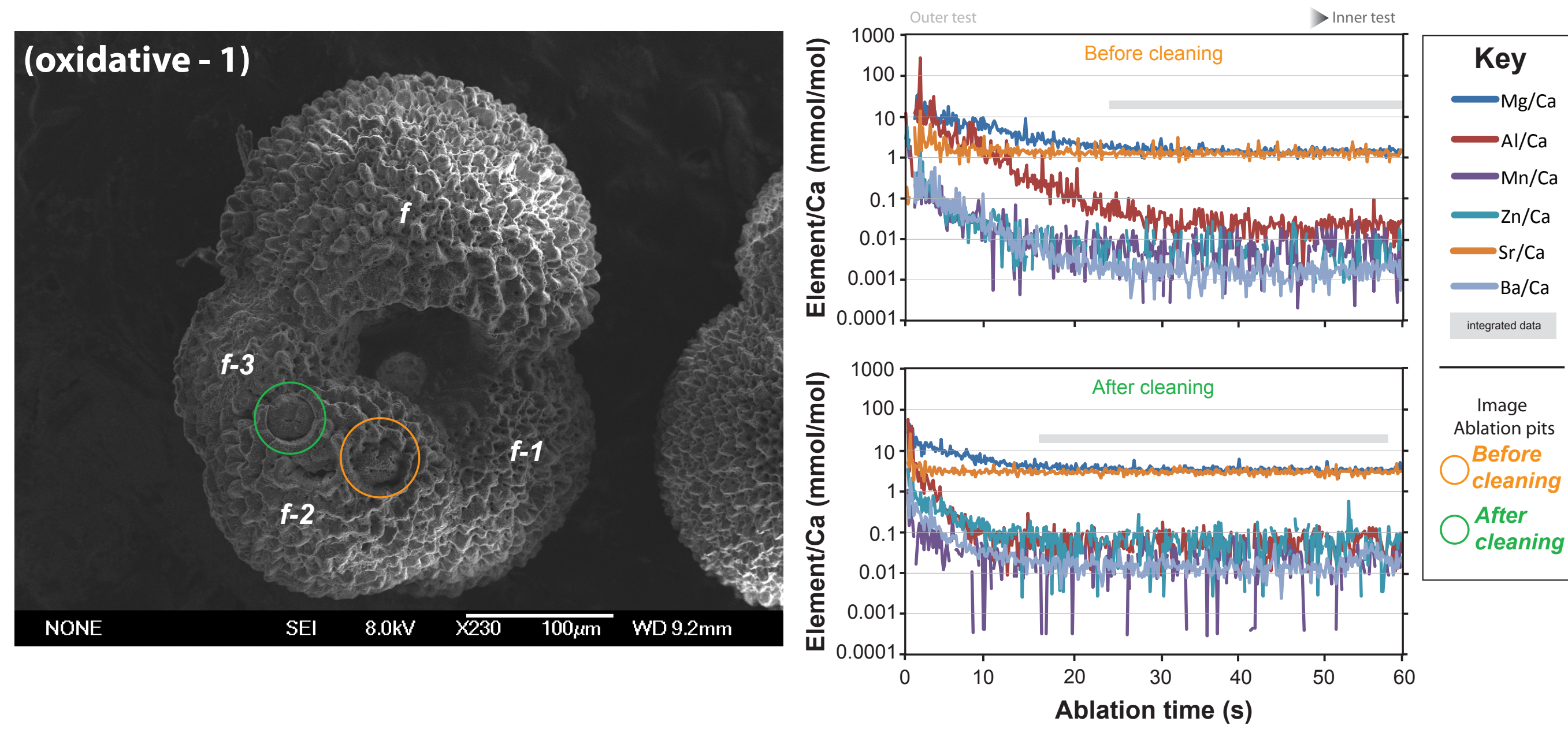

Sample: Oxidative - 1

\begin{tabular}{|c|c|c|c|c|c|c|}
\hline Before cleaning & $\begin{array}{c}\mathrm{Mg} / \mathrm{Ca} \\
(\mathrm{mmol} / \mathrm{mol})\end{array}$ & $\begin{array}{c}\mathrm{Al} / \mathrm{Ca} \\
(\mathrm{mmol} / \mathrm{mol})\end{array}$ & $\begin{array}{c}\mathrm{Mn} / \mathrm{Ca} \\
(\mathrm{mmol} / \mathrm{mol})\end{array}$ & $\begin{array}{c}\mathrm{Zn} / \mathrm{Ca} \\
(\mathrm{mmol} / \mathrm{mol})\end{array}$ & $\begin{array}{c}\mathrm{Sr} / \mathrm{Ca} \\
(\mathrm{mmol} / \mathrm{mol})\end{array}$ & $\begin{array}{c}\mathrm{Ba} / \mathrm{Ca} \\
(\mathrm{mmol} / \mathrm{mol})\end{array}$ \\
\hline intergrated profile mean & 1.48 & 0.025 & 0.006 & 0.002 & 1.31 & 0.002 \\
\hline 2 sd & 0.50 & 0.026 & 0.012 & 0.015 & 0.59 & 0.002 \\
\hline \multicolumn{7}{|l|}{ After cleaning } \\
\hline intergrated profile mean & 1.55 & 0.012 & 0.002 & 0.013 & 1.30 & 0.003 \\
\hline 2 sd & 0.50 & 0.020 & 0.015 & 0.031 & 0.35 & 0.003 \\
\hline \multicolumn{7}{|l|}{ Difference } \\
\hline mean & -0.07 & 0.013 & 0.004 & -0.011 & 0.00 & -0.001 \\
\hline
\end{tabular}



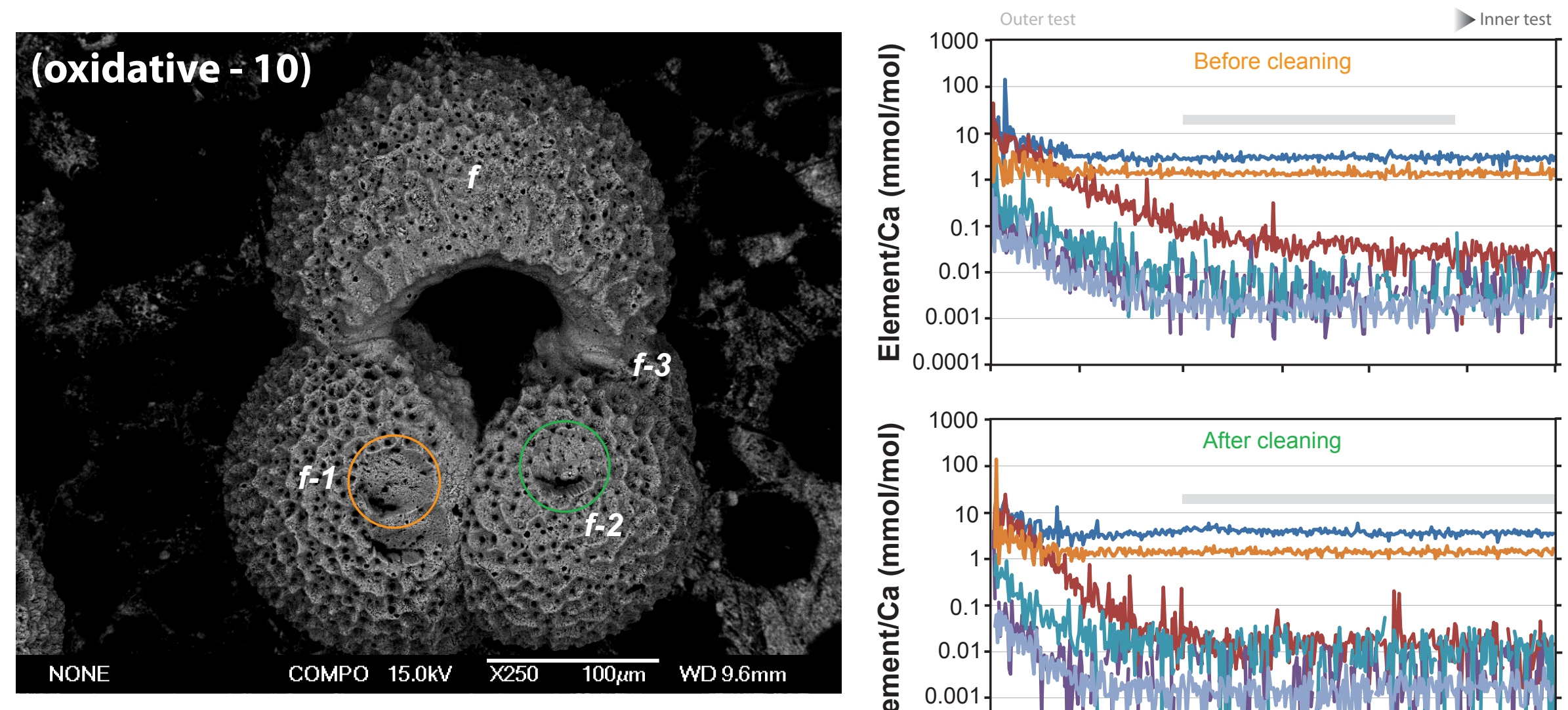

Key

흘

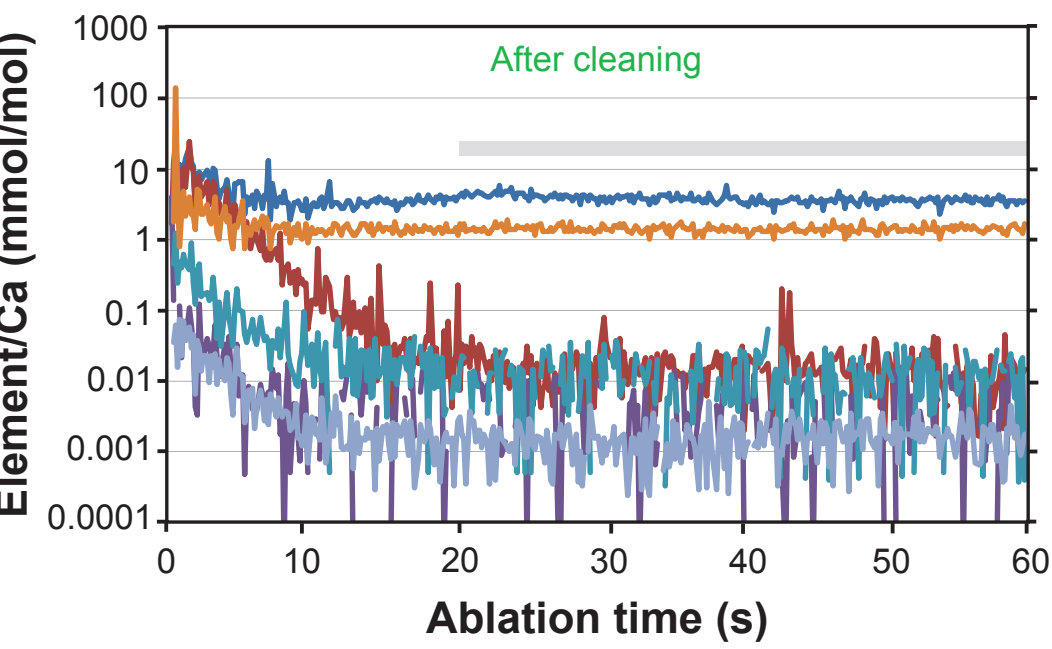

$\mathrm{Mg} / \mathrm{Ca}$

$\mathrm{Al} / \mathrm{Ca}$

$\longrightarrow \mathrm{Mn} / \mathrm{Ca}$

$\mathrm{Zn} / \mathrm{Ca}$

$\mathrm{Sr} / \mathrm{Ca}$

$\mathrm{Ba} / \mathrm{Ca}$

integrated data

Image Ablation pits

Before

cleaning

After

cleaning

Ablation time (s)

Sample: Oxidative - 10

$\mathrm{Mg} / \mathrm{Ca} \quad \mathrm{Al} / \mathrm{Ca}$

$(\mathrm{mmol} / \mathrm{mol})(\mathrm{mmol} / \mathrm{mol})$ \begin{tabular}{|l|l|l|l}
$\mathrm{Mn} / \mathrm{Ca}$ & $\mathrm{Zn} / \mathrm{Ca}$ & $\mathrm{Sr} / \mathrm{Ca}$ & $\mathrm{Ba} / \mathrm{Ca}$ \\
\hline
\end{tabular} $(\mathrm{mmol} / \mathrm{mol})(\mathrm{mmol} / \mathrm{mol})(\mathrm{mmol} / \mathrm{mol})(\mathrm{mmol} / \mathrm{mol})$

Before cleaning

\begin{tabular}{l|r}
2.975 & 0.039
\end{tabular}

$\% 2$ se

After cleaning

intergrated profile mean

1.5

9.2

0.003

0.004

\begin{tabular}{|r|r|}
\hline 1.368 & 0.002 \\
\hline 1.7 & 5.2 \\
\hline
\end{tabular}

\begin{tabular}{|l|l|}
\hline intergrated profile mean \\
\hline \% 2se \\
\hline Difference \\
\hline
\end{tabular}

mean

$-0.609$

0.025

0.015

0.002

69.9

0.008

1.313



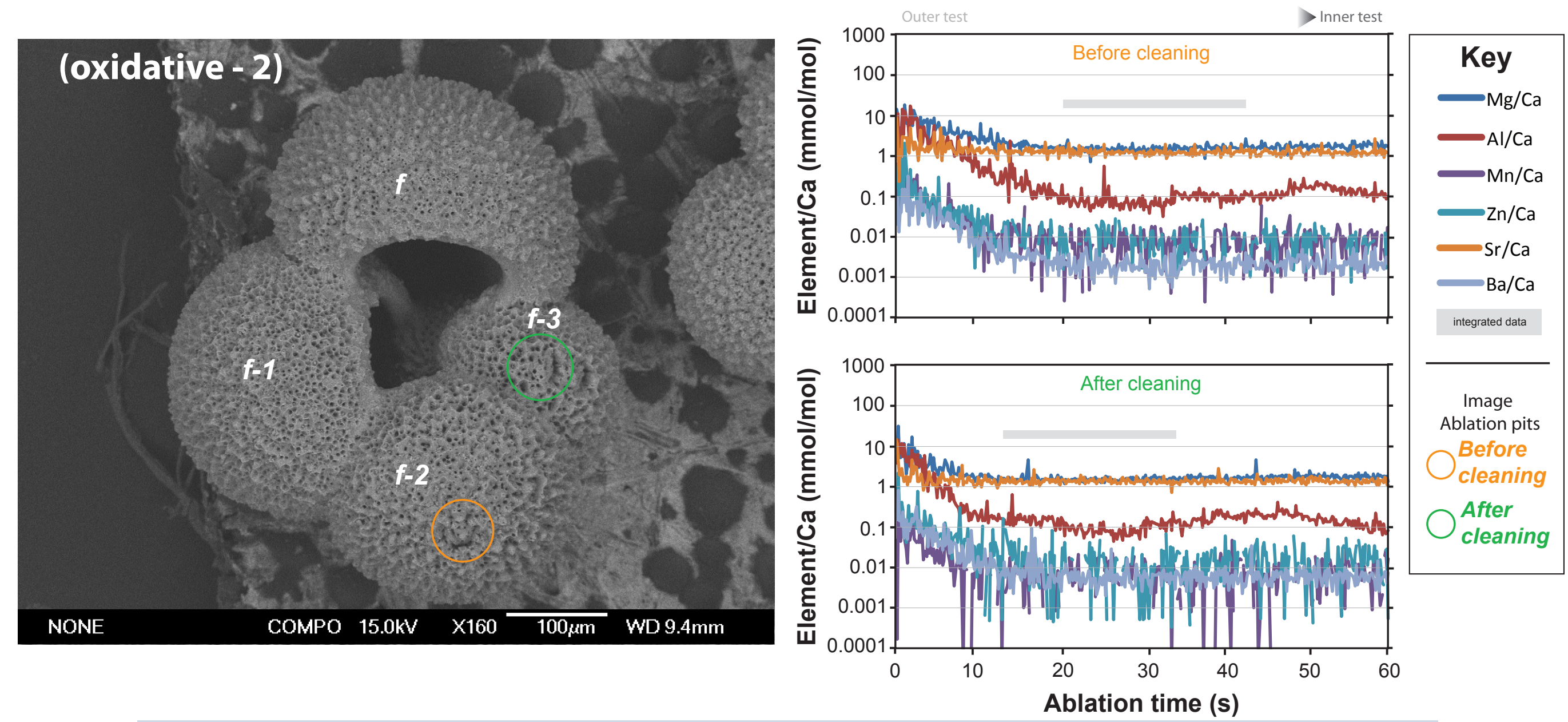

\begin{tabular}{|c|c|c|c|c|c|c|c|}
\hline \multicolumn{2}{|c|}{ Sample: Oxidative - 2} & \multirow[b]{2}{*}{$\begin{array}{c}\mathrm{Mg} / \mathrm{Ca} \\
(\mathrm{mmol} / \mathrm{mol})\end{array}$} & \multirow[b]{2}{*}{$\begin{array}{c}\mathrm{Al} / \mathrm{Ca} \\
(\mathrm{mmol} / \mathrm{mol})\end{array}$} & \multirow[b]{2}{*}{$\begin{array}{c}\mathrm{Mn} / \mathrm{Ca} \\
(\mathrm{mmol} / \mathrm{mol})\end{array}$} & \multirow[b]{2}{*}{$\begin{array}{c}\mathrm{Zn} / \mathrm{Ca} \\
(\mathrm{mmol} / \mathrm{mol})\end{array}$} & \multirow[b]{2}{*}{$\begin{array}{c}\mathrm{Sr} / \mathrm{Ca} \\
(\mathrm{mmol} / \mathrm{mol})\end{array}$} & \multirow[b]{2}{*}{$\begin{array}{c}\mathrm{Ba} / \mathrm{Ca} \\
(\mathrm{mmol} / \mathrm{mol})\end{array}$} \\
\hline Before cl & eaning & & & & & & \\
\hline & intergrated profile mean & 1.65 & 0.113 & 0.007 & 0.006 & 1.28 & 0.002 \\
\hline & $2 \mathrm{sd}$ & 0.55 & 0.105 & 0.014 & 0.016 & 0.45 & 0.002 \\
\hline \multicolumn{8}{|c|}{ After cleaning } \\
\hline & intergrated profile mean & 1.49 & 0.099 & 0.003 & 0.010 & 1.37 & 0.007 \\
\hline & 2 sd & 0.33 & 0.072 & 0.016 & 0.032 & 0.34 & 0.012 \\
\hline \multicolumn{8}{|c|}{ Difference } \\
\hline & mean & 0.16 & 0.013 & 0.004 & -0.004 & -0.09 & -0.004 \\
\hline
\end{tabular}



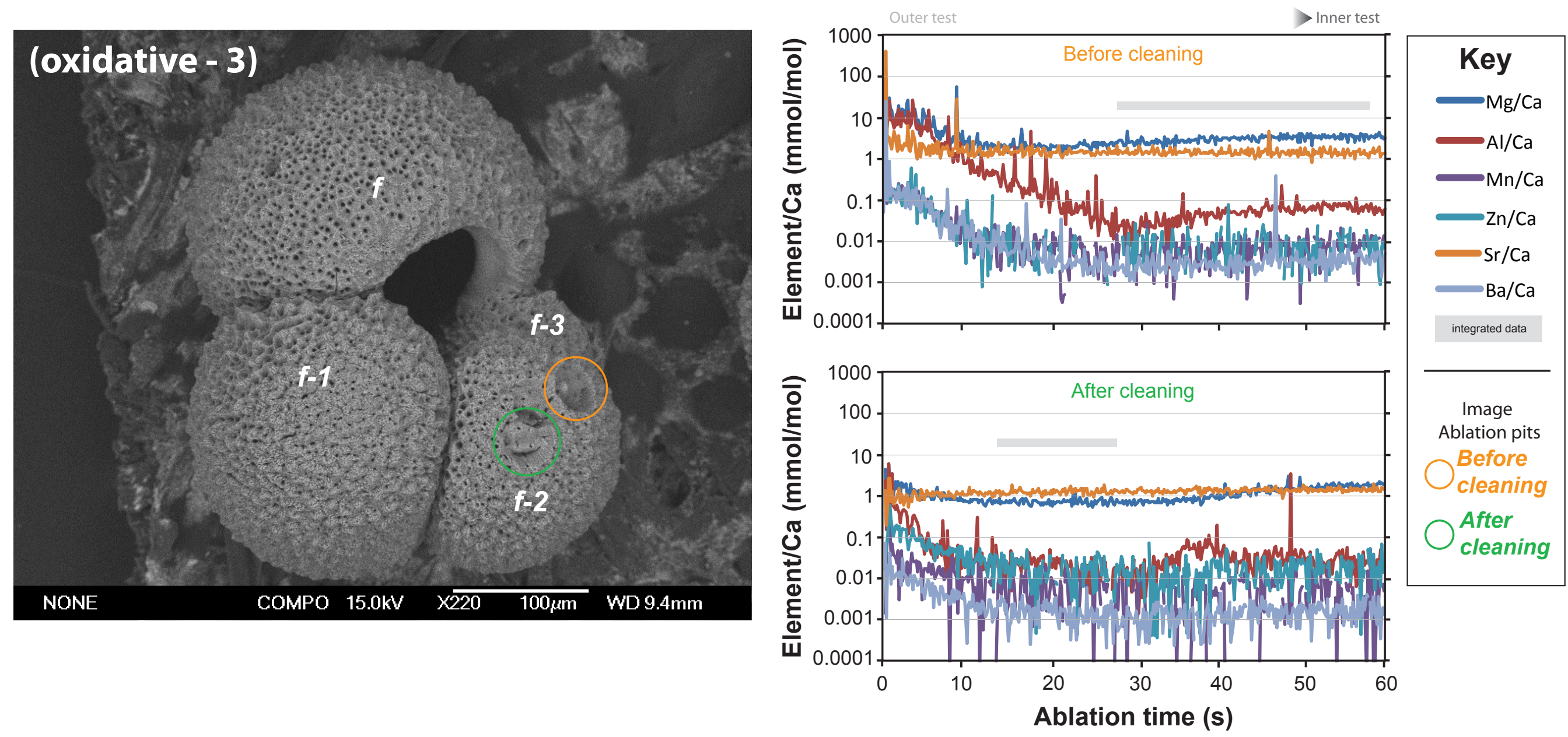

\begin{tabular}{|c|c|c|c|c|c|c|c|}
\hline \multicolumn{8}{|c|}{ Sample: Oxidative - 3} \\
\hline \multicolumn{2}{|c|}{ Before cleaning } & $\begin{array}{c}\mathrm{Mg} / \mathrm{Ca} \\
(\mathrm{mmol} / \mathrm{mol})\end{array}$ & $\begin{array}{c}\mathrm{Al} / \mathrm{Ca} \\
(\mathrm{mmol} / \mathrm{mol})\end{array}$ & $\begin{array}{c}\mathrm{Mn} / \mathrm{Ca} \\
(\mathrm{mmol} / \mathrm{mol})\end{array}$ & $\begin{array}{c}\mathrm{Zn} / \mathrm{Ca} \\
(\mathrm{mmol} / \mathrm{mol})\end{array}$ & $\begin{array}{c}\mathrm{Sr} / \mathrm{Ca} \\
(\mathrm{mmol} / \mathrm{mol})\end{array}$ & $\begin{array}{c}\mathrm{Ba} / \mathrm{Ca} \\
(\mathrm{mmol} / \mathrm{mol})\end{array}$ \\
\hline & intergrated profile mean & 3.16 & 0.052 & 0.006 & 0.005 & 1.49 & 0.005 \\
\hline & $2 \mathrm{sd}$ & 1.12 & 0.049 & 0.011 & 0.019 & 0.66 & 0.055 \\
\hline \multicolumn{8}{|c|}{ After cleaning } \\
\hline & intergrated profile mean & 0.73 & 0.019 & 0.005 & 0.015 & 1.29 & 0.002 \\
\hline & $2 \mathrm{sd}$ & 0.21 & 0.021 & 0.011 & 0.028 & 0.35 & 0.002 \\
\hline \multicolumn{8}{|c|}{ Difference } \\
\hline & mean & 2.43 & 0.033 & 0.001 & -0.010 & 0.19 & 0.004 \\
\hline
\end{tabular}



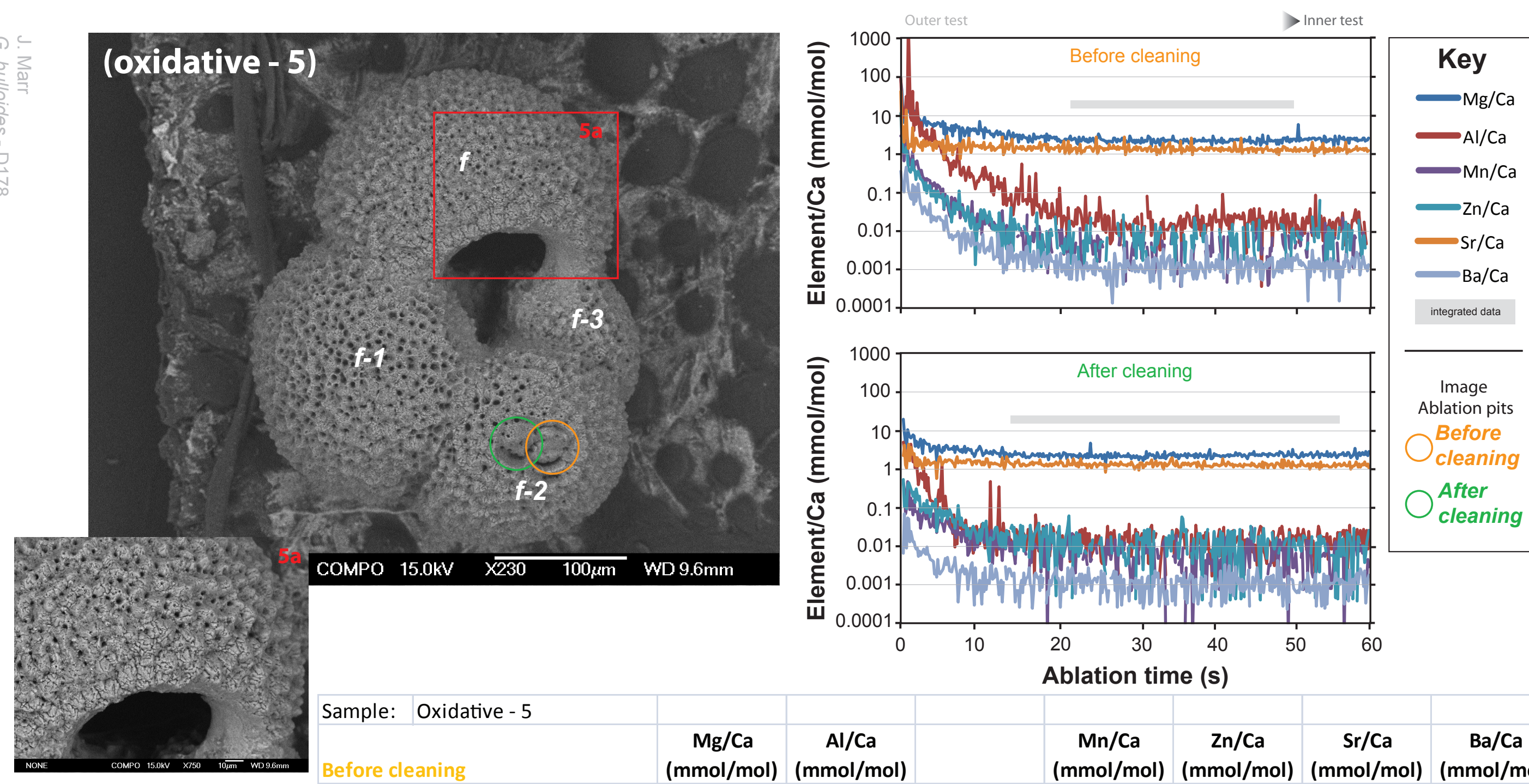

Image Ablation pits Before

cleaning

After

cleaning

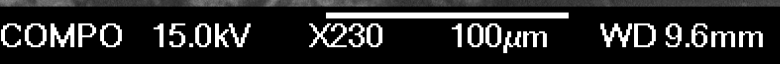

Ablation time (s)

Sample: Oxidative -5

$\mathrm{Mg} / \mathrm{Ca} \quad \mathrm{Al} / \mathrm{Ca}$

Before cleaning

\begin{tabular}{|l|l|}
\hline intergrated profile mean \\
\hline 2 sd
\end{tabular}

After cleaning

$2 \mathrm{so}$

Difference

\section{$(\mathrm{mmol} / \mathrm{mol})(\mathrm{mmol} / \mathrm{mol})$}

$\begin{array}{ll}2.29 & 0.020\end{array}$

0.74

0.60

0.046

0.014

0.019

\section{intergrated profile mean}

$\mathrm{Mn} / \mathrm{Ca}$

$\mathrm{Zn} / \mathrm{Ca}$

$\mathrm{Sr} / \mathrm{Ca}$

$\mathrm{Ba} / \mathrm{Ca}$

( $\mathrm{mmol} / \mathrm{mol})(\mathrm{mmol} / \mathrm{mol})(\mathrm{mmol} / \mathrm{mol})(\mathrm{mmol} / \mathrm{mol})$

\begin{tabular}{|l|l|l|l|}
\hline 0.010 & 0.016 & 0.53 & 0.001 \\
\hline
\end{tabular}

mean

0.02

0.006

0.014

0.011

0.026

1.33

0.34

0.001

0.001

$-0.008$

0.02

0.000 

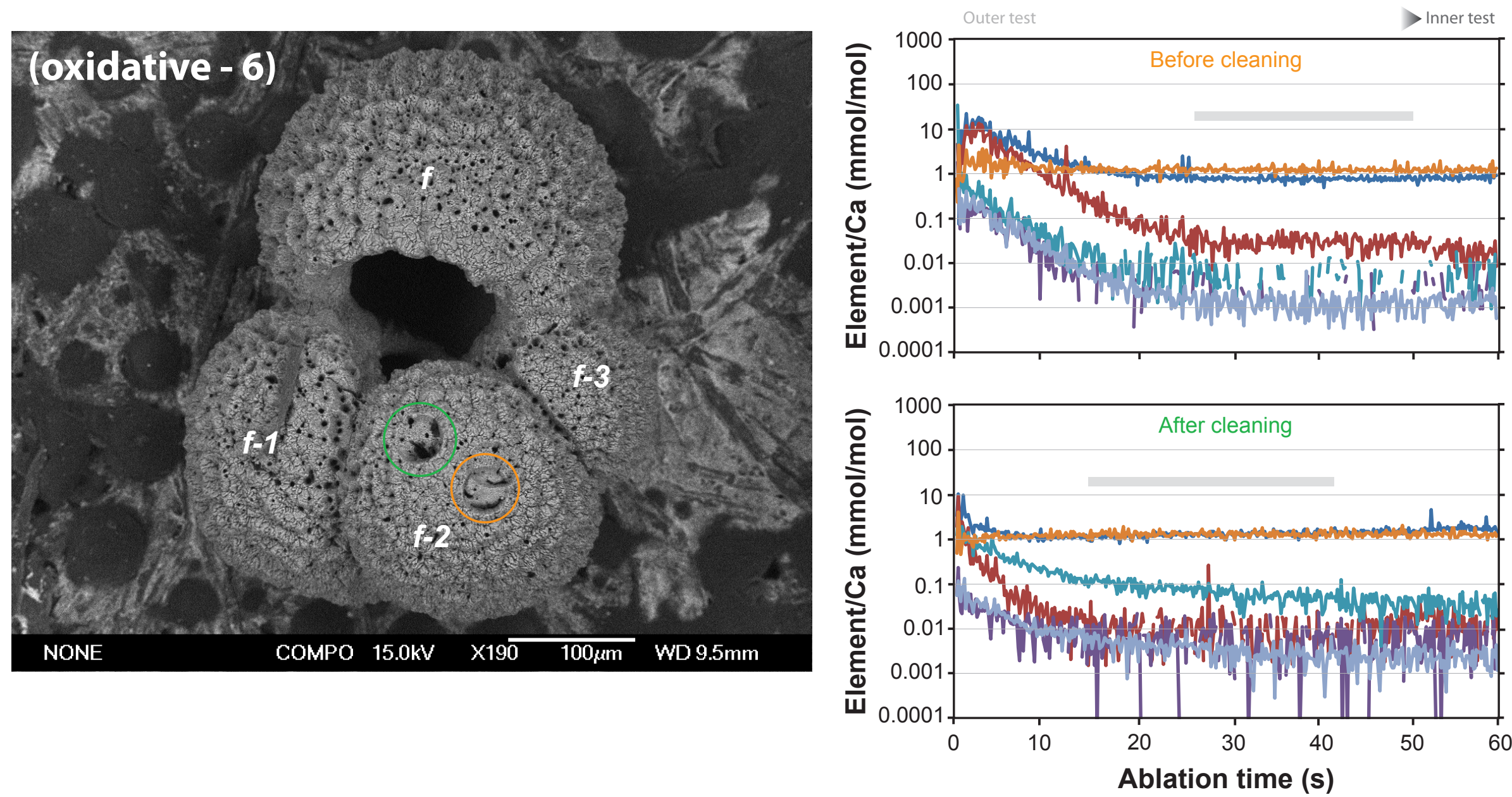

Key

$\mathrm{Mg} / \mathrm{Ca}$

$\mathrm{Al} / \mathrm{Ca}$

$\mathrm{Mn} / \mathrm{Ca}$

$\mathrm{Zn} / \mathrm{Ca}$

$\mathrm{Sr} / \mathrm{Ca}$

$\mathrm{Ba} / \mathrm{Ca}$

integrated data

Image Ablation pits

Before

cleaning

After

cleaning

$100 \mathrm{um} \quad W D 9.5 \mathrm{~mm}$

Ablation time (s)

\begin{tabular}{|c|c|c|c|c|c|c|c|}
\hline \multicolumn{8}{|c|}{ Sample: Oxidative - 6} \\
\hline \multicolumn{2}{|c|}{ Before cleaning } & $\begin{array}{c}\mathrm{Mg} / \mathrm{Ca} \\
(\mathrm{mmol} / \mathrm{mol})\end{array}$ & $\begin{array}{c}\mathrm{Al} / \mathrm{Ca} \\
(\mathrm{mmol} / \mathrm{mol})\end{array}$ & $\begin{array}{c}\mathrm{Mn} / \mathrm{Ca} \\
(\mathrm{mmol} / \mathrm{mol})\end{array}$ & $\begin{array}{c}\mathrm{Zn} / \mathrm{Ca} \\
(\mathrm{mmol} / \mathrm{mol})\end{array}$ & $\begin{array}{c}\mathrm{Sr} / \mathrm{Ca} \\
(\mathrm{mmol} / \mathrm{mol})\end{array}$ & $\begin{array}{c}\mathrm{Ba} / \mathrm{Ca} \\
(\mathrm{mmol} / \mathrm{mol})\end{array}$ \\
\hline & intergrated profile mean & 0.84 & 0.034 & 0.000 & 0.002 & 1.28 & 0.001 \\
\hline & $2 \mathrm{sd}$ & 0.36 & 0.039 & 0.010 & 0.015 & 0.35 & 0.001 \\
\hline \multicolumn{8}{|c|}{ After cleaning } \\
\hline & intergrated profile mean & 1.20 & 0.011 & 0.005 & 0.083 & 1.28 & 0.004 \\
\hline & $2 \mathrm{sd}$ & 0.26 & 0.051 & 0.012 & 0.049 & 0.35 & 0.003 \\
\hline \multicolumn{8}{|c|}{ Difference } \\
\hline & mean & -0.37 & 0.023 & -0.005 & -0.081 & 0.00 & -0.003 \\
\hline
\end{tabular}



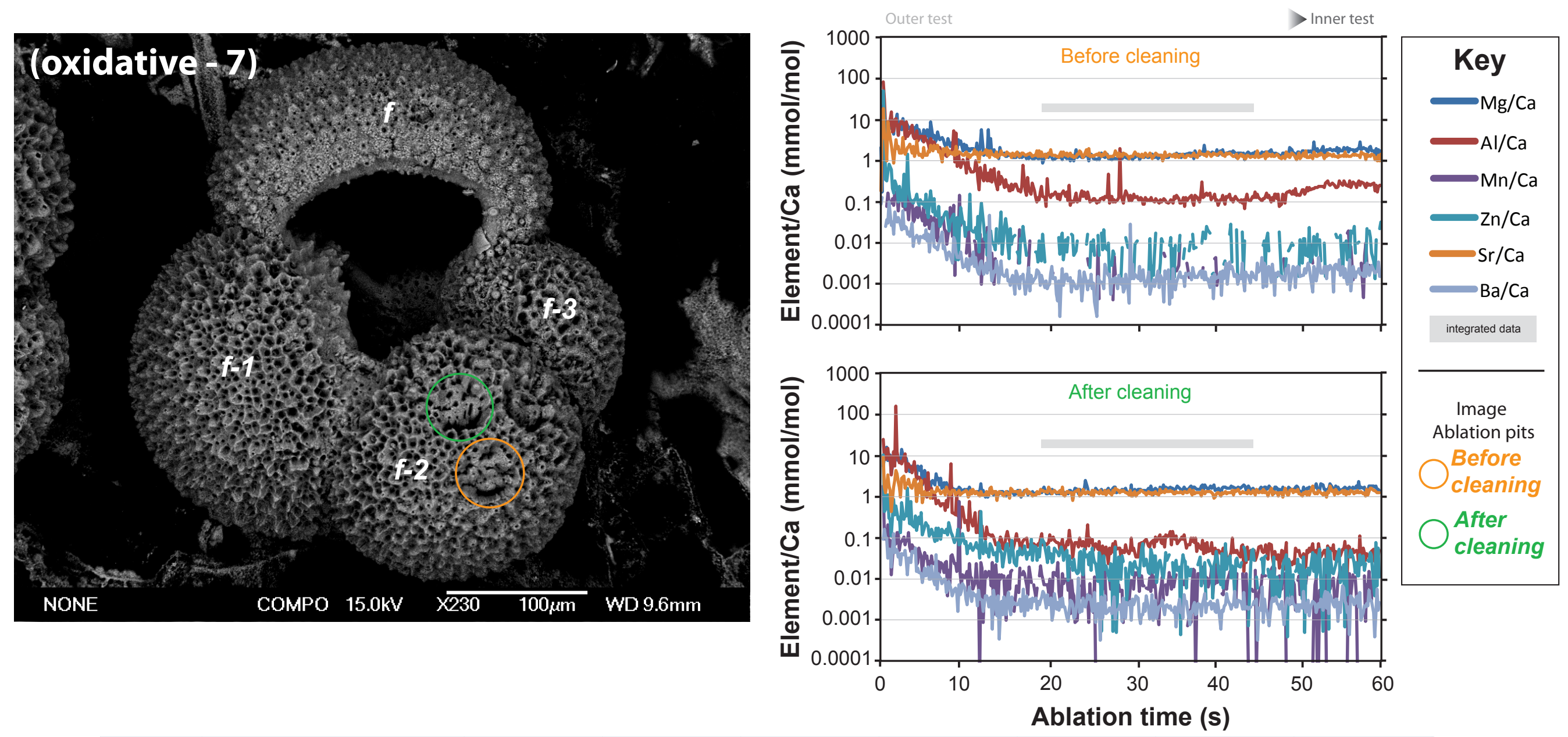

\begin{tabular}{|c|c|c|c|c|c|c|c|}
\hline \multicolumn{2}{|c|}{ Sample: Oxidative - 7} & & & & & & \\
\hline \multicolumn{2}{|c|}{ Before cleaning } & $\begin{array}{c}\mathrm{Mg} / \mathrm{Ca} \\
\text { (mmol/mol) }\end{array}$ & $\begin{array}{c}\mathrm{Al} / \mathrm{Ca} \\
(\mathrm{mmol} / \mathrm{mol})\end{array}$ & $\begin{array}{c}\mathrm{Mn} / \mathrm{Ca} \\
(\mathrm{mmol} / \mathrm{mol})\end{array}$ & $\begin{array}{c}\mathrm{Zn} / \mathrm{Ca} \\
(\mathrm{mmol} / \mathrm{mol})\end{array}$ & $\begin{array}{c}\mathrm{Sr} / \mathrm{Ca} \\
(\mathrm{mmol} / \mathrm{mol})\end{array}$ & $\begin{array}{c}\mathrm{Ba} / \mathrm{Ca} \\
(\mathrm{mmol} / \mathrm{mol})\end{array}$ \\
\hline & intergrated profile mean & 1.35 & 0.147 & 0.000 & 0.004 & 1.39 & 0.002 \\
\hline & $2 \mathrm{sd}$ & 0.42 & 0.309 & 0.011 & 0.018 & 0.31 & 0.004 \\
\hline \multicolumn{8}{|c|}{ After cleaning } \\
\hline & intergrated profile mean & 1.44 & 0.075 & 0.007 & 0.032 & 1.32 & 0.002 \\
\hline & $2 \mathrm{sd}$ & 0.43 & 0.054 & 0.013 & 0.040 & 0.30 & 0.002 \\
\hline \multicolumn{8}{|c|}{ Difference } \\
\hline & mean & -0.09 & 0.072 & -0.007 & -0.028 & 0.07 & -0.001 \\
\hline
\end{tabular}



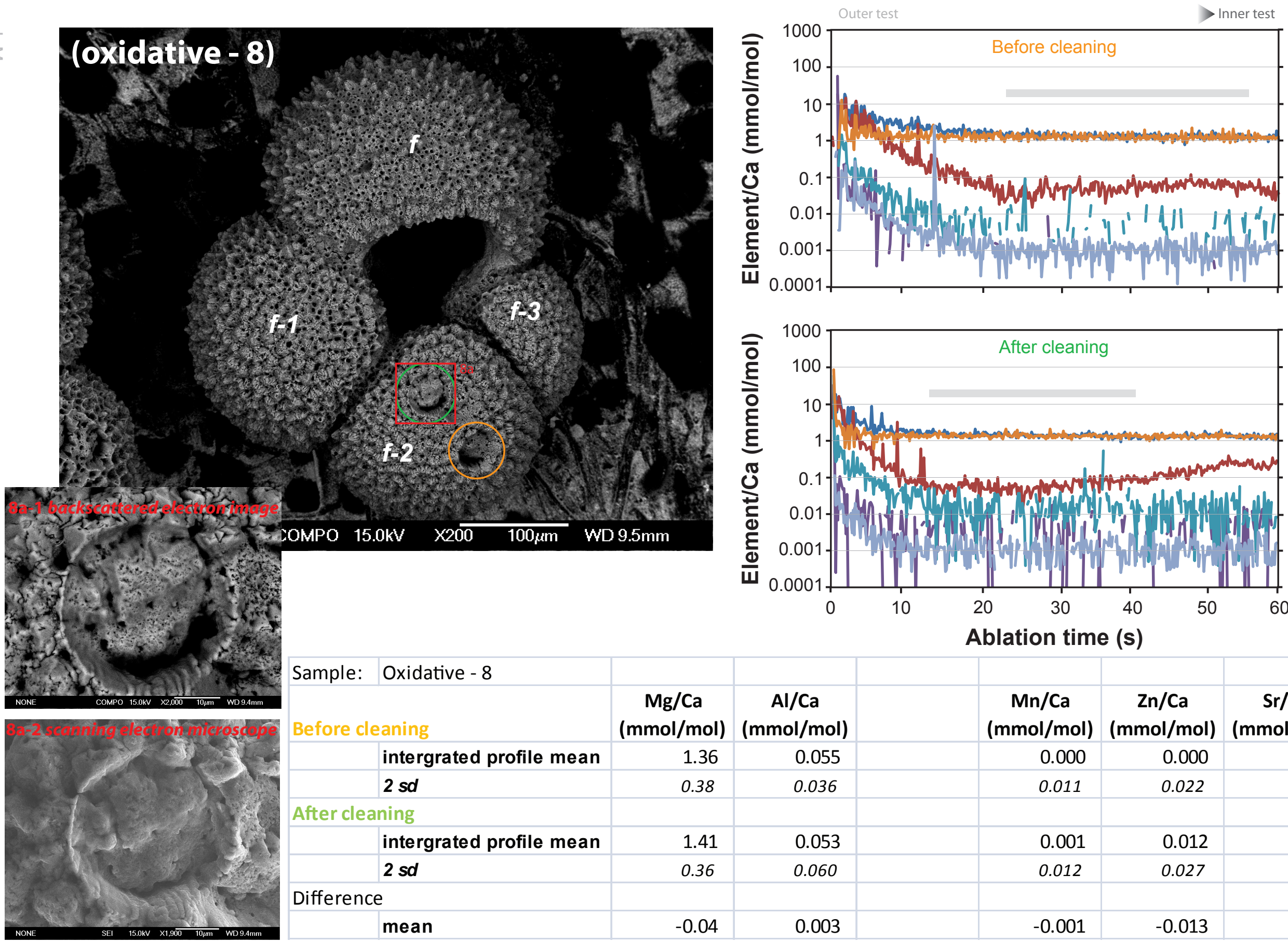

Key

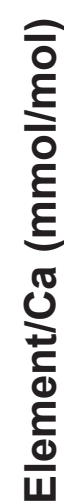

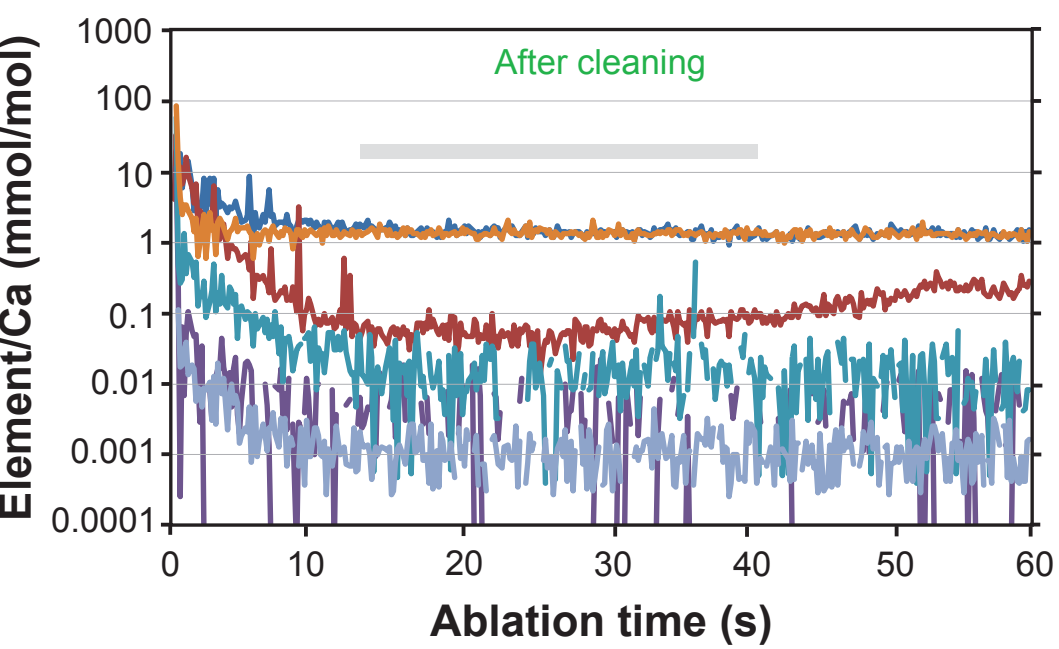

$-\mathrm{Mg} / \mathrm{Ca}$

$-\mathrm{Al} / \mathrm{Ca}$

$\longrightarrow \mathrm{Mn} / \mathrm{Ca}$

$\mathrm{Zn} / \mathrm{Ca}$

$\mathrm{Sr} / \mathrm{Ca}$

$\mathrm{Ba} / \mathrm{Ca}$

integrated data

Image Ablation pits

Before

cleaning

After

cleaning

COMPO $15.0 \mathrm{k} \quad \times 200 \quad 100 \mathrm{~km} \quad W D 9.5 \mathrm{~mm}$

Ablation time (s)

Sample: Oxidative - 8

\begin{tabular}{|c|c|c|c|c|c|c|}
\hline Before cleaning & $\begin{array}{c}\mathrm{Mg} / \mathrm{Ca} \\
(\mathrm{mmol} / \mathrm{mol})\end{array}$ & $\begin{array}{c}\mathrm{Al} / \mathrm{Ca} \\
(\mathrm{mmol} / \mathrm{mol})\end{array}$ & $\begin{array}{c}\mathrm{Mn} / \mathrm{Ca} \\
(\mathrm{mmol} / \mathrm{mol})\end{array}$ & $\begin{array}{c}\mathrm{Zn} / \mathrm{Ca} \\
(\mathrm{mmol} / \mathrm{mol})\end{array}$ & $\begin{array}{c}\mathrm{Sr} / \mathrm{Ca} \\
(\mathrm{mmol} / \mathrm{mol})\end{array}$ & $\begin{array}{c}\mathrm{Ba} / \mathrm{Ca} \\
(\mathrm{mmol} / \mathrm{mol})\end{array}$ \\
\hline intergrated profile mean & 1.36 & 0.055 & 0.000 & 0.000 & 1.29 & 0.001 \\
\hline $2 \mathrm{sd}$ & 0.38 & 0.036 & 0.011 & 0.022 & 0.47 & 0.001 \\
\hline \multicolumn{7}{|l|}{ After cleaning } \\
\hline intergrated profile mean & 1.41 & 0.053 & 0.001 & 0.012 & 1.32 & 0.001 \\
\hline $2 \mathrm{sd}$ & 0.36 & 0.060 & 0.012 & 0.027 & 0.33 & 0.001 \\
\hline \multicolumn{7}{|l|}{ Difference } \\
\hline mean & -0.04 & 0.003 & -0.001 & -0.013 & -0.03 & 0.0001 \\
\hline
\end{tabular}



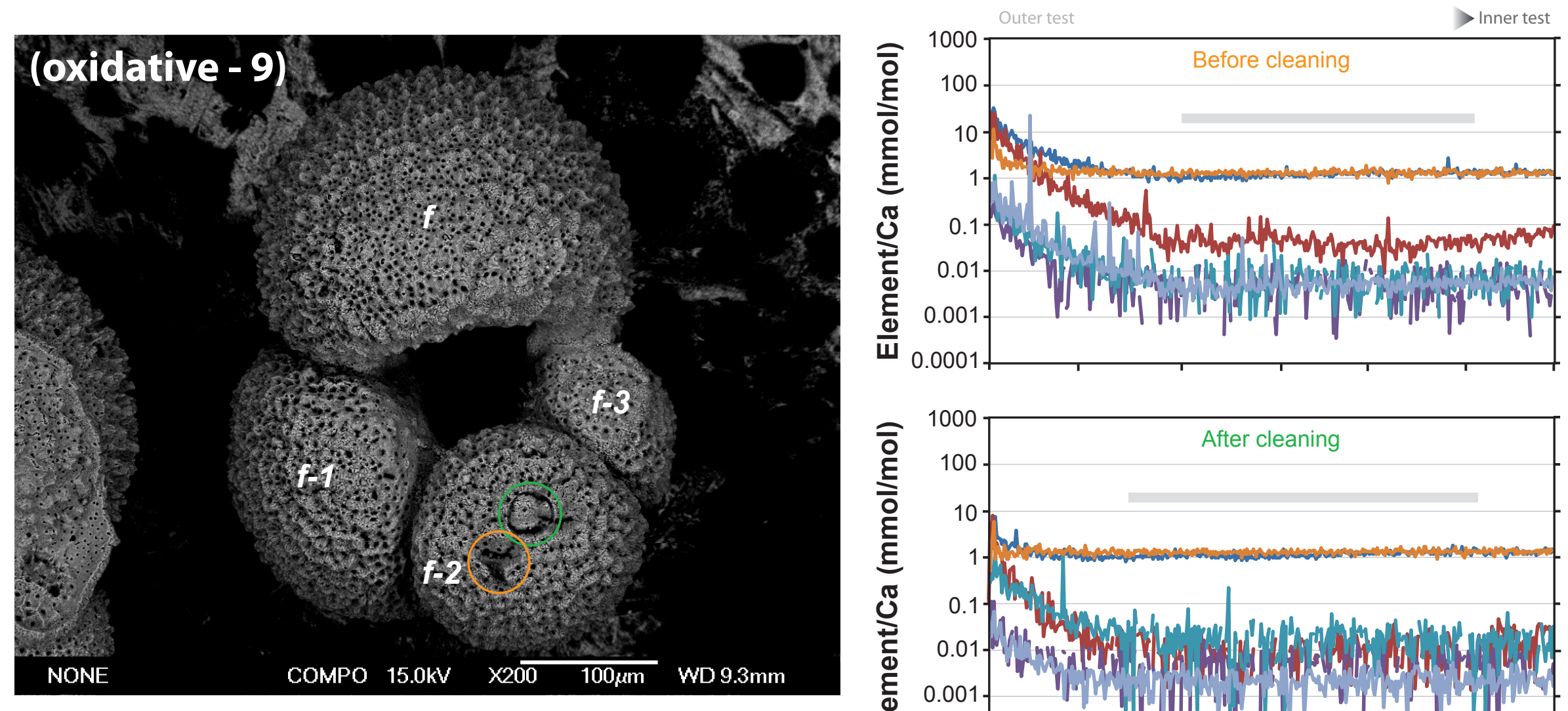

Key

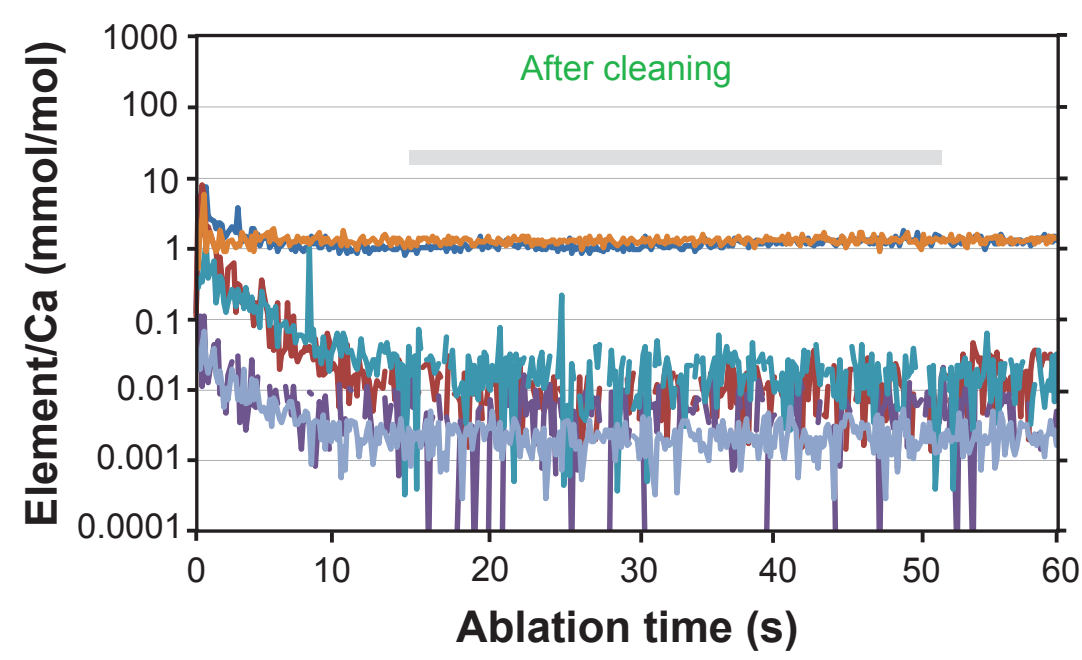

$\mathrm{Mg} / \mathrm{Ca}$

$\mathrm{Al} / \mathrm{Ca}$

$\longrightarrow \mathrm{Mn} / \mathrm{Ca}$

$\mathrm{Zn} / \mathrm{Ca}$

$\mathrm{Sr} / \mathrm{Ca}$

$\mathrm{Ba} / \mathrm{Ca}$

integrated data

Image Ablation pits

Before

cleaning

After

cleaning

\begin{tabular}{|l|l|l|l|}
\hline $\mathrm{Mn} / \mathrm{Ca}$ & $\mathrm{Zn} / \mathrm{Ca}$ & $\mathrm{Sr} / \mathrm{Ca}$ & $\mathrm{Ba} / \mathrm{Ca}$
\end{tabular}

$(\mathrm{mmol} / \mathrm{mol})(\mathrm{mmol} / \mathrm{mol})(\mathrm{mmol} / \mathrm{mol}) \quad(\mathrm{mmol} / \mathrm{mol})$ (mmol/mol) ( $\mathrm{mmol} / \mathrm{mol})$

Before cleaning

\begin{tabular}{|c|c|c|c|c|c|c|c|}
\hline \multicolumn{8}{|c|}{ Sample: Oxidative-9 } \\
\hline \multicolumn{2}{|c|}{ Before cleaning } & $\begin{array}{c}\mathrm{Mg} / \mathrm{Ca} \\
(\mathrm{mmol} / \mathrm{mol})\end{array}$ & $\begin{array}{c}\mathrm{Al} / \mathrm{Ca} \\
(\mathrm{mmol} / \mathrm{mol})\end{array}$ & $\begin{array}{c}\mathrm{Mn} / \mathrm{Ca} \\
(\mathrm{mmol} / \mathrm{mol})\end{array}$ & $\begin{array}{c}\mathrm{Zn} / \mathrm{Ca} \\
(\mathrm{mmol} / \mathrm{mol})\end{array}$ & $\begin{array}{c}\mathrm{Sr} / \mathrm{Ca} \\
(\mathrm{mmol} / \mathrm{mol})\end{array}$ & $\begin{array}{c}\mathrm{Ba} / \mathrm{Ca} \\
(\mathrm{mmol} / \mathrm{mol})\end{array}$ \\
\hline & intergrated profile mean & 1.21 & 0.043 & 0.003 & 0.004 & 1.30 & 0.005 \\
\hline & $2 \mathrm{sd}$ & 0.36 & 0.039 & 0.010 & 0.013 & 0.29 & 0.007 \\
\hline \multicolumn{8}{|c|}{ After cleaning } \\
\hline & intergrated profile mean & 1.11 & 0.008 & 0.002 & 0.017 & 1.27 & 0.002 \\
\hline & $2 \mathrm{sd}$ & 0.27 & 0.015 & 0.011 & 0.040 & 0.25 & 0.002 \\
\hline \multicolumn{8}{|c|}{ Difference } \\
\hline & mean & 0.10 & 0.035 & 0.001 & -0.012 & 0.04 & 0.003 \\
\hline
\end{tabular}

2 sd

After cleaning

intergrated profile mean

2 sd

\begin{tabular}{|c|c|c|c|c|c|c|c|}
\hline \multicolumn{8}{|c|}{ Sample: Oxidative-9 } \\
\hline \multicolumn{2}{|c|}{ Before cleaning } & $\begin{array}{c}\mathrm{Mg} / \mathrm{Ca} \\
(\mathrm{mmol} / \mathrm{mol})\end{array}$ & $\begin{array}{c}\mathrm{Al} / \mathrm{Ca} \\
(\mathrm{mmol} / \mathrm{mol})\end{array}$ & $\begin{array}{c}\mathrm{Mn} / \mathrm{Ca} \\
(\mathrm{mmol} / \mathrm{mol})\end{array}$ & $\begin{array}{c}\mathrm{Zn} / \mathrm{Ca} \\
(\mathrm{mmol} / \mathrm{mol})\end{array}$ & $\begin{array}{c}\mathrm{Sr} / \mathrm{Ca} \\
(\mathrm{mmol} / \mathrm{mol})\end{array}$ & $\begin{array}{c}\mathrm{Ba} / \mathrm{Ca} \\
(\mathrm{mmol} / \mathrm{mol})\end{array}$ \\
\hline & intergrated profile mean & 1.21 & 0.043 & 0.003 & 0.004 & 1.30 & 0.005 \\
\hline & $2 \mathrm{sd}$ & 0.36 & 0.039 & 0.010 & 0.013 & 0.29 & 0.007 \\
\hline \multicolumn{8}{|c|}{ After cleaning } \\
\hline & intergrated profile mean & 1.11 & 0.008 & 0.002 & 0.017 & 1.27 & 0.002 \\
\hline & $2 \mathrm{sd}$ & 0.27 & 0.015 & 0.011 & 0.040 & 0.25 & 0.002 \\
\hline \multicolumn{8}{|c|}{ Difference } \\
\hline & mean & 0.10 & 0.035 & 0.001 & -0.012 & 0.04 & 0.003 \\
\hline
\end{tabular}

Difference

mean

$\begin{array}{ll}0.10 & 0.035\end{array}$

0.003

\begin{tabular}{|c|c|c|c|c|c|c|c|}
\hline \multicolumn{8}{|c|}{ Sample: Oxidative-9 } \\
\hline \multicolumn{2}{|c|}{ Before cleaning } & $\begin{array}{c}\mathrm{Mg} / \mathrm{Ca} \\
(\mathrm{mmol} / \mathrm{mol})\end{array}$ & $\begin{array}{c}\mathrm{Al} / \mathrm{Ca} \\
(\mathrm{mmol} / \mathrm{mol})\end{array}$ & $\begin{array}{c}\mathrm{Mn} / \mathrm{Ca} \\
(\mathrm{mmol} / \mathrm{mol})\end{array}$ & $\begin{array}{c}\mathrm{Zn} / \mathrm{Ca} \\
(\mathrm{mmol} / \mathrm{mol})\end{array}$ & $\begin{array}{c}\mathrm{Sr} / \mathrm{Ca} \\
(\mathrm{mmol} / \mathrm{mol})\end{array}$ & $\begin{array}{c}\mathrm{Ba} / \mathrm{Ca} \\
(\mathrm{mmol} / \mathrm{mol})\end{array}$ \\
\hline & intergrated profile mean & 1.21 & 0.043 & 0.003 & 0.004 & 1.30 & 0.005 \\
\hline & $2 \mathrm{sd}$ & 0.36 & 0.039 & 0.010 & 0.013 & 0.29 & 0.007 \\
\hline \multicolumn{8}{|c|}{ After cleaning } \\
\hline & intergrated profile mean & 1.11 & 0.008 & 0.002 & 0.017 & 1.27 & 0.002 \\
\hline & $2 \mathrm{sd}$ & 0.27 & 0.015 & 0.011 & 0.040 & 0.25 & 0.002 \\
\hline \multicolumn{8}{|c|}{ Difference } \\
\hline & mean & 0.10 & 0.035 & 0.001 & -0.012 & 0.04 & 0.003 \\
\hline
\end{tabular}

\begin{tabular}{|l|l|l|l|}
\hline 0.010 & 0.013 & 0.29 & 0.007 \\
\hline
\end{tabular}

\begin{tabular}{|c|c|c|c|c|c|c|c|}
\hline \multicolumn{8}{|c|}{ Sample: Oxidative-9 } \\
\hline \multicolumn{2}{|c|}{ Before cleaning } & $\begin{array}{c}\mathrm{Mg} / \mathrm{Ca} \\
(\mathrm{mmol} / \mathrm{mol})\end{array}$ & $\begin{array}{c}\mathrm{Al} / \mathrm{Ca} \\
(\mathrm{mmol} / \mathrm{mol})\end{array}$ & $\begin{array}{c}\mathrm{Mn} / \mathrm{Ca} \\
(\mathrm{mmol} / \mathrm{mol})\end{array}$ & $\begin{array}{c}\mathrm{Zn} / \mathrm{Ca} \\
(\mathrm{mmol} / \mathrm{mol})\end{array}$ & $\begin{array}{c}\mathrm{Sr} / \mathrm{Ca} \\
(\mathrm{mmol} / \mathrm{mol})\end{array}$ & $\begin{array}{c}\mathrm{Ba} / \mathrm{Ca} \\
(\mathrm{mmol} / \mathrm{mol})\end{array}$ \\
\hline & intergrated profile mean & 1.21 & 0.043 & 0.003 & 0.004 & 1.30 & 0.005 \\
\hline & $2 \mathrm{sd}$ & 0.36 & 0.039 & 0.010 & 0.013 & 0.29 & 0.007 \\
\hline \multicolumn{8}{|c|}{ After cleaning } \\
\hline & intergrated profile mean & 1.11 & 0.008 & 0.002 & 0.017 & 1.27 & 0.002 \\
\hline & $2 \mathrm{sd}$ & 0.27 & 0.015 & 0.011 & 0.040 & 0.25 & 0.002 \\
\hline \multicolumn{8}{|c|}{ Difference } \\
\hline & mean & 0.10 & 0.035 & 0.001 & -0.012 & 0.04 & 0.003 \\
\hline
\end{tabular}

\begin{tabular}{|c|c|c|c|c|c|c|c|}
\hline \multicolumn{8}{|c|}{ Sample: Oxidative-9 } \\
\hline \multicolumn{2}{|c|}{ Before cleaning } & $\begin{array}{c}\mathrm{Mg} / \mathrm{Ca} \\
(\mathrm{mmol} / \mathrm{mol})\end{array}$ & $\begin{array}{c}\mathrm{Al} / \mathrm{Ca} \\
(\mathrm{mmol} / \mathrm{mol})\end{array}$ & $\begin{array}{c}\mathrm{Mn} / \mathrm{Ca} \\
(\mathrm{mmol} / \mathrm{mol})\end{array}$ & $\begin{array}{c}\mathrm{Zn} / \mathrm{Ca} \\
(\mathrm{mmol} / \mathrm{mol})\end{array}$ & $\begin{array}{c}\mathrm{Sr} / \mathrm{Ca} \\
(\mathrm{mmol} / \mathrm{mol})\end{array}$ & $\begin{array}{c}\mathrm{Ba} / \mathrm{Ca} \\
(\mathrm{mmol} / \mathrm{mol})\end{array}$ \\
\hline & intergrated profile mean & 1.21 & 0.043 & 0.003 & 0.004 & 1.30 & 0.005 \\
\hline & $2 \mathrm{sd}$ & 0.36 & 0.039 & 0.010 & 0.013 & 0.29 & 0.007 \\
\hline \multicolumn{8}{|c|}{ After cleaning } \\
\hline & intergrated profile mean & 1.11 & 0.008 & 0.002 & 0.017 & 1.27 & 0.002 \\
\hline & $2 \mathrm{sd}$ & 0.27 & 0.015 & 0.011 & 0.040 & 0.25 & 0.002 \\
\hline \multicolumn{8}{|c|}{ Difference } \\
\hline & mean & 0.10 & 0.035 & 0.001 & -0.012 & 0.04 & 0.003 \\
\hline
\end{tabular}




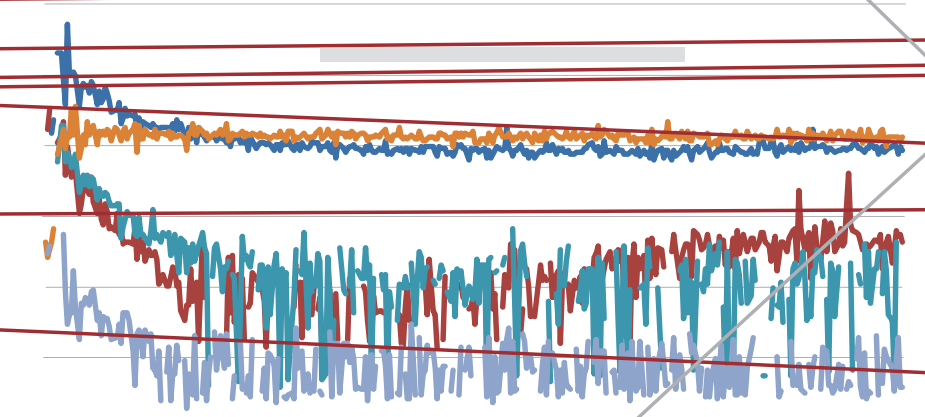



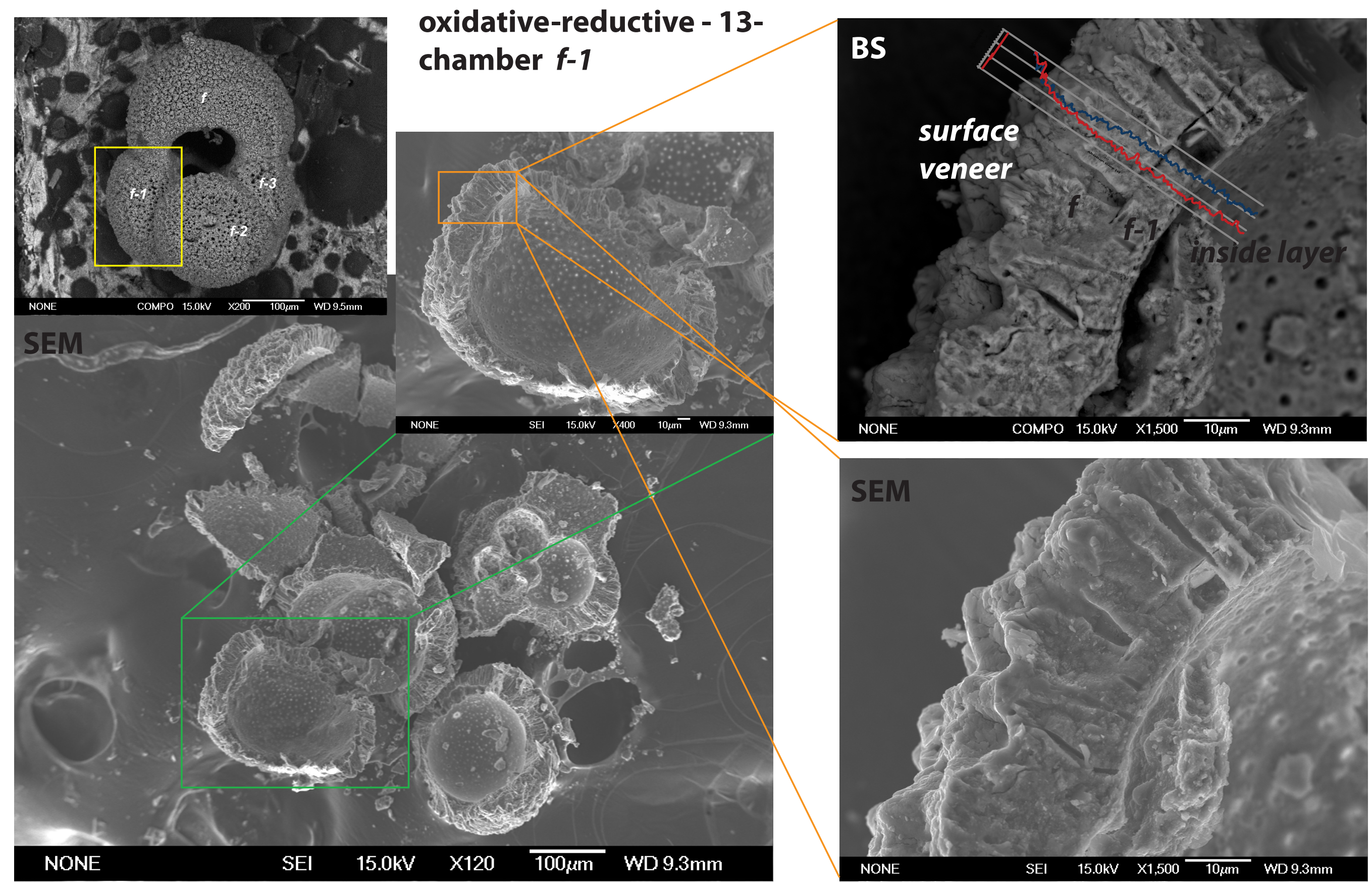


\section{BS}

surface

\section{veneer}



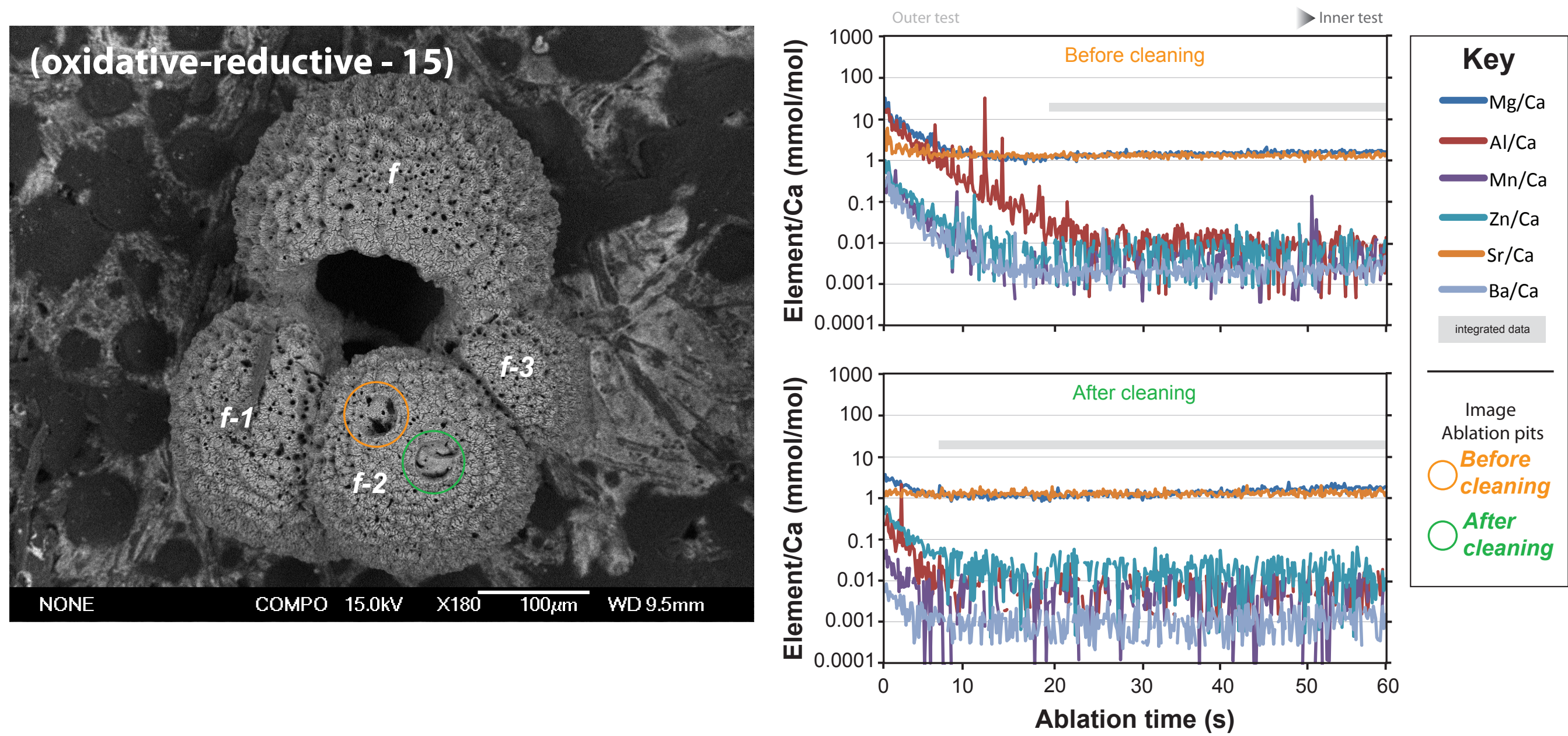

\begin{tabular}{|c|c|c|c|c|c|c|c|}
\hline \multicolumn{8}{|c|}{ Sample: Oxidative-Reductive - 15} \\
\hline \multicolumn{2}{|c|}{ Before cleaning } & $\begin{array}{c}\mathrm{Mg} / \mathrm{Ca} \\
(\mathrm{mmol} / \mathrm{mol})\end{array}$ & $\begin{array}{c}\mathrm{Al} / \mathrm{Ca} \\
(\mathrm{mmol} / \mathrm{mol})\end{array}$ & $\begin{array}{c}\mathrm{Mn} / \mathrm{Ca} \\
(\mathrm{mmol} / \mathrm{mol})\end{array}$ & $\begin{array}{c}\mathrm{Zn} / \mathrm{Ca} \\
(\mathrm{mmol} / \mathrm{mol})\end{array}$ & $\begin{array}{c}\mathrm{Sr} / \mathrm{Ca} \\
(\mathrm{mmol} / \mathrm{mol})\end{array}$ & $\begin{array}{c}\mathrm{Ba} / \mathrm{Ca} \\
(\mathrm{mmol} / \mathrm{mol})\end{array}$ \\
\hline & intergrated profile mean & 1.50 & 0.010 & 0.003 & 0.005 & 1.32 & 0.002 \\
\hline & 2 sd & 0.34 & 0.019 & 0.020 & 0.013 & 0.26 & 0.003 \\
\hline \multicolumn{8}{|c|}{ After cleaning } \\
\hline & intergrated profile mean & 1.26 & 0.002 & 0.003 & 0.015 & 1.28 & 0.001 \\
\hline & $2 s d$ & 0.40 & 0.015 & 0.013 & 0.029 & 0.33 & 0.001 \\
\hline \multicolumn{8}{|c|}{ Difference } \\
\hline & mean & 0.24 & 0.008 & 0.000 & -0.010 & 0.04 & 0.001 \\
\hline
\end{tabular}




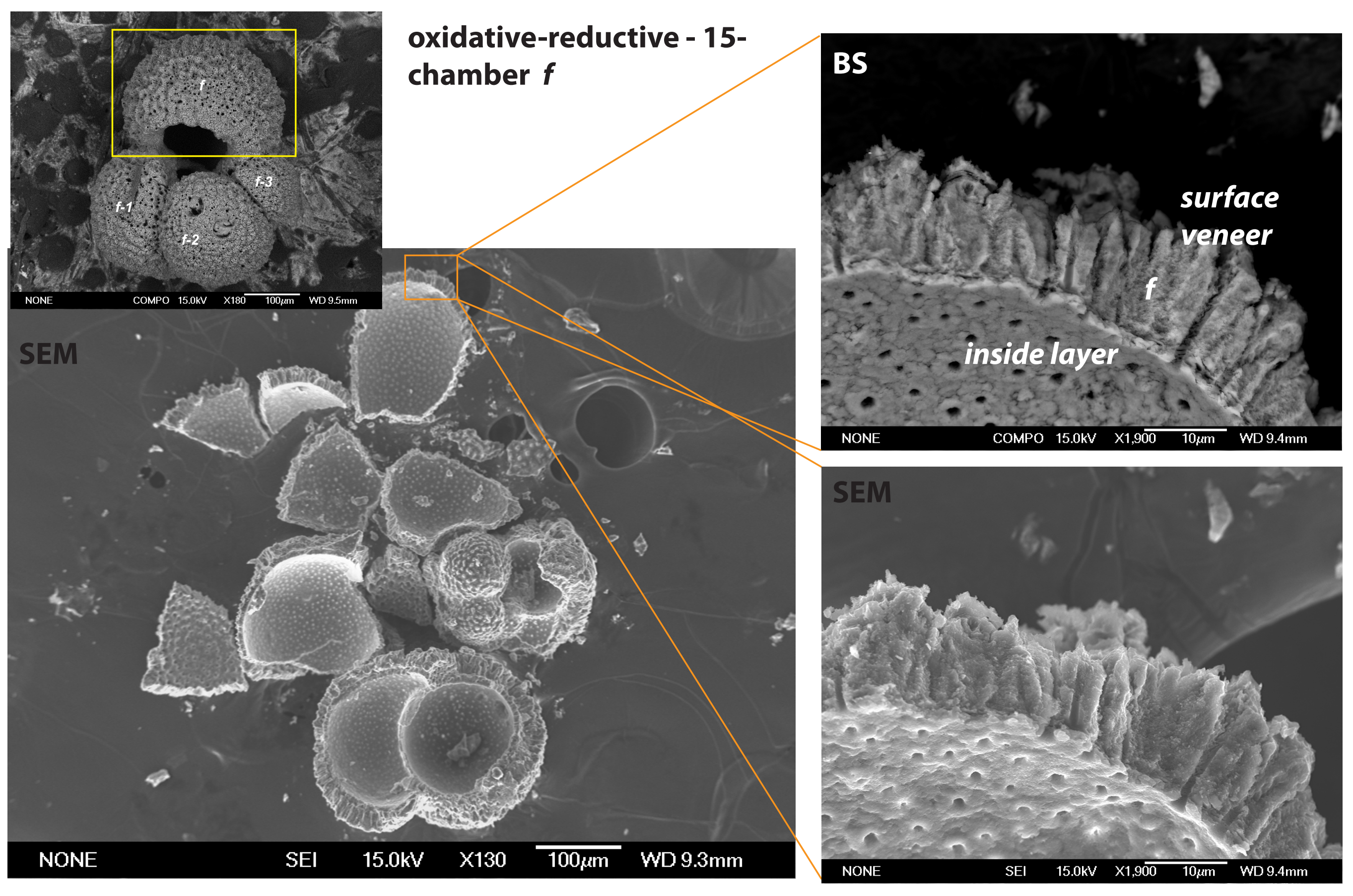




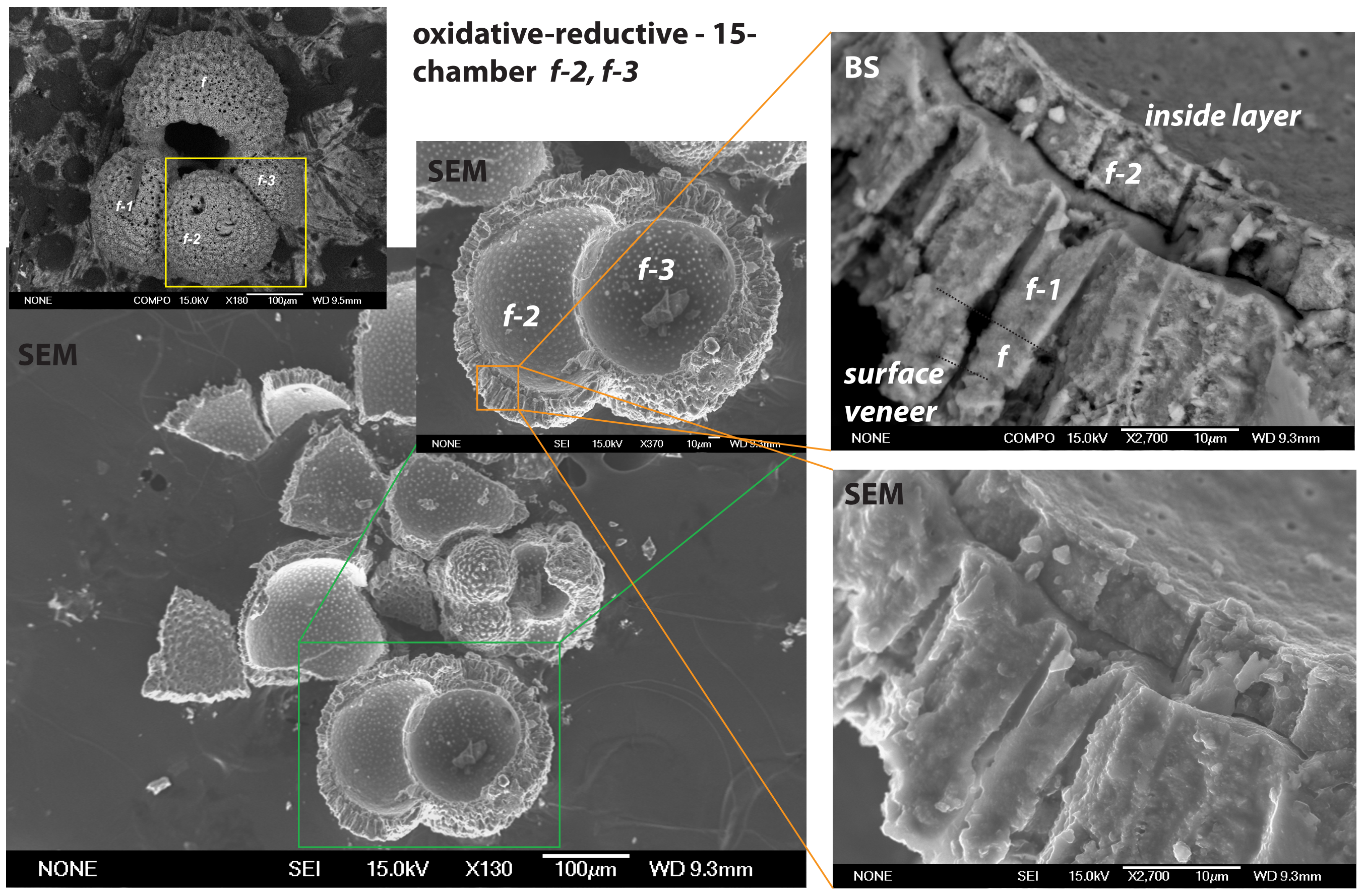



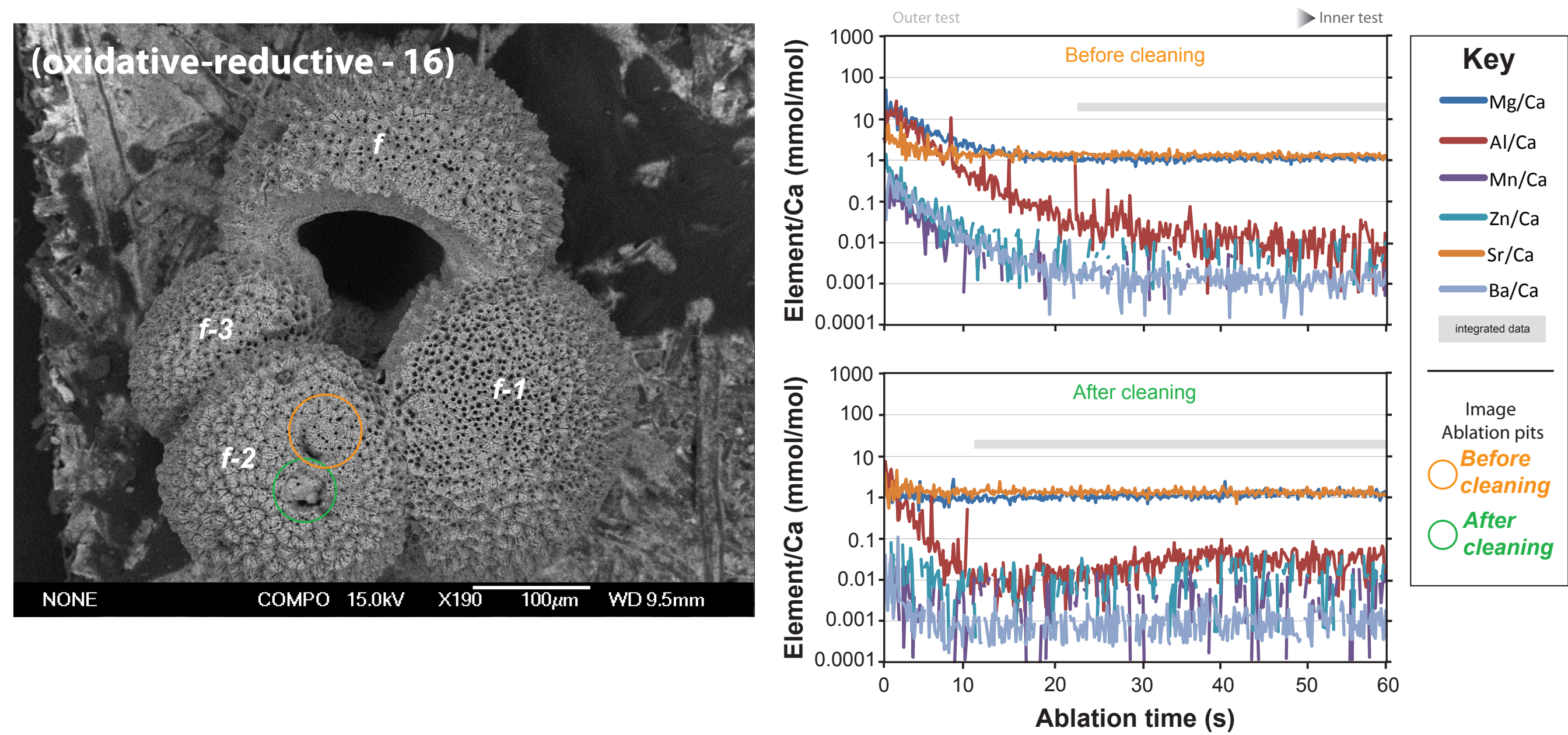

\begin{tabular}{|c|c|c|c|c|c|c|c|}
\hline Sample: & Oxidative-Reductive - 16 & & & & & & \\
\hline \multicolumn{2}{|c|}{ Before cleaning } & $\begin{array}{c}\mathrm{Mg} / \mathrm{Ca} \\
(\mathrm{mmol} / \mathrm{mol})\end{array}$ & $\begin{array}{c}\mathrm{Al} / \mathrm{Ca} \\
(\mathrm{mmol} / \mathrm{mol})\end{array}$ & $\begin{array}{c}\mathrm{Mn} / \mathrm{Ca} \\
(\mathrm{mmol} / \mathrm{mol})\end{array}$ & $\begin{array}{c}\mathrm{Zn} / \mathrm{Ca} \\
(\mathrm{mmol} / \mathrm{mol})\end{array}$ & $\begin{array}{c}\mathrm{Sr} / \mathrm{Ca} \\
(\mathrm{mmol} / \mathrm{mol})\end{array}$ & $\begin{array}{c}\mathrm{Ba} / \mathrm{Ca} \\
(\mathrm{mmol} / \mathrm{mol})\end{array}$ \\
\hline & intergrated profile mean & 1.08 & 0.018 & 0.000 & 0.000 & 1.32 & 0.001 \\
\hline & $\%$ 2se & 1.5 & 15.1 & -19.0 & -68.8 & 1.5 & 6.5 \\
\hline \multicolumn{8}{|c|}{ After cleaning } \\
\hline & intergrated profile mean & 1.02 & 0.017 & 0.000 & 0.002 & 1.35 & 0.001 \\
\hline & $\% 2$ se & 2.1 & 12.7 & -387 & 106 & 2.4 & 13.5 \\
\hline \multicolumn{8}{|c|}{ Difference } \\
\hline & mean & 0.06 & 0.000 & 0.000 & -0.002 & -0.03 & 0.001 \\
\hline
\end{tabular}



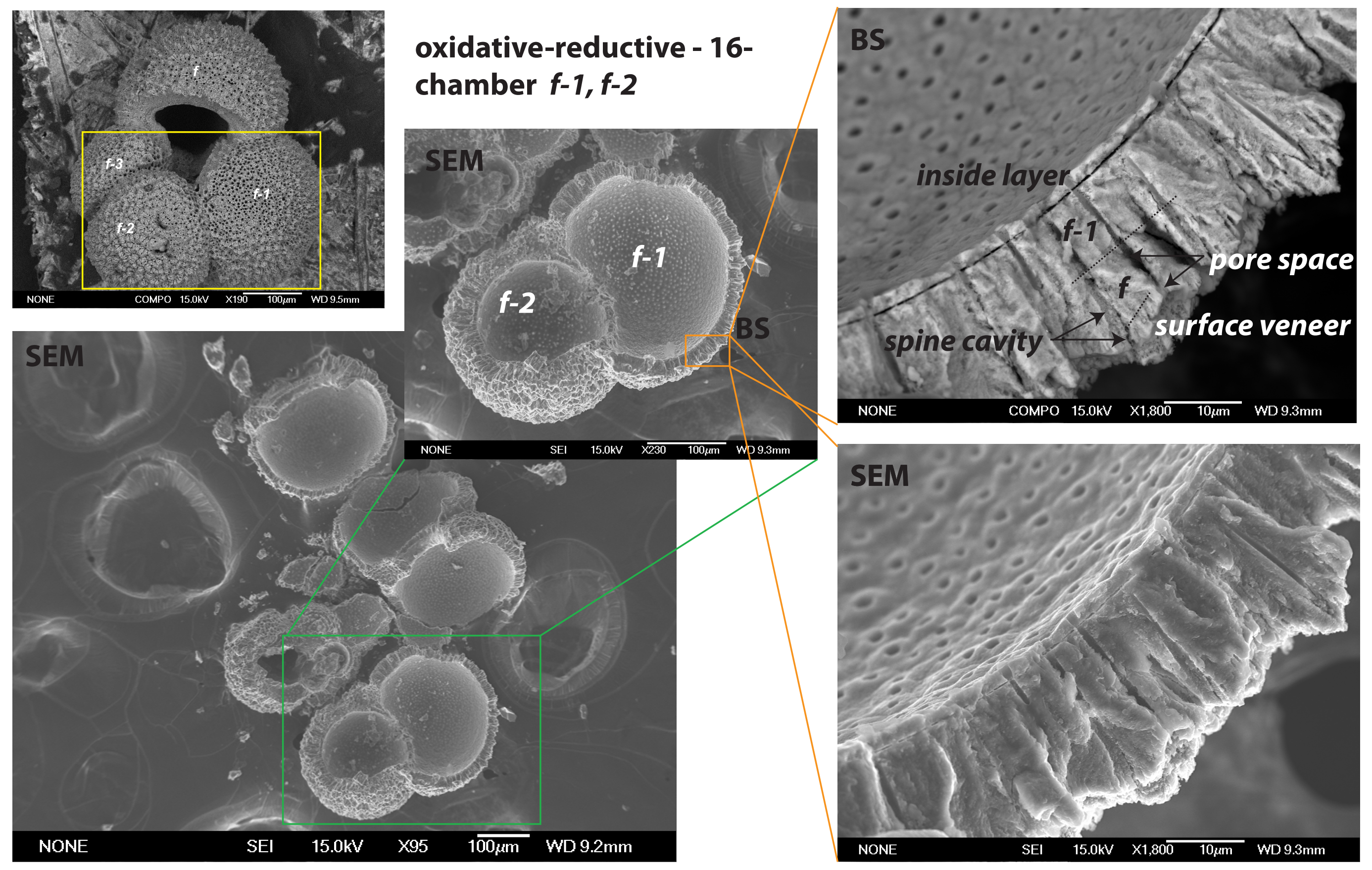

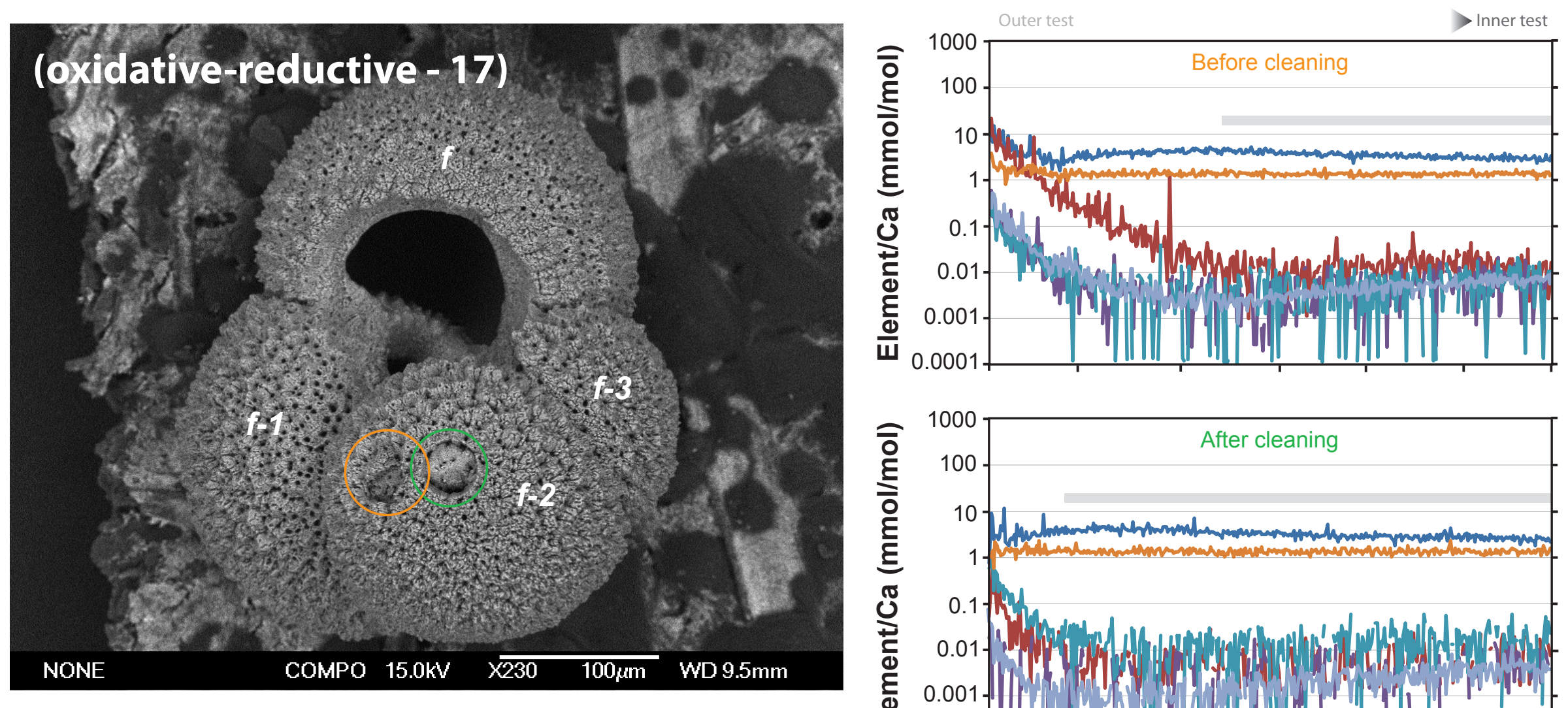

Key

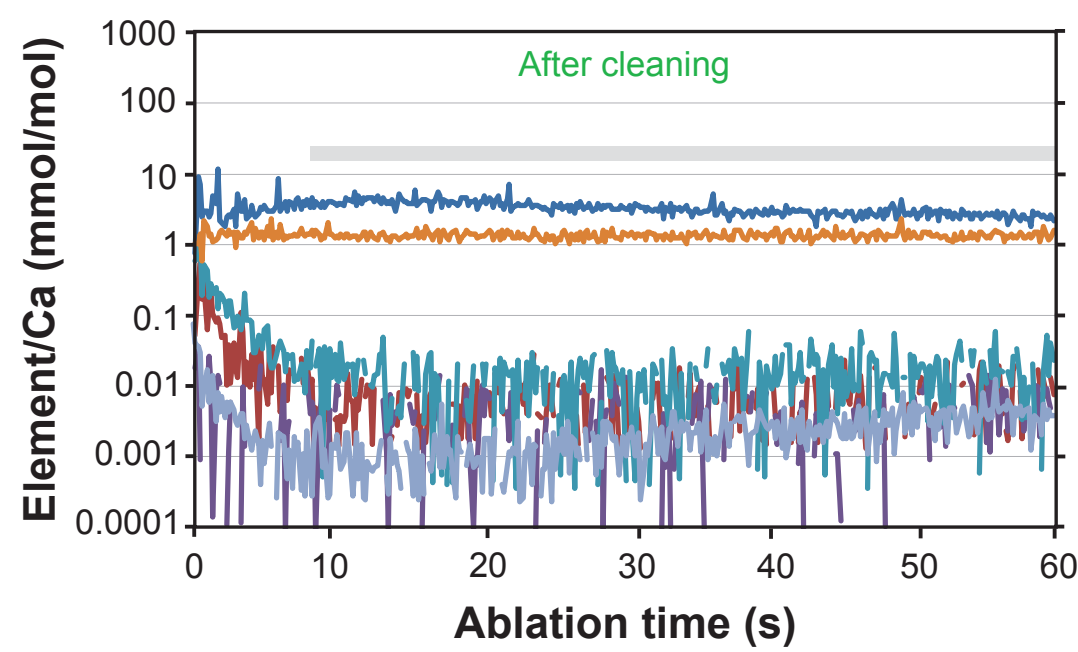

$\mathrm{Mg} / \mathrm{Ca}$

$\mathrm{Al} / \mathrm{Ca}$

$\mathrm{Mn} / \mathrm{Ca}$

$\mathrm{Zn} / \mathrm{Ca}$

$\mathrm{Sr} / \mathrm{Ca}$

$\mathrm{Ba} / \mathrm{Ca}$

integrated data

Image Ablation pits

Before

cleaning

After

cleaning

Ablation time (s)

Sample: Oxidative-Reductive - 17

\begin{tabular}{|c|c|c|c|c|c|c|}
\hline Before cleaning & $\begin{array}{c}\mathrm{Mg} / \mathrm{Ca} \\
(\mathrm{mmol} / \mathrm{mol})\end{array}$ & $\begin{array}{c}\mathrm{Al} / \mathrm{Ca} \\
(\mathrm{mmol} / \mathrm{mol})\end{array}$ & $\begin{array}{c}\mathrm{Mn} / \mathrm{Ca} \\
(\mathrm{mmol} / \mathrm{mol})\end{array}$ & $\begin{array}{c}\mathrm{Zn} / \mathrm{Ca} \\
\text { (mmol/mol) }\end{array}$ & $\begin{array}{c}\mathrm{Sr} / \mathrm{Ca} \\
(\mathrm{mmol} / \mathrm{mol})\end{array}$ & $\begin{array}{c}\mathrm{Ba} / \mathrm{Ca} \\
(\mathrm{mmol} / \mathrm{mol})\end{array}$ \\
\hline intergrated profile mean & 3.52 & 0.019 & 0.004 & 0.004 & 1.31 & 0.004 \\
\hline 2 sd & 1.16 & 0.148 & 0.009 & 0.010 & 0.23 & 0.004 \\
\hline \multicolumn{7}{|l|}{ After cleaning } \\
\hline intergrated profile mean & 3.24 & 0.003 & 0.001 & 0.010 & 1.31 & 0.002 \\
\hline 2 sd & 1.25 & 0.013 & 0.011 & 0.024 & 0.30 & 0.002 \\
\hline \multicolumn{7}{|l|}{ Difference } \\
\hline mean & 0.28 & 0.016 & 0.003 & -0.006 & 0.00 & 0.002 \\
\hline
\end{tabular}



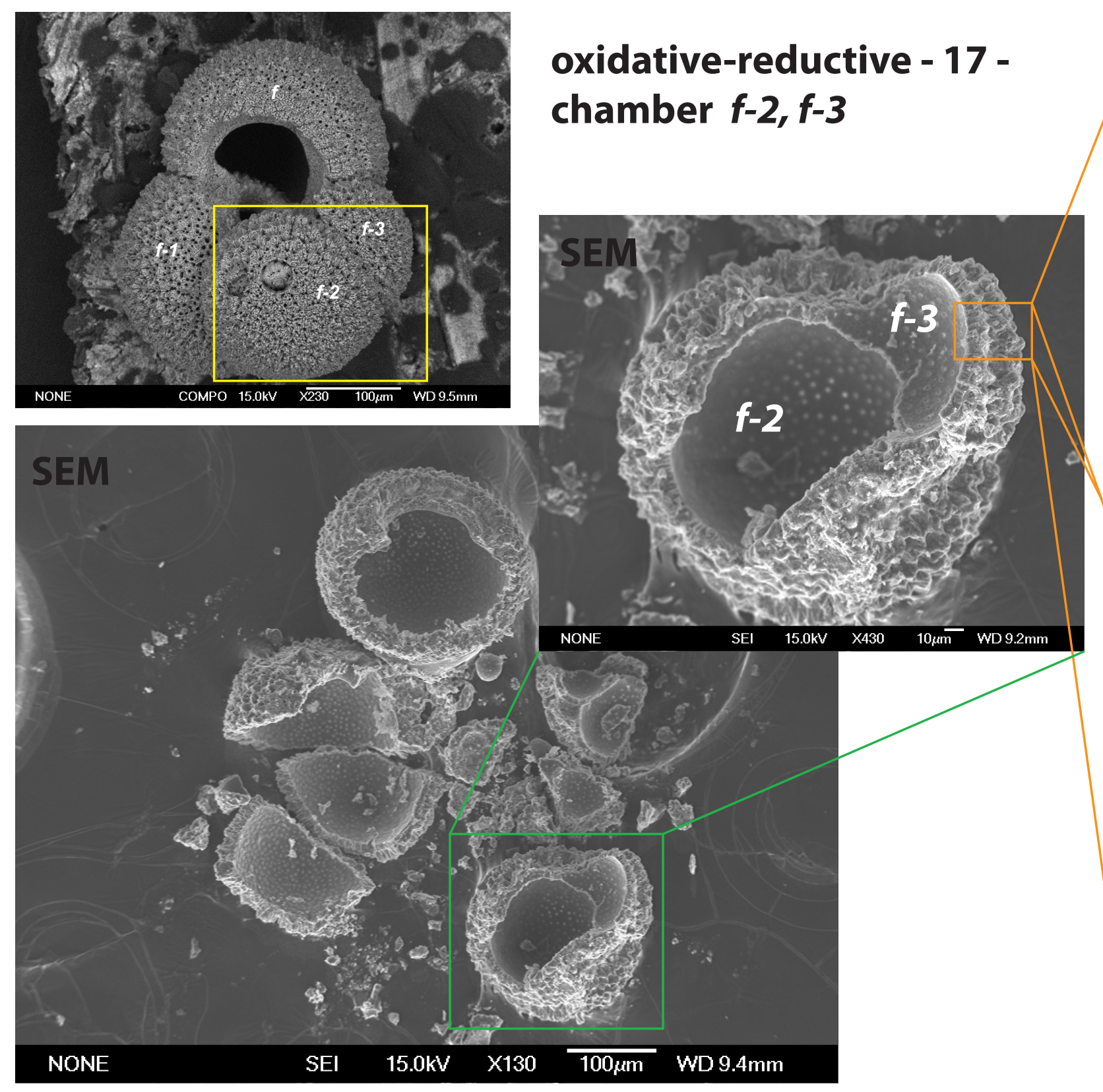

oxidative-reductive - 17 chamber $f-2, f-3$

\section{BS}

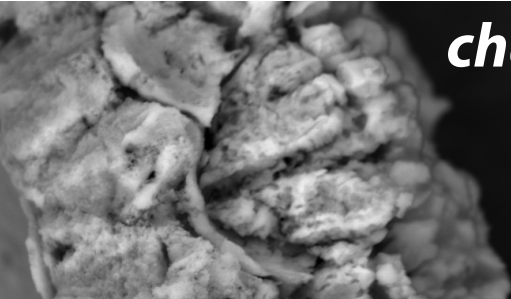

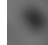

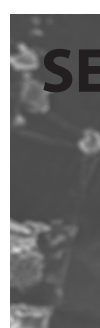

4.

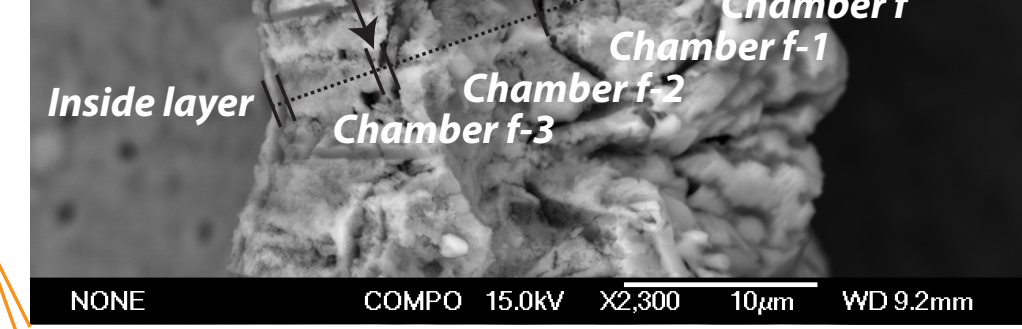

COMPO 15.0kV $\times 2,300 \quad 10 \mu \mathrm{m} \quad$ WD $9.2 \mathrm{~mm}$

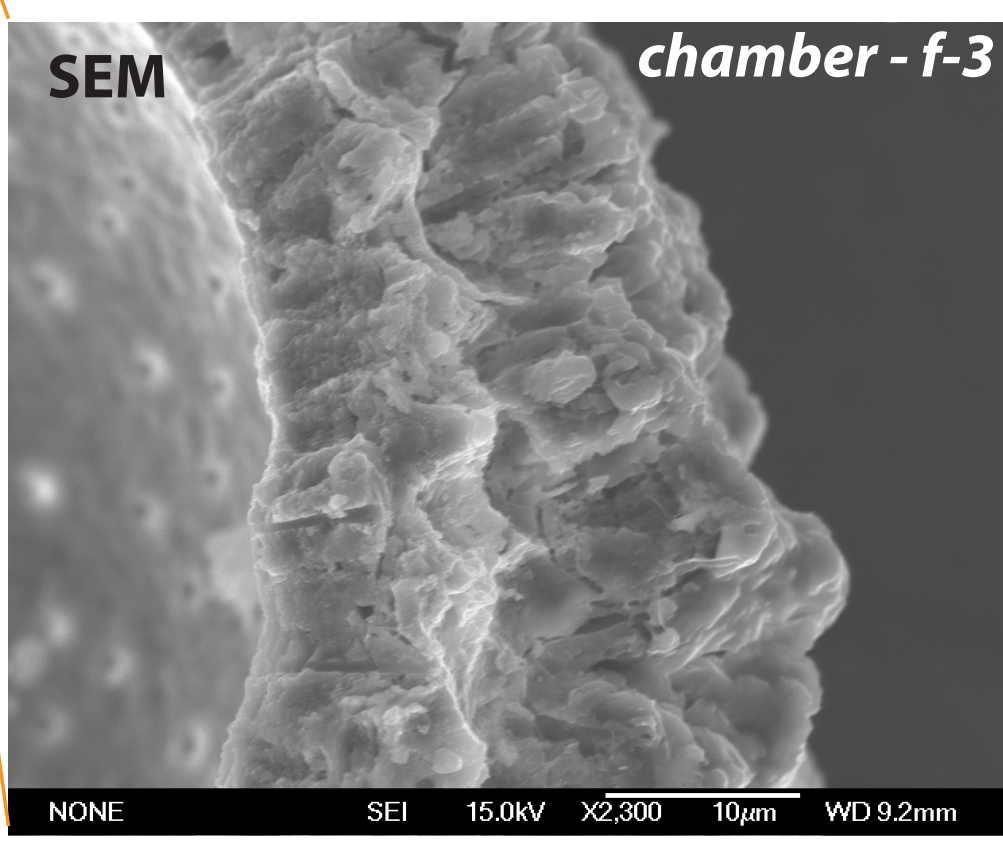



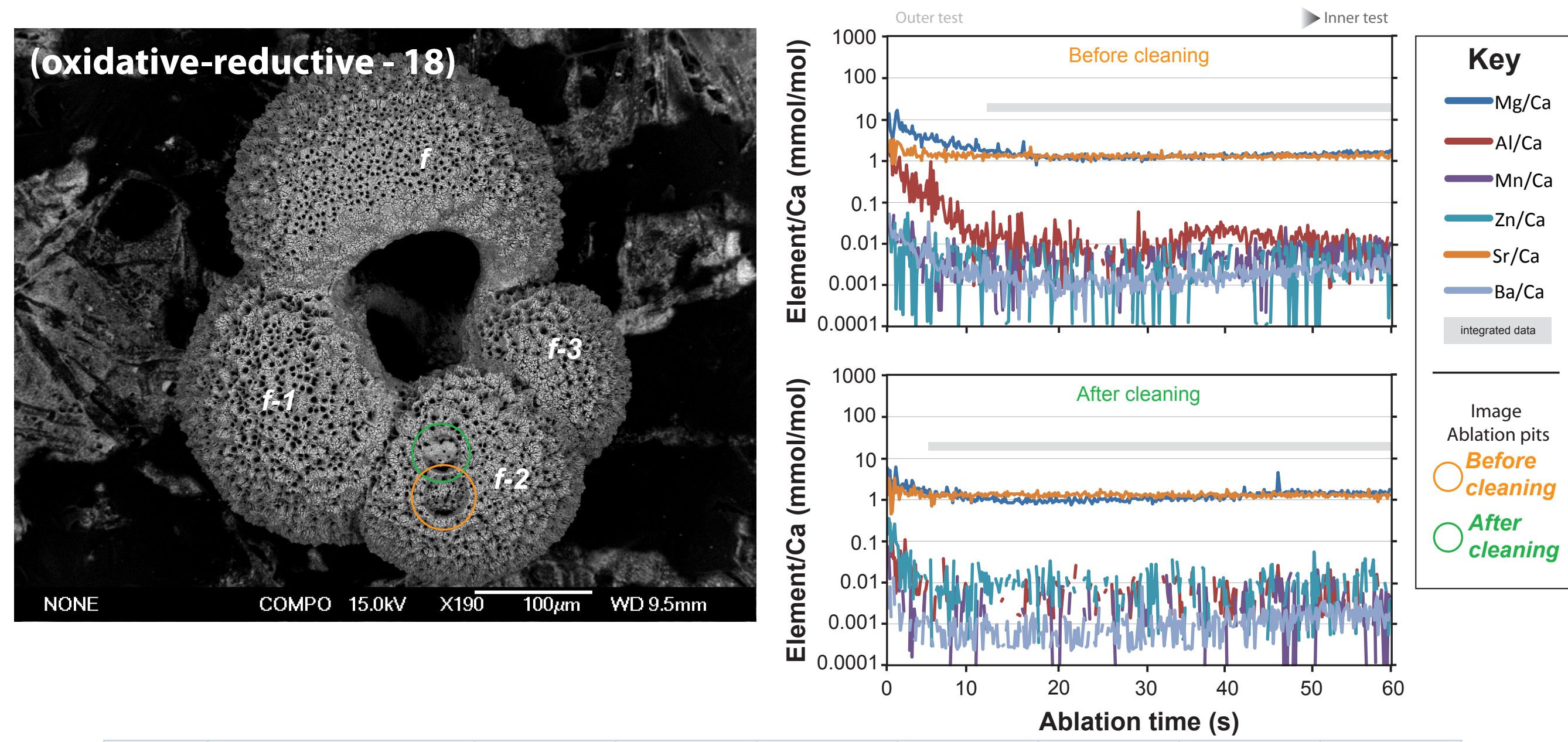

Image Ablation pits Before

cleaning

After

cleaning

Ablation time (s)

\begin{tabular}{|c|c|c|c|c|c|c|c|}
\hline \multicolumn{8}{|c|}{ Sample: Oxidative-Reductive - 18} \\
\hline \multicolumn{2}{|c|}{ Before cleaning } & $\begin{array}{c}\mathrm{Mg} / \mathrm{Ca} \\
(\mathrm{mmol} / \mathrm{mol})\end{array}$ & $\begin{array}{c}\mathrm{Al} / \mathrm{Ca} \\
(\mathrm{mmol} / \mathrm{mol})\end{array}$ & $\begin{array}{c}\mathrm{Mn} / \mathrm{Ca} \\
(\mathrm{mmol} / \mathrm{mol})\end{array}$ & $\begin{array}{c}\mathrm{Zn} / \mathrm{Ca} \\
(\mathrm{mmol} / \mathrm{mol})\end{array}$ & $\begin{array}{c}\mathrm{Sr} / \mathrm{Ca} \\
(\mathrm{mmol} / \mathrm{mol})\end{array}$ & $\begin{array}{c}\mathrm{Ba} / \mathrm{Ca} \\
(\mathrm{mmol} / \mathrm{mol})\end{array}$ \\
\hline & intergrated profile mean & 1.34 & 0.011 & 0.003 & 0.001 & 1.29 & 0.002 \\
\hline & 2 sd & 0.41 & 0.019 & 0.009 & 0.009 & 0.24 & 0.002 \\
\hline \multicolumn{8}{|c|}{ After cleaning } \\
\hline & intergrated profile mean & 1.03 & 0.002 & 0.000 & 0.003 & 1.30 & 0.001 \\
\hline & 2 sd & 0.32 & 0.013 & 0.012 & 0.020 & 0.25 & 0.002 \\
\hline \multicolumn{8}{|c|}{ Difference } \\
\hline & mean & 0.31 & 0.010 & 0.004 & -0.002 & -0.01 & 0.001 \\
\hline
\end{tabular}



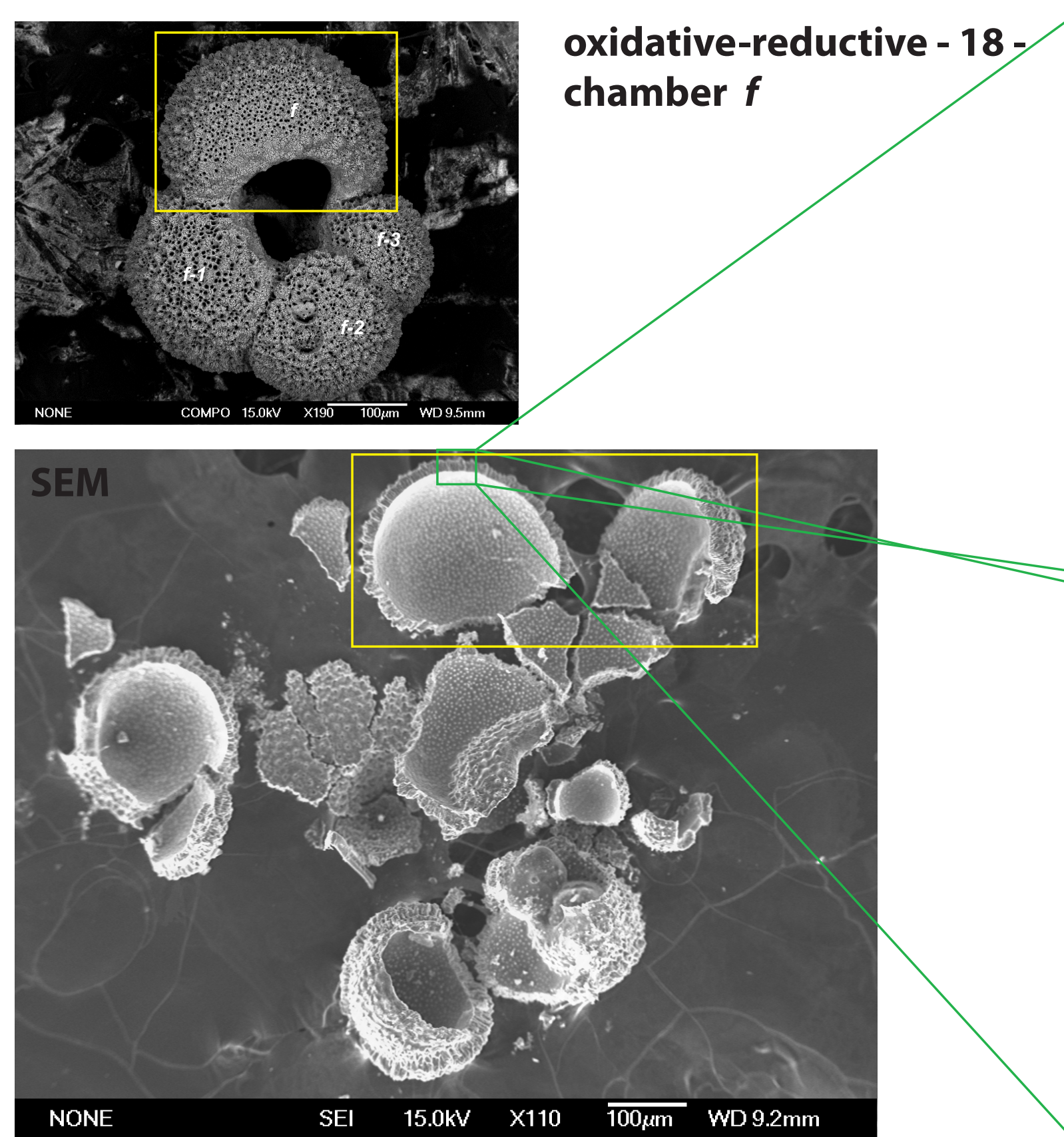

BS

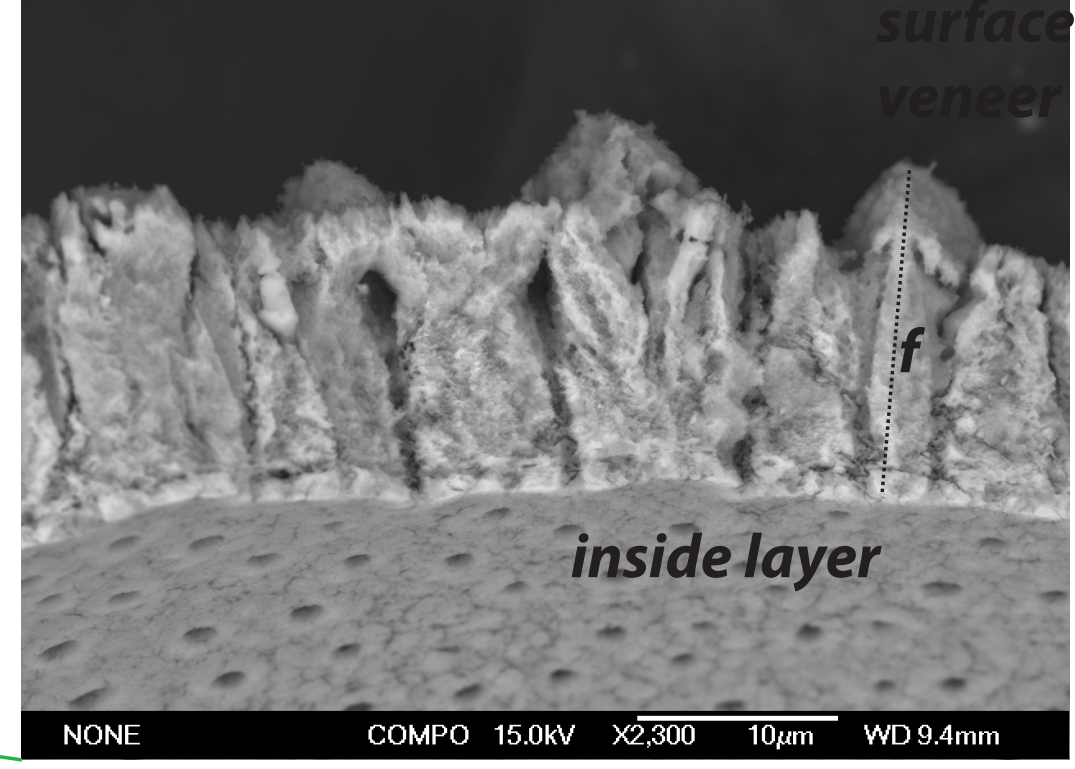

SEM 


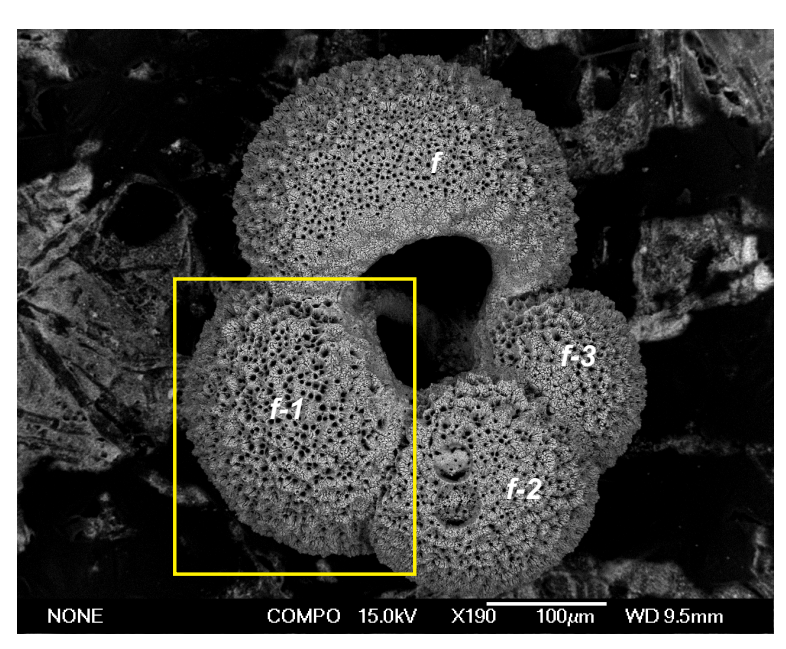

oxidative-reductive - 18 chamber $f-1$
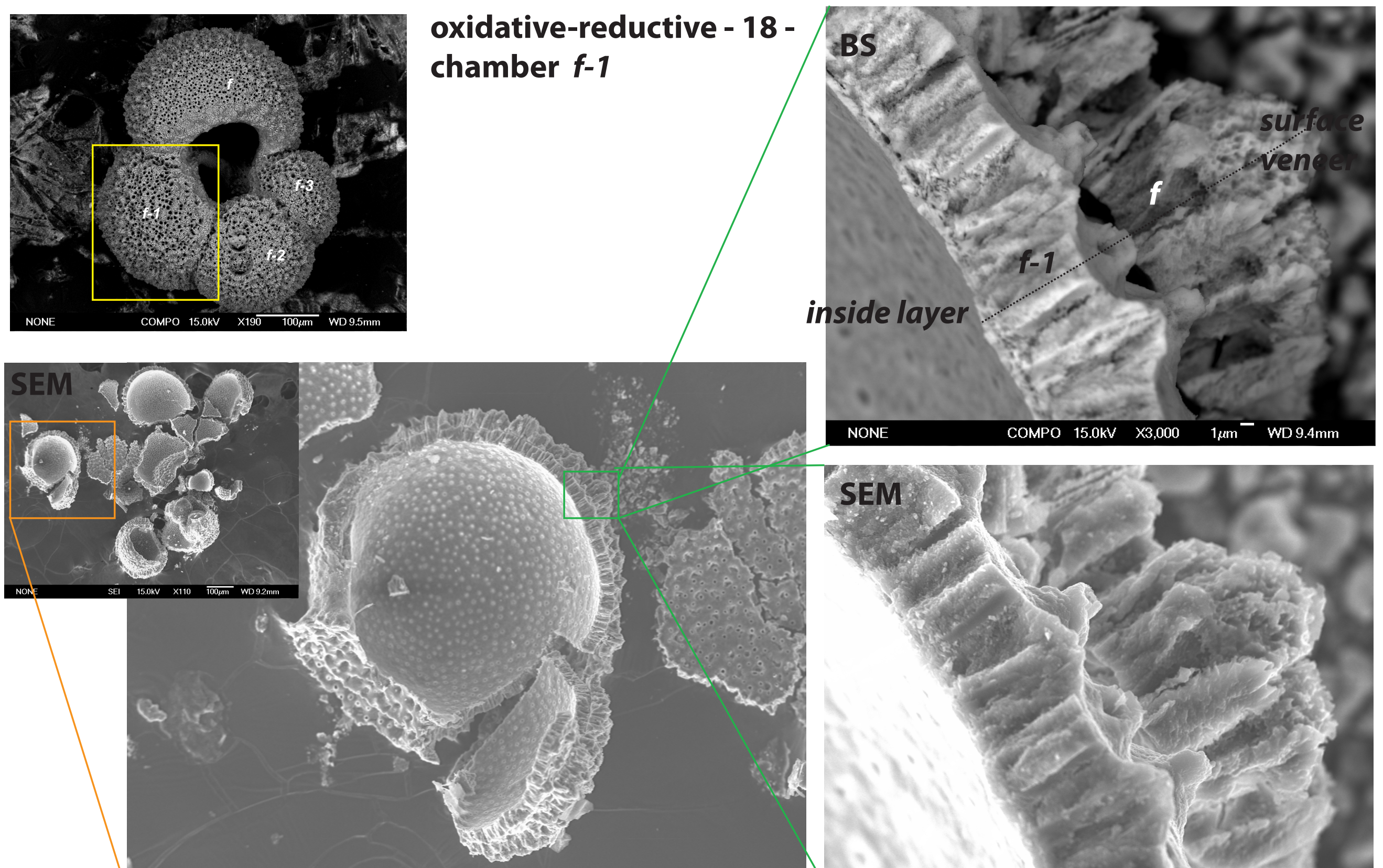

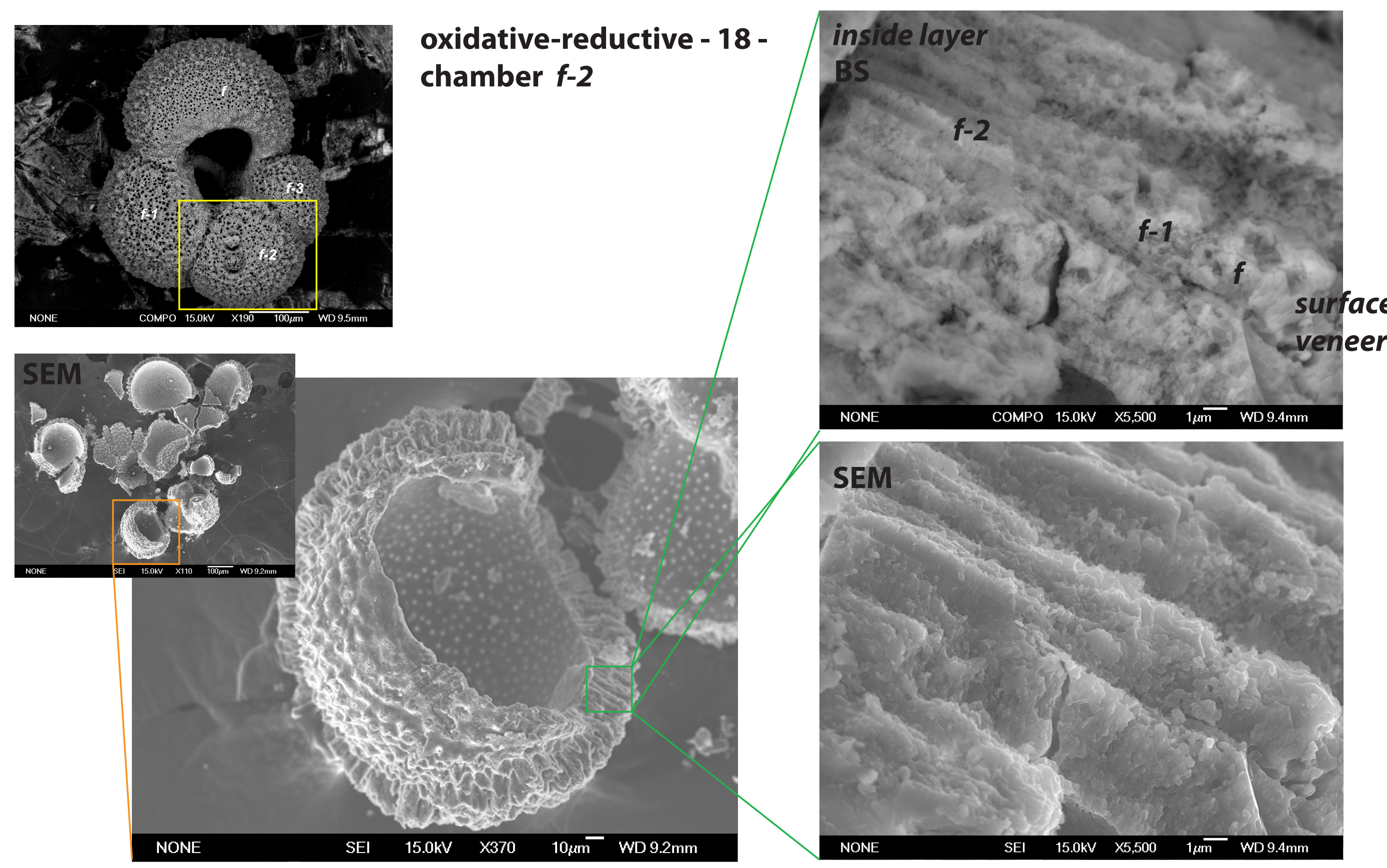


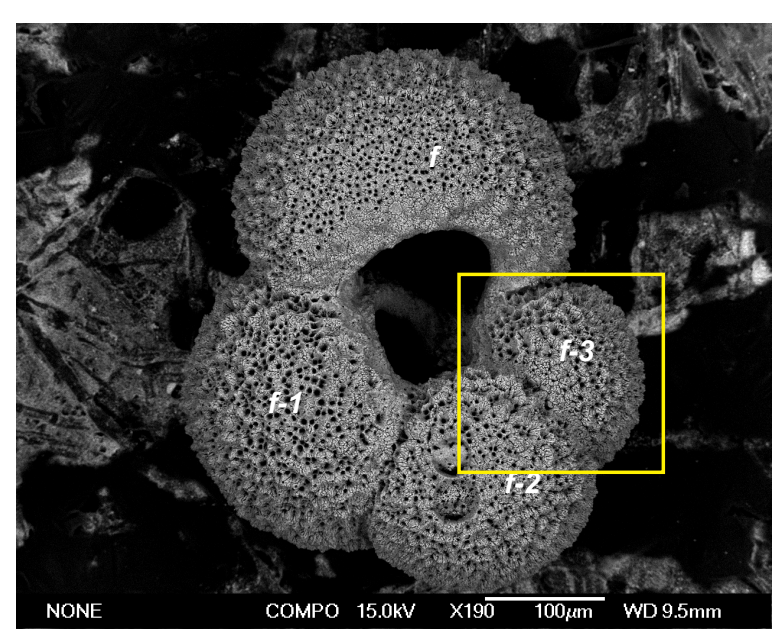
oxidative-reductive - 18 chamber $f-3$
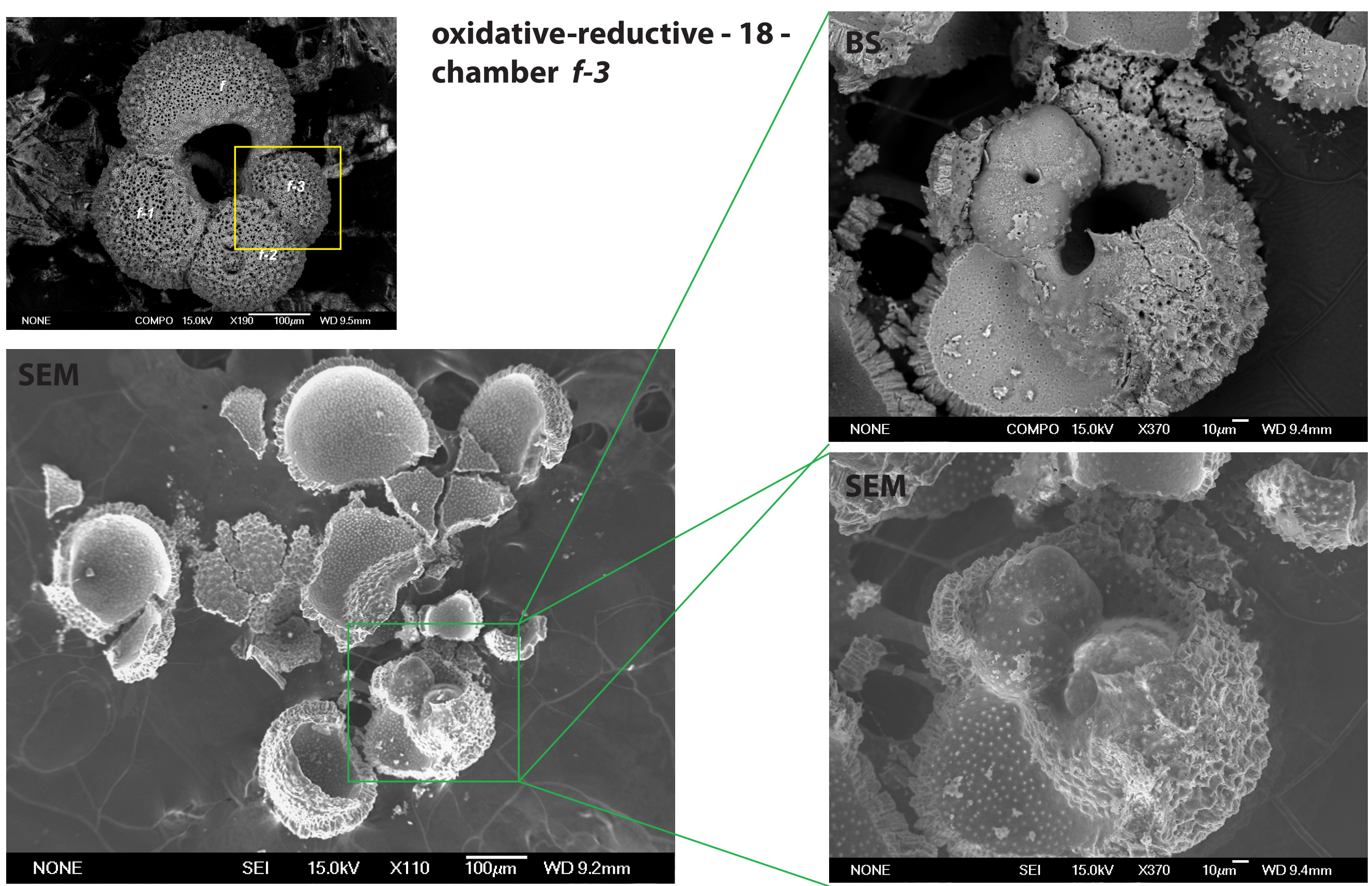


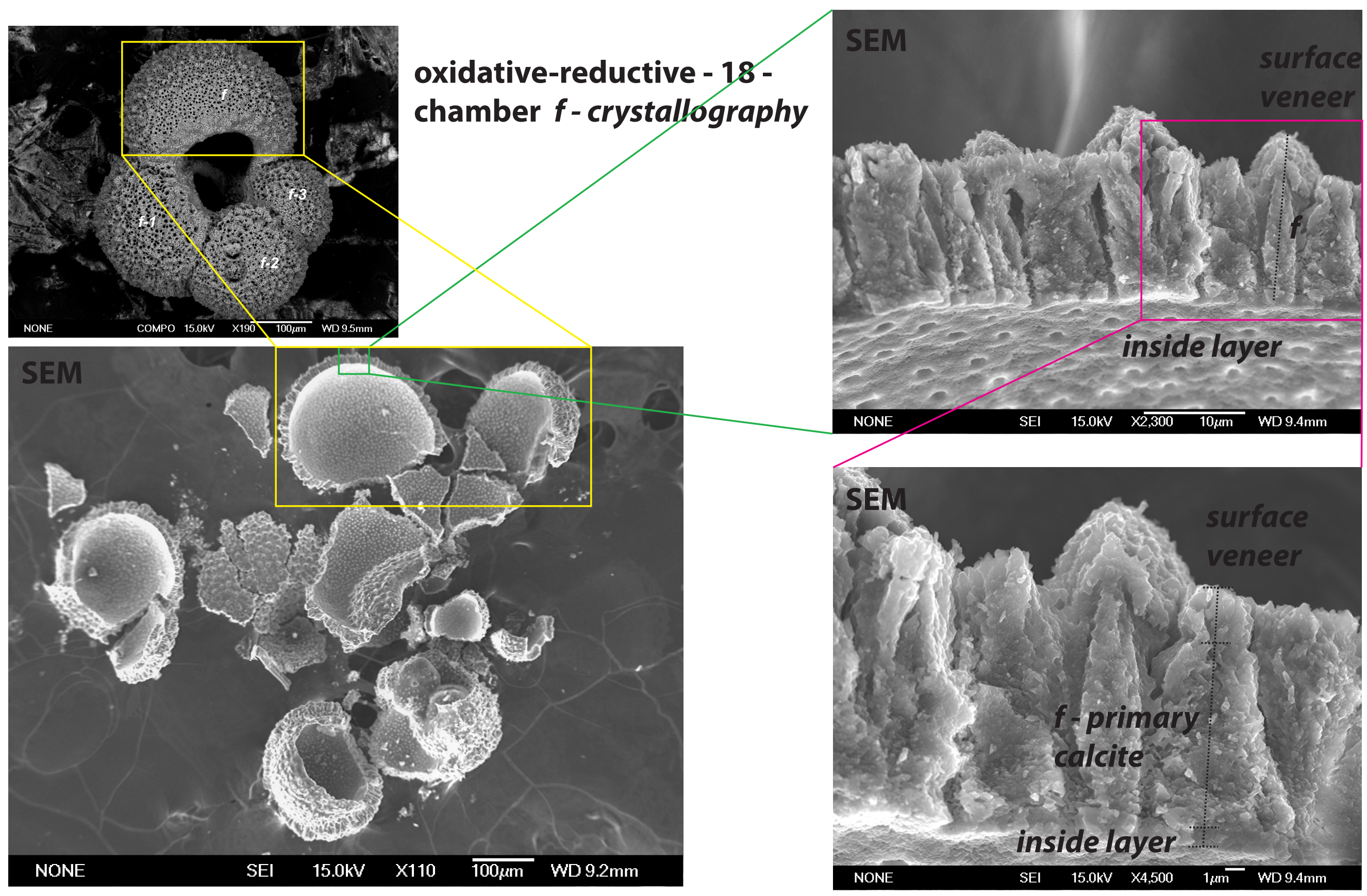




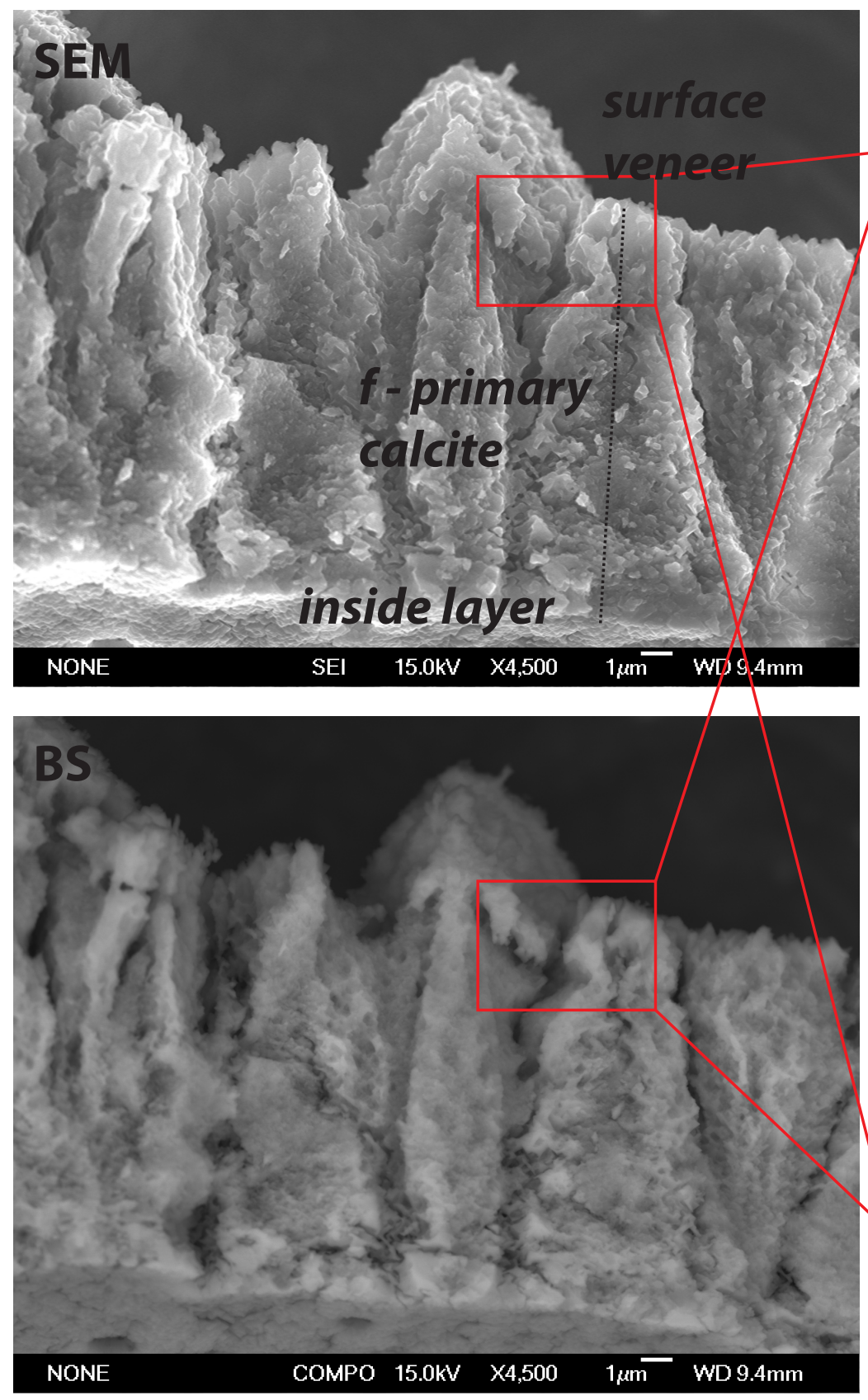

oxidative-reductive - 18 - chamber $f$-crystallography surface veneer

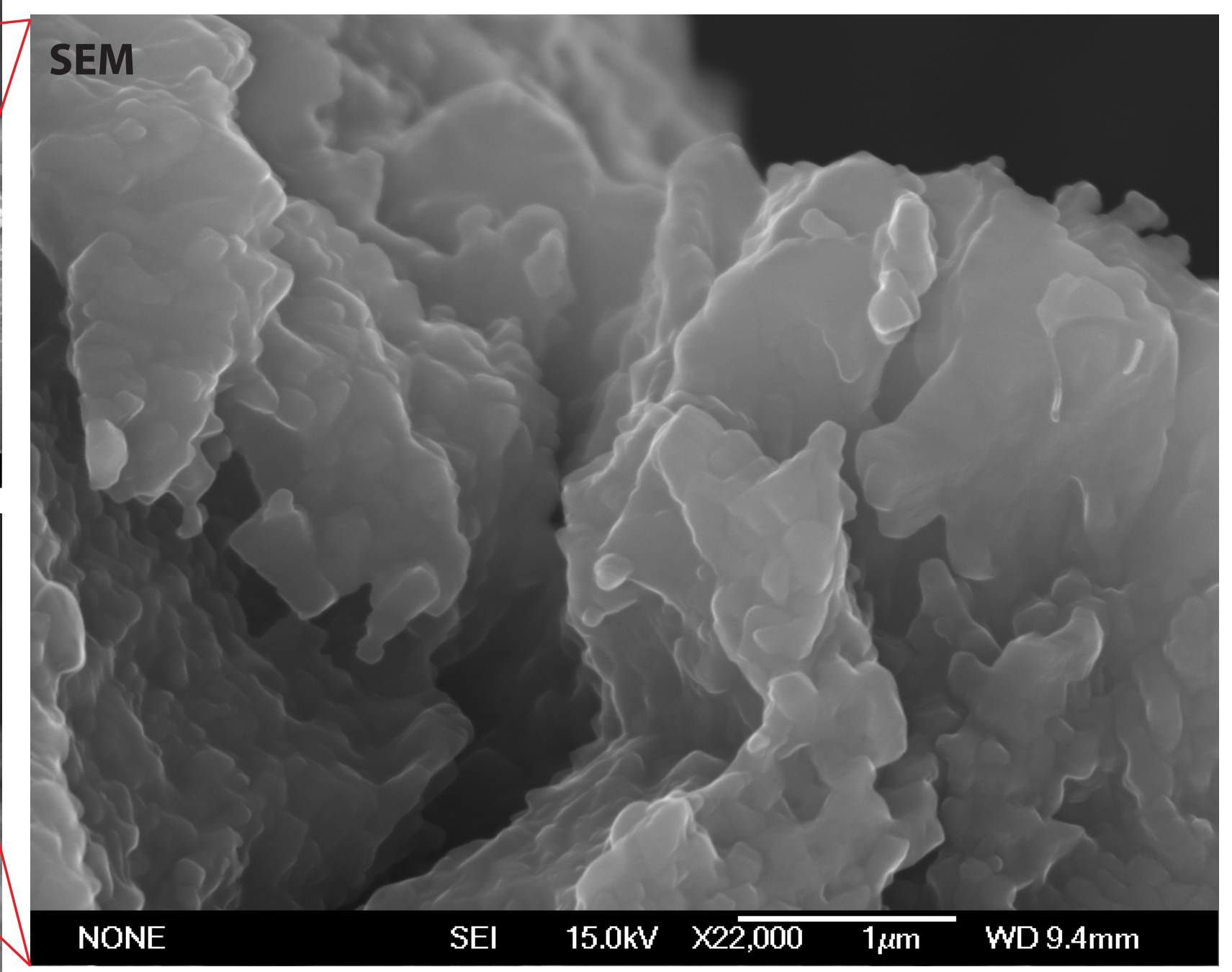




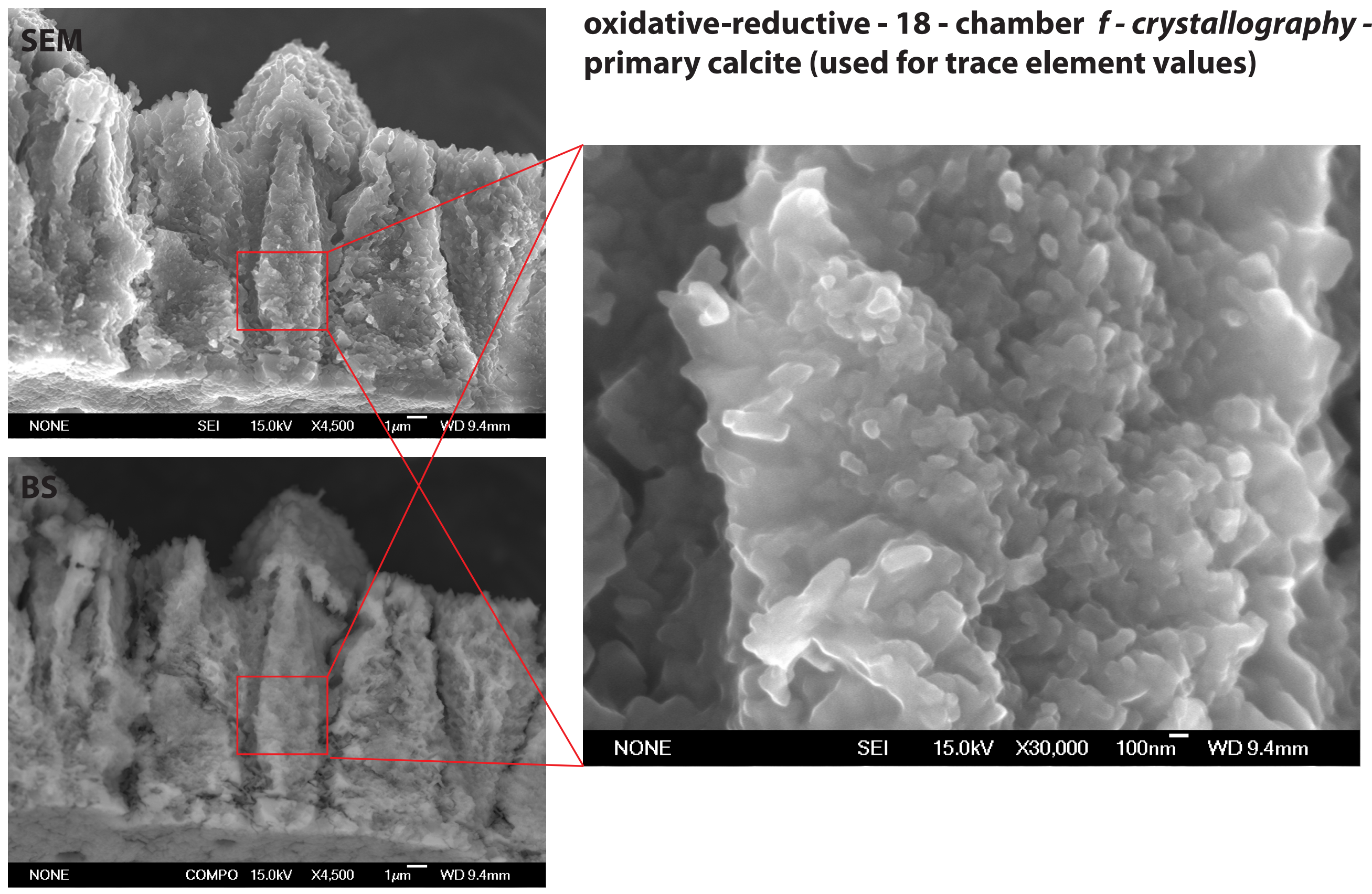




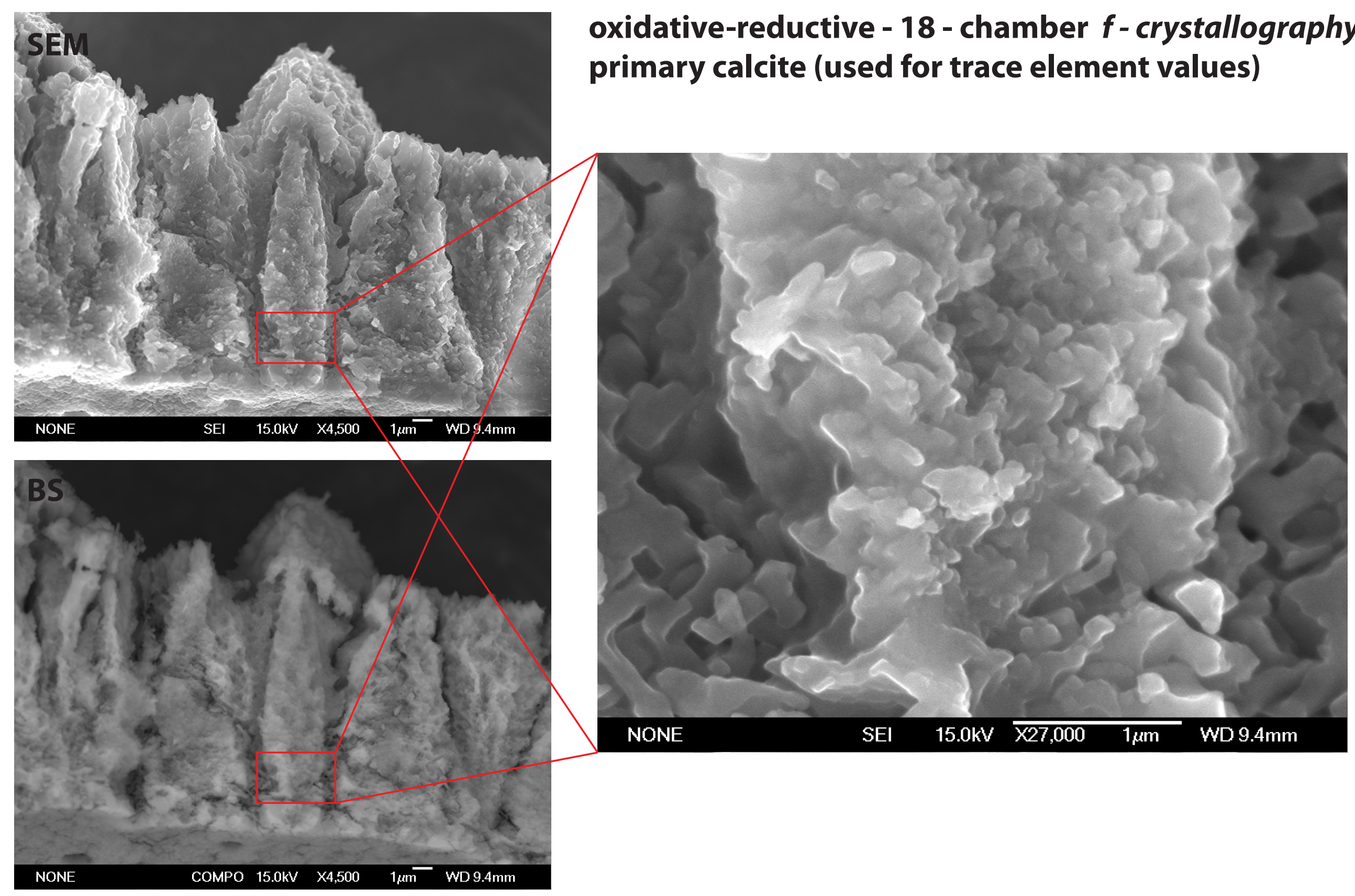




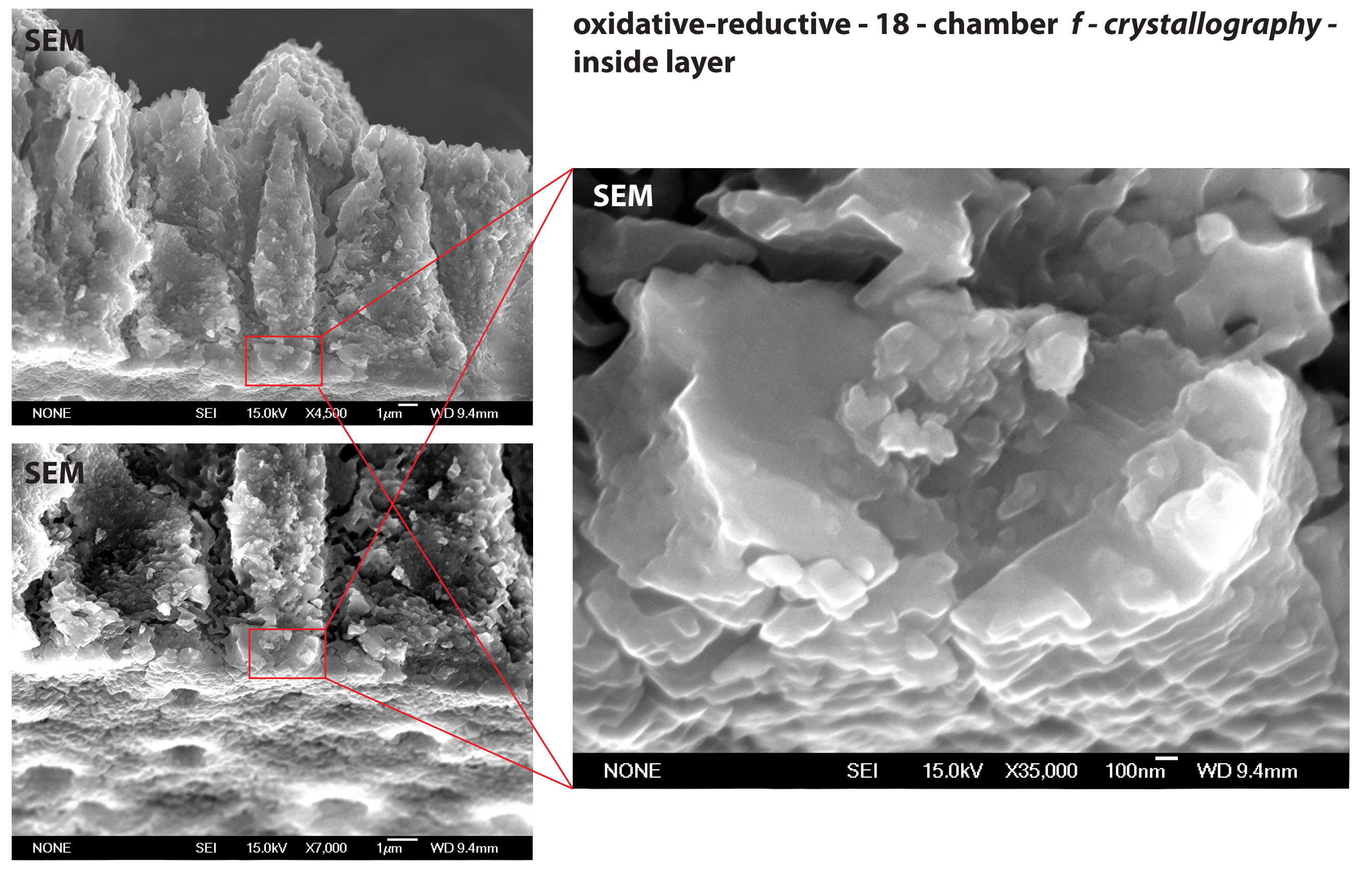



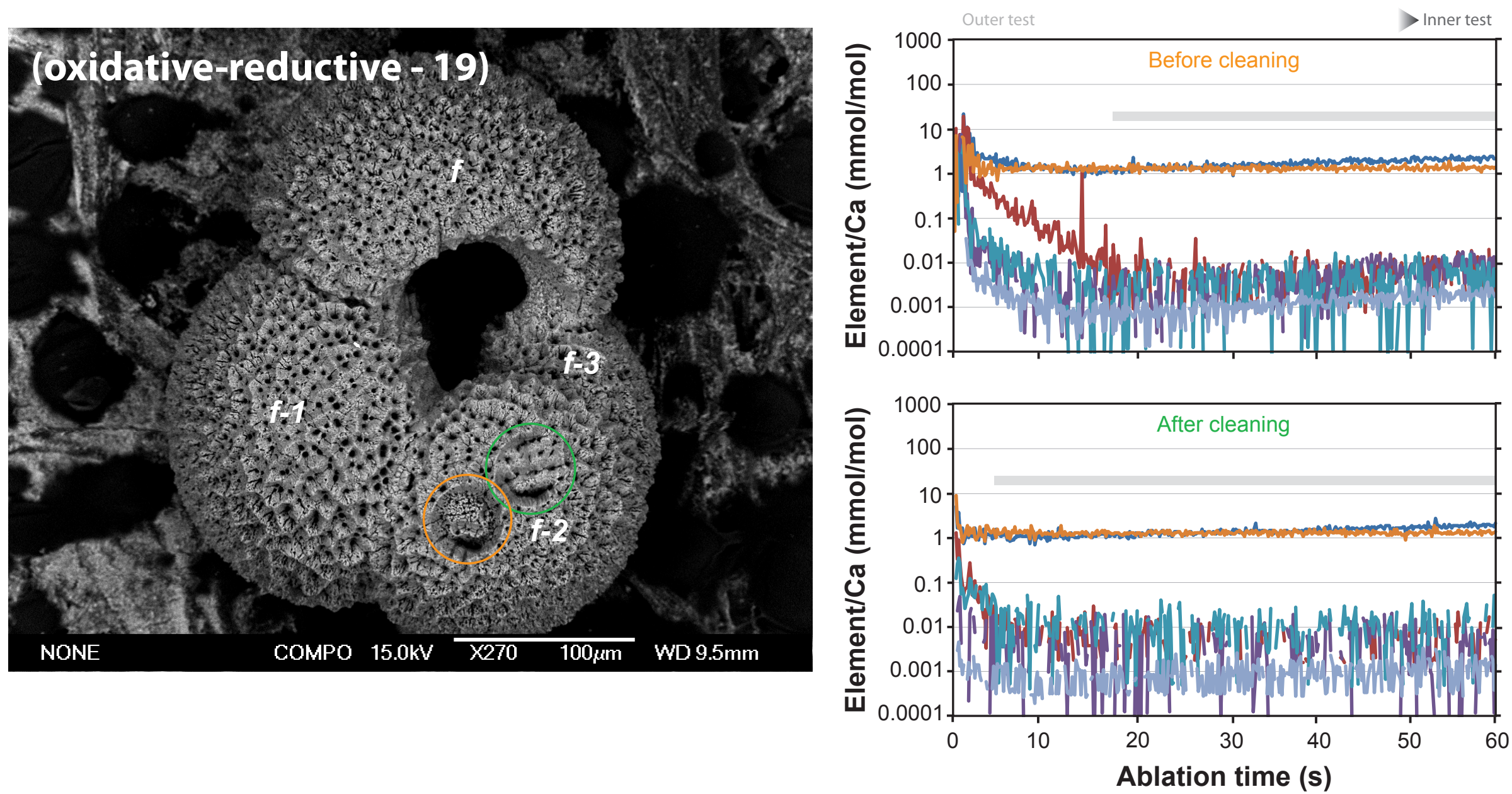

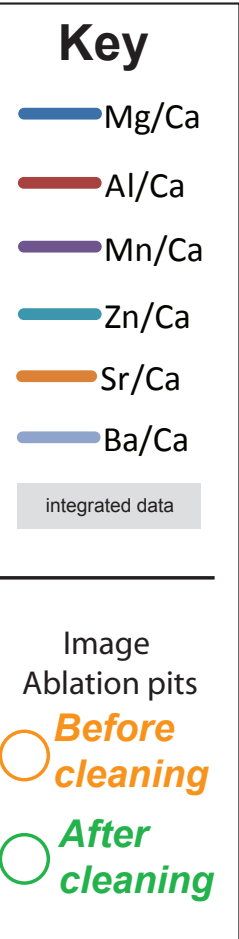

\begin{tabular}{|c|c|c|c|c|c|c|c|}
\hline \multicolumn{8}{|c|}{ Sample: Oxidative-Reductive - 19} \\
\hline \multicolumn{2}{|c|}{ Before cleaning } & $\begin{array}{c}\mathrm{Mg} / \mathrm{Ca} \\
(\mathrm{mmol} / \mathrm{mol})\end{array}$ & $\begin{array}{c}\mathrm{Al} / \mathrm{Ca} \\
(\mathrm{mmol} / \mathrm{mol})\end{array}$ & $\begin{array}{c}\mathrm{Mn} / \mathrm{Ca} \\
(\mathrm{mmol} / \mathrm{mol})\end{array}$ & $\begin{array}{c}\mathrm{Zn} / \mathrm{Ca} \\
(\mathrm{mmol} / \mathrm{mol})\end{array}$ & $\begin{array}{c}\mathrm{Sr} / \mathrm{Ca} \\
(\mathrm{mmol} / \mathrm{mol})\end{array}$ & $\begin{array}{c}\mathrm{Ba} / \mathrm{Ca} \\
(\mathrm{mmol} / \mathrm{mol})\end{array}$ \\
\hline & intergrated profile mean & 1.67 & 0.005 & 0.005 & 0.003 & 1.31 & 0.001 \\
\hline & 2 sd & 0.70 & 0.014 & 0.009 & 0.009 & 0.26 & 0.001 \\
\hline \multicolumn{8}{|c|}{ After cleaning } \\
\hline & intergrated profile mean & 1.39 & 0.001 & 0.002 & 0.005 & 1.28 & 0.001 \\
\hline & 2 sd & 0.43 & 0.013 & 0.014 & 0.024 & 0.23 & 0.001 \\
\hline \multicolumn{8}{|c|}{ Difference } \\
\hline & mean & 0.28 & 0.004 & 0.002 & -0.002 & 0.02 & 0.001 \\
\hline
\end{tabular}




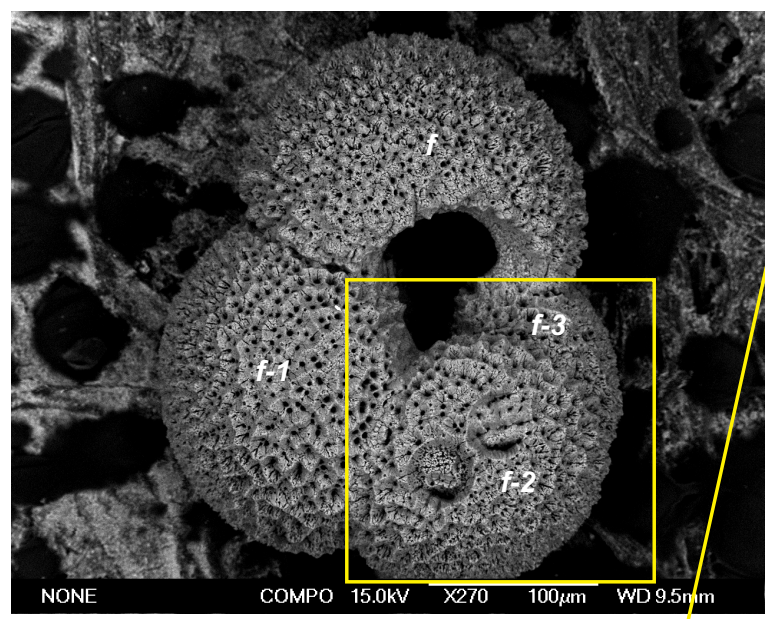

oxidative-reductive - 19 - chamber $f-2$
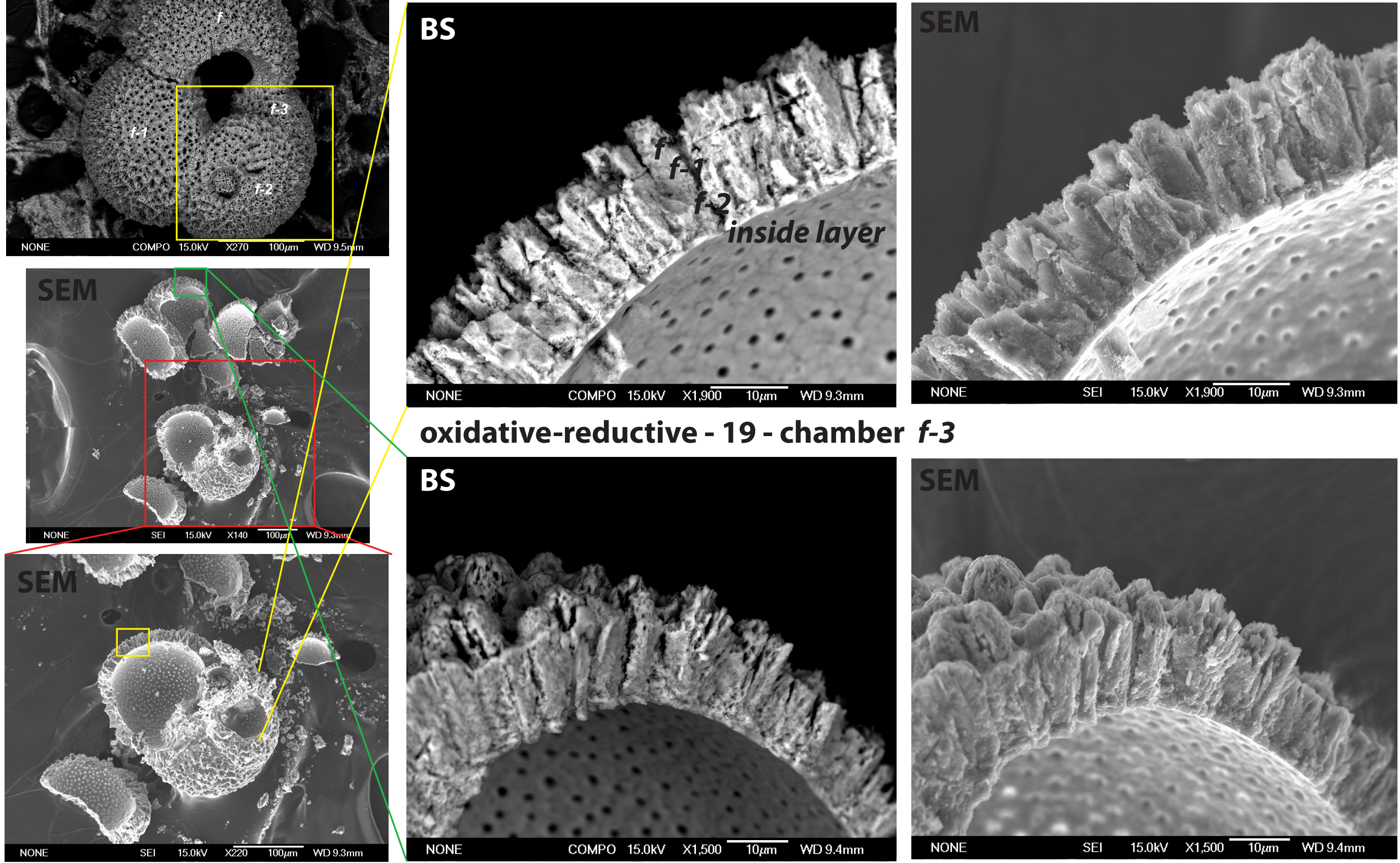

oxidative-reductive - 19 - chamber $f-3$

BS

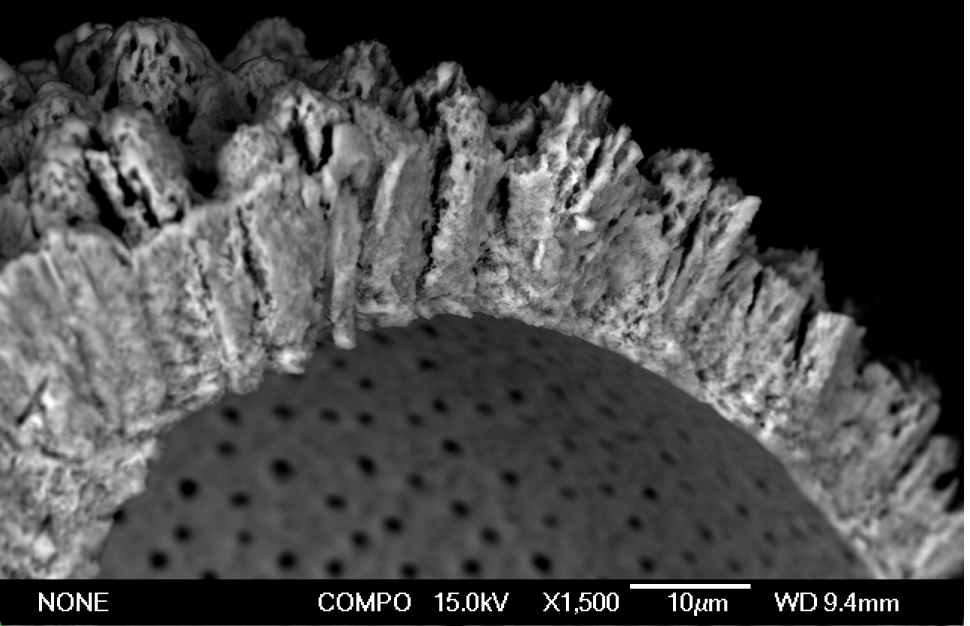

SEM

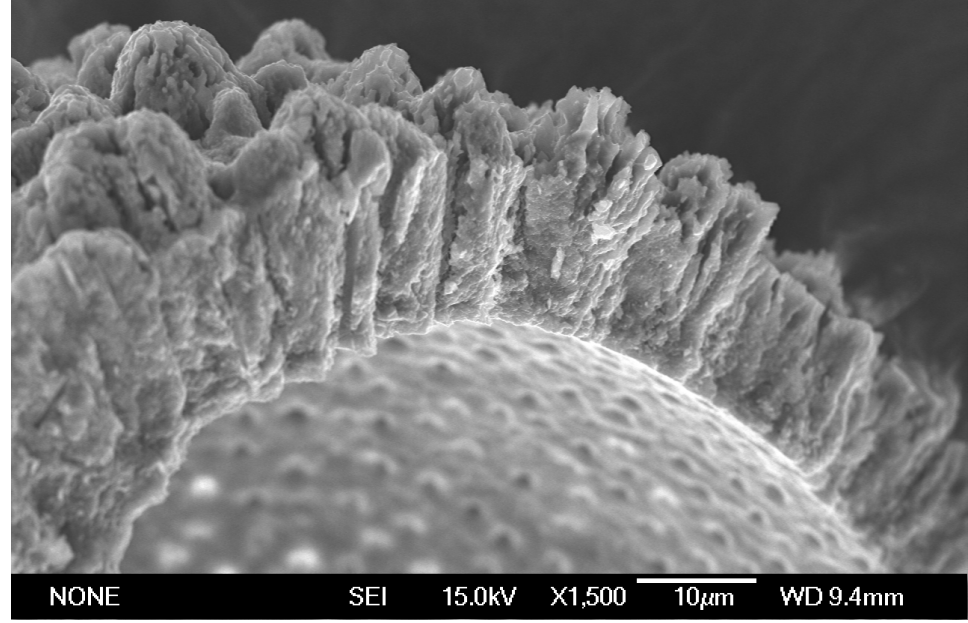




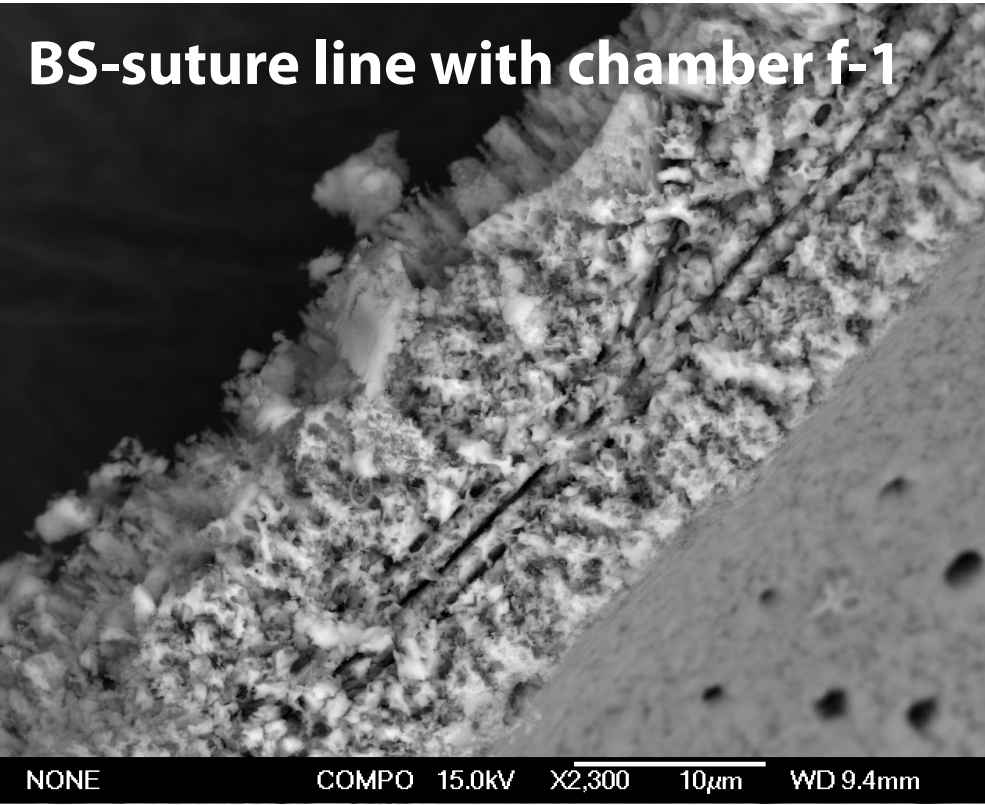

SEM-suture line with chamber $\mathrm{f}-1$

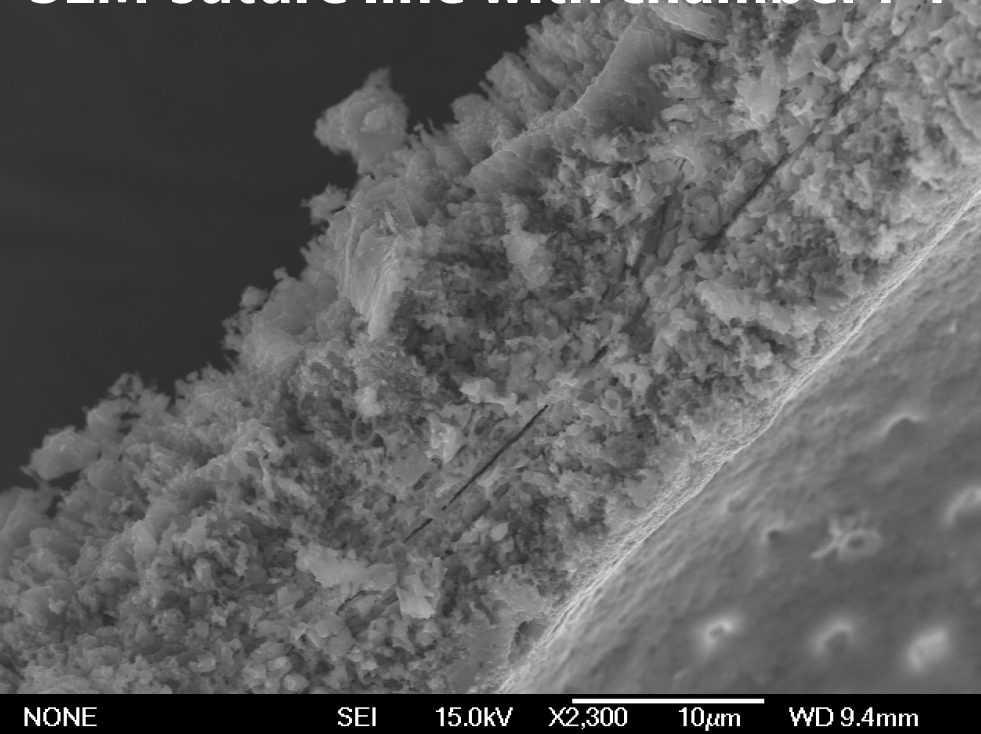

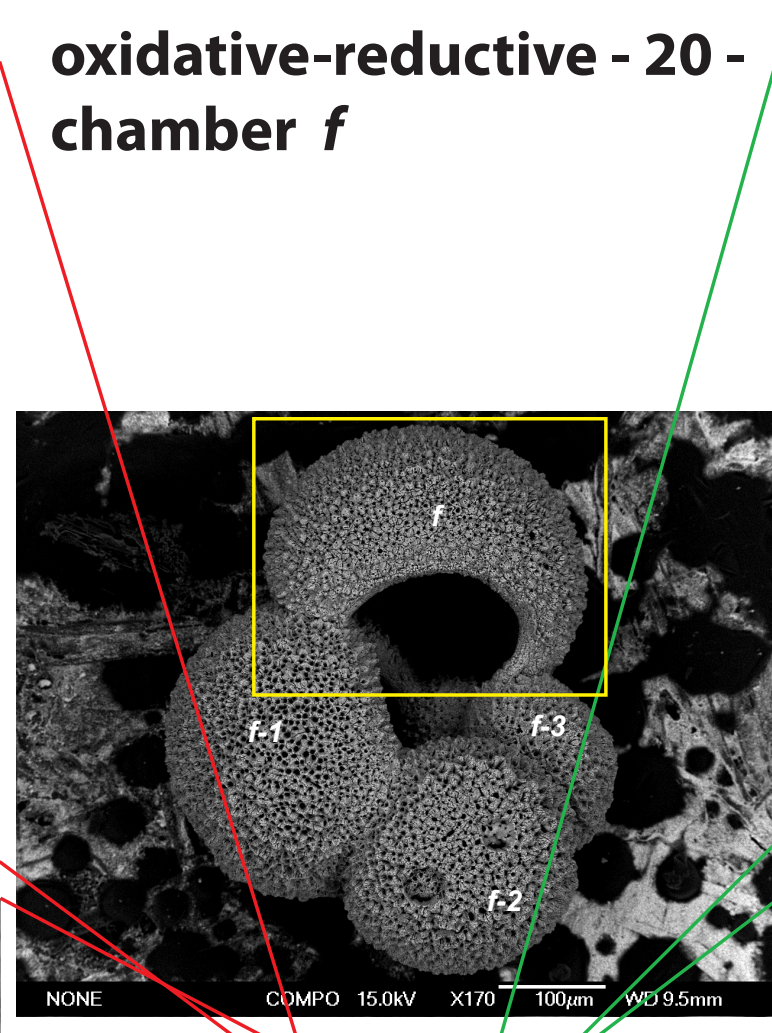
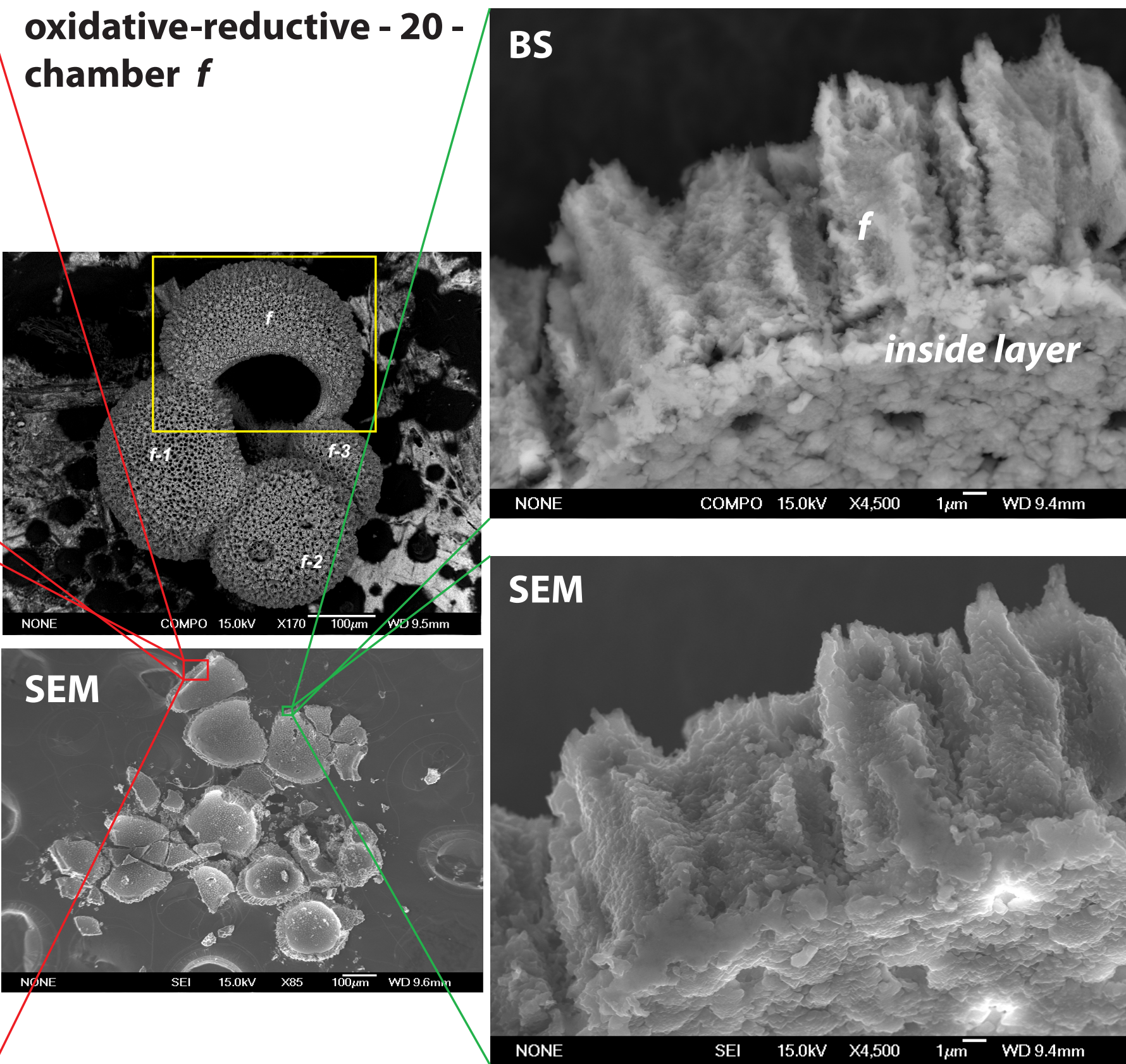

\section{SEM}

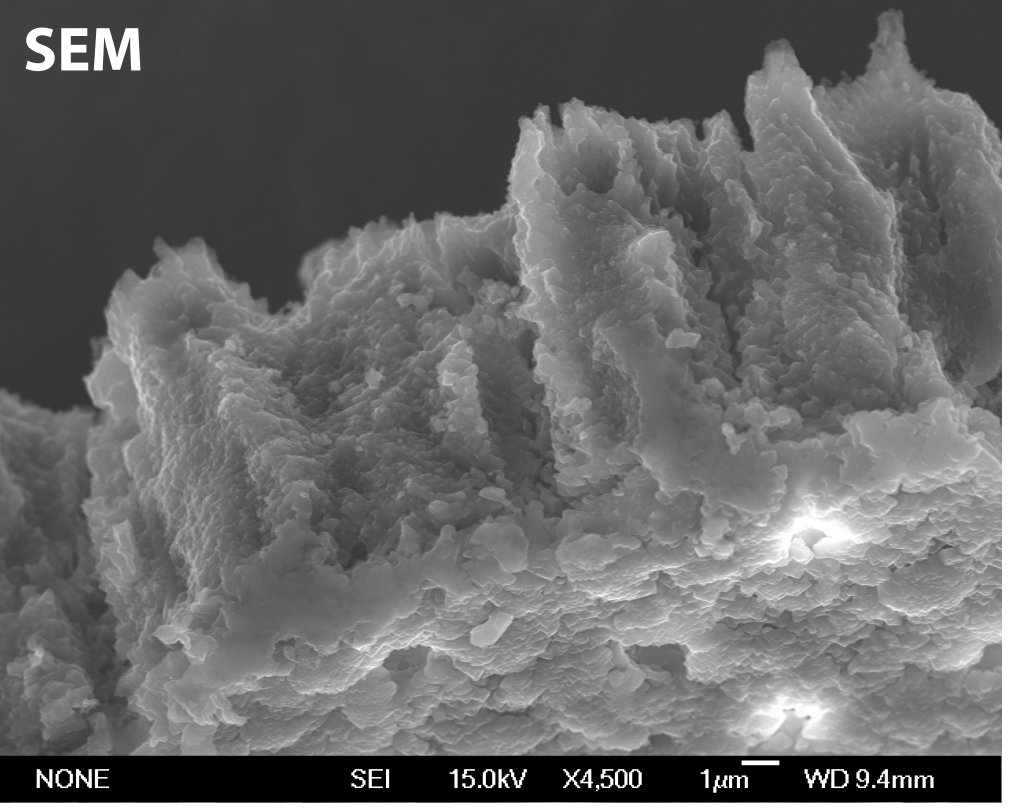



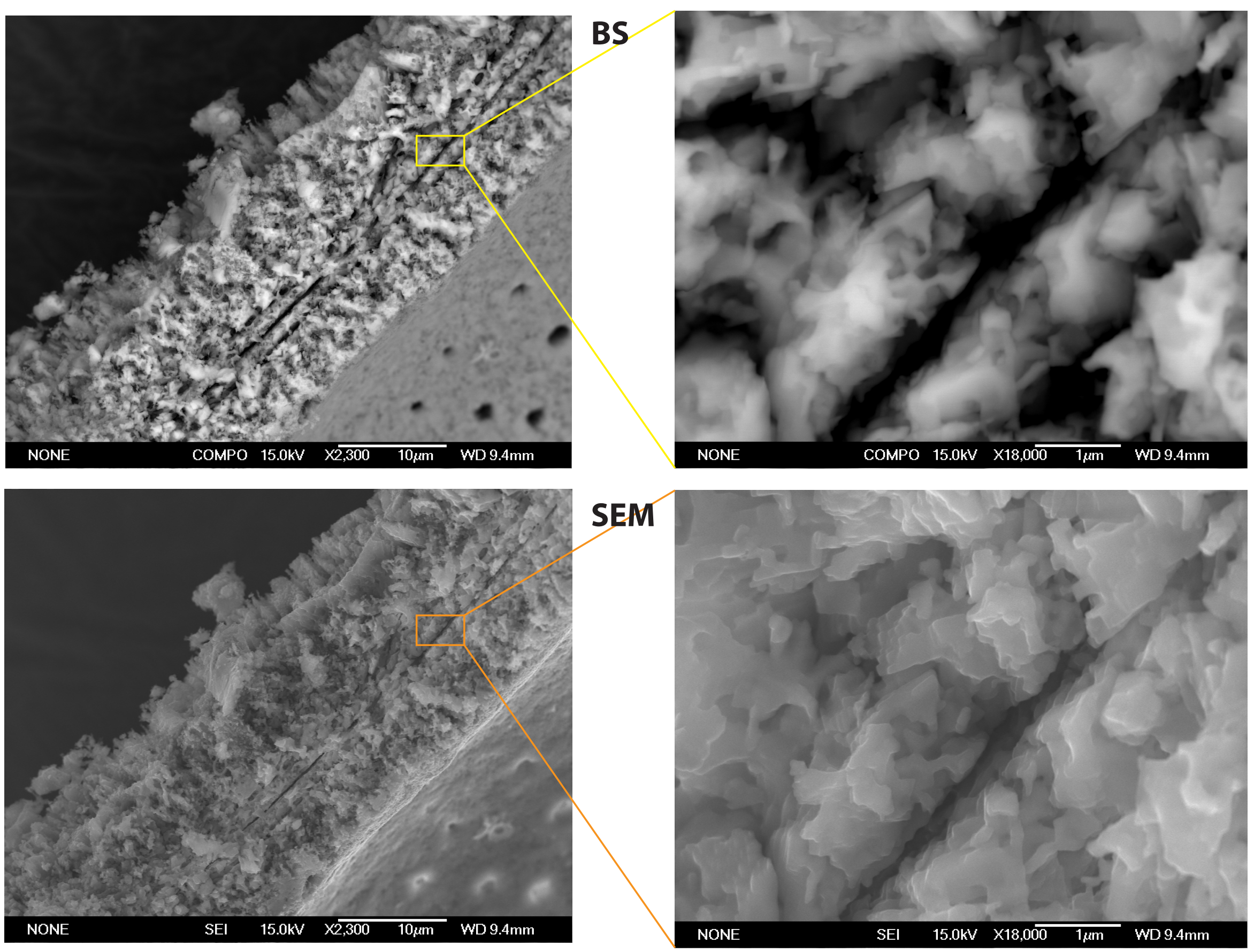

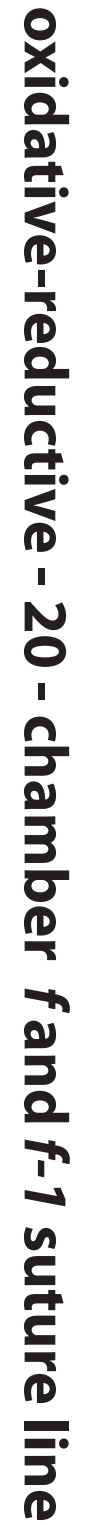



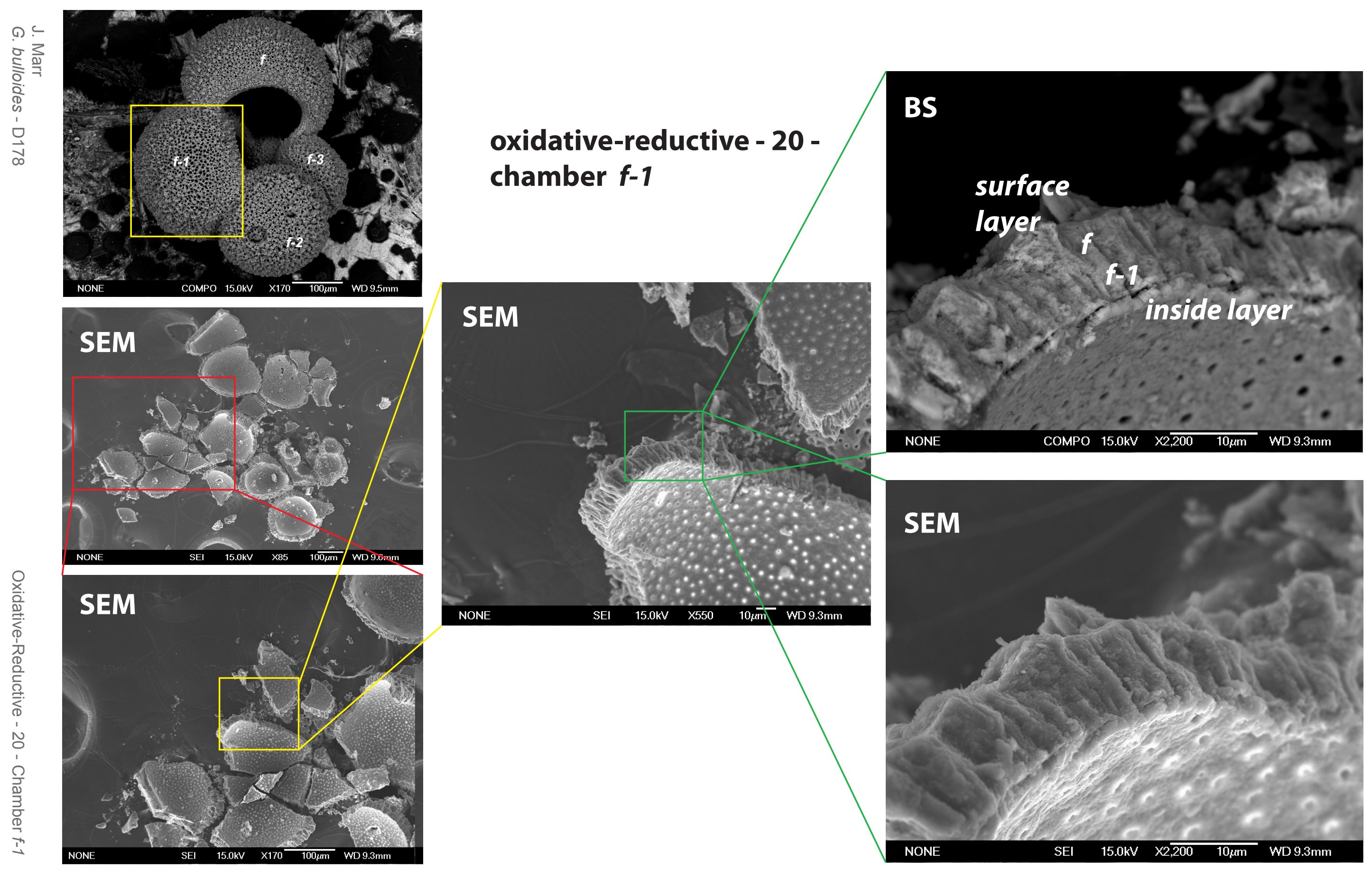


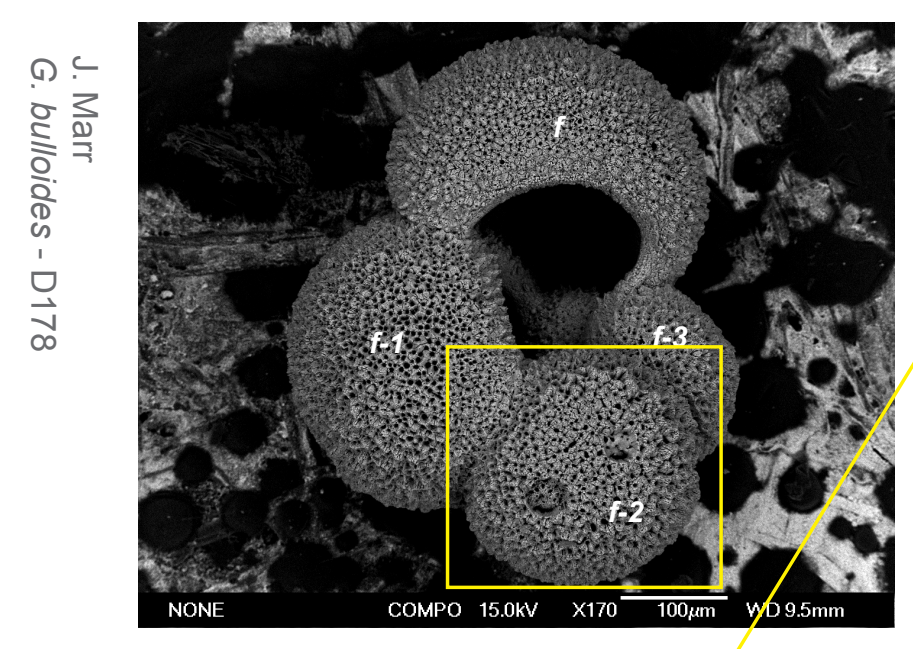

oxidative-reductive - 20 chamber $f-2$
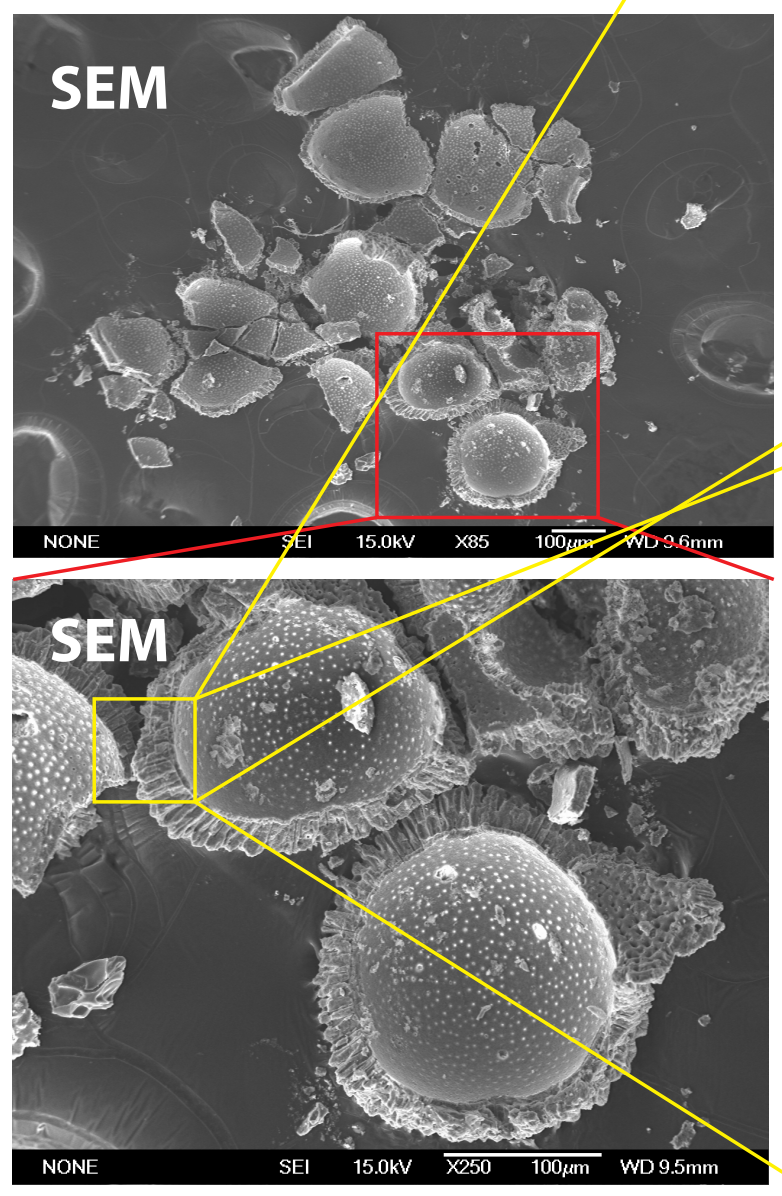
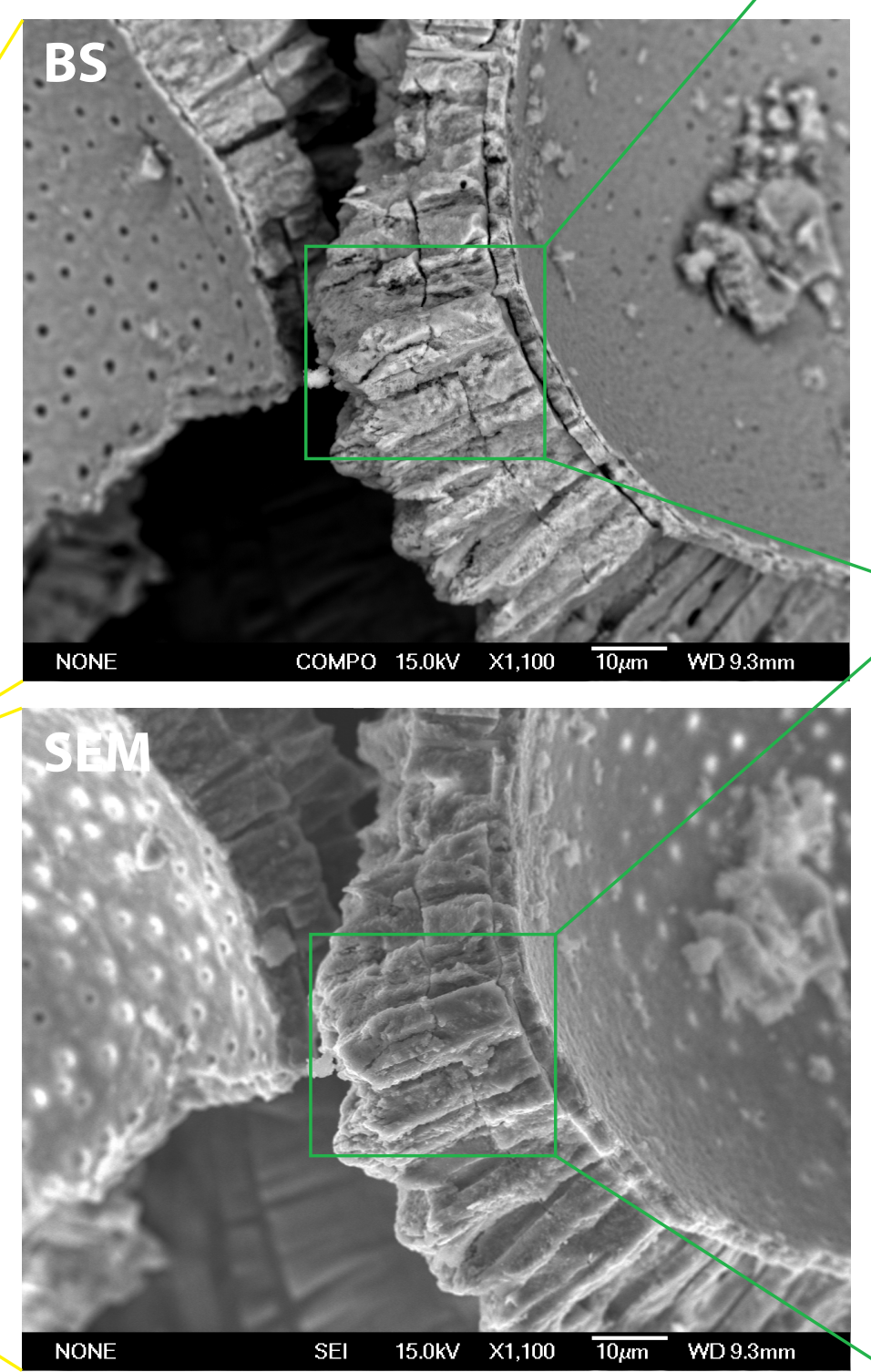
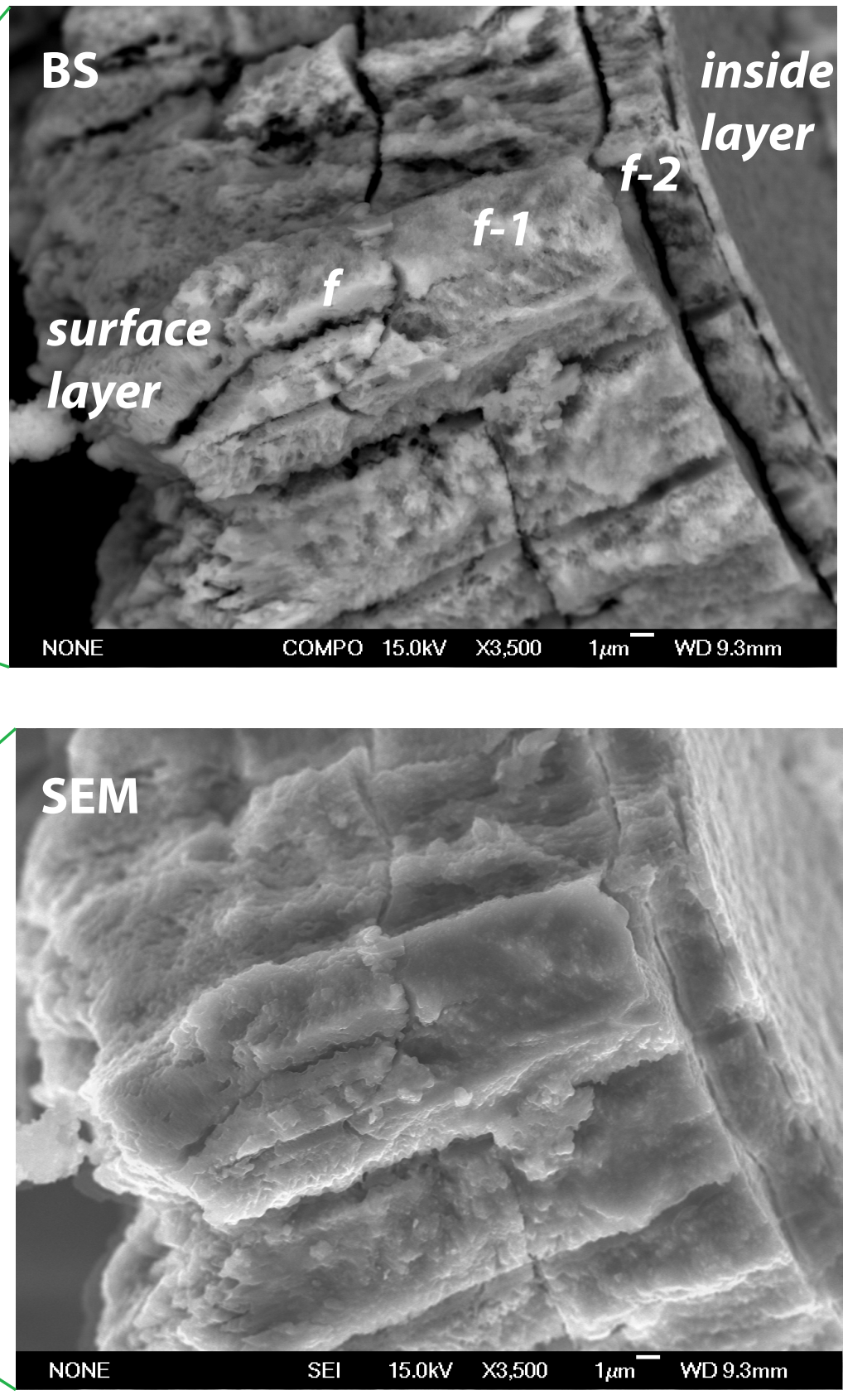

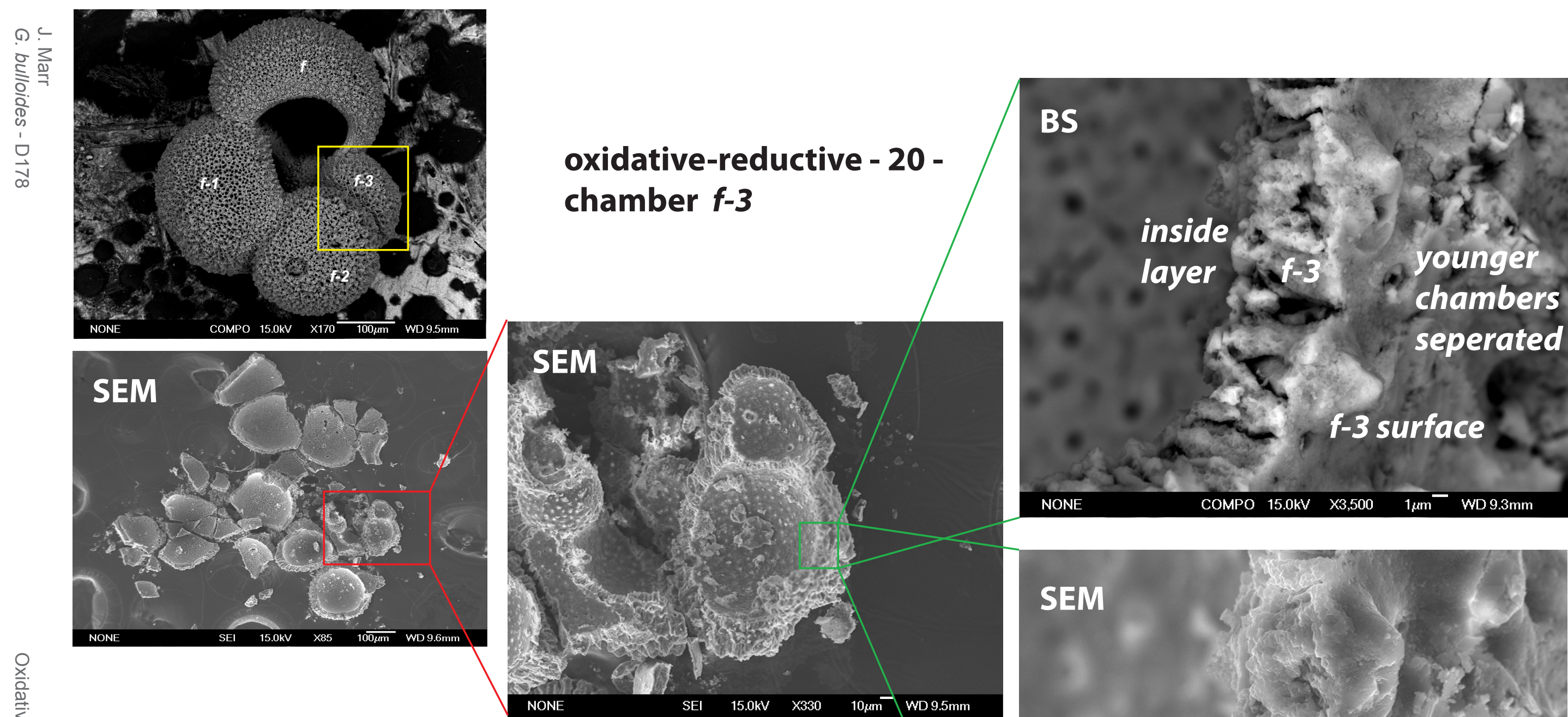

SEM 

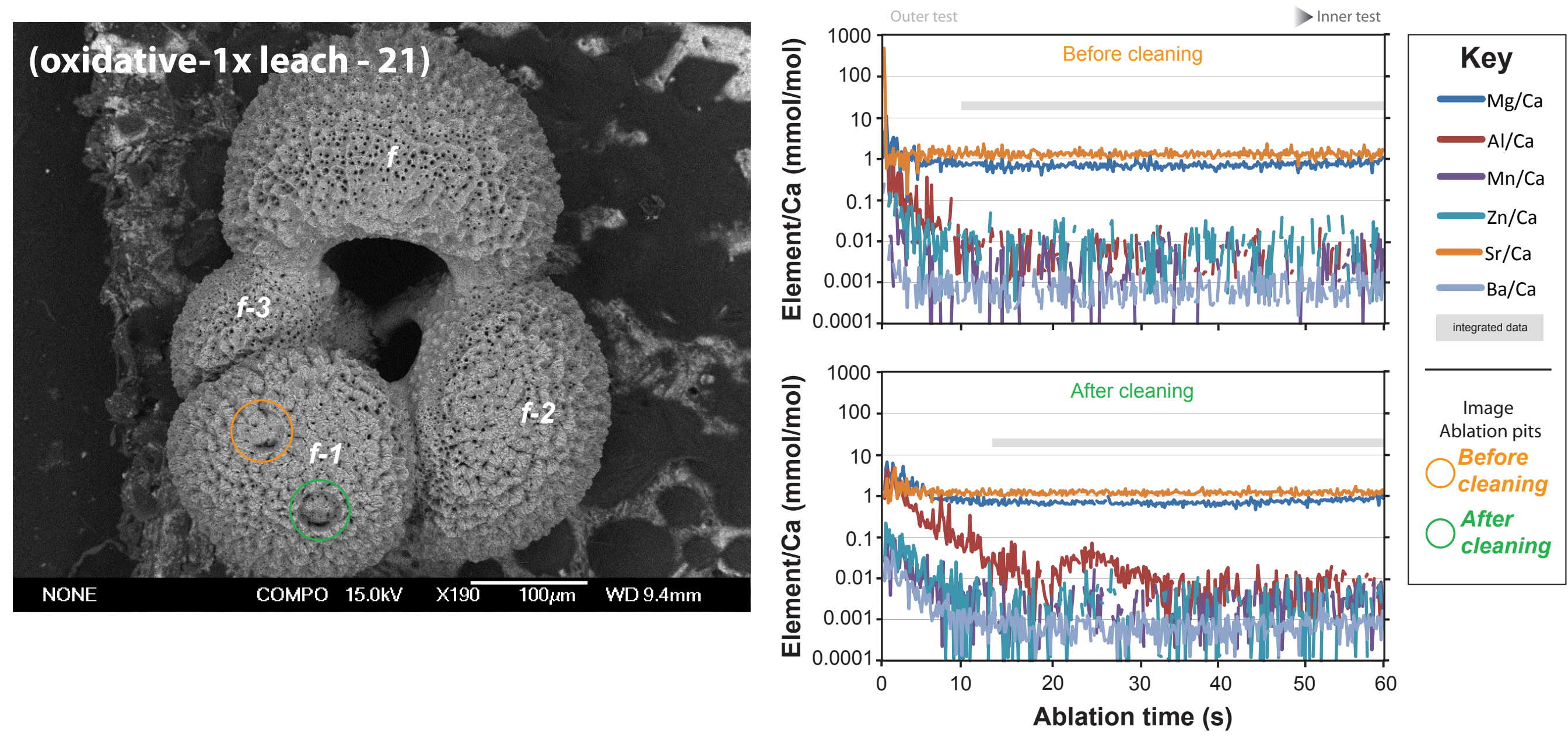

\begin{tabular}{|c|c|c|c|c|c|c|c|}
\hline Sample: & Oxidative-1x Leach - 21 & & & & & & \\
\hline \multicolumn{2}{|c|}{ Before cleaning } & $\begin{array}{c}\mathrm{Mg} / \mathrm{Ca} \\
(\mathrm{mmol} / \mathrm{mol})\end{array}$ & $\begin{array}{c}\mathrm{Al} / \mathrm{Ca} \\
(\mathrm{mmol} / \mathrm{mol})\end{array}$ & $\begin{array}{c}\mathrm{Mn} / \mathrm{Ca} \\
(\mathrm{mmol} / \mathrm{mol})\end{array}$ & $\begin{array}{c}\mathrm{Zn} / \mathrm{Ca} \\
(\mathrm{mmol} / \mathrm{mol})\end{array}$ & $\begin{array}{c}\mathrm{Sr} / \mathrm{Ca} \\
(\mathrm{mmol} / \mathrm{mol})\end{array}$ & $\begin{array}{c}\mathrm{Ba} / \mathrm{Ca} \\
(\mathrm{mmol} / \mathrm{mol})\end{array}$ \\
\hline & intergrated profile mean & 0.67 & 0.002 & 0.000 & 0.002 & 1.28 & 0.001 \\
\hline & 2 sd & 0.25 & 0.013 & 0.012 & 0.024 & 0.38 & 0.001 \\
\hline \multicolumn{8}{|c|}{ After cleaning } \\
\hline & intergrated profile mean & 0.73 & 0.012 & 0.001 & 0.001 & 1.25 & 0.001 \\
\hline & 2 sd & 0.18 & 0.026 & 0.007 & 0.008 & 0.26 & 0.001 \\
\hline \multicolumn{8}{|c|}{ Difference } \\
\hline & mean & -0.06 & -0.010 & -0.001 & 0.001 & 0.03 & 0.000 \\
\hline
\end{tabular}


oxidative, 1x leach - 21 - chamber $f$
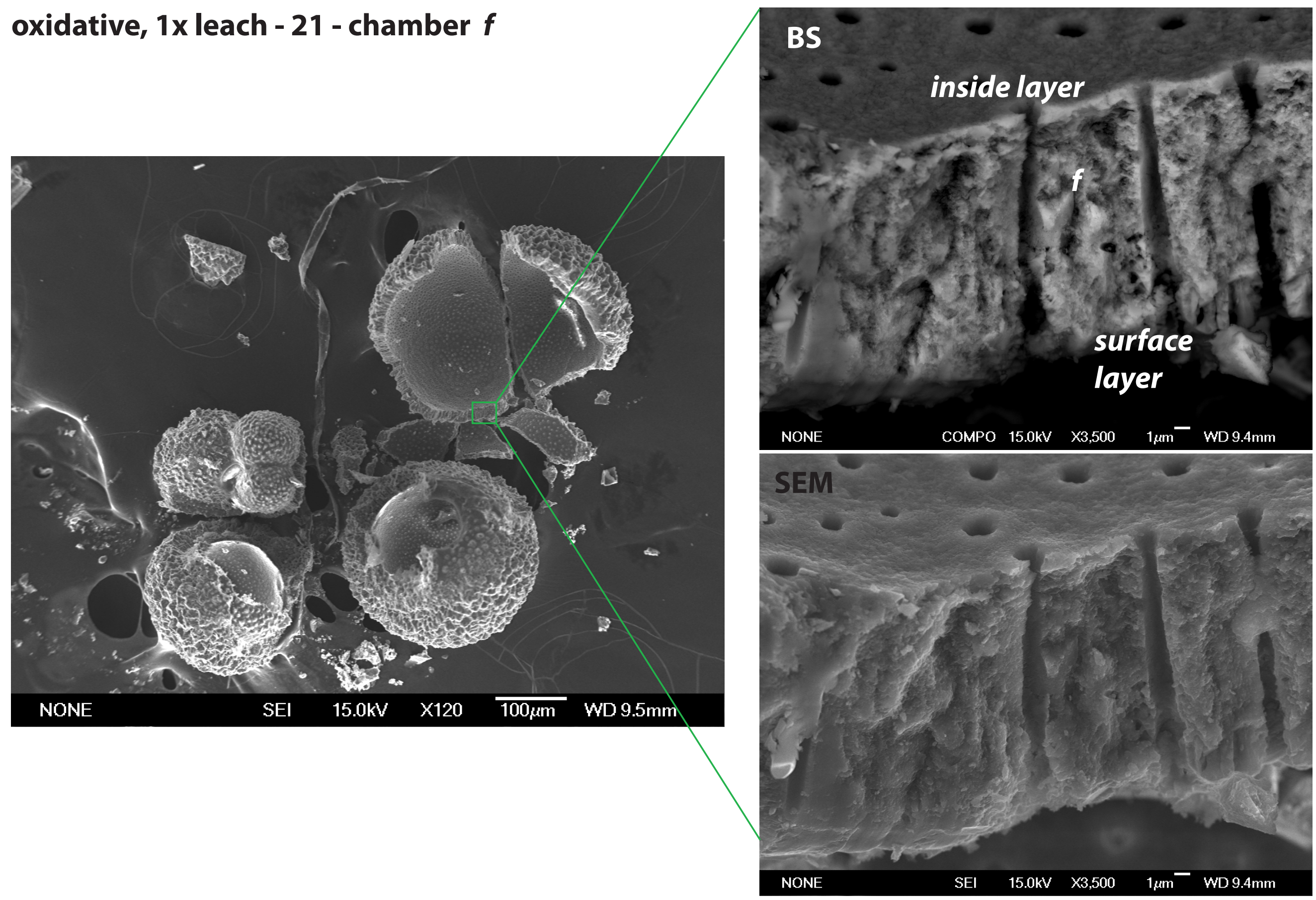

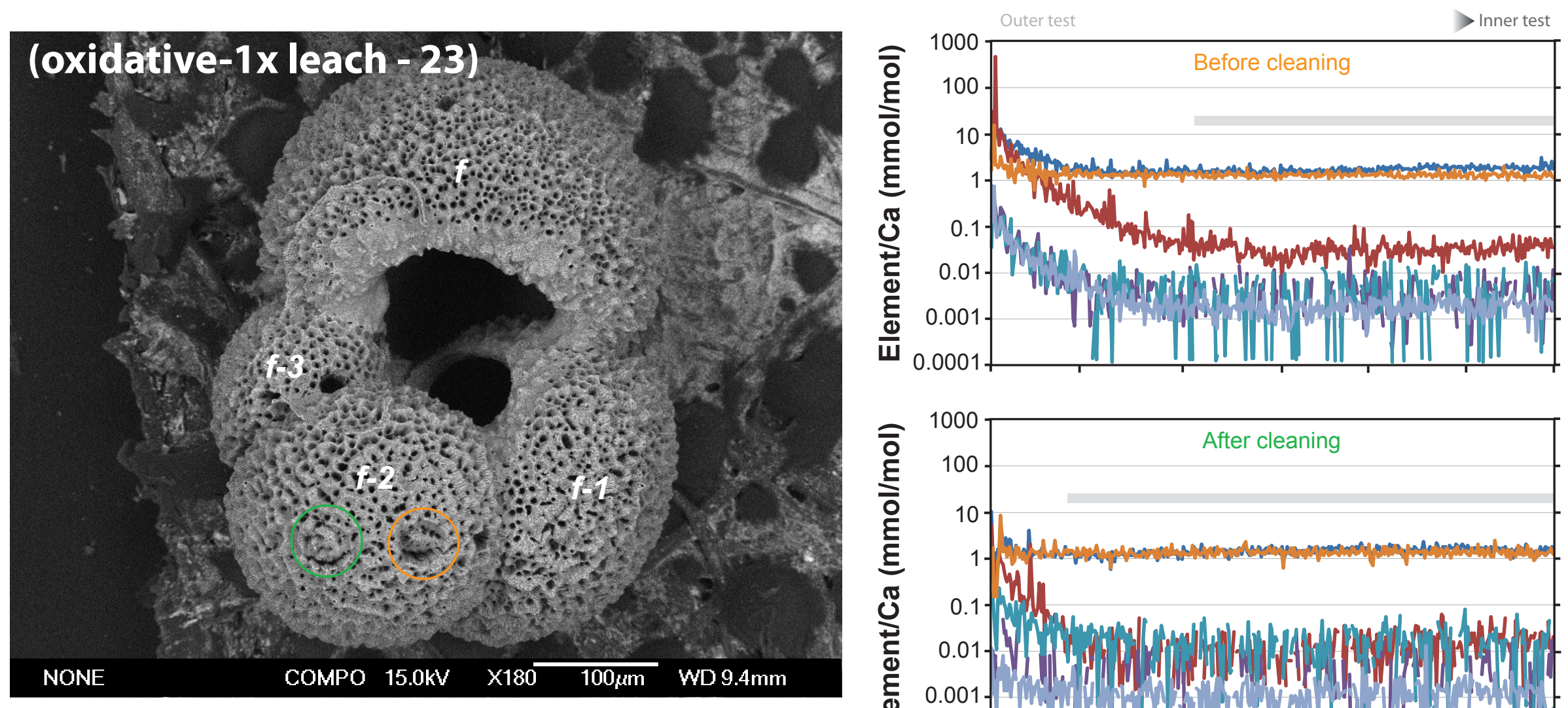

Key

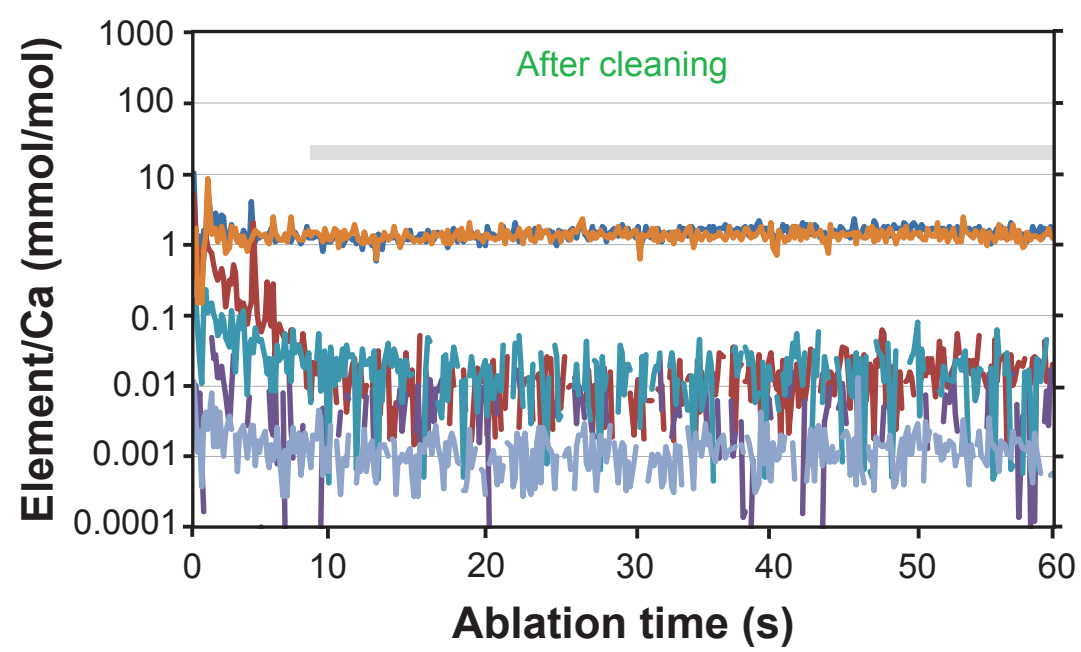

$\mathrm{Mg} / \mathrm{Ca}$

$\mathrm{Al} / \mathrm{Ca}$

$\mathrm{Mn} / \mathrm{Ca}$

$\mathrm{Zn} / \mathrm{Ca}$

$\mathrm{Sr} / \mathrm{Ca}$

$\mathrm{Ba} / \mathrm{Ca}$

integrated data

Image Ablation pits

Before

cleaning

After

cleaning

O0um WD $9.4 \mathrm{~mm}$

Ablation time (s)

\begin{tabular}{|c|c|c|c|c|c|c|c|}
\hline \multicolumn{8}{|c|}{ Sample: Oxidative-1x Leach - 23} \\
\hline \multicolumn{2}{|c|}{ Before cleaning } & $\begin{array}{c}\mathrm{Mg} / \mathrm{Ca} \\
(\mathrm{mmol} / \mathrm{mol})\end{array}$ & $\begin{array}{c}\mathrm{Al} / \mathrm{Ca} \\
(\mathrm{mmol} / \mathrm{mol})\end{array}$ & $\begin{array}{c}\mathrm{Mn} / \mathrm{Ca} \\
(\mathrm{mmol} / \mathrm{mol})\end{array}$ & $\begin{array}{c}\mathrm{Zn} / \mathrm{Ca} \\
(\mathrm{mmol} / \mathrm{mol})\end{array}$ & $\begin{array}{c}\mathrm{Sr} / \mathrm{Ca} \\
(\mathrm{mmol} / \mathrm{mol})\end{array}$ & $\begin{array}{c}\mathrm{Ba} / \mathrm{Ca} \\
(\mathrm{mmol} / \mathrm{mol})\end{array}$ \\
\hline & intergrated profile mean & 1.70 & 0.035 & 0.002 & 0.002 & 1.30 & 0.002 \\
\hline & 2 sd & 0.50 & 0.036 & 0.009 & 0.010 & 0.30 & 0.002 \\
\hline \multicolumn{8}{|c|}{ After cleaning } \\
\hline & intergrated profile mean & 1.40 & 0.008 & 0.000 & 0.011 & 1.32 & 0.001 \\
\hline & 2 sd & 0.44 & 0.019 & 0.014 & 0.030 & 0.45 & 0.001 \\
\hline \multicolumn{8}{|c|}{ Difference } \\
\hline & mean & 0.30 & 0.028 & 0.002 & -0.008 & -0.02 & 0.001 \\
\hline
\end{tabular}




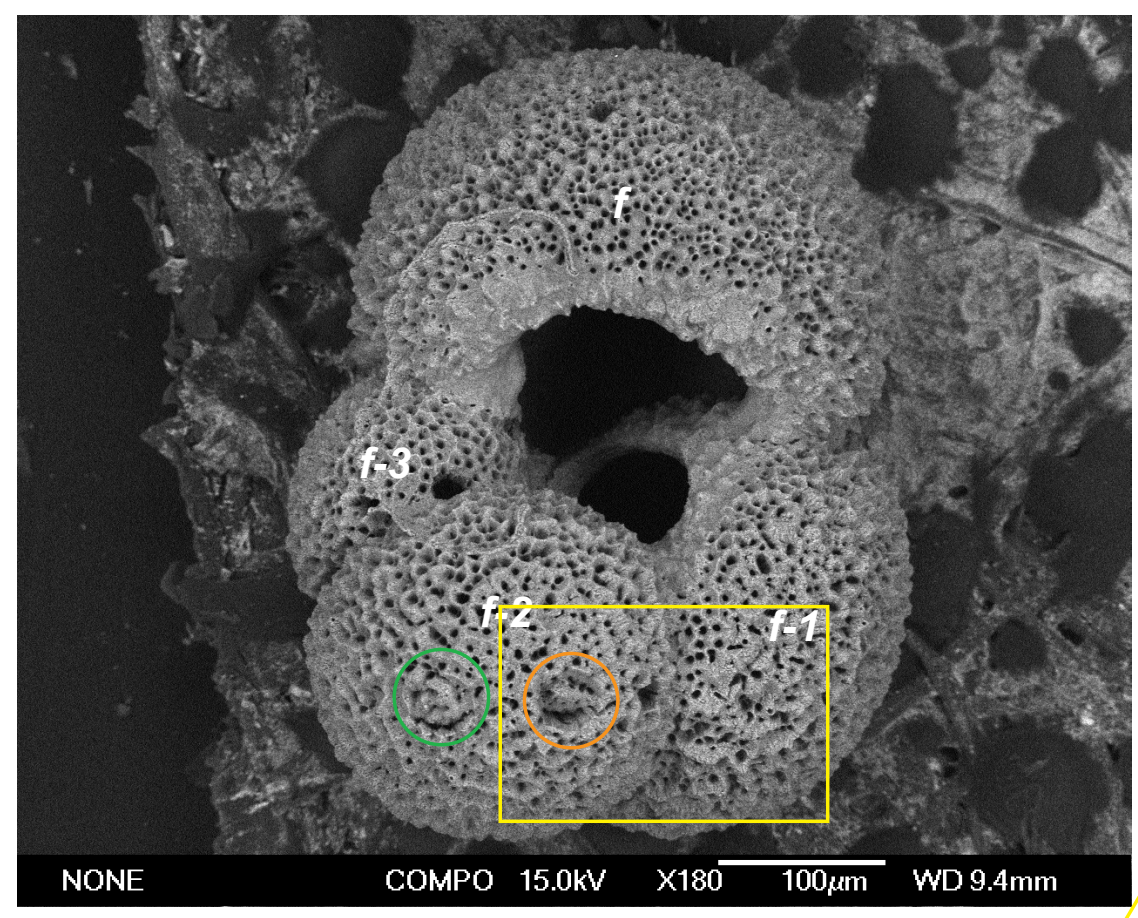

oxidative-1

$x$ leach - 23 -

chamber f-2 -

ablation pit -

before cleaning
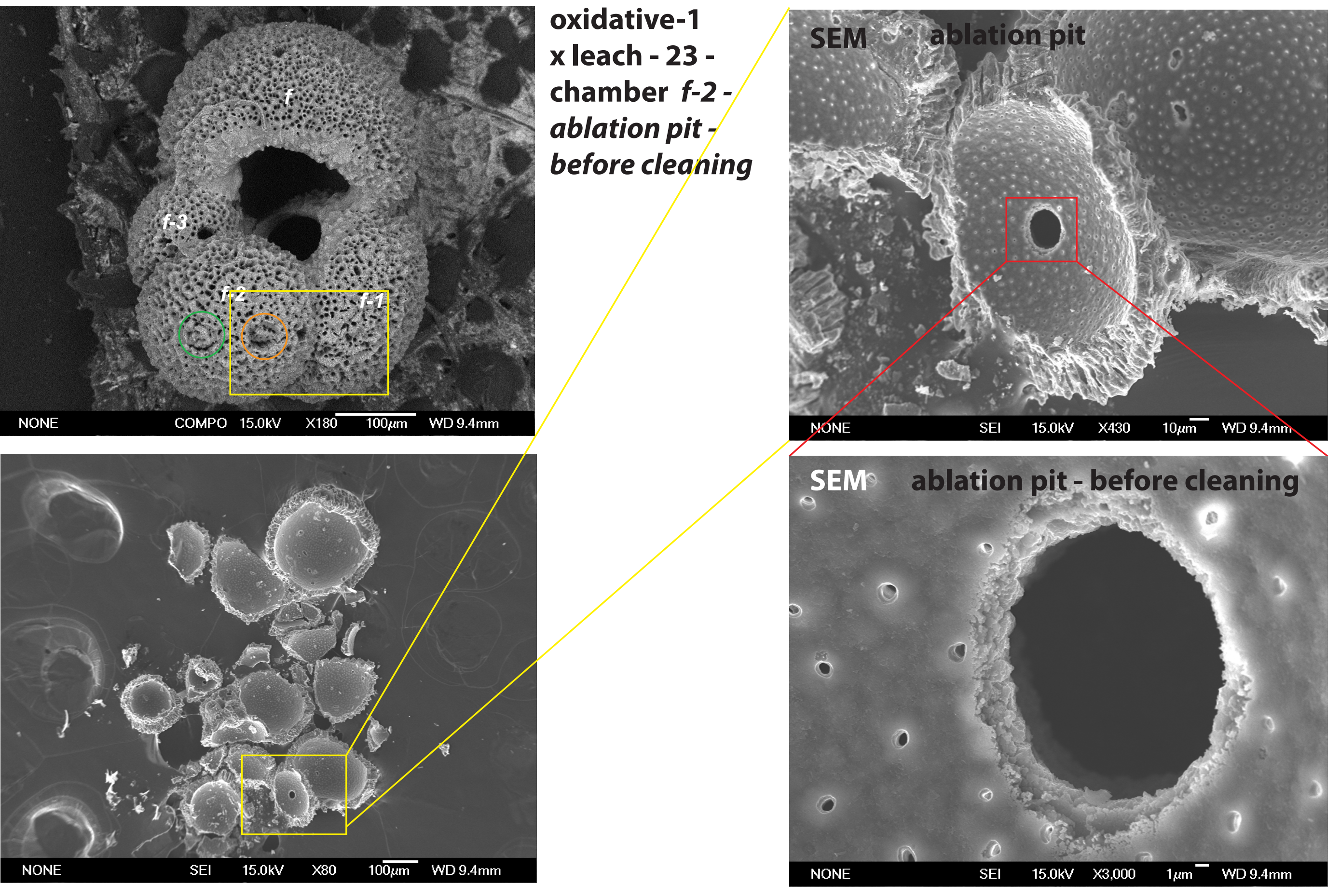


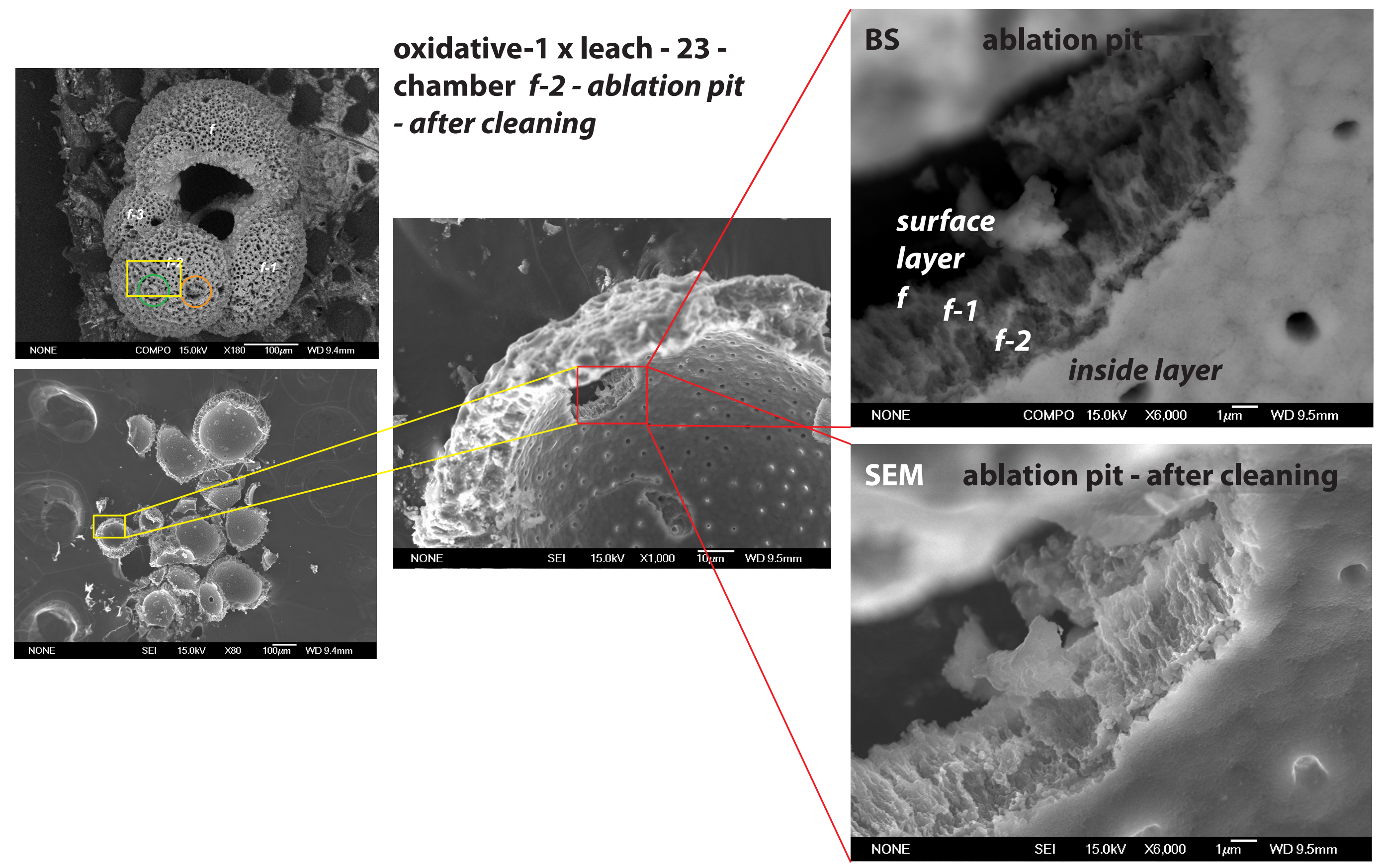



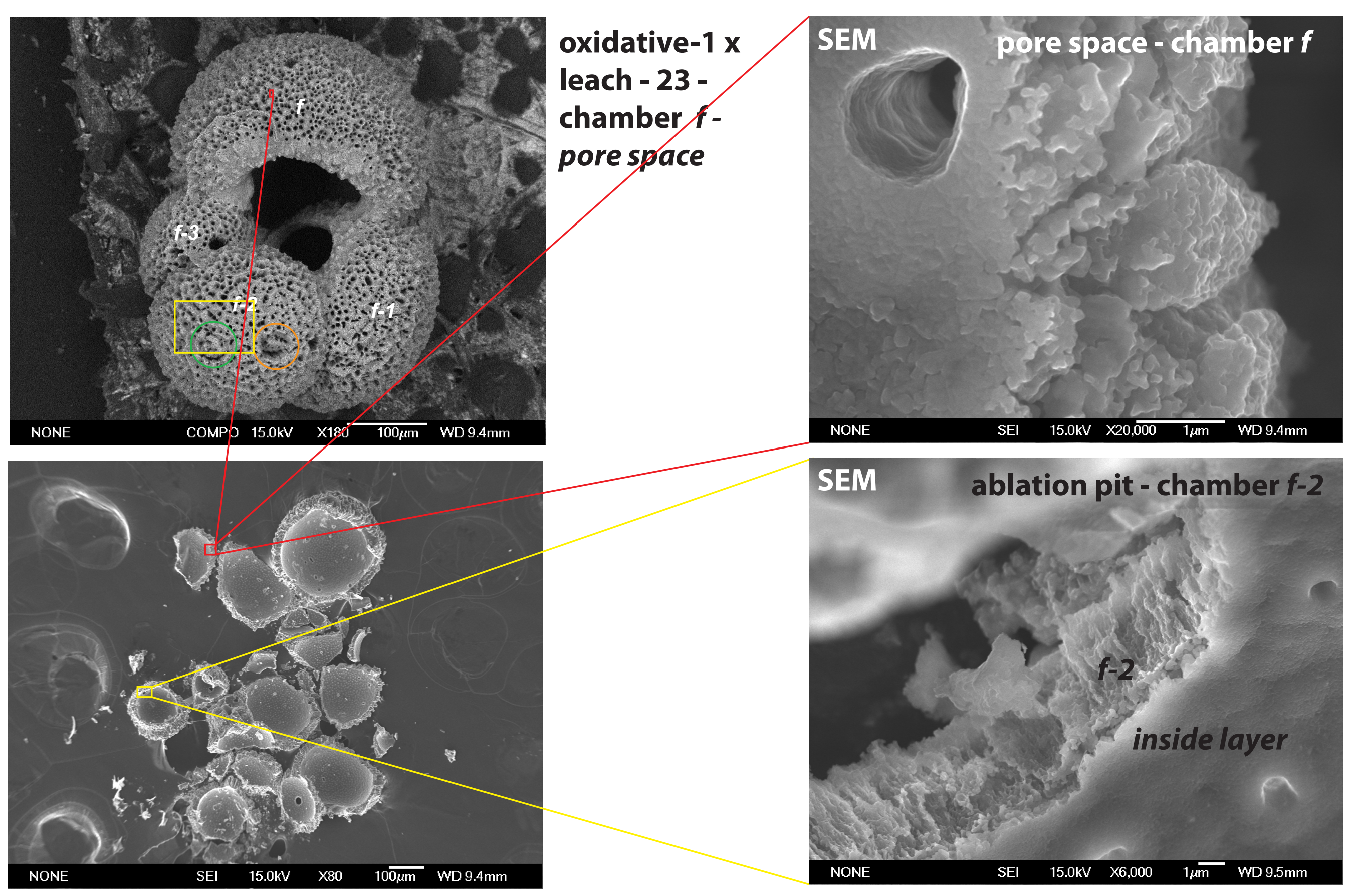

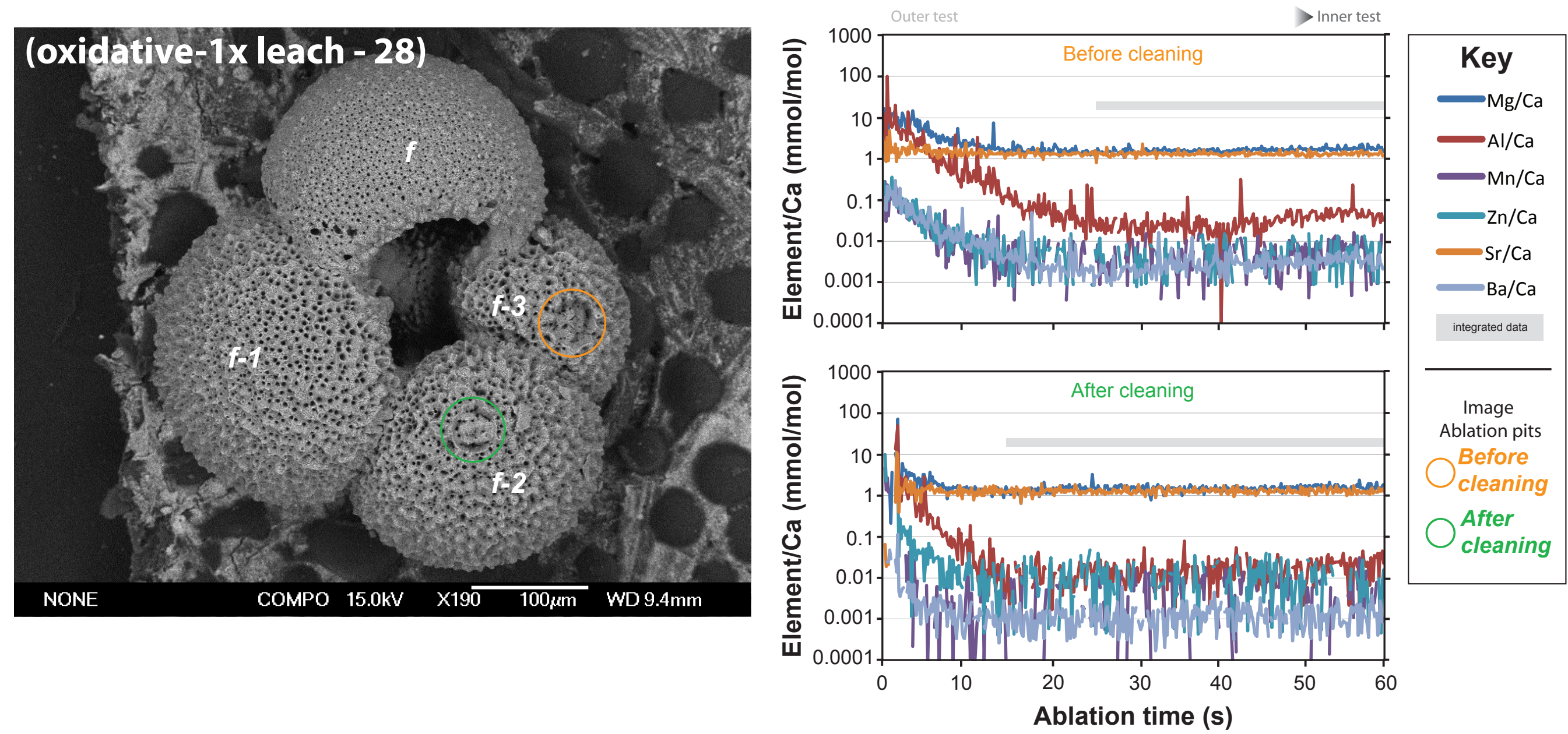

\begin{tabular}{|c|c|c|c|c|c|c|c|}
\hline Sample: & Oxidative-1x Leach - 28 & & & & & & \\
\hline \multicolumn{2}{|c|}{ Before cleaning } & $\begin{array}{c}\mathrm{Mg} / \mathrm{Ca} \\
(\mathrm{mmol} / \mathrm{mol})\end{array}$ & $\begin{array}{c}\mathrm{Al} / \mathrm{Ca} \\
(\mathrm{mmol} / \mathrm{mol})\end{array}$ & $\begin{array}{c}\mathrm{Mn} / \mathrm{Ca} \\
(\mathrm{mmol} / \mathrm{mol})\end{array}$ & $\begin{array}{c}\mathrm{Zn} / \mathrm{Ca} \\
(\mathrm{mmol} / \mathrm{mol})\end{array}$ & $\begin{array}{c}\mathrm{Sr} / \mathrm{Ca} \\
\text { (mmol/mol) }\end{array}$ & $\begin{array}{c}\mathrm{Ba} / \mathrm{Ca} \\
(\mathrm{mmol} / \mathrm{mol})\end{array}$ \\
\hline & intergrated profile mean & 1.60 & 0.035 & 0.003 & 0.002 & 1.30 & 0.003 \\
\hline & $2 \mathrm{sd}$ & 0.40 & 0.063 & 0.008 & 0.010 & 0.28 & 0.003 \\
\hline \multicolumn{8}{|c|}{ After cleaning } \\
\hline & intergrated profile mean & 1.48 & 0.013 & 0.000 & 0.006 & 1.30 & 0.001 \\
\hline & $2 \mathrm{sd}$ & 0.49 & 0.022 & 0.014 & 0.027 & 0.38 & 0.002 \\
\hline \multicolumn{8}{|c|}{ Difference } \\
\hline & mean & 0.12 & 0.022 & 0.003 & -0.004 & 0.00 & 0.002 \\
\hline
\end{tabular}



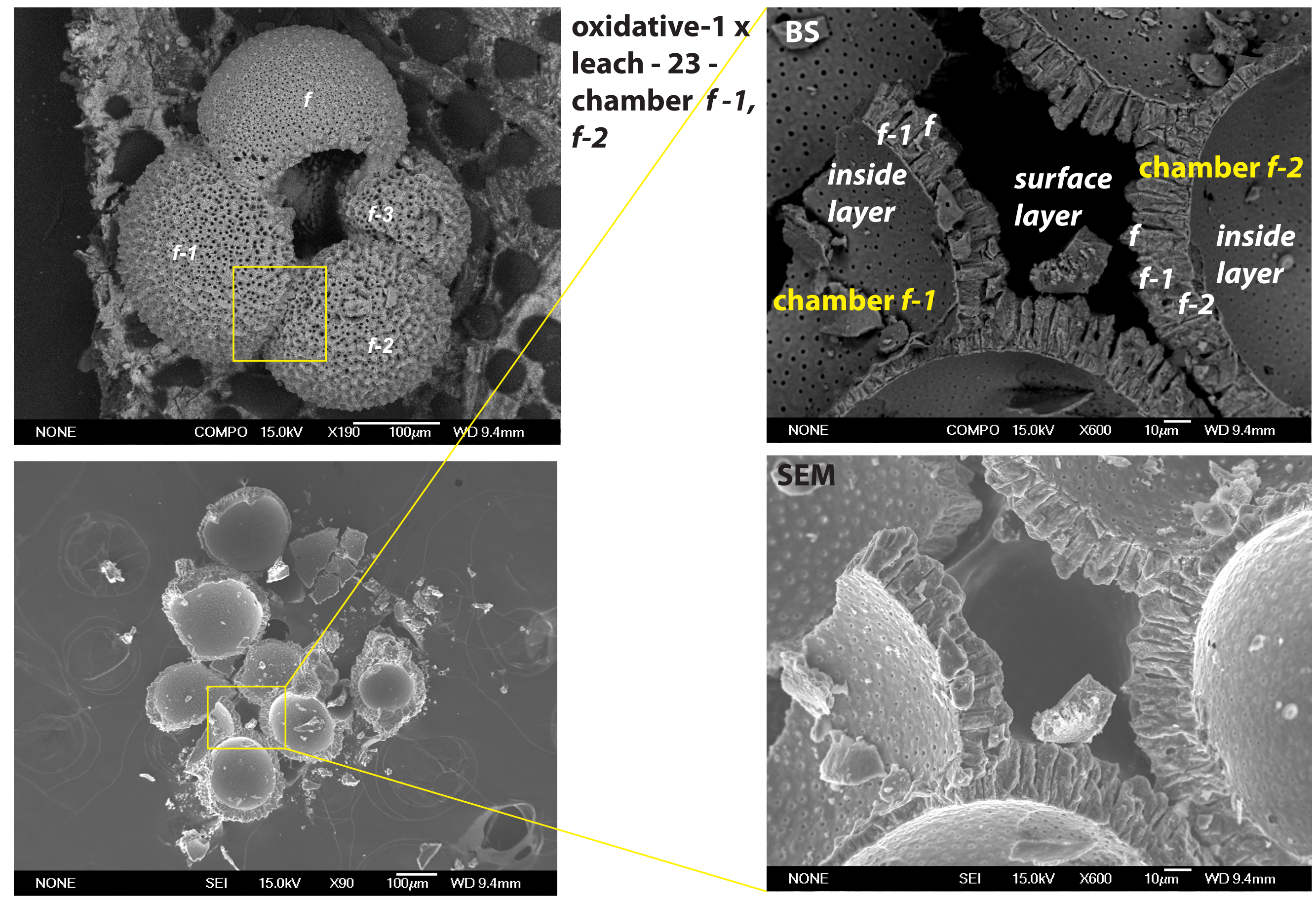

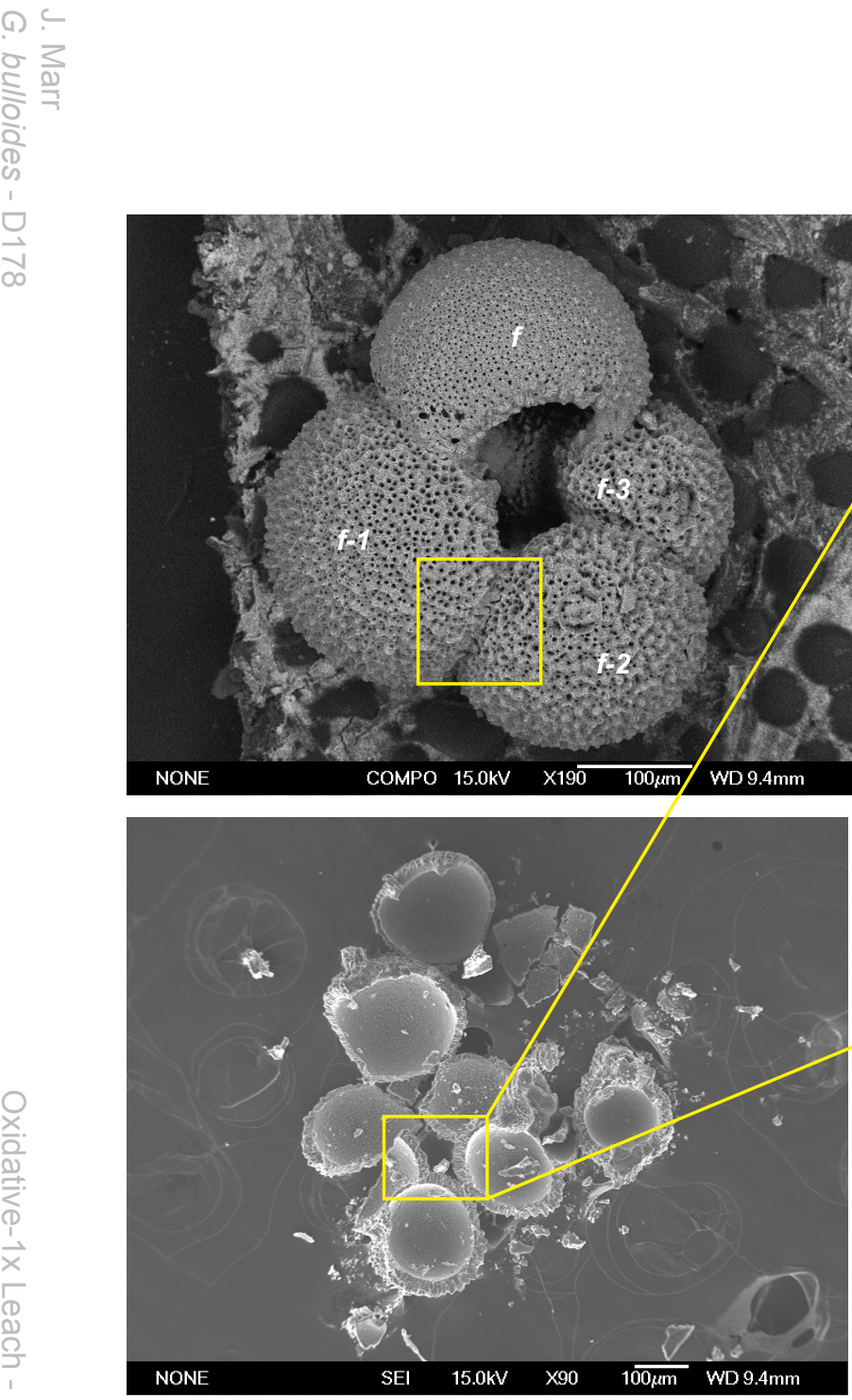

oxidative-1 x leach - 23 chamber $f-2$

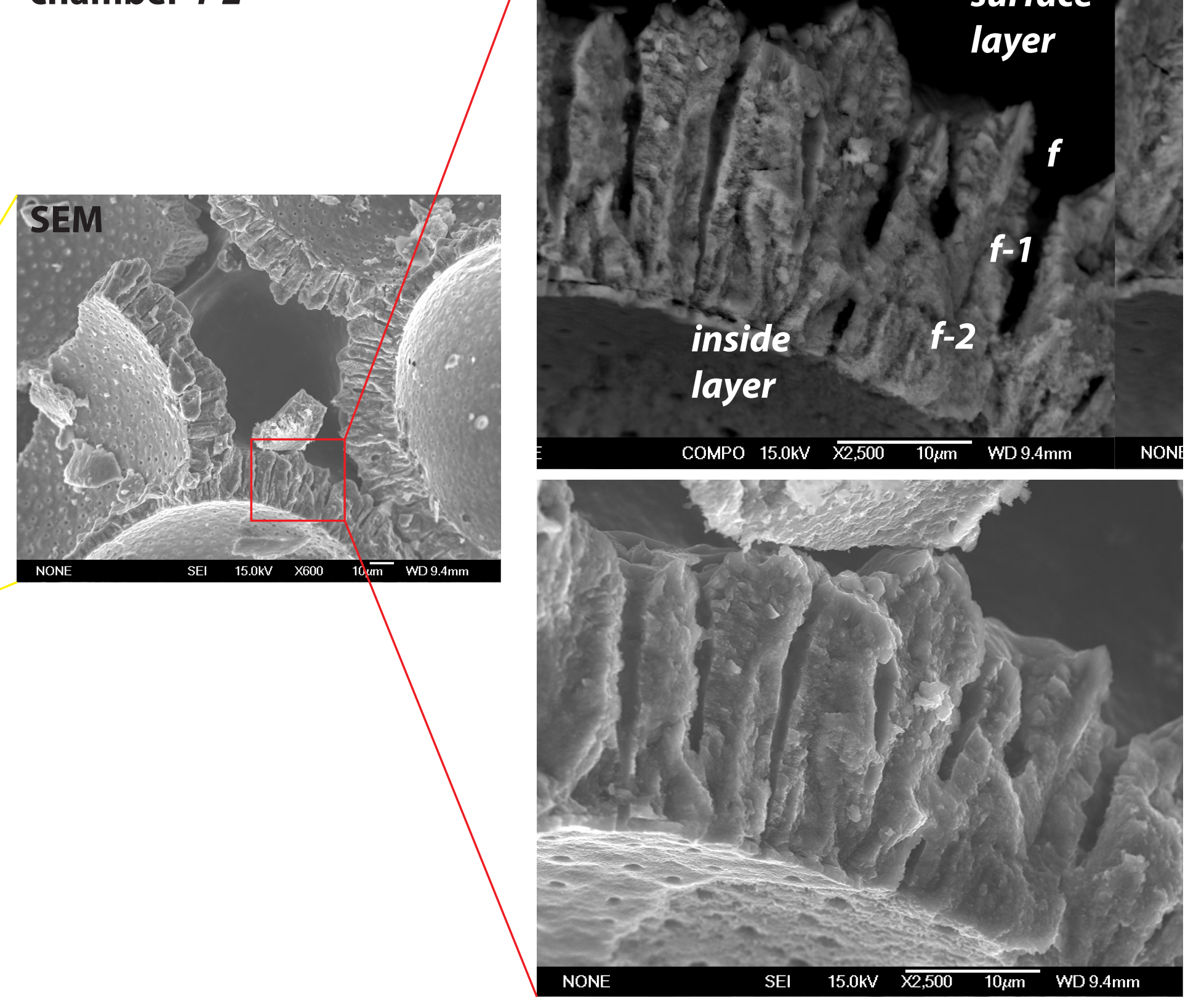



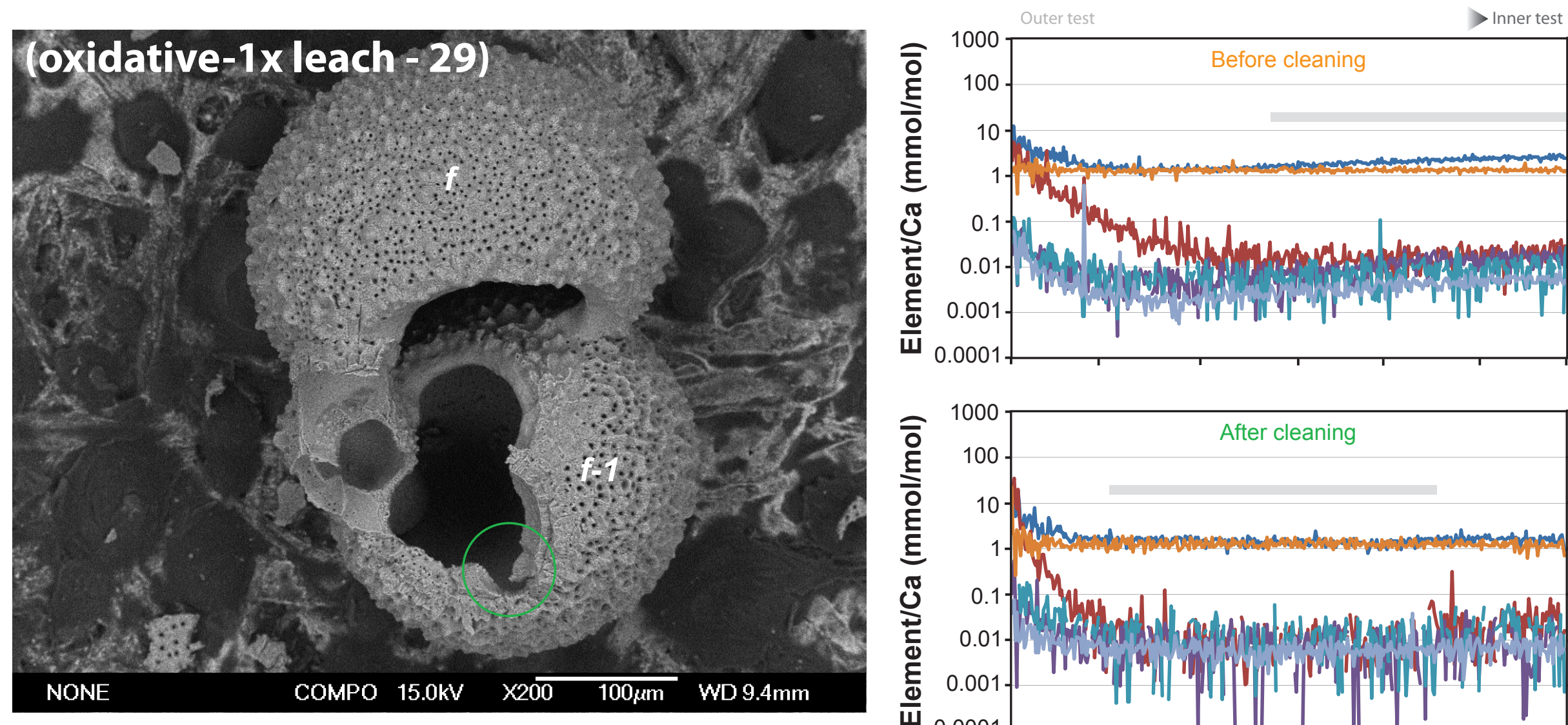

Key

$\mathrm{Mg} / \mathrm{Ca}$

$\mathrm{Al} / \mathrm{Ca}$

$\mathrm{Mn} / \mathrm{Ca}$

$\mathrm{Zn} / \mathrm{Ca}$

$\mathrm{Sr} / \mathrm{Ca}$

$\mathrm{Ba} / \mathrm{Ca}$

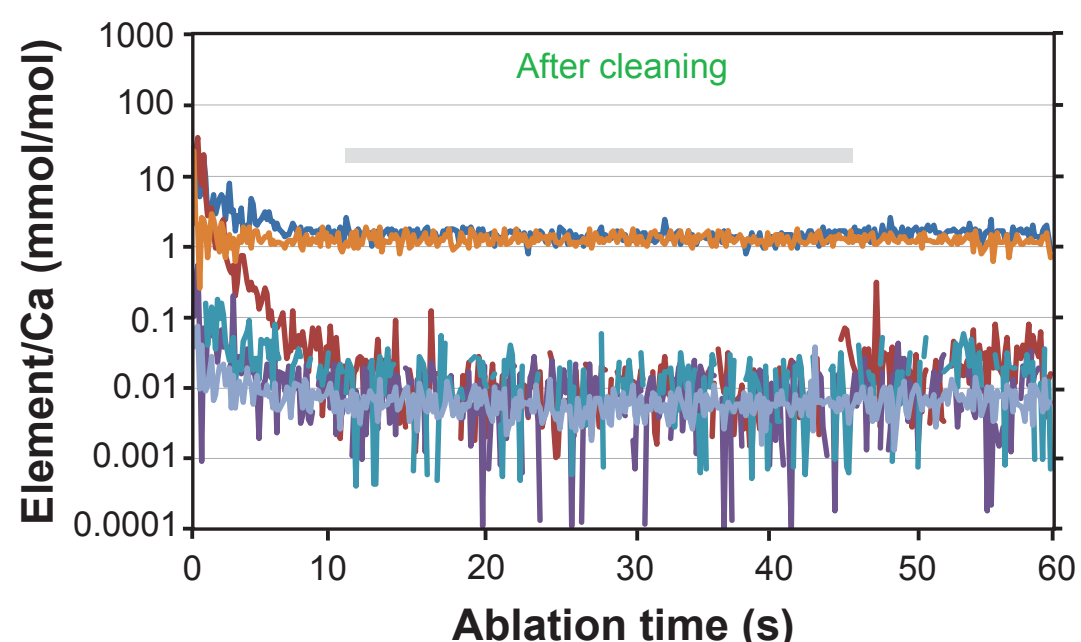

integrated data

Image Ablation pits

Before

cleaning

After

cleaning

Ablation time (s)

\begin{tabular}{|c|c|c|c|c|c|c|c|}
\hline \multicolumn{8}{|c|}{ Sample: Oxidative-1x Leach - 29} \\
\hline \multicolumn{2}{|c|}{ Before cleaning } & $\begin{array}{c}\mathrm{Mg} / \mathrm{Ca} \\
(\mathrm{mmol} / \mathrm{mol})\end{array}$ & $\begin{array}{c}\mathrm{Al} / \mathrm{Ca} \\
(\mathrm{mmol} / \mathrm{mol})\end{array}$ & $\begin{array}{c}\mathrm{Mn} / \mathrm{Ca} \\
(\mathrm{mmol} / \mathrm{mol})\end{array}$ & $\begin{array}{c}\mathrm{Zn} / \mathrm{Ca} \\
(\mathrm{mmol} / \mathrm{mol})\end{array}$ & $\begin{array}{c}\mathrm{Sr} / \mathrm{Ca} \\
(\mathrm{mmol} / \mathrm{mol})\end{array}$ & $\begin{array}{c}\mathrm{Ba} / \mathrm{Ca} \\
(\mathrm{mmol} / \mathrm{mol})\end{array}$ \\
\hline & intergrated profile mean & 1.86 & 0.021 & 0.010 & 0.006 & 1.31 & 0.004 \\
\hline & $2 \mathrm{sd}$ & 0.88 & 0.032 & 0.012 & 0.015 & 0.25 & 0.003 \\
\hline \multicolumn{8}{|c|}{ After cleaning } \\
\hline & intergrated profile mean & 1.42 & 0.009 & 0.007 & 0.005 & 1.28 & 0.006 \\
\hline & $2 \mathrm{sd}$ & 0.46 & 0.028 & 0.016 & 0.032 & 0.45 & 0.005 \\
\hline \multicolumn{8}{|c|}{ Difference } \\
\hline & mean & 0.44 & 0.012 & 0.003 & 0.001 & 0.03 & -0.002 \\
\hline
\end{tabular}




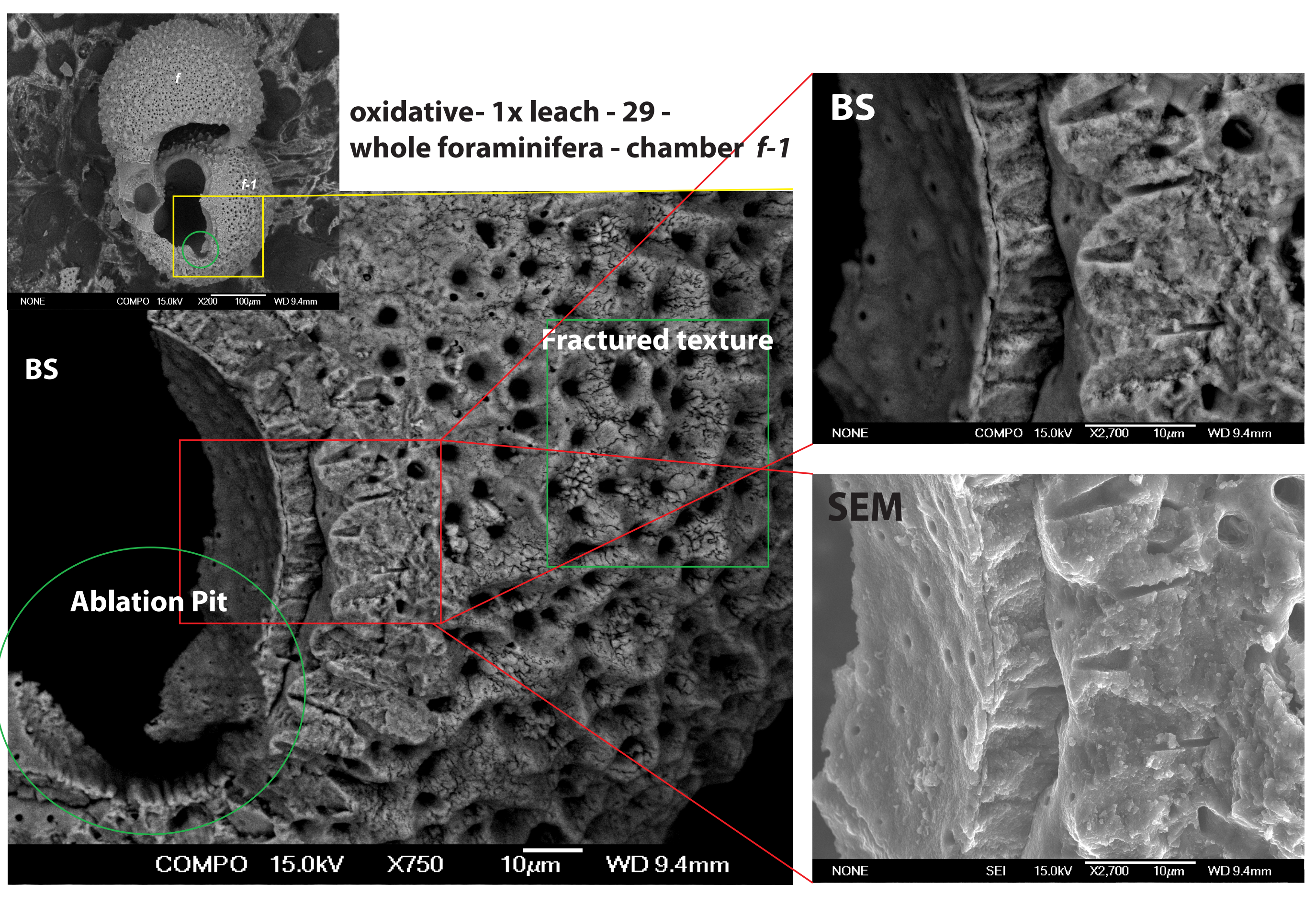



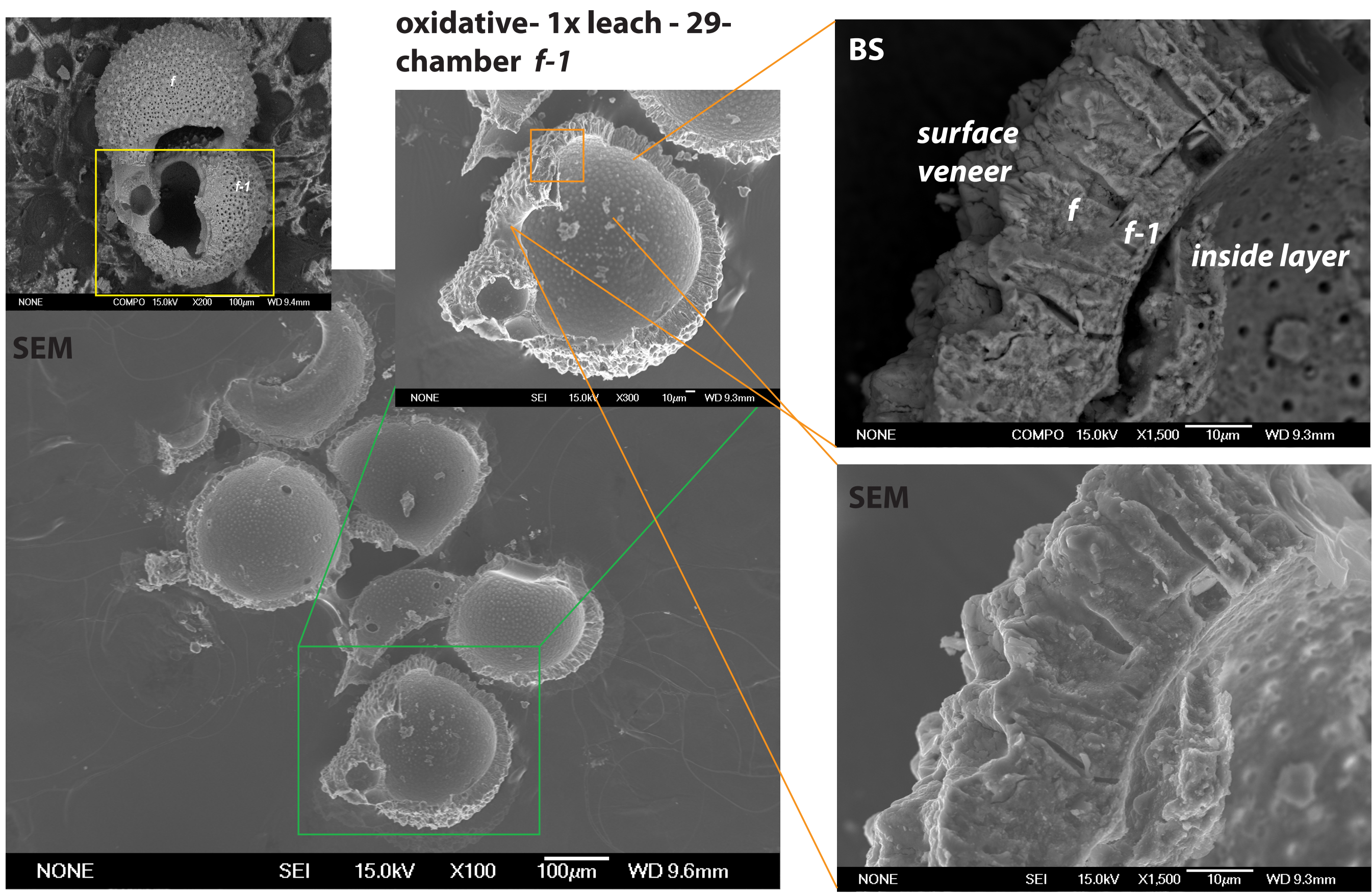


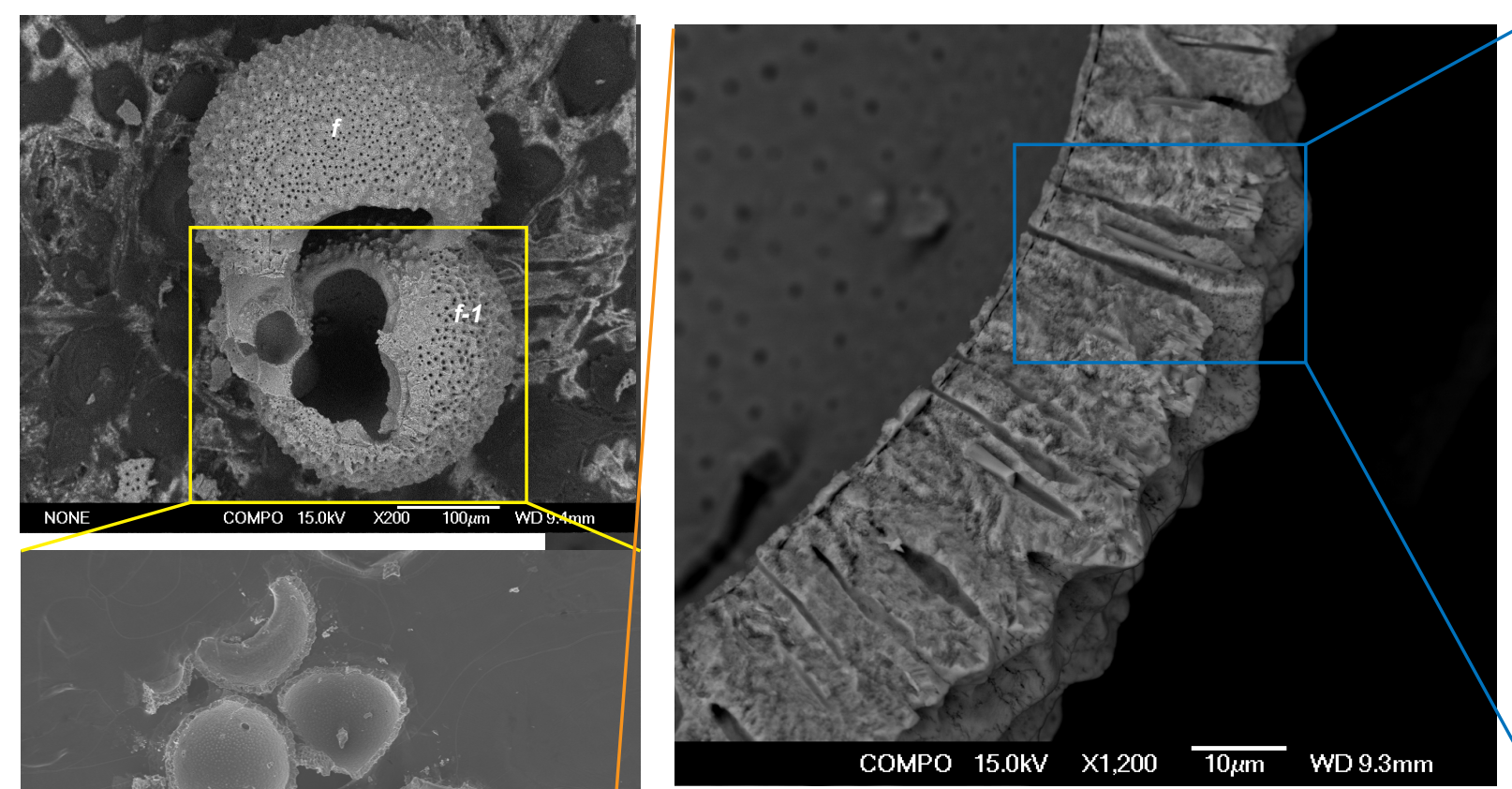

insidel layer
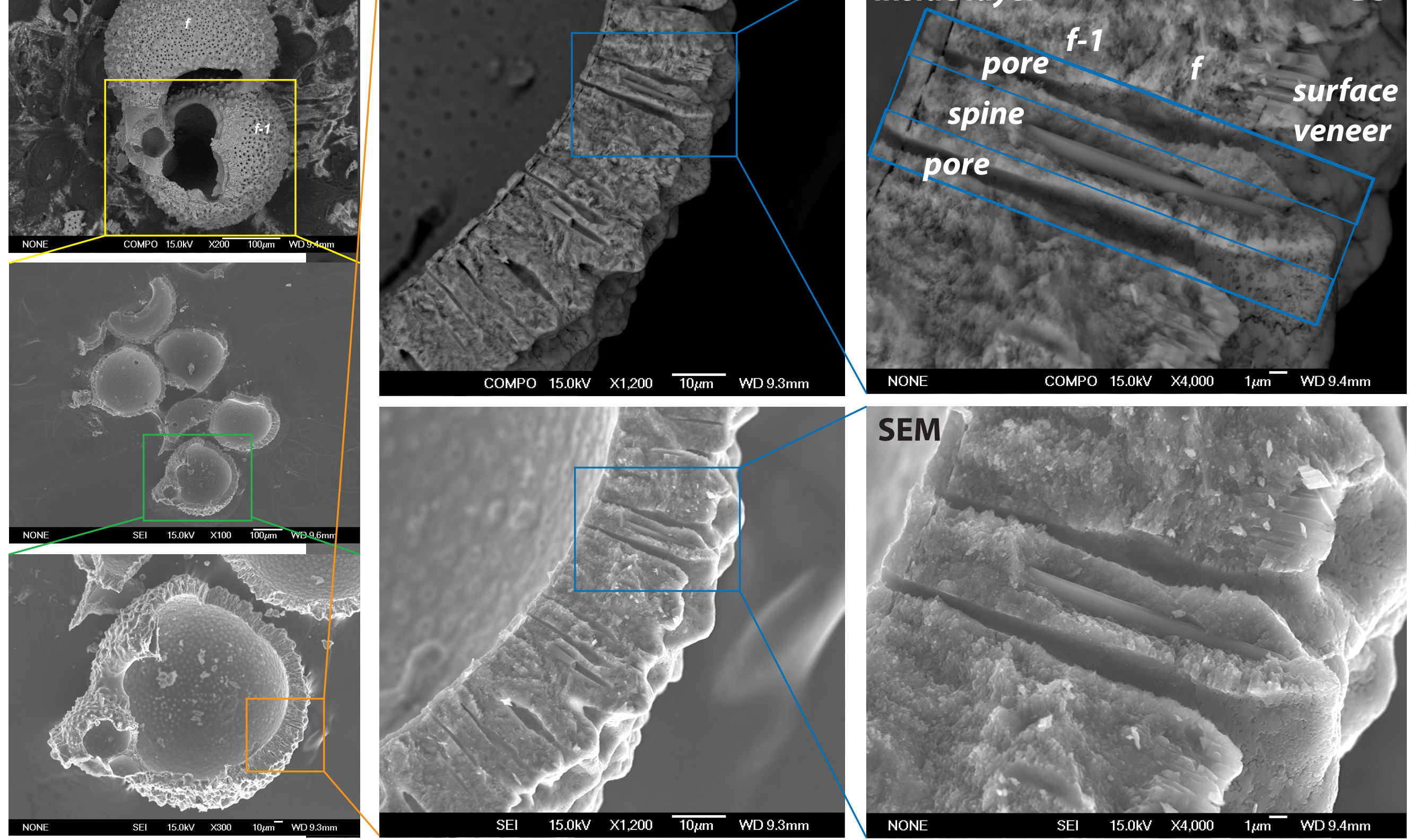

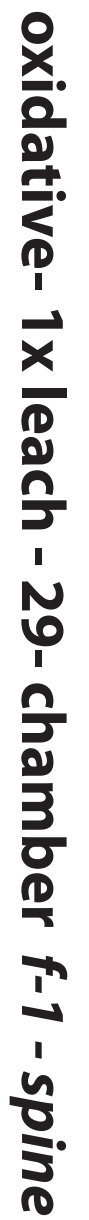

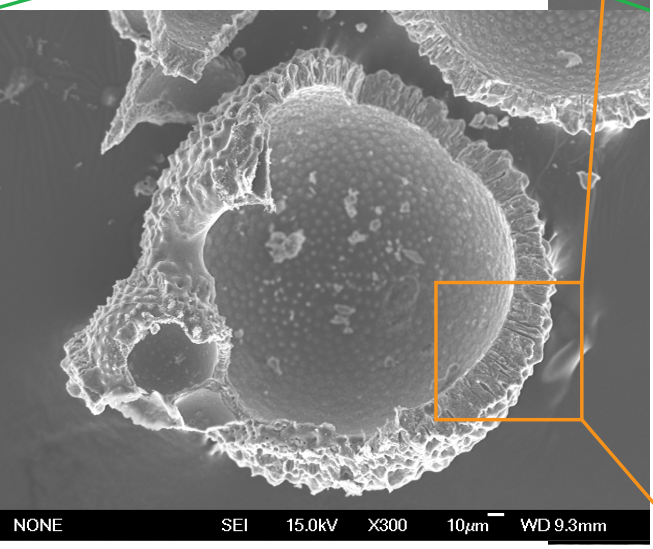



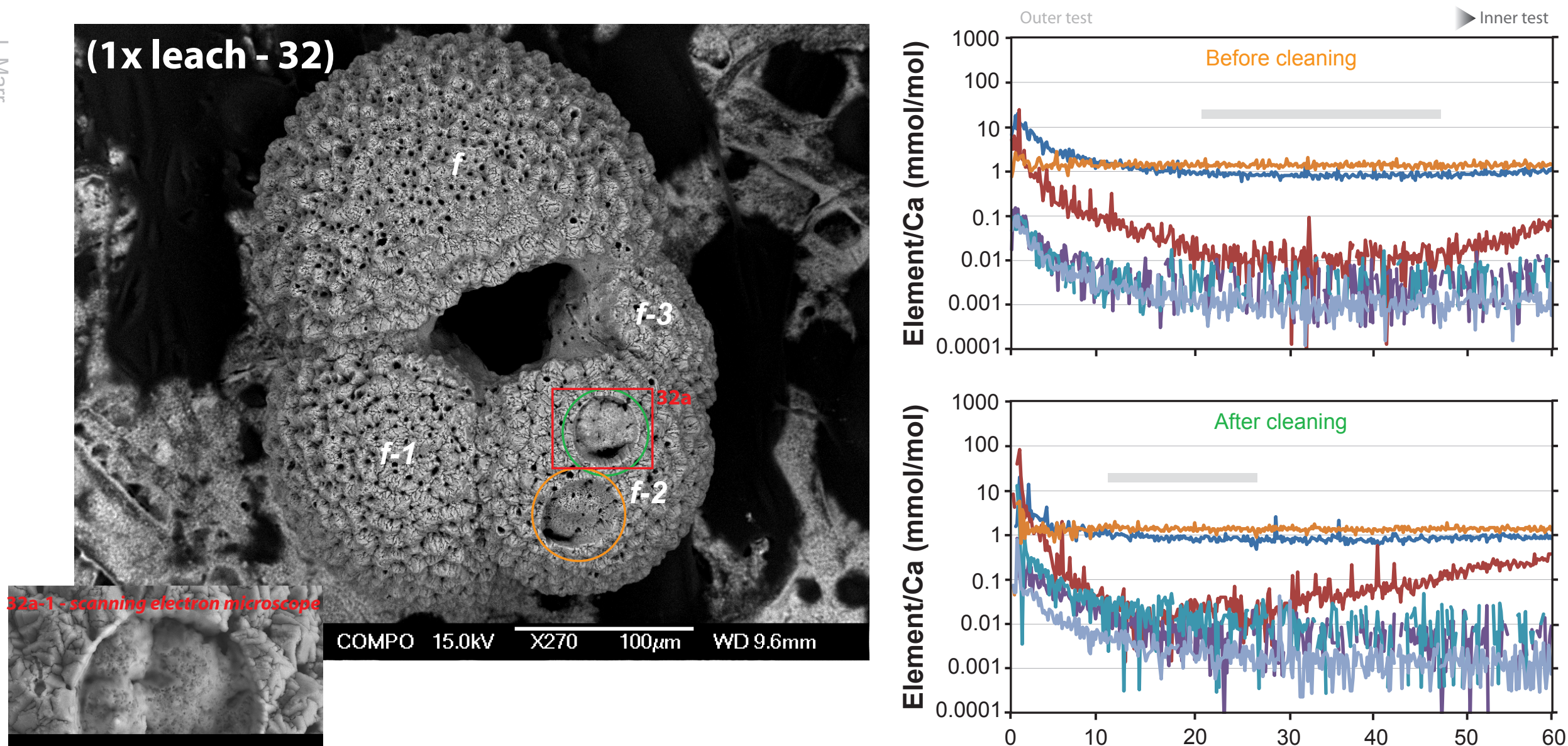

Key

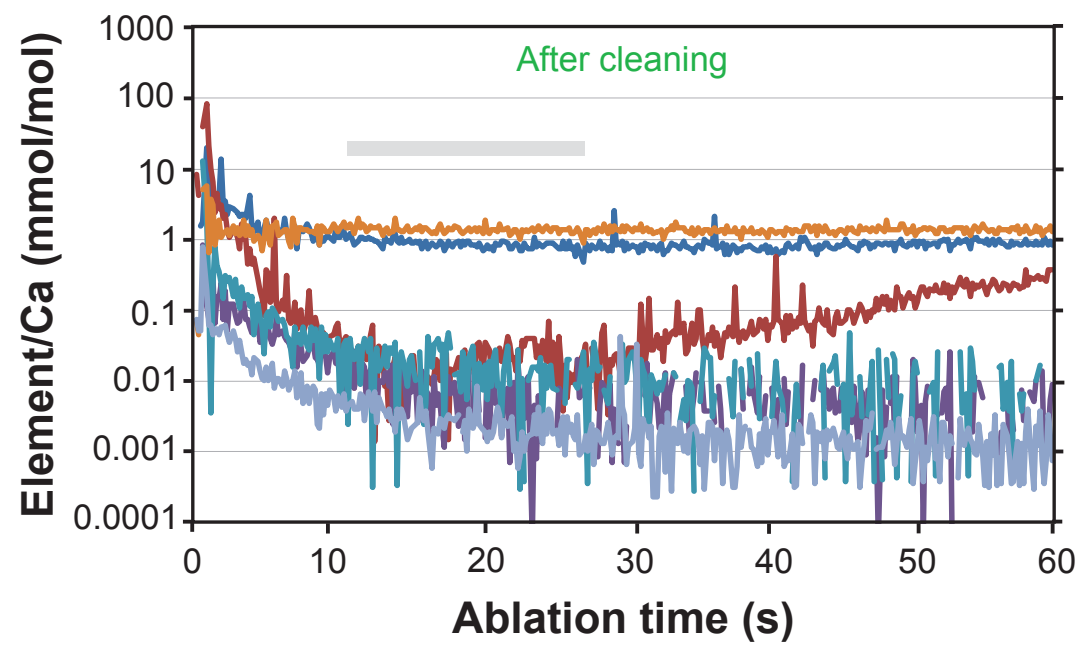

$\mathrm{Mg} / \mathrm{Ca}$

$\mathrm{Al} / \mathrm{Ca}$

$\mathrm{Mn} / \mathrm{Ca}$

$\mathrm{Zn} / \mathrm{Ca}$

$\mathrm{Sr} / \mathrm{Ca}$

$\mathrm{Ba} / \mathrm{Ca}$

integrated data

Image Ablation pits

Before

cleaning

After

cleaning

ing

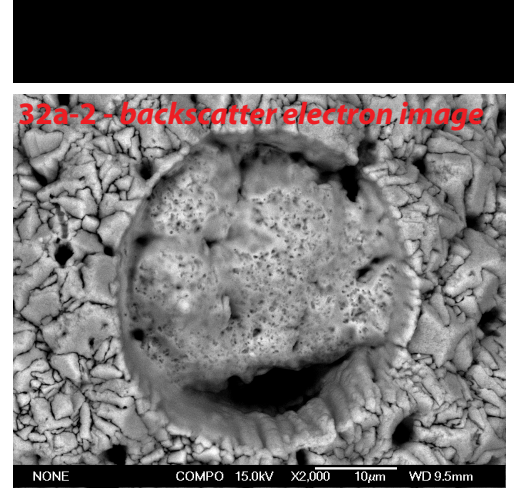

Sample: 1x Leach - 32

\section{$\mathrm{Mg} / \mathrm{Ca} \quad \mathrm{Al} / \mathrm{Ca}$}

Before cleaning

intergrated profile mean

2 sd

After cleaning

intergrated profile mean

2 sd

Difference $(\mathrm{mmol} / \mathrm{mol})(\mathrm{mmol} / \mathrm{mol})$

\begin{tabular}{l|l}
0.86 & 0.016 \\
\hline
\end{tabular}

\begin{tabular}{|l|l|}
\hline 0.30 & 0.027
\end{tabular}

0.88

0.22

$-0.02$
$\mathrm{Mn} / \mathrm{Ca} \quad \mathrm{Zn} / \mathrm{Ca}$

$\mathrm{Sr} / \mathrm{Ca}$

$\mathrm{Ba} / \mathrm{Ca}$

$(\mathrm{mmol} / \mathrm{mol})(\mathrm{mmol} / \mathrm{mol})(\mathrm{mmol} / \mathrm{mol})(\mathrm{mmol} / \mathrm{mol})$

\begin{tabular}{|l|l|l|l|}
\hline 0.002 & 0.001 & 1.36 & 0.001 \\
\hline 0.007 & 0.008 & 0.32 & 0.002 \\
\hline & & & \\
\hline 0.008 & 0.017 & 1.39 & 0.003 \\
\hline 0.012 & 0.026 & 0.31 & 0.003 \\
\hline
\end{tabular}




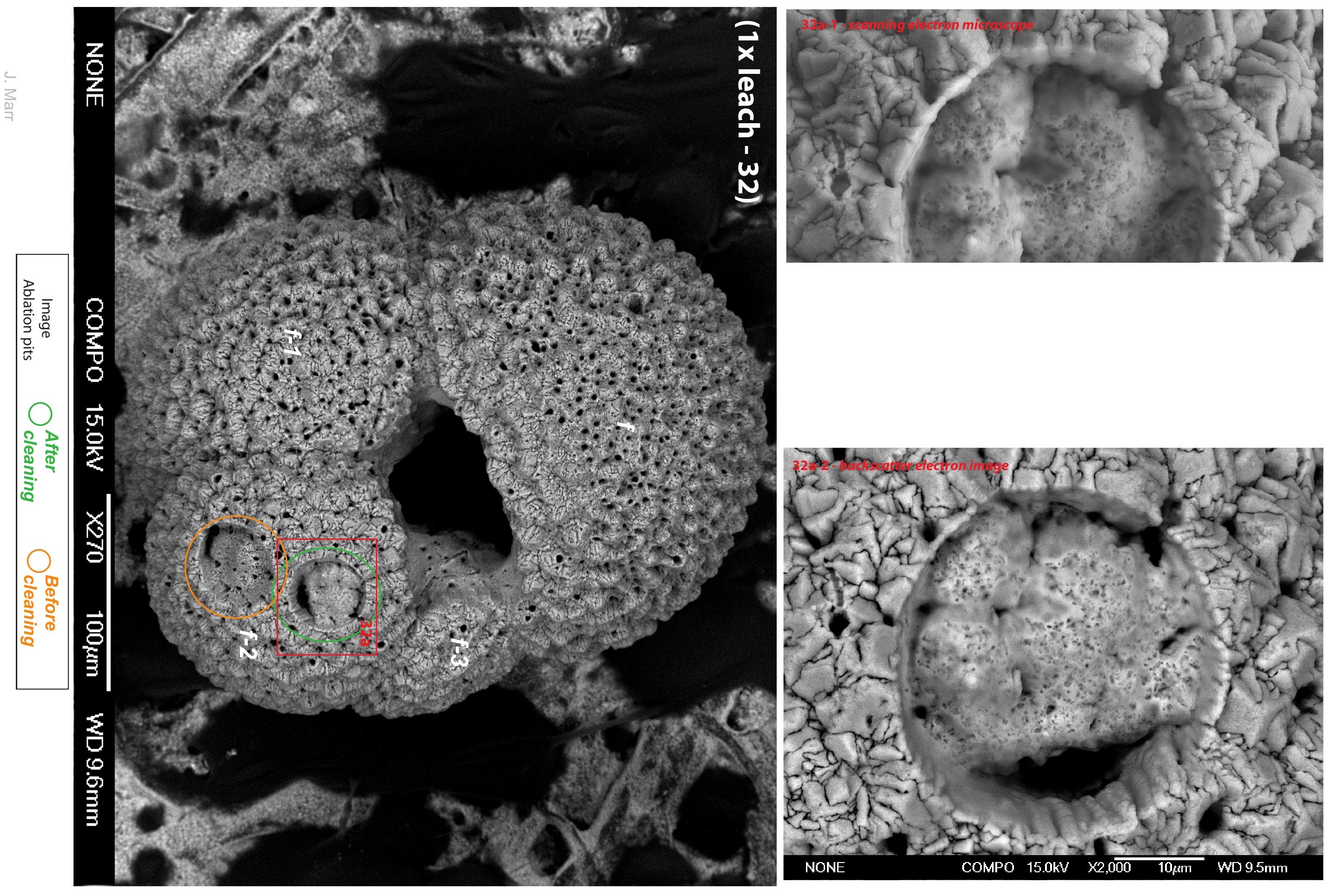




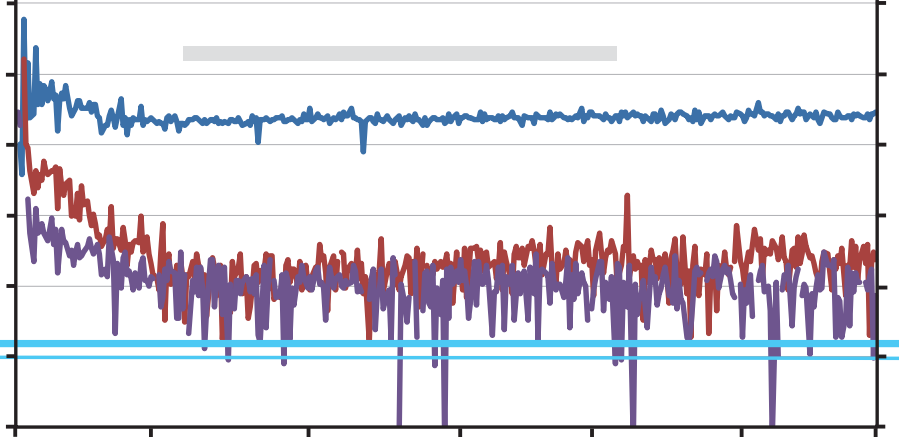



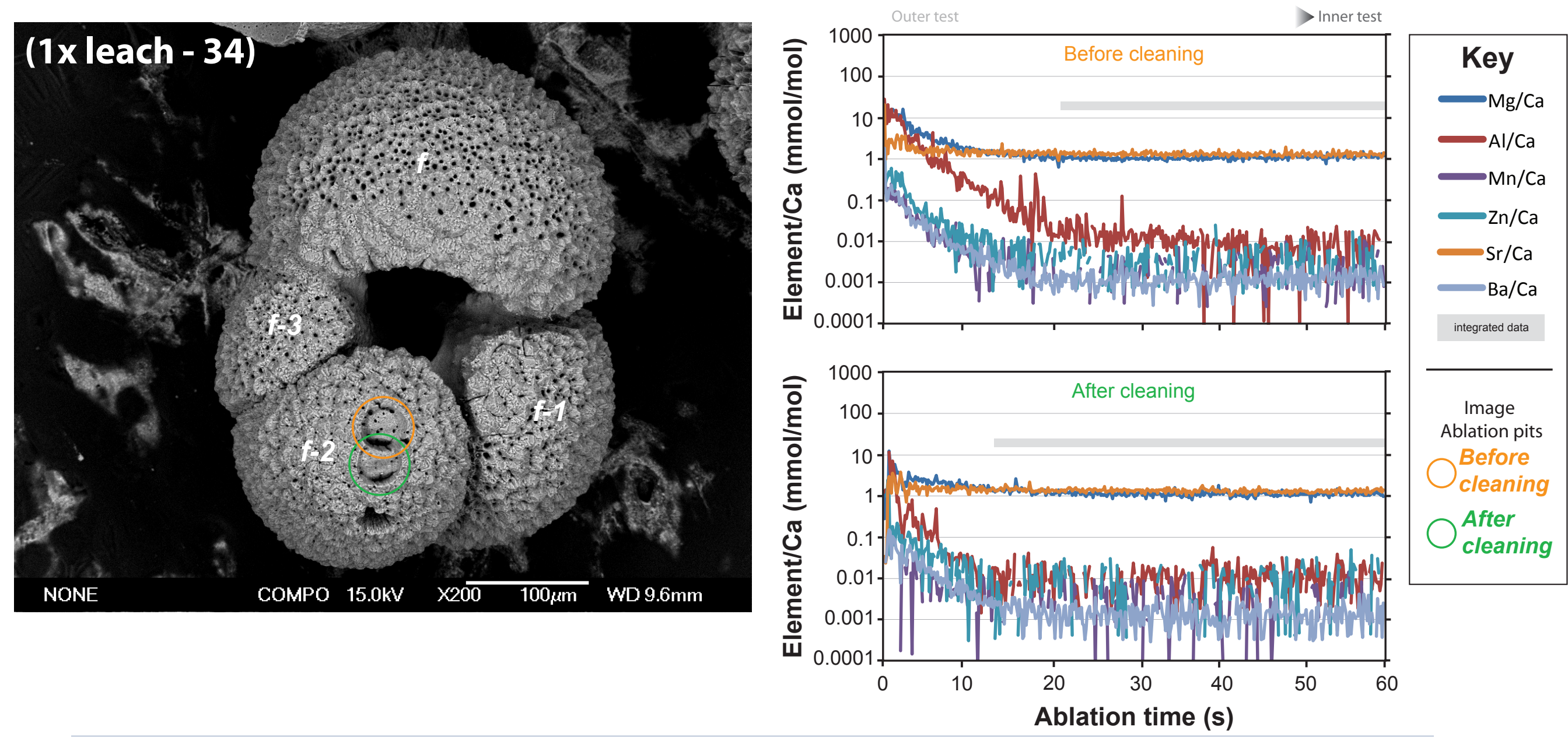

\begin{tabular}{|l|l|}
\hline Sample: & $1 x$ Leach -34 \\
Before cleaning \\
\hline intergrated profile mean \\
\hline $\mathbf{2}$ sd \\
\hline After cleaning \\
\hline intergrated profile mean \\
\hline $\mathbf{2}$ sd \\
\hline
\end{tabular}

$\mathrm{Mg} / \mathrm{Ca} \quad \mathrm{Al} / \mathrm{Ca}$

(mmol/mol) (mmol/mol)

$\begin{array}{ll}1.04 & 0.011\end{array}$

\begin{tabular}{l|l}
1.04 & 0.020
\end{tabular}

Difference
1.10

0.27

$-0.05$
$\mathrm{Mn} / \mathrm{Ca}$

$\mathrm{Zn} / \mathrm{Ca}$

$\mathrm{Sr} / \mathrm{Ca}$

$\mathrm{Ba} / \mathrm{Ca}$

$(\mathrm{mmol} / \mathrm{mol})(\mathrm{mmol} / \mathrm{mol})(\mathrm{mmol} / \mathrm{mol})(\mathrm{mmol} / \mathrm{mol})$

\begin{tabular}{|l|l|l|l|}
\hline 0.001 & 0.002 & 1.27 & 0.001 \\
\hline 0.007 & 0.008 & 0.27 & 0.001 \\
\hline & & & \\
\hline 0.000 & 0.000 & 1.30 & 0.001 \\
\hline 0.012 & 0.024 & 0.25 & 0.002 \\
\hline & & & \\
\hline 0.001 & 0.001 & -0.03 & 0.000 \\
\hline
\end{tabular}



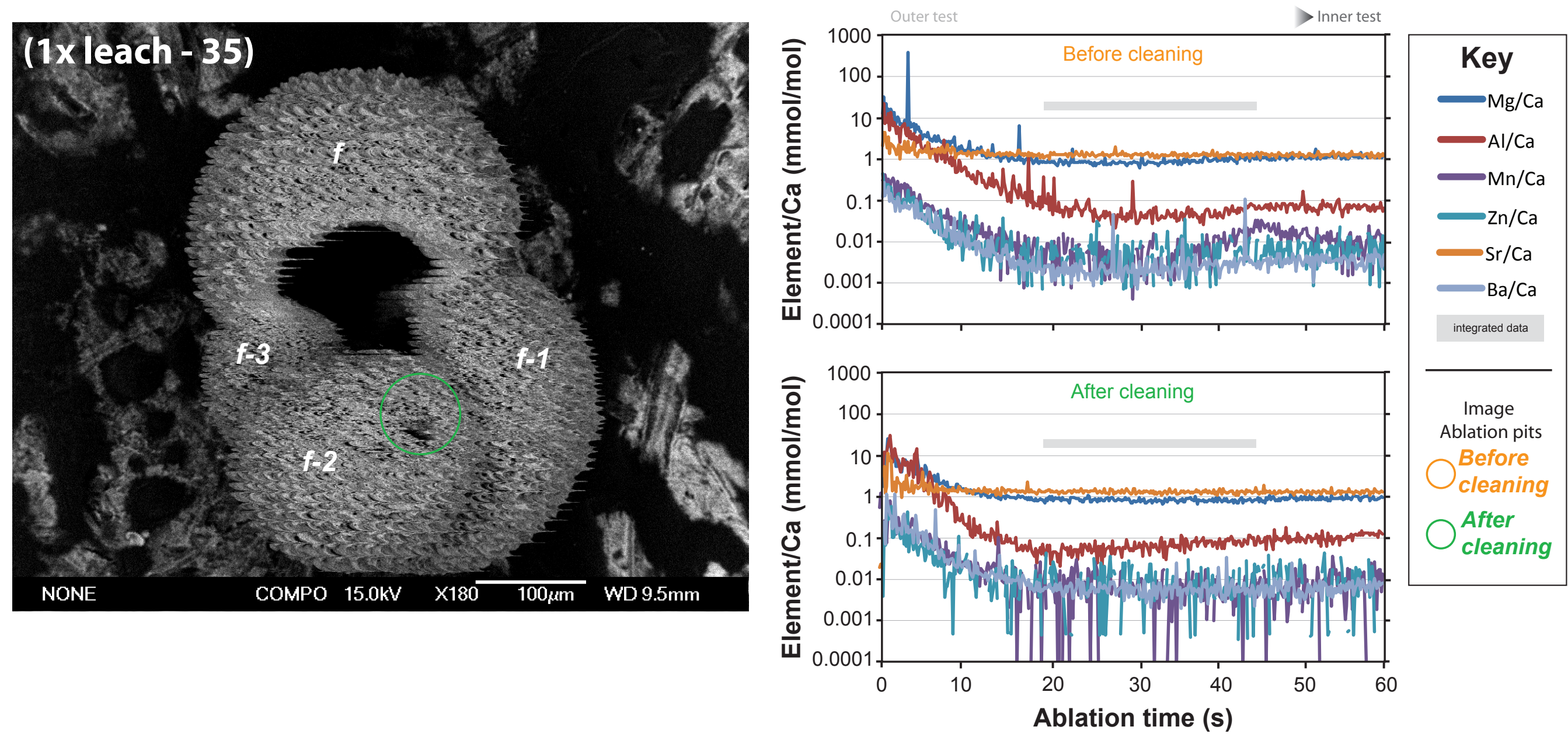

Sample: 1x Leach - 35

\begin{tabular}{|c|c|c|c|c|c|c|}
\hline Before cleaning & $\begin{array}{c}\mathrm{Mg} / \mathrm{Ca} \\
(\mathrm{mmol} / \mathrm{mol})\end{array}$ & $\begin{array}{c}\mathrm{Al} / \mathrm{Ca} \\
(\mathrm{mmol} / \mathrm{mol})\end{array}$ & $\begin{array}{c}\mathrm{Mn} / \mathrm{Ca} \\
(\mathrm{mmol} / \mathrm{mol})\end{array}$ & $\begin{array}{c}\mathrm{Zn} / \mathrm{Ca} \\
(\mathrm{mmol} / \mathrm{mol})\end{array}$ & $\begin{array}{c}\mathrm{Sr} / \mathrm{Ca} \\
(\mathrm{mmol} / \mathrm{mol})\end{array}$ & $\begin{array}{c}\mathrm{Ba} / \mathrm{Ca} \\
(\mathrm{mmol} / \mathrm{mol})\end{array}$ \\
\hline intergrated profile mean & 0.98 & 0.060 & 0.009 & 0.005 & 1.28 & 0.003 \\
\hline $2 s d$ & 0.37 & 0.059 & 0.015 & 0.012 & 0.23 & 0.014 \\
\hline \multicolumn{7}{|l|}{ After cleaning } \\
\hline intergrated profile mean & 0.83 & 0.068 & 0.006 & 0.003 & 1.30 & 0.006 \\
\hline 2 sd & 0.17 & 0.048 & 0.013 & 0.027 & 0.23 & 0.007 \\
\hline \multicolumn{7}{|l|}{ Difference } \\
\hline mean & 0.15 & -0.008 & 0.003 & 0.002 & -0.02 & -0.003 \\
\hline
\end{tabular}



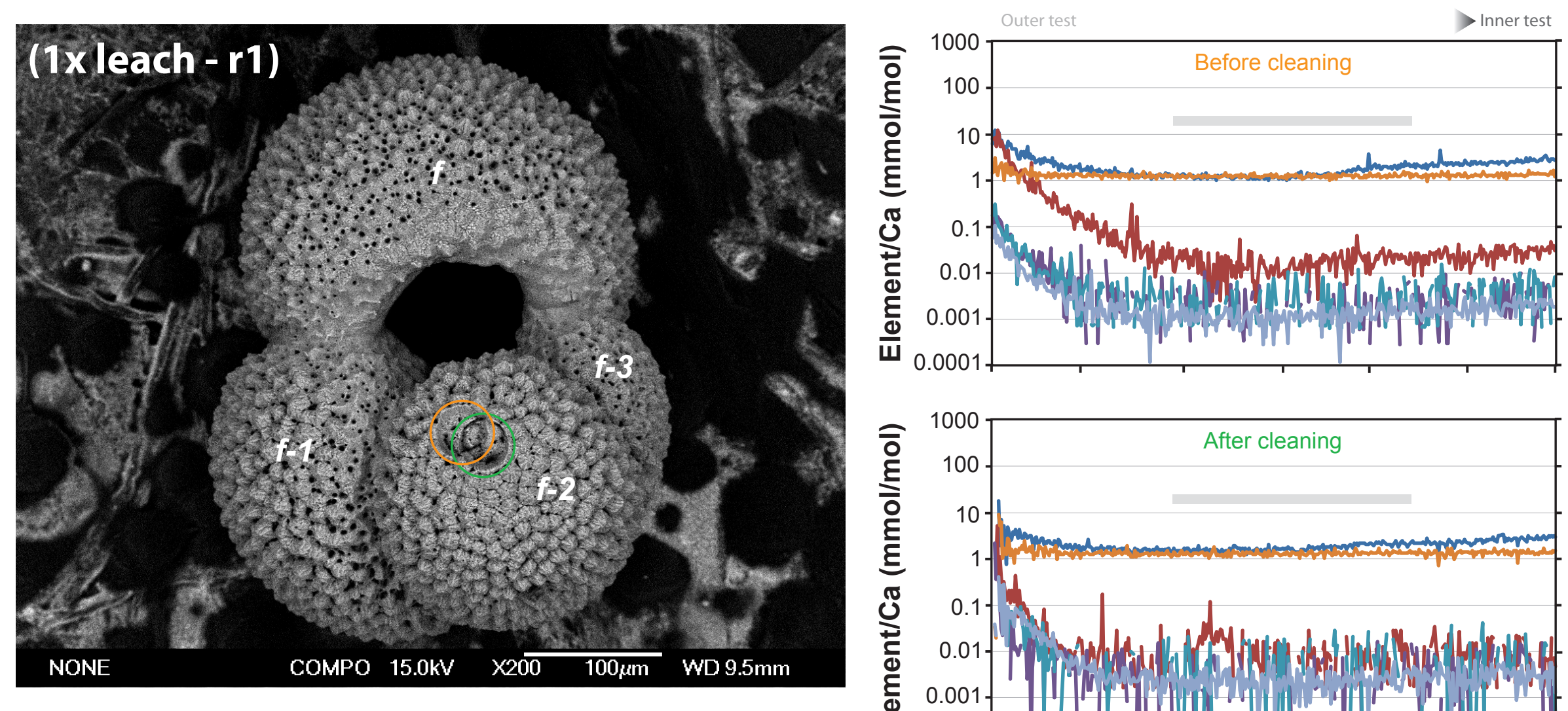

Key

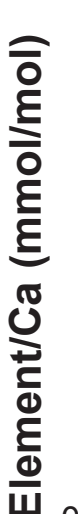

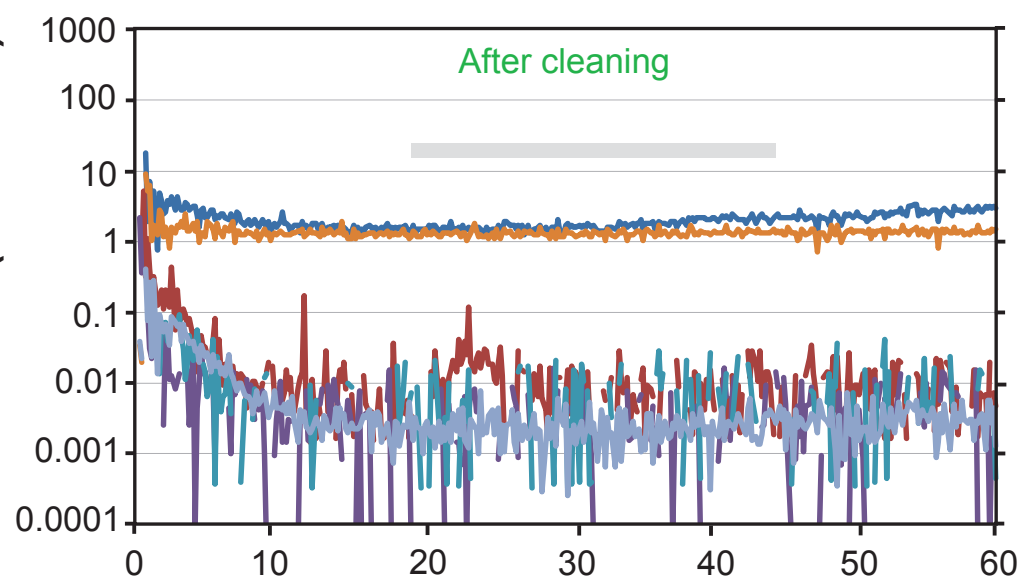

$\mathrm{Mg} / \mathrm{Ca}$

$\mathrm{Al} / \mathrm{Ca}$

$\mathrm{Mn} / \mathrm{Ca}$

$\mathrm{Zn} / \mathrm{Ca}$

$\mathrm{Sr} / \mathrm{Ca}$

$\mathrm{Ba} / \mathrm{Ca}$

integrated data

Image Ablation pits

Before

cleaning

After

cleaning

Ablation time (s)

\begin{tabular}{|c|c|c|c|c|c|c|c|}
\hline \multicolumn{8}{|c|}{ Sample: $1 x$ Leach - r1 } \\
\hline \multicolumn{2}{|c|}{ Before cleaning } & $\begin{array}{c}\mathrm{Mg} / \mathrm{Ca} \\
(\mathrm{mmol} / \mathrm{mol})\end{array}$ & $\begin{array}{c}\mathrm{Al} / \mathrm{Ca} \\
(\mathrm{mmol} / \mathrm{mol})\end{array}$ & $\begin{array}{c}\mathrm{Mn} / \mathrm{Ca} \\
(\mathrm{mmol} / \mathrm{mol})\end{array}$ & $\begin{array}{c}\mathrm{Zn} / \mathrm{Ca} \\
(\mathrm{mmol} / \mathrm{mol})\end{array}$ & $\begin{array}{c}\mathrm{Sr} / \mathrm{Ca} \\
(\mathrm{mmol} / \mathrm{mol})\end{array}$ & $\begin{array}{c}\mathrm{Ba} / \mathrm{Ca} \\
(\mathrm{mmol} / \mathrm{mol})\end{array}$ \\
\hline & intergrated profile mean & 1.74 & 0.022 & 0.001 & 0.002 & 1.26 & 0.001 \\
\hline \multicolumn{8}{|c|}{ After cleaning } \\
\hline & intergrated profile mean & 1.61 & 0.008 & 0.000 & 0.000 & 1.27 & 0.002 \\
\hline & $2 \mathrm{sd}$ & 0.49 & 0.024 & 0.012 & 0.021 & 0.26 & 0.002 \\
\hline & mean & 0.13 & 0.014 & 0.001 & 0.002 & 0.00 & -0.001 \\
\hline
\end{tabular}



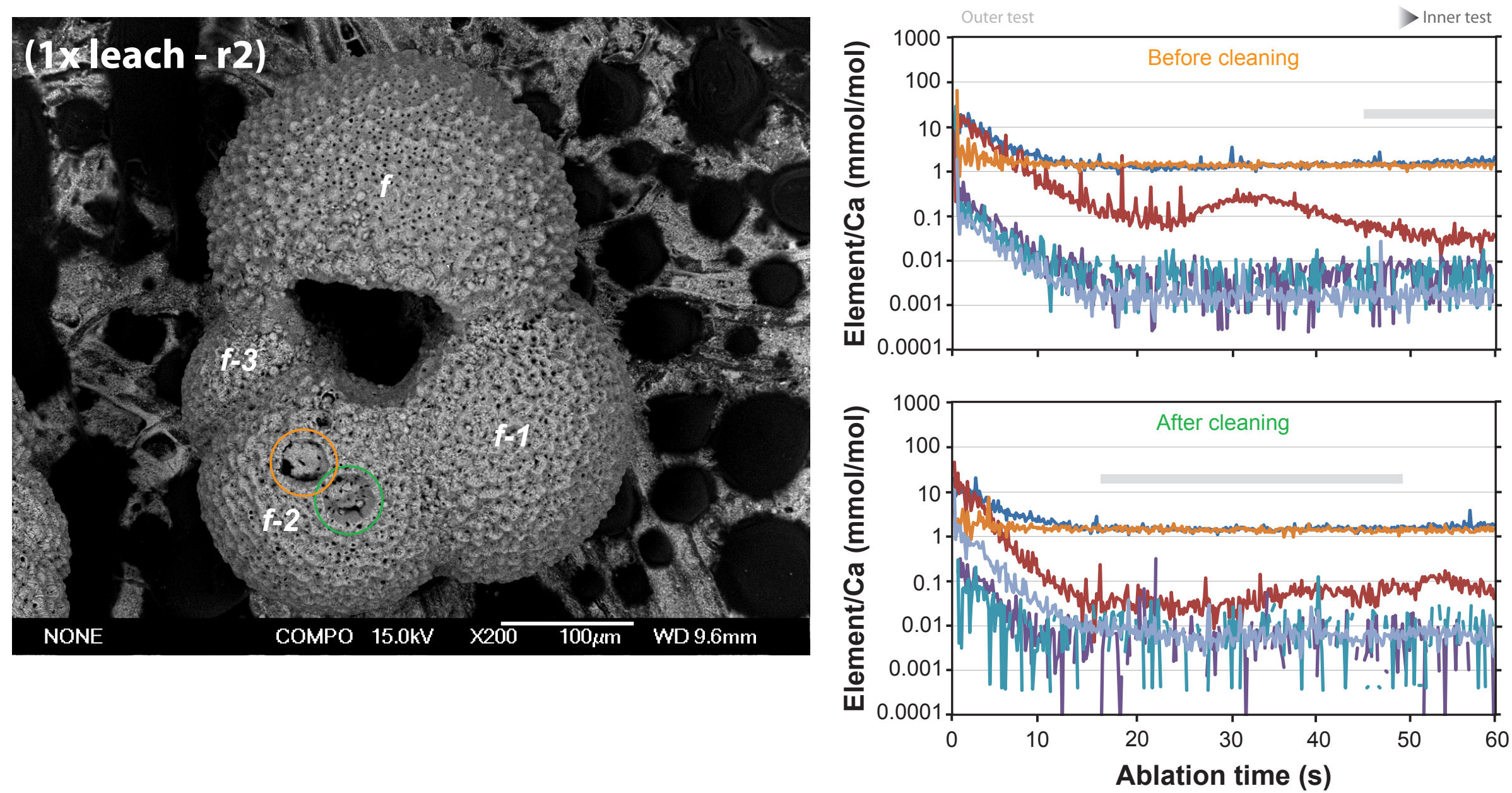

Key

$\mathrm{Mg} / \mathrm{Ca}$

$\mathrm{Al} / \mathrm{Ca}$

$\mathrm{Mn} / \mathrm{Ca}$

$\mathrm{Zn} / \mathrm{Ca}$

$\mathrm{Sr} / \mathrm{Ca}$

$\mathrm{Ba} / \mathrm{Ca}$

integrated data

Image Ablation pits

Before

cleaning

After

cleaning

Ablation time (s)

Sample: $1 x$ Leach $-r 2$

\section{$\mathrm{Mg} / \mathrm{Ca} \quad \mathrm{Al} / \mathrm{Ca}$} $(\mathrm{mmol} / \mathrm{mol})(\mathrm{mmol} / \mathrm{mol})$

Before cleaning

intergrated profile mean

2 sd

After cleaning

intergrated profile mean

2 sd

1.25

\begin{tabular}{l|l}
0.22 & 0.603
\end{tabular}

\begin{tabular}{ll}
1.41 & 0.041 \\
\hline
\end{tabular}

\begin{tabular}{l|l}
0.29 & 0.042
\end{tabular}

Difference

$-0.17$

0.108

\section{$\mathrm{Mn} / \mathrm{Ca}$}

$\mathrm{Zn} / \mathrm{Ca}$

$\mathrm{Sr} / \mathrm{Ca}$

$\mathrm{Ba} / \mathrm{Ca}$

$(\mathrm{mmol} / \mathrm{mol}) \quad(\mathrm{mmol} / \mathrm{mol}) \quad(\mathrm{mmol} / \mathrm{mol}) \quad(\mathrm{mmol} / \mathrm{mol})$

\begin{tabular}{|l|l|l|l|}
\hline 0.003 & 0.003 & 1.44 & 0.002 \\
\hline 0.006 & 0.010 & 0.22 & 0.004 \\
\hline & & & \\
\hline 0.004 & 0.002 & 1.37 & 0.007 \\
\hline 0.052 & 0.029 & 0.27 & 0.009 \\
\hline & & & \\
\hline-0.001 & 0.001 & 0.06 & -0.005 \\
\hline
\end{tabular}




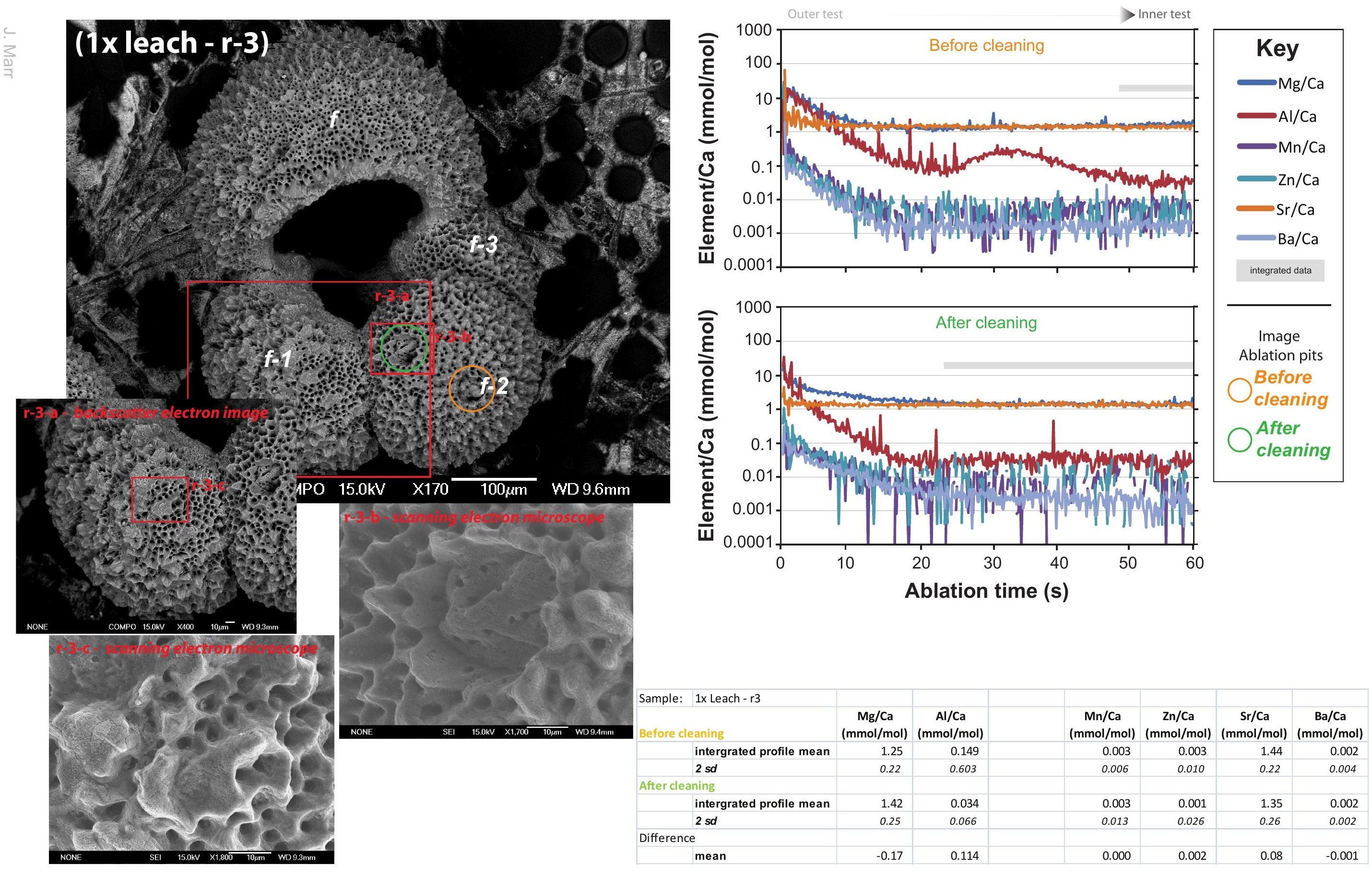



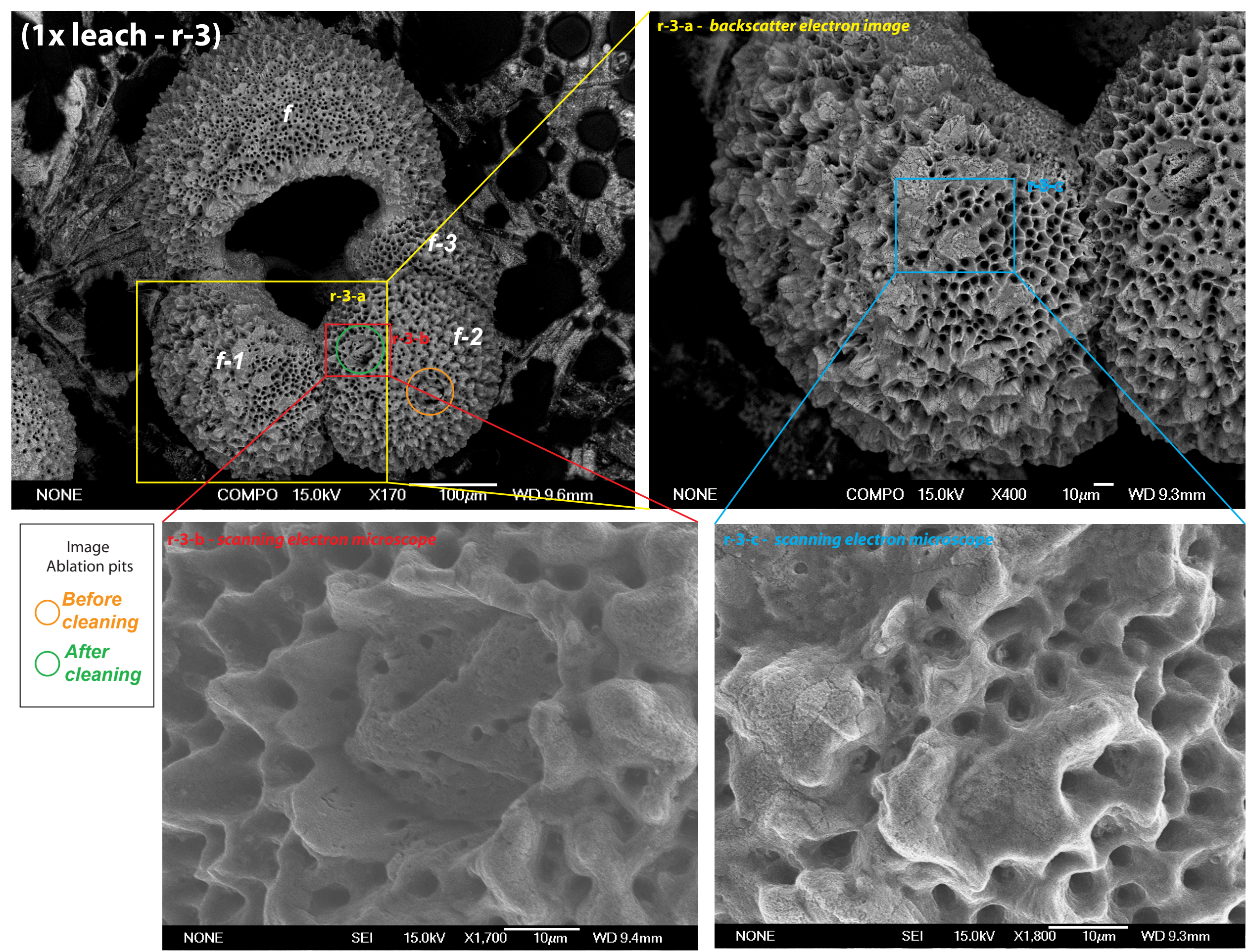


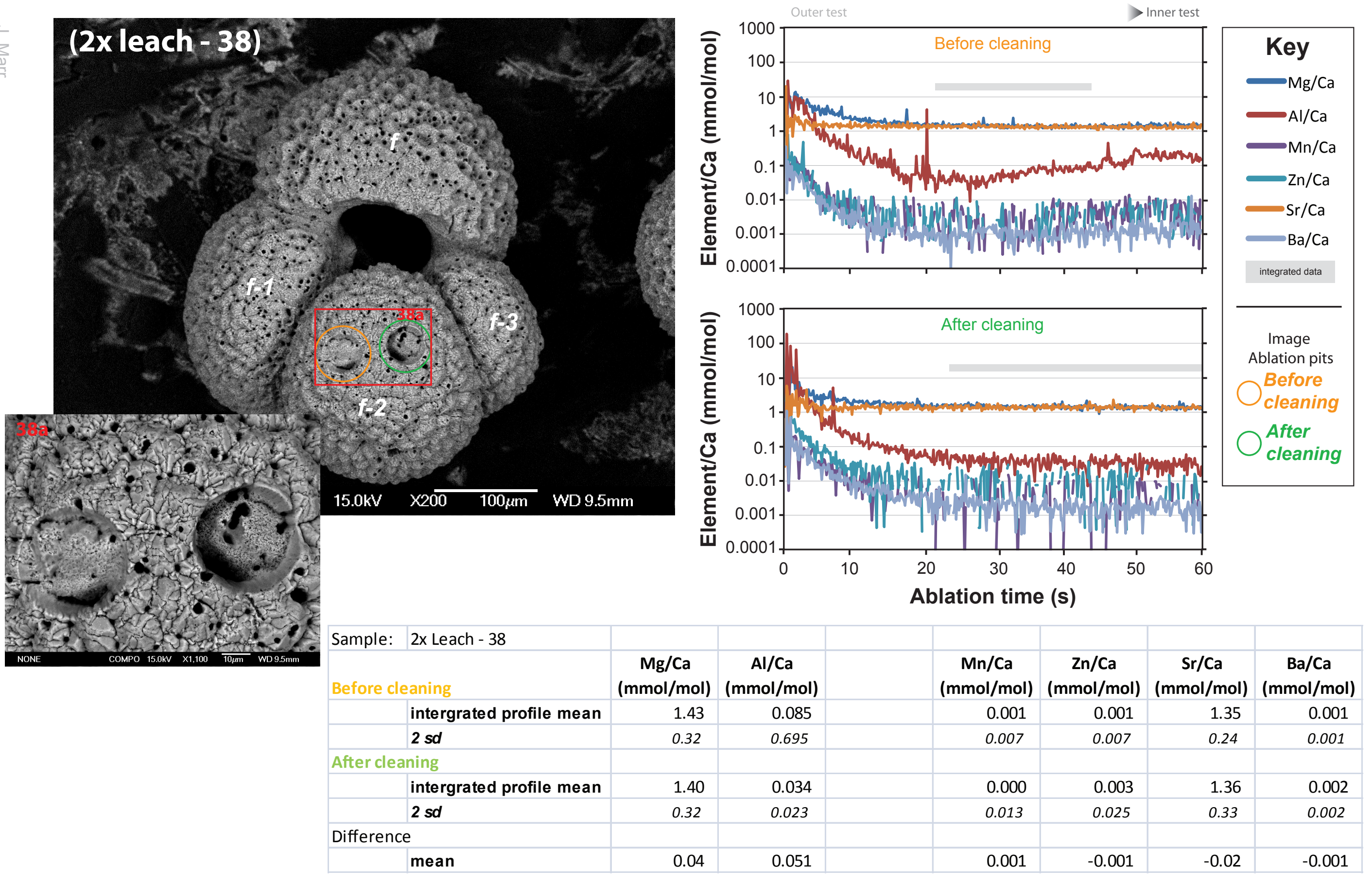



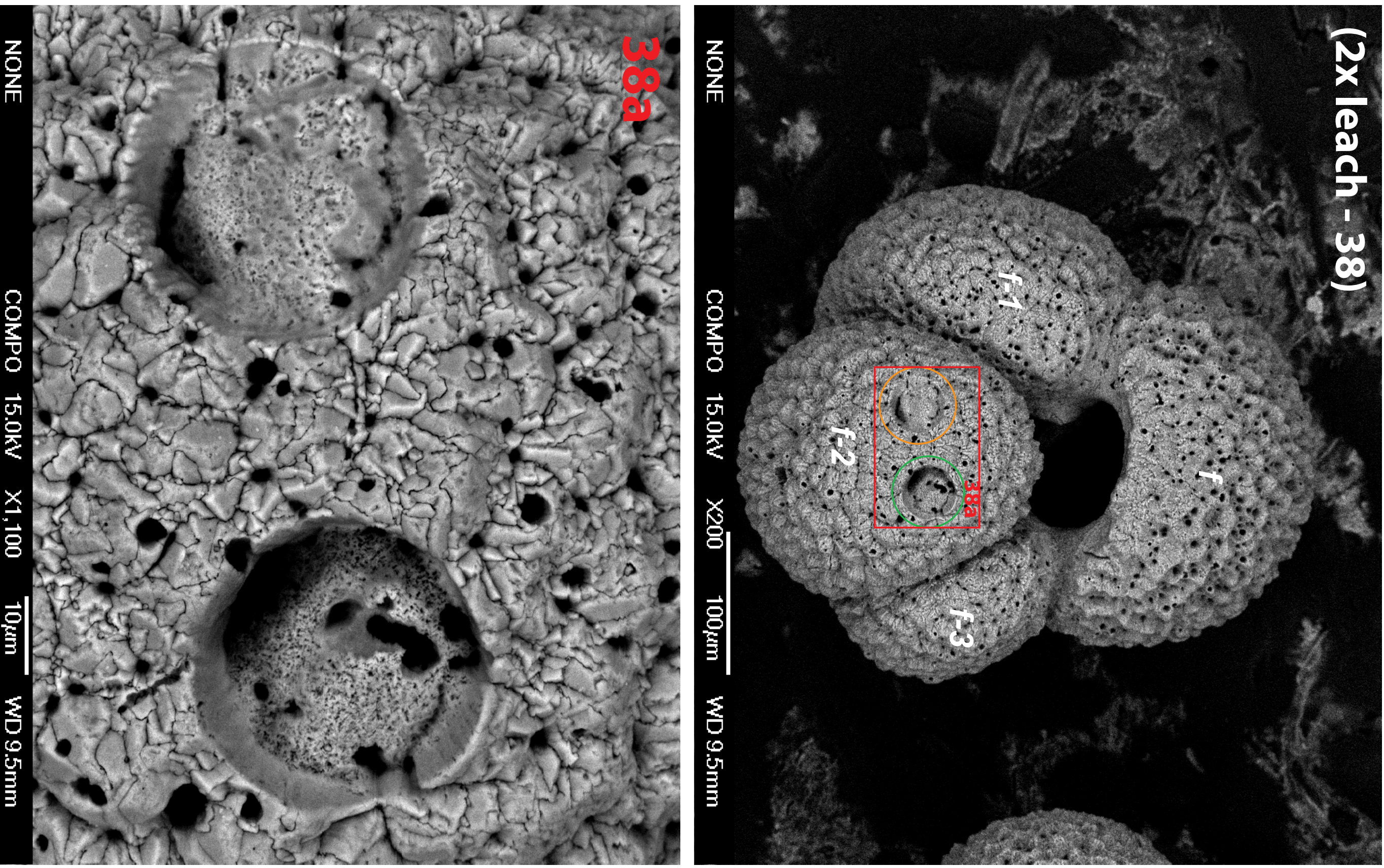

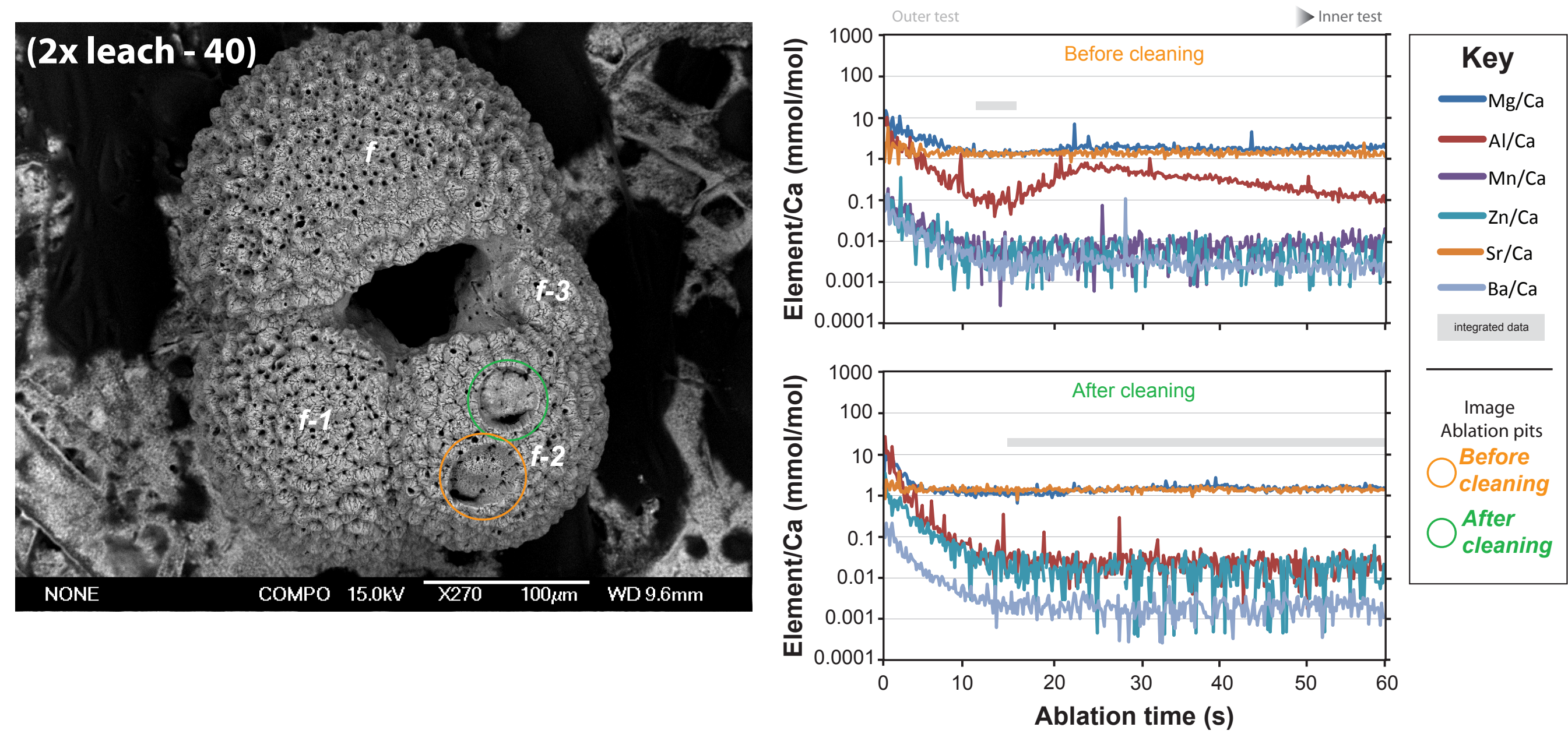

\begin{tabular}{|c|c|c|c|c|c|c|c|}
\hline \multicolumn{8}{|c|}{ Sample: $2 x$ Leach - 40} \\
\hline \multicolumn{2}{|c|}{ Before cleaning } & $\begin{array}{c}\mathrm{Mg} / \mathrm{Ca} \\
(\mathrm{mmol} / \mathrm{mol})\end{array}$ & $\begin{array}{c}\mathrm{Al} / \mathrm{Ca} \\
(\mathrm{mmol} / \mathrm{mol})\end{array}$ & $\begin{array}{c}\mathrm{Mn} / \mathrm{Ca} \\
(\mathrm{mmol} / \mathrm{mol})\end{array}$ & $\begin{array}{c}\mathrm{Zn} / \mathrm{Ca} \\
(\mathrm{mmol} / \mathrm{mol})\end{array}$ & $\begin{array}{c}\mathrm{Sr} / \mathrm{Ca} \\
(\mathrm{mmol} / \mathrm{mol})\end{array}$ & $\begin{array}{c}\mathrm{Ba} / \mathrm{Ca} \\
(\mathrm{mmol} / \mathrm{mol})\end{array}$ \\
\hline & intergrated profile mean & 1.40 & 0.141 & 0.007 & 0.004 & 1.32 & 0.004 \\
\hline & $2 \mathrm{sd}$ & 0.42 & 0.378 & 0.008 & 0.008 & 0.31 & 0.004 \\
\hline \multicolumn{8}{|c|}{ After cleaning } \\
\hline & intergrated profile mean & 1.49 & 0.023 & 0.004 & 0.015 & 1.39 & 0.002 \\
\hline & 2 sd & 0.39 & 0.041 & 0.015 & 0.025 & 0.25 & 0.002 \\
\hline \multicolumn{8}{|c|}{ Difference } \\
\hline & mean & -0.10 & 0.118 & 0.003 & -0.011 & -0.07 & 0.002 \\
\hline
\end{tabular}



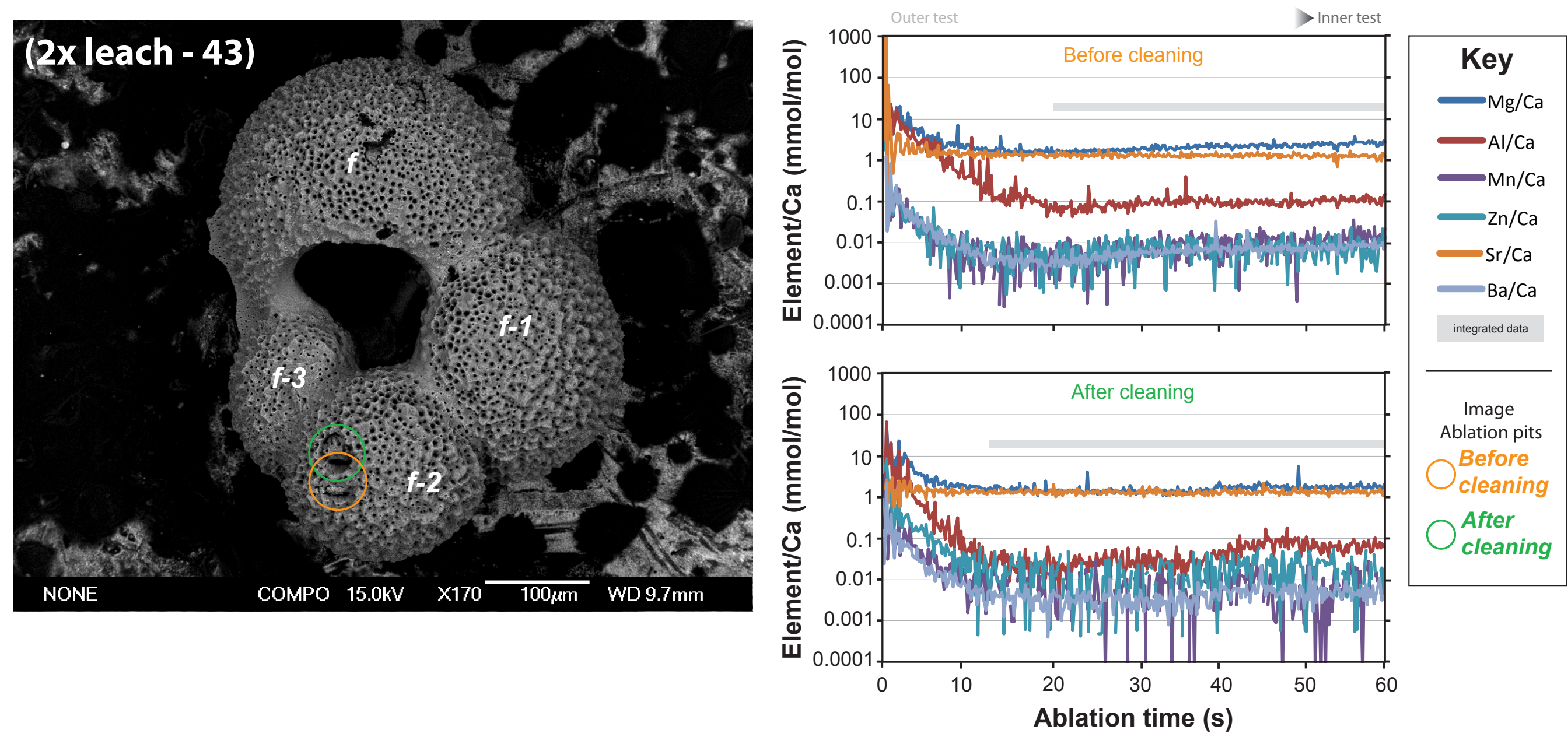

\begin{tabular}{|c|c|c|c|c|c|c|c|}
\hline \multicolumn{8}{|c|}{ Sample: $2 x$ Leach - 43} \\
\hline \multicolumn{2}{|c|}{ Before cleaning } & $\begin{array}{c}\mathrm{Mg} / \mathrm{Ca} \\
(\mathrm{mmol} / \mathrm{mol})\end{array}$ & $\begin{array}{c}\mathrm{Al} / \mathrm{Ca} \\
(\mathrm{mmol} / \mathrm{mol})\end{array}$ & $\begin{array}{c}\mathrm{Mn} / \mathrm{Ca} \\
(\mathrm{mmol} / \mathrm{mol})\end{array}$ & $\begin{array}{c}\mathrm{Zn} / \mathrm{Ca} \\
(\mathrm{mmol} / \mathrm{mol})\end{array}$ & $\begin{array}{c}\mathrm{Sr} / \mathrm{Ca} \\
(\mathrm{mmol} / \mathrm{mol})\end{array}$ & $\begin{array}{c}\mathrm{Ba} / \mathrm{Ca} \\
(\mathrm{mmol} / \mathrm{mol})\end{array}$ \\
\hline & intergrated profile mean & 2.06 & 0.092 & 0.009 & 0.007 & 1.29 & 0.006 \\
\hline & $2 \mathrm{sd}$ & 0.75 & 0.059 & 0.010 & 0.009 & 0.25 & 0.005 \\
\hline \multicolumn{8}{|c|}{ After cleaning } \\
\hline & intergrated profile mean & 1.42 & 0.025 & 0.004 & 0.009 & 1.31 & 0.003 \\
\hline & 2 sd & 0.59 & 0.025 & 0.015 & 0.029 & 0.31 & 0.003 \\
\hline \multicolumn{8}{|c|}{ Difference } \\
\hline & mean & 0.64 & 0.067 & 0.005 & -0.002 & -0.02 & 0.003 \\
\hline
\end{tabular}



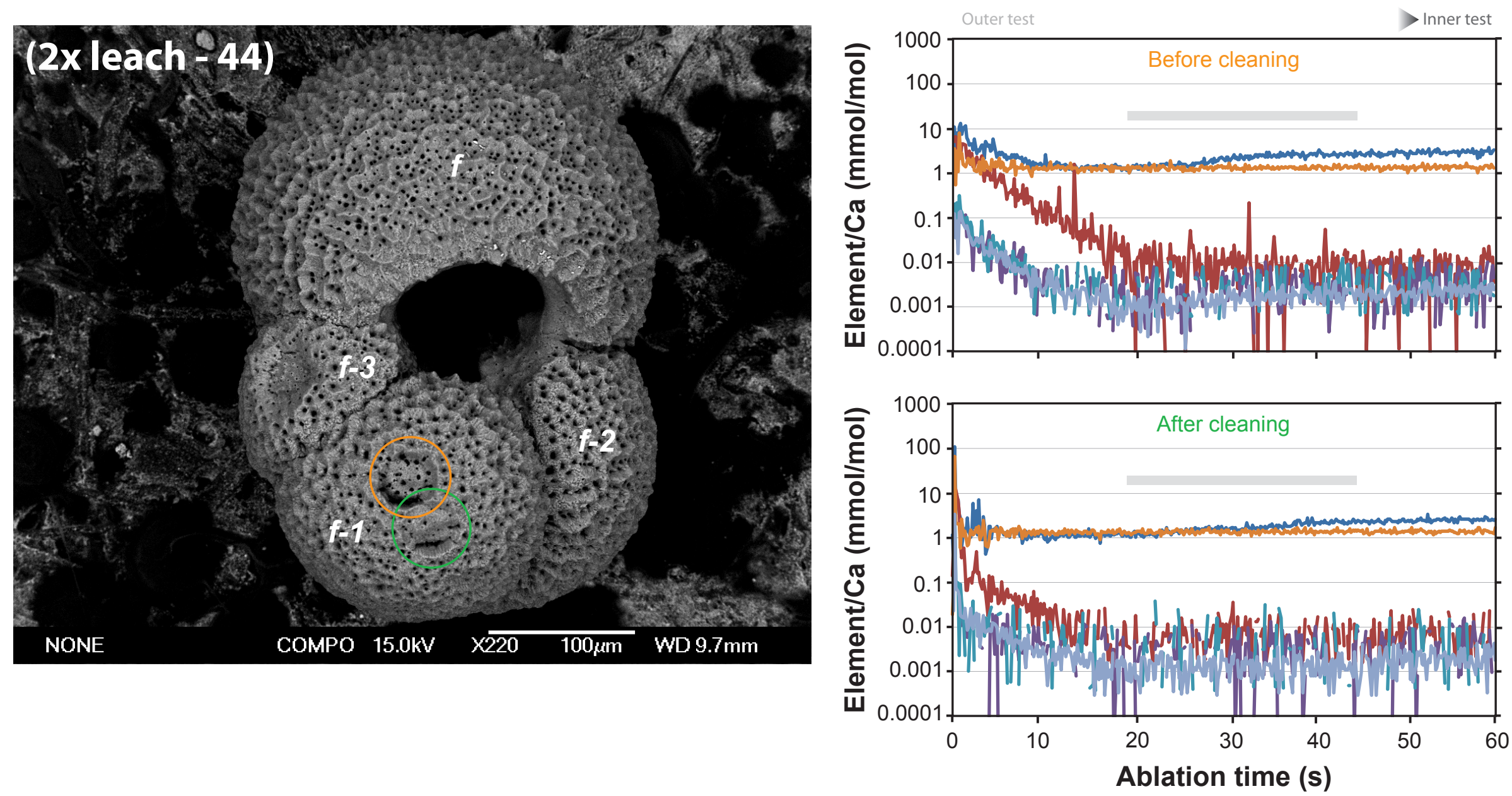

Ablation time (s)

\begin{tabular}{|c|c|c|c|c|c|c|c|}
\hline Sample & 2x Leach - 44 & & & & & & \\
\hline \multicolumn{2}{|c|}{ Before cleaning } & $\begin{array}{c}\mathrm{Mg} / \mathrm{Ca} \\
(\mathrm{mmol} / \mathrm{mol})\end{array}$ & $\begin{array}{c}\mathrm{Al} / \mathrm{Ca} \\
(\mathrm{mmol} / \mathrm{mol})\end{array}$ & $\begin{array}{c}\mathrm{Mn} / \mathrm{Ca} \\
(\mathrm{mmol} / \mathrm{mol})\end{array}$ & $\begin{array}{c}\mathrm{Zn} / \mathrm{Ca} \\
(\mathrm{mmol} / \mathrm{mol})\end{array}$ & $\begin{array}{c}\mathrm{Sr} / \mathrm{Ca} \\
(\mathrm{mmol} / \mathrm{mol})\end{array}$ & $\begin{array}{c}\mathrm{Ba} / \mathrm{Ca} \\
(\mathrm{mmol} / \mathrm{mol})\end{array}$ \\
\hline & intergrated profile mean & 2.38 & 0.010 & 0.002 & 0.001 & 1.31 & 0.002 \\
\hline & 2 sd & 1.12 & 0.029 & 0.007 & 0.007 & 0.23 & 0.001 \\
\hline \multicolumn{8}{|c|}{ After cleaning } \\
\hline & intergrated profile mean & 1.48 & 0.005 & 0.001 & 0.000 & 1.33 & 0.001 \\
\hline & 2 sd & 0.59 & 0.014 & 0.011 & 0.022 & 0.23 & 0.001 \\
\hline \multicolumn{8}{|c|}{ Difference } \\
\hline & mean & 0.91 & 0.005 & 0.001 & 0.001 & -0.01 & 0.001 \\
\hline
\end{tabular}



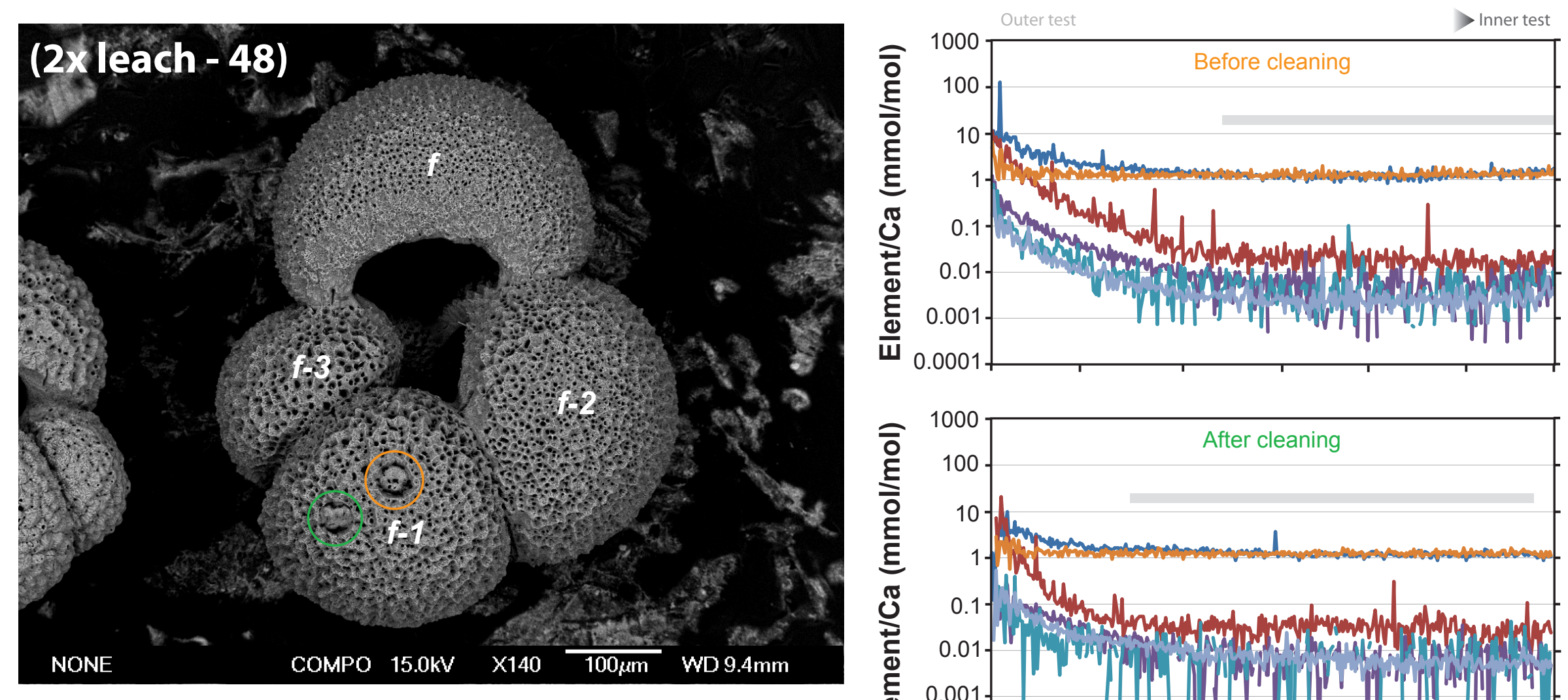

$\mathrm{Mg} / \mathrm{Ca}$

$\mathrm{Al} / \mathrm{Ca}$

$\mathrm{Mn} / \mathrm{Ca}$

$\mathrm{Zn} / \mathrm{Ca}$

$\mathrm{Sr} / \mathrm{Ca}$

$\mathrm{Ba} / \mathrm{Ca}$

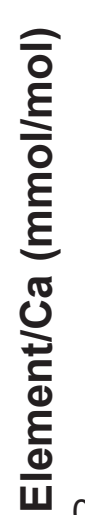

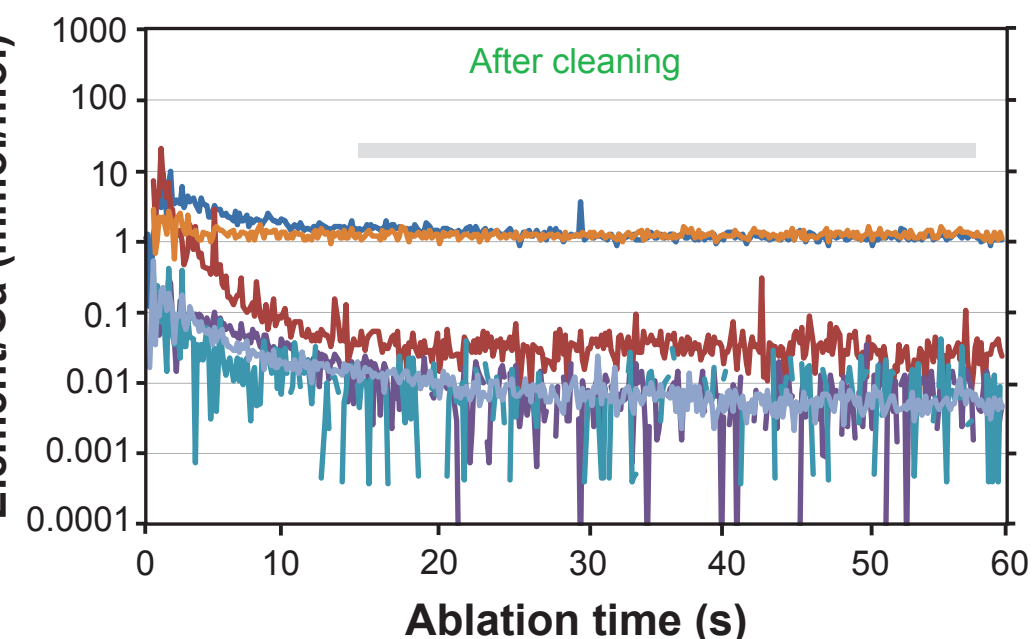

integrated data

Image Ablation pits

Before

cleaning

After

cleaning

Ablation time (s)

\begin{tabular}{|c|c|c|c|c|c|c|c|}
\hline \multicolumn{8}{|c|}{ Sample: $2 x$ Leach - 48} \\
\hline \multicolumn{2}{|c|}{ Before cleaning } & $\begin{array}{c}\mathrm{Mg} / \mathrm{Ca} \\
(\mathrm{mmol} / \mathrm{mol})\end{array}$ & $\begin{array}{c}\mathrm{Al} / \mathrm{Ca} \\
(\mathrm{mmol} / \mathrm{mol})\end{array}$ & $\begin{array}{c}\mathrm{Mn} / \mathrm{Ca} \\
(\mathrm{mmol} / \mathrm{mol})\end{array}$ & $\begin{array}{c}\mathrm{Zn} / \mathrm{Ca} \\
(\mathrm{mmol} / \mathrm{mol})\end{array}$ & $\begin{array}{c}\mathrm{Sr} / \mathrm{Ca} \\
(\mathrm{mmol} / \mathrm{mol})\end{array}$ & $\begin{array}{c}\mathrm{Ba} / \mathrm{Ca} \\
(\mathrm{mmol} / \mathrm{mol})\end{array}$ \\
\hline & intergrated profile mean & 1.27 & 0.023 & 0.005 & 0.004 & 1.30 & 0.003 \\
\hline & $2 \mathrm{sd}$ & 0.40 & 0.048 & 0.008 & 0.015 & 0.34 & 0.003 \\
\hline \multicolumn{8}{|c|}{ After cleaning } \\
\hline & intergrated profile mean & 1.26 & 0.035 & 0.005 & 0.000 & 1.25 & 0.007 \\
\hline & $2 \mathrm{sd}$ & 0.48 & 0.046 & 0.013 & 0.025 & 0.23 & 0.006 \\
\hline \multicolumn{8}{|c|}{ Difference } \\
\hline & mean & 0.02 & -0.012 & 0.000 & 0.003 & 0.06 & -0.004 \\
\hline
\end{tabular}



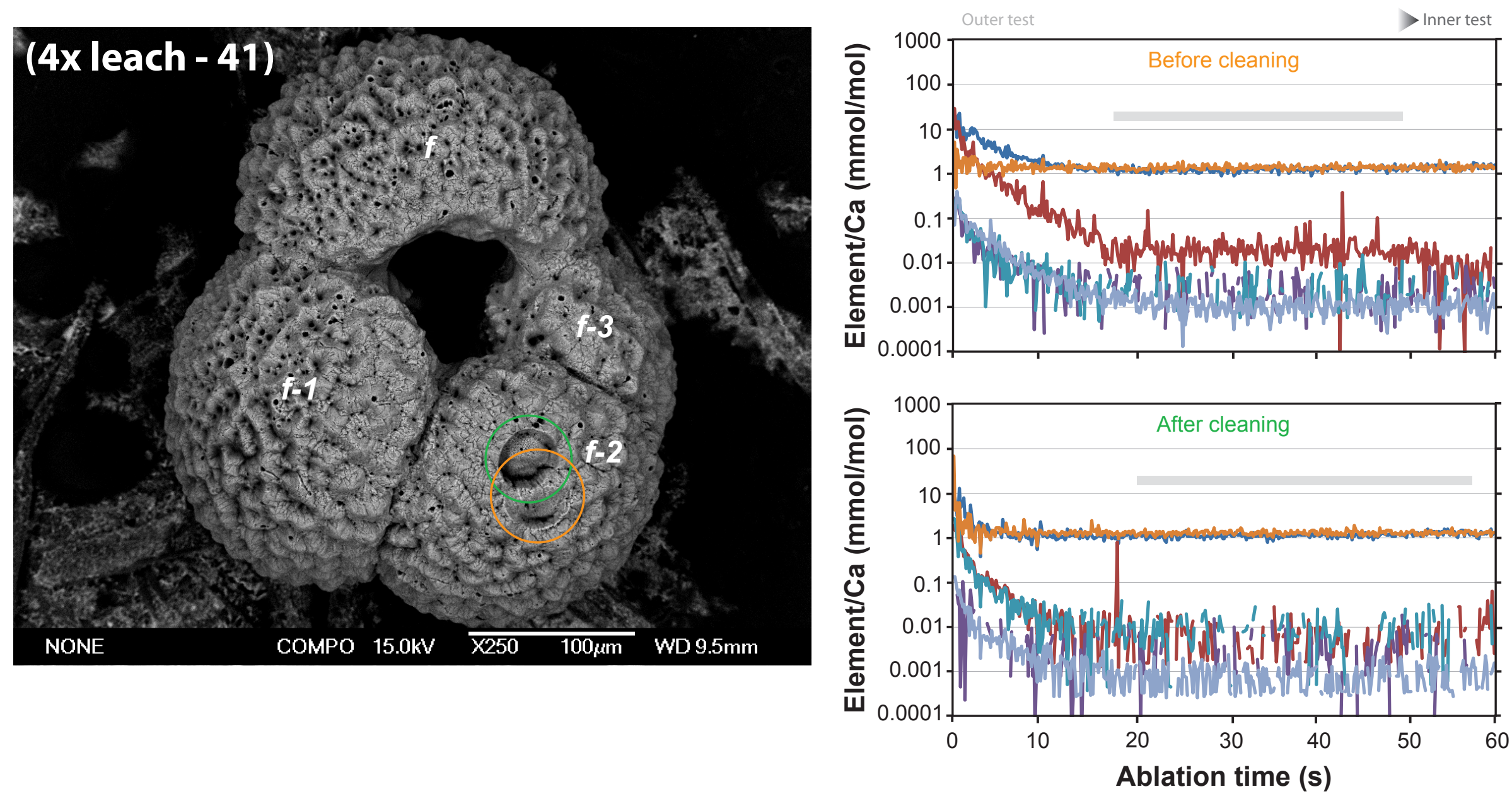

Ablation time (s)

\begin{tabular}{|c|c|c|c|c|c|c|c|}
\hline Sample: & 4x Leach - 41 & & & & & & \\
\hline \multicolumn{2}{|c|}{ Before cleaning } & $\begin{array}{c}\mathrm{Mg} / \mathrm{Ca} \\
(\mathrm{mmol} / \mathrm{mol})\end{array}$ & $\begin{array}{c}\mathrm{Al} / \mathrm{Ca} \\
(\mathrm{mmol} / \mathrm{mol})\end{array}$ & $\begin{array}{c}\mathrm{Mn} / \mathrm{Ca} \\
(\mathrm{mmol} / \mathrm{mol})\end{array}$ & $\begin{array}{c}\mathrm{Zn} / \mathrm{Ca} \\
(\mathrm{mmol} / \mathrm{mol})\end{array}$ & $\begin{array}{c}\mathrm{Sr} / \mathrm{Ca} \\
(\mathrm{mmol} / \mathrm{mol})\end{array}$ & $\begin{array}{c}\mathrm{Ba} / \mathrm{Ca} \\
(\mathrm{mmol} / \mathrm{mol})\end{array}$ \\
\hline & intergrated profile mean & 1.23 & 0.023 & 0.001 & 0.000 & 1.36 & 0.001 \\
\hline & $2 s d$ & 0.28 & 0.058 & 0.006 & 0.008 & 0.31 & 0.001 \\
\hline \multicolumn{8}{|c|}{ After cleaning } \\
\hline & intergrated profile mean & 1.17 & 0.003 & 0.000 & 0.001 & 1.37 & 0.001 \\
\hline & 2 sd & 0.26 & 0.015 & 0.013 & 0.023 & 0.32 & 0.001 \\
\hline \multicolumn{8}{|c|}{ Difference } \\
\hline & mean & 0.07 & 0.020 & 0.001 & -0.001 & -0.01 & 0.000 \\
\hline
\end{tabular}



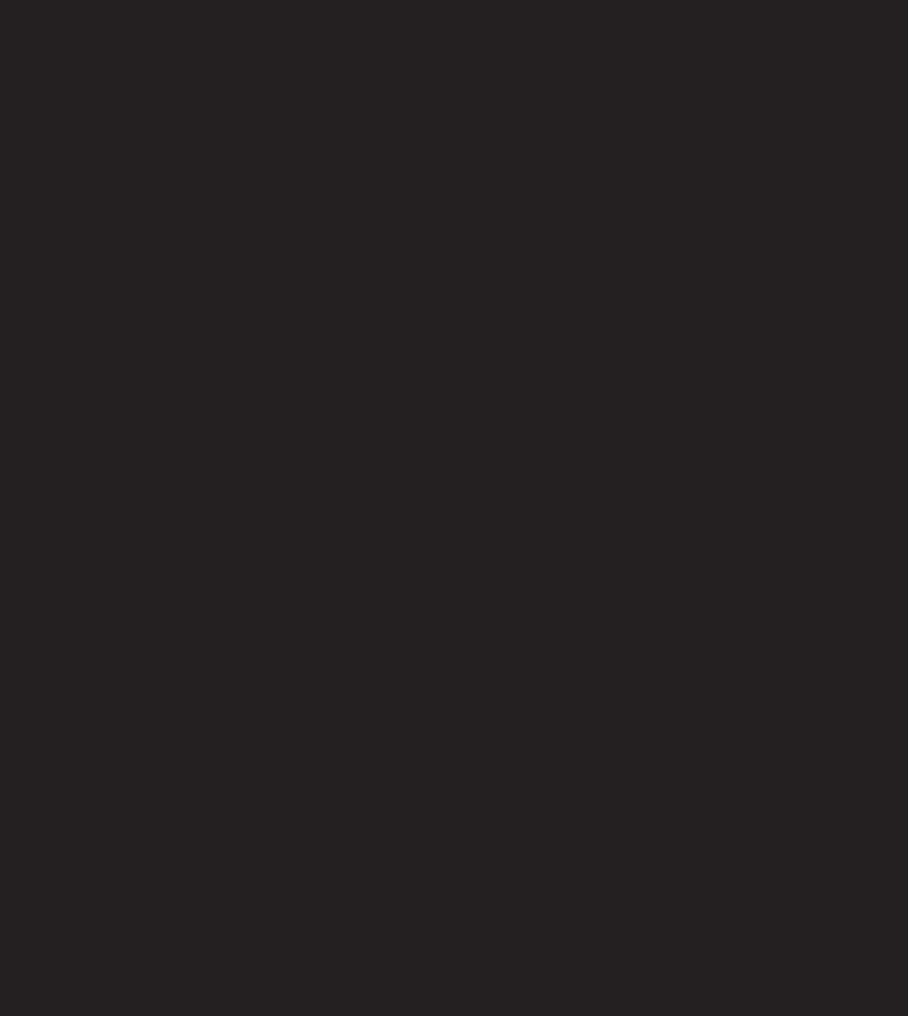


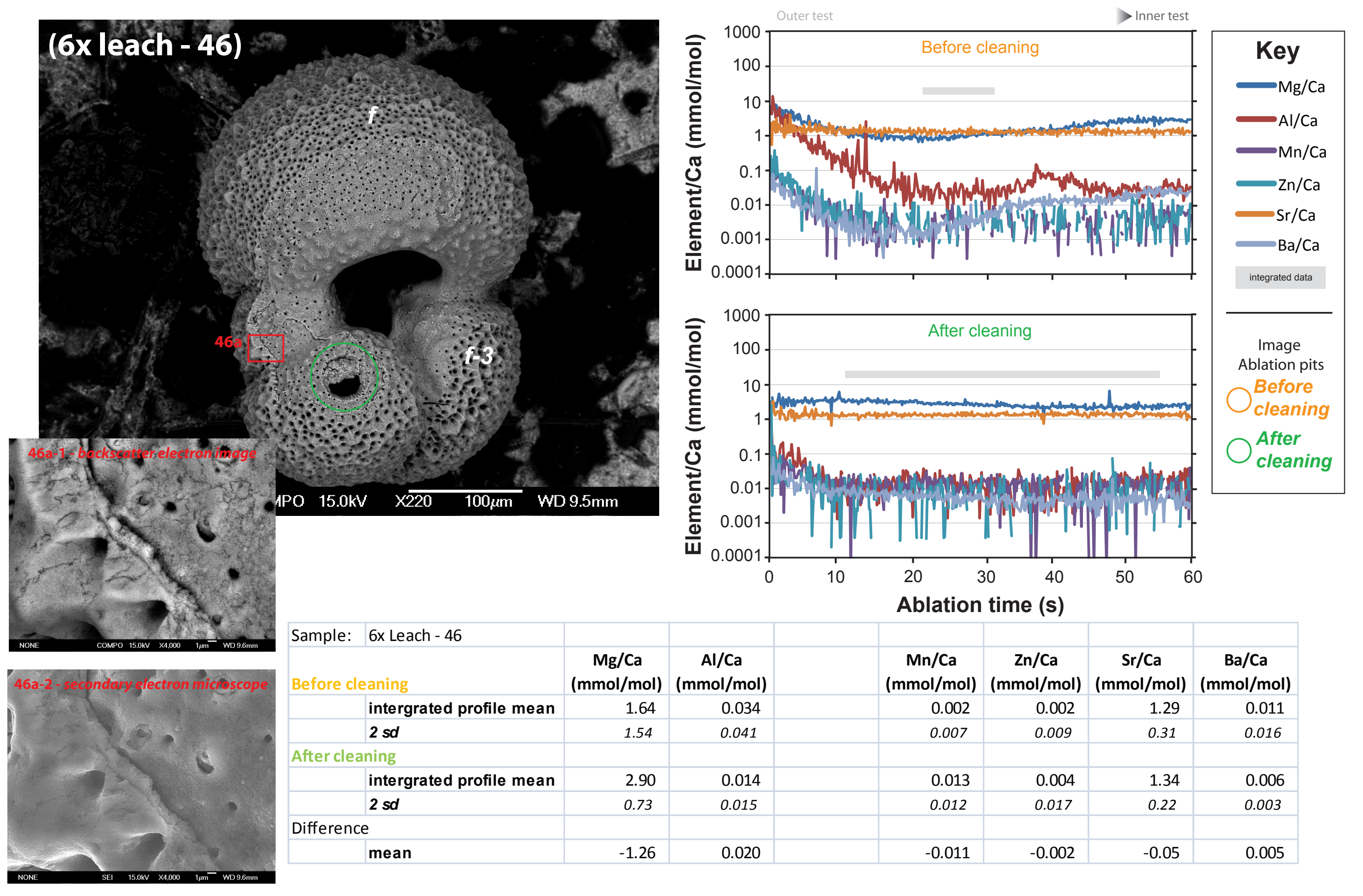



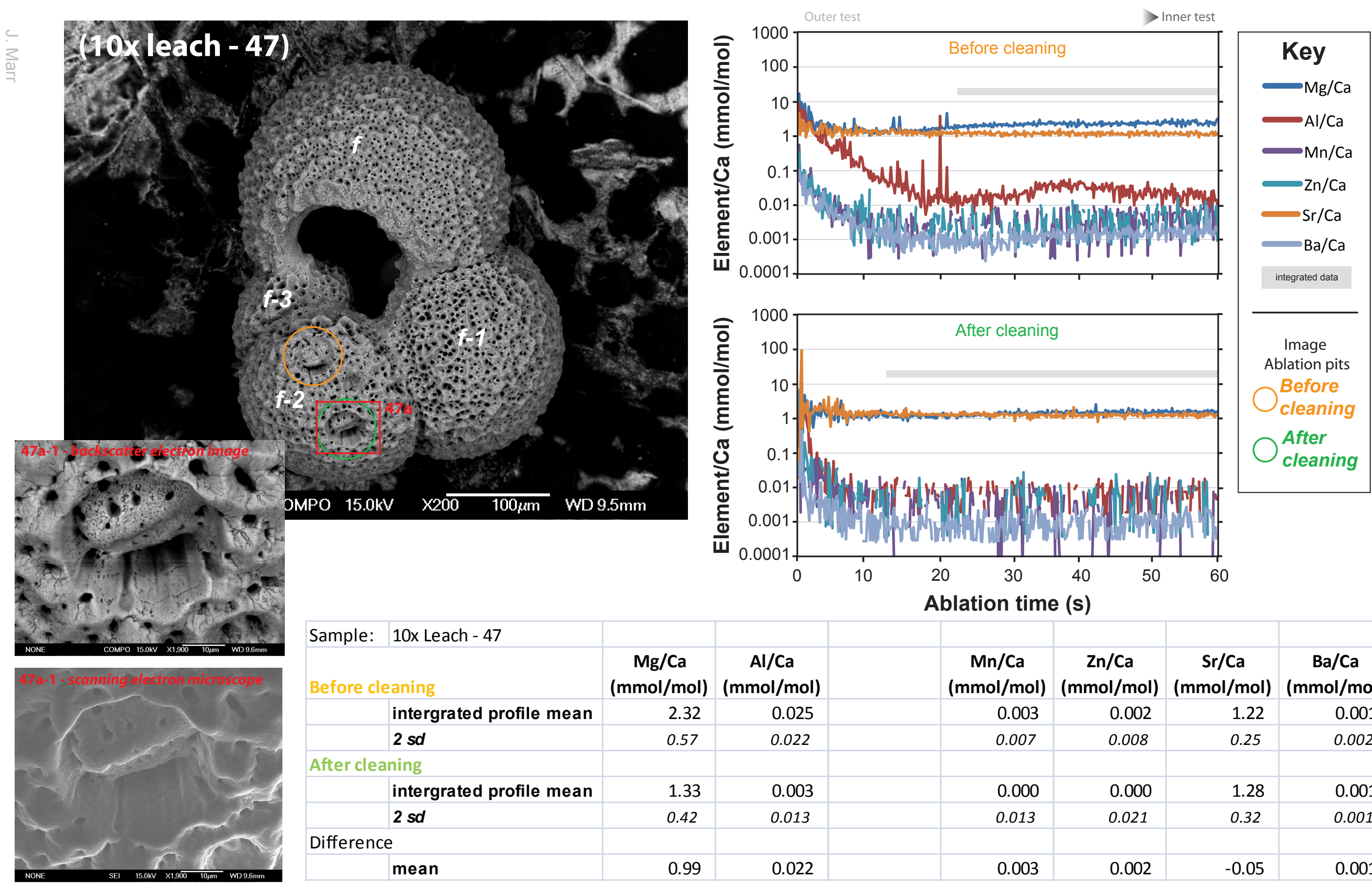

Ablation time (s)

Sample: 10x Leach - 47

\section{$\mathrm{Mg} / \mathrm{Ca}$}

Before cleaning

\section{intergrated profile mean}

2 sd

After cleaning

intergrated profile mean

2 sd

Difference $(\mathrm{mmol} / \mathrm{mol})(\mathrm{mmol} / \mathrm{mol})$

$\begin{array}{ll}2.32 & 0.025\end{array}$

0.57

1.33

0.42

0.99

0.022

0.003

0.013

mean

$\mathrm{Mn} / \mathrm{Ca}$

$\mathrm{Zn} / \mathrm{Ca}$

$\mathrm{Sr} / \mathrm{Ca}$

$\mathrm{Ba} / \mathrm{Ca}$

$(\mathrm{mmol} / \mathrm{mol})(\mathrm{mmol} / \mathrm{mol})(\mathrm{mmol} / \mathrm{mol})(\mathrm{mmol} / \mathrm{mol})$

\begin{tabular}{|l|l|l|l|}
\hline 0.003 & 0.002 & 1.22 & 0.001 \\
\hline 0.007 & 0.008 & 0.25 & 0.002 \\
\hline & & & \\
\hline 0.000 & 0.000 & 1.28 & 0.001 \\
\hline 0.013 & 0.021 & 0.32 & 0.001 \\
\hline & & & \\
\hline 0.003 & 0.002 & -0.05 & 0.001 \\
\hline
\end{tabular}



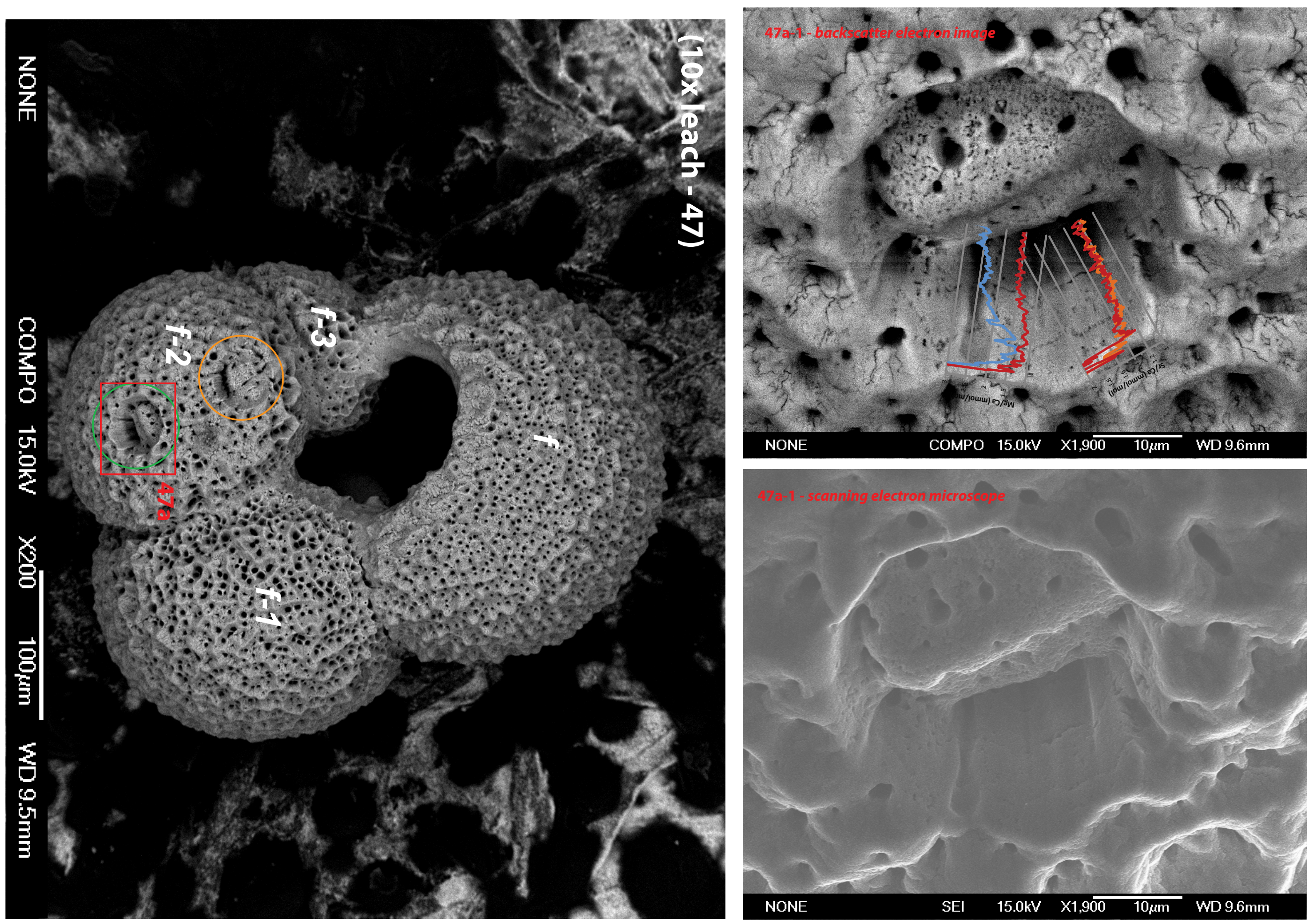
Chap. 2 - Table 1

\begin{tabular}{|c|c|c|c|c|c|c|c|}
\hline \multirow[b]{2}{*}{ Cleaning protocol } & \multicolumn{6}{|c|}{ 'LA processed' - before chemical cleaning (mmol/mol) } & \multirow[b]{2}{*}{$n=$} \\
\hline & $\mathrm{Mg} / \mathrm{Ca}$ & $\mathrm{Al} / \mathrm{Ca}$ & $\mathrm{Mn} / \mathrm{Ca}$ & $\mathrm{Zn} / \mathrm{Ca}$ & $\mathrm{Sr} / \mathrm{Ca}$ & $\mathrm{Ba} / \mathrm{Ca}$ & \\
\hline Oxidative & 1.81 & 0.06 & 0.003 & 0.003 & 1.34 & 0.002 & 8 \\
\hline Oxidative-Reductive & 1.60 & 0.01 & 0.002 & 0.004 & 1.30 & 0.002 & 7 \\
\hline Oxidative-1x Leach & 1.46 & 0.02 & 0.004 & 0.003 & 1.30 & 0.002 & 4 \\
\hline $1 x$ Leach & 1.33 & 0.06 & 0.004 & 0.003 & 1.32 & 0.003 & 7 \\
\hline $2 x$ Leach & 1.71 & 0.07 & 0.005 & 0.003 & 1.32 & 0.003 & 5 \\
\hline $4 x$ Leach & 1.23 & 0.02 & 0.001 & 0.000 & 1.36 & 0.001 & 1 \\
\hline $6 x$ Leach & 2.22 & 0.02 & 0.008 & 0.002 & 1.32 & 0.006 & 2 \\
\hline \multirow[t]{2}{*}{ 10x Leach } & 2.32 & 0.03 & 0.003 & 0.002 & 1.22 & 0.001 & 1 \\
\hline & \multicolumn{6}{|c|}{ 'LA processed'- after chemical cleaning (mmol/mol) } & $\mathrm{n}=$ \\
\hline Oxidative & 1.64 & 0.03 & 0.004 & 0.022 & 1.31 & 0.003 & 8 \\
\hline Oxidative-Reductive & 1.45 & 0.01 & 0.001 & 0.006 & 1.31 & 0.001 & 7 \\
\hline Oxidative-1x Leach & 1.26 & 0.01 & 0.002 & 0.006 & 1.29 & 0.002 & 4 \\
\hline $1 \mathrm{x}$ Leach & 1.38 & 0.03 & 0.004 & 0.006 & 1.32 & 0.003 & 7 \\
\hline $2 x$ Leach & 1.41 & 0.02 & 0.003 & 0.005 & 1.33 & 0.003 & 5 \\
\hline $4 \mathrm{x}$ Leach & 1.17 & 0.00 & 0.000 & 0.001 & 1.37 & 0.001 & 1 \\
\hline 6x Leach & 2.61 & 0.01 & 0.007 & 0.002 & 1.33 & 0.004 & 2 \\
\hline \multirow[t]{2}{*}{ 10x Leach } & 1.33 & 0.00 & 0.000 & 0.000 & 1.28 & 0.001 & 1 \\
\hline & \multicolumn{6}{|c|}{ 'Solution processed'- before chemical cleaning (mmol/mol) } & $n=$ \\
\hline Oxidative & 2.68 & 0.81 & 0.018 & 0.033 & 1.45 & 0.010 & 8 \\
\hline Oxidative-Reductive & 2.27 & 0.39 & 0.009 & 0.013 & 1.39 & 0.008 & 7 \\
\hline Oxidative-1x Leach & 2.13 & 0.98 & 0.010 & 0.012 & 1.37 & 0.009 & 4 \\
\hline 1x Leach & 2.17 & 0.49 & 0.014 & 0.015 & 1.38 & 0.009 & 7 \\
\hline $2 x$ Leach & 2.25 & 0.42 & 0.013 & 0.010 & 1.38 & 0.004 & 5 \\
\hline $4 x$ Leach & 1.93 & 0.39 & 0.007 & 0.008 & 1.40 & 0.021 & 1 \\
\hline $6 x$ Leach & 2.57 & 0.39 & 0.342 & 0.013 & 1.37 & 0.008 & 2 \\
\hline \multirow[t]{2}{*}{ 10x Leach } & 2.24 & 0.24 & 0.007 & 0.007 & 1.30 & 0.010 & 1 \\
\hline & \multicolumn{6}{|c|}{ 'Solution processed'- after chemical cleaning (mmol/mol) } & $n=$ \\
\hline Oxidative & 1.96 & 0.31 & 0.008 & 0.049 & 1.34 & 0.006 & 8 \\
\hline Oxidative-Reductive & 1.72 & 0.07 & 0.001 & 0.002 & 1.32 & 0.002 & 7 \\
\hline Oxidative-1x Leach & 1.55 & 0.12 & 0.004 & 0.021 & 1.32 & 0.004 & 4 \\
\hline $1 \mathrm{x}$ Leach & 1.84 & 0.42 & 0.016 & 0.027 & 1.37 & 0.022 & 7 \\
\hline $2 x$ Leach & 1.74 & 0.24 & 0.011 & 0.032 & 1.35 & 0.009 & 5 \\
\hline $4 x$ Leach & 1.38 & 0.05 & 0.003 & 0.044 & 1.61 & 0.003 & 1 \\
\hline 6x Leach & 2.48 & 0.02 & 0.010 & 0.011 & 1.34 & 0.004 & 2 \\
\hline 10x Leach & 1.40 & 0.02 & 0.004 & 0.006 & 1.34 & 0.001 & 1 \\
\hline
\end{tabular}


Chap. 2 - SI 3.0

\begin{tabular}{|c|c|c|c|}
\hline Element & Isotope measured & $\begin{array}{c}\text { Mean concentration } \\
(\mathrm{ppm})\end{array}$ & $\begin{array}{c}\text { Mean LOD } \\
(\mathrm{ppm})\end{array}$ \\
\hline $\mathrm{Mg}$ & 24 & 441 & 0.22 \\
\hline $\mathrm{Al}$ & 27 & 16.2 & 0.48 \\
\hline $\mathrm{Mn}$ & 55 & 2.87 & 0.84 \\
\hline $\mathrm{Zn}$ & 64 & 2.75 & 1.17 \\
\hline $\mathrm{Sr}$ & 88 & 1218 & 0.05 \\
\hline $\mathrm{Ba}$ & 138 & 3.54 & 0.05 \\
\hline
\end{tabular}




\begin{tabular}{|c|c|c|c|c|c|c|}
\hline \multirow[b]{3}{*}{ Oxidative -1} & \multicolumn{6}{|c|}{ - TE/Ca (mmol/mol) } \\
\hline & $\mathrm{Mg} / \mathrm{Ca}$ & $\mathrm{Al} / \mathrm{Ca}$ & $\mathrm{Mn} / \mathrm{Ca}$ & $\mathrm{Zn} / \mathrm{Ca}$ & $\mathrm{Sr} / \mathrm{Ca}$ & $\mathrm{Ba} / \mathrm{Ca}$ \\
\hline & 1.48 & 0.025 & 0.006 & 0.002 & 1.31 & 0.002 \\
\hline Oxidative - 2 & 1.65 & 0.113 & 0.007 & 0.006 & 1.28 & 0.002 \\
\hline dative -3 & 3.16 & 0.052 & 0.006 & 0.005 & 1.49 & 0.005 \\
\hline lative -4 & 1.94 & 0.269 & 0.013 & 0.011 & 32 & 0.007 \\
\hline Aative -5 & 2.29 & 0.020 & 0.001 & 0.003 & 1.35 & 0.001 \\
\hline dative -6 & 0.84 & 0.034 & 0.000 & 0.002 & 1.28 & 0.001 \\
\hline Oxidative - 7 & 1.35 & 0.147 & 0.000 & 0.004 & 1.39 & 0.002 \\
\hline Oxidative - 8 & 1.36 & 0.055 & 0.000 & 0.000 & 1.29 & 0.001 \\
\hline $\begin{array}{l}\text { Oxidative - } 9 \\
\text { Oxidative } 10\end{array}$ & 1.21 & 0.043 & 0.003 & 0.004 & 1.30 & 0.005 \\
\hline $\begin{array}{l}\begin{array}{l}\text { oxidativiv - } 10 \\
\text { Oxidative-Reductive - }\end{array}\end{array}$ & $\begin{array}{l}2.98 \\
3.21\end{array}$ & $\begin{array}{l}0.039 \\
0.037\end{array}$ & $\begin{array}{l}0.003 \\
0.012\end{array}$ & 0.004 & 1.37 & 0.002 \\
\hline $\begin{array}{l}\text { oxidative-Reductive - } 11 \\
\text { Oxidative-Reductive - } 12\end{array}$ & $\begin{array}{l}3.21 \\
2.40\end{array}$ & 0.052 & $\begin{array}{l}0.012 \\
0.008\end{array}$ & $\begin{array}{l}0.005 \\
0.008\end{array}$ & $\begin{array}{l}1.32 \\
1.28\end{array}$ & 0.002 \\
\hline Oxidative-Reductive - 13 & 0.91 & 0.005 & 0.001 & 0.0109 & 1.34 & \\
\hline Oxidative-Reductive - 14 & 1.64 & 0.041 & 0.006 & 0.0021 & 1.43 & $\begin{array}{l}0.001 \\
0.002\end{array}$ \\
\hline Oxidative-Reductive - 15 & 1.50 & 0.010 & 0.003 & 0.0049 & 1.32 & \\
\hline Oxidative-Reductive - 16 & 1.08 & 0.018 & 0.000 & 0.0000 & 1.32 & 0.002 \\
\hline Oxidative-Reductive - 17 & 3.52 & 0.019 & 0.004 & 0.0038 & 1.31 & 0.004 \\
\hline Oxidative-Reductive - 18 & 1.34 & 0.011 & 0.003 & 0.0009 & 1.29 & 0.002 \\
\hline Oxidative-Reductive - 19 & 1.67 & 0.005 & 0.005 & 0.0031 & 1.31 & 0.001 \\
\hline Oxidative-Reductive - 20 & 1.19 & 0.025 & 0.002 & 0.0013 & 1.24 & 0.002 \\
\hline Oxidative-1x Leach - 21 & 0.67 & 0.002 & 0.000 & 0.002 & 28 & 0.001 \\
\hline Oxidative-1x Leach - 22 & 0.91 & 0.031 & 0.005 & 0.003 & 35 & \\
\hline Oxidative-1x Leach - 23 & 1.70 & 0.035 & & 0.002 & 1.30 & 0.002 \\
\hline dative-1x Leach - 24 & & 0.035 & & & & \\
\hline dative-1x Leach -25 & 1.73 & 0.183 & & & 38 & 0.006 \\
\hline Oxidative-1x Leach - 26 & 1.41 & 0.014 & 0.002 & 0.00 & $1.28 \mathrm{Z}>\mathrm{C}$ & 0.002 \\
\hline Oxidative-1x Leach - 27 & 4.54 & 0.043 & 0.010 & $0.011>3$ & 1.3 & \\
\hline dative-1x Leach - 28 & 1.60 & 0.035 & 0.003 & $0.00 \mathrm{C}-2 \mathrm{c}$ & $1.3 \mathrm{Y}-3 \mathrm{C}$ & 0.003 \\
\hline Oxidative-1x Leach - 29 & 1.86 & 0.021 & & & 1.31 & 0.004 \\
\hline Oxidative-1x Leach - 30 & 2.06 & 0.034 & 0.006 & 0.002 & 1.46 & 0.002 \\
\hline 1x Leach - 31 & 2.23 & 0.016 & 0.001 & 0.002 & 1.37 & 0.001 \\
\hline $1 \times$ Leach - 32 & 0.86 & 0.016 & 0.002 & 0.001 & 1.36 & 0.001 \\
\hline 1x Leach -33 & 2.04 & 0.110 & 0.010 & 0.008 & 1.23 & 0.005 \\
\hline 1x Leach - 34 & 1.04 & 0.011 & 0.001 & 0.002 & 1.27 & 0.001 \\
\hline 1x Leach - 35 & 0.98 & 0.060 & 0.009 & 0.005 & 1.28 & 0.003 \\
\hline 1x Leach - 36 & 1.60 & 0.028 & 0.005 & 0.005 & 1.30 & 0.003 \\
\hline 1x Leach - 37 & 1.91 & 0.030 & 0.015 & & & 0.004 \\
\hline 1× Leach - r1 & 1.74 & 0.022 & 0.001 & 0.002 & 1.26 & 0.001 \\
\hline 1x Leach $-r 2$ & 1.41 & 0.041 & 0.004 & 0.002 & 1.37 & 0.007 \\
\hline $1 \times$ Leach $-r 3$ & 1.25 & 0.149 & 0.003 & 0.003 & 44 & 0.002 \\
\hline $2 \times$ Leach -38 & 1.43 & 0.085 & 0.001 & 0.001 & 35 & 0.001 \\
\hline $2 \times$ Leach -40 & 1.40 & 0.141 & 0.007 & 0.004 & 32 & 0.004 \\
\hline $2 \times$ Leach -43 & 2.06 & 0.092 & 0.009 & 0.007 & 29 & 0.006 \\
\hline $2 \times$ Leach -44 & 2.38 & 0.010 & 0.002 & 0.001 & 31 & 0.002 \\
\hline $2 \times$ Leach -48 & 1.27 & 0.023 & 0.005 & 0.004 & 1.30 & 0.003 \\
\hline $\begin{array}{l}2 \times \text { Leach }-49 \\
29\end{array}$ & 1.29 & 0.009 & 0.001 & 0.001 & 1.28 & 0.001 \\
\hline 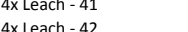 & $\begin{array}{l}1.23 \\
2.52\end{array}$ & $\begin{array}{l}0.023 \\
0.062\end{array}$ & $\begin{array}{l}0.001 \\
0.009\end{array}$ & 0.000 & 136 & $\begin{array}{l}0.001 \\
0.003\end{array}$ \\
\hline $4 \times$ Leach -50 & 1.43 & $\begin{array}{l}.0062 \\
0.030\end{array}$ & $\begin{array}{l}0.004 \\
0.004\end{array}$ & 0.004 & $\begin{array}{l}1.36 \\
1.37\end{array}$ & $\begin{array}{l}0.003 \\
0.001\end{array}$ \\
\hline $6 x$ Leach - 45 & 2.79 & 0.010 & 0.014 & 0.001 & 1.35 & 0.001 \\
\hline each - 46 & 1.64 & 0.034 & 0.002 & 0.002 & 29 & 0.011 \\
\hline $10 x$ & 2.32 & 0.025 & 0.003 & 0.002 & 1.22 & 0.001 \\
\hline
\end{tabular}

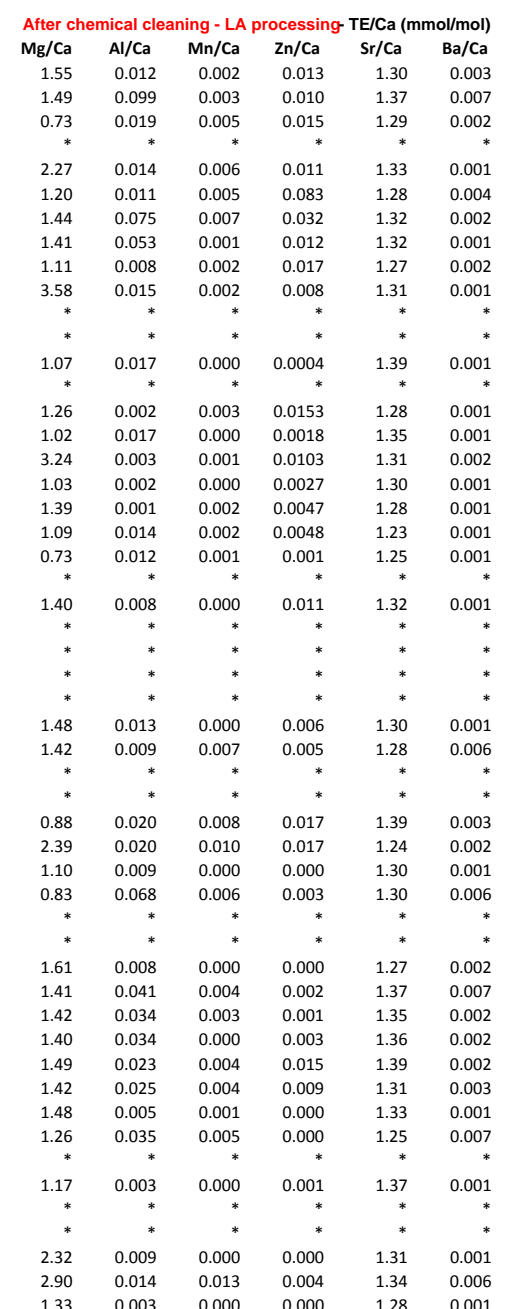

\begin{tabular}{|c|c|c|c|c|c|}
\hline $\mathrm{Mg} / \mathrm{Ca}$ & $\mathrm{Al} / \mathrm{Ca}$ & $\mathrm{Mn} / \mathrm{Ca}$ & $\mathrm{Zn} / \mathrm{Ca}$ & $\mathrm{Sr} / \mathrm{Ca}$ & \\
\hline & 1.76 & 0.042 & 0.076 & 1.44 & 0.022 \\
\hline 2.41 & 0.72 & 0.024 & 0.030 & 1.40 & \\
\hline 3.92 & 1.11 & 0.022 & 0.022 & 1.66 & 0.020 \\
\hline 2.84 & 0.35 & 0.023 & 0.018 & 1.41 & 0.005 \\
\hline 2.00 & 0.81 & 0.015 & 0.042 & 1.35 & 0.019 \\
\hline 2.08 & 0.83 & 0.012 & 0.032 & 1.48 & 0.005 \\
\hline 2.12 & 0.54 & 0.005 & 0.028 & 1.41 & 0.013 \\
\hline 2.09 & 0.62 & 0.012 & 0.024 & 1.44 & 0.091 \\
\hline 3.39 & 0.52 & 0.011 & 0.026 & 1.44 & 0.006 \\
\hline * & * & * & * & $*$ & ${ }^{*}$ \\
\hline 2.47 & 0.32 & 0.005 & 0.010 & 1.46 & 0.006 \\
\hline 2.08 & 0.69 & 0.016 & 0.028 & 1.40 & 0.013 \\
\hline 2.13 & 0.89 & 0.010 & 0.024 & 1.48 & .017 \\
\hline 3.61 & & & & 1.34 & .012 \\
\hline 1.85 & & & & 1.33 & 003 \\
\hline 1.77 & & & & 1.29 & \\
\hline 1.94 & & & & $\begin{array}{l}1.45 \\
1.27\end{array}$ & 0.006 \\
\hline 0.88 & 0.11 & $\begin{array}{l}0.004 \\
*\end{array}$ & 0.006 & $\begin{array}{l}1.27 \\
*\end{array}$ & $\begin{array}{r}0.002 \\
*\end{array}$ \\
\hline 2.19 & 1.69 & 0.010 & 0.011 & 1.41 & 0.008 \\
\hline * & * & & & * & \\
\hline & & & & & \\
\hline${ }^{*}$ & $*$ & ${ }^{*}$ & * & * & * \\
\hline 2.11 & 0.38 & 0.008 & 0.008 & 1.33 & 0.008 \\
\hline 3.34 & 1.74 & 0.019 & 0.024 & 1.46 & 0.022 \\
\hline * & $*$ & * & * & $*$ & $*$ \\
\hline 1.52 & 0.22 & 0.006 & 0.006 & 1.37 & 0.004 \\
\hline 2.15 & & & & .26 & . \\
\hline 1.77 & 0.5 & & & 37 & 0.008 \\
\hline 2.72 & 0.57 & 0.025 & 0.014 & 1.35 & 0.011 \\
\hline * & ${ }_{*}^{*}$ & ${ }_{*}^{*}$ & * & * & * \\
\hline 2.06 & 0.32 & 0.008 & 0.008 & 1.30 & 0.004 \\
\hline 2.7 & 0.4 & & & 1.39 & 0.026 \\
\hline 2.2. & 0.8 & & & 65 & 312 \\
\hline 2.0 & 0.4 & & & & \\
\hline 2.07 & 0.4 & 0.012 & 0.008 & 1.40 & 0.006 \\
\hline 2.5 & 0.6 & 0.012 & 0.013 & 41 & 0.013 \\
\hline 2.39 & 0.20 & 0.006 & 0.007 & .35 & 0.005 \\
\hline 2.16 & 0.27 & 0.026 & 0.013 & 1.33 & 0.009 \\
\hline 1.93 & 0.39 & 0.007 & 0.008 & 1.40 & 0.009 \\
\hline * & * & $*$ & * & $*$ & \\
\hline 3.28 & & $0.0 \%$ & 0.010 & 1.38 & 0.010 \\
\hline 1.8 & 0.33 & & 0.010 & 1.35 & 0.6 \\
\hline & 24 & 0.007 & 0.007 & 30 & \\
\hline
\end{tabular}

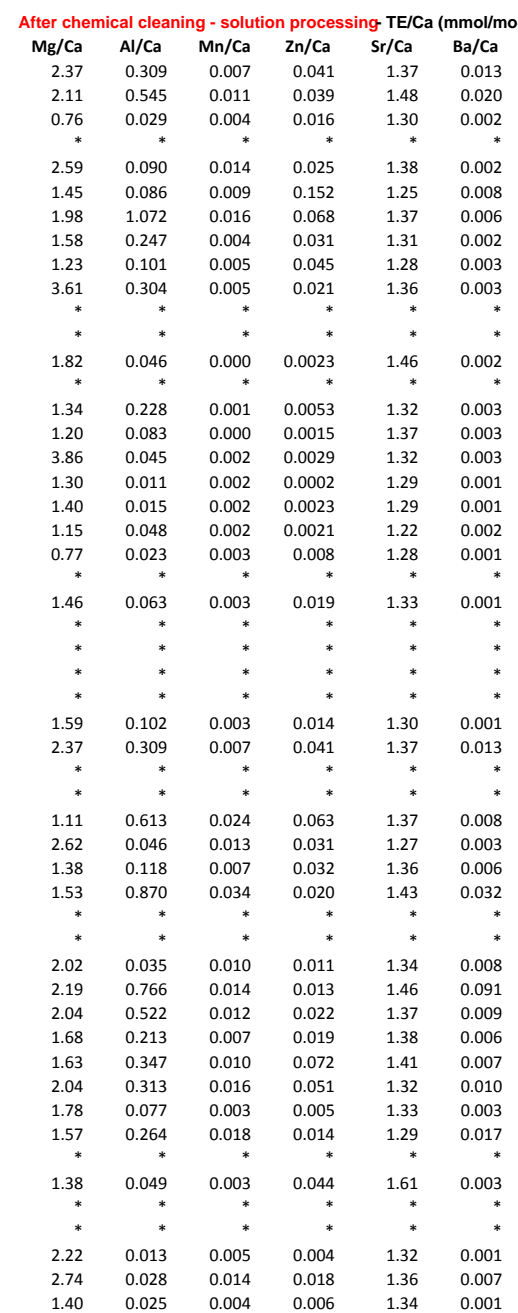




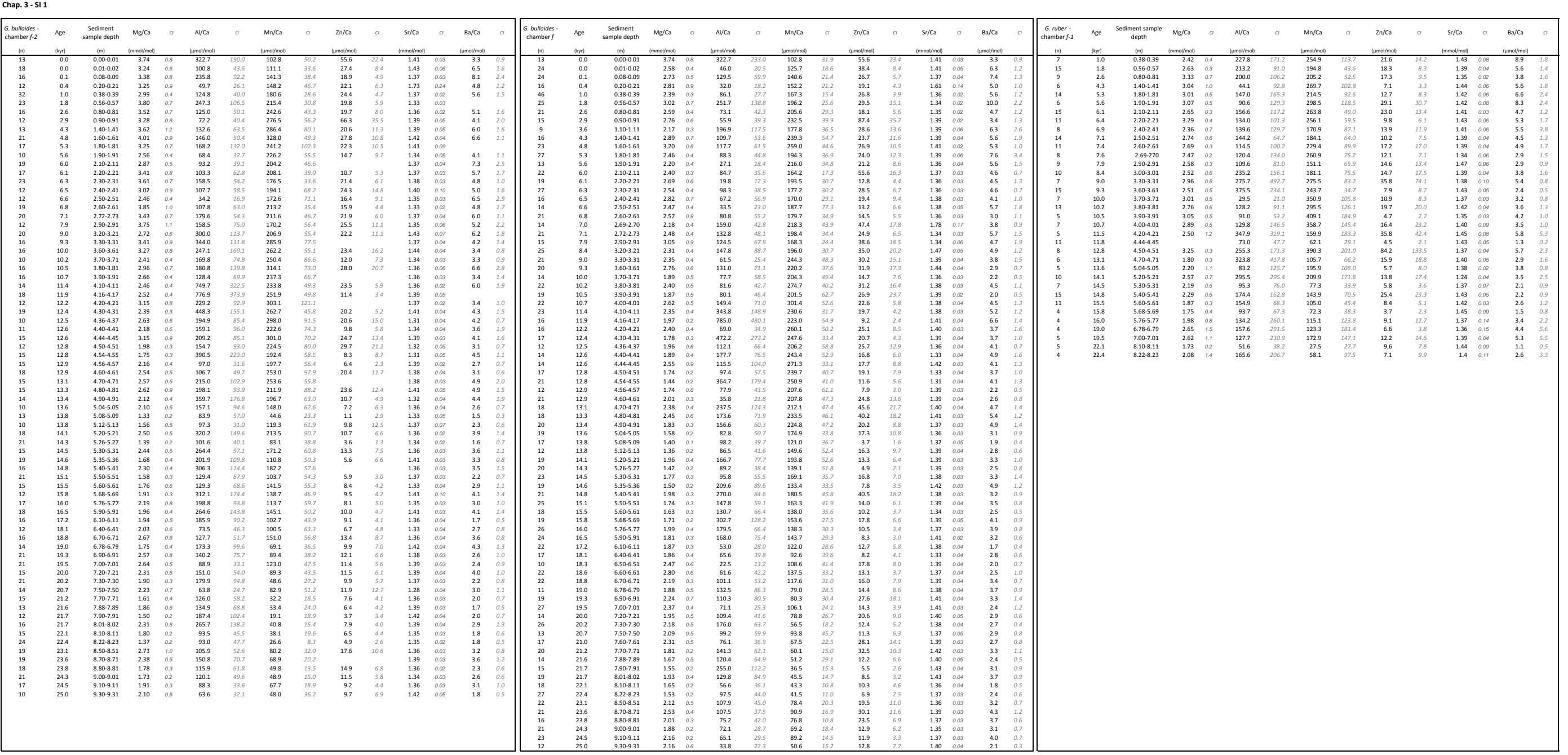


Chap. 4 - SI 2

\begin{tabular}{|c|c|c|c|c|c|c|c|}
\hline & \multicolumn{3}{|c|}{ Glacial } & \multicolumn{2}{|c|}{ Termination (ACR) } & \multicolumn{2}{|c|}{ Interglacial } \\
\hline & \multicolumn{7}{|c|}{ Depth $(m)$} \\
\hline & $9.01-9.02$ & $7.21-7.22$ & $6.10-6.11$ & $5.60-5.61$ & $5.04-5.05$ & $3.79-3.80$ & $2.10-2.11$ \\
\hline & \multicolumn{7}{|c|}{ Age $(\mathrm{ka})$} \\
\hline Species & 24.3 & 20.0 & 17.2 & \begin{tabular}{|c|}
15.5 \\
\end{tabular} & 13.7 & 10.5 & 6.0 \\
\hline Coccolithus palagicus & 9 & 4 & 7 & 17 & 15 & 7 & 1 \\
\hline Calcidiscus leptoporus & 25 & 13 & 12 & 7 & & 1 & 8 \\
\hline Gephyrocapsa spp. & 22 & 27 & 43 & 37 & 5 & 19 & 1 \\
\hline Emiliania huxleyi & 24 & 9 & 19 & & & 9 & 1 \\
\hline Umbilicosphaera & 1 & 2 & 4 & 1 & & & \\
\hline Helicosphaera carteri & & 1 & & 1 & 1 & 1 & \\
\hline Oolithotus antillarum & & & & 1 & & & \\
\hline Total identified & 81 & 56 & 85 & $64 \mid$ & 21 & 37 & 11 \\
\hline
\end{tabular}


Chap. 5 - S1 1

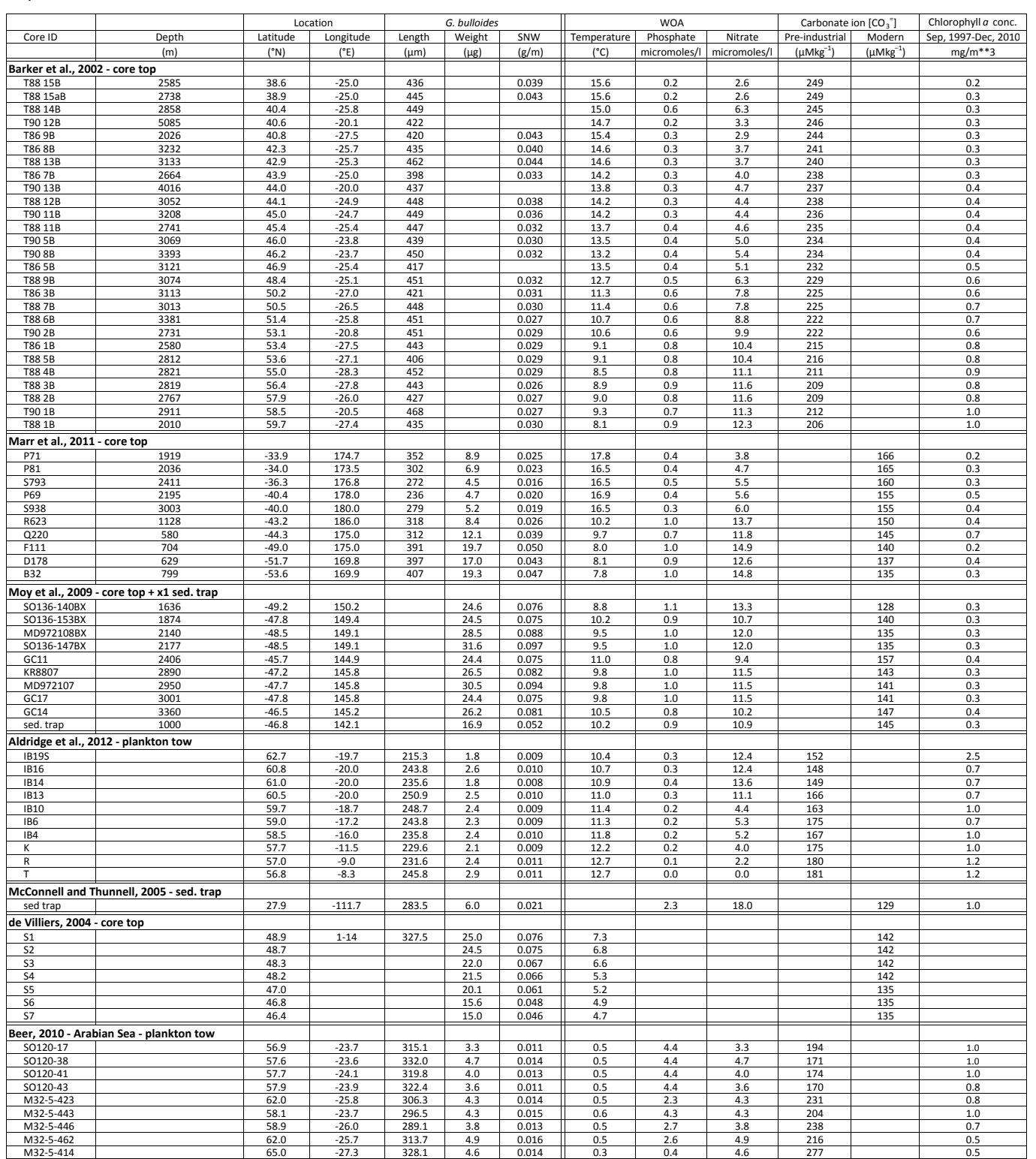


Chap. 5 - SI 2

\begin{tabular}{|c|c|c|c|}
\hline \multicolumn{4}{|c|}{ MD97 2121} \\
\hline Age (ka) & Weight $(\mu \mathrm{g})$ & Length $(\mu \mathrm{m})$ & SNW (g/m) \\
\hline 0.0 & 4.0 & 263 & 0.015 \\
\hline 0.0 & 5.5 & 311 & 0.018 \\
\hline 0.1 & 5.2 & 302 & 0.017 \\
\hline 0.4 & 4.6 & 274 & 0.017 \\
\hline 1.0 & 5.0 & 302 & 0.017 \\
\hline 1.8 & 5.7 & 309 & 0.018 \\
\hline 2.6 & 5.1 & 303 & 0.017 \\
\hline 2.9 & 5.2 & 296 & 0.018 \\
\hline 4.3 & 5.5 & 308 & 0.018 \\
\hline 4.8 & 5.3 & 307 & 0.017 \\
\hline 5.3 & 5.8 & 295 & 0.019 \\
\hline 5.6 & 7.7 & 344 & 0.022 \\
\hline 6.0 & 7.4 & 292 & 0.025 \\
\hline 6.1 & 7.4 & 318 & 0.023 \\
\hline 6.3 & 6.7 & 313 & 0.021 \\
\hline 6.5 & 5.3 & 282 & 0.019 \\
\hline 6.6 & 5.7 & 304 & 0.019 \\
\hline 6.8 & 6.3 & 305 & 0.021 \\
\hline 7.1 & 6.2 & 303 & 0.020 \\
\hline 7.9 & 5.0 & 288 & 0.017 \\
\hline 9.0 & 5.5 & 288 & 0.019 \\
\hline 9.3 & 7.7 & 347 & 0.022 \\
\hline 10.0 & 6.0 & 319 & 0.019 \\
\hline 10.2 & 8.5 & 367 & 0.023 \\
\hline 10.5 & 5.6 & 316 & 0.018 \\
\hline 10.7 & 7.6 & 360 & 0.021 \\
\hline 11.4 & 6.3 & 303 & 0.021 \\
\hline 11.9 & 7.0 & 335 & 0.021 \\
\hline 12.2 & 5.9 & 298 & 0.020 \\
\hline 12.4 & 6.0 & 310 & 0.019 \\
\hline 12.5 & 7.2 & 317 & 0.023 \\
\hline 12.6 & 7.1 & 328 & 0.022 \\
\hline 12.6 & 6.0 & 314 & 0.019 \\
\hline 12.8 & 8.6 & 348 & 0.025 \\
\hline 12.8 & 9.6 & 366 & 0.026 \\
\hline 12.9 & 12.7 & 358 & 0.035 \\
\hline 12.9 & 7.5 & 332 & 0.023 \\
\hline 13.1 & 6.9 & 324 & 0.021 \\
\hline 13.3 & 13.6 & 376 & 0.036 \\
\hline 13.4 & 10.1 & 382 & 0.026 \\
\hline 13.6 & 13.6 & 376 & 0.036 \\
\hline 13.8 & 15.1 & 417 & 0.036 \\
\hline 13.8 & 11.0 & 376 & 0.029 \\
\hline 14.1 & 11.1 & 369 & 0.030 \\
\hline 14.3 & 19.8 & 434 & 0.046 \\
\hline 14.5 & 11.7 & 386 & 0.030 \\
\hline 14.6 & 12.2 & 373 & 0.033 \\
\hline 14.8 & 12.4 & 367 & 0.033 \\
\hline 15.1 & 17.5 & 374 & 0.047 \\
\hline 15.5 & 11.4 & 374 & 0.030 \\
\hline 15.8 & 11.1 & 381 & 0.029 \\
\hline 16.0 & 12.6 & 383 & 0.033 \\
\hline 16.5 & 12.7 & 383 & 0.033 \\
\hline 17.2 & 12.2 & 394 & 0.031 \\
\hline 18.1 & 5.7 & 310 & 0.018 \\
\hline 18.8 & 8.8 & 341 & 0.026 \\
\hline 19.0 & 7.93 & 311 & 0.026 \\
\hline 19.3 & 8.96 & 323 & 0.028 \\
\hline 19.5 & 9.2 & 349 & 0.027 \\
\hline 20.0 & 8.9 & 385 & 0.023 \\
\hline 20.2 & 10.0 & 354 & 0.028 \\
\hline 20.7 & 10.1 & 350 & 0.029 \\
\hline 21.2 & 12.7 & 367 & 0.031 \\
\hline 21.6 & 13.2 & 367 & 0.036 \\
\hline 21.7 & 13.6 & 356 & 0.038 \\
\hline 21.9 & 8.1 & 302 & 0.027 \\
\hline 22.1 & 12.7 & 364 & 0.035 \\
\hline 22.4 & 13.6 & 377 & 0.036 \\
\hline 23.1 & 10.9 & 367 & 0.030 \\
\hline 23.6 & 9.5 & 351 & 0.027 \\
\hline 23.8 & 9.4 & 351 & 0.027 \\
\hline 24.3 & 11.3 & 356 & 0.032 \\
\hline 24.5 & 11.3 & 366 & 0.031 \\
\hline 25.0 & 12.9 & 352 & 0.036 \\
\hline
\end{tabular}


This thesis investigates the use of foraminiferal calcite geochemical and physical properties as paleoceanographic proxies, to improve identification of past climatic change and provide a more quantitative basis for forecasts of future climate.

Various analytical methods to measure foraminiferal calcite trace element geochemistry were first investigated using core top samples. Two main analytical techniques were deployed; "pseudo" solutionor laser ablation-based ICPMS analysis. Ratios tested include $\mathrm{Mg} / \mathrm{Ca}, \mathrm{Sr} / \mathrm{Ca}, \mathrm{Ba} / \mathrm{Ca}, \mathrm{Zn} / \mathrm{Ca}, \mathrm{Mn} / \mathrm{Ca}$ and $\mathrm{Al} / \mathrm{Ca}$. Trace element/calcium ratios $\mathrm{Mg} / \mathrm{Ca}$ and $\mathrm{Sr} / \mathrm{Ca}$ values were consistent between these methods, provided that currently recommended 'Mg-cleaning' protocols were followed for solution-based measurements. However, discrepancies of up to an order-of-magnitude for $\mathrm{Zn} / \mathrm{Ca}, \mathrm{Mn} / \mathrm{Ca}$ and $\mathrm{Ba} / \mathrm{Ca}$ occurred between solution and laser ablation-based measurements if both oxidative and reductive cleaning techniques were not employed prior to solution-based analysis.

Using down-core trace element values $\mathrm{Mg} / \mathrm{Ca}, \mathrm{Zn} / \mathrm{Ca}, \mathrm{Mn} / \mathrm{Ca}$ and $\mathrm{Ba} / \mathrm{Ca}$ from $\mathrm{MD} 97$ 2121, coupled with modern core top and plankton-tow samples, multiple geochemical proxies for the SW Pacific Ocean were developed and/or tested. Results suggest that $\mathrm{Zn} / \mathrm{Ca}$ may act as (i) a surface water mass tracer, in this case differentiating between subtropical and subantarctic surface waters and (ii) a proxy for nutrients. $\mathrm{Mg} / \mathrm{Ca}$ and $\mathrm{Zn} / \mathrm{Ca}$ values from different test chambers in Globigerina bulloides were also found to reliably re-construct surface ocean temperature and nutrient stratification. Using these new proxies, coupled with oxygen isotopes, standard $\mathrm{Mg} / \mathrm{Ca}$ paleothermometry and foraminiferal assemblage data, surface water nutrient and thermal stratification significantly reduced during the last glacial period.

The high resolution $\mathrm{Mg} / \mathrm{Ca}$ paleotemperature record developed here, together with published alkenone paleotemperatures were compared to core MD97 2120, south of the STF to evaluate the relationship between $\mathrm{Mg} / \mathrm{Ca}$ and alkenones temperatures and how these reflect environmental change. It appears that the season of maximum alkenone and G. bulloides flux varied over the last $25 \mathrm{kyr}$ in response to insolation and water mass changes. These seasonal offsets may have acted to dampen or exacerbate the glacial-Holocene temperature offsets by up to $4^{\circ} \mathrm{C}$ especially for the surface dwelling, alkenone producing coccolithophores. Seasonality changes of the coccolithophore and foraminifera make direct comparison of alkenone and $\mathrm{Mg} / \mathrm{Ca}$ G. bulloides paleothermometers challenging.

The use of G. bulloides size normalised weight (SNW) as a proxy for surface water carbonate ion concentration $\left(\left[\mathrm{CO}_{3}{ }^{\circ}\right]\right.$ ) was investigated by comparing modern SNW data sets from five different ocean regions to their specific environmental variables including $\left[\mathrm{CO}_{3}{ }^{=}\right]$, chlorophyll- $a$, nutrient and temperature values. It was identified that the 'ocean' from which the foraminifera originated appeared to have the strongest control over shell SNW, potentially reflecting geographically distinct, genetic variations within the G. bulloides species. Within 'ocean' regions no consistent environmental variable(s) could be identified that appeared to control shell SNW in all regions. From the $25 \mathrm{ka}$ to present, shell SNWs from the SW Pacific Ocean were compared to the North Atlantic and were found to be heavier during the glacial period regardless of ocean region. Calcification of G. bulloides tests appears to be region specific; therefore, proxy calibrations based on shell SNW for one ocean are not applicable to other settings. 